\title{
Total Synthesis of (-)-Bacchopetiolone via an Asymmetric Hydroxylative Phenol Dearomatization/[4+2]-Dimerization Cascade Promoted by a Novel Salen-type Chiral Iodane
}

Romain Coffinier, ${ }^{\dagger},{ }^{\S}$ Mourad El Assal, ${ }^{\dagger},{ }^{8}$ Philippe A. Peixoto, ${ }^{\dagger}$ Cyril Bosset, $^{\dagger}$ Karinne Miqueu, ${ }^{\ddagger}$ Jean-Marc Sotiropoulos, ${ }^{\ddagger}$ Laurent Pouységu ${ }^{*}, \dagger$ and Stéphane Quideau*,†

$\dagger \quad$ Univ. Bordeaux, ISM (CNRS-UMR 5255)

351 cours de la Libération, 33405 Talence Cedex (France)

Fax: (+33) 5-4000-2215

E-mail: laurent.pouysegu@u-bordeaux.fr or stephane.quideau@u-bordeaux.fr

* Univ. Pau et Pays de l'Adour, IPREM (CNRS-UMR 5254)

Hélioparc, 2 avenue Pierre Angot, 64053 Pau Cedex 09 (France)

$\S$ These authors contributed equally to this work.

\section{SUPPORTING INFORMATION}

\section{CONTENTS}

Pages S1 - S53: $\quad$ Experimental Section

Page S2: $\quad$ Synthesis of $(R)$ - and $(S)$-curcuphenols and their (S)IBX-mediated $\mathrm{HPD} /[4+2]$-dimerization cascade conversions into the corresponding orthoquinol-based cyclodimers

N.B.: Figure $S 4$ appears on page $S 7$

Page S8: $\quad$ Synthesis of $C_{2}$-symmetrical Salen-type bis(iodoarenes)

Page S18: $\quad$ DMDO-mediated oxidation of Salen-type bis(iodoarenes) into bis $\left(\lambda^{5}\right.$-iodanes)

Page S21: $\quad$ Asymmetric hydroxylative phenol dearomatization (HPD)/[4+2]-dimerization cascade conversion of carvacrol promoted by Salen-type bis $\left(\lambda^{5}\right.$-iodanes $)$

N.B.: Table S1 appears on page S22

Page S34: Evaluation of the influence of an alcoholic co-solvent on the HPD/[4+2]dimerization cascade conversion of carvacrol promoted by Salen-type bis $\left(\lambda^{5}-\right.$ iodanes)

N.B.: Table S2 appears on page S35

Page S38: $\quad$ Asymmetric HPD/[4+2]-dimerization cascade conversion of 2-alkylphenols promoted by Salen-type bis $\left(\lambda^{5}\right.$-iodanes $)$

N.B.: Table $S 3$ appears on page $S 39$

Page S44: Asymmetric HPD/[4+2]-dimerization cascade conversion of $(R)$ - and $(S)$ curcuphenols for the diastereoselective synthesis of ent-bacchopetiolone and bacchopetiolone, respectively

Pages S54 - S134: NMR Spectra

Pages S135 - S144: Theoretical Calculations

Pages S145 - S146: Additional References 


\section{Experimental Section}

General. All moisture and oxygen sensitive reactions were carried out in flame-dried glassware under $\mathrm{N}_{2}$. Tetrahydrofuran (THF) and dichloromethane $\left(\mathrm{CH}_{2} \mathrm{Cl}_{2}\right)$ were purified by filtration through alumina under $\mathrm{N}_{2}$. Dimethylformamide (DMF) was distilled on calcium hydride $\left(\mathrm{CaH}_{2}\right)$ under $\mathrm{N}_{2}$ prior to use. Acetone, cyclohexane, hexanes, ethyl acetate (EtOAc), and dimethylsulfoxide (DMSO) were used as received. Fluorinated solvents [i.e., 2,2,2-trifluoroethanol (TFE) and 1,1,1,3,3,3hexafluoroisopropan-2-ol (HFIP)] were dried over activated $4 \AA$ molecular sieves (beads). HPLC grade solvents [i.e., $n$-hexane and iso-propanol $(i-\mathrm{PrOH})]$ were used for analytical and preparative HPLC-based studies. Commercially available reagents (Aldrich) and stabilized 2-iodylbenzoic acid (SIBX; Simafex) were used as received. Reactions run at room temperature were performed between 20 and $25{ }^{\circ} \mathrm{C}$. Solvent evaporations were conducted under reduced pressure at temperatures less than $40{ }^{\circ} \mathrm{C}$ unless otherwise noted (e.g., volatile compounds). Column chromatography was carried out under positive pressure using 40-63 $\mu \mathrm{m}$ silica gel and the indicated solvents [v/v; used without purification, including petroleum ether (PET, boiling range $40-60{ }^{\circ} \mathrm{C}$ )]. Melting points of either recrystallized solids or amorphous powders were measured in open capillary tubes, using a digital Büchi B-540 melting point apparatus, and are uncorrected. Optical rotations were determined on a Krüss P3001 digital polarimeter at $\lambda=589 \mathrm{~nm}$ (i.e., sodium D line), using a $1.0 \mathrm{~mL}$ cell $(1=0.5 \mathrm{dm})$, and are given as $[\alpha]^{20}$ (concentration in $\mathrm{g} / 100 \mathrm{~mL}$ solvent). Circular dichroism (CD) measurements were performed on a Jasco J-815 spectropolarimeter. Spectra were recorded between 400 and $180 \mathrm{~nm}$, at a concentration of 1 or $3 \mathrm{mM}$ in methanol (MeOH, HPLC grade, using a quartz cell with a path length of $2 \mathrm{~mm}$ (Hellma Analytics). Sample temperature was regulated at $20^{\circ} \mathrm{C}$. Data were collected in a continuous scan mode with a data pitch of $0.1 \mathrm{~mm}$, a scanning speed of $100 \mathrm{~nm} / \mathrm{min}$, a $2 \mathrm{~nm}$ bandwith, and 2 accumulations per sample. IR spectra were recorded between 4000 and $400 \mathrm{~cm}^{-1}$ with a Bruker IFS55 (OPUS/IR 3.0.2) FT-IR spectrometer, and samples were dissolved in dichloromethane or acetone before analysis as a thin film on a zinc-selenium pellet after solvent evaporation (neat), unless otherwise noted $(\mathrm{NaCl}$ pellets). ${ }^{1} \mathrm{H}$ NMR spectra of samples in the indicated solvent were run at $300 \mathrm{MHz}$ on a Bruker DPX-300 spectrometer. Chemical shifts are given in $\operatorname{ppm}(\delta)$ comparatively to the residual solvent signal, which was used as an internal reference $\left(\mathrm{CDCl}_{3}: \delta=7.26 \mathrm{ppm}\right.$; DMSO- $\left.d_{6}: \delta=2.50 \mathrm{ppm}\right) .{ }^{[1]}$ Coupling constants $(J)$ are given in Hertz $(\mathrm{Hz})$, and the following abbreviations are used to describe the signal multiplicity: s (singlet), bs (broad singlet), $\mathrm{d}$ (doublet), $\mathrm{t}$ (triplet), q (quadruplet), $\mathrm{m}$ (multiplet). ${ }^{13} \mathrm{C}$ NMR spectra of samples in the indicated solvent were run at $75.5 \mathrm{MHz}$ on a Bruker DPX-300 spectrometer. Chemical shifts are given in $\operatorname{ppm}(\delta)$ comparatively to the residual solvent signal, which was used as an internal reference $\left(\mathrm{CDCl}_{3}: \delta=77.16 \mathrm{ppm}\right.$; DMSO- $\left.d_{6}: \delta=39.52 \mathrm{ppm}\right)$. Low resolution (HRMS) mass spectra were obtained by electrospray ionization (ESIMS), and were recorded on a Thermo Finnigan LCQ Deca XP spectrometer using an ion trap mass with an electrospray source under atmospheric pressure, at the mass spectrometry laboratory of the Institut Européen de Chimie et Biologie (IECB, CNRS-UMS 3033). High resolution (HRMS) mass spectrometric analyses were obtained from the Centre d'Etude Structurale et d'Analyse des Molécules Organiques (CESAMO, Université de Bordeaux), France. Semi-preparative HPLC separations were performed using a Chiralcel ${ }^{\circledR}$ AS-H column $(250 \times 20 \mathrm{~mm}$ I.D. $)$ on a Varian system equipped with ProStar 215 pumps and a ProStar 320 UV-visible detector. Analytical HPLC experiments were performed using Chiralcel ${ }^{\circledR} \mathrm{OD}-\mathrm{H}, \mathrm{OJ}-\mathrm{H}$ and AS-H columns $(250 \times 4.6 \mathrm{~mm}$ I.D. $)$ on a Thermo system equipped with P1500 pumps and a UV 6000LP diode array detector. X-Ray analyses were carried out at the IECB X-ray facility (CNRS-UMS 3033) on a Rigaku ultrabright FR-X rotating anode at the copper K $\alpha$ wavelength $(1.54178 \AA)$. This diffractometer has a highly focused beam $(70 \mu \mathrm{m})$ achieved with the new VariMax VHF (Very High Flux) optics. The setup is completed with an AFC12 goniometer and an enhanced sensitivity Dectris Pilatus 200 detector. 
Synthesis of $(R)$ - and $(S)$-curcuphenols and their (S)IBX-mediated HPD/[4+2]-dimerization cascade conversions into the corresponding ortho-quinol-based cyclodimers

Preparation of the racemic curcuphenol ( \pm )-1e (Scheme S1). Racemic curcuphenol $( \pm)$-1e was synthesized using a four step sequence starting from commercially available 2-hydroxy-4methylacetophenone (4) and adapting/improving previously described procedures. ${ }^{[2,3]}$ The first step consisted in the methylation of phenol 4 upon treatment with methyliodide in the presence of potassium hydroxide, in dry THF at room temperature, to give compound $\mathbf{1 0}$ in an excellent yield of 97\% (Scheme S1). Freshly prepared Grignard reagent 4-methylpent-3-enemagnesium bromide ${ }^{[4]}$ was added to $\mathbf{1 0}$ in THF to afford the benzylic tertiary alcohol $\mathbf{1 1}$ in a very good yield of $90 \%$. Dehydroxylation of $\mathbf{1 1}$ was then performed using triethylsilane and $\mathrm{BF}_{3} \cdot \mathrm{Et}_{2} \mathrm{O}$ in $\mathrm{CH}_{2} \mathrm{Cl}_{2}$ at $-78{ }^{\circ} \mathrm{C}$, and furnished in an excellent yield of $96 \%$ compound 12, which was successfully demethylated, upon treatment with sodium ethanethiolate (NaSEt) in DMF at $130{ }^{\circ} \mathrm{C}$, to afford racemic curcuphenol $( \pm)$-1e in a very good $91 \%$ yield. Straightforward synthesis of $( \pm)$-1e was thus achieved in a $76 \%$ overall yield in 4 steps (Scheme $\mathrm{S} 1$ ).

N.B.: a scale-up allowed the preparation of a minimum of 2 grams of $( \pm)-1$ e per 4 step-sequence.

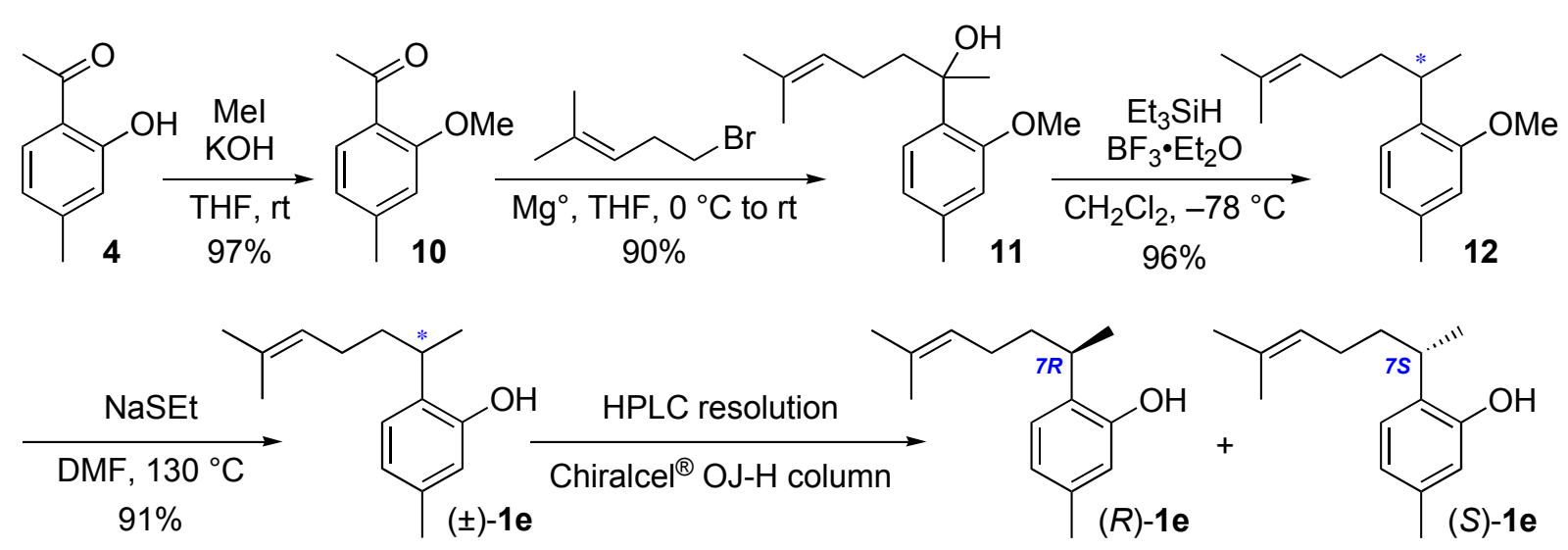

\section{Scheme S1.}

Separation of the two enantiomers of $( \pm)$-1e was then achieved by chiral normal phase semipreparative HPLC, which was performed on a Varian ProStar system equipped with a Daicel Chiralcel $^{\circledR} \mathrm{OJ}$-H column $(250 \times 21 \mathrm{~mm}$ I.D. $)$, and eluting with $n$-hexane/i-PrOH (98:2) at a flow rate of $10 \mathrm{~mL} / \mathrm{min}$. Successive injections (ca. $20 \mathrm{mg}$ each) of $( \pm)$-1e thus afforded pure (-)curcuphenol $(R)$-1e and pure (+)-curcuphenol $(S)$-1e ( $c a .8 \mathrm{mg}$ each by injection), and $4 \mathrm{mg}$ of a mixture $[$ i.e., $( \pm)-1 \mathrm{e}]$ that was further successfully separated. Column effluent was monitored by UV detection at $254 \mathrm{~nm}$ using a ProStar $320 \mathrm{UV}$-visible detector [analytical HPLC: retention time = $12.1 \mathrm{~min}$ for $(S)-1 \mathbf{e}$, and $17.5 \mathrm{~min}$ for $(R)$-1e] (Figure $\mathrm{S} 1$ ).

N.B.: attempts to use a chiral auxiliary (i.e., L-Boc-phenylalanine, L-Boc-valine, L-Boc-methionine, $(+)$-menthol, a tartaric acid or a mandelic acid derivative) were all unsuccessful. 


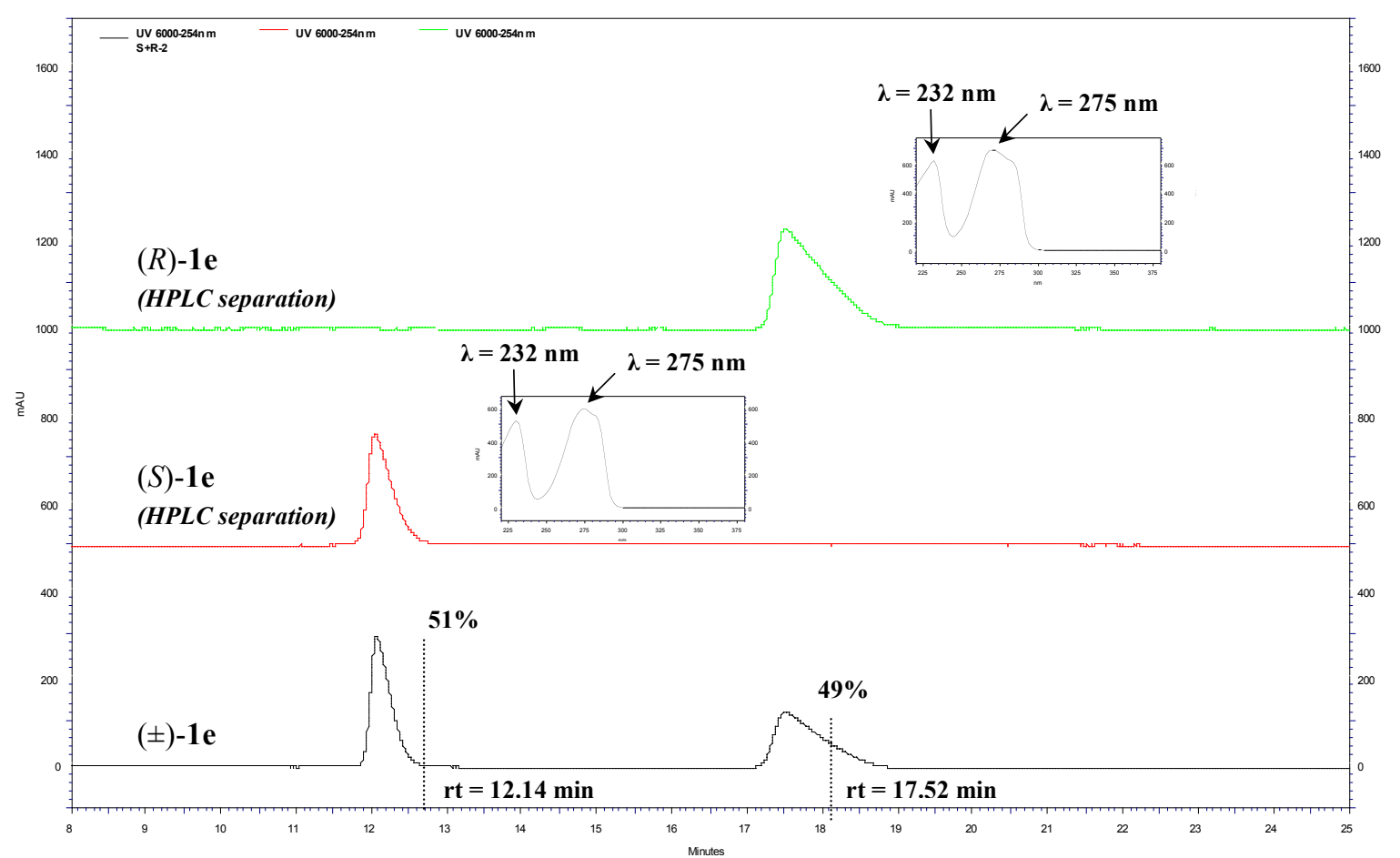

Figure S1. Chiral HPLC traces of curcuphenol $1 \mathbf{e}$.

Chiralcel ${ }^{\circledR}$ OJ-H column $(250 \times 4.6 \mathrm{~mm}$ I.D. $), n$-hexane $/ i$-PrOH $(98: 2), 1 \mathrm{~mL} / \mathrm{min}$, $\mathrm{UV}$ detection at $254 \mathrm{~nm}$ [retention time $=12.1 \mathrm{~min}$ for $(S)-1 \mathbf{e}$, and $17.5 \mathrm{~min}$ for $(R)-\mathbf{1 e}]$.

1-(2-Methoxy-4-methylphenyl)ethanone (10). To a stirred solution of commercial 2-hydroxy-4-

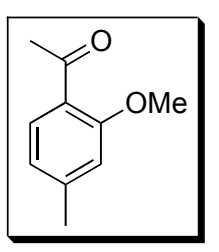
methylacetophenone $(4,0.50 \mathrm{~g}, 3.33 \mathrm{mmol})$ and $\mathrm{KOH}(0.28 \mathrm{~g}, 5.0 \mathrm{mmol})$ in dry THF $(8 \mathrm{~mL})$ was added dropwise MeI $(1.18 \mathrm{~g}, 8.31 \mathrm{mmol})$. The reaction mixture was stirred overnight at room temperature, after which time it was diluted with $\mathrm{CH}_{2} \mathrm{Cl}_{2}$ $\left(15 \mathrm{~mL}\right.$ ), washed with saturated aqueous $\mathrm{NH}_{4} \mathrm{Cl}$ and $\mathrm{H}_{2} \mathrm{O}$ until $\mathrm{pH} \approx 7$. The organic layer was dried over $\mathrm{MgSO}_{4}$, filtered and evaporated to dryness to give acetophenone 10 as a white powder (530 mg, 97\%), which was used without further purification: CAS Registry Number [35633-35-3]; mp 38-39 ${ }^{\circ} \mathrm{C}$ (lit. ${ }^{[3]} 37-38{ }^{\circ} \mathrm{C}$ ); IR (neat): $v=1670,1607$, 1465, $1259 \mathrm{~cm}^{-1} ;{ }^{1} \mathbf{H}$ NMR $\left(\mathrm{CDCl}_{3}, 300 \mathrm{MHz}\right) \delta=2.38(\mathrm{~s}, 3 \mathrm{H}), 2.59$ (s, 3H), 3.90 (s, 3H), $6.77(\mathrm{~s}$, $1 \mathrm{H}), 6.80(\mathrm{~d}, J=7.8 \mathrm{~Hz}, 1 \mathrm{H}), 7.67(\mathrm{~d}, J=7.8 \mathrm{~Hz}, 1 \mathrm{H}) ;{ }^{13} \mathbf{C ~ N M R}\left(\mathrm{CDCl}_{3}, 75 \mathrm{MHz}\right): \delta=199.2$, 159.1, 144.8, 130.6, 125.5, 121.4, 112.3, 55.4, 31.8, 21.9; LRMS (ESIMS): $m / z(\%)=165$ (70) $\left[\mathrm{MH}^{+}\right], 164(15)\left[\mathrm{M}^{+}\right], 149(10)$. These data were consistent with those previously reported. ${ }^{[3]}$

2-(2-Methoxy-4-methylphenyl)-6-methylhept-5-en-ol (11). To a stirred ice-cold solution of freshly prepared 4-methylpent-3-enemagnesium bromide ${ }^{[4]}(0.35 \mathrm{M}$ in THF,

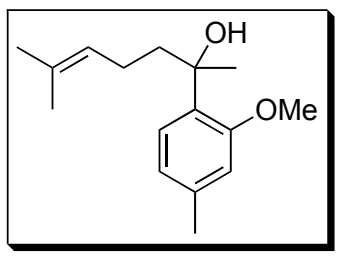
$1.74 \mathrm{mmol})$ in dry THF $(5 \mathrm{~mL})$ was added dropwise a solution of acetophenone $10(220 \mathrm{mg}, 1.34 \mathrm{mmol})$ in dry THF $(4 \mathrm{~mL})$. The resulting solution was stirred at room temperature for $1 \mathrm{~h}$, after which time it was cooled at $0{ }^{\circ} \mathrm{C}$, and saturated aqueous $\mathrm{NH}_{4} \mathrm{Cl}(10 \mathrm{~mL})$ was added. The reaction mixture was diluted with $\mathrm{CH}_{2} \mathrm{Cl}_{2}(15 \mathrm{~mL})$, and washed with saturated aqueous $\mathrm{NH}_{4} \mathrm{Cl}(15 \mathrm{~mL})$ and $\mathrm{H}_{2} \mathrm{O}$ until $\mathrm{pH} \approx 7$. The organic layer was dried over $\mathrm{MgSO}_{4}$, filtered and evaporated to dryness. Purification of the oily residue by column chromatography, eluting with PET/acetone (97:3), gave the benzylic alcohol 11 as a pale yellow oil (300 mg, 90\%): CAS Registry Number [31573-16-7]; IR (neat) $v=3472,2964,2920$, 1612, 1455, $1252 \mathrm{~cm}^{-1} ;{ }^{1} \mathbf{H}$ NMR $\left(\mathrm{CDCl}_{3}, 300 \mathrm{MHz}\right) \delta=1.52(\mathrm{bs}, 3 \mathrm{H}), 1.55(\mathrm{~s}, 3 \mathrm{H}), 1.65$ (bs, 3H), 1.52-2.03 (m, 4H), $2.34(\mathrm{~s}, 3 \mathrm{H}), 3.87(\mathrm{~s}, 3 \mathrm{H}), 5.05-5.11(\mathrm{~m}, 1 \mathrm{H}), 6.72(\mathrm{bs}, 1 \mathrm{H}), 6.76(\mathrm{~m}, 1 \mathrm{H}), 7.16$ $(\mathrm{d}, J=7.8 \mathrm{~Hz}, 1 \mathrm{H}) ;{ }^{13} \mathbf{C} \mathbf{N M R}\left(\mathrm{CDCl}_{3}, 75 \mathrm{MHz}\right): \delta=156.7,137.9,131.8,131.3,126.6,124.6$, 
121.3, 121.2, 74.9, 55.2, 42.1, 27.4, 25.6, 23.3, 21.2, 17.5; LRMS (ESIMS): $m / z(\%)=248(10)$ $\left[M^{+}\right], 165(85), 147(5)$. These data were consistent with those previously reported. ${ }^{[3]}$

2-Methoxy-4-methyl-1-(6-methylhept-5-en-2-yl)benzene (12). A stirred solution of 11 (295 mg,

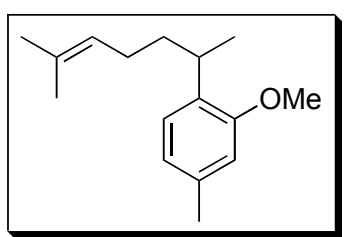
$1.19 \mathrm{mmol})$ in dry $\mathrm{CH}_{2} \mathrm{Cl}_{2}(5 \mathrm{~mL})$ was cooled at $-78{ }^{\circ} \mathrm{C}$, and then treated dropwise with $\mathrm{Et}_{3} \mathrm{SiH}(166 \mathrm{mg}, 1.42 \mathrm{mmol})$. Stirring at $-78{ }^{\circ} \mathrm{C}$ was maintained for $10 \mathrm{~min}$, after which time $\mathrm{BF}_{3} \bullet \mathrm{Et}_{2} \mathrm{O}(270 \mathrm{mg}, 1.90 \mathrm{mmol})$ was added dropwise. The reaction mixture was stirred at $-78^{\circ} \mathrm{C}$ for 1 additional hour, then diluted with $\mathrm{CH}_{2} \mathrm{Cl}_{2}(15 \mathrm{~mL})$, and washed with saturated aqueous $\mathrm{NH}_{4} \mathrm{Cl}(15 \mathrm{~mL})$ and $\mathrm{H}_{2} \mathrm{O}$ until $\mathrm{pH} \approx 7$. The organic layer was dried over $\mathrm{MgSO}_{4}$, filtered and evaporated to dryness to furnish 12 as a colorless oil (265 $\mathrm{mg}$, 96\%), which was used without further purification: CAS Registry Number [66879-51-4]; IR (neat): $v=2959$, 2924, 2855, 1610, 1575, 1411, $1259 \mathrm{~cm}^{-1} ;{ }^{1} \mathbf{H}$ NMR $\left(\mathrm{CDCl}_{3}, 300 \mathrm{MHz}\right) \delta=1.17(\mathrm{~d}, J=7.0 \mathrm{~Hz}$, $3 \mathrm{H}), 1.45-1.55(\mathrm{~m}, 1 \mathrm{H}), 1.54(\mathrm{bs}, 3 \mathrm{H}), 1.60-1.70(\mathrm{~m}, 1 \mathrm{H}), 1.67(\mathrm{bs}, 3 \mathrm{H}), 1.84-1.98(\mathrm{~m}, 2 \mathrm{H}), 2.33(\mathrm{~s}$, $3 \mathrm{H}), 3.12(\mathrm{~m}, 1 \mathrm{H}), 3.80(\mathrm{~s}, 3 \mathrm{H}), 5.09-5.15(\mathrm{~m}, 1 \mathrm{H}), 6.67(\mathrm{~s}, 1 \mathrm{H}), 6.73(\mathrm{~d}, J=8.0 \mathrm{~Hz}, 1 \mathrm{H}), 7.04(\mathrm{~d}, J$ $=8.0 \mathrm{~Hz}, 1 \mathrm{H}) ;{ }^{13} \mathbf{C ~ N M R}\left(\mathrm{CDCl}_{3}, 75 \mathrm{MHz}\right): \delta=156.9,136.2,132.9,131.0,126.5,124.9,121.1$, 111.5, 55.3, 37.2 31.4, 26.3, 25.7, 21.4, 21.1, 17.6; LRMS (ESIMS): $\mathrm{m} / z(\%)=232(40)\left[M^{+}\right], 217$ (35), 189 (19). These data were consistent with those previously reported. ${ }^{[3]}$

5-Methyl-2-(6-methylhept-5-en-2-yl)phenol $[( \pm)$-curcuphenol, $( \pm)-1 \mathrm{e}]$. To a stirred ice-cold

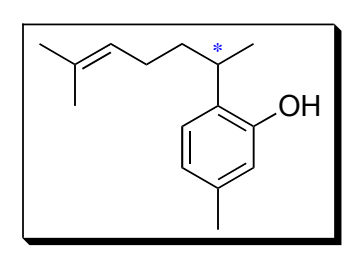
suspension of $\mathrm{NaH}(60 \%$ in mineral oil, $775 \mathrm{mg}, 19.4 \mathrm{mmol})$ in dry DMF (10 $\mathrm{mL})$, was added dropwise EtSH (1,018 $\mathrm{g}, 16.4 \mathrm{mmol})$. The resulting mixture was stirred at room temperature for 2 hours, after which time a solution of $\mathbf{1 2}$ (347 mg, $1.49 \mathrm{mmol})$ in dry DMF $(5 \mathrm{~mL})$ was added. The reaction mixture was then refluxed (i.e., $150^{\circ} \mathrm{C}$ ) for $3 \mathrm{~h}$. A $0.1 \mathrm{M} \mathrm{HCl}$ aqueous solution $(8 \mathrm{~mL})$ and $\mathrm{CH}_{2} \mathrm{Cl}_{2}(35 \mathrm{~mL})$ were added, and after separation of the two phases, the organic layer was washed with $\mathrm{H}_{2} \mathrm{O}(2 \times 10 \mathrm{~mL})$, dried over $\mathrm{MgSO}_{4}$, filtered and evaporated to dryness. The resulting oily residue was subjected to column chromatography, eluting with PET/acetone (95:5), to afford phenol $( \pm)$-1e as a pale yellow oil (297 mg, 91\%): CAS Registry Number [69301-27-5]; IR (neat): $v=3425,2959,2855,1620,1517,1419,1259 \mathrm{~cm}^{-1}$; ${ }^{1} \mathbf{H}$ NMR $\left(\mathrm{CDCl}_{3}, 300 \mathrm{MHz}\right) \delta=1.22(\mathrm{~d}, J=7.0 \mathrm{~Hz}, 3 \mathrm{H}), 1.54(\mathrm{bs}, 3 \mathrm{H}), 1.56-1.66(\mathrm{~m}, 2 \mathrm{H}), 1.68(\mathrm{bs}, 3 \mathrm{H})$, 1.90-1.97 (m, 2H), 2.27 (s, 3H), 2.96 (sext., $J=7.0 \mathrm{~Hz}, 1 \mathrm{H}), 4.66$ (s, 1H), 5.10-5.15 (m, 1H), 6.59 $(\mathrm{s}, 1 \mathrm{H}), 6.72(\mathrm{~d}, J=7.5 \mathrm{~Hz}, 1 \mathrm{H}), 7.03(\mathrm{~d}, J=7.5 \mathrm{~Hz}, 1 \mathrm{H}) ;{ }^{13} \mathbf{C} \mathbf{N M R}\left(\mathrm{CDCl}_{3}, 75 \mathrm{MHz}\right): \delta=152.8$, 135.5, 132.0, 129.9, 126.8, 124.6, 121.7, 116.2, 37.3, 31.4, 26.1, 25.7, 21.1, 20.9, 17.7; LRMS (ESIMS, negative mode): $m / z(\%)=217(25)\left[M^{+}-\mathrm{H}\right], 228(70), 242$ (100). These data were consistent with those previously reported. ${ }^{[2,3]}$

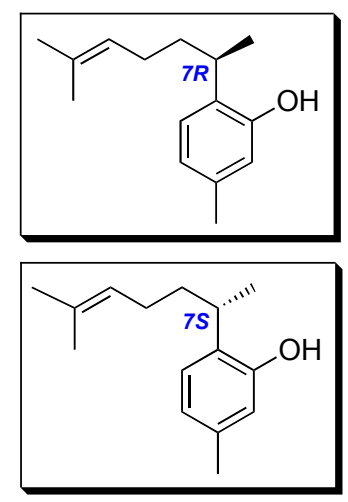

(R)-(-)-Curcuphenol [(R)-1e].

CAS Registry Number [69301-27-5].

$[\alpha]^{\mathbf{2 5}}=-33.1\left(c=1.0, \mathrm{CHCl}_{3}\right)\left[{ }^{[\text {lit. }}{ }^{[5]}[\alpha]_{\mathrm{D}}^{25}=-23.6\left(c=1.0, \mathrm{CHCl}_{3}\right)\right]$.

${ }^{1} \mathrm{H}$ and ${ }^{13} \mathrm{C}$ NMR data were identical to those reported for $( \pm)-\mathbf{1 e}$.

(S)-(+)-Curcuphenol [(S)-1e].

CAS Registry Number [70878-71-6].

$[\alpha]^{25}=+30.3\left(c=1.0, \mathrm{CHCl}_{3}\right)\left[{ }_{\mathrm{D}}{ }^{[\mathrm{it} .}{ }^{[6]}[\alpha]_{\mathrm{D}}^{25}=+24.6\left(c=1.0, \mathrm{CHCl}_{3}\right)\right]$.

${ }^{1} \mathrm{H}$ and ${ }^{13} \mathrm{C}$ NMR data were identical to those reported for $( \pm)-\mathbf{1 e}$.

(S)IBX-mediated HPD/[4+2]-dimerization cascade conversion of $(R)-(-)$ - and $(S)-(+)-$ curcuphenols $(\boldsymbol{R})-1 \mathrm{e}$ and $(S)-1 \mathrm{e}$. Each enantiomer of curcuphenol 1e was subjected to our (S)IBXmediated hydroxylative phenol dearomatization (HPD) reaction, using either IBX (i.e., 2- 
iodylbenzoic acid) or its stabilized version SIBX (vide supra). ${ }^{[7,8]}$ These HPD-induced transformations were performed in dry THF at room temperature, followed by the addition of trifluoroacetic acid (TFA), and furnished 3:2 diastereomeric mixtures of the corresponding cyclodimers in good yields of 62-69\% (see the main text: Scheme 2).

Separation of these two 3:2 diastereomeric mixtures was next achieved by chiral normal phase semi-preparative HPLC, which was performed on a Varian ProStar system equipped with a Daicel Chiralpak $^{\circledR}$ AS-H column $(250 \times 21 \mathrm{~mm}$ I.D. $)$, and eluting with $n$-hexane $/ i$-PrOH $(95: 5)$ at a flow rate of $10 \mathrm{~mL} / \mathrm{min}$. Column effluent was monitored by UV detection at $254 \mathrm{~nm}$ using a ProStar 320 $\mathrm{UV}$-visible detector [see analytical HPLC traces $(1 \mathrm{~mL} / \mathrm{min})$ in Figures $\mathrm{S} 2$ and $\mathrm{S} 3)$ ].

Procedure. To a stirred solution of curcuphenol, either $(R)$ - or $(S)$-1e (ca. $70 \mathrm{mg}, 0.15 \mathrm{mmol})$, in dry THF (4 mL, ca. $0.04 \mathrm{M}$ ) was added (S)IBX (3 equiv of IBX) in one portion. The resulting suspension was stirred at room temperature for 18 hours, after which time TFA (1 equiv) was added and the mixture stirred for an additional 6 hours. The mixture was then diluted with $\mathrm{CH}_{2} \mathrm{Cl}_{2}(10$ $\mathrm{mL})$ and $\mathrm{H}_{2} \mathrm{O}(10 \mathrm{~mL})$. An aqueous $1 \mathrm{M}$ solution of $\mathrm{NaOH}(5 \mathrm{~mL})$ was added dropwise until $\mathrm{pH} \approx$ 8 , with the aim of both neutralizing the reaction mixture and discarding the stabilizing agents when SIBX was used. After separation of the phases, the aqueous layer was extracted with $\mathrm{CH}_{2} \mathrm{Cl}_{2}(3 \mathrm{x}$ $10 \mathrm{~mL})$. The combined organic layers were successively washed with aqueous $1 \mathrm{M} \mathrm{NaOH}(15 \mathrm{~mL})$ and brine $(15 \mathrm{~mL})$, shaken vigorously with a saturated aqueous solution of $\mathrm{Na}_{2} \mathrm{~S}_{2} \mathrm{O}_{4}$ with the aim of reducing the potentially formed ortho-quinone by-product, ${ }^{[18]}$ washed again with brine $(40 \mathrm{~mL})$, dried over $\mathrm{MgSO}_{4}$, filtered and evaporated to dryness. The resulting oily residue was subjected to column chromatography, eluting with cyclohexane/EtOAc $(9: 1)$, to give a clean 3:2 diastereomeric mixture of the corresponding cyclodimers as yellow oils [i.e., $(3 R, 10 R, 13 R, 22 R)-3 \mathbf{e} /$ $(3 S, 10 S, 13 R, 22 R)-3 \mathbf{e}$ obtained from $(R)-\mathbf{1 e}$, and $(3 S, 10 S, 13 S, 22 S)-\mathbf{3 e} /(3 R, 10 R, 13 S, 22 S)-\mathbf{3 e}$ obtained from $(S)-1 e]$ in $62-69 \%$ isolated yield]. Further separation of each diastereoisomer was performed by semi-preparative HPLC (vide supra, and Figures S2-3).

N.B.: no catechol resulting from the reduction of the potentially formed ortho-quinone by-product was observed.

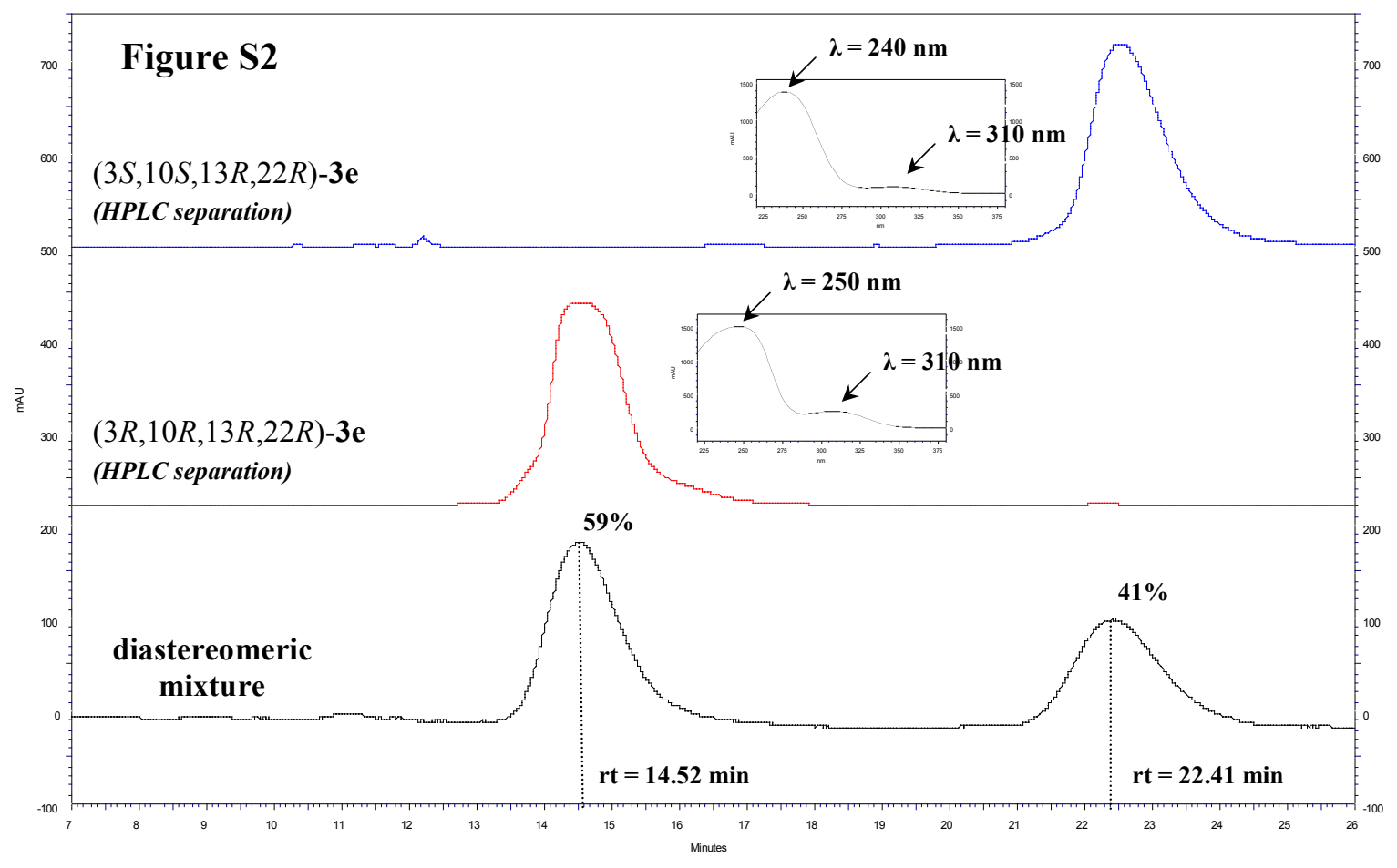




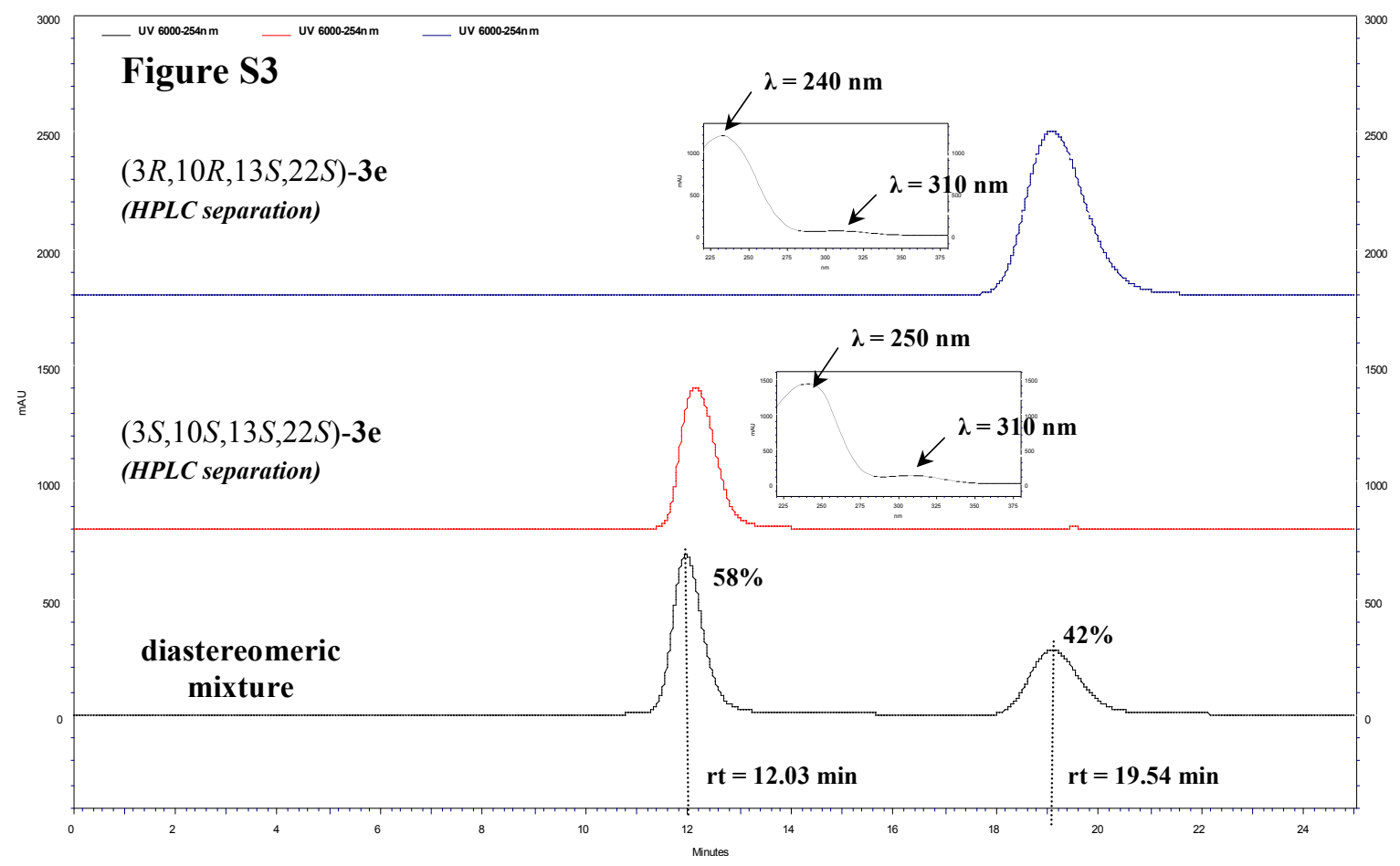

$(3 R, 10 R, 13 R, 22 R)-(+)-3,10-D i h y d r o x y-3,10-d i(6-m e t h y l h e p t-5-e n-2-y l) t r i c y c l o\left[6.2 .2 .0^{2,7}\right]$ dodeca-5,11-diene-4,9-dione [ent-bacchopetiolone, $(3 R, 10 R, 13 R, 22 R)-3 \mathrm{e}=(\mathrm{all} R)-3 \mathrm{e}]$. Yellow

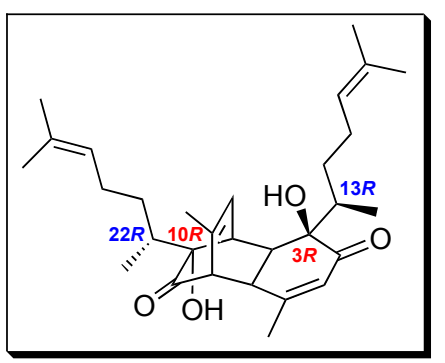
oil (65\% HPLC yield, i.e., $48 \mathrm{mg}$ isolated from $74 \mathrm{mg}$ of the $3: 2$ diastereomeric mixture): $[\boldsymbol{\alpha}]^{\mathbf{2 0}}{ }_{\mathbf{D}}=+135.8\left(c=2.17, \mathrm{CHCl}_{3}\right) ; \mathbf{C D}(c=$ $0.001, \mathrm{MeOH}): \lambda(\Delta \varepsilon)=342(-0.9), 310(+7.1)$; IR (neat): $v=3459$, $2967,2930,1719,1678,1448,1379,1153,733 \mathrm{~cm}^{-1} ;{ }^{1} \mathbf{H} \mathbf{~ N M R}\left(\mathrm{CDCl}_{3}\right.$, $300 \mathrm{MHz}): \delta=0.59(\mathrm{~d}, J=6.6 \mathrm{~Hz}, 3 \mathrm{H}), 0.86(\mathrm{~d}, J=6.9 \mathrm{~Hz}, 3 \mathrm{H}), 1.04-$ $1.45(\mathrm{~m}, 5 \mathrm{H}), 1.56(\mathrm{bs}, 6 \mathrm{H}), 1.61(\mathrm{~d}, J=1.2 \mathrm{~Hz}, 3 \mathrm{H}), 1.66(\mathrm{bs}, 6 \mathrm{H})$, $1.73-1.90(\mathrm{~m}, 3 \mathrm{H}), 1.96(\mathrm{~s}, 3 \mathrm{H}), 1.96-2.10(\mathrm{~m}, 2 \mathrm{H}), 2.27(\mathrm{~s}, 1 \mathrm{H}, \mathrm{OH})$; 3.02 (br dd, $J=1.8,8.1 \mathrm{~Hz}, 1 \mathrm{H}), 3.16$ (t, $J=1.8 \mathrm{~Hz}, 1 \mathrm{H}), 3.28(\mathrm{~d}, J=$ $8.1 \mathrm{~Hz}, 1 \mathrm{H}), 3.34(\mathrm{dd}, J=1.8,6.6 \mathrm{~Hz}, 1 \mathrm{H}), 3.81(\mathrm{~s}, 1 \mathrm{H}, \mathrm{OH}), 5.01(\mathrm{t}, J$ $=6.6 \mathrm{~Hz}, 1 \mathrm{H}), 5.07(\mathrm{t}, J=6.6 \mathrm{~Hz}, 1 \mathrm{H}), 5.80(\mathrm{~d}, J=6.6 \mathrm{~Hz}, 1 \mathrm{H}), 5.98(\mathrm{~s}, 1 \mathrm{H}) ;{ }^{13} \mathbf{C ~ N M R}\left(\mathrm{CDCl}_{3}, 75\right.$ $\mathrm{MHz}): \delta=214.7,201.6,155.8,135.4,131.8,131.7,126.6,125.4,124.4,124.1,78.7,78.3,57.2$, 47.4, 41.8, 41.4, 37.3, 37.1, 30.6, 30.0, 26.2, 25.7, 25.6, 22.0, 21.3, 17.7, 17.6, 13.9, 12.7; LRMS (ESIMS): $m / z(\%)=491(40)\left[M \mathrm{Na}^{+}\right], 959(100)\left[2 M+\mathrm{Na}^{+}\right]$; HRMS (ESI): calcd for $\mathrm{C}_{30} \mathrm{H}_{44} \mathrm{O}_{4} \mathrm{Na}$ 491.3132, found 491.3133 .

$(3 S, 10 S, 13 R, 22 R)-(-)-3,10-D i h y d r o x y-3,10-d i(6-m e t h y l h e p t-5-e n-2-y l) t r i c y c l o\left[6.2 .2 .0^{2,7}\right]$

dodeca-5,11-diene-4,9-dione $\left[(3 S, 10 S, 13 R, 22 R)-3 d=3 \mathrm{e}^{\prime}\right]$. Colourless plates obtained by

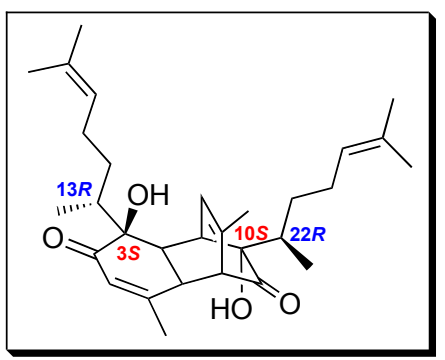
crystallization from hot hexanes (35\% HPLC yield, i.e., $26 \mathrm{mg}$ isolated from $74 \mathrm{mg}$ of the $2: 3$ diastereomeric mixture): $[\alpha]^{20}{ }_{\mathbf{D}}=-48.7(c=$ $\left.2.17, \mathrm{CHCl}_{3}\right) ; \mathbf{C D}(c=0.003, \mathrm{MeOH}): \lambda(\Delta \varepsilon)=342(+16.4), 310(-$ 26.1); IR (neat): $v=3459,2970,2927,1719,1682,1445,1383,1131$, $1018 \mathrm{~cm}^{-1} ;{ }^{1} \mathbf{H}$ NMR $\left(\mathrm{CDCl}_{3}, 300 \mathrm{MHz}\right): \delta=0.82(\mathrm{~d}, J=6.9 \mathrm{~Hz}, 3 \mathrm{H})$, $0.82-0.91(\mathrm{~m}, 1 \mathrm{H}), 0.97(\mathrm{~d}, J=6.6 \mathrm{~Hz}, 3 \mathrm{H}), 0.96-1.10(\mathrm{~m}, 2 \mathrm{H}), 1.33-$ $1.47(\mathrm{~m}, 1 \mathrm{H}), 1.51-1.61(\mathrm{~m}, 2 \mathrm{H}), 1.54(\mathrm{~d}, J=3.0 \mathrm{~Hz}, 6 \mathrm{H}), 1.61(\mathrm{~d}, J=$ $1.2 \mathrm{~Hz}, 3 \mathrm{H}) ; 1.64(\mathrm{~d}, J=3.6 \mathrm{~Hz}, 6 \mathrm{H}), 1.69-1.85(\mathrm{~m}, 2 \mathrm{H}), 1.91-2.05(\mathrm{~m}$, 2H), 1.96 (bs, 3H), 2.18 (s, 1H, OH), 3.09 (d, $J=8.1 \mathrm{~Hz}, 1 \mathrm{H}), 3.17$ (t, $J$ $=1.8 \mathrm{~Hz}, 1 \mathrm{H}), 3.28(\mathrm{bt}, J=6.9 \mathrm{~Hz}, 2 \mathrm{H}), 3.75(\mathrm{~s}, 1 \mathrm{H}, \mathrm{OH}), 4.92(\mathrm{t}, J=6.9 \mathrm{~Hz}, 1 \mathrm{H}), 5.00(\mathrm{t}, J=6.9$ $\mathrm{Hz}, 1 \mathrm{H}), 5.81(\mathrm{~d}, J=6.9 \mathrm{~Hz}, 1 \mathrm{H}), 5.97(\mathrm{~s}, 1 \mathrm{H}) ;{ }^{13} \mathbf{C ~ N M R}\left(\mathrm{CDCl}_{3}, 75 \mathrm{MHz}\right): \delta=214.7,202.6$, $155.8,135.5,131.7,131.7,126.7,125.5,124.2,124.1,78.6,78.6,57.3,47.3,41.7,41.7,37.9,37.3$, 

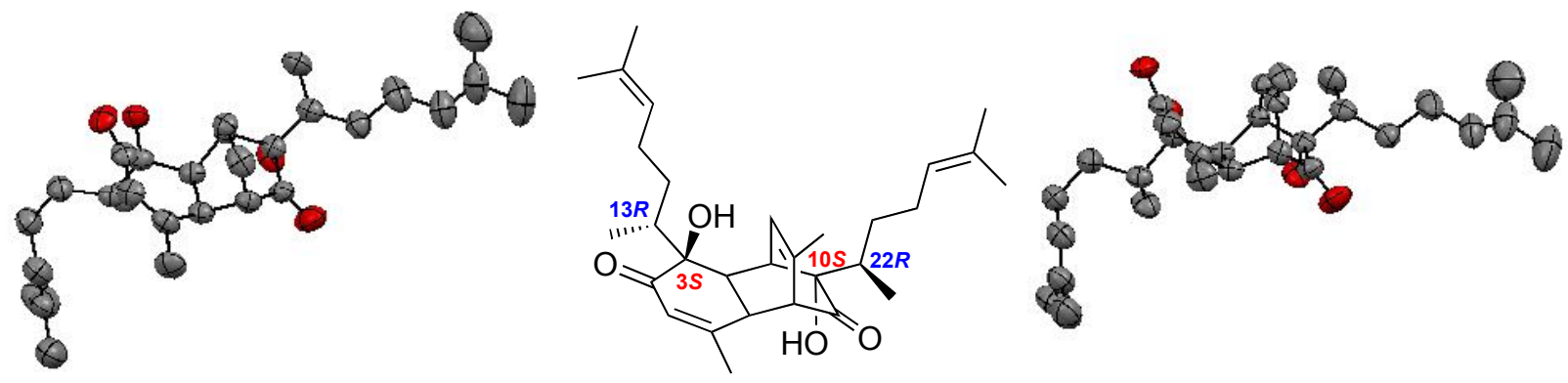

Figure S4. ORTEP views of 3e' [CCDC-993815].

(3S,10S,13S,22S)-(-)-3,10-Dihydroxy-3,10-di(6-methylhept-5-en-2-yl)tricyclo[6.2.2.0 $\left.{ }^{2,7}\right]$ dodeca-5,11-diene-4,9-dione [bacchopetiolone, $(3 S, 10 S, 13 S, 22 S)-3 \mathrm{e}=($ all $S)-3 \mathrm{e}]$. Yellow oil

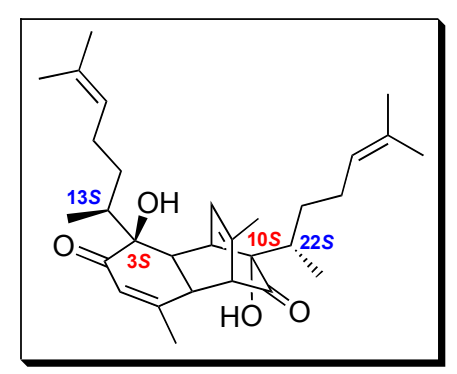
(60\% HPLC yield, i.e., $40 \mathrm{mg}$ isolated from $67 \mathrm{mg}$ of the $3: 2$ diastereomeric mixture): CAS Registry Number [135100-33-3]; $[\boldsymbol{\alpha}]^{\mathbf{2 0}}{ }_{\mathbf{D}}$ $=-135.6\left(c=2.17, \mathrm{CHCl}_{3}\right)\left\{\right.$ lit. $\left.^{[9]}[\alpha]^{24}{ }_{\mathrm{D}}-125\left(c=2.17, \mathrm{CHCl}_{3}\right)\right\} ; \mathbf{C D}$ $(c=0.001, \mathrm{MeOH}): \lambda(\Delta \varepsilon)=342(+1.3), 310(-8.5)\left[{ }^{1 i t}{ }^{[9]} \mathrm{CD}(\mathrm{MeOH})\right.$ : $\lambda(\Delta \varepsilon)=342(+0.2), 306(-4.6)]$; IR (neat): $v=3459,2967,2930$, $1719,1678,1448,1379,1153,733 \mathrm{~cm}^{-1} ;{ }^{1} \mathbf{H} \mathbf{N M R}\left(\mathrm{CDCl}_{3}, 300 \mathrm{MHz}\right)$ : $\delta=0.59(\mathrm{~d}, J=6.6 \mathrm{~Hz}, 3 \mathrm{H}), 0.86(\mathrm{~d}, J=6.9 \mathrm{~Hz}, 3 \mathrm{H}), 1.04-1.45(\mathrm{~m}$, $5 \mathrm{H}), 1.56(\mathrm{bs}, 6 \mathrm{H}), 1.61(\mathrm{~d}, J=1.2 \mathrm{~Hz}, 3 \mathrm{H}), 1.66(\mathrm{bs}, 6 \mathrm{H}), 1.73-1.90$ (m, 3H), $1.96(\mathrm{~s}, 3 \mathrm{H}), 1.96-2.10(\mathrm{~m}, 2 \mathrm{H}), 2.27(\mathrm{~s}, 1 \mathrm{H}, \mathrm{OH}) ; 3.02(\mathrm{br} \mathrm{dd}, J=1.8,8.1 \mathrm{~Hz}, 1 \mathrm{H}), 3.16$ $(\mathrm{t}, J=1.8 \mathrm{~Hz}, 1 \mathrm{H}), 3.28(\mathrm{~d}, J=8.1 \mathrm{~Hz}, 1 \mathrm{H}), 3.34(\mathrm{dd}, J=1.8,6.6 \mathrm{~Hz}, 1 \mathrm{H}), 3.81(\mathrm{~s}, 1 \mathrm{H}, \mathrm{OH}), 5.01$ $(\mathrm{t}, J=6.6 \mathrm{~Hz}, 1 \mathrm{H}), 5.07(\mathrm{t}, J=6.6 \mathrm{~Hz}, 1 \mathrm{H}), 5.80(\mathrm{~d}, J=6.6 \mathrm{~Hz}, 1 \mathrm{H}), 5.98(\mathrm{~s}, 1 \mathrm{H}) ;{ }^{13} \mathbf{C}$ NMR $\left(\mathrm{CDCl}_{3}, 75 \mathrm{MHz}\right): \delta=214.7,201.6,155.8,135.4,131.8,131.7,126.6,125.4,124.4,124.1,78.7$, 78.3, 57.2, 47.4, 41.8, 41.4, 37.3, 37.1, 30.6, 30.0, 26.2, 25.7, 25.6, 22.0, 21.3, 17.7, 17.6, 13.9, 12.7; LRMS (ESIMS): $m / z(\%)=491(40)\left[\mathrm{MNa}^{+}\right], 959(100)\left[2 M+\mathrm{Na}^{+}\right]$; HRMS (ESI): calcd for $\mathrm{C}_{30} \mathrm{H}_{44} \mathrm{O}_{4} \mathrm{Na}$ 491.3132, found 491.3133. These data were consistent with those previously reported. ${ }^{[9]}$

$(3 R, 10 R, 13 S, 22 S)-(+)-3,10-D i h y d r o x y-3,10-d i(6-m e t h y l h e p t-5-e n-2-y l) t r i c y c l o\left[6.2 .2 .0^{2,7}\right]$

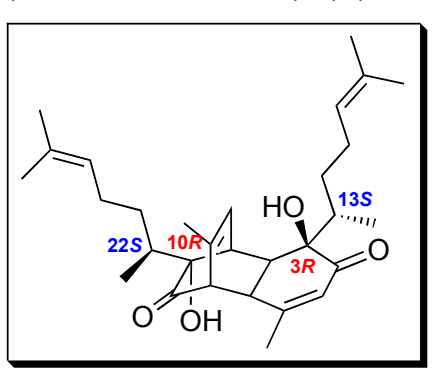
dodeca-5,11-diene-4,9-dione $\left[(3 R, 10 R, 13 S, 22 S)-3 \mathrm{e}=3 \mathrm{e}^{\prime \prime}\right]$. Yellow oil (40\% HPLC yield, i.e., $27 \mathrm{mg}$ isolated from $67 \mathrm{mg}$ of the $2: 3$ diastereomeric mixture): $[\alpha]^{\mathbf{2 0}} \mathbf{D}=+49.3\left(c=2.17, \mathrm{CHCl}_{3}\right) ; \mathbf{C D}(c=$ $0.003, \mathrm{MeOH}): \lambda(\Delta \varepsilon)=342(-16.7), 310(+27.3)$; IR (neat): $v=3459$, 2970, 2927, 1719, 1682, 1445, 1383, 1131, $1018 \mathrm{~cm}^{-1} ;{ }^{1} \mathbf{H}$ NMR $\left(\mathrm{CDCl}_{3}, 300 \mathrm{MHz}\right): \delta=0.82(\mathrm{~d}, J=6.9 \mathrm{~Hz}, 3 \mathrm{H}), 0.82-0.91(\mathrm{~m}, 1 \mathrm{H})$, $0.97(\mathrm{~d}, J=6.6 \mathrm{~Hz}, 3 \mathrm{H}), 0.96-1.10(\mathrm{~m}, 2 \mathrm{H}), 1.33-1.47(\mathrm{~m}, 1 \mathrm{H}), 1.51-$ $1.61(\mathrm{~m}, 2 \mathrm{H}), 1.54(\mathrm{~d}, J=3.0 \mathrm{~Hz}, 6 \mathrm{H}), 1.61(\mathrm{~d}, J=1.2 \mathrm{~Hz}, 3 \mathrm{H}) ; 1.64(\mathrm{~d}$, $J=3.6 \mathrm{~Hz}, 6 \mathrm{H}), 1.69-1.85(\mathrm{~m}, 2 \mathrm{H}), 1.91-2.05(\mathrm{~m}, 2 \mathrm{H}), 1.96(\mathrm{bs}, 3 \mathrm{H}), 2.18(\mathrm{~s}, 1 \mathrm{H}, \mathrm{OH}), 3.09(\mathrm{~d}, J=$ $8.1 \mathrm{~Hz}, 1 \mathrm{H}) ; 3.17(\mathrm{t}, J=1.8 \mathrm{~Hz}, 1 \mathrm{H}), 3.28(\mathrm{bt}, J=6.9 \mathrm{~Hz}, 2 \mathrm{H}), 3.75(\mathrm{~s}, 1 \mathrm{H}, \mathrm{OH}), 4.92(\mathrm{t}, J=6.9$ $\mathrm{Hz}, 1 \mathrm{H}), 5.00(\mathrm{t}, J=6.9 \mathrm{~Hz}, 1 \mathrm{H}), 5.81(\mathrm{~d}, J=6.9 \mathrm{~Hz}, 1 \mathrm{H}), 5.97(\mathrm{~s}, 1 \mathrm{H}) ;{ }^{13} \mathbf{C} \mathbf{N M R}\left(\mathrm{CDCl}_{3}, 75\right.$ MHz): $\delta=214.7,202.6,155.8,135.5,131.7,131.7,126.7,125.5,124.2,124.1,78.6,78.6,57.3$, 47.3, 41.7, 41.7, 37.9, 37.3, 30.7, 29.9, 26.0, 25.7, 25.6, 25.5, 22.0, 21.3, 17.6, 13.7, 12.5; LRMS (ESIMS): $m / z(\%)=491(28)\left[M \mathrm{Na}^{+}\right], 959(100)\left[2 M+\mathrm{Na}^{+}\right]$; HRMS (ESI) calcd for $\mathrm{C}_{30} \mathrm{H}_{44} \mathrm{O}_{4} \mathrm{Na}$ 491.3132, found 491.3140 . 
Preparation of the $C_{2}$-symmetrical Salen-type bis(iodoarenes) (Scheme S2). Amide bond formation between a chiral diamine and an ortho-iodinated aromatic carboxylic acid was carried out under standard peptide coupling conditions (i.e., DIEA and $\mathrm{HBTU}$ in $\mathrm{CH}_{2} \mathrm{Cl}_{2}$; vide infra), and gave a straightforward access to a series of $C_{2}$-symmetrical Salen-type bis(iodoarenes) (Scheme S2). Commercially available $(1 R, 2 R)-(-)$-diaminocyclohexane $[(R, R)-\mathbf{1 3}], \quad(1 S, 2 S)-(+)$-diaminocyclohexane $[(S, S)-13]$ and $(1 S, 2 S)-(-)$-diphenyl-ethylenediamine $[(S, S)-14]$, as well as $(R, R)-$ and $(S, S)$-trans-11,12-diamino-9,10-dihydro-9,10-ethanoanthracenes $[(R, R)-15$ and $(S, S)-15]$, were selected as chiral diamines, while commercial 2-iodo- and 2-iodo-3-methyl-benzoic acids, as well as 3,5-dimethyl-2-iodobenzoic acid (16) and 3-iodo-2-naphthoic acid (17), were chosen as orthoiodinated aromatic carboxylic acids (Scheme S2). Iodocompounds $\mathbf{1 6}$ and $\mathbf{1 7}$ were easily prepared from their corresponding aromatic primary amines using standard Sandmeyer reaction conditions (vide infra).

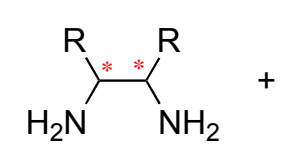

chiral diamine<smiles>C=CC1C=CCC1</smiles>

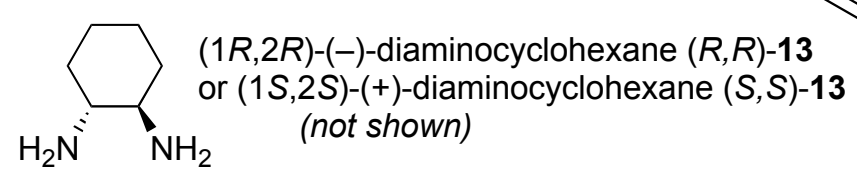<smiles>NC(c1ccccc1)C1c2ccccc2-c2ccccc21</smiles><smiles>[X][14c]1ccc2cc(I)c(C(=O)O)cc2c1</smiles>
ortho-iodinated aromatic carboxylic acid

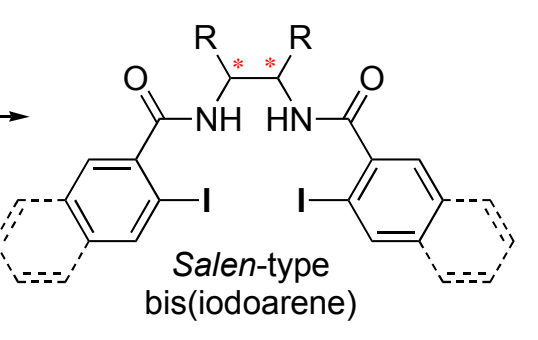
selection bis(iodoarene)

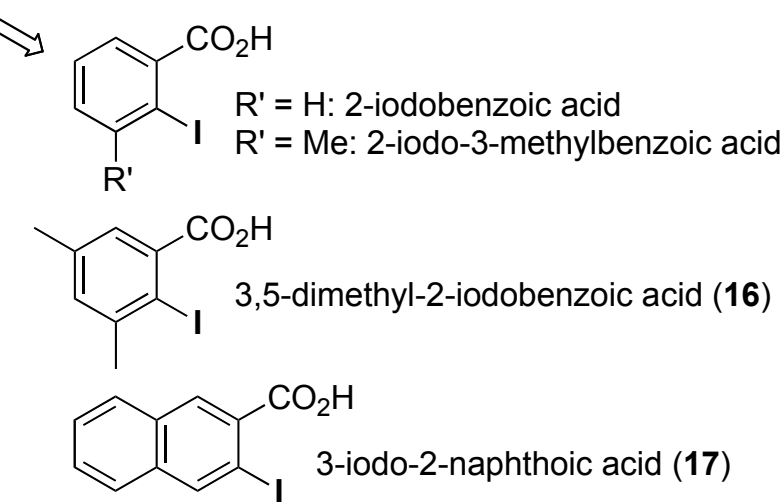

\section{Scheme S2.}

General procedure for the preparation of the ortho-iodinated acids $\mathbf{1 6}$ and $\mathbf{1 7}$. To an ice-cold stirred suspension of aromatic amine ( $c a .1 .0 \mathrm{~g}, 1$ equiv) in $40 \mathrm{~mL}$ of a $1: 1$ mixture of $37 \%$ aqueous $\mathrm{HCl}(20 \mathrm{~mL})$ and $\mathrm{H}_{2} \mathrm{O}(20 \mathrm{~mL})$ was slowly added an aqueous solution of $\mathrm{NaNO}_{2}$ (2 equiv in $10 \mathrm{~mL}$ of distilled water). The resulting solution was stirred at $0{ }^{\circ} \mathrm{C}$ for 3 hours, after which time an aqueous solution of KI (5.0 equiv in $10 \mathrm{~mL}$ of distilled water) was added dropwise. The mixture was stirred at $0{ }^{\circ} \mathrm{C}$ for $30 \mathrm{~min}$, then at room temperature for $1 \mathrm{~h}$, and finally heated at $60{ }^{\circ} \mathrm{C}$ for $1 \mathrm{~h}$. EtOAc $(30 \mathrm{~mL})$ was then poured into the mixture and heating was maintained for an additional 30 min. Powdered $\mathrm{Na}_{2} \mathrm{~S}_{2} \mathrm{O}_{3}$ was added until complete discoloration of the solution, and the reaction mixture was then extracted with EtOAc $(4 \times 30 \mathrm{~mL})$. The organic layers were combined, washed with brine $(100 \mathrm{~mL})$, dried over $\mathrm{Na}_{2} \mathrm{SO}_{4}$, filtered and evaporated to dryness. The resulting brown oily residue was purified by column chromatography, eluting with PET/EtOAc (1:1), to yield the iodinated compound.

3,5-Dimethyl-2-iodobenzoic acid (16). Commercially available 3,5-dimethylanthranilic acid was

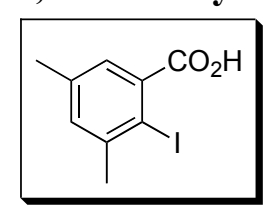
used as starting material, and the titled compound was obtained as a pale yellow powder (92\%): CAS Registry Number [198220-36-9]; m.p. 156-157 ${ }^{\circ} \mathrm{C}$ (lit. ${ }^{[10]}$ $\left.158-160{ }^{\circ} \mathrm{C}\right) ; \mathbf{R}_{\boldsymbol{f}}=0.26$ (PET/EtOAc, 1:1); IR (neat): $v=3150,2917,1693,864$, 
$719 \mathrm{~cm}^{-1} ;{ }^{1} \mathbf{H}$ NMR (DMSO- $\left.d_{6}, 300 \mathrm{MHz}\right): \delta=2.25(\mathrm{~s}, 3 \mathrm{H}), 2.39$ (s, 3H), 7.10-7.17 (m, 1Har), 7.22-7.28 (m, 1Har), 13.22 (bs, 1H); ${ }^{13} \mathbf{C}$ NMR (DMSO- $\left.d_{6}, 75 \mathrm{MHz}\right): \delta=169.7,140.1,137.6$, 132.0, 126.8, 95.6, 28.7, 20.1; LRMS (ESIMS, negative mode): $\mathrm{m} / \mathrm{z}(\%)=573$ (45) $\left[2 M^{-}\right.$ $-2 \mathrm{H}+\mathrm{Na}$ ], 275 (100) [M-H]; HRMS (ESITOF): calcd for $\mathrm{C}_{9} \mathrm{H}_{8} \mathrm{IO}_{2} 274.9574$, found 274.9568.

3-Iodo-2-naphthoic acid (17). Commercially available 3-amino-2-naphthoic acid was used as

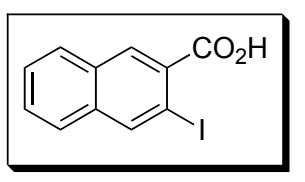
starting material, and the titled compound was obtained as a beige solid (86\%): CAS Registry Number [63212-42-0]; m.p. $202{ }^{\circ} \mathrm{C}$ (lit. ${ }^{[11]} 214-215{ }^{\circ} \mathrm{C}$ ); $\mathbf{R}_{\boldsymbol{f}}=$ 0.63 (PET/EtOAc, 1:1); IR (neat): $v=3250,3058,2955,2921,1690,1449$, 1399, 1288, 1135, $741 \mathrm{~cm}^{-1} ;{ }^{1} \mathbf{H}$ NMR $\left(\mathrm{CDCl}_{3}, 300 \mathrm{MHz}\right): \delta=7.58-7.66(\mathrm{~m}$, 2Har), 7.77 (d, $J=8.1 \mathrm{~Hz}, 1 \mathrm{Har}), 7.92$ (d, $J=7.8 \mathrm{~Hz}, 1 \mathrm{Har}), 8.57$ (s, 1Har), 8.60 (s, 1Har); ${ }^{13} \mathbf{C}$ NMR (acetone- $\left.d_{6}, 75 \mathrm{MHz}\right): \delta=167.8,141.4,136.6,133.0,132.7,132.0,129.7,129.6,128.4$, 127.6, 89.2; LRMS (ESIMS, negative mode): $m / z(\%)=297(100)[M-H]$.

General procedure for the preparation of $(R, R)$ - or $(\mathrm{S}, \mathrm{S})$-trans-cyclohexanediamine-based and $(S, S)$-diphenylethylenediamine Salen-type diiodoarenes $(R, R)-6 a-d,(S, S)-6 a$ and $(S, S)-18$, respectively. To a stirred solution of ortho-iodinated acid (3.0 equiv) in dry $\mathrm{CH}_{2} \mathrm{Cl}_{2}(10 \mathrm{~mL})$ was added freshly distilled $N, N$-diisopropylethylamine (DIEA, 3.3 equiv) and 2-(1H-benzotriazole-1yl)-1,1,3,3-tetramethyluronium hexafluorophosphate (HBTU, 3.2 equiv). The resulting mixture was stirred at room temperature for 10 minutes before the addition of the chiral diamine $\mathbf{1 3}$ or $\mathbf{1 4}$ (1.0 equiv). The solution was stirred at room temperature for 18 hours, after which time it was successively washed with $1 \mathrm{M}$ aqueous $\mathrm{HCl}(15 \mathrm{~mL}), 1 \mathrm{M}$ aqueous $\mathrm{NaOH}(15 \mathrm{~mL})$, and distilled water $(15 \mathrm{~mL})$. After evaporation of the dichloromethane, the resulting amorphous solid residue was taken in acetone $(15 \mathrm{~mL})$, and further filtered and washed with acetone $(2 \times 15 \mathrm{~mL})$, to furnish a white sticky solid, which was then recovered with $\mathrm{CH}_{2} \mathrm{Cl}_{2}(15 \mathrm{~mL})$. The resulting suspension was evaporated, and gave a white dry fine powder, which was used without further purification.

$(1 R, 2 R)-(-)-B i s-N, N^{\prime}-(2 '-i o d o b e n z o y l)-1,2-c y c l o h e x a n e d i a m i n e \quad \quad[(R, R)-6 a] . \quad$ Commercially

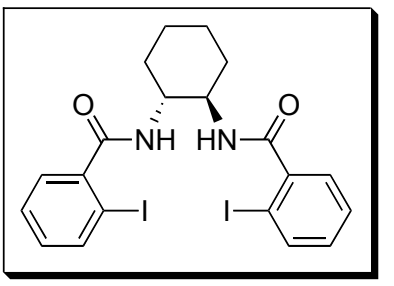
available $(R, R)-\mathbf{1 3}$ and 2-iodobenzoic acid were used as starting materials, and the titled compound was obtained as a white amorphous powder (94\%): m.p. 306-308 ${ }^{\circ} \mathrm{C} ; \mathbf{R}_{\boldsymbol{f}}=0.74\left(\mathrm{CH}_{2} \mathrm{Cl}_{2} / \mathrm{MeOH}, 95: 5\right) ;[\boldsymbol{\alpha}]^{\mathbf{2 0}}{ }_{\mathbf{D}}=$ $-562.5(c=0.2$, DMSO); IR (neat): $v=3274,3060,2920,2851,1633$, 1527, $744 \mathrm{~cm}^{-1} ;{ }^{1} \mathbf{H}$ NMR (DMSO- $\left.d_{6}, 300 \mathrm{MHz}\right): \delta=1.26$ (bt, $J=10.2$ $\mathrm{Hz}, 2 \mathrm{H}), 1.46$ (bq, $J=8.2 \mathrm{~Hz}, 2 \mathrm{H}), 1.72(\mathrm{bd}, J=7.7 \mathrm{~Hz}, 2 \mathrm{H}), 1.94$ (bd, $J=$ $12.2 \mathrm{~Hz}, 2 \mathrm{H}$ ), 3.80 (m, 2H), 7.13 (ddd, $J=1.8,7.5,7.8 \mathrm{~Hz}, 2 \mathrm{Har}$ ), 7.30 (dd, $J=1.5,7.5 \mathrm{~Hz}, 2 \mathrm{Har}$ ), 7.41 (bdd, $J=7.2,7.5 \mathrm{~Hz}, 2 \mathrm{Har}), 7.86$ (bd , $J=7.8 \mathrm{~Hz}, 2 \mathrm{Har}), 8.28$ (bd, $J=7.8 \mathrm{~Hz}, 2 \mathrm{H}) ;{ }^{13} \mathbf{C}$ NMR (DMSO- $\left.d_{6}, 75 \mathrm{MHz}\right): \delta=168.4,142.9,139.1,130.7,128.0,127.9,93.7,52.3,31.5,24.3$; LRMS (ESIMS): $m / z(\%)=1171(100)\left[2 M^{+}+\mathrm{Na}\right], 597(7)\left[\mathrm{MNa}^{+}\right], 575(11)\left[\mathrm{MH}^{+}\right]$; HRMS (ESITOF): calcd for $\mathrm{C}_{20} \mathrm{H}_{20} \mathrm{I}_{2} \mathrm{~N}_{2} \mathrm{O}_{2} \mathrm{Na} 596.9506$, found 596.9500.

$(1 S, 2 S)-(+)-B i s-N, N^{\prime}-(2$ '-iodobenzoyl)-1,2-cyclohexanediamine $\quad[(S, S)-6 a] . \quad$ Commercially

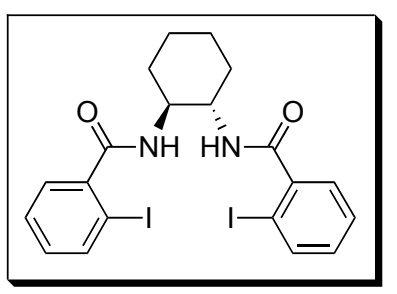
available $(S, S)$-13 and 2-iodo-benzoic acid were used as starting materials, and the titled compound was obtained as a white amorphous powder (95\%): m.p. $305-310{ }^{\circ} \mathrm{C} ; \mathbf{R}_{\boldsymbol{f}}=0.74\left(\mathrm{CH}_{2} \mathrm{Cl}_{2} / \mathrm{MeOH}, 95: 5\right) ;[\boldsymbol{\alpha}]^{\mathbf{2 0}}{ }_{\mathbf{D}}=$ $+562.5(c=0.2$, DMSO); IR (neat): $v=3275,3060,2919,2850,1630$, $1525,744 \mathrm{~cm}^{-1} ;{ }^{1} \mathbf{H}$ NMR (DMSO- $\left.d_{6}, 300 \mathrm{MHz}\right): \delta=1.26$ (bt, $J=10.1$ $\mathrm{Hz}, 2 \mathrm{H}), 1.47$ (bq, $J=8.1 \mathrm{~Hz}, 2 \mathrm{H}), 1.71$ (bd, $J=7.7 \mathrm{~Hz}, 2 \mathrm{H}), 1.94$ (bd, $J=$ $12.2 \mathrm{~Hz}, 2 \mathrm{H}), 3.81(\mathrm{~m}, 2 \mathrm{H}), 7.13$ (ddd, $J=1.8,7.5,7.8 \mathrm{~Hz}, 2 \mathrm{Har}$ ), 7.31 (dd, $J=1.6,7.5 \mathrm{~Hz}, 2 \mathrm{Har}$ ), 7.41 (bdd, $J=7.2,7.6 \mathrm{~Hz}, 2 \mathrm{Har}), 7.86$ (dd $J=1.9,7.8 \mathrm{~Hz}, 2 \mathrm{Har}), 8.28$ (bd, $J=7.8 \mathrm{~Hz}, 2 \mathrm{H}) ;{ }^{13} \mathbf{C}$ NMR (DMSO- $\left.d_{6}, 75 \mathrm{MHz}\right): \delta=168.4,142.9,139.1,130.7,128.0,127.9,93.7,52.3,31.5,24.4$; 
LRMS (ESIMS): $m / z(\%)=1171(100)\left[2 M^{+}+\mathrm{Na}\right], 597(12)\left[\mathrm{MNa}^{+}\right]$; HRMS (ESITOF): calcd for $\mathrm{C}_{20} \mathrm{H}_{20} \mathrm{I}_{2} \mathrm{~N}_{2} \mathrm{O}_{2} \mathrm{Na}$ 596.9506, found 596.9495.

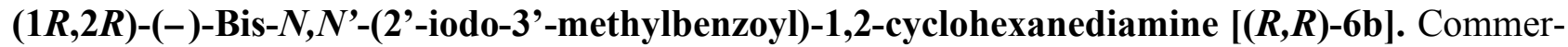

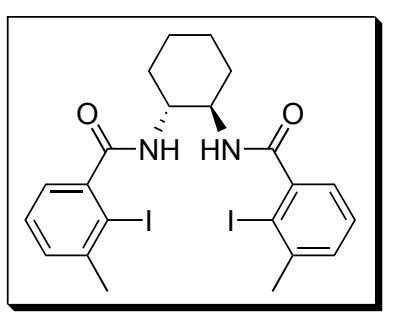
cially available $(R, R)$-13 and 3-methyl-2-iodobenzoic acid were used as starting materials, and the titled compound was obtained as a white amorphous powder $(87 \%)$ : m.p. $335-336{ }^{\circ} \mathrm{C} ; \mathbf{R}_{\boldsymbol{f}}=0.73\left(\mathrm{CH}_{2} \mathrm{Cl}_{2} / \mathrm{MeOH}\right.$, 95:5); $[\alpha]^{\mathbf{2 0}}{ }_{\mathbf{D}}=-84.0(c=0.26, \mathrm{DMSO}) ; \mathbf{I R}$ (neat): $v=3270,3056,2921$, 2855, 1636, 1532, $792 \mathrm{~cm}^{-1} ;{ }^{1} \mathbf{H}$ NMR (DMSO- $\left.d_{6}, 300 \mathrm{MHz}\right): \delta=1.21$ $1.30(\mathrm{~m}, 2 \mathrm{H}), 1.37-1.51(\mathrm{~m}, 2 \mathrm{H}), 1.71(\mathrm{bd}, J=7.7 \mathrm{~Hz}, 2 \mathrm{H}), 1.96(\mathrm{bd}, J=$ $12.5 \mathrm{~Hz}, 2 \mathrm{H}), 2.41(\mathrm{~s}, 6 \mathrm{H}), 3.72-3.87(\mathrm{~m}, 2 \mathrm{H}), 7.06(\mathrm{dd}, J=1.6,7.1 \mathrm{~Hz}$, 2H), 7.25-7.34 (m, 4H), 8.23 (bd, $J=7.8,2 \mathrm{H}) ;{ }^{13}$ C NMR (DMSO-d, $\left.75 \mathrm{MHz}\right): \delta=169.2,144.6$, 141.6, 129.8, 127.8, 125.0, 100.2, 52.3, 31.3, 28.6, 24.3; LRMS (ESIMS): $m / z(\%)=1226(100)$ $\left[2 M^{+}+\mathrm{Na}\right], 625(4)\left[\mathrm{MNa}^{+}\right], 602(10)\left[\mathrm{MH}^{+}\right]$; HRMS (ESITOF): calcd for $\mathrm{C}_{22} \mathrm{H}_{24} \mathrm{I}_{2} \mathrm{~N}_{2} \mathrm{O}_{2} \mathrm{Na}$ 624.9819 , found 624.9837 .

$(1 R, 2 R)-(-)-B i s-N, N^{\prime}-(2 '-i o d o-3 ', 5 '$-dimethylbenzoyl)-1,2-cyclohexanediamine [(R,R)-6c]. 3,5-

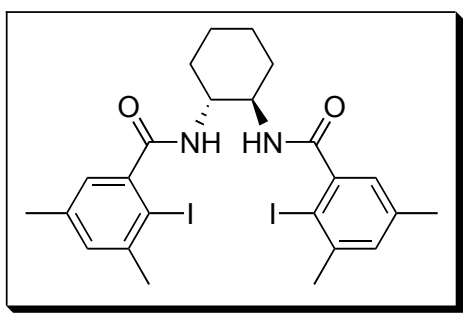
Dimethyl-2-iodobenzoic (16) acid and commercially available $(R, R)$ 13 were used as starting materials, and the titled compound was obtained as a white powder (quantitative yield): m.p. $344-345{ }^{\circ} \mathrm{C} ; \boldsymbol{R}_{\boldsymbol{f}}$ $=$ not soluble in most common solvents; $[\alpha]^{20}{ }_{D}=$ not soluble in most common solvents; IR (neat): $v=3263,3055,2923,2855,1634,1526$, $779 \mathrm{~cm}^{-1} ;{ }^{1} \mathbf{H}$ NMR (DMSO- $\left.d_{6}, 300 \mathrm{MHz}\right): \delta=1.18-1.59(\mathrm{~m}, 4 \mathrm{H})$, $1.63-1.83(\mathrm{~m}, 4 \mathrm{H}), 1.71(\mathrm{bd}, J=6.0 \mathrm{~Hz}, 2 \mathrm{H}), 2.21(\mathrm{~s}, 3 \mathrm{H}), 2.37(\mathrm{~s}$, $3 \mathrm{H}), 3.69-3.91(\mathrm{~m}, 2 \mathrm{H}), 6.91(\mathrm{~s}, 2 \mathrm{H}), 7.18(\mathrm{~s}, 2 \mathrm{H}), 8.20$ (bd, $J=3.9 \mathrm{~Hz}, 2 \mathrm{H}) ;{ }^{13} \mathrm{C}$ NMR (DMSO- $d_{6}$, $75 \mathrm{MHz}): \delta=169.3,144.4,141.5,137.2,130.7,125.8,96.2,52.2,31,4,28.4,24.3,20.2$; LRMS (ESIMS): $m / z(\%)=1283$ (7) $\left[2 M^{+}+\mathrm{Na}\right], 653(100)\left[M \mathrm{Na}^{+}\right]$; HRMS (ESITOF): calcd for $\mathrm{C}_{24} \mathrm{H}_{28} \mathrm{I}_{2} \mathrm{~N}_{2} \mathrm{O}_{2} \mathrm{Na}$ 653.0132, found 653.0157.

(1R,2R)-(-)-Bis- $N, N^{\prime}$-(3'-iodo-2'-naphthoyl)-1,2-cyclohexanediamine $\quad[(R, R)-6 \mathrm{~d}] . \quad 3$-Iodo-2-

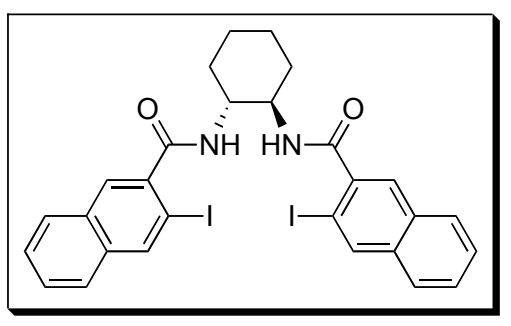
naphthoic acid (17) and commercially available $(R, R)-\mathbf{1 3}$ were used as starting materials, and the titled compound was obtained as a pale beige solid (83\%): m.p. $344-345 \quad{ }^{\circ} \mathrm{C} ; \quad \mathbf{R}_{\boldsymbol{f}}=0.75$ $\left(\mathrm{CH}_{2} \mathrm{Cl}_{2} / \mathrm{MeOH}, 95: 5\right) ;[\alpha]^{\mathbf{2 0}}{ }_{\mathbf{D}}=-256(c=0.24, \mathrm{DMSO}) ; \mathbf{I R}$ (neat): $v=3261,3005,2985,2854,1669,1530,745 \mathrm{~cm}^{-1} ;{ }^{1} \mathbf{H}$ NMR (DMSO- $\left.d_{6}, 300 \mathrm{MHz}\right): \delta=1.29-1.38(\mathrm{~m}, 2 \mathrm{H}), 1.44-1.59(\mathrm{~m}$, 2H), 1.77 (bd, $J=7.3 \mathrm{~Hz}, 2 \mathrm{H}), 1.96$ (bd, $J=12.7 \mathrm{~Hz}, 2 \mathrm{H}), 3.86-$ $3.96(\mathrm{~m}, 2 \mathrm{H}), 7.53-7.61(\mathrm{~m}, 2 \mathrm{H}), 7.79-7.84(\mathrm{~m}, 2 \mathrm{H}), 7.88-7.93(\mathrm{~m}, 2 \mathrm{H}), 7.91(\mathrm{~s}, 2 \mathrm{H}), 8.46(\mathrm{bd}, J=$ $7.7 \mathrm{~Hz}, 2 \mathrm{H}), 8.53(\mathrm{~s}, 2 \mathrm{H}) ;{ }^{13} \mathbf{C}$ NMR (DMSO- $\left.d_{6}, 75 \mathrm{MHz}\right): \delta=168.4,139.2,138.4,134.2,131.2$, 127.7, 127.6, 127.3, 126.9, 126.6, 90.6, 52.6, 31.5, 24.3; LRMS (ESIMS): $m / z(\%)=1370(100)$ [2M+ $+\mathrm{H}], 675$ (4) $\left[\mathrm{MH}^{+}\right]$; HRMS (ESITOF): calcd for $\mathrm{C}_{28} \mathrm{H}_{24} \mathrm{I}_{2} \mathrm{~N}_{2} \mathrm{O}_{2} \mathrm{Na} 696.9819$, found 696.9815 .

(1S,2S)-(-)-Bis- $N, N^{\prime}-(2$ '-iodobenzoyl)-1,2-diphenylethylenediamine $[(S, S)-18]$. Commercially

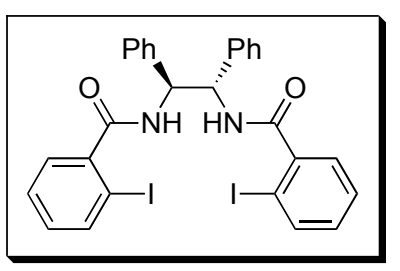
available $(S, S)-\mathbf{1 4}$ and 2-iodobenzoic acid were used as starting materials, and the titled compound was obtained as a amorphous white powder (91\%): m.p. $354-355{ }^{\circ} \mathrm{C} ; \boldsymbol{R}_{\boldsymbol{f}}=$ not soluble in most common solvents; $[\alpha]^{20}{ }_{D}=$ not soluble in most common solvents; IR (neat): $\boldsymbol{v}=3297,3065$, 3036, 1636, 1523, $769 \mathrm{~cm}^{-1} ;{ }^{1} \mathbf{H}$ NMR (DMSO- $\left.d_{6}, 300 \mathrm{MHz}\right): \delta=5.71(\mathrm{~d}$, $J=8.1 \mathrm{~Hz}, 2 \mathrm{H}), 6.84(\mathrm{dd}, J=1.5,7.5 \mathrm{~Hz}, 2 \mathrm{H}), 7.12(\mathrm{td}, J=1.5,7.5 \mathrm{~Hz}$, 2H), 7.26-7.31 (m, 2H), 7.36-7.43 (m, 6H), $7.56(\mathrm{~d}, J=7.2 \mathrm{~Hz}, 4 \mathrm{H}), 7.83(\mathrm{~d}, J=7.2 \mathrm{~Hz}, 2 \mathrm{H}), 8.70$ $(\mathrm{d}, J=8.4 \mathrm{~Hz}, 2 \mathrm{H}) ;{ }^{13} \mathbf{C}$ NMR (DMSO- $\left.d_{6}, 75 \mathrm{MHz}\right): \delta=168.2,142.7,140.0,139.2,130.9,128.1$, 
127.9, 127.8, 127.1, 127.0, 92.9, 56.6; LRMS (ESIMS): $m / z(\%)=1367(100)\left[2 M^{+}+\mathrm{Na}\right], 695(73)$ [MNa ${ }^{+}$; HRMS (ESITOF): calcd for $\mathrm{C}_{28} \mathrm{H}_{22} \mathrm{I}_{2} \mathrm{~N}_{2} \mathrm{O}_{2} \mathrm{Na} 694.9663$, found 694.9676.

Preparation of (11,12-diamino-9,10-dihydro-9,10-ethanoanthracene)-based Salen-type diiodoarenes $( \pm)-\mathbf{7 a} / \mathbf{b}$ (Scheme S3). The key anthracenyl-derived diamine $( \pm)$-15 was prepared according to the procedure described by Lennon and co-workers, ${ }^{[12]}$ but with modifications on reaction times and equivalents of reagents used. Thus, the first step consisted in a Diels-Alder reaction between commercially available anthracene and fumaryl chloride, which provided, after heating in toluene at reflux for $4 \mathrm{~h}$, the bis(acyl chloride) ( \pm )-19 in a quantitative yield (Scheme S3). Conversion of this material into the corresponding bis(acyl azide), upon treatment with sodium azide in a 1:1 toluene/water mixture at $0{ }^{\circ} \mathrm{C}$ for $3 \mathrm{~h}$, followed by a Curtius rearrangement, which was conducted in refluxing toluene until nitrogen bubbling stopped, and a subsequent saponification afforded the racemic diamine $( \pm)$-15. It is important to note that this isocyanate hydrolysis step was performed with 4 equivalents of sodium hydroxide, and that the use of a 1:1 mixture of tetrahydrofuran/water, as proposed by Trost and co-workers, ${ }^{[13]}$ offered better solubility than toluene. Next, careful addition of $37 \%$ aqueous $\mathrm{HCl}$ allowed removal of the carbon dioxide, and the resulting mixture containing the ammonium salt was carefully treated with sodium hydroxide pellets. Racemic diamine $( \pm)-15$ was finally extracted with dichloromethane, further evaporated to dryness, and obtained as beige crystals in a very good yield of $85 \%$ (Scheme S3). Coupling of this material with ortho-iodobenzoic acids was performed as described for the cyclohexanediamine (vide supra), and the resulting Salen-type diiodoarenes were obtained as white precipitates, which were used without purification.

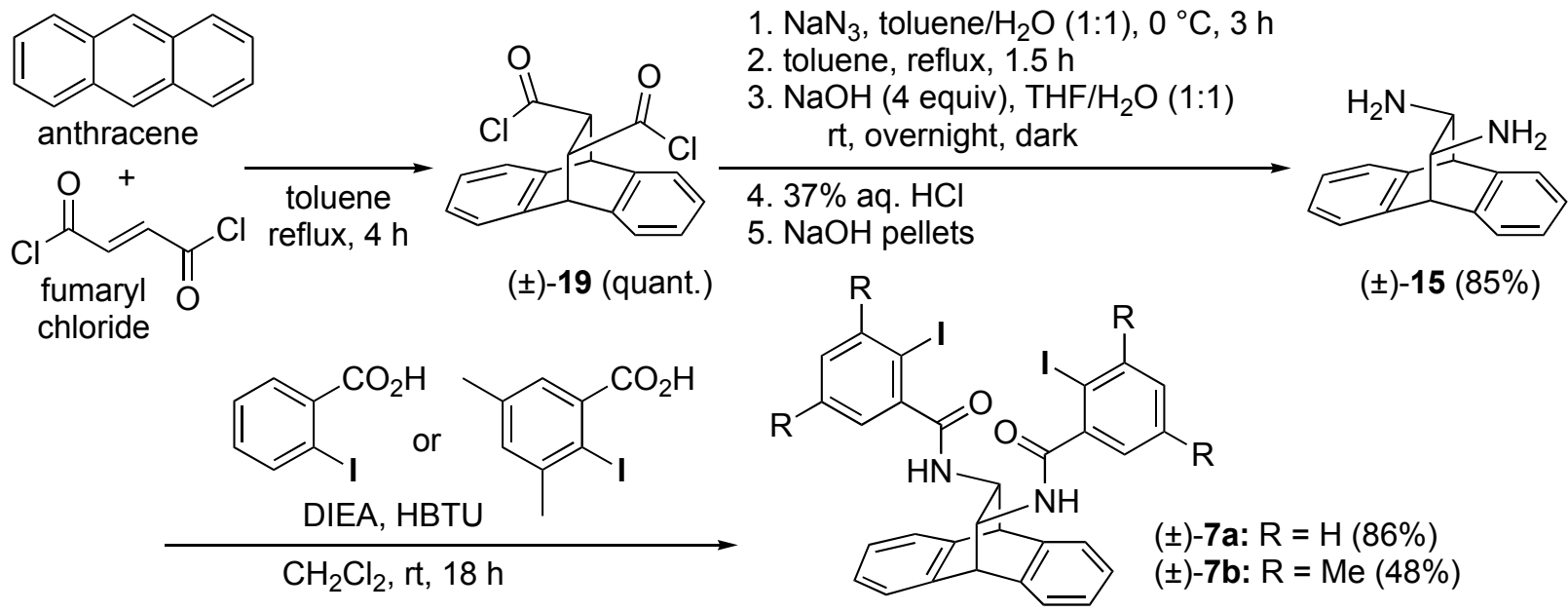

Scheme S3.

$( \pm)$-Bis(acyl chloride) $[( \pm)-19]$. To a stirred suspension of anthracene $(10.0 \mathrm{~g}, 56.1 \mathrm{mmol})$ in

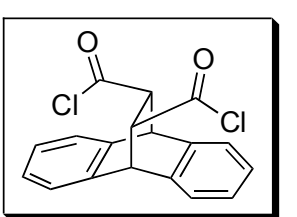
toluene $(50 \mathrm{~mL})$ was added fumaryl chloride $(6.1 \mathrm{~mL}, 56.1 \mathrm{mmol})$. The resulting bloody solution was stirred under reflux for 4 hours, and the solution became pale yellow. After cooling down to room temperature, toluene was evaporated under reduced pressure, and the resulting dark brown solution was further dried under high vacuum to give $\mathbf{1 9}$ as a pale green solid (18.6 g, quantitative yield): CAS Registry Number [90602-78-3]; m.p. $252-253{ }^{\circ} \mathrm{C} ;{ }^{1} \mathbf{H}$ NMR $\left(\mathrm{CDCl}_{3}, 300 \mathrm{MHz}\right): \delta=3.78-3.85$ $(\mathrm{m}, 2 \mathrm{H}), 4.96$ (bs, 2H), 7.16-7.24 (m, 4Har), 7.35-7.43 (m, 4Har); ${ }^{13} \mathbf{C} \mathbf{~ N M R}\left(\mathrm{CDCl}_{3}, 75 \mathrm{MHz}\right): \delta=$ $173.1,140.3,138.8,127.5,127.4,125.3,124.4,59.4,47.0$. These data were consistent with those previously reported. ${ }^{[13]}$

( \pm -trans-11,12-Diamino-9,10-dihydro-9,10-ethanoanthracene $[( \pm)-15]$. The bis(acyl chloride) $19(18.6 \mathrm{~g}, 56.1 \mathrm{mmol})$ was added to toluene $(120 \mathrm{~mL})$, and the resulting suspension was stirred at 0 ${ }^{\circ} \mathrm{C}$ for at least $1 \mathrm{~h}$, until complete dissolution. A solution of $\mathrm{NaN}_{3}$ (4.0 equiv, $7.29 \mathrm{~g}$ ) in water (30 
$\mathrm{mL}$ ) was added, and the biphasic system was vigorously stirred for $4 \mathrm{~h}$ at a temperature kept

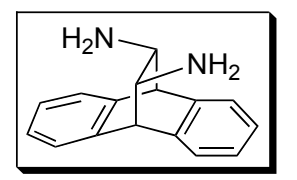
between 0 and $4{ }^{\circ} \mathrm{C}$. The organic layer was separated, dried over $\mathrm{Na}_{2} \mathrm{SO}_{4}$, filtered and added dropwise into boiling toluene $(20 \mathrm{~mL})$. This toluene solution was stirred under reflux for $1.5 \mathrm{~h}$ until $\mathrm{N}_{2}$ bubbling stopped. After cooling down to room temperature, evaporation to dryness gave a beige solid, which was dissolved in THF (70 mL), added to $\mathrm{NaOH}(4.49 \mathrm{~g}, 4.0$ equiv) in water $(70 \mathrm{~mL})$, and stirred at room temperature in the dark for $16 \mathrm{~h}$. The pale yellow mixture was then acidified to $\mathrm{pH}<1$ by addition of $37 \%$ aqueous $\mathrm{HCl}$, and the layers were separated. The aqueous phase was extracted with $\mathrm{Et}_{2} \mathrm{O}(2$ $\times 40 \mathrm{~mL}$ ), basified until $\mathrm{pH}>14$ by careful addition of $\mathrm{NaOH}$ pellets, and extracted again with $\mathrm{CH}_{2} \mathrm{Cl}_{2}(2 \times 50 \mathrm{~mL})$. The combined organic layers were dried over $\mathrm{Na}_{2} \mathrm{CO}_{3}$, filtered and evaporated under reduced pressure to give 15 as a pale yellow solid (11.0 g, 85\%), which was used without further purification: CAS Registry Number [893618-17-2]; m.p. 156-157 ${ }^{\circ} \mathrm{C}$ (lit. ${ }^{[12]} 156-157{ }^{\circ} \mathrm{C}$ ); ${ }^{1}$ H NMR $\left(\mathrm{CDCl}_{3}, 300 \mathrm{MHz}\right): \delta=1.16\left(\mathrm{bs}, 4 \mathrm{H}, 2 \times-\mathrm{NH}_{2}\right), 2.65-2.67$ (m, 2H), 4.04 (m, 2Har), 7.117.18 (m, 4Har), 7.28-7.34 (m, 4Har); ${ }^{13} \mathbf{C}$ NMR $\left(\mathrm{CDCl}_{3}, 75 \mathrm{MHz}\right): \delta=142.1,138.9,126.4,126.3$, $126.1,124.0,62.3,53.6$. These data were consistent with those previously reported. ${ }^{[12,13]}$

( \pm )-Bis- $N, N^{\prime}-(2$ '-iodobenzoyl)-11,12-diamino-9,10-dihydro-9,10-ethanoanthracene $\quad[( \pm)-7 \mathrm{a}]$.

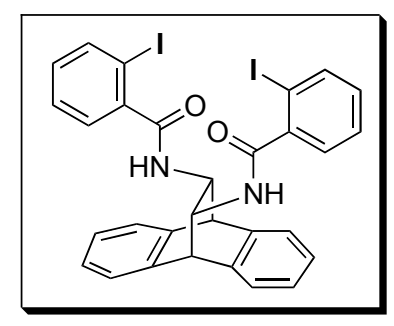

Racemic 11,12-diamino-9,10-dihydro-9,10-ethanoanthracene [( \pm -15] and commercial 2-iodobenzoic acid were used as starting materials, and the titled compound $( \pm)-7 \mathbf{a}$ was obtained as a white powder $(86 \%)$, which was used without further purification: m.p. $325-326{ }^{\circ} \mathrm{C} ; \boldsymbol{R}_{\boldsymbol{f}}=$ not soluble in most common solvents; IR (neat): $v=3266,3061,1643,1586,1542,1464$, 1366, 1317, $748 \mathrm{~cm}^{-1}$; ${ }^{1} \mathbf{H}$ NMR (DMSO- $\left.d_{6}, 300 \mathrm{MHz}\right): \delta=4.17(\mathrm{~d}, J=6.6$ $\mathrm{Hz}, 2 \mathrm{H}), 4.59$ (bs, 2H), 7.10-7.20 (m, 8Har), 7.36-7.39 (m, 4Har), 7.447.47 (m, 2Har), 7.85 (bd, $J=7.8 \mathrm{~Hz}, 2 \mathrm{H}), 8.49$ (bd, $J=6.6 \mathrm{~Hz}, 2 \mathrm{H}$ ); ${ }^{13} \mathbf{C}$ NMR (DMSO- $d_{6}, 75$ MHz): $\delta=169.0,142.8,141.9,139.9,138.9,130.6,128.2,127.8,126.2,126.0,125.9,124.2,93.8$, 54.9, 48.4; LRMS (ESIMS): $m / z(\%)=1415(100)\left[2 M+\mathrm{Na}^{+}\right], 718(35)\left[M \mathrm{Na}^{+}\right], 697$ (2) $\left[M \mathrm{H}^{+}\right]$; HRMS (TOF): calcd for $\mathrm{C}_{30} \mathrm{H}_{22} \mathrm{I}_{2} \mathrm{~N}_{2} \mathrm{O}_{2} \mathrm{Na} 718.9663$, found 718.9688.

( \pm )-Bis- $N, N$ '-(2'-iodo-3',5'-dimethylbenzoyl)-11,12-diamino-9,10-dihydro-9,10-ethanoanthracene $[( \pm)-7 \mathbf{b}]$. Racemic 11,12-diamino-9,10-dihydro-9,10-ethanoanthracene $[( \pm)-15]$ and 2-iodo-

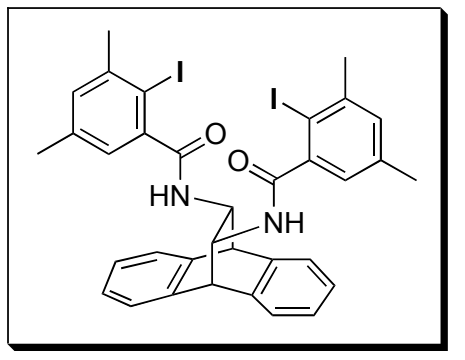
3,5-dimethylbenzoic acid (16) were used as starting materials, and the resulting yellow syrup was purified by column chromatography, eluting with cyclohexane/EtOAc (4:1), and further precipitated using cold acetone. Repeated washings of this precipitate with hexanes furnished ( \pm )-7b as a white powder (48\%): m.p. $139-141{ }^{\circ} \mathrm{C} ; \mathbf{R}_{\boldsymbol{f}}=$ 0.33 (cyclohexane/EtOAc, 4:1); IR (neat): $v=3407,3263,2943$, 1649, 1613, 1572, 1535, 1460, $750 \mathrm{~cm}^{-1} ;{ }^{1} \mathbf{H}$ NMR (DMSO- $d_{6}, 300$ $\mathrm{MHz}): \delta=2.21\left(\mathrm{~s}, 6 \mathrm{H}, 2 \times \mathrm{CH}_{3}\right), 2.37\left(\mathrm{~s}, 6 \mathrm{H}, 2 \times \mathrm{CH}_{3}\right), 4.16(\mathrm{~d}, J=$ $6.5 \mathrm{~Hz}, 2 \mathrm{H}), 6.78$ (bd, $J=1.2 \mathrm{~Hz}, 2 \mathrm{H}), 7.10-7.15$ (m, 6Har), 7.36-7.39 (m, 2Har), 7.46-7.49 (m, 2Har), 8.43 (bd, $J=6.4,2 \mathrm{H}) ;{ }^{13} \mathbf{C}$ NMR (DMSO-d $\left.d_{6}, 75 \mathrm{MHz}\right): \delta=169.6,144.1,142.0,141.3$, $140.0,137.2130 .6,126.3,126.0,125.9,125.8,124.2,96.4,54.8,48.5,28.3,20.2$; LRMS (ESIMS): 1527 (3) $\left[2 \mathrm{M}+\mathrm{Na}^{+}\right], 775$ (100) $\left[\mathrm{MNa}^{+}\right]$; HRMS (TOF): calcd for $\mathrm{C}_{34} \mathrm{H}_{30} \mathrm{I}_{2} \mathrm{~N}_{2} \mathrm{O}_{2} \mathrm{Na}$ 775.0289, found 775.0311. Elem. Anal.: calcd for $\mathrm{C}_{34} \mathrm{H}_{30} \mathrm{I}_{2} \mathrm{~N}_{2} \mathrm{O}_{2}$ : C, 54.27; H, 4.02; I, 33.73; N, 3.72; O, 4.25. Found: C, 54.14; H, 4.02; I, 34.16; N, 3.69; O, 4.25.

Preparation of the enantiopure $(11 R, 12 R)$ - and $(11 S, 12 S)$-trans-11,12-diamino-9,10-dihydro9,10-ethanoanthracenes $(R, R)-15$ and $(S, S)$-15 (Scheme S4). Mandelic acid-mediated resolution of racemic trans-11,12-diamino-9,10-dihydro-9,10-ethanoanthracene [( \pm -15] was performed according to the procedure described by Lennon and co-workers. ${ }^{[12]}$ The first step consisted in the formation of the $(S)$-mandelate monoammonium salt $\mathbf{2 0}$, which was isolated in a good $77 \%$ yield by 
simple filtration of the resulting precipitate; treatment of $\mathbf{2 0}$ with $1 \mathrm{M}$ sodium hydroxide $(\mathrm{NaOH})$ in a 1:1 dichloromethane/water mixture, at room temperature for $1 \mathrm{~h}$, gave quantitatively the diamine $(R, R)-15$ (Scheme $\mathrm{S} 4)$. The filtrate containing the $(S)$-mandelate monoammonium salt derived from the enantiomeric diamine was evaporated, treated with $1 \mathrm{M} \mathrm{NaOH}$ in similar conditions, and subsequent reaction with $(R)$-mandelic acid gave the $(R)$-mandelate monoammonium salt 21 in a modest $28 \%$ yield; diamine $(S, S)-15$ was next quantitatively recovered upon treatment with $1 \mathrm{M}$ $\mathrm{NaOH}$ (Scheme S4). In addition, a control of the enantiomeric purity was performed by chiral HPLC analysis of the mandelate monoammonium salts $\mathbf{2 0}$ and $\mathbf{2 1}$ derivatized with $m$-tolyl chloride (see Scheme S5 and Figure S5).

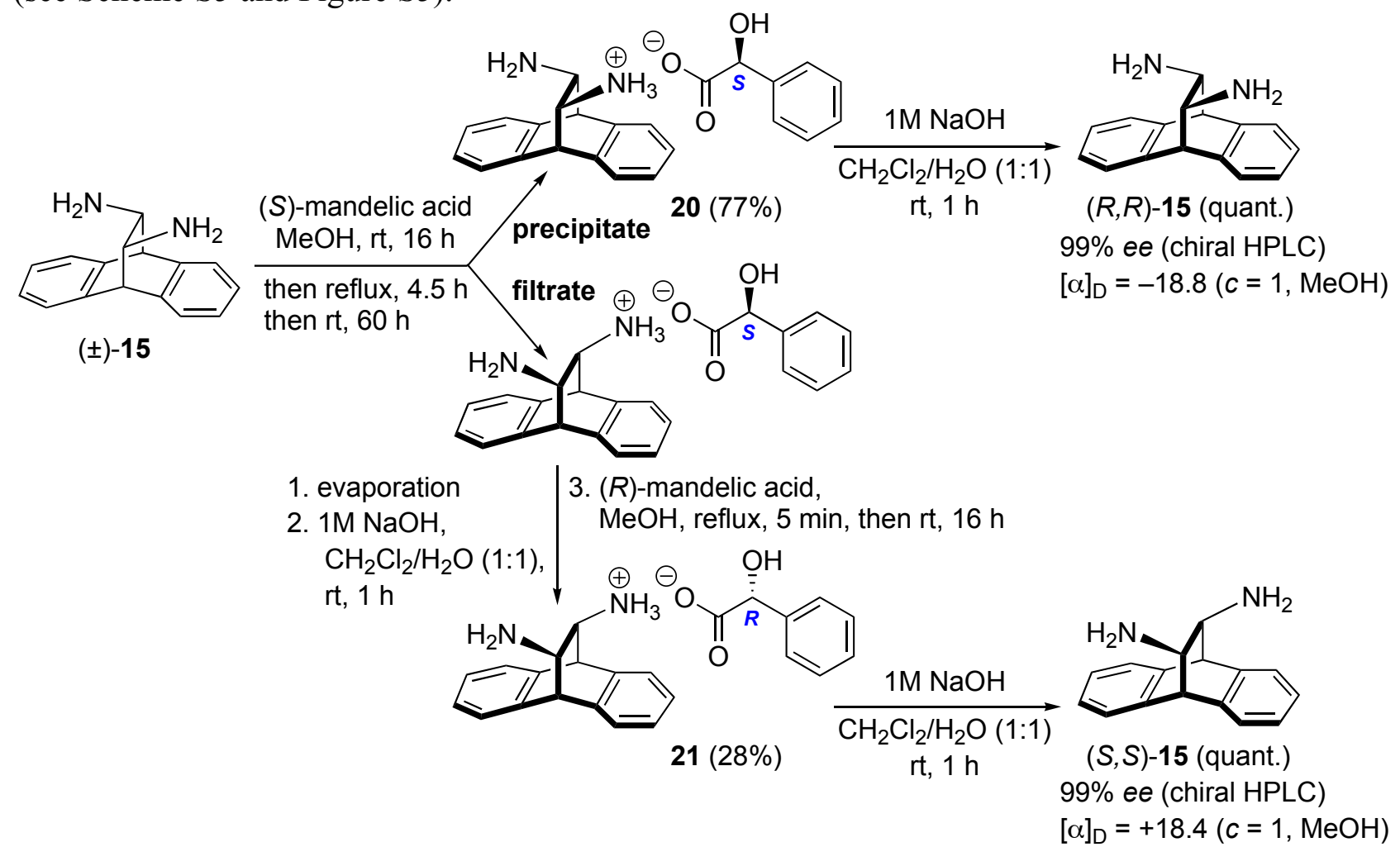

Scheme S4.

(11R,12R)-11,12-Diamino-9,10-dihydro-9,10-ethanoanthracene $(S)$-mandelate monoammonium salt (20). Commercially available $(S)$-mandelic acid $(966 \mathrm{mg}, 6.35 \mathrm{mmol})$ was added in one

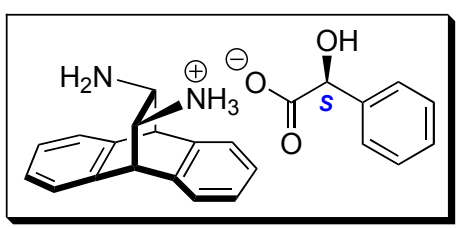
portion to a solution of racemic diamine $( \pm)-15(1.50 \mathrm{~g}, 6.35 \mathrm{mmol})$ in $\mathrm{MeOH}(35 \mathrm{~mL})$. The resulting homogeneous mixture was stirred at room temperature for $16 \mathrm{~h}$, then refluxed for $4.5 \mathrm{~h}$, and finally cooled down and maintained at room temperature for $60 \mathrm{~h}$. The resulting precipitate was filtered and washed with $\mathrm{MeOH}$ to furnish the $(S)$ mandelate monoammonium salt $\mathbf{2 0}$ as a white solid. The combined filtrates were concentrated under reduced pressure to give a yellow solid, which was dissolved in hot $\mathrm{MeOH}$ (12 mL). After cooling down to room temperature, the resulting suspension was stirred for $16 \mathrm{~h}$, and the precipitate was filtered, washed with $\mathrm{MeOH}$ to provide a second crop of $\mathbf{2 0}$ as a white solid. The two solids were combined and dried under high vacuum to afford the desired salt $\mathbf{2 0}$ as a white solid (943 $\mathrm{mg}$, 77\%): CAS Registry Number [876611-43-7]; m.p. $228-229{ }^{\circ} \mathrm{C}$ (lit. $\left.{ }^{[12]} 223-224{ }^{\circ} \mathrm{C}\right) ;[\alpha]^{20}{ }_{D}=$ not soluble in $\mathrm{MeOH}, \mathrm{DMSO}, \mathrm{H}_{2} \mathrm{O}, \mathrm{CH}_{2} \mathrm{Cl}_{2}, \mathrm{CHCl}_{3}, \mathrm{CH}_{3} \mathrm{CN}$ and acetone; ${ }^{\mathbf{1}} \mathbf{H}$ NMR (DMSO-d, 300 $\mathrm{MHz}): \delta=2.82(\mathrm{bs}, 2 \mathrm{H}), 4.25(\mathrm{~s}, 2 \mathrm{H}), 4.59(\mathrm{~s}, 1 \mathrm{H}), 5.19\left(\mathrm{bs}, 6 \mathrm{H},-\mathrm{OH},-\mathrm{NH}_{2}\right.$ and $\left.-\mathrm{NH}_{3}{ }^{+}\right), 7.11-7.18$ $(\mathrm{m}, 5 \mathrm{H}), 7.19-7.32(\mathrm{~m}, 6 \mathrm{H}), 7.40(\mathrm{bd}, J=7.5 \mathrm{~Hz}, 2 \mathrm{H}) ;{ }^{13} \mathbf{C}$ NMR (DMSO- $\left.d_{6}, 75 \mathrm{MHz}\right): \delta=175.0$, $143.5,141.6,138.6,127.4,126.3,126.2,126.1,124.0,73.4,58.2,49.4$. These data were consistent with those previously reported. ${ }^{[12]}$ 
$(11 S, 12 S)-11,12-D i a m i n o-9,10-d i h y d r o-9,10-e t h a n o a n t h r a c e n e \quad(R)$-mandelate monoammonium salt (21). The filtrate obtained from the previous resolution step was concentrated in vacuo,

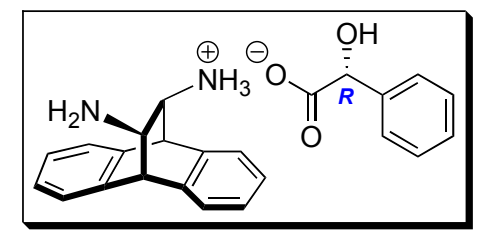
and the resulting yellow solid was treated with $1 \mathrm{M}$ aqueous $\mathrm{NaOH}$ at room temperature for $1 \mathrm{~h}$. The solution was then extracted with $\mathrm{CH}_{2} \mathrm{Cl}_{2}(3 \times 15 \mathrm{~mL})$, and the organic layer was dried over $\mathrm{Na}_{2} \mathrm{SO}_{4}$, filtered and evaporated under reduced pressure to afford enantioenriched $(S, S)-\mathbf{1 5}$ as a pale grey powder $(c a .950 \mathrm{mg}) .(R)$ Mandelic acid $(612 \mathrm{mg}, 4.0 \mathrm{mmol})$ was added in one portion to the crude solution of $(S, S)-15$ in $\mathrm{MeOH}(20 \mathrm{~mL})$; the resulting suspension was refluxed for $5 \mathrm{~min}$, then allowed to cool down to room temperature and further stirred for $16 \mathrm{~h}$. The resulting precipitate was filtered and washed with $\mathrm{MeOH}$, before being dried under high vacuum to furnish the $(R)$-mandelate monoammonium salt 21 (347 mg, 28\%): CAS Registry Number [876611-41-5]; m.p. $227^{\circ} \mathrm{C}$ (lit. $\left.{ }^{[12]} 218{ }^{\circ} \mathrm{C}\right) ;[\alpha]^{20}{ }_{D}$ = not soluble in $\mathrm{MeOH}, \mathrm{DMSO}, \mathrm{H}_{2} \mathrm{O}, \mathrm{CH}_{2} \mathrm{Cl}_{2}, \mathrm{CHCl}_{3}, \mathrm{CH}_{3} \mathrm{CN}$ and acetone; ${ }^{1} \mathbf{H}$ NMR (DMSO- $d_{6}$, $300 \mathrm{MHz}): \delta=2.82(\mathrm{bs}, 2 \mathrm{H}), 4.25(\mathrm{~s}, 2 \mathrm{H}), 4.58(\mathrm{~s}, 1 \mathrm{H}), 5.26\left(\mathrm{bs}, 6 \mathrm{H},-\mathrm{OH},-\mathrm{NH}_{2}\right.$ and $\left.-\mathrm{NH}_{3}{ }^{+}\right), 7.10-$ $7.19(\mathrm{~m}, 5 \mathrm{H}), 7.22-7.33(\mathrm{~m}, 6 \mathrm{H}), 7.39(\mathrm{bd}, J=6.9 \mathrm{~Hz}, 2 \mathrm{H})$. These data were consistent with those previously reported. ${ }^{[12]}$

$(-)-(11 R, 12 R)-11,12-D i a m i n o-9,10-d i h y d r o-9,10-e t h a n o a n t h r a c e n e \quad[(R, R)-15] . \quad$ The $\quad(S)$ -

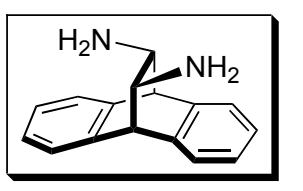
mandelate monoammonium salt $20(525 \mathrm{mg}, 1.35 \mathrm{mmol})$ was treated with a solution of $1 \mathrm{M}$ aqueous $\mathrm{NaOH}(20 \mathrm{~mL})$, and the resulting slurry was stirred at room temperature for $1 \mathrm{~h}$, after which time $\mathrm{CH}_{2} \mathrm{Cl}_{2}(20 \mathrm{~mL})$ was added and two clear layers were obtained. The organic layer was discarded, and the aqueous layer was extracted with $\mathrm{CH}_{2} \mathrm{Cl}_{2}(3 \times 25 \mathrm{~mL})$. The combined layers were dried over $\mathrm{Na}_{2} \mathrm{SO}_{4}$, filtered and concentrated under vacuum to give the diamine $(R, R)-\mathbf{1 5}$ as an off-white solid (320 mg, quantitative yield): CAS Registry Number [181139-49-1]; m.p. $162{ }^{\circ} \mathrm{C}$ (lit. $\left.{ }^{[12]} 156-157{ }^{\circ} \mathrm{C}\right) ;[\boldsymbol{\alpha}]^{\mathbf{2 0}}{ }_{\mathrm{D}}$ $=-18.8(c=1.0, \mathrm{MeOH})\left[\right.$ lit. $\left.^{[12]}[\alpha]^{20}{ }_{\mathrm{D}}=-18.8(c=1.0, \mathrm{MeOH})\right] ;{ }^{1} \mathbf{H}$ NMR $\left(\mathrm{CDCl}_{3}, 300 \mathrm{MHz}\right): \delta$ $=1.16\left(\mathrm{bs}, 4 \mathrm{H}, 2 \times-\mathrm{NH}_{2}\right), 2.66-2.68(\mathrm{~m}, 2 \mathrm{H}), 4.04(\mathrm{bs}, 2 \mathrm{H}), 7.10-7.19(\mathrm{~m}, 4 \mathrm{H}), 7.27-7.35(\mathrm{~m}, 4 \mathrm{H})$. These data were consistent with those reported for the racemic compound $( \pm)-\mathbf{1 5}$.

$(+)-(11 S, 12 S)-11,12-D i a m i n o-9,10-d i h y d r o-9,10-e t h a n o a n t h r a c e n e \quad[(S, S)-15] . \quad$ The $\quad(R)-$

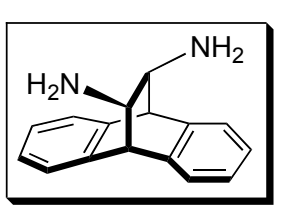

mandelate monoammonium salt 21 (500 $\mathrm{mg}, 1.29 \mathrm{mmol}$ ) was submitted to the same procedure as the one described for $\mathbf{2 0}$, and diamine $(S, S)-\mathbf{1 5}$ was obtained as a white solid (306 mg, quantitative yield): CAS Registry Number [138517-665]; m.p. $158{ }^{\circ} \mathrm{C}$ (lit. $\left.{ }^{[13]} 153-156{ }^{\circ} \mathrm{C}\right) ;[\alpha]^{\mathbf{2 0}}{ }_{\mathbf{D}}=+18.4(c=1.0, \mathrm{MeOH})\left[\right.$ lit. $^{[13]}$ $\left.[\alpha]^{20}{ }_{\mathrm{D}}=+20.5(c=2.275, \mathrm{MeOH})\right] ;{ }^{1} \mathbf{H}$ NMR $\left(\mathrm{CDCl}_{3}, 300 \mathrm{MHz}\right): \delta=1.20(\mathrm{bs}$, $\left.4 \mathrm{H}, 2 \times-\mathrm{NH}_{2}\right), 2.64(\mathrm{bs}, 2 \mathrm{H}), 4.02(\mathrm{bs}, 2 \mathrm{H}), 7.10-7.17(\mathrm{~m}, 4 \mathrm{H}), 7.25-7.33(\mathrm{~m}, 4 \mathrm{H})$. These data were consistent with those reported for the racemic compound $( \pm)-\mathbf{1 5}$.

Derivatization of the racemic diamine ( \pm )-15 and its mandelate monoammonium salts 20 and 21 for chiral HPLC analysis. Derivatization of the racemic diamine $( \pm)-\mathbf{1 5}$ and its mandelate monoammonium salts 20 and 21 was adapted from the procedure described by Maruoka and coworkers, ${ }^{[14]}$ and carried out with $m$-tolyl chloride to furnish in good to excellent yields $( \pm)-22$ $(73 \%),(R, R)-22(82 \%)$ and $(S, S)-22(79 \%)$ (Scheme S5). The enantiomeric purity was determined by HPLC analysis on a Daicel Chiralcel ${ }^{\circledR}$ OD-H column $(250 \times 4.6 \mathrm{~mm}$ I.D. $)$, eluting with $n$ hexane $/ i-\mathrm{PrOH}(95: 5)$ at a flow rate of $0.5 \mathrm{~mL} / \mathrm{min}$. Column effluent was monitored by UV detection at $254 \mathrm{~nm}$ [retention time $=10.0 \mathrm{~min}$ for $(R, R)-\mathbf{2 2}$, and $13.0 \mathrm{~min}$ for $(S, S)-22]$ (Figure S5). 

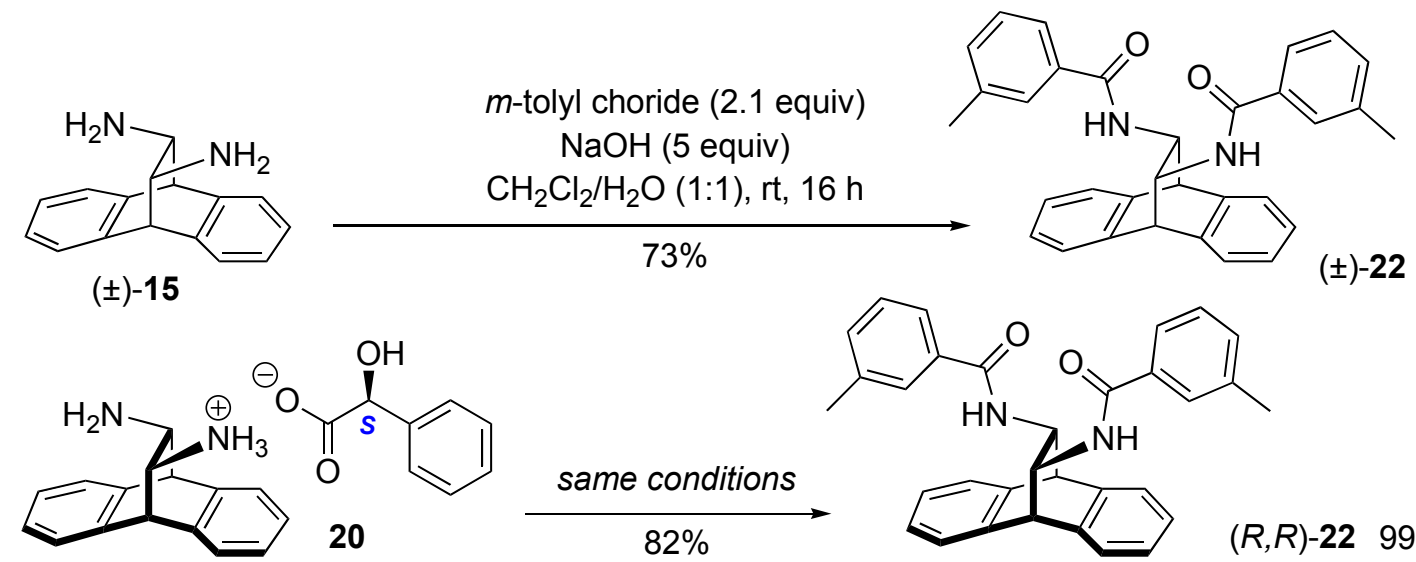<smiles>Cc1cccc(C(=O)NCCNC(=O)c2cccc(C)c2)c1</smiles>

$( \pm)-22$
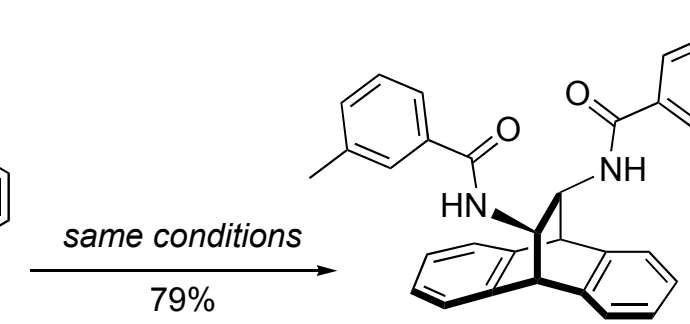

$(R, R)-22 \quad 99 \%$ ee (chiral HPLC)

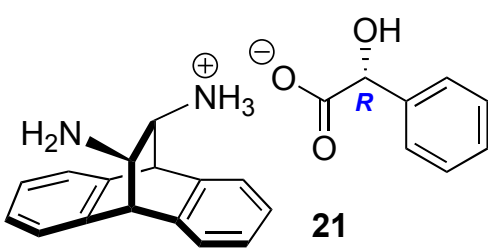

$79 \%$

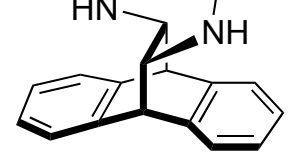

Scheme S5.

(S,S)-22 99\% ee (chiral HPLC)

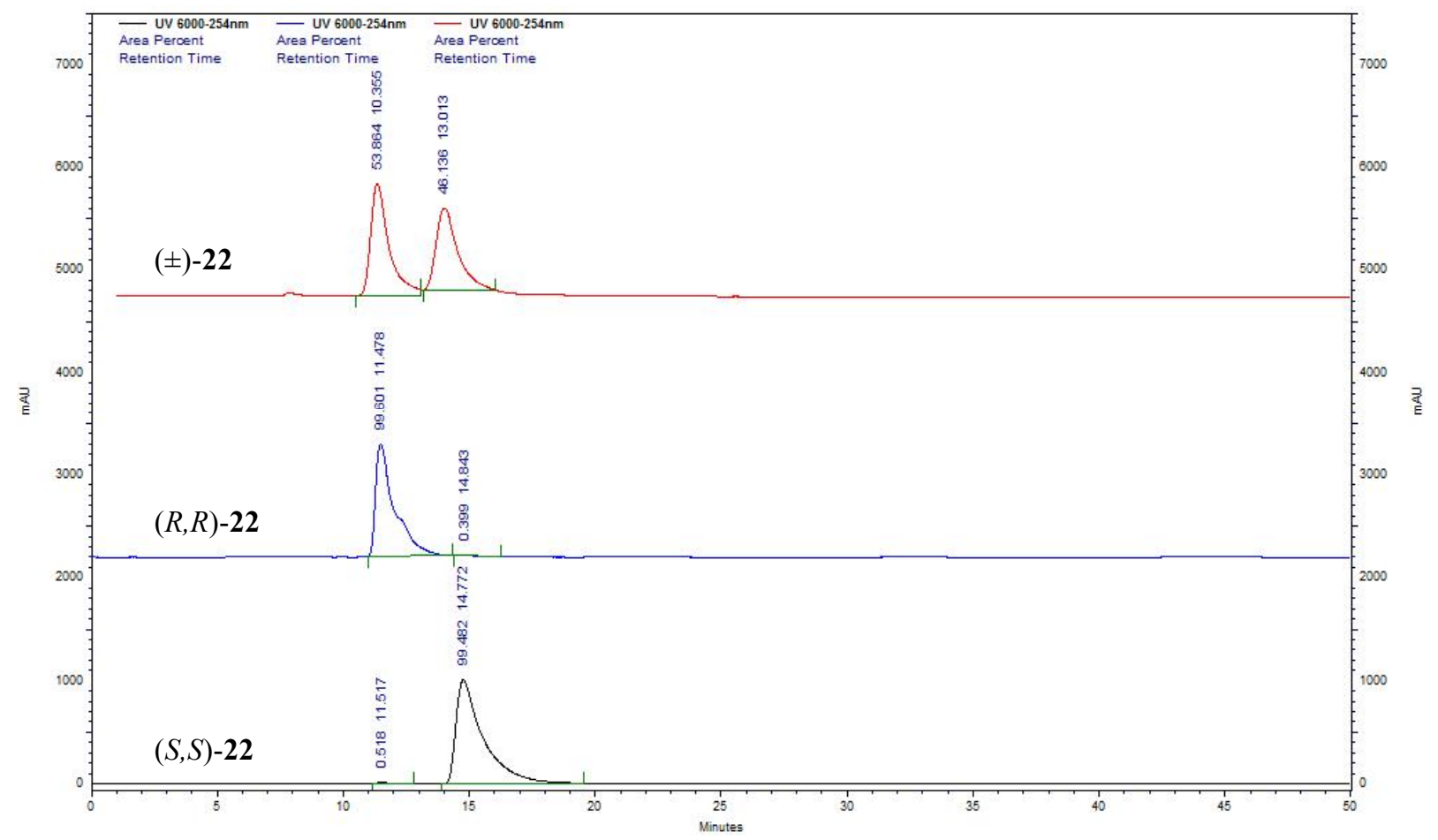

Figure S5. Chiral HPLC traces of $m$-tolyl-derivatized diamines 22.

Chiralcel ${ }^{\circledR}$ OD-H column $(250 \times 4.6 \mathrm{~mm}$ I.D. $), n$-hexane $/ i$-PrOH $(95: 5), 0.5 \mathrm{~mL} / \mathrm{min}$,

$\mathrm{UV}$ detection at $254 \mathrm{~nm}$ [retention time $=10.0 \mathrm{~min}$ for $(R, R)-\mathbf{2 2}$, and $13.0 \mathrm{~min}$ for $(S, S)-22]$.

Bis- $N, N$ '-(m-tolyl)-11,12-diamino-9,10-dihydro-9,10-ethanoanthracene [( \pm -22]. $\mathrm{NaOH}$ pellets

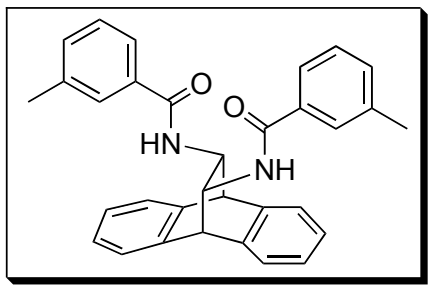

(43 $\mathrm{mg}, 1.10 \mathrm{mmol}$ ) were added to a suspension of racemic diamine $( \pm)-15(50 \mathrm{mg}, 0.21 \mathrm{mmol})$ in $\mathrm{H}_{2} \mathrm{O}(3 \mathrm{~mL})$, at room temperature, and the mixture was stirred vigorously until it became a clear solution. A solution of commercial $m$-tolyl chloride $(59 \mu \mathrm{L}, 0.44 \mathrm{mmol})$ in dry $\mathrm{CH}_{2} \mathrm{Cl}_{2}(3 \mathrm{~mL})$ was then added dropwise. After completion of the reaction, as indicated by TLC monitoring, eluting with PET/EtOAC 
(3:1), the mixture was diluted with $\mathrm{H}_{2} \mathrm{O}(10 \mathrm{~mL})$ and extracted with $\mathrm{CH}_{2} \mathrm{Cl}_{2}(3 \times 10 \mathrm{~mL})$. The combined organic layers were then dried over $\mathrm{Na}_{2} \mathrm{SO}_{4}$, filtered and concentrated. The resulting sticky solid residue was purified by column chromatography, eluting with cyclohexane/EtOAc (4:1), to furnish 22 as a white powder $(73 \mathrm{mg}, 73 \%)$ : m.p. $140-142{ }^{\circ} \mathrm{C} ; \mathbf{R}_{\boldsymbol{f}}=0.29$ [PET/EtOAc (3:1)]; IR (neat): $v=3256,3044,2953,1631,1531,743,695 \mathrm{~cm}^{-1} ;{ }^{1} \mathbf{H ~ N M R}\left(\mathrm{CDCl}_{3}, 300 \mathrm{MHz}\right): \delta$ $=2.32(\mathrm{~s}, 6 \mathrm{H}), 4.29-4.34(\mathrm{~m}, 2 \mathrm{H}), 4.52(\mathrm{~d}, J=2.4 \mathrm{~Hz}, 2 \mathrm{H}), 6.08(\mathrm{~d}, J=7.4 \mathrm{~Hz}, 2 \mathrm{H}), 7.14-7.36(\mathrm{~m}$, 12H), 7.40-7.50 (m, 4H); ${ }^{13} \mathbf{C}$ NMR $\left(\mathrm{CDCl}_{3}, 75 \mathrm{MHz}\right): \delta=167.6,141.1,139.0,138.6,134.1,132.5$, 128.5, 127.9, 127.1, 126.9, 125.9, 125.1, 124.0, 57.4, 49.5, 21.4; LRMS (ESIMS): $m / z(\%)=967$ (4) $\left[2 M^{+}+\mathrm{Na}\right], 495$ (100) $\left[\mathrm{MNa}^{+}\right]$; HRMS (ESITOF): calcd for $\mathrm{C}_{32} \mathrm{H}_{28} \mathrm{~N}_{2} \mathrm{O}_{2} \mathrm{Na}$ 495.2042, found 495.2050.

$(11 R, 12 R)$-Bis- $N, N^{\prime}-(m$-tolyl)-11,12-diamino-9,10-dihydro-9,10-ethanoanthracene $[(R, R)-22]$.

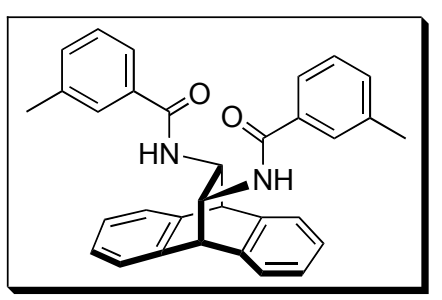

The $(S)$-mandelate monoammonium salt $20(20 \mathrm{mg}, 0.051 \mathrm{mmol})$ was submitted to the same procedure as the one described for $( \pm)-\mathbf{1 5}$, and compound $(R, R)-\mathbf{2 2}$ was obtained as a white amorphous powder (19 mg, 82\%): ${ }^{1} \mathbf{H}$ NMR $\left(\mathrm{CDCl}_{3}, 300 \mathrm{MHz}\right): \delta=2.32(\mathrm{~s}, 6 \mathrm{H}), 4.29-4.32(\mathrm{~m}$, 2H), 4.57 (bs, 2H), $6.04(\mathrm{~d}, J=7.1 \mathrm{~Hz}, 2 \mathrm{H}), 7.16-7.36(\mathrm{~m}, 12 \mathrm{H}), 7.42-$ $7.49(\mathrm{~m}, 4 \mathrm{H})$; chiral HPLC analysis of this sample (vide supra) indicated an enantiomeric excess (ee) of 99\% (Figure S5).

(11S,12S)-Bis- $N, N^{\prime}$-(m-tolyl)-11,12-diamino-9,10-dihydro-9,10-ethanoanthracene $\quad[(S, S)-22]$.

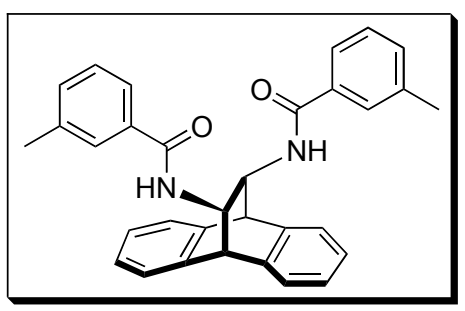

The $(R)$-mandelate monoammonium salt $21(20 \mathrm{mg}, 0.051 \mathrm{mmol})$ was submitted to the same procedure as the one described for $( \pm)-\mathbf{1 5}$, and compound $(S, S)$-22 was obtained as a white amorphous powder (18 $\mathrm{mg}, 79 \%) ;{ }^{1} \mathbf{H}$ NMR $\left(\mathrm{CDCl}_{3}, 300 \mathrm{MHz}\right): \delta=2.28(\mathrm{~s}, 6 \mathrm{H}), 4.35-4.39$ $(\mathrm{m}, 2 \mathrm{H}), 4.57(\mathrm{~d}, J=2.2 \mathrm{~Hz}, 2 \mathrm{H}), 6.20(\mathrm{~d}, J=7.6 \mathrm{~Hz}, 2 \mathrm{H}), 7.13-7.37$ $(\mathrm{m}, 12 \mathrm{H}), 7.47-7.50(\mathrm{~m}, 4 \mathrm{H})$; chiral HPLC analysis of this sample (vide supra) indicated an enantiomeric excess (ee) of 99\% (Fig. S5).

Preparation of the chiral 11,12-diamino-9,10-dihydro-9,10-ethanoanthracene-based diiodoarenes $(R, R)-7 \mathbf{a} / \mathbf{b}$ and $(S, S)-7 \mathbf{a} / \mathbf{b}$ (Scheme S6). Coupling of the chiral 11,12-diamino-9,10dihydro-9,10-ethanoanthracenes $(R, R)$-15 and $(S, S)$-15 with the ortho-iodinated aromatic carboxylic acids, either 2-iodobenzoic acid or 3,5-dimethyl-2-iodobenzoic acid (16), was carried out under standard peptide coupling conditions (i.e., DIEA and $\mathrm{HBTU}$ in $\mathrm{CH}_{2} \mathrm{Cl}_{2}$ ) as previously described for the racemic diamine $( \pm)-\mathbf{1 5}$ (vide supra). The corresponding 11,12-diamino-9,10-dihydro-9,10ethanoanthracene-based $C_{2}$-symmetrical Salen-type diiodoarenes were thus obtained in good to excellent yields between 76 to $94 \%$ (Scheme S6). 


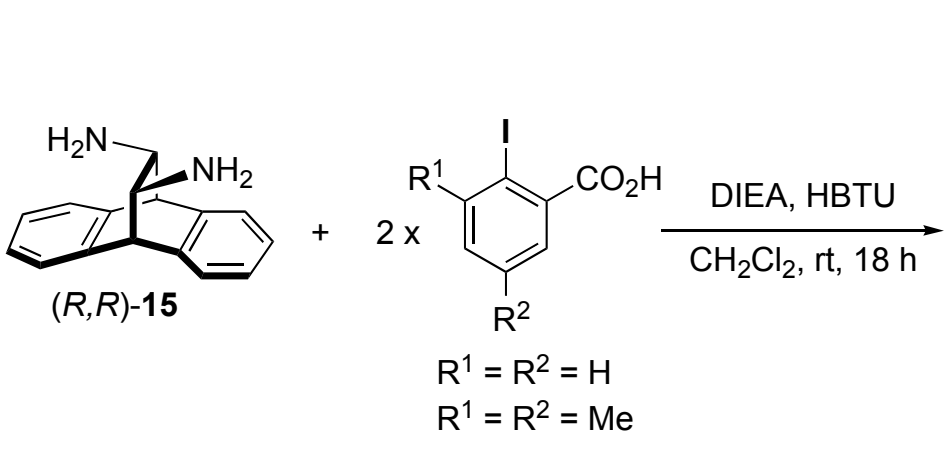

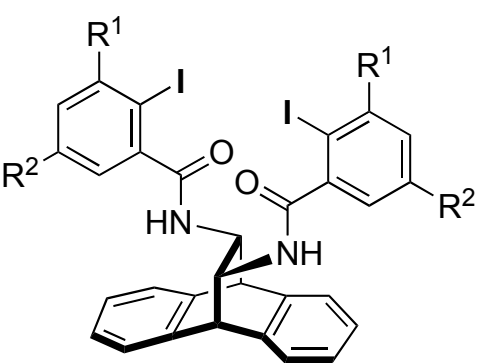

$(R, R)-7 \mathrm{a}: \mathrm{R}^{1}=\mathrm{R}^{2}=\mathrm{H}(76 \%)$

$(R, R)-7 \mathrm{~b}: \mathrm{R}^{1}=\mathrm{R}^{2}=\mathrm{Me}(94 \%)$

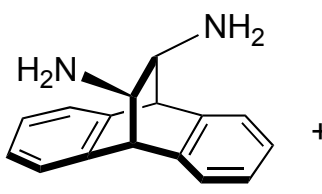

$(S, S)-15$

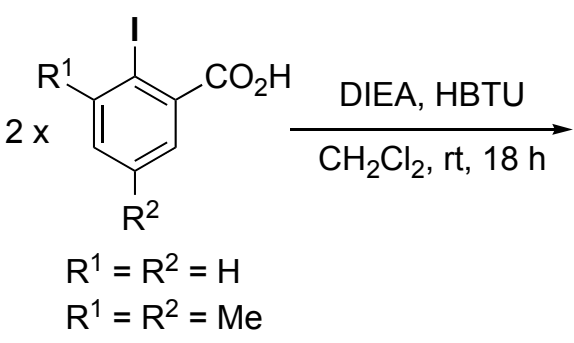

Scheme S6.

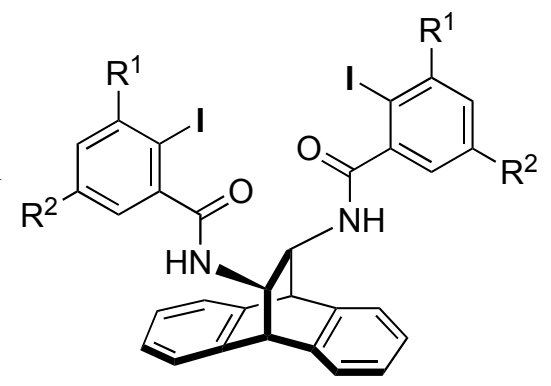

$(S, S)-7 \mathrm{a}: \mathrm{R}^{1}=\mathrm{R}^{2}=\mathrm{H}(86 \%)$ $(S, S)-7 b: R^{1}=R^{2}=\operatorname{Me}(85 \%)$

\section{Scheme S6.}

(-)-(11R,12R)-Bis- $N, N^{\prime}-(2$ '-iodobenzoyl)-11,12-diamino-9,10-dihydro-9,10-ethanoanthracene

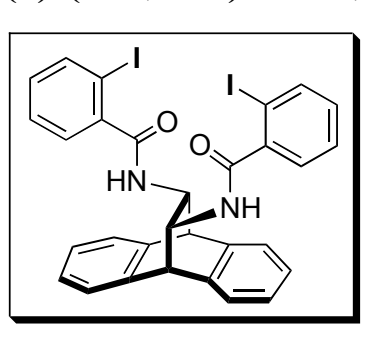

$[(\boldsymbol{R}, \boldsymbol{R})-\mathbf{7 a}]$. Coupling of chiral diamine $(R, R)-\mathbf{1 5}(1.02 \mathrm{~g}, 4.31 \mathrm{mmol})$ and commercial 2-iodobenzoic acid $(3.23 \mathrm{~g}, 13.02 \mathrm{mmol})$ was achieved according to the protocol previously described for racemic $( \pm)-\mathbf{1 5}$. Purification by column chromatography, eluting with cyclohexane/EtOAc (4:1) first to remove the urea byproduct, and then with $\mathrm{CHCl}_{3} / \mathrm{MeOH}(6: 1)$, afforded after solvent evaporation the Salen-type iodoarene $(R, R)-7 \mathbf{a}$ as a white solid (2.29 g, 76\%): $[\alpha]^{\mathbf{2 0}}{ }_{\mathbf{D}}=-134.2(c=1.0, \mathrm{DMSO}) ;{ }^{1} \mathbf{H}$ NMR (DMSO- $\left.d_{6}, 300 \mathrm{MHz}\right): \delta=4.17(\mathrm{~d}, J=6.6 \mathrm{~Hz}, 2 \mathrm{H}), 4.59$ (bs, 2H), 7.10-7.20 (m, 8H), 7.36-7.47 $(\mathrm{m}, 6 \mathrm{H}), 7.84(\mathrm{dd}, J=0.7,7.8 \mathrm{~Hz}, 2 \mathrm{H}), 8.49(\mathrm{~d}, J=6.2 \mathrm{~Hz}, 2 \mathrm{H})$. These data were consistent with those reported for the racemic compound $( \pm)-7 \mathbf{a}$.

\section{(+)-(11S,12S)-Bis- $N, N^{\prime}-(2$ '-iodobenzoyl)-11,12-diamino-9,10-dihydro-9,10-ethanoanthracene}

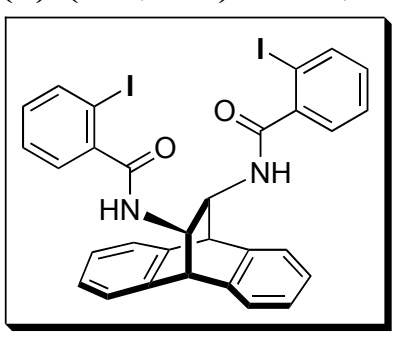

$[(S, S)-7 a]$. Coupling of chiral diamine $(S, S)-15(238 \mathrm{mg}, 1.01 \mathrm{mmol})$ and commercial 2-iodobenzoic acid $(749 \mathrm{mg}, 3.02 \mathrm{mmol})$ was achieved according to the protocol previously described for racemic $( \pm)-\mathbf{1 5}$. Purification by column chromatography, eluting with cyclohexane/EtOAc (4:1) first to remove the urea byproduct, and then with $\mathrm{CHCl}_{3} / \mathrm{MeOH}$ (6:1), gave after solvent evaporation the Salen-type diiodoarene $(S, S)-7 \mathbf{a}$ as a white solid $(603 \mathrm{mg}, 86 \%):[\alpha]^{\mathbf{2 0}}{ }_{\mathbf{D}}=+129.0(c=1.0, \mathrm{DMSO}) ;{ }^{1} \mathbf{H}$ NMR (DMSO- $\left.d_{6}, 300 \mathrm{MHz}\right): \delta=4.17(\mathrm{~d}, J=6.6 \mathrm{~Hz}, 2 \mathrm{H}), 4.59$ (bs, 2H), 7.10-7.20 (m, 8H), 7.35$7.47(\mathrm{~m}, 6 \mathrm{H}), 7.84(\mathrm{dd}, J=0.8,7.9 \mathrm{~Hz}, 2 \mathrm{H}), 8.49(\mathrm{~d}, J=6.3 \mathrm{~Hz}, 2 \mathrm{H})$. These data were consistent with those reported for the racemic compound $( \pm)-7 \mathbf{a}$.

(11R,12R)-Bis- $N, N^{\prime}-(2$ '-iodo-3',5'-dimethylbenzoyl)-11,12-diamino-9,10-dihydro-9,10-ethano-

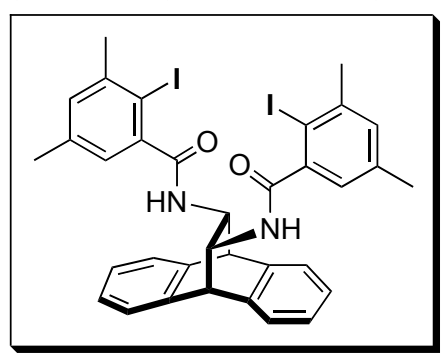
anthracene $[(\boldsymbol{R}, \boldsymbol{R})-\mathbf{7 b}]$. Coupling of chiral diamine $(R, R)-\mathbf{1 5}(150 \mathrm{mg}$, $0.634 \mathrm{mmol})$ and 2-iodo-3,5-dimethylbenzoic acid (16) (438 $\mathrm{mg}, 1.648$ $\mathrm{mmol}$ ) was achieved according to the protocol previously described for racemic $( \pm)$-15. Purification by column chromatography, eluting with cyclohexane/ EtOAc (4:1) first to remove the urea byproduct, and then 
with cyclohexane/EtOAc (1:1), furnished after solvent evaporation the Salen-type diiodoarene $(R, R)-7 \mathbf{b}$ as a pale yellow foam $(450 \mathrm{mg}, 94 \%) . N . B .:[\alpha]^{20}{ }_{D}=$ not soluble in MeOH, DMSO, $\mathrm{H}_{2} \mathrm{O}$, $\mathrm{CH}_{2} \mathrm{Cl}_{2}, \mathrm{CHCl}_{3}, \mathrm{CH}_{3} \mathrm{CN}$ and acetone. ${ }^{1} \mathrm{H}$ and ${ }^{13} \mathrm{C}$ NMR data were consistent with those reported for the racemic compound $( \pm)-\mathbf{7 b}$.

(11S,12S)-Bis- $N, N^{\prime}-(2$ '-iodo-3',5'-dimethylbenzoyl)-11,12-diamino-9,10-dihydro-9,10-ethano-

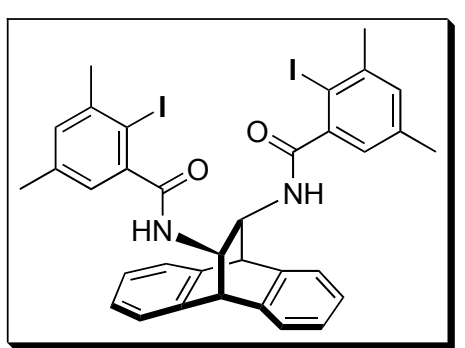
anthracene $[(S, S)-7 \mathbf{b}]$. Coupling of chiral diamine $(S, S)-15(150 \mathrm{mg}$, $0.634 \mathrm{mmol}$ ) and 2-iodo-3,5-dimethylbenzoic acid (16) (438 mg, $1.648 \mathrm{mmol}$ ) was achieved according to the protocol previously described for racemic $( \pm)-15$. Purification by column chromatography, eluting with cyclohexane/ EtOAc (4:1) first to remove the urea byproduct, and with cyclohexane /EtOAc (1:1), gave after solvent evaporation the Salen-type iodoarene $(S, S)$-7b as a white foam $(405$ mg, 85\%). N.B.: $[\alpha]^{20}{ }_{D}=$ not soluble in $\mathrm{MeOH}, \mathrm{DMSO}, \mathrm{H}_{2} \mathrm{O}, \mathrm{CH}_{2} \mathrm{Cl}_{2}$, $\mathrm{CHCl}_{3}, \mathrm{CH}_{3} \mathrm{CN}$ and acetone. ${ }^{1} \mathrm{H}$ and ${ }^{13} \mathrm{C}$ NMR data were consistent with those reported for the racemic compound $( \pm)-\mathbf{7 b}$.

DMDO-Mediated oxidation of Salen-type bis(iodoarenes) into bis $\left(\lambda^{5}\right.$-iodanes)

A screening of oxidizing systems among those classically used in hypervalent iodine chemistry [i.e., Oxone ${ }^{\circledR}$ in $\mathrm{H}_{2} \mathrm{O}, \mathrm{H}_{2} \mathrm{O} / \mathrm{CH}_{3} \mathrm{CN}(1: 1)$ or $\mathrm{CH}_{2} \mathrm{Cl}_{2}$, TBA-Oxone ${ }^{\circledR}$ in $\mathrm{CH}_{2} \mathrm{Cl}_{2}$ or acetone, DMDO in acetone, $m$-CPBA in $\mathrm{CH}_{2} \mathrm{Cl}_{2}$ or DMSO, $\mathrm{AcOOH}$ in $\mathrm{AcOH}$, aqueous $\mathrm{NaOCl}$ in $\mathrm{CH}_{2} \mathrm{Cl}_{2}, \mathrm{H}_{2} \mathrm{O}_{2}$-urea in $\mathrm{CH}_{2} \mathrm{Cl}_{2}, 30$ or $90 \% \mathrm{H}_{2} \mathrm{O}_{2}$ in $\mathrm{CH}_{2} \mathrm{Cl}_{2}, t \mathrm{BuOOH}$ in $\mathrm{CH}_{2} \mathrm{Cl}_{2}, \mathrm{KBrO}_{3}$ in $\mathrm{H}_{2} \mathrm{SO}_{4}$, Selectfluor ${ }^{\circledR}$ in $\mathrm{CH}_{3} \mathrm{CN}$; DMDO $=3,3$-dimethyldioxirane, TBA = tetra- $n$-butylammonium] revealed that effective oxygenation of the Salen-type bis(iodoarenes) could be achieved only with DMDO.

General procedure for the DMDO-mediated oxidation of diiodoarenes $6 \mathrm{a}-\mathrm{d}$ and $7 \mathbf{a} / \mathbf{b}$. To an ice-cold stirred solution of freshly prepared and previously titrated 3,3-dimethyldioxirane (DMDO) in acetone (typically $70-80 \mathrm{mM})^{[15]}$ was added the iodoarene. Salen-type bis(iodoarenes) 6a-d and $7 \mathbf{a} / \mathbf{b}$ were successfully oxidized into iodanes 8 and $\mathbf{9}$, respectively, with a total of 8 equivalents of DMDO (4 equiv per iodine atom): 6 equivalents were initially used, and the mixture was stirred at room temperature for 16 hours, after which time 2 equivalents of DMDO were added, and the reaction stirred for 6 additional hours (see Scheme 5 in the main text). The resulting precipitate was filtered, washed with acetone $(2 \times 10 \mathrm{~mL})$ and dried under vacuum to give the corresponding bis(iodyl) compounds [i.e., bis $\left(\lambda^{5}\right.$-iodanes $\left.)\right]$ as white powders, which were used without further purification.

N.B.: the iodocompound $(S, S)-\mathbf{1 8}$ surprisingly resisted this oxidation protocol.

$(1 R, 2 R)-B i s-N, N^{\prime}-(2$ '-iodylbenzoyl)-1,2-cyclohexanediamine $\quad[(R, R)-8 a] . \quad$ DMDO-mediated

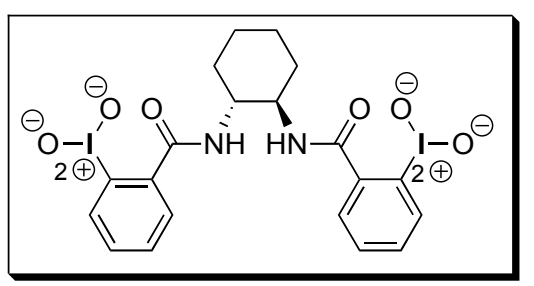
oxidation of $(R, R)-6 \mathbf{a}(110 \mathrm{mg}, 0.192 \mathrm{mmol})$ furnished the corresponding bis $\left(\lambda^{5}\right.$-iodane $)(R, R)-\mathbf{8 a}$ as a white powder $(109 \mathrm{mg}$, $89 \%$ ): m.p. $239-240{ }^{\circ} \mathrm{C}$ (decomposition); $[\alpha]^{20}{ }_{D}=$ not soluble in most common solvents; IR (neat): $v=3330,3177,2922,2851$, 1602, 1559, $747 \mathrm{~cm}^{-1} ;{ }^{1} \mathbf{H}$ NMR (DMSO- $\left.d_{6}, 300 \mathrm{MHz}\right): \delta=1.27-$ $1.42(\mathrm{~m}, 2 \mathrm{H}), 1.43-1.66(\mathrm{~m}, 2 \mathrm{H}), 1.69-1.84(\mathrm{~m}, 2 \mathrm{H}), 1.94(\mathrm{bd}, J=$ $12.2 \mathrm{~Hz}, 2 \mathrm{H}), 4.11(\mathrm{bs}, 2 \mathrm{H}), 7.65(\mathrm{t}, J=7.5 \mathrm{~Hz}, 2 \mathrm{H}), 7.86(\mathrm{t}, J=7.5 \mathrm{~Hz}, 2 \mathrm{H}), 8.08(\mathrm{~d}, J=7.5 \mathrm{~Hz}$, 2H), $8.22(\mathrm{~d}, J=7.5 \mathrm{~Hz}, 2 \mathrm{H}), 9.20(\mathrm{bd}, J=3.9 \mathrm{~Hz}, 2 \mathrm{H}) ;{ }^{13}$ C NMR (DMSO-d, $\left.75 \mathrm{MHz}\right): \delta=165.9$, 148.8, 132.6, 131.5, 128.7, 127.6, 122.9, 53.0, 31.4, 24.4; LRMS (ESIMS): $m / z(\%)=1299(62)$ $\left[2 M^{+}+\mathrm{Na}\right], 661(50)\left[M \mathrm{Na}^{+}\right], 639(100)\left[\mathrm{MH}^{+}\right]$; HRMS (ESITOF): calcd for $\mathrm{C}_{20} \mathrm{H}_{20} \mathrm{I}_{2} \mathrm{~N}_{2} \mathrm{O}_{6} \mathrm{Na}$ 660.9303 , found 660.9290 . 
(1S,2S)-Bis- $N, N^{\prime}$-(2'-iodylbenzoyl)-1,2-cyclohexanediamine $\quad[(S, S)-8$ a $] . \quad$ DMDO-mediated

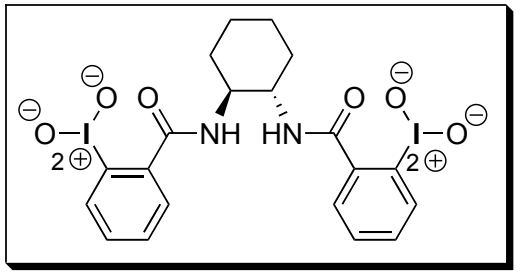
oxidation of $(S, S)-\mathbf{6 a}(120 \mathrm{mg}, 0.209 \mathrm{mmol})$ furnished the corresponding bis $\left(\lambda^{5}\right.$-iodane $)(S, S)-8 \mathbf{a}$ as a white powder $(124 \mathrm{mg}$, 93\%): m.p. $240{ }^{\circ} \mathrm{C}$ (decomposition); $[\alpha]^{20}{ }_{D}=$ not soluble in most common solvents; IR (neat): $v=3329,3176,2922,2851,1601$, 1559, $747 \mathrm{~cm}^{-1}$; ${ }^{1} \mathbf{H}$ NMR (DMSO- $\left.d_{6}, 300 \mathrm{MHz}\right): \delta=1.29-1.38(\mathrm{~m}$, $2 \mathrm{H}), 1.48-1.62(\mathrm{~m}, 2 \mathrm{H}), 1.65-1.82(\mathrm{~m}, 2 \mathrm{H}), 1.94(\mathrm{bd}, J=12.1 \mathrm{~Hz}$, 2H), $4.10(\mathrm{bs}, 2 \mathrm{H}), 7.65$ (t, $J=7.5 \mathrm{~Hz}, 2 \mathrm{H}), 7.85(\mathrm{t}, J=7.3 \mathrm{~Hz}, 2 \mathrm{H}), 8.09$ (d, $J=7.3 \mathrm{~Hz}, 2 \mathrm{H}), 8.22$ $(\mathrm{d}, J=7.3 \mathrm{~Hz}, 2 \mathrm{H}), 9.21$ (bs, $2 \mathrm{H}) ;{ }^{13} \mathbf{C}$ NMR (DMSO- $\left.d_{6}, 75 \mathrm{MHz}\right): \delta=165.9,148.8,132.6,131.5$, 128.8, 127.6, 123.0, 53.0, 31.4, 24.5; LRMS (ESIMS): $m / z(\%)=1299(43)\left[2 M^{+}+\mathrm{Na}\right], 661(100)$ $\left[M \mathrm{Na}^{+}\right]$; HRMS (ESITOF): calcd for $\mathrm{C}_{20} \mathrm{H}_{20} \mathrm{I}_{2} \mathrm{~N}_{2} \mathrm{O}_{6} \mathrm{Na} 660.9303$, found 660.9297 .

$(1 R, 2 R)-B i s-N, N^{\prime}-(2 '$ 'iodyl-3'-methylbenzoyl)-1,2-cyclohexanediamine $\quad[(R, R)-8 b] . \quad D M D O-$

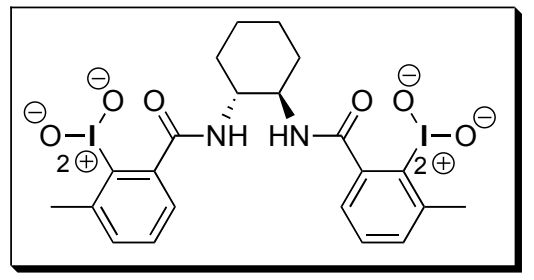
mediated oxidation of $(R, R)-6 \mathbf{b}(180 \mathrm{mg}, 0.299 \mathrm{mmol})$ gave the corresponding bis $\left(\lambda^{5}\right.$-iodane $)(R, R)-\mathbf{8 b}$ as a white powder $(197$ $\mathrm{mg}$, quantitative yield): m.p. $162-163{ }^{\circ} \mathrm{C}$ (decomposition); $[\alpha]^{20}{ }_{D}$ $=$ not soluble in most common solvents; IR (neat): $v=3240$, 3071, 2924, 2853, 1621, 1574, $763 \mathrm{~cm}^{-1} ;{ }^{1} \mathbf{H}$ NMR (DMSO- $d_{6}$, $300 \mathrm{MHz}): \delta=1.20-1.38(\mathrm{~m}, 2 \mathrm{H}), 1.40-1.60(\mathrm{~m}, 2 \mathrm{H}), 1.76$ (bd, $J$ $=7.3 \mathrm{~Hz}, 2 \mathrm{H}), 1.96(\mathrm{bd}, J=11.8 \mathrm{~Hz}, 2 \mathrm{H}), 2.88(\mathrm{~s}, 6 \mathrm{H}), 3.90-4.08(\mathrm{~m}, 2 \mathrm{H}), 7.36(\mathrm{bt}, J=8.3 \mathrm{~Hz}$, 2H), 7.41 (bt, $J=7.3 \mathrm{~Hz}, 2 \mathrm{H}), 7.59$ (bd, $J=7.3 \mathrm{~Hz}, 2 \mathrm{H}), 8.97$ (bd, $J=7.7 \mathrm{~Hz}, 2 \mathrm{H}) ;{ }^{13} \mathbf{C}$ NMR (DMSO- $\left.d_{6}, 75 \mathrm{MHz}\right): \delta=166.9,147.7,140.6,136.8,133.5,130.4,125.2,52.9,31.3,24.5,16.7$ (N.B.: partial reduction was observed during ${ }^{13} \mathrm{C}$ NMR spectrum acquisition); LRMS (ESIMS): $m / z(\%)=689(100)\left[\mathrm{MNa}^{+}\right]$; HRMS (ESITOF): calcd for $\mathrm{C}_{22} \mathrm{H}_{24} \mathrm{I}_{2} \mathrm{~N}_{2} \mathrm{O}_{6} \mathrm{Na}$ 688.9616, found 688.9629 .

(1R,2R)-Bis- $N, N^{\prime}-(2$ '-iodyl-3',5'-dimethylbenzoyl)-1,2-cyclohexanediamine [(R,R)-8c]. DMDO-

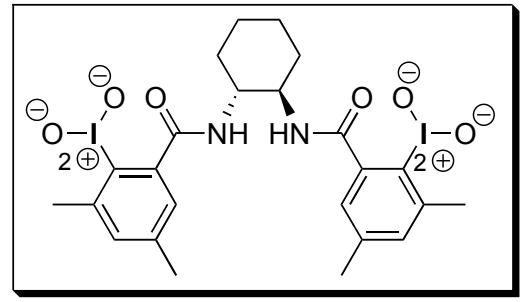
mediated oxidation of $(R, R)-6 \mathbf{c}(100 \mathrm{mg}, 0.159 \mathrm{mmol})$ gave the corresponding bis $\left(\lambda^{5}\right.$-iodane $)(R, R)-\mathbf{8 c}$ as a white powder $(111 \mathrm{mg}$, quantitative yield): m.p. $138-139{ }^{\circ} \mathrm{C}$ (decomposition); $[\alpha]^{20}{ }_{D}=$ not soluble in most common solvents; IR (neat): $v=3385,3056$, 2931, 2860, 1616, 1546, $749 \mathrm{~cm}^{-1} ;{ }^{1} \mathbf{H}$ NMR (DMSO-d 6,300 $\mathrm{MHz}): \delta=1.22-1.35(\mathrm{~m}, 2 \mathrm{H}), 1.44-1.57(\mathrm{~m}, 2 \mathrm{H}), 1.73-1.77(\mathrm{~m}$, $2 \mathrm{H}), 1.91-1.95(\mathrm{~m}, 2 \mathrm{H}), 2.27(\mathrm{~s}, 6 \mathrm{H}), 2.83(\mathrm{~s}, 6 \mathrm{H}), 3.87-4.05(\mathrm{~m}$, 2H), 7.16 (s, 2Har), 7.42 (s, 2Har), 8.92 (d, $J=6.6 \mathrm{~Hz}, 2 \mathrm{H}) ;{ }^{13}$ C NMR (DMSO-d, $\left.75 \mathrm{MHz}\right): \delta=$ $167.0,144.8,140.5,140.4,137.2,133.5,125.7,53.2,31.2,24.6,20.5,16.7$ (N.B.: partial degradation was observed during ${ }^{13} \mathrm{C}$ NMR spectrum acquisition); LRMS (ESITOF): $\mathrm{m} / \mathrm{z}(\%)=$ 717 (46) $\left[\mathrm{MNa}^{+}\right], 685$ (10) $\left[M^{+}-2 \mathrm{O}+\mathrm{Na}\right]$; HRMS (ESITOF): calcd for $\mathrm{C}_{24} \mathrm{H}_{28} \mathrm{I}_{2} \mathrm{~N}_{2} \mathrm{O}_{6} \mathrm{Na} 716.9929$ found 716.9963 .

(1R,2R)-Bis- $N, N^{\prime}-(3$ '-iodyl-2'-naphthoyl)-1,2-cyclohexanediamine [( $\left.R, R)-8 \mathrm{~d}\right]$. DMDO-mediated

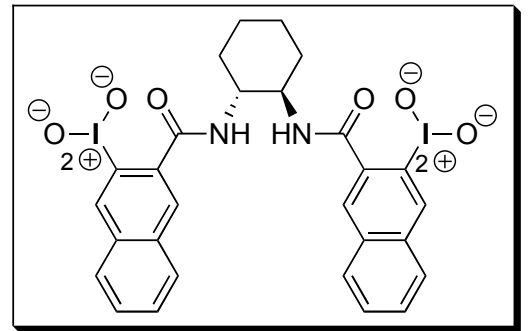
oxidation of $(R, R)-\mathbf{6 d}(200 \mathrm{mg}, 0.297 \mathrm{mmol})$ gave the corresponding bis $\left(\lambda^{5}\right.$-iodane) $(R, R)-\mathbf{8 d}$ as a pale yellow powder (187 mg, 86\%): m.p. $295{ }^{\circ} \mathrm{C}$ (decomposition); $[\alpha]^{20}{ }_{D}=$ not soluble in most common solvents; IR (neat): $v=3333,3163$, 2922, 2851, 1590, 1542, $759 \mathrm{~cm}^{-1}$; ${ }^{\mathbf{1}} \mathbf{H}$ NMR (DMSO-d 6,300 $\mathrm{MHz}): \delta=1.27-1.41(\mathrm{~m}, 2 \mathrm{H}), 1.56-1.70(\mathrm{~m}, 2 \mathrm{H}), 1.73-1.85(\mathrm{~m}$, $2 \mathrm{H}), 1.99(\mathrm{bd}, J=12.2 \mathrm{~Hz}, 2 \mathrm{H}), 4.13-4.26(\mathrm{~m}, 2 \mathrm{H}), 7.58-7.71(\mathrm{~m}$, $4 \mathrm{H}), 8.11(\mathrm{~d}, J=7.7 \mathrm{~Hz}, 2 \mathrm{H}), 8.17(\mathrm{~d}, J=7.8 \mathrm{~Hz}, 2 \mathrm{H}), 8.70(\mathrm{bs}, 2 \mathrm{H}), 8.71(\mathrm{bs}, 2 \mathrm{H}), 9.43(\mathrm{bd}, J=$ $4.9 \mathrm{~Hz}, 2 \mathrm{H}) ;{ }^{13} \mathbf{C}$ NMR (DMSO- $\left.d_{6}, 75 \mathrm{MHz}\right): \delta=166.4,145.2,133.5,133.0,129.4,129.1,128.7$, 128.6, 128.5, 125.7, 123.8, 53.2, 31.5, 24.5 (N.B.: partial degradation was observed during ${ }^{13} \mathrm{C}$ 
NMR spectrum acquisition); LRMS (ESIMS): $m / z(\%)=761(100)\left[\mathrm{MNa}^{+}\right]$; HRMS (ESITOF): calcd for $\mathrm{C}_{28} \mathrm{H}_{24} \mathrm{I}_{2} \mathrm{~N}_{2} \mathrm{O}_{6} \mathrm{Na} 760.9616$, found 760.9632 .

( \pm )-Bis- $N, N^{\prime}-\left({ }^{\prime}\right.$ '-iodylbenzoyl)-11,12-diamino-9,10-dihydro-9,10-ethanoanthracene $\quad[( \pm)-9 \mathrm{a}]$. DMDO-mediated oxidation of $( \pm)-7 \mathbf{a}(300 \mathrm{mg}, 0.431 \mathrm{mmol})$ gave the corresponding bis $\left(\lambda^{5}\right.$-iodane $)$ $( \pm)-9 a$ as a white fine powder (332 mg, quantitative yield): m.p. $193-194{ }^{\circ} \mathrm{C}$ (decomposition); IR

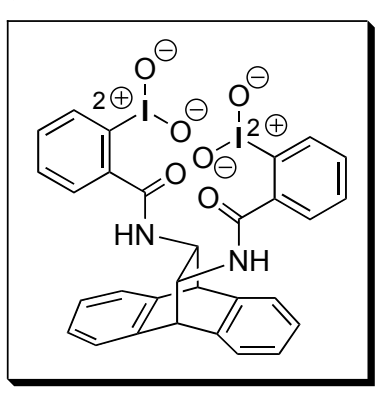
(neat): $v=3338,3060,2959,2917,1638,1582,1537,1450,1403,663 \mathrm{~cm}^{-}$ ${ }^{1} ;{ }^{1} \mathbf{H}$ NMR (DMSO- $\left.d_{6}, 300 \mathrm{MHz}\right): \delta=4.61(\mathrm{~s}, 2 \mathrm{H}), 4.64(\mathrm{~d}, J=5.7 \mathrm{~Hz}$, 2H), 7.13-7.29 (m, 6H), 7.49 (d, $J=6.9 \mathrm{~Hz}, 2 \mathrm{H}), 7.65$ (t, $J=7.2 \mathrm{~Hz}, 2 \mathrm{H})$, $7.91(\mathrm{t}, J=7.2 \mathrm{~Hz}, 2 \mathrm{H}), 8.02(\mathrm{~d}, J=7.2 \mathrm{~Hz}, 2 \mathrm{H}), 8.27(\mathrm{dd}, J=3.9,7.8 \mathrm{~Hz}$, $2 \mathrm{H}$ ), 9.05 (bd, $J=5.7 \mathrm{~Hz}, 2 \mathrm{H}) ;{ }^{13} \mathbf{C}$ NMR (DMSO- $\left.d_{6}, 75 \mathrm{MHz}\right): \delta=$ 166.6, 149.2, 141.5, 139.4, 133.0, 131.2, 128.6, 127.6, 126.4, 125.8, 124.5, 123.2, 55.2, 48.4; LRMS (ESITOF): 783 (100) $\left[\mathrm{MNa}^{+}\right]$; HRMS (ESITOF): calcd for $\mathrm{C}_{30} \mathrm{H}_{22} \mathrm{I}_{2} \mathrm{~N}_{2} \mathrm{O}_{6} \mathrm{Na} 782.9459$, found 782.9489 .

( \pm )-Bis- $N, N^{\prime}-(2$ '-iodyl-3',5'-dimethylbenzoyl)-11,12-diamino-9,10-dihydro-9,10-ethano-

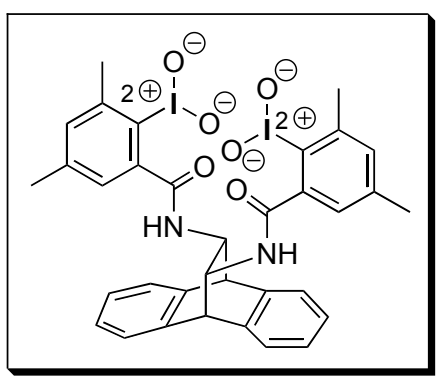
anthracene $[( \pm)-9 \mathbf{b}]$. DMDO-mediated oxidation of $( \pm)-7 \mathbf{b}(100 \mathrm{mg}$, $0.133 \mathrm{mmol})$ afforded the corresponding bis $\left(\lambda^{5}\right.$-iodane $)( \pm)-9 \mathbf{b}$ as a pale yellow powder (62 mg, 57\%): m.p. $136-138{ }^{\circ} \mathrm{C}$ (decomposition); IR (neat): $v=3270,3066,2977,2922,1655,1585,1543,1457,1411,763$ $\mathrm{cm}^{-1} ;{ }^{1} \mathbf{H}$ NMR (DMSO- $\left.d_{6}, 300 \mathrm{MHz}\right): \delta=2.26\left(\mathrm{~s}, 6 \mathrm{H}, 2 \times \mathrm{CH}_{3}\right), 2.88$ $\left(\mathrm{s}, 6 \mathrm{H}, 2 \times \mathrm{CH}_{3}\right), 4.46(\mathrm{~d}, J=5.3 \mathrm{~Hz}, 2 \mathrm{H}), 4.61$ (bs, $\left.2 \mathrm{H}\right), 7.06-7.51(\mathrm{~m}$, 12 Har), 8.90 (bd, $J=5.8 \mathrm{~Hz}, 2 \mathrm{H})$ (N.B.: partial degradation was observed during ${ }^{1} \mathrm{H}$ NMR spectrum acquisition, and thus no ${ }^{13} \mathrm{C}$ NMR spectrum could be recorded); LRMS (ESIMS): $m / z(\%)=839$ (100) [ $\left.\mathrm{MNa}^{+}\right]$; HRMS (TOF): calcd for $\mathrm{C}_{34} \mathrm{H}_{30} \mathrm{I}_{2} \mathrm{~N}_{2} \mathrm{O}_{6} \mathrm{Na} 839.0085$, found 839.0125.

$(11 R, 12 R)$-Bis- $N$, $N$ '-(2'-iodylbenzoyl)-11,12-diamino-9,10-dihydro-9,10-ethanoanthracene

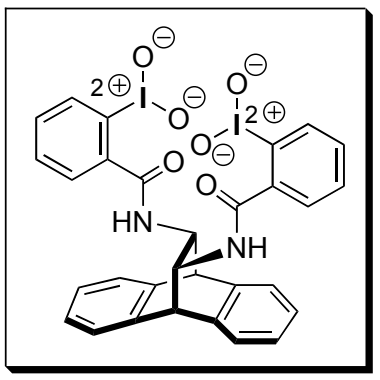

[(R,R)-9a]. DMDO-mediated oxidation of $(R, R)-7 \mathbf{a}(300 \mathrm{mg}, 0.431 \mathrm{mmol})$ afforded the titled compound $(R, R)-9$ a as an off-white powder $(332 \mathrm{mg}$, quantitative yield). N.B.: $[\alpha]^{20}{ }_{D}=$ not soluble in most common solvents; ${ }^{1} \mathbf{H}$ NMR (DMSO- $\left.d_{6}, 300 \mathrm{MHz}\right): \delta=4.60(\mathrm{~s}, 2 \mathrm{H}), 4.65(\mathrm{~d}, J=4.9 \mathrm{~Hz}, 2 \mathrm{H})$, 7.13-7.29 (m, 6H), $7.49(\mathrm{~d}, J=6.7 \mathrm{~Hz}, 2 \mathrm{H}), 7.65(\mathrm{bt}, J=7.5 \mathrm{~Hz}, 2 \mathrm{H}), 7.90$ (bt, $J=7.3 \mathrm{~Hz}, 2 \mathrm{H}), 8.02(\mathrm{~d}, J=7.0 \mathrm{~Hz}, 2 \mathrm{H}), 8.27(\mathrm{dd}, J=1.1,7.3 \mathrm{~Hz}, 2$ $\mathrm{H}), 9.06$ (bd, $J=5.7 \mathrm{~Hz}, 2 \mathrm{H})$. These data were consistent with those reported for $( \pm)-9$.

\section{(11S,12S)-Bis- $N, N$ '-(2'-iodylbenzoyl)-11,12-diamino-9,10-dihydro-9,10-ethanoanthracene}

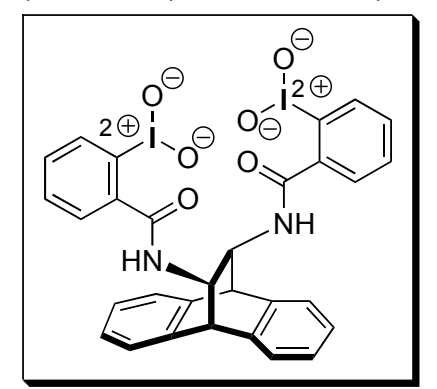

[(S,S)-9a]. DMDO-mediated oxidation of $(S, S)-7 \mathbf{a}(250 \mathrm{mg}, 0.359 \mathrm{mmol})$ gave the titled compound $(S, S)-9$ a as a pale yellow powder $(280 \mathrm{mg}$, quantitative yield). N.B.: $[\alpha]^{20}{ }_{D}=$ not soluble in most common solvents; ${ }^{1}$ H NMR (DMSO- $\left.d_{6}, 300 \mathrm{MHz}\right): \delta=4.60(\mathrm{~s}, 2 \mathrm{H}), 4.65(\mathrm{~d}, J=5.9 \mathrm{~Hz}$, 2H), 7.13-7.29 (m, 6H), 7.49 (d, $J=6.9 \mathrm{~Hz}, 2 \mathrm{H}), 7.66$ (bt, $J=7.3 \mathrm{~Hz}$, 2H), 7.91 (bt, $J=7.7 \mathrm{~Hz}, 2 \mathrm{H}), 8.03(\mathrm{~d}, J=7.6 \mathrm{~Hz}, 2 \mathrm{H}), 8.28$ (dd, $J=0.9$, $7.8 \mathrm{~Hz}, 2 \mathrm{H}), 9.05(\mathrm{bd}, J=5.4 \mathrm{~Hz}, 2 \mathrm{H})$. These data were consistent with those reported for $( \pm)-9 \mathbf{a}$. 


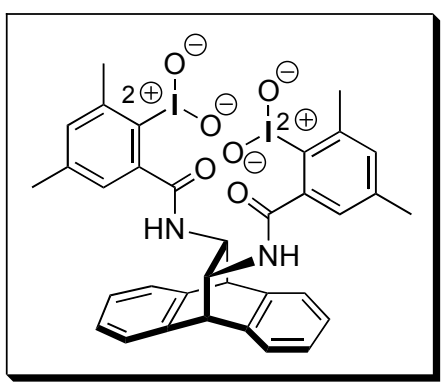
anthracene $[(\boldsymbol{R}, \boldsymbol{R})-9 \mathbf{b}]$. DMDO-mediated oxidation of $(R, R)-7 \mathbf{b}(200$ $\mathrm{mg}, 0.266 \mathrm{mmol}$ ) afforded the titled compound $(R, R)-9 \mathbf{b}$ as an offwhite amorphous powder $(212 \mathrm{mg}, 98 \%)$. N.B.: $[\alpha]^{20}{ }_{D}=$ not soluble in most common solvents. ${ }^{1} \mathrm{H}$ NMR data were consistent with those reported for $( \pm)-9 \mathbf{b}$, and partial degradation during ${ }^{1} \mathrm{H}$ NMR spectrum acquisition was also observed.

(11S,12S)-Bis- $N, N^{\prime}-(2$ '-iodyl-3',5'-dimethylbenzoyl)-11,12-diamino-9,10-dihydro-9,10-ethano-

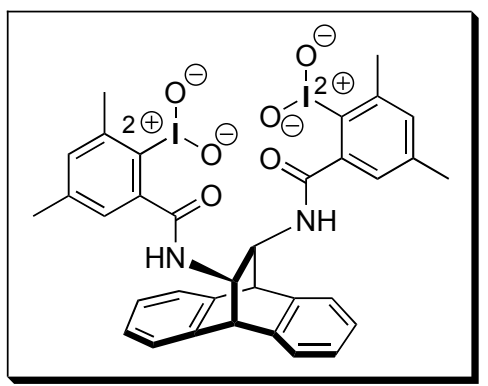
anthracene $[(\boldsymbol{S}, \boldsymbol{S})-9 \mathbf{b}]$. DMDO-mediated oxidation of $(S, S)-7 \mathbf{b}(200$ $\mathrm{mg}, 0.266 \mathrm{mmol})$ and gave the titled compound $(S, S)-9 \mathbf{b}$ as a pale yellow amorphous powder (209 mg, 96\%). N.B.: $[\alpha]^{20}{ }_{D}=$ not soluble in most common solvents. ${ }^{1} \mathrm{H}$ NMR data were consistent with those reported for $( \pm)-9 \mathbf{b}$, and partial degradation during ${ }^{1} \mathrm{H}$ NMR spectrum acquisition was also observed.

\section{Asymmetric hydroxylative phenol dearomatization (HPD)/[4+2]-dimerization cascade conversion of carvacrol promoted by Salen-type bis $\left(\lambda^{5}\right.$-iodanes $)$}

The capacity of the chiral Salen-type bis( $\lambda^{5}$-iodanes) 8 and $\mathbf{9}$ to transfer their oxygen atom(s) in an asymmetric fashion was then evaluated in the context of the HPD/[4+2] dimerization cascade conversion of carvacrol (1a) into bis(carvacrol) (+)-3a, our benchmark reaction (Scheme S7). Enantiomeric excesses (ee) were determined by HPLC analysis on a chiral stationary phase [Daicel Chiralpak $^{\circledR}$ AS-H column, $250 \times 4.6 \mathrm{~mm}$ I.D.] and by comparison with the HPLC trace obtained for the racemic biscarvacrol $( \pm)-\mathbf{3 a} .^{[8,16,17]}$

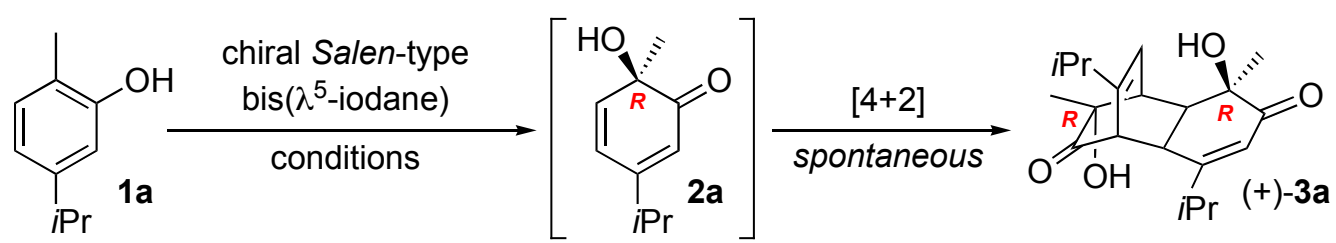

\section{Scheme S7.}

The results of the most revealing experiments using the chiral bis( $\lambda^{5}$-iodanes) 8 and 9 are summarized in Table S1. Reactions run at room temperature in THF (iodane not soluble), DMSO (iodane perfectly soluble) or $\mathrm{CH}_{2} \mathrm{Cl}_{2}$ (iodane partially soluble) all left 1a intact, even after 48 hours, but a good compromise between the solubility of the iodane and the conversion of 1a into 3a was found by using a $85: 15(\mathrm{v} / \mathrm{v}) \mathrm{CH}_{2} \mathrm{Cl}_{2} /$ TFE solvent mixture (TFE $=2$,2,2-trifluoroethanol) ${ }^{[18]}$ In this solvent system at room temperature, using a slight excess of the cyclohexyl-mounted bis(iodane) $(R, R)-8 \mathbf{a}$ (i.e., 0.65 equiv), complete consumption of $1 \mathbf{a}$ was reached after 16 hours, and the resulting $R$-enantioenriched ortho-quinol 2 a spontaneously dimerized as expected ${ }^{[7,8]}$ to furnish (+)$\mathbf{3 a}$ in $68 \%$ yield, but with only $15 \%$ ee (Table S1, entry 1 ). Under similar conditions, iodanes $\mathbf{8 b}$ and $8 \mathbf{c}$ also led to disappointing levels of stereoselectivity (entries 2 and 3), but we were gratified by the performance of the less flexible anthracenyl-mounted iodanes $(R, R)-9 \mathbf{a}$ and $(S, S)-9 \mathbf{a}$, which respectively afforded (+)-3a and (-)-3a in yields above $60 \%$ and with promising ee values of 55 and 
$60 \%$ (entries 4 and 6). Decreasing the reaction temperature down to $-35{ }^{\circ} \mathrm{C}$ surprisingly led to a loss of enantioselectivity at the further expense of an increased reaction time (entries 5 and 7). However, the addition of trifluoroacetic acid (TFA) to $\mathrm{CH}_{2} \mathrm{Cl}_{2}$ greatly and positively influenced the reaction course and outcome, 1a being converted at lower temperature and with much shorter reaction times (Table S1, entries 8 and 9). These observations might be explained by a TFAmediated "depolymerization" 16 of the hypothesized structure of our Salen-type iodanes (vide supra), thus providing the phenolic substrate with a better access to the electrophilic $\mathrm{I}^{\mathrm{V}}$-centers. At $-50{ }^{\circ} \mathrm{C}$, with 1.0 equiv of TFA, the use of 1.10 equiv of iodane $(R, R)-8 \mathbf{a}$ was necessary to fully convert, in only 1 hour, $1 \mathbf{a}$ into $3 \mathbf{a}$, which was isolated in $68 \%$ yield, but with a modest $e e$ of $28 \%$ (entry 8). A much more satisfactory result was obtained using 0.65 equivalent of $(R, R)-9 \mathbf{a}$ still in the presence of 1.0 equiv of TFA at $-50{ }^{\circ} \mathrm{C}$ for 2 hours to convert $1 \mathrm{a}$ into $3 \mathrm{a}$ in $65 \%$ yield with $68 \%$ ee (entry 9). Running this reaction at $-78{ }^{\circ} \mathrm{C}$ and/or using 1.10 equiv of the iodane 9a did not improve neither its enantioselectivity nor its chemical yield.

Table S1. Reaction conditions for HPD/[4+2]-dimerization cascade conversion of carvacrol (1a) into bis(carvacrol) (3a) promoted by Salen-type bis $\left(\lambda^{5}\right.$-iodanes). ${ }^{a}$

\begin{tabular}{lllllllll} 
entry & iodane & (equiv) & solvent & temp $\left({ }^{\circ} \mathrm{C}\right)$ & time $(\mathrm{h})$ & yield $(\%)^{b}$ & \multicolumn{2}{l}{$e e(\%)^{c}$} \\
1 & $(R, R)-8 \mathbf{a}$ & $(0.65)$ & $\mathrm{CH}_{2} \mathrm{Cl}_{2} / \mathrm{TFE}(85: 15)$ & $\mathrm{rt}$ & 16 & 68 & 15 & $(+)^{d}$ \\
2 & $(R, R)-8 \mathbf{b}$ & $(0.65)$ & $\mathrm{CH}_{2} \mathrm{Cl}_{2} / \mathrm{TFE}(85: 15)$ & $\mathrm{rt}$ & 16 & 65 & 22 & $(+)$ \\
3 & $(R, R)-8 \mathbf{c}$ & $(0.65)$ & $\mathrm{CH}_{2} \mathrm{Cl}_{2} / \mathrm{TFE}(85: 15)$ & $\mathrm{rt}$ & 16 & 50 & 19 & $(+)$ \\
4 & $(R, R)-9 \mathbf{a}$ & $(0.65)$ & $\mathrm{CH}_{2} \mathrm{Cl}_{2} / \mathrm{TFE}(85: 15)$ & $\mathrm{rt}$ & 16 & 65 & $\mathbf{5 5}$ & $(+)$ \\
5 & $(R, R)-9 \mathbf{a}$ & $(0.65)$ & $\mathrm{CH}_{2} \mathrm{Cl}_{2} / \mathrm{TFE}(85: 15)$ & -35 & 72 & 54 & 48 & $(+)$ \\
6 & $(S, S)-9 \mathbf{a}$ & $(0.65)$ & $\mathrm{CH}_{2} \mathrm{Cl}_{2} / \mathrm{TFE}(85: 15)$ & $\mathrm{rt}$ & 16 & 61 & $\mathbf{6 0}$ & $(-)$ \\
7 & $(S, S)-9 \mathbf{a}$ & $(0.65)$ & $\mathrm{CH}_{2} \mathrm{Cl}_{2} / \mathrm{TFE}(85: 15)$ & -35 & 72 & 50 & 48 & $(-)$ \\
8 & $(R, R)-8 \mathbf{8}$ & $(1.10)$ & $\mathrm{CH}_{2} \mathrm{Cl}_{2}, \mathrm{TFA}^{e}$ & -50 & 1 & 68 & 28 & $(+)$ \\
9 & $(R, R)-9 \mathbf{a}$ & $(0.65)$ & $\mathrm{CH}_{2} \mathrm{Cl}_{2}, \mathrm{TFA}^{e}$ & -50 & 2 & 65 & $\mathbf{6 8}$ & $(+)$
\end{tabular}

${ }^{a}$ Reactions run using [1a] $=17 \mathrm{mM}$ in the indicated solvent. ${ }^{b}$ Isolated yield. ${ }^{c}$ Enantiomeric excess determined by chiral HPLC analysis of pure cyclodimer 3a. ${ }^{d}$ Optical rotation of the major enantiomer. ${ }^{e} 1.0$ equiv. TFA $=$ trifluoroacetic acid, TFE $=2,2,2$-trifluoroethanol.

General procedure for the asymmetric HPD/[4+2]-dimerization cascade conversion of carvacrol (1a) using Salen-type chiral iodanes. To a stirred solution (17 mM) of carvacrol (1a, 25 $\mathrm{mg}, 1.0$ equiv) in the indicated solvent $(10 \mathrm{~mL})$, and in the presence of $4 \AA$ molecular sieves, was added the Salen-type bis $\left(\lambda^{5}\right.$-iodane) 8 or 9 ( 0.65 or 1.10 equiv according to the experiment), and the resulting solution was stirred at the indicated temperature until TLC monitoring indicated complete disappearance of the starting material. It was concentrated under reduced pressure, and the residue was dissolved with the minimum of EtOAc (typically $1 \mathrm{~mL}$ ). A first crop of the corresponding Salen-type diiodoarene (i.e., 6 or 7) was precipitated by adding PET (typically $5 \mathrm{~mL}$ ). Its filtration, followed by evaporation of the filtrate, afforded a residue, which was dissolved in $\mathrm{Et}_{2} \mathrm{O}$ (typically 5 $\mathrm{mL}$ ), and further filtered to discard a second crop of diiodoarene. Evaporation of the solvent furnished a brown residue, which was purified by column chromatography, eluting with PET/EtOAc (5:1), to give pure biscarvacrol (3a), which was subjected to chiral HPLC analysis.

Each experiment and its corresponding HPLC trace are given hereafter. 
Experiment \#1 (see Table S1, entry 1). Carvacrol (1a, $25 \mathrm{mg}, 0.167 \mathrm{mmol}$ ) was dearomatized in $\mathrm{CH}_{2} \mathrm{Cl}_{2} / \mathrm{TFE}$ (85:15) at room temperature for 16 hours using the Salen-type bis $\left(\lambda^{5}\right.$-iodane) $(R, R)-8 \mathbf{a}$ (69 $\mathrm{mg}, 0.109 \mathrm{mmol}, 0.65$ equiv) to afford biscarvacrol (3a) $(19 \mathrm{mg}, 68 \%)$ in $\mathbf{1 5 \%} e \boldsymbol{e}$ in favour of (+)-3a (Figure S6).

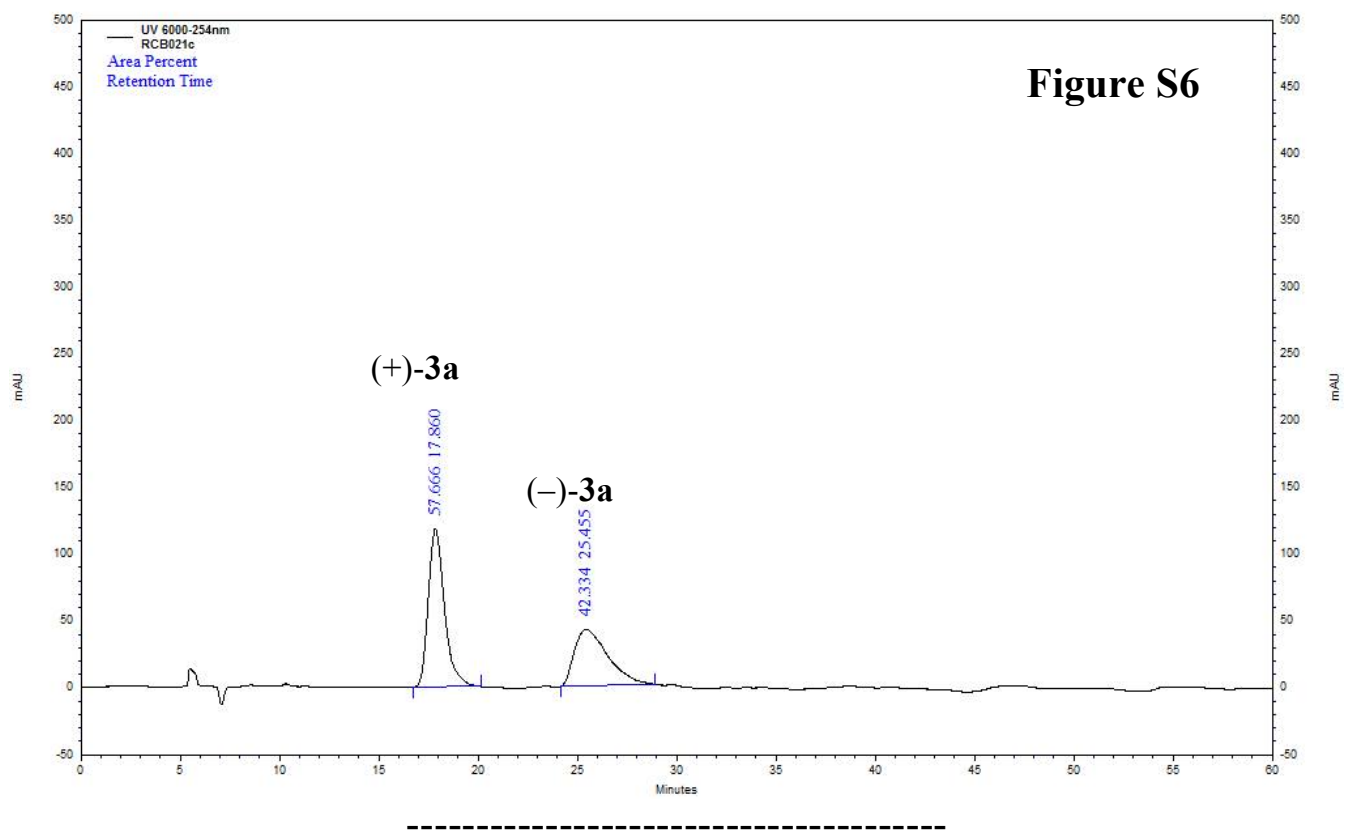

Experiment \#2 (see Table S1, entry 2). Carvacrol (1a, $25 \mathrm{mg}, 0.167 \mathrm{mmol}$ ) was dearomatized in $\mathrm{CH}_{2} \mathrm{Cl}_{2} / \mathrm{TFE}(85: 15)$ at room temperature for 16 hours using the Salen-type bis( $\lambda^{5}$-iodane) $(R, R)-8 \mathbf{b}$ (73 mg, $0.109 \mathrm{mmol}, 0.65$ equiv) to afford biscarvacrol (3a) $(18 \mathrm{mg}, 65 \%)$ in $\mathbf{2 2 \%} \boldsymbol{e} e$ in favour of (+)-3a (Figure S7).

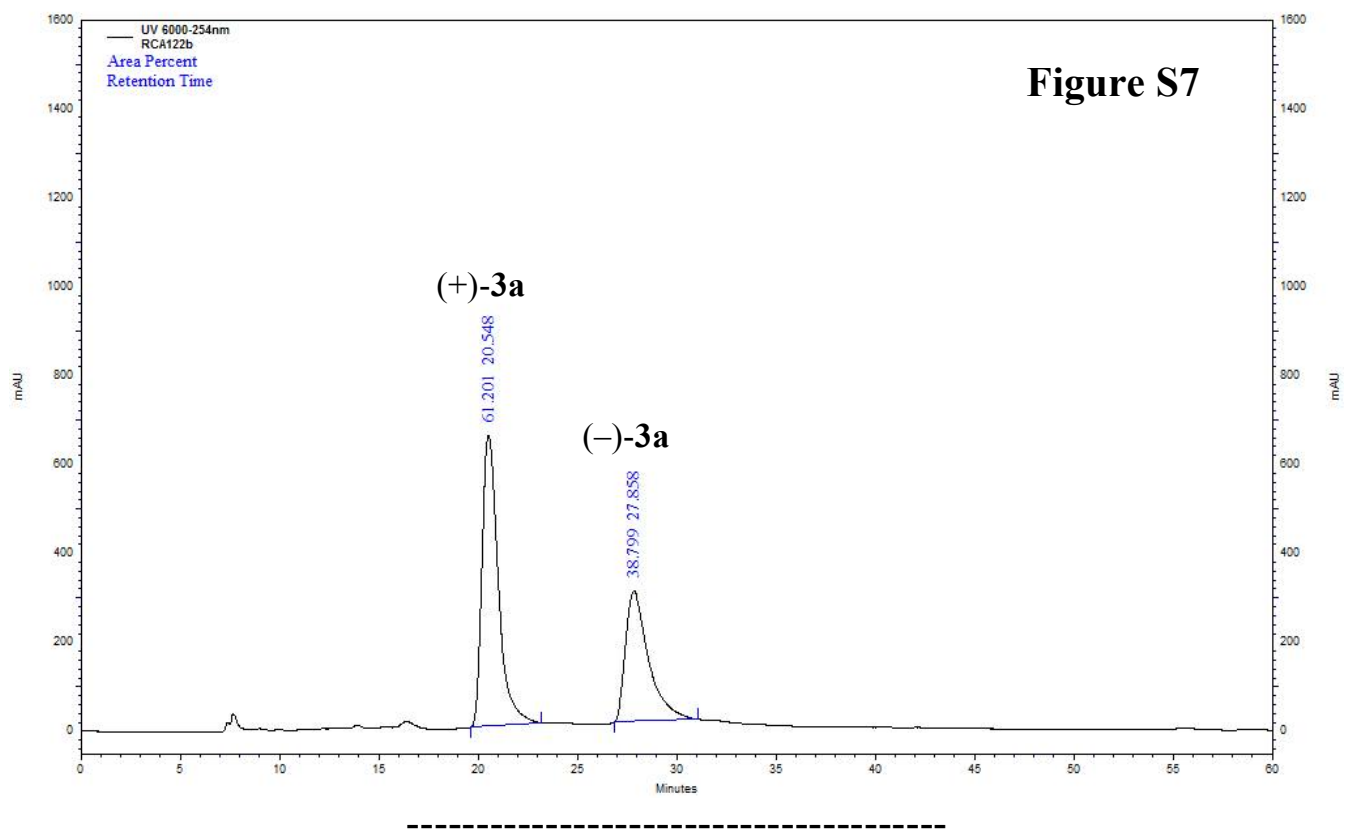


Experiment \#3 (see Table S1, entry 3). Carvacrol (1a, $25 \mathrm{mg}, 0.167 \mathrm{mmol}$ ) was dearomatized in $\mathrm{CH}_{2} \mathrm{Cl}_{2} / \mathrm{TFE}$ (85:15) at room temperature for 16 hours using the Salen-type bis $\left(\lambda^{5}\right.$-iodane) $(R, R)-8 \mathbf{c}$ (75 mg, $0.109 \mathrm{mmol}, 0.65$ equiv) to afford biscarvacrol (3a) $(13.8 \mathrm{mg}, 50 \%)$ in $\mathbf{1 9 \%} \boldsymbol{e} e$ in favour of $(+)-3 a(F i g u r e ~ S 8)$. N.B.: partial degradation of iodane $8 c$ in solution.

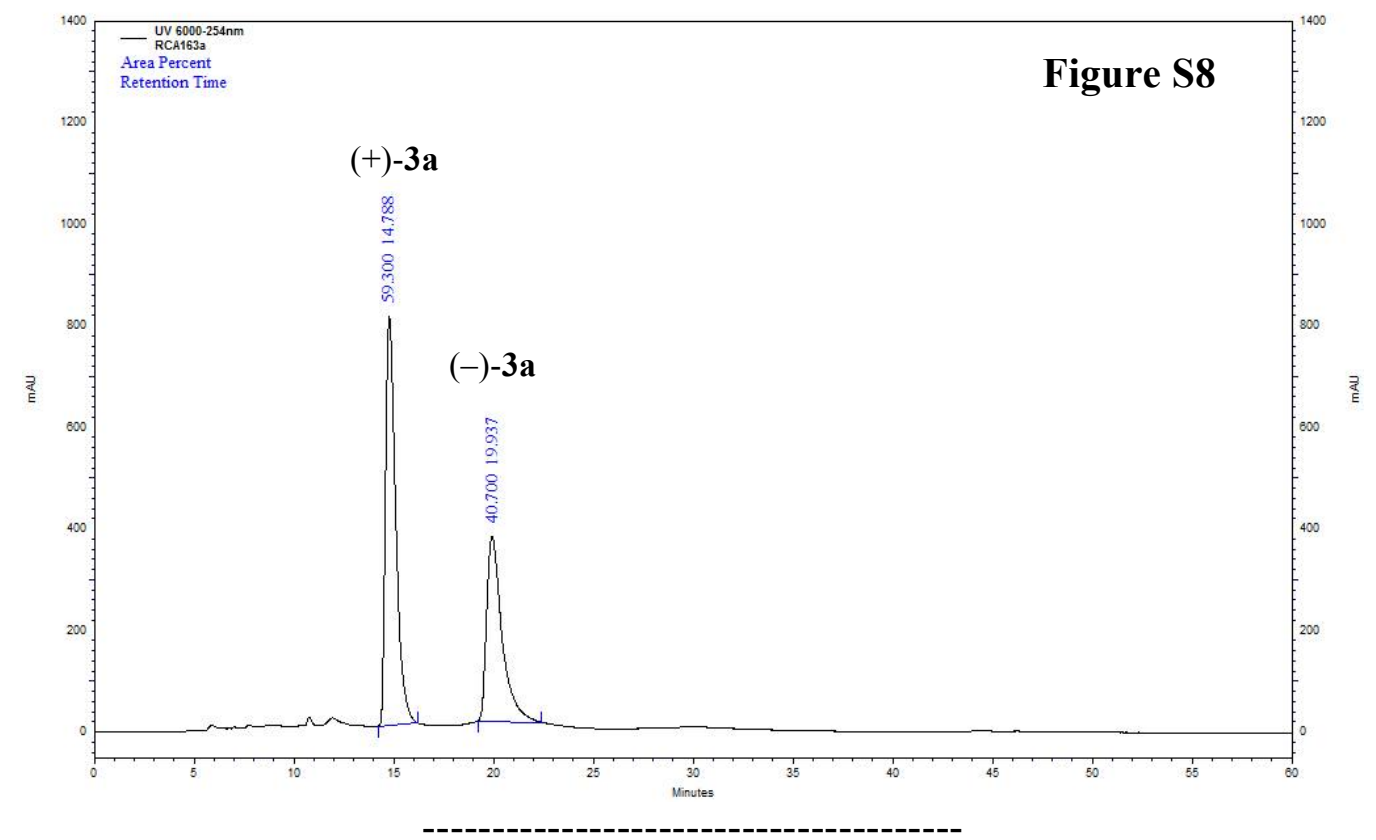

Experiment \#4. Carvacrol (1a, $25 \mathrm{mg}, 0.167 \mathrm{mmol}$ ) was dearomatized in $\mathrm{CH}_{2} \mathrm{Cl}_{2} / \mathrm{TFE}(85: 15)$ at $35^{\circ} \mathrm{C}$ for 72 hours using the Salen-type bis $\left(\lambda^{5}\right.$-iodane) $(R, R)-8 \mathbf{a}(69 \mathrm{mg}, 0.109 \mathrm{mmol}, 0.65$ equiv) to give biscarvacrol (3a) $(22.7 \mathrm{mg}, 82 \%)$ in $\mathbf{2 5 \%} \boldsymbol{e e}$ in favour of (+)-3a (Figure S9).

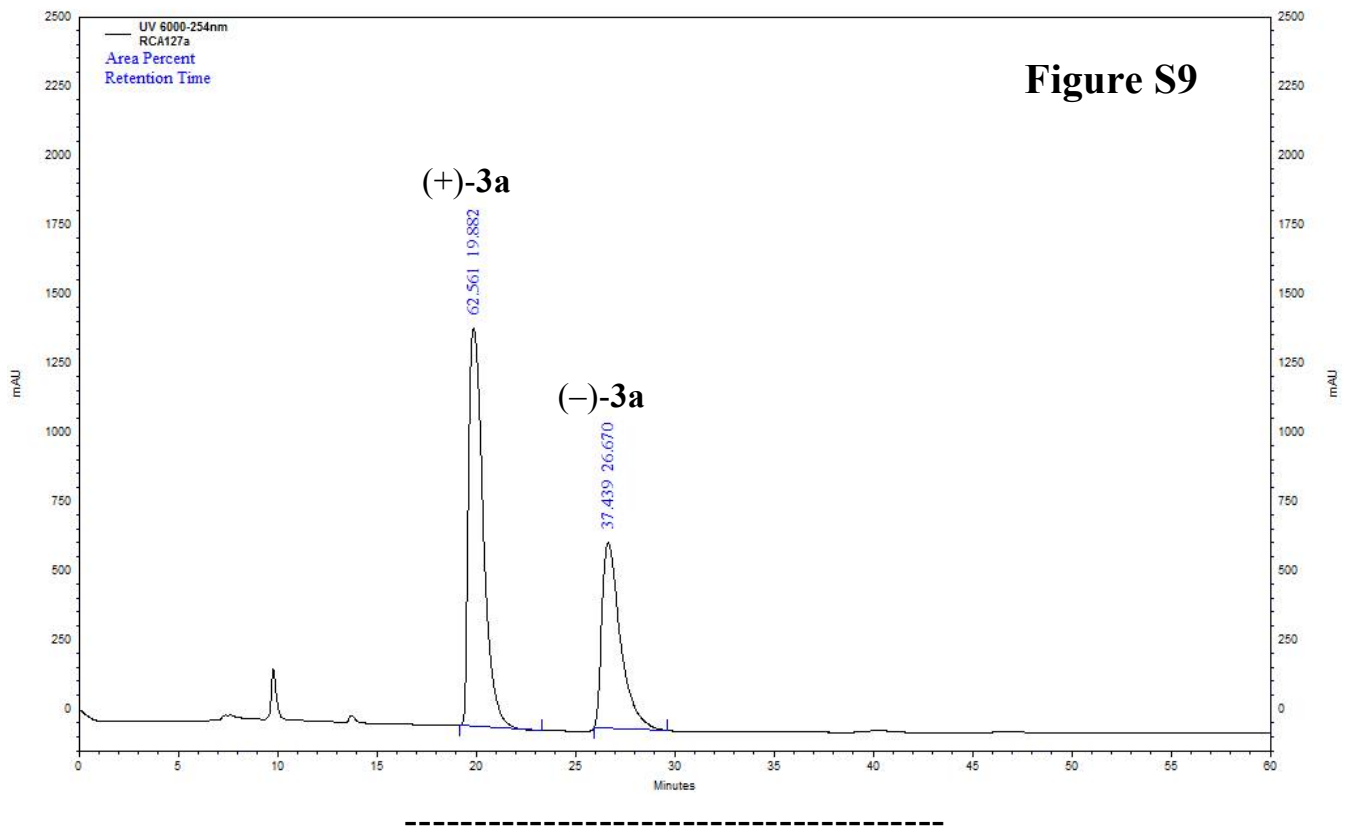


Experiment \#5 (see Table S1, entry 4). Carvacrol (1a, $25 \mathrm{mg}, 0.167 \mathrm{mmol}$ ) was dearomatized in $\mathrm{CH}_{2} \mathrm{Cl}_{2} / \mathrm{TFE}$ (85:15) at room temperature for 16 hours using the Salen-type bis( $\lambda^{5}$-iodane) $(R, R)$-9a (69 $\mathrm{mg}, 0.109 \mathrm{mmol}, 0.65$ equiv) to give biscarvacrol (3a) $(18 \mathrm{mg}, 65 \%)$ in $\mathbf{5 5 \%} \boldsymbol{e} e$ in favour of (+)-3a (Figure S10).

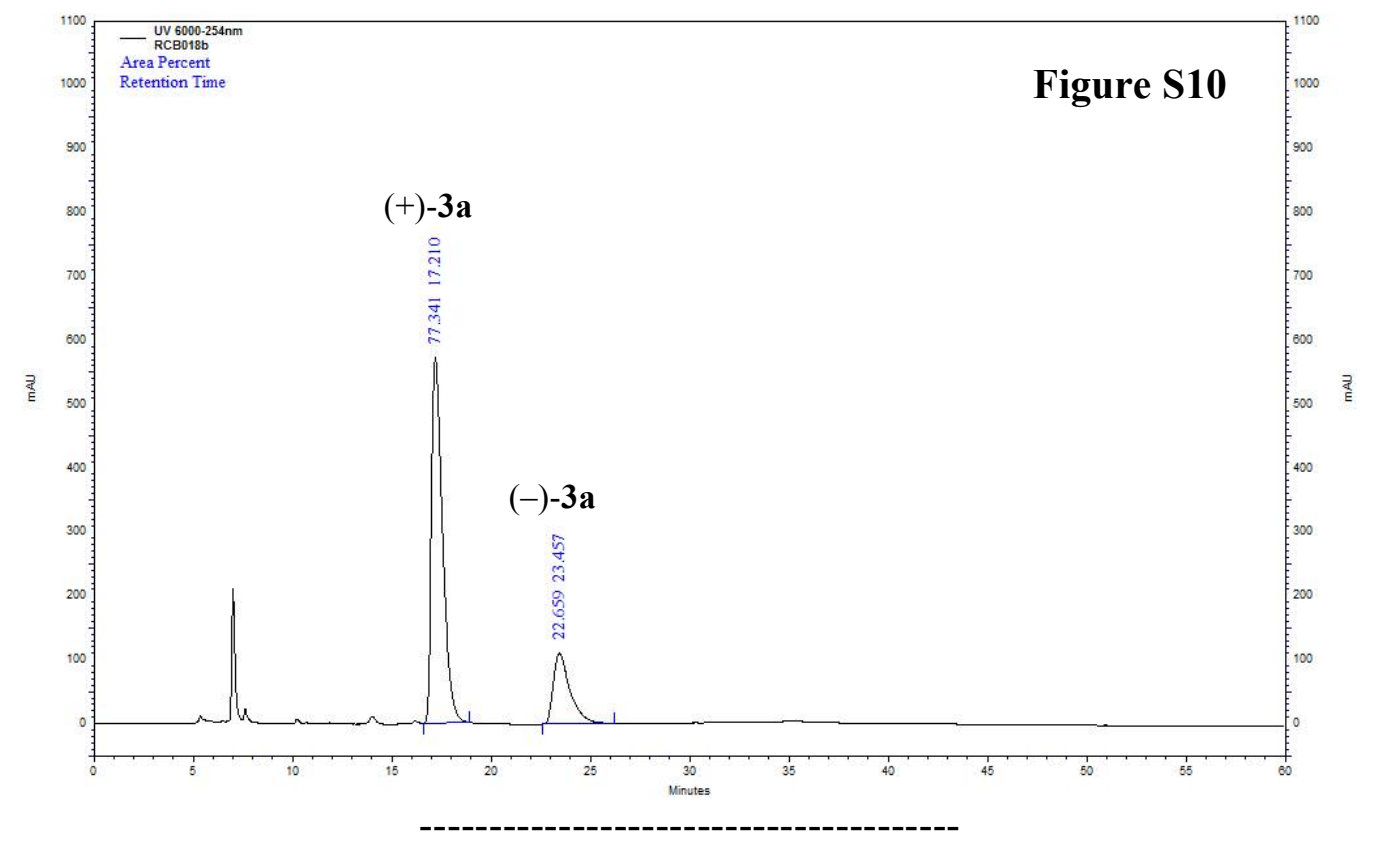

Experiment \#6 (see Table S1, entry 5). Carvacrol (1a, $25 \mathrm{mg}, 0.167 \mathrm{mmol}$ ) was dearomatized in $\mathrm{CH}_{2} \mathrm{Cl}_{2} / \mathrm{TFE}(85: 15)$ at $-35{ }^{\circ} \mathrm{C}$ for 72 hours using the Salen-type bis( $\lambda^{5}$-iodane) $(R, R)-9 \mathrm{a}$ (83 mg, 0.109 mmol, 0.65 equiv) to give biscarvacrol (3a) $(15 \mathrm{mg}, 54 \%)$ in $\mathbf{4 8 \%} \boldsymbol{e} e$ in favour of (+)-3a (Figure S11).

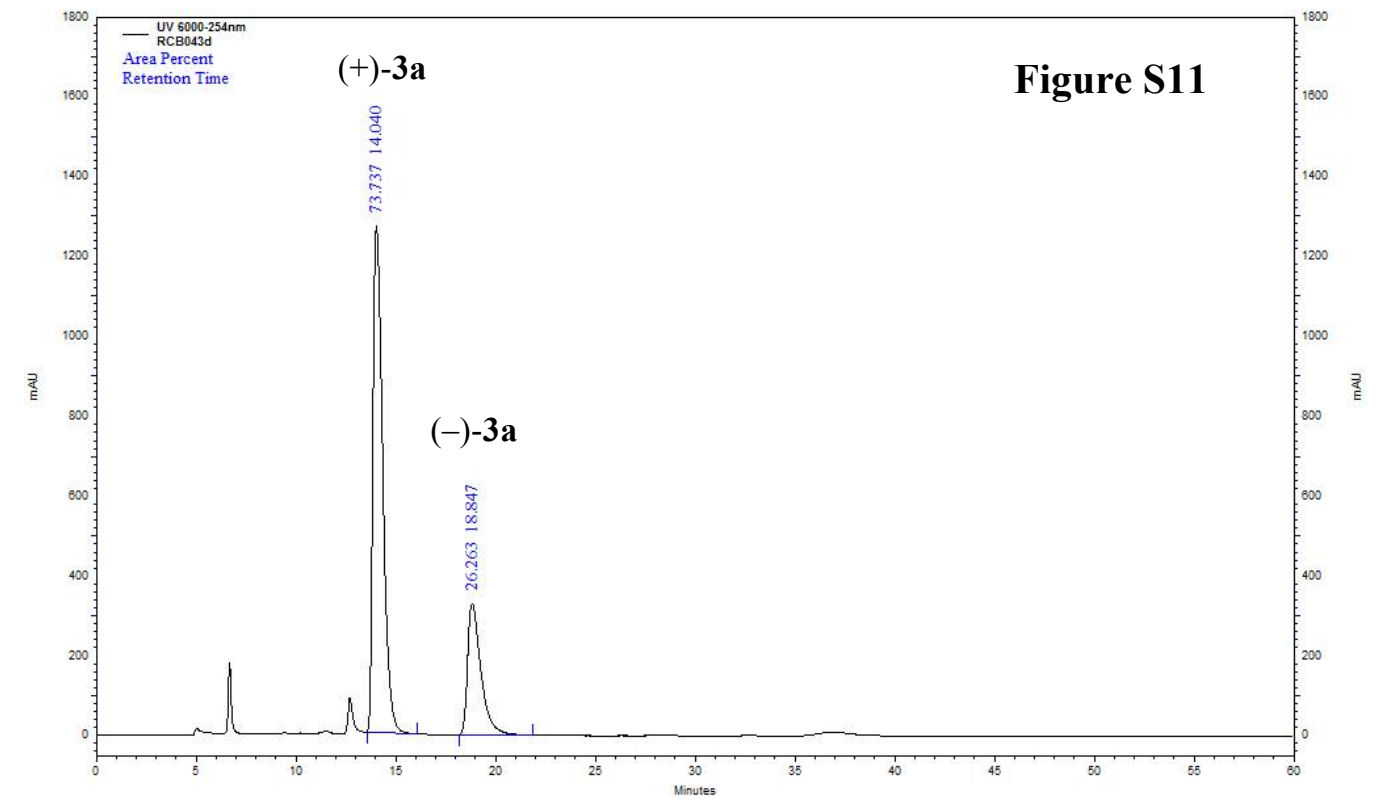


Experiment \#7 (see Table S1, entry 6). Carvacrol (1a, $25 \mathrm{mg}, 0.167 \mathrm{mmol}$ ) was dearomatized in $\mathrm{CH}_{2} \mathrm{Cl}_{2} / \mathrm{TFE}$ (85:15) at room temperature for 16 hours using the Salen-type bis $\left(\lambda^{5}\right.$-iodane) $(S, S)$-9a (83 mg, $0.109 \mathrm{mmol}, 0.65$ equiv) to give biscarvacrol (3a) $(17 \mathrm{mg}, 61 \%)$ in $\mathbf{6 0 \%}$ ee in favour of ()-3a (Figure S12).

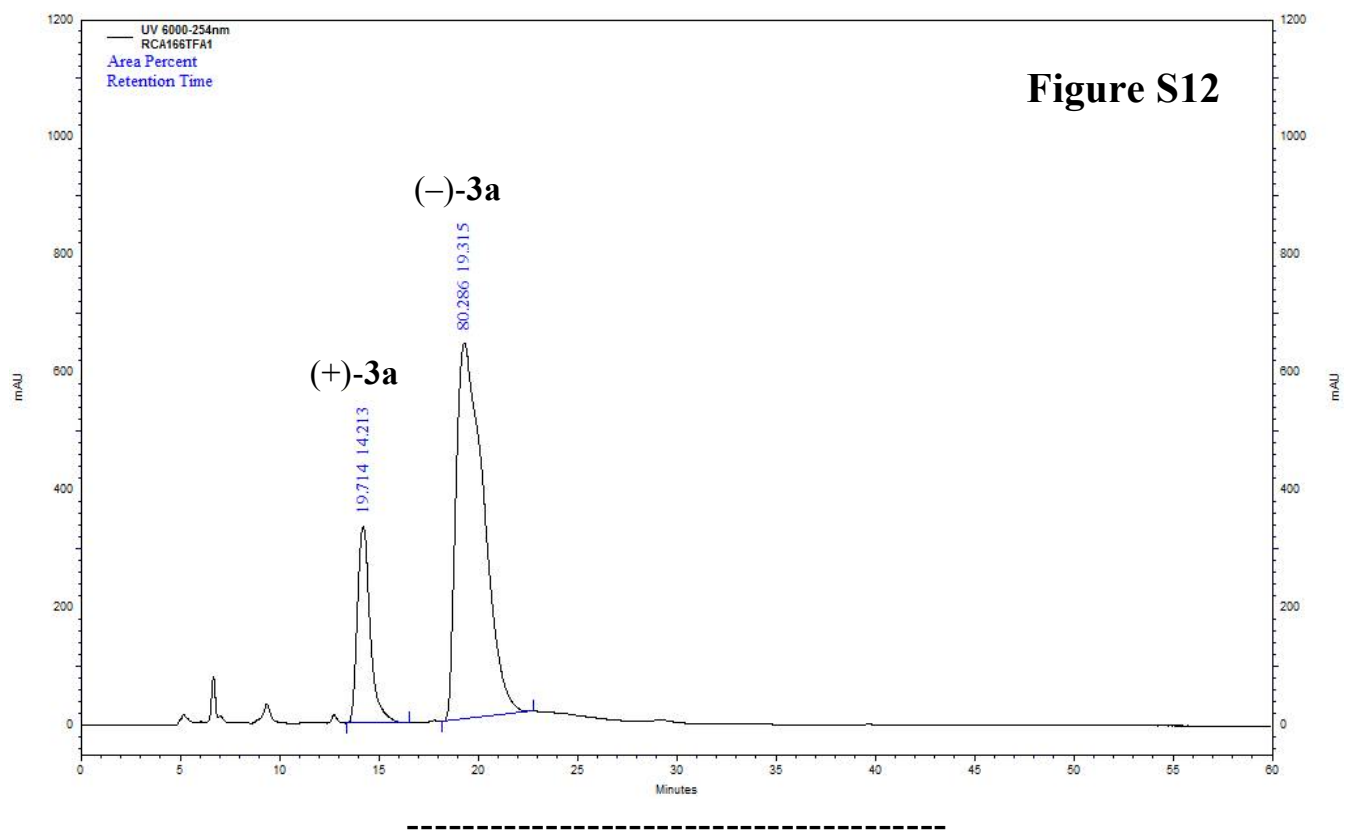

Experiment \#8 (see Table S1, entry 7). Carvacrol (1a, $25 \mathrm{mg}, 0.167 \mathrm{mmol}$ ) was dearomatized in $\mathrm{CH}_{2} \mathrm{Cl}_{2} / \mathrm{TFE}(85: 15)$ at $-35{ }^{\circ} \mathrm{C}$ for 72 hours using the Salen-type bis( $\lambda^{5}$-iodane) $(S, S)-9 \mathbf{a}(83 \mathrm{mg}$, $0.109 \mathrm{mmol}, 0.65$ equiv) to afford biscarvacrol (3a) $(13.8 \mathrm{mg}, 50 \%)$ in $\mathbf{4 8 \%} \boldsymbol{e} e$ in favour of (-)-3a (Figure S13).

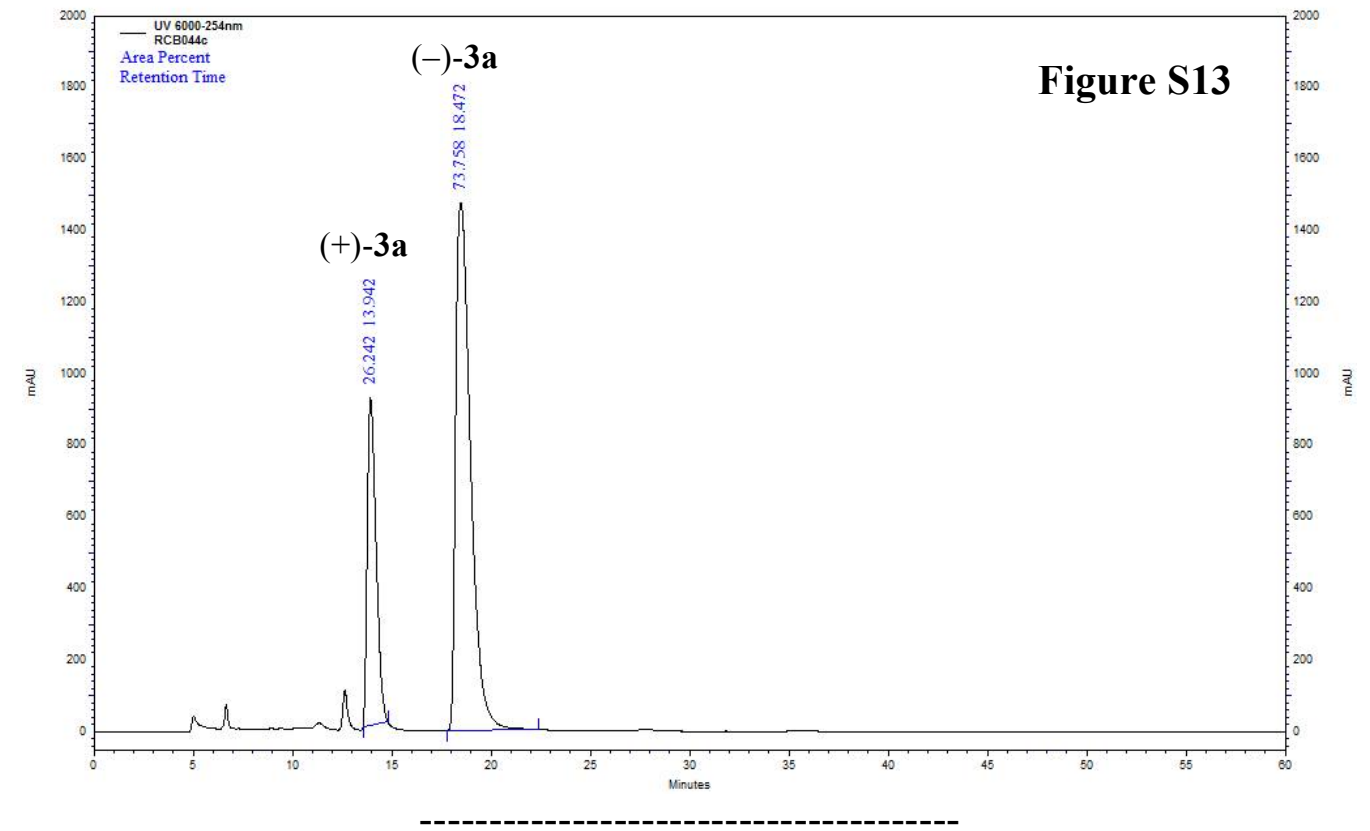


Experiment \#9. Carvacrol (1a, $25 \mathrm{mg}, 0.167 \mathrm{mmol})$ was dearomatized in $\mathrm{CH}_{2} \mathrm{Cl}_{2} / \mathrm{TFE}(85: 15)$ at room temperature for 16 hours using the Salen-type bis $\left(\lambda^{5}\right.$-iodane) $(R, R)-9 \mathbf{b}(89 \mathrm{mg}, 0.109 \mathrm{mmol}$, 0.65 equiv) to give biscarvacrol (3a) $(8 \mathrm{mg}, 29 \%)$ in $\mathbf{4 \%} \boldsymbol{e e}$ in favour of (+)-3a (Figure S14).

N.B.: partial degradation of iodane $\mathbf{9 b}$ in solution; in addition, full conversion of $1 \mathbf{a}$ not reached under these experimental conditions.

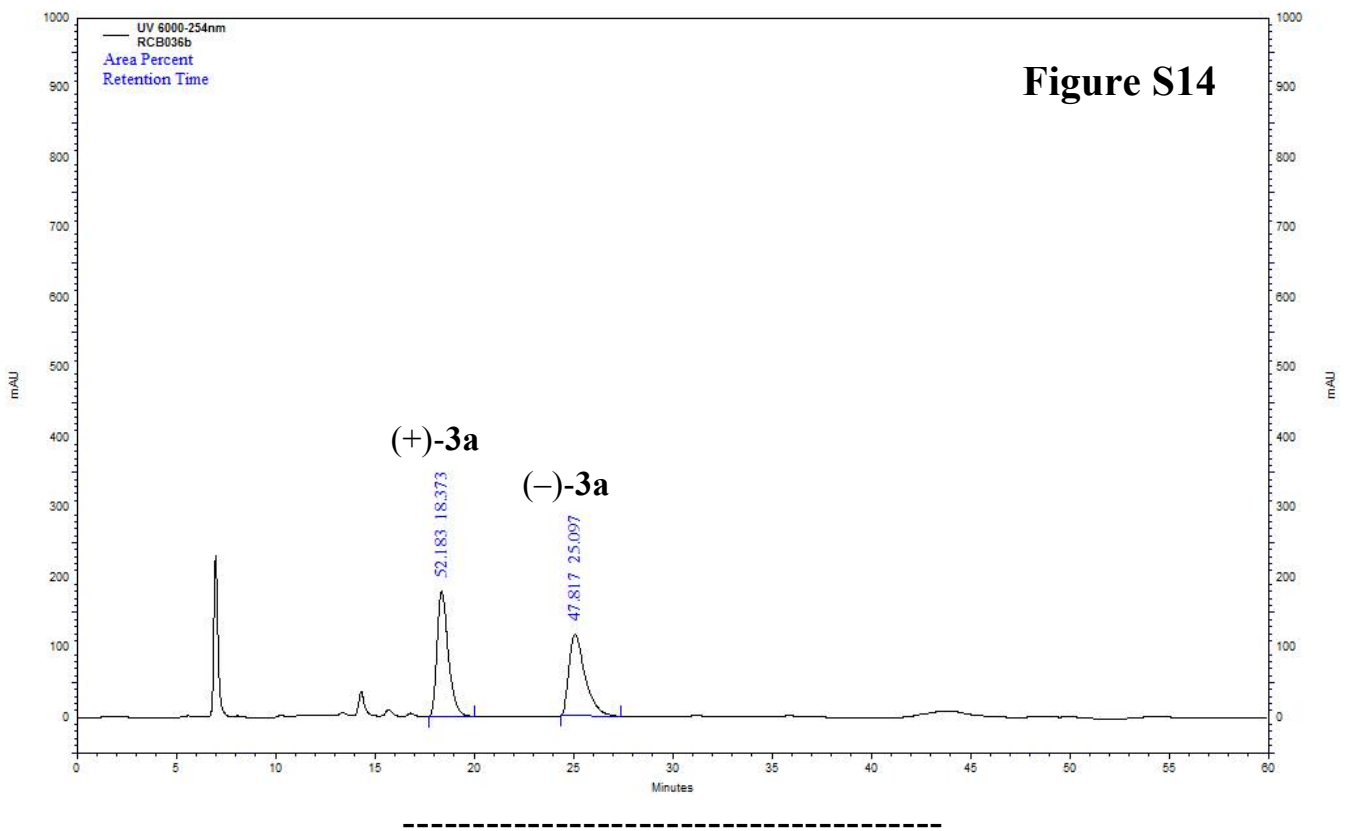

Experiment \#10. Carvacrol (1a, $25 \mathrm{mg}, 0.167 \mathrm{mmol})$ was dearomatized in $\mathrm{CH}_{2} \mathrm{Cl}_{2} / \mathrm{TFE}(85: 15)$ at room temperature for 16 hours using the Salen-type bis $\left(\lambda^{5}\right.$-iodane) $(S, S)-9 \mathbf{b}(89 \mathrm{mg}, 0.109 \mathrm{mmol}$, 0.65 equiv) to give biscarvacrol (3a) $(10 \mathrm{mg}, 36 \%)$ in $\mathbf{5 \%}$ ee in favour of (-)-3a (Figure S15).

N.B.: partial degradation of iodane $\mathbf{9 b}$ in solution; in addition, full conversion of $1 \mathbf{a}$ not reached under these experimental conditions.

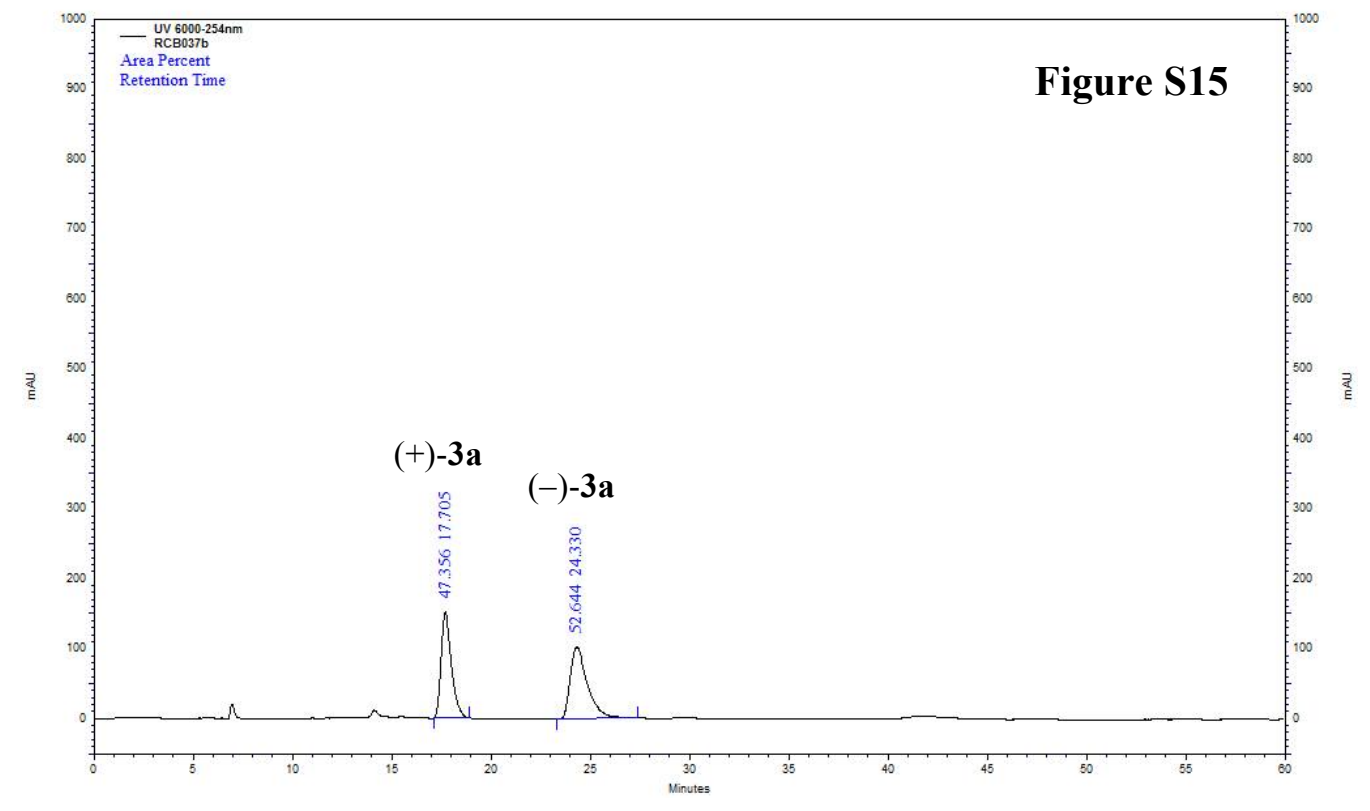


Experiment \#11 (see Table S1, entry 8). Carvacrol (1a, $25 \mathrm{mg}, 0.167 \mathrm{mmol}$ ) was dearomatized in $\mathrm{CH}_{2} \mathrm{Cl}_{2}$ at $-50{ }^{\circ} \mathrm{C}$ for 1 hour, in the presence of TFA (13 $\mu \mathrm{L}, 1.0$ equiv), using the Salen-type bis $\left(\lambda^{5}\right.$-iodane) $(R, R)-\mathbf{8 a}(117 \mathrm{mg}, 0.183 \mathrm{mmol}, 1.10$ equiv) to give biscarvacrol (3a) $(18.8 \mathrm{mg}, 68 \%)$ in $\mathbf{2 8 \%}$ ee in favour of $(+)-\mathbf{3 a}$ (Figure S16).

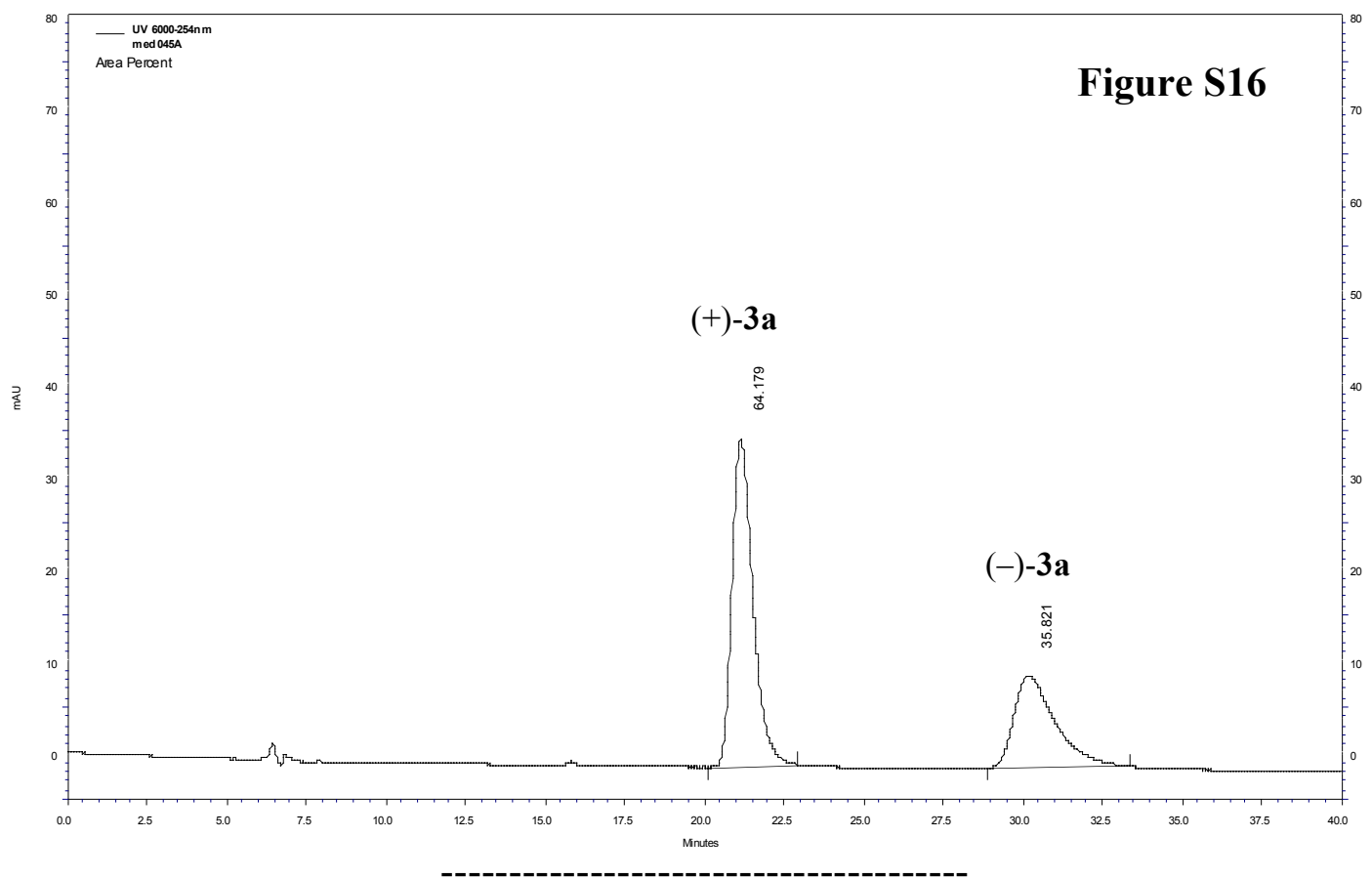

Experiment \#12. Carvacrol (1a, $25 \mathrm{mg}, 0.167 \mathrm{mmol}$ ) was dearomatized in $\mathrm{CH}_{2} \mathrm{Cl}_{2}$ at $-50{ }^{\circ} \mathrm{C}$ for 1 hour, in the presence of TFA (13 $\mu \mathrm{L}, 1.0$ equiv), using the Salen-type bis( $\lambda^{5}$-iodane) $(S, S)-8 \mathbf{a}(117$ $\mathrm{mg}, 0.183 \mathrm{mmol}, 1.10$ equiv) to give biscarvacrol (3a) (16.6 $\mathrm{mg}, 60 \%)$ in $\mathbf{2 9 \%} \boldsymbol{e} \boldsymbol{e}$ in favour of (-)3a (Figure S17).

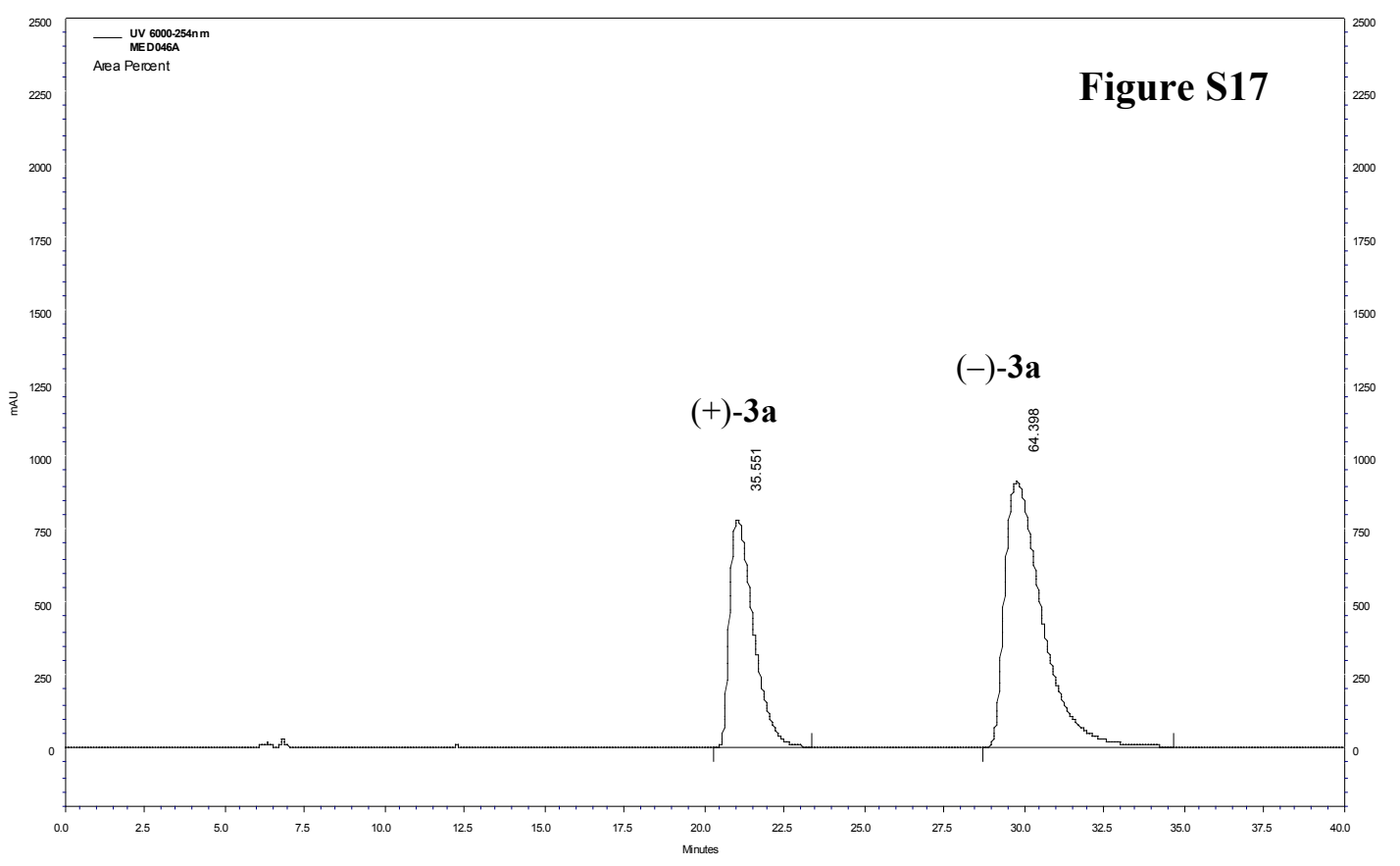


Experiment \#13. Carvacrol (1a, $25 \mathrm{mg}, 0.167 \mathrm{mmol})$ was dearomatized in $\mathrm{CH}_{2} \mathrm{Cl}_{2} / \mathrm{TFE}(85: 15)$ at room temperature for 30 minutes, in the presence of TFA (13 $\mu \mathrm{L}, 1.0$ equiv), using the Salen-type $\operatorname{bis}\left(\lambda^{5}\right.$-iodane) $(R, R)-8 \mathbf{a}(69 \mathrm{mg}, 0.109 \mathrm{mmol}, 0.65$ equiv) to furnish biscarvacrol (3a) $(16 \mathrm{mg}, 58 \%)$ in $\mathbf{1 5 \%}$ ee in favour of (+)-3a (Figure S18). N.B.: incompatibility of TFA with TFE.

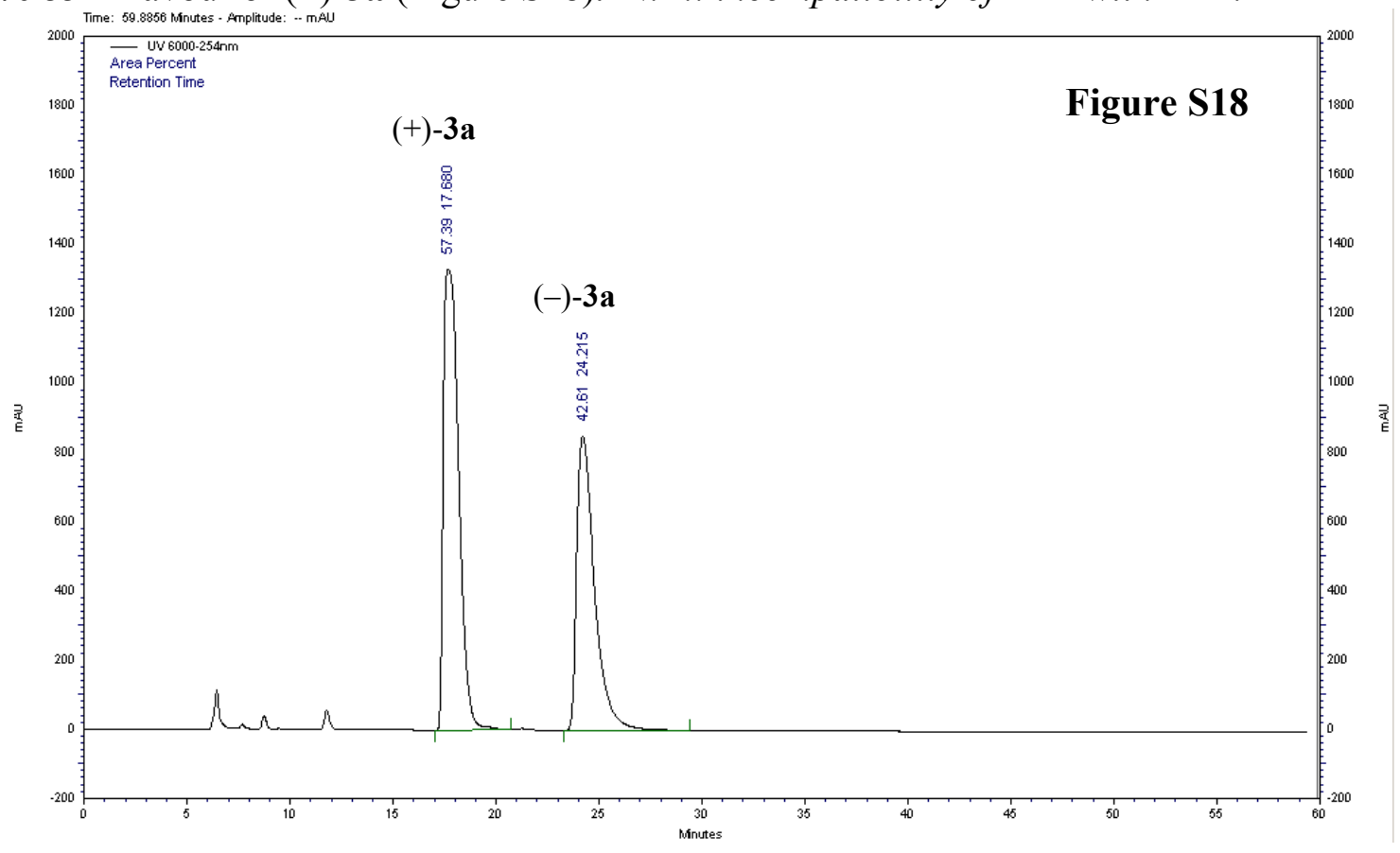

Experiment \#14. Carvacrol (1a, $25 \mathrm{mg}, 0.167 \mathrm{mmol})$ was dearomatized in $\mathrm{CH}_{2} \mathrm{Cl}_{2}$ at $-78{ }^{\circ} \mathrm{C}$ for 3 hours, in the presence of TFA ( $26 \mu \mathrm{L}, 2.0$ equiv), using the Salen-type bis( $\lambda^{5}$-iodane) $(S, S)-8 \mathrm{a}(97$ $\mathrm{mg}, 0.152 \mathrm{mmol}, 1.10$ equiv) to furnish biscarvacrol (3a) (15 mg, 54\%) in $\mathbf{3 3 \%}$ ee in favour of (-)3a (Figure S19).

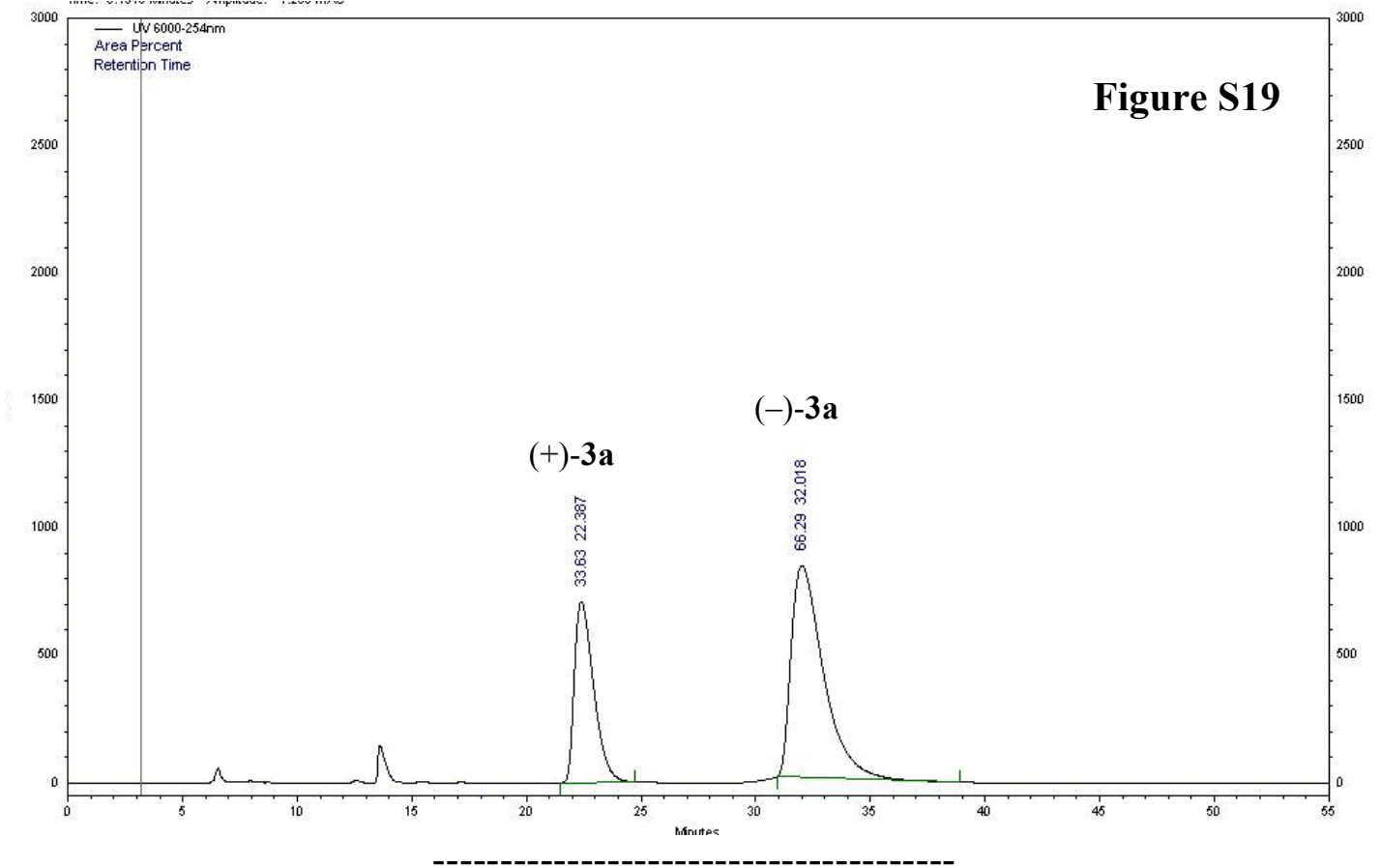


Experiment \#15 (see Table S1, entry 9). Carvacrol (1a, $25 \mathrm{mg}, 0.167 \mathrm{mmol}$ ) was dearomatized in $\mathrm{CH}_{2} \mathrm{Cl}_{2}$ at $-50{ }^{\circ} \mathrm{C}$ for 2 hours, in the presence of TFA (13 $\mu \mathrm{L}, 1.0$ equiv), using the Salen-type bis $\left(\lambda^{5}\right.$-iodane) $(R, R)-9 a(83 \mathrm{mg}, 0.109 \mathrm{mmol}, 0.65$ equiv) to give biscarvacrol (3a) $(18 \mathrm{mg}, 65 \%)$ in $\mathbf{6 8 \%}$ ee in favour of $(+)-3 \mathrm{a}$ (Figure $\mathrm{S} 20$ ).

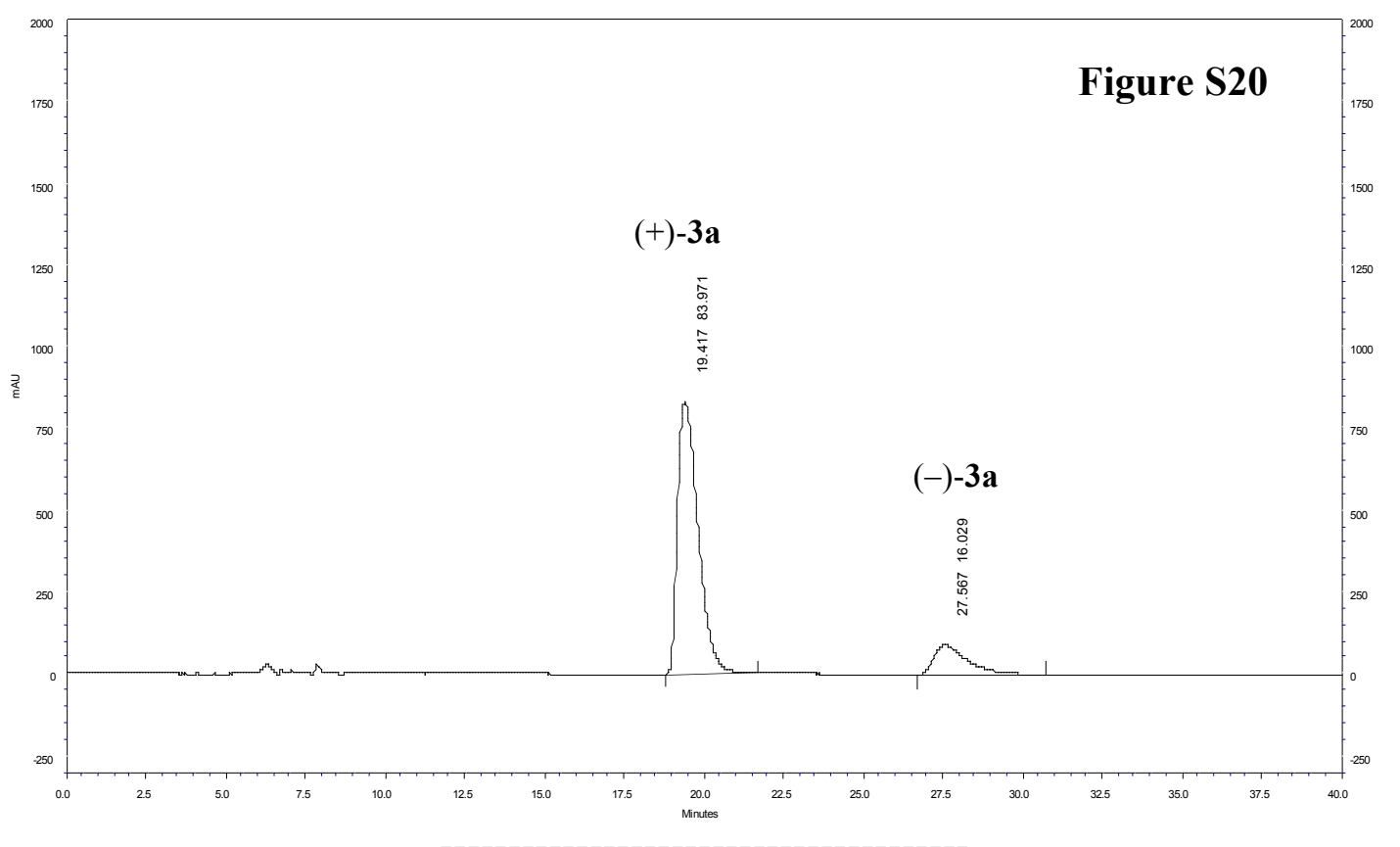

Experiment \#16. Carvacrol (1a, $25 \mathrm{mg}, 0.167 \mathrm{mmol})$ was dearomatized in $\mathrm{CH}_{2} \mathrm{Cl}_{2} / \mathrm{TFE}(85: 15)$ at room temperature for 20 minutes, in the presence of TFA ( $13 \mu \mathrm{L}, 1.0$ equiv), using the Salen-type bis $\left(\lambda^{5}\right.$-iodane) $(R, R)-9 \mathrm{a}(83 \mathrm{mg}, 0.109 \mathrm{mmol}, 0.65$ equiv) to furnish biscarvacrol (3a) $(17 \mathrm{mg}, 61 \%)$ in $\mathbf{1 8 \%}$ ee in favour of (+)-3a (Figure S21). N.B.: incompatibility of TFA with TFE.

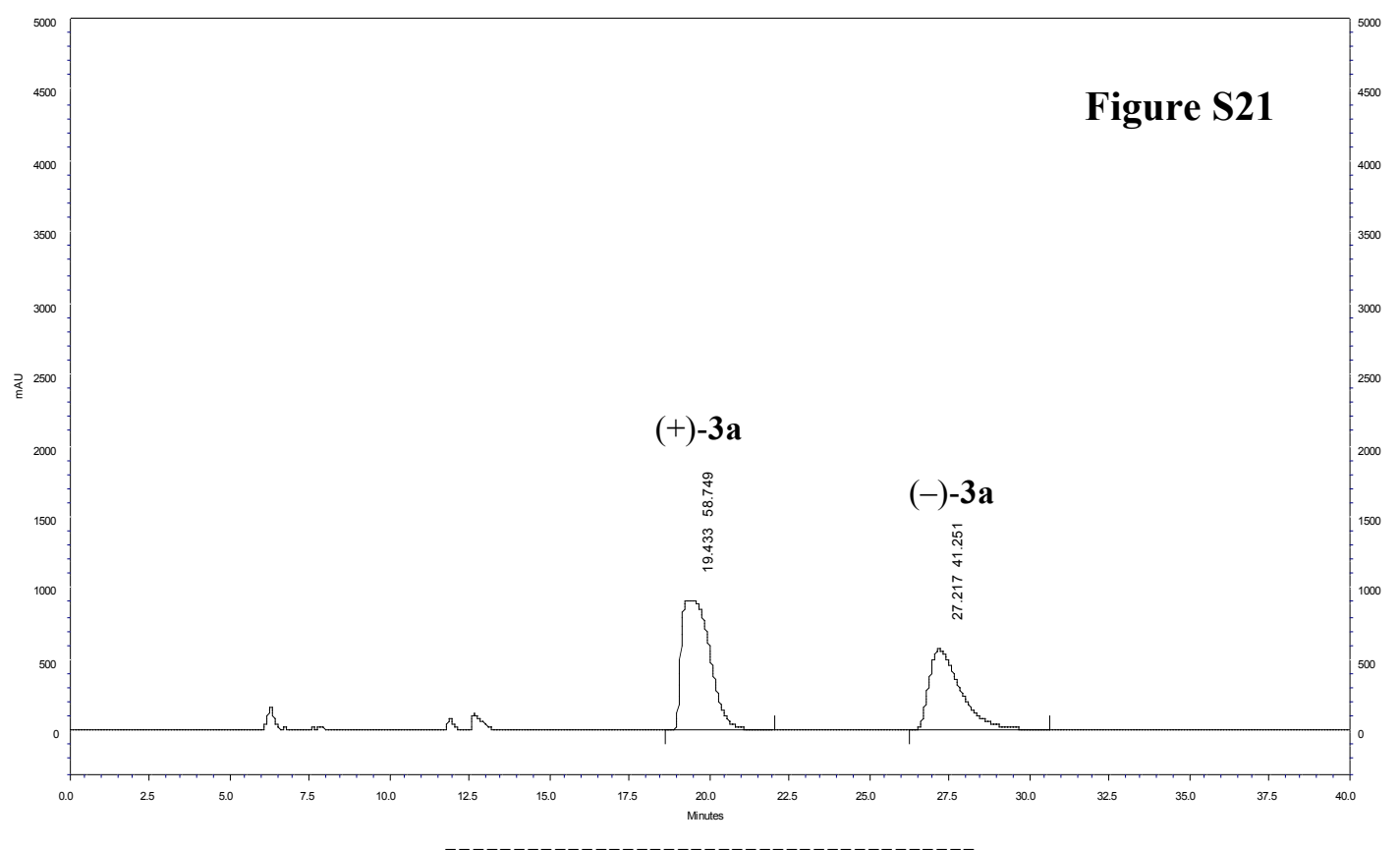


Experiment \#17. Carvacrol (1a, $25 \mathrm{mg}, 0.167 \mathrm{mmol})$ was dearomatized in $\mathrm{CH}_{2} \mathrm{Cl}_{2}([\mathbf{1 a}]=34 \mathrm{mM})$ at $-78{ }^{\circ} \mathrm{C}$ for 3 hours, in the presence of TFA $\left(13 \mu \mathrm{L}, 1.0\right.$ equiv), using the Salen-type bis $\left(\lambda^{5}\right.$ iodane) $(R, R)-8 \mathbf{a}(117 \mathrm{mg}, 0.183 \mathrm{mmol}, 1.10$ equiv) to furnish biscarvacrol (3a) $(8.3 \mathrm{mg}, 30 \%)$ in $19 \%$ ee in favour of $(+)-3 a$ (Figure S22).

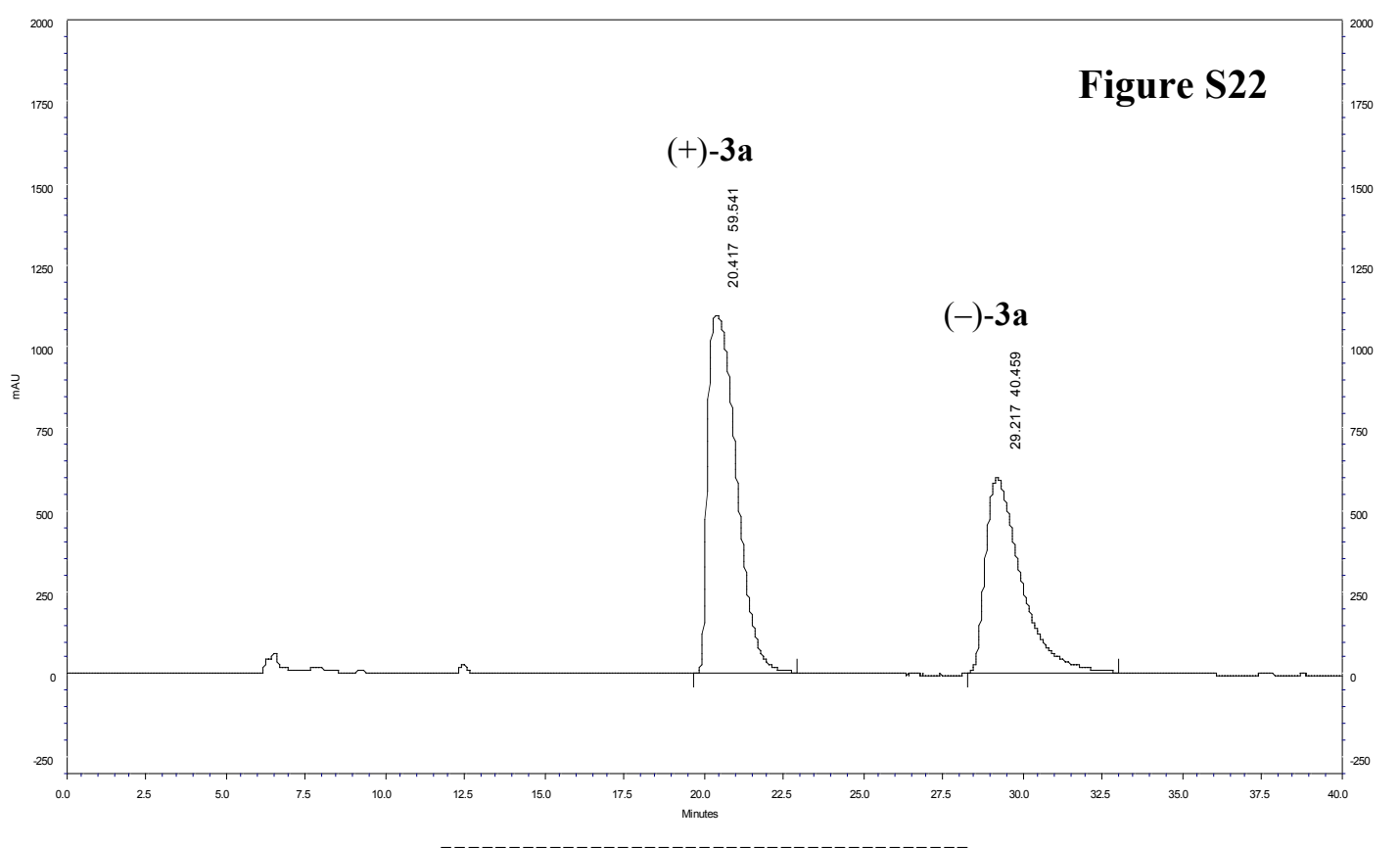

Experiment \#18. Carvacrol (1a, $25 \mathrm{mg}, 0.167 \mathrm{mmol})$ was dearomatized in $\mathrm{CH}_{2} \mathrm{Cl}_{2}([\mathbf{1 a}]=68 \mathrm{mM})$ at $-78{ }^{\circ} \mathrm{C}$ for 5 hours, in the presence of TFA $\left(13 \mu \mathrm{L}, 1.0\right.$ equiv), using the Salen-type bis $\left(\lambda^{5}\right.$ iodane) $(R, R)-8 \mathbf{a}(117 \mathrm{mg}, 0.183 \mathrm{mmol}, 1.10$ equiv) to furnish biscarvacrol (3a) $(18.3 \mathrm{mg}, 66 \%)$ in $\mathbf{3 1 \%}$ ee in favour of $(+)-3$ a (Figure S23).

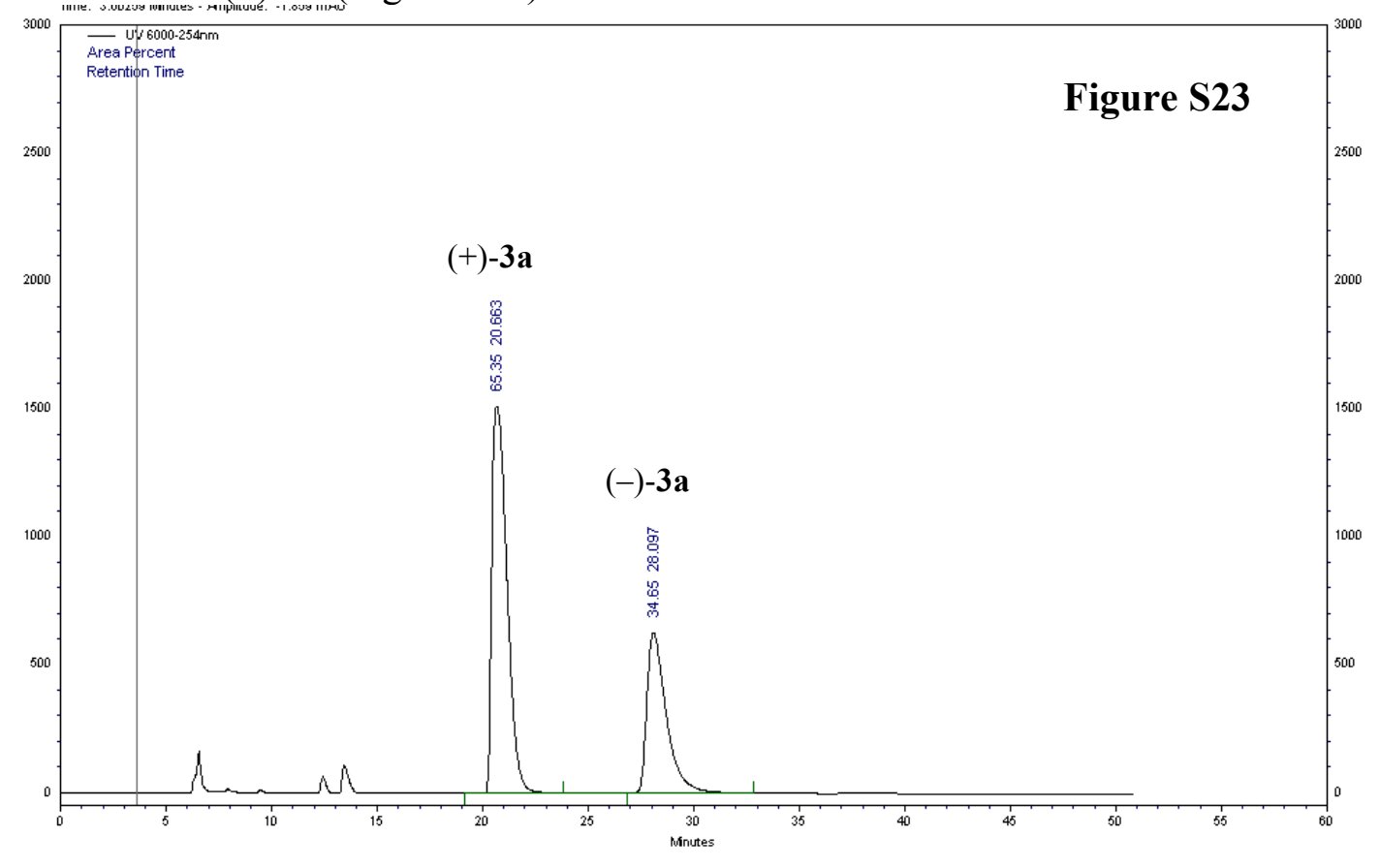


Experiment \#19. Carvacrol (1a, $25 \mathrm{mg}, 0.167 \mathrm{mmol})$ was dearomatized in $\mathrm{CH}_{2} \mathrm{Cl}_{2}([\mathbf{1 a}]=68 \mathrm{mM})$ at $-78{ }^{\circ} \mathrm{C}$ for 5 hours, in the presence of TFA $(26 \mu \mathrm{L}, 2.0$ equiv $)$, using the Salen-type bis $\left(\lambda^{5}\right.$ iodane) $(R, R)-8 \mathbf{a}(117 \mathrm{mg}, 0.183 \mathrm{mmol}, 1.10$ equiv) to furnish biscarvacrol (3a) $(25 \mathrm{mg}, 90 \%)$ in $\mathbf{2 1 \%}$ ee in favour of $(+)-3$ a (Figure S24).

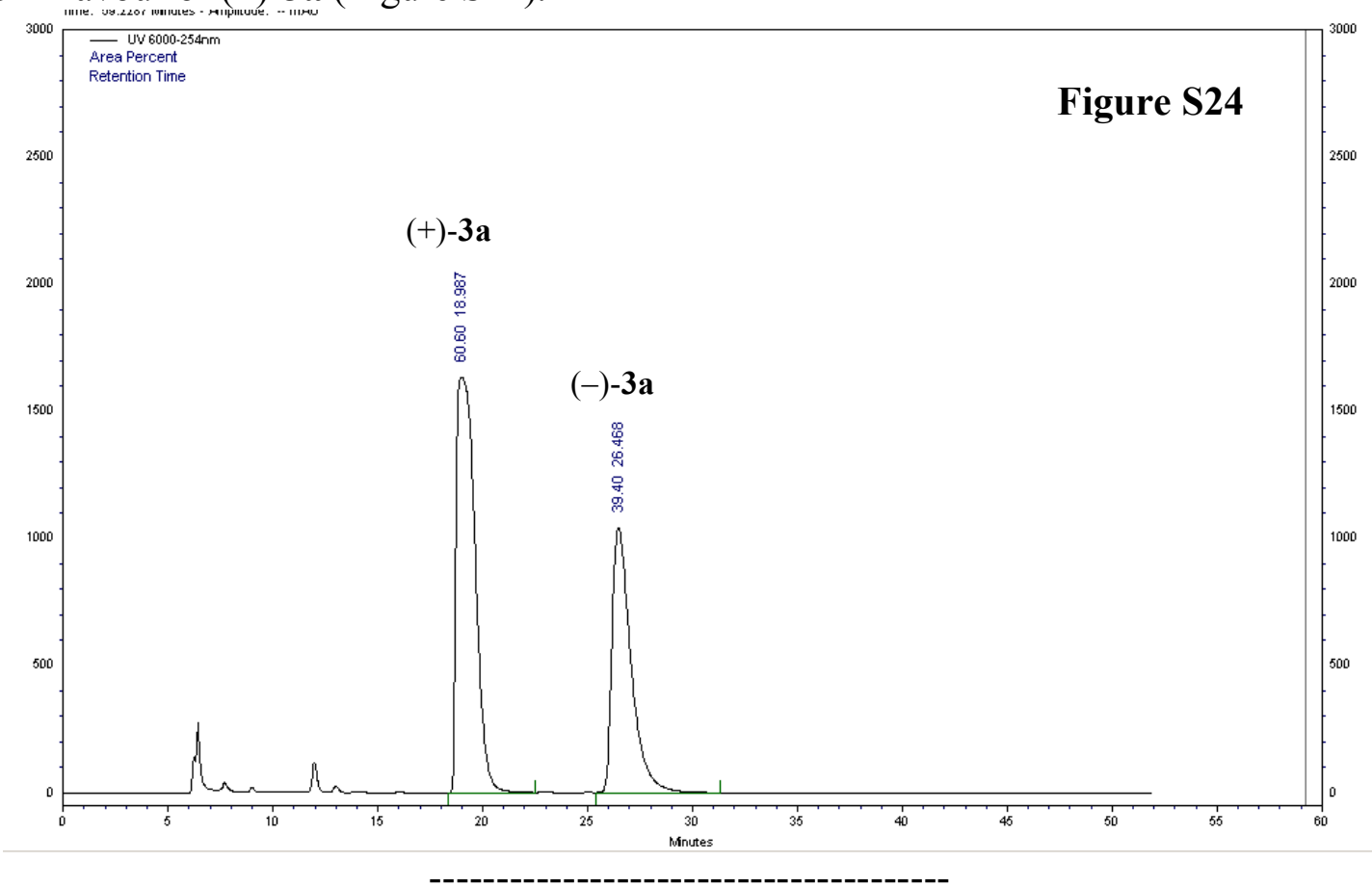

Experiment \#20. Carvacrol (1a, $35 \mathrm{mg}, 0.233 \mathrm{mmol}$ ) was dearomatized in dry $\mathrm{CH}_{2} \mathrm{Cl}_{2}$ at room temperature over a 24 hours period of time using the Salen-type bis $\left(\lambda^{5}\right.$-iodane) $(R, R)-8 \mathbf{a}(186 \mathrm{mg}$, $0.291 \mathrm{mmol}, 1.25$ equiv; a first addition of 0.5 equiv, followed by $3 \times 0.25$ equiv during TLC monitoring). As no reaction was observed during these 24 hours, $\mathrm{CH}_{2} \mathrm{Cl}_{2}$ was evaporated under reduced pressure, and replaced by TFE $(10 \mathrm{~mL})$. The resulting reddish solution was stirred at room temperature for 16 hours, after which time it was evaporated under reduced pressure. The resulting residue was submitted to the precipitation/filtration/evaporation/purification protocol to afford biscarvacrol (3a) (28.7 mg, 74\%) in 27\% ee in favour of (+)-3a (Figure S25).

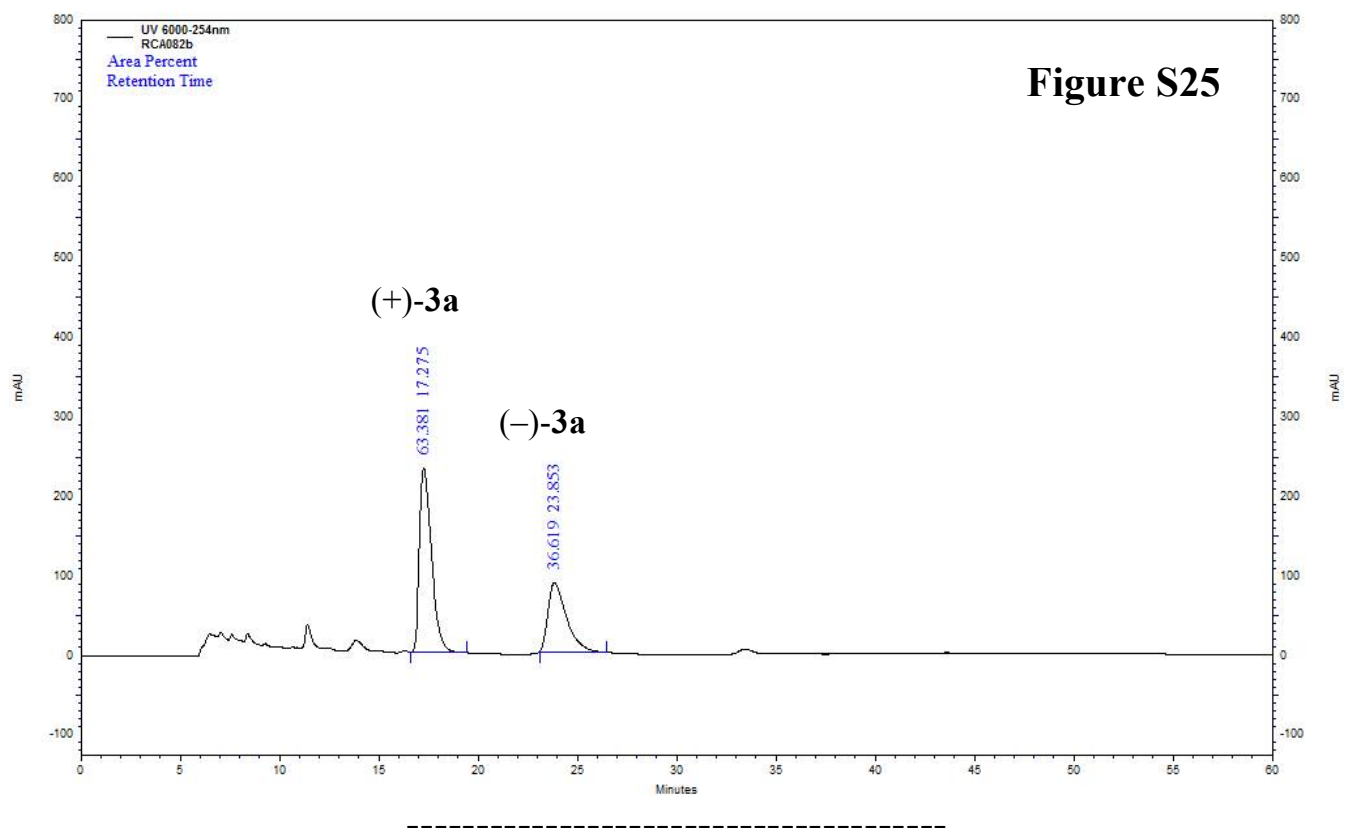


Experiment \#21. Carvacrol (1a, $25 \mathrm{mg}, 0.167 \mathrm{mmol}$ ) was dearomatized in dry $\mathrm{CH}_{2} \mathrm{Cl}_{2}$ at room temperature for 7 days using the Salen-type $\operatorname{bis}\left(\lambda^{5}\right.$-iodane) $(R, R)-8 \mathbf{a}(69 \mathrm{mg}, 0.109 \mathrm{mmol}, 0.65$ equiv). As no reaction was observed during these 7 days, $\mathrm{CH}_{2} \mathrm{Cl}_{2}$ was evaporated under reduced pressure, and replaced by TFE $(10 \mathrm{~mL})$. This new solution was stirred at room temperature for 48 hours, after which time it was evaporated under reduced pressure. The resulting residue was submitted to the precipitation/filtration/evaporation/purification protocol to furnish biscarvacrol (3a) $(22.7 \mathrm{mg}, 82 \%)$ in $\mathbf{2 6 \%}$ ee in favour of (+)-3a (Figure S26).

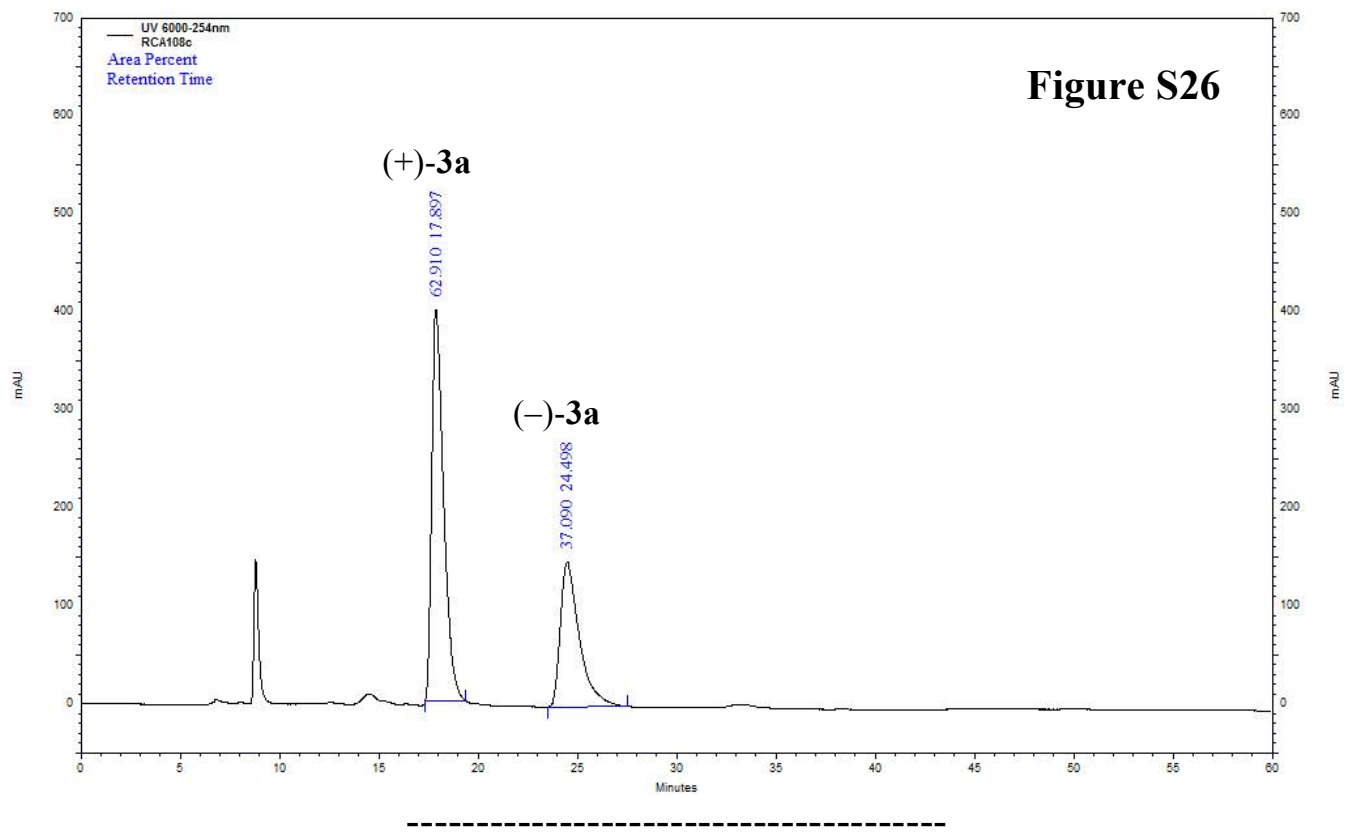

Experiment \#22. Carvacrol (1a, $25 \mathrm{mg}, 0.167 \mathrm{mmol}$ ) was dearomatized in dry $\mathrm{CH}_{2} \mathrm{Cl}_{2}$ at room temperature for 7 days using the Salen-type bis $\left(\lambda^{5}\right.$-iodane) $(R, R)-\mathbf{8 d}(81 \mathrm{mg}, 0.109 \mathrm{mmol}, 0.65$ equiv). As no reaction was observed during these 7 days, $\mathrm{CH}_{2} \mathrm{Cl}_{2}$ was evaporated under reduced pressure, and replaced by TFE $(10 \mathrm{~mL})$. This new solution was stirred at room temperature for 48 hours, after which time it was evaporated under reduced pressure. The resulting residue was submitted to the precipitation/filtration/evaporation/purification protocol to give biscarvacrol (3a) (12 $\mathrm{mg}, 43 \%$ ) in $\mathbf{2 1 \%}$ ee in favour of (+)-3a (Figure S27). N.B.: no full conversion of $\mathbf{1 a}$.

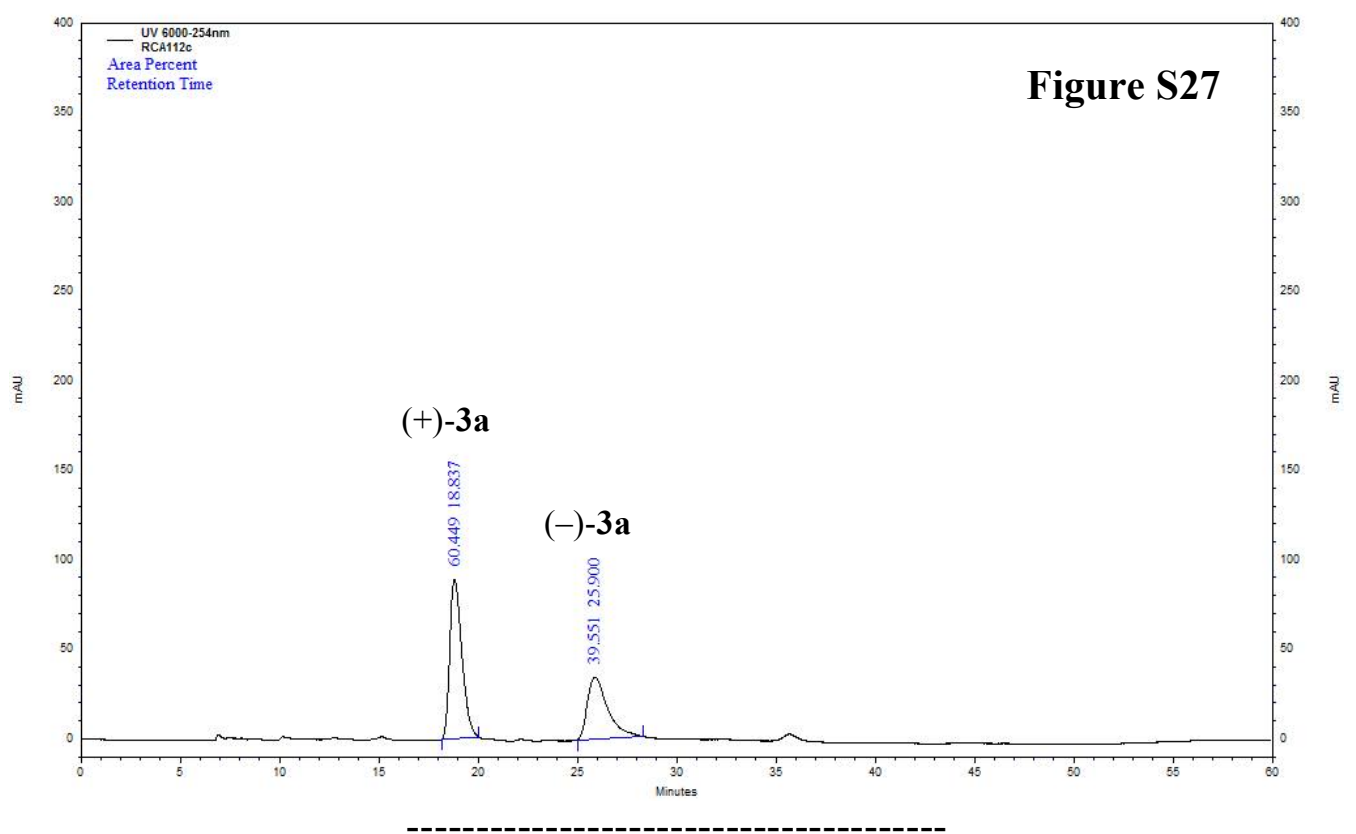


Experiment \#23. Carvacrol (1a, $25 \mathrm{mg}, 0.167 \mathrm{mmol}$ ) was dearomatized in dry $\mathrm{CH}_{2} \mathrm{Cl}_{2}$ at room temperature for 7 days using the Salen-type $\operatorname{bis}\left(\lambda^{5}\right.$-iodane) $(R, R)-9 \mathbf{a}(83 \mathrm{mg}, 0.109 \mathrm{mmol}, 0.65$ equiv). As no reaction was observed during these 7 days, $\mathrm{CH}_{2} \mathrm{Cl}_{2}$ was evaporated under reduced pressure, and replaced by TFE $(10 \mathrm{~mL})$. This new solution was stirred at room temperature for 48 hours, after which time it was evaporated under reduced pressure. The resulting residue was submitted to the precipitation/filtration/evaporation/purification protocol to furnish biscarvacrol (3a) $(19.7 \mathrm{mg}, 71 \%)$ in $\mathbf{5 0 \%}$ ee in favour of (+)-3a (Figure S28).

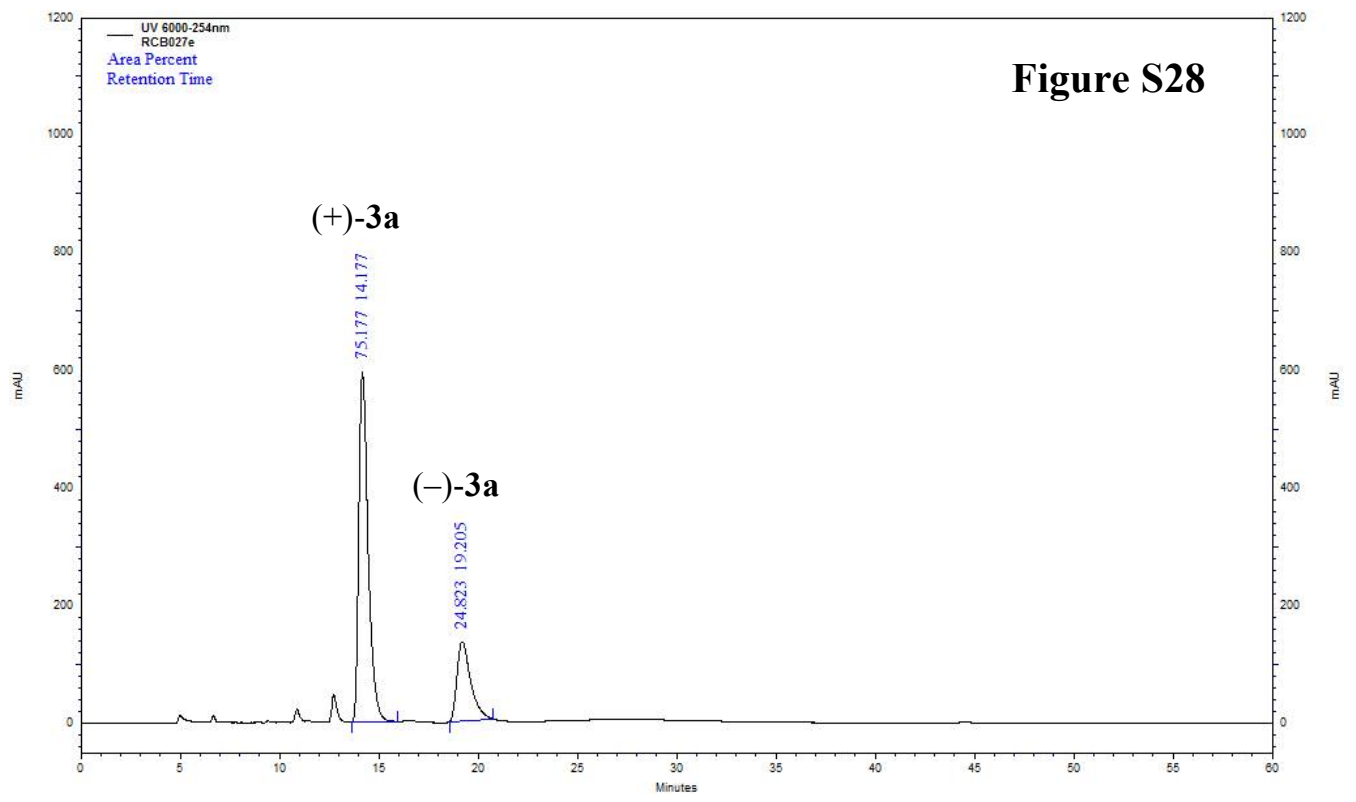

\section{Evaluation of the influence of an alcoholic co-solvent on the HPD/[4+2]-dimerization cascade conversion of carvacrol promoted by Salen-type bis $\left(\lambda^{5}\right.$-iodanes $)$}

In light of the crucial role played by either TFE or TFA in our Salen-type iodane-mediated HPD reaction/[4+2] cyclodimerization sequence for the synthesis of biscarvacrol 3a (vide supra), we decided to carry out a short study in which TFE was replaced either by another fluorinated alcohol (e.g., HFIP) or an alcohol (e.g., EtOH), both having been reported as interesting co-solvent and/or additive in the hypervalent iodine chemistry. ${ }^{[18,19]}$ This study was performed on our benchmark reaction [i.e., the conversion of carvacrol (1a) into biscarvacrol (3a)], using the bis $\left(\lambda^{5}\right.$-iodane) $(R, R)-9 a(0.65$ equiv) (Scheme $\mathrm{S} 8)$. Enantiomeric excesses (ee) were determined by HPLC analysis on a chiral stationary phase [Daicel Chiralpak ${ }^{\circledR}$ AS-H column, $250 \times 4.6 \mathrm{~mm}$ I.D.].
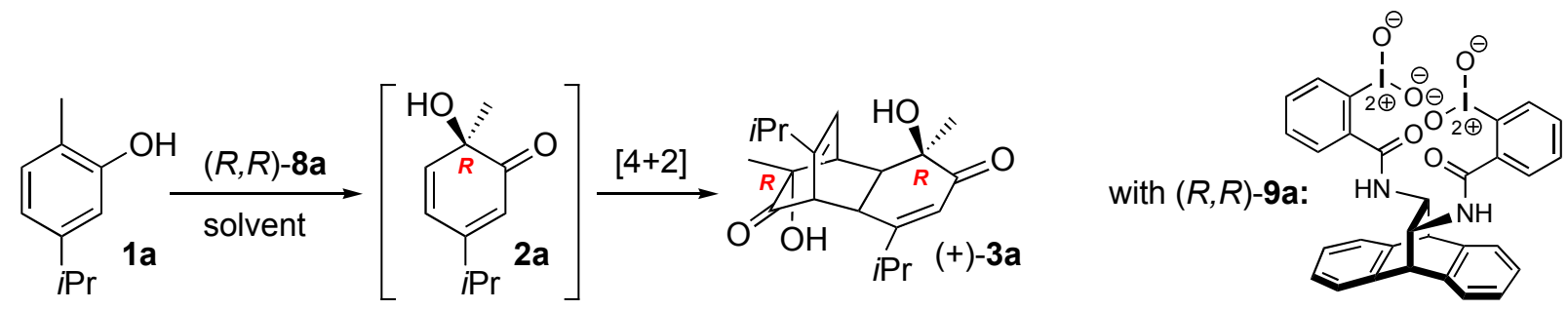

Scheme S8.

Table S2 summarizes the main results of this study. The replacement of TFE by the polar and more acidic HFIP [i.e., pKa $(\mathrm{HFIP})=9.3$ versus $\mathrm{pKa}(\mathrm{TFE})=12.4$ ], in the same 85:15 ratio with $\mathrm{CH}_{2} \mathrm{Cl}_{2}$, led to a dramatic loss of both yield (only $28 \%$ of cyclodimer 3a, as the major product observed was the carvacrol-derived para-quinone) and enantiomeric excess (20\% ee; Table S2, entry 2). In contrast, the use of absolute ethanol as additive (typically 12 equiv) to $\mathrm{CH}_{2} \mathrm{Cl}_{2}$ led to an increase of 
yield ( $82 \%$ of 3a), but with a lower $13 \%$ ee (Table S2, entry 3). Replacement of $\mathrm{CH}_{2} \mathrm{Cl}_{2}$ by 1 ,2dichloroethane (DCE) or $\mathrm{CHCl}_{3}$, while maintaining the same amount of EtOH as additive, did not give significant improvement, as biscarvacrol 3a was isolated in $c a$. 60\% yield with $c a$. 20\% ee (Table S2, entries 4 and 5). Finally, the use of commercially available $\mathrm{CHCl}_{3}$ as solvent, which is known to contain a small amount of $\mathrm{EtOH}$ as stabilizer, led to very similar results and poor selectivity (Table S2, entry 6).

Table S2. Evaluation of the influence of an alcoholic co-solvent on the asymmetric HPD/[4+2]dimerization cascade conversion of carvacrol (1a) using the bis $\left(\lambda^{5}\right.$-iodane) $(R, R)-\mathbf{9 a}{ }^{a}$

$\begin{array}{llllll}\text { entry } & \text { solvent } & \text { temp }\left({ }^{\circ} \mathrm{C}\right) & \text { time }(\mathrm{h}) & \text { yield }(\%)^{b} & e e(\%)^{c} \\ 1 & \mathrm{CH}_{2} \mathrm{Cl}_{2} / \mathrm{TFE}^{d}(85: 15) & \mathrm{rt} & 16 & 65 & 55 \\ 2 & \mathrm{CH}_{2} \mathrm{Cl}_{2} / \mathrm{HFIP}^{d}(85: 15) & \mathrm{rt} & 36 & 28 & 20 \\ 3 & \mathrm{CH}_{2} \mathrm{Cl}_{2} / \mathrm{EtOH}^{e}(12 \text { equiv) } & \mathrm{rt} & 24 & 82 & 13 \\ 4 & \mathrm{DCE} \mathrm{EtOH}^{e}(12 \text { equiv }) & \mathrm{rt} & 48 & 64 & 23 \\ 5 & \mathrm{CHCl}_{3} / \mathrm{EtOH}^{e}(12 \text { equiv) } & \mathrm{rt} & 24 & 68 & 20 \\ 6 & \mathrm{CHCl}_{3}^{f} & \mathrm{rt} & 72 & 58 & 18\end{array}$

${ }^{a}$ Reactions run using $[\mathbf{1 a}]=17 \mathrm{mM}$ and $(R, R)-9 a\left(0.65\right.$ equiv). ${ }^{b}$ Isolated yield. ${ }^{c}$ Enantiomeric excess determined by chiral HPLC analysis of pure cyclodimer 3a (i.e., Chiralpak ${ }^{\circledR}$ AS-H column), with all values in favour of $(+)-\mathbf{3 a} .{ }^{d}$ Commercial fluoroalcohols were dried over activated $4 \AA$ molecular sieves. ${ }^{e}$ Absolute $\geq 99.5 \%$. ${ }^{f}$ Commercial $\mathrm{CHCl}_{3}$ contains $0.5-1 \%$ (i.e., ca. 10 equiv) of $\mathrm{EtOH}$ as stabilizer. DCE = 1,2-dichloroethane, HFIP = 1,1,1,3,3,3-hexafluoropropan-2-ol, TFE = 2,2,2trifluoroethanol.

General procedure for the bis $\left(\lambda^{5}\right.$-iodane) (R,R)-7a-mediated asymmetric HPD/[4+2]dimerization cascade conversion of carvacrol (1a). To a stirred solution of carvacrol (1a, $25 \mathrm{mg}$, $0.167 \mathrm{mmol})$ in dry chlorinated solvent, in the presence of $4 \AA$ molecular sieves, was added the bis $\left(\lambda^{5}\right.$-iodane) $(R, R)-9 \mathrm{a}(83 \mathrm{mg}, 0.109 \mathrm{mmol}, 0.65$ equiv). The (fluoro)alcohol was then added dropwise, and the reaction was stirred at room temperature until complete conversion of the starting material. The reaction was then filtered, evaporated under reduced pressure, and dissolved with the minimum of EtOAc (typically $1 \mathrm{~mL}$ ), before adding PET (typically $5 \mathrm{~mL}$ ) to precipitate a first crop of Salen-type diiodoarene [i.e., $(R, R)-7 \mathbf{a}]$. The resulting suspension was filtered off, and the filtrate was evaporated under vacuum, dissolved in $\mathrm{Et}_{2} \mathrm{O}$ (typically $5 \mathrm{~mL}$ ) to precipitate a second crop of diiodoarene, filtered again, and evaporated under reduced pressure. The brown residue was finally purified by column chromatography, eluting with PET/EtOAc $(5: 1)$, to give the cyclodimer $3 \mathbf{a}$. 
Entry 1. When the reaction was performed in a $85: 15(\mathrm{v} / \mathrm{v}) \mathrm{CH}_{2} \mathrm{Cl}_{2} / \mathrm{TFE}$ mixture $(10 \mathrm{~mL})$, biscarvacrol 3a was isolated in 65\% yield and in $\mathbf{5 5 \%} \boldsymbol{e} e$ in favour of (+)-3a (see Figure S10).

Entry 2. When the reaction was performed in a $85: 15(\mathrm{v} / \mathrm{v}) \mathrm{CH}_{2} \mathrm{Cl}_{2} / \mathrm{HFIP}$ mixture (10 $\left.\mathrm{mL}\right)$, biscarvacrol 3a was isolated in 28\% yield and in $\mathbf{2 0 \%}$ ee in favour of $(+)-3 \mathbf{a}$ (Figure S29).

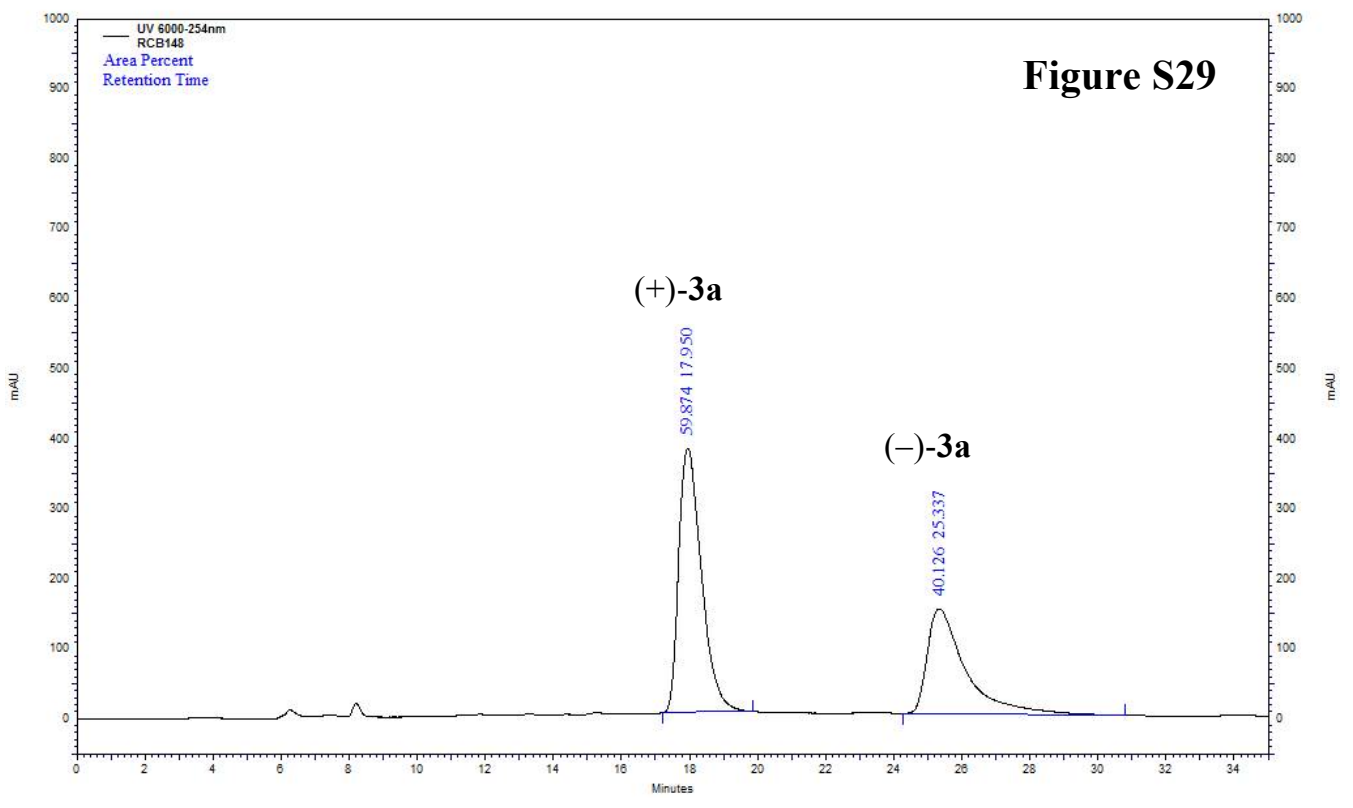

Entry 3. When the reaction was performed in $\mathrm{CH}_{2} \mathrm{Cl}_{2}(10 \mathrm{~mL})$ and absolute EtOH $[77 \mu \mathrm{L}, 1.31$ mmol, 12.0 equiv relative to the $\lambda^{5}$-iodane $\left.(R, R)-9 \mathbf{a}\right]$, biscarvacrol 3a was isolated in $82 \%$ yield and in $\mathbf{1 3 \%}$ ee in favour of $(+)-\mathbf{3 a}$ (Figure S30).

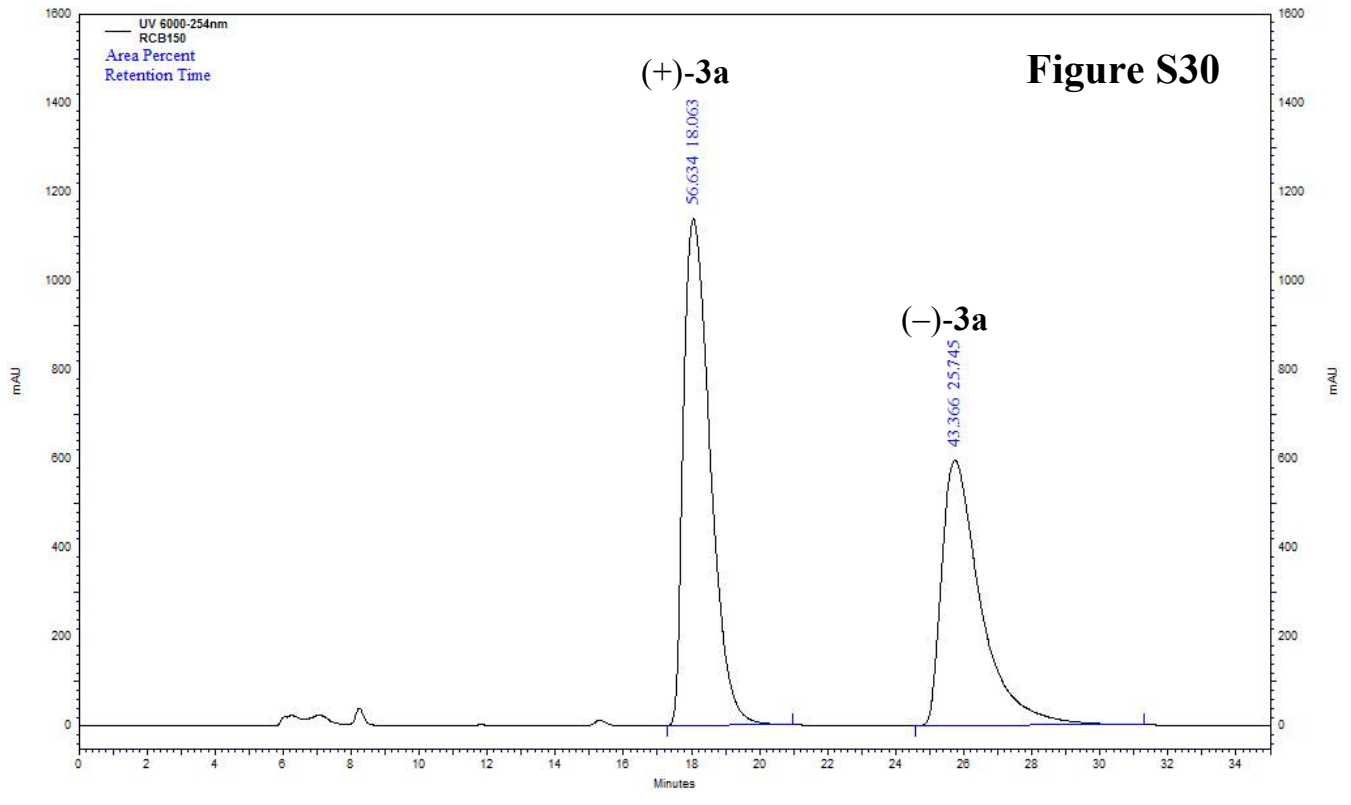


Entry 4. When the reaction was performed in 1,2-dichloroethane (DCE, $10 \mathrm{~mL}$ ) and absolute EtOH $\left[77 \mu \mathrm{L}, 1.31 \mathrm{mmol}, 12.0\right.$ equiv relative to the $\lambda^{5}$-iodane $\left.(R, R)-9 \mathbf{a}\right]$, biscarvacrol 3a was isolated in $64 \%$ yield and in $\mathbf{2 3 \%}$ ee in favour of $(+)-\mathbf{3 a}$ (Figure S31).

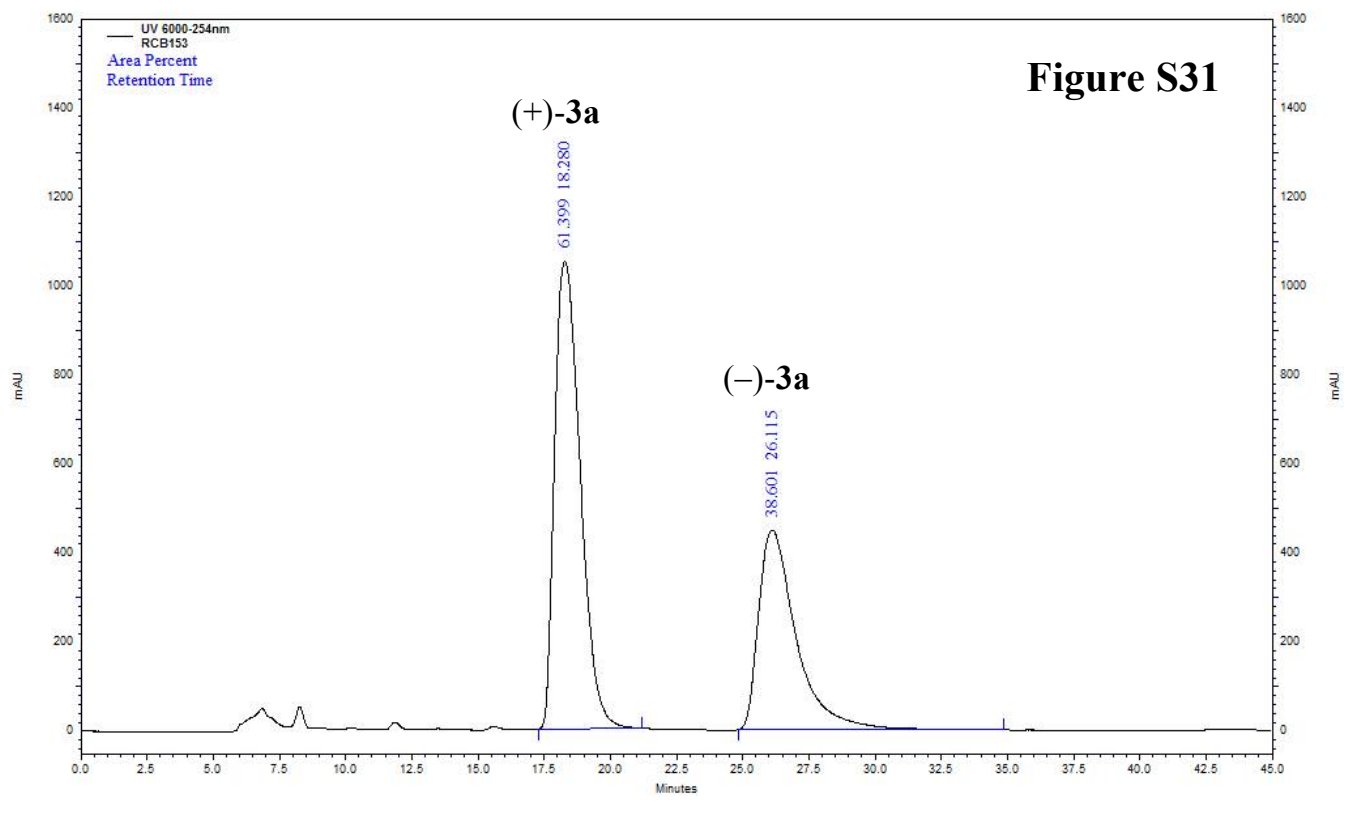

Entry 5. When the reaction was performed in $\mathrm{CHCl}_{3}(10 \mathrm{~mL})$ and absolute $\mathrm{EtOH}[77 \mu \mathrm{L}, 1.31$ mmol, 12.0 equiv relative to the $\lambda^{5}$-iodane $\left.(R, R)-9 \mathbf{a}\right]$, biscarvacrol 3a was isolated in $68 \%$ yield and in $\mathbf{2 0 \%} \boldsymbol{e} e$ in favour of $(+)-\mathbf{3 a}$ (Figure S32).

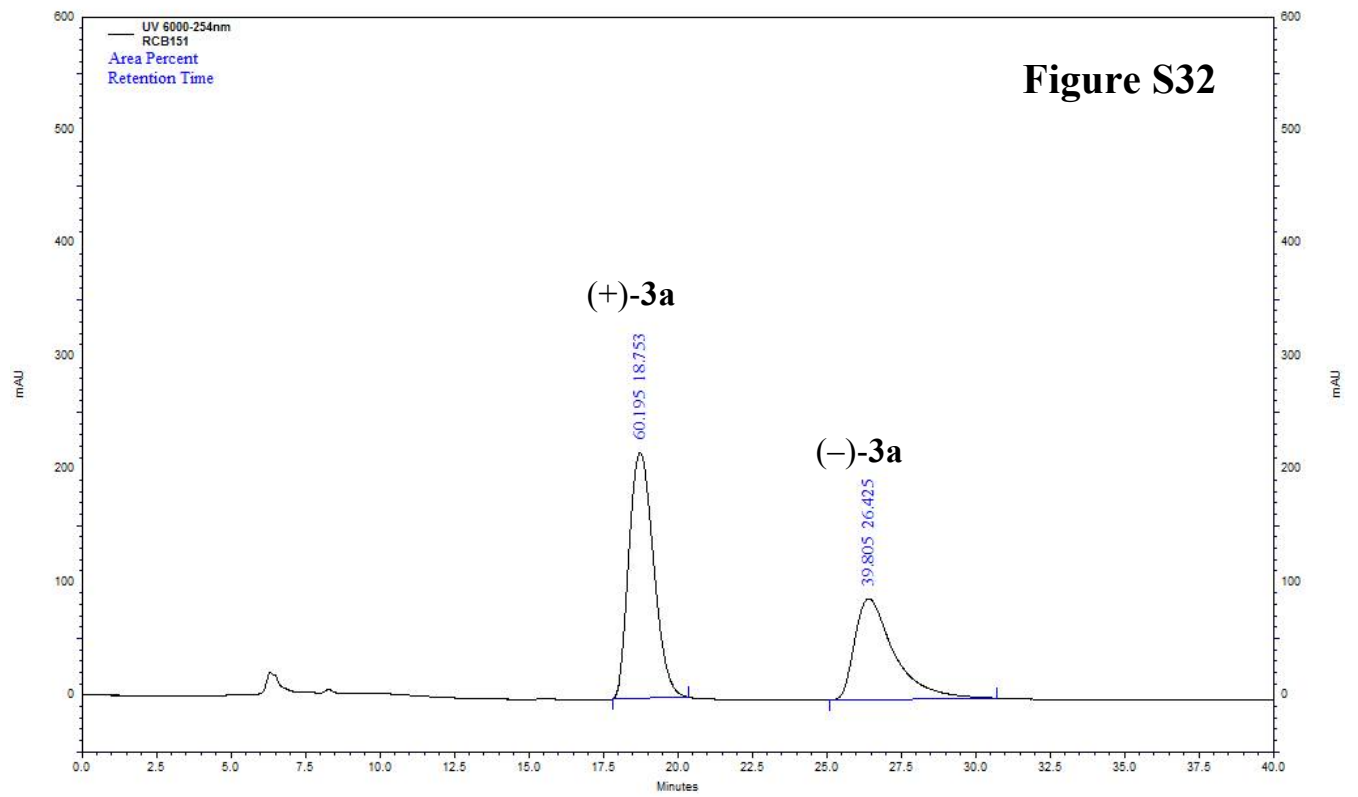


Entry 6. When the reaction was performed in commercially available $\mathrm{CHCl}_{3}(10 \mathrm{~mL}$; SigmaAldrich), which contained $0.5-1.0 \%$ of EtOH as stabilizer, biscarvacrol 3a was isolated in 58\% yield and in $\mathbf{1 8 \%}$ ee in favour of (+)-3a (Figure S33).

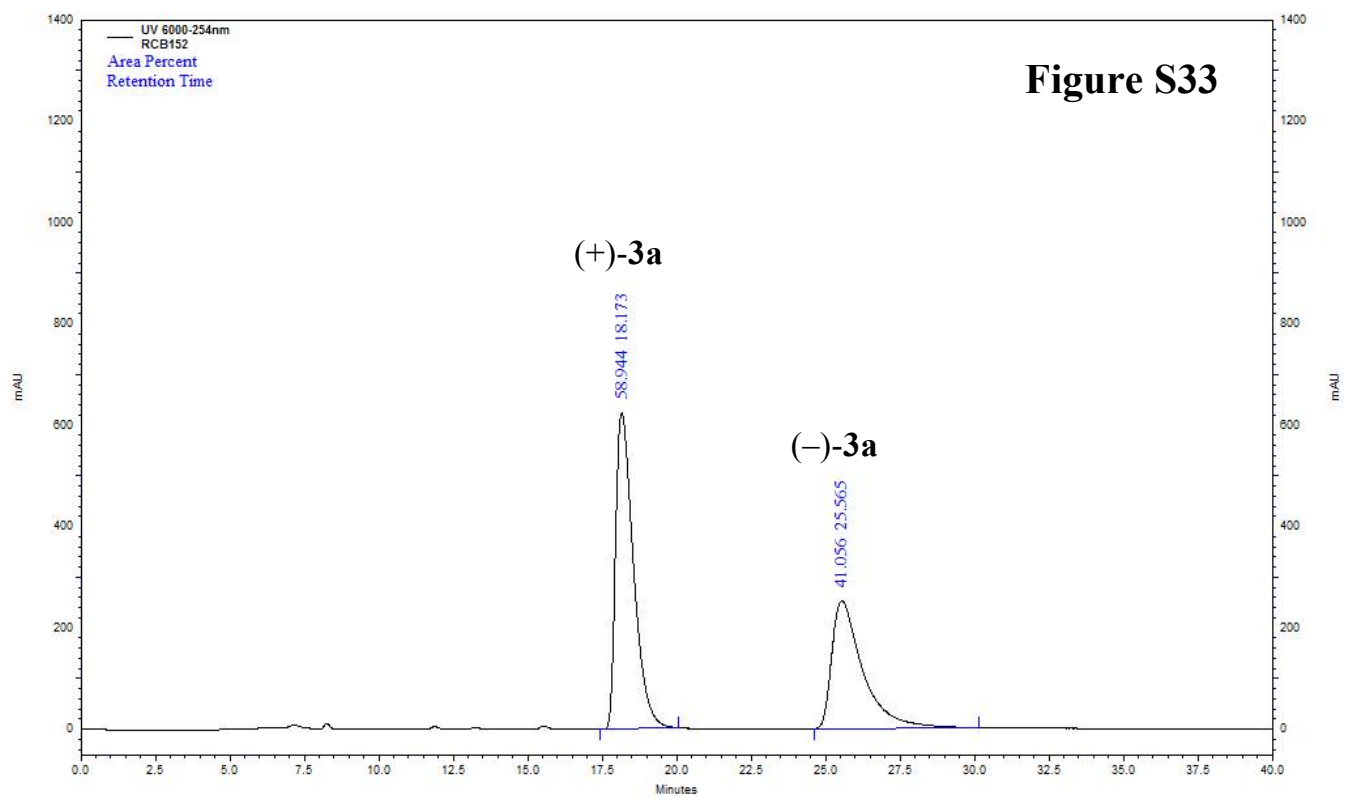

\section{Asymmetric HPD/[4+2]-dimerization cascade conversion of 2-alkylphenols promoted by Salen-type bis $\left(\lambda^{5}\right.$-iodanes $)$}

The bis $\left(\lambda^{5}\right.$-iodane) $(R, R)$-9a was then used, either in $\mathrm{CH}_{2} \mathrm{Cl}_{2} / \mathrm{TFE}(85: 15)$ at room temperature for 16 hours (conditions $\mathrm{A}$ ) or in $\mathrm{CH}_{2} \mathrm{Cl}_{2}$ with TFA (1.0 equiv) at $-50{ }^{\circ} \mathrm{C}$ for 2 hours (conditions $\mathrm{B}$ ), on other 2-alkylphenols to touch upon its performance in $\mathrm{HPD} /[4+2]$ dimerization cascade reactions (Scheme S9).

Enantiomeric excesses (ee) were determined by HPLC analysis on a chiral stationary phase [Daicel Chiralpak $^{\circledR}$ AS-H column, $250 \times 4.6 \mathrm{~mm}$ I.D.] (see Table S3) and compared with the HPLC traces of the corresponding racemic cyclodimers previously synthesized using SIBX. ${ }^{[7,16,17]}$

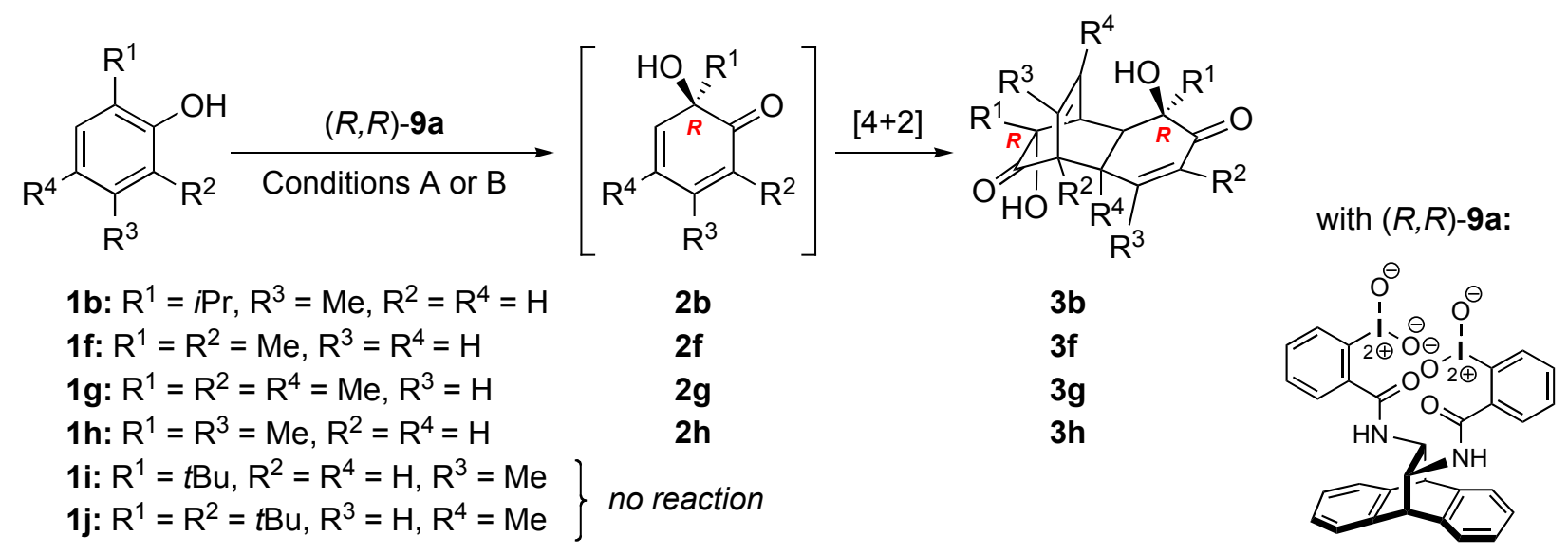

Scheme S9.

It is worth noting that no reaction was observed in the case of the 2-tert-butylphenols $\mathbf{1 i}$ and $\mathbf{1 j}$, probably because of a too high steric demand at the ortho position of the phenolic substrate, thus preventing its approach to the iodine $(\mathrm{V})$ center of $(R, R)-\mathbf{9 a}$. In contrast, phenols $\mathbf{1} \mathbf{f}-\mathbf{h}$ and $\mathbf{1 b}$ were successfully converted into their corresponding cyclodimers $\mathbf{3 f}-\mathbf{h}$ and $\mathbf{3 b}$ (Table S3). The 
symmetrical 2,6-dimethyl- and 2,4,6-trimethylphenols (1f/g) furnished the expected cyclodimers $\mathbf{3 f}$ and $\mathbf{3 g}$ in good to high yields but with poor enantioselectivities (entries 1 and 2). Treated with $(R, R)-9 \mathbf{a}$ or $(S, S)-9 \mathbf{a}$, the non-symmetrical 2,5-dimethyphenol (1h) gave rise to the cyclodimer $\mathbf{3 h}$ in relatively good yields with reverse but still disappointing ee values (entries 3 and 4). A much better outcome was observed when thymol (1b), the 2-isopropylated regioisomer of 1a, was dearomatized under these conditions, as bis(thymol) $(+)-3 \mathbf{b}^{[17]}$ was isolated in good to high yields with ee values up to $74 \%$ (entries 5-7).

Table S3. Asymmetric HPD/[4+2]-dimerization cascade reaction of 2-alkylphenols (1), 1f-h) promoted by the Salen-type bis $\left(\lambda^{5}\right.$-iodane $)(R, R)-9 \mathbf{a} .^{a}$

entry $^{2}$

${ }^{a}$ Reactions run using [1/a] $=17 \mathrm{mM} .{ }^{b}$ 2-tert-Butyl-5-methylphenol (1i) and 2,6-di-tert-butyl-4methylphenol (1j) remained unreacted. ${ }^{c}$ Conditions: (A) $\mathrm{CH}_{2} \mathrm{Cl}_{2} / \mathrm{TFE}$ (85:15), rt, $16 \mathrm{~h}$; (B) $\mathrm{CH}_{2} \mathrm{Cl}_{2}$, TFA (1.0 equiv), $-50{ }^{\circ} \mathrm{C}, 2 \mathrm{~h} .{ }^{d}$ Isolated yield. ${ }^{e}$ Enantiomeric excess determined by chiral HPLC analysis of pure cyclodimer 3a. ${ }^{f}$ Reaction run with $(S, S)-9$ a. ${ }^{g}$ Optical rotation of the major enatiomer. TFA $=$ trifluoroacetic acid, TFE $=2,2,2$-trifluoroethanol.

General procedure for the asymmetric HPD/[4+2]-dimerization cascade conversion of 2alkylphenols (1b, f-h) using chiral bis $\left(\lambda^{5}\right.$-iodane) $(\boldsymbol{R}, \boldsymbol{R})-9 \mathrm{a}$. To a stirred solution $(17 \mathrm{mM})$ of 2 alkylphenol $\mathbf{1 b}, \mathbf{f}-\mathbf{h}(25 \mathrm{mg}, 1.0$ equiv) in the indicated solvent $(c a .10 \mathrm{~mL})$, in the presence of $4 \AA$ molecular sieves, was added the bis $\left(\lambda^{5}\right.$-iodane) $(R, R)-9 \mathrm{a}(0.65$ or 1.10 equiv according to the experiment). The resulting solution was subjected to conditions $\mathrm{A}$ [i.e., $\mathrm{CH}_{2} \mathrm{Cl}_{2} / \mathrm{TFE}$ (85:15) at $\mathrm{RT}$ for $16 \mathrm{~h}$ ] or $\mathrm{B}$ [i.e., $\mathrm{CH}_{2} \mathrm{Cl}_{2}$, TFA (1.0 equiv) at $-50{ }^{\circ} \mathrm{C}$ ] until TLC monitoring indicated disappearance of the starting material. The reaction mixture was then filtered, evaporated under reduced pressure, and dissolved with the minimum of EtOAc (typically $1 \mathrm{~mL}$ ) before adding PET (typically $5 \mathrm{~mL}$ ) to precipitate a first crop of the Salen-type diiodoarene [i.e., $(R, R)-7 \mathbf{a}]$. The resulting suspension was filtered off, and the filtrate was evaporated under vacuum, dissolved in $\mathrm{Et}_{2} \mathrm{O}$ (typically $5 \mathrm{~mL}$ ) to precipitate a second crop of diiodoarene, filtered again, and evaporated under reduced pressure. The resulting brown residue was finally purified by column chromatography, eluting with PET/EtOAc (5:1), to give the corresponding ortho-quinol-based [4+2] cyclodimer $\mathbf{3 b}, \mathbf{f}-\mathbf{h}$, which was analyzed by chiral HPLC.

Each experiment and its corresponding HPLC trace are given hereafter. 
Experiment \#1 (see Table S3, entry 1). 2,6-Dimethylphenol 1f (25 $\mathrm{mg}, 0.205 \mathrm{mmol}$ ) was subjected to conditions A using $(R, R)-9 \mathbf{a}(101 \mathrm{mg}, 0.133 \mathrm{mmol}, 0.65$ equiv) to afford cyclodimer $\mathbf{3 f}$ (24 $\mathrm{mg}, 86 \%$ ) in $\mathbf{2 8 \%}$ ee in favour of enantiomer 1 (Figure S34).

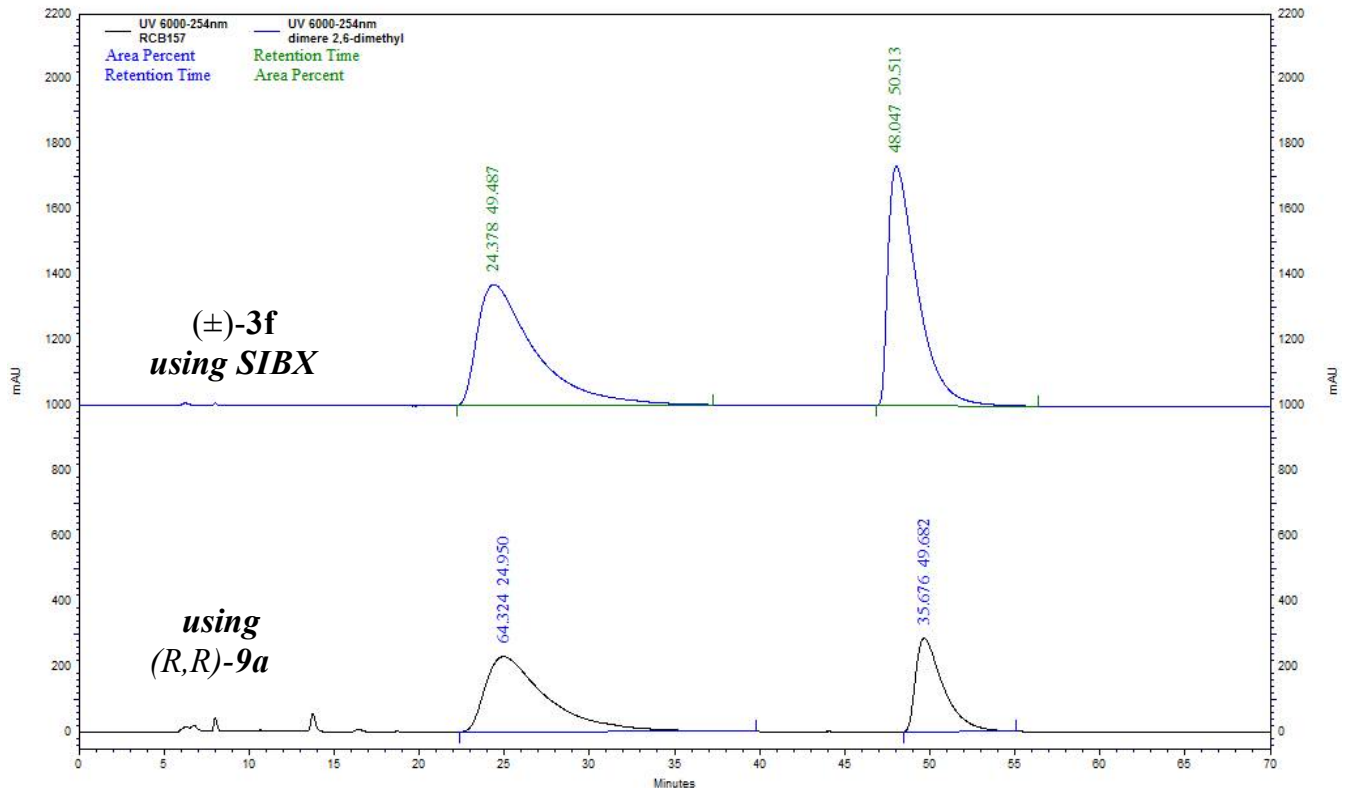

Figure S34. Chiral HPLC traces of $3 \mathbf{f}$ synthesized using either SIBX or $(R, R)-9 \mathbf{a}$.

Chiralpak ${ }^{\circledR}$ AS-H column $(250 \times 4.6 \mathrm{~mm}$ I.D. $), n$-hexane $/ i$-PrOH $(90: 10), 0.5 \mathrm{~mL} / \mathrm{min}$,

$\mathrm{UV}$ detection at $254 \mathrm{~nm}$ [retention time $=24.4 \mathrm{~min}$ for enantiomer 1; $48.1 \mathrm{~min}$ for enantiomer 2].

Experiment \#2 (see Table S3, entry 2). 2,4,6-Trimethylphenol $1 \mathrm{~g}$ (25 $\mathrm{mg}, 0.184 \mathrm{mmol}$ ) was subjected to conditions A using $(R, R)-9 \mathbf{a}(91 \mathrm{mg}, 0.119 \mathrm{mmol}, 0.65$ equiv) to afford cyclodimer $\mathbf{3 g}$ (18 $\mathrm{mg}, 64 \%)$ in $\mathbf{1 8 \%}$ ee in favour of enantiomer 1 (Figure S35).

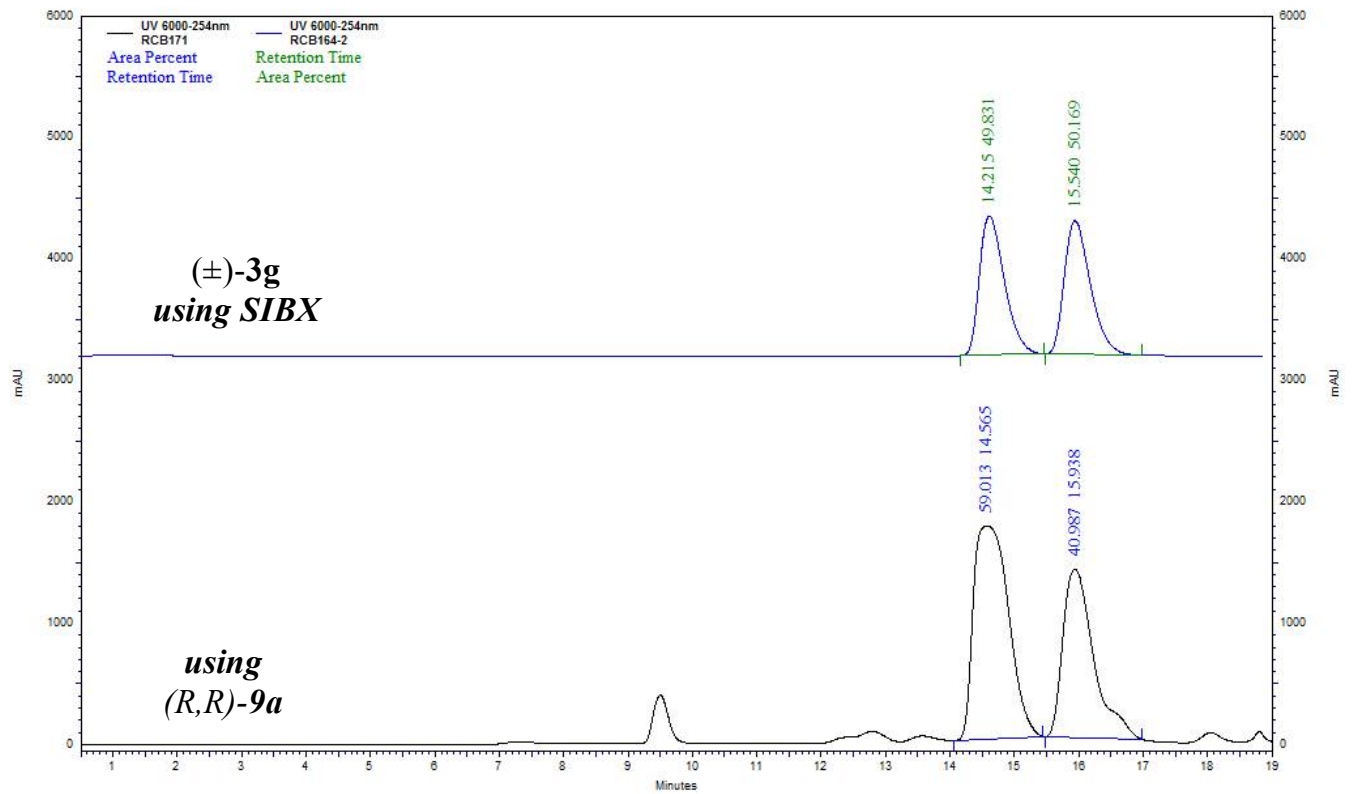

Figure S35. Chiral HPLC traces of $\mathbf{3 g}$ synthesized using either $\operatorname{SIBX}$ or $(R, R)-\mathbf{9 a}$.

Chiralpak ${ }^{\circledR}$ AS-H column $(250 \times 4.6 \mathrm{~mm}$ I.D. $), n$-hexane $/ i$-PrOH (95:5), $0.5 \mathrm{~mL} / \mathrm{min}$,

$\mathrm{UV}$ detection at $254 \mathrm{~nm}$ [retention time $=14.0 \mathrm{~min}$ for enantiomer 1; $15.5 \mathrm{~min}$ for enantiomer 2]. 
Experiment \#3 (see Table S3, entry 3). 2,5-Dimethylphenol 1h (25 $\mathrm{mg}, 0.205 \mathrm{mmol}$ ) was subjected to conditions B using $(R, R)-9 \mathrm{a}(101 \mathrm{mg}, 0.133 \mathrm{mmol}, 0.65$ equiv) and furnished cyclodimer $\mathbf{3 h}$ (15.8 $\mathrm{mg}, 56 \%)$ in $\mathbf{3 1 \%} \boldsymbol{e e}$ in favour of enantiomer 1 (Figure S36).

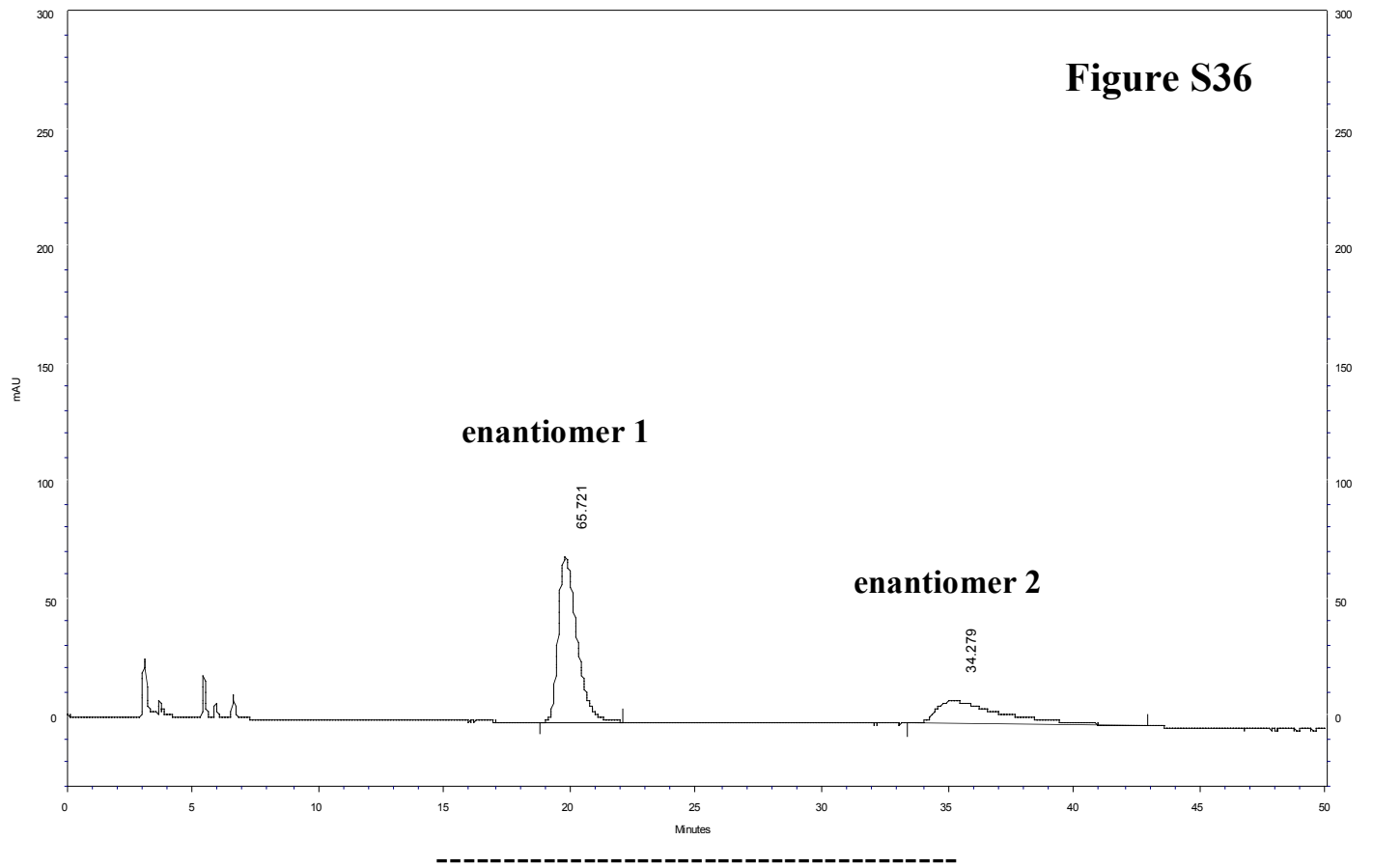

Experiment \#4 (see Table S3, entry 4). 2,5-Dimethylphenol 1h (25 $\mathrm{mg}, 0.205 \mathrm{mmol}$ ) was subjected to conditions B using $(S, S)-9 \mathrm{a}(101 \mathrm{mg}, 0.133 \mathrm{mmol}, 0.65$ equiv) and afforded cyclodimer $\mathbf{3 h}$ (12.4 mg, 44\%) in $\mathbf{2 7 \%}$ ee in favour of enantiomer 2 (Figure S37).

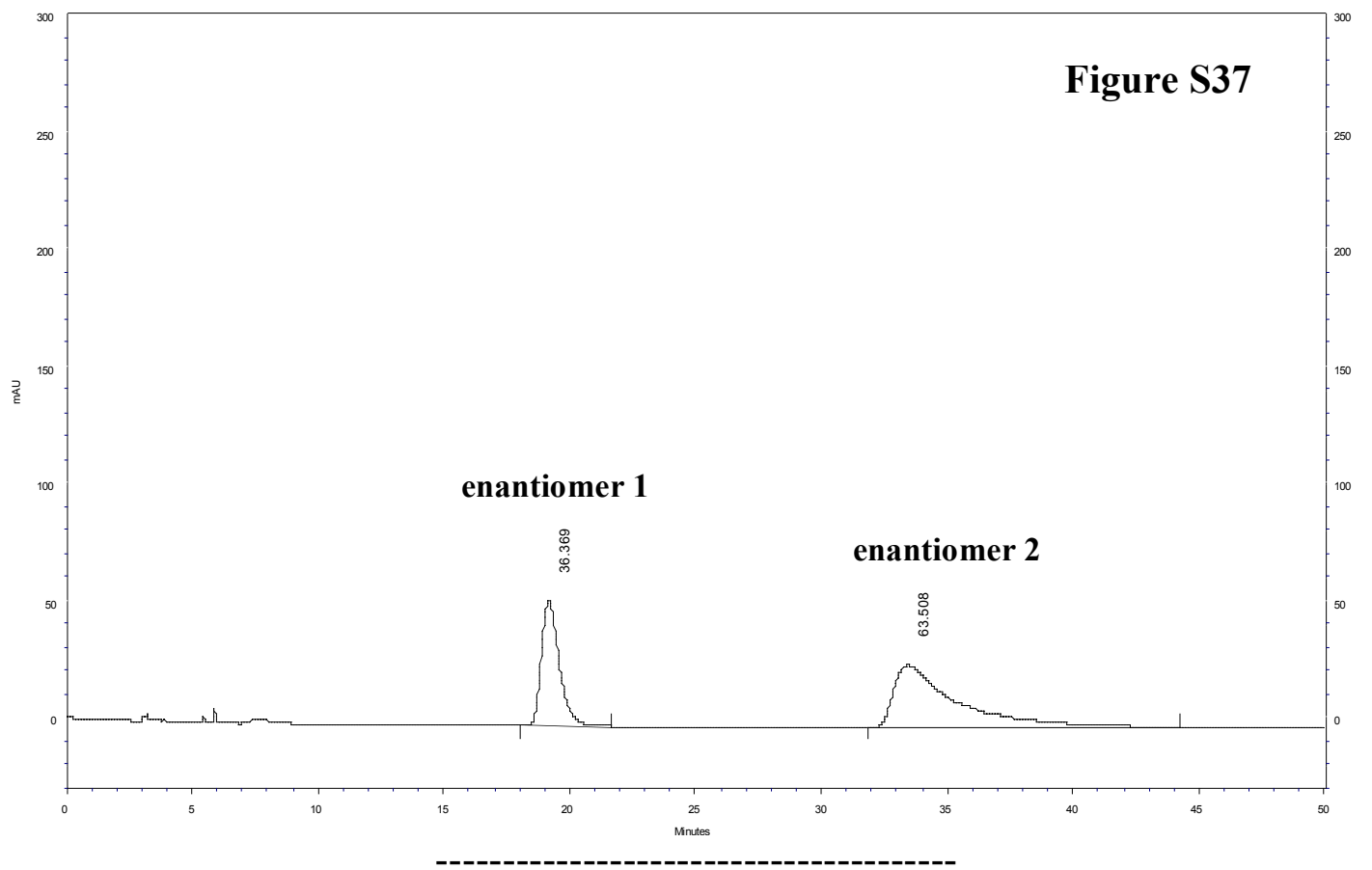


Experiment \#5 (see Table S3, entry 5). Thymol 1b (25 mg, $0.167 \mathrm{mmol})$ was subjected to conditions A using $(R, R)-9 \mathbf{a}(83 \mathrm{mg}, 0.109 \mathrm{mmol}, 0.65$ equiv) and afforded bis(thymol) (3b, 22.7 $\mathrm{mg}, 82 \%$ ) in $67 \%$ ee in favour of $(+)-3 b$ (Figure $\mathrm{S} 38$ ).

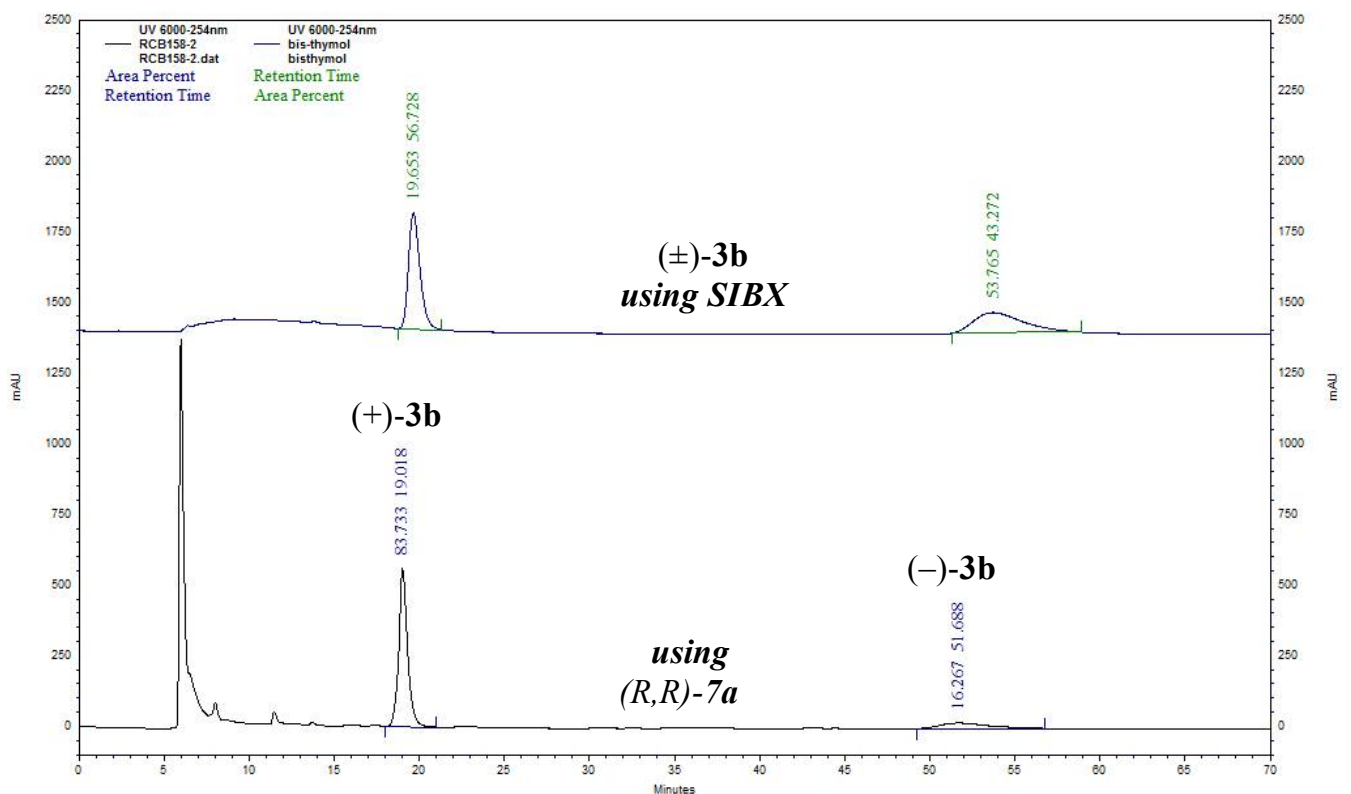

Figure S38. Chiral HPLC traces of $\mathbf{3 b}$ synthesized using either $\operatorname{SIBX}$ or $(R, R)-9 \mathbf{a}$. Chiralpak $^{\circledR}$ AS-H column $(250 \times 4.6 \mathrm{~mm}$ I.D. $), n$-hexane $/ i$-PrOH $(90: 10), 0.5 \mathrm{~mL} / \mathrm{min}$, $\mathrm{UV}$ detection at $254 \mathrm{~nm}$ [retention time $=19.0 \mathrm{~min}$ for $(+)-\mathbf{3 b}$, and $53.0 \mathrm{~min}$ for $(-)-\mathbf{3 b}$ ].

Experiment \#6 (see Table S3, entry 6). Thymol 1b (25 $\mathrm{mg}, 0.167 \mathrm{mmol})$ was subjected to conditions A using ( $R, R)-9 \mathbf{a}(139 \mathrm{mg}, 0.184 \mathrm{mmol}, 1.10$ equiv), and gave bis(thymol) (3b, $19 \mathrm{mg}$, $68 \%$ ) in $72 \%$ ee in favour of (+)-3b (Figure S39).

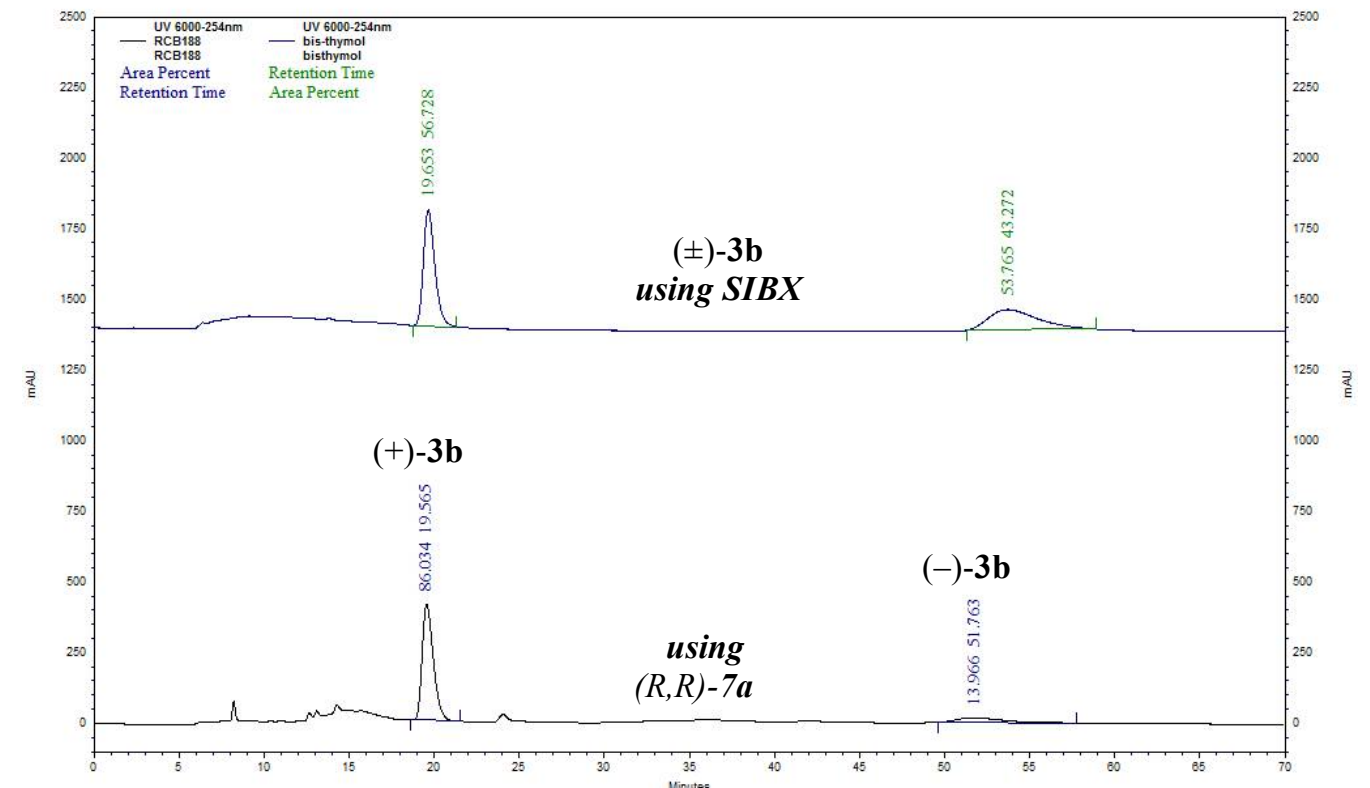

Figure S39. Chiral HPLC traces of $\mathbf{3 b}$ synthesized using either $\operatorname{SIBX}$ or $(R, R)-\mathbf{9 a}$.

Chiralpak ${ }^{\circledR}$ AS-H column $(250 \times 4.6 \mathrm{~mm}$ I.D. $), n$-hexane $/ i$-PrOH $(90: 10), 0.5 \mathrm{~mL} / \mathrm{min}$, $\mathrm{UV}$ detection at $254 \mathrm{~nm}$ [retention time $=19.0 \mathrm{~min}$ for $(+)-\mathbf{3 b}$, and $53.0 \mathrm{~min}$ for $(-)-\mathbf{3 b}$ ]. 
Experiment \#7 (see Table S3, entry 7). Thymol 1b (25 mg, $0.167 \mathrm{mmol})$ was subjected to conditions B using $(R, R)-9 \mathrm{a}$ ( $83 \mathrm{mg}, 0.109 \mathrm{mmol}, 0.65$ equiv) and gave bis(thymol) (3b, $19.1 \mathrm{mg}$, $69 \%$ ) in $\mathbf{7 4 \%} e e$ in favour of $(+)-3 b$ (Figure $\mathrm{S} 40)$.

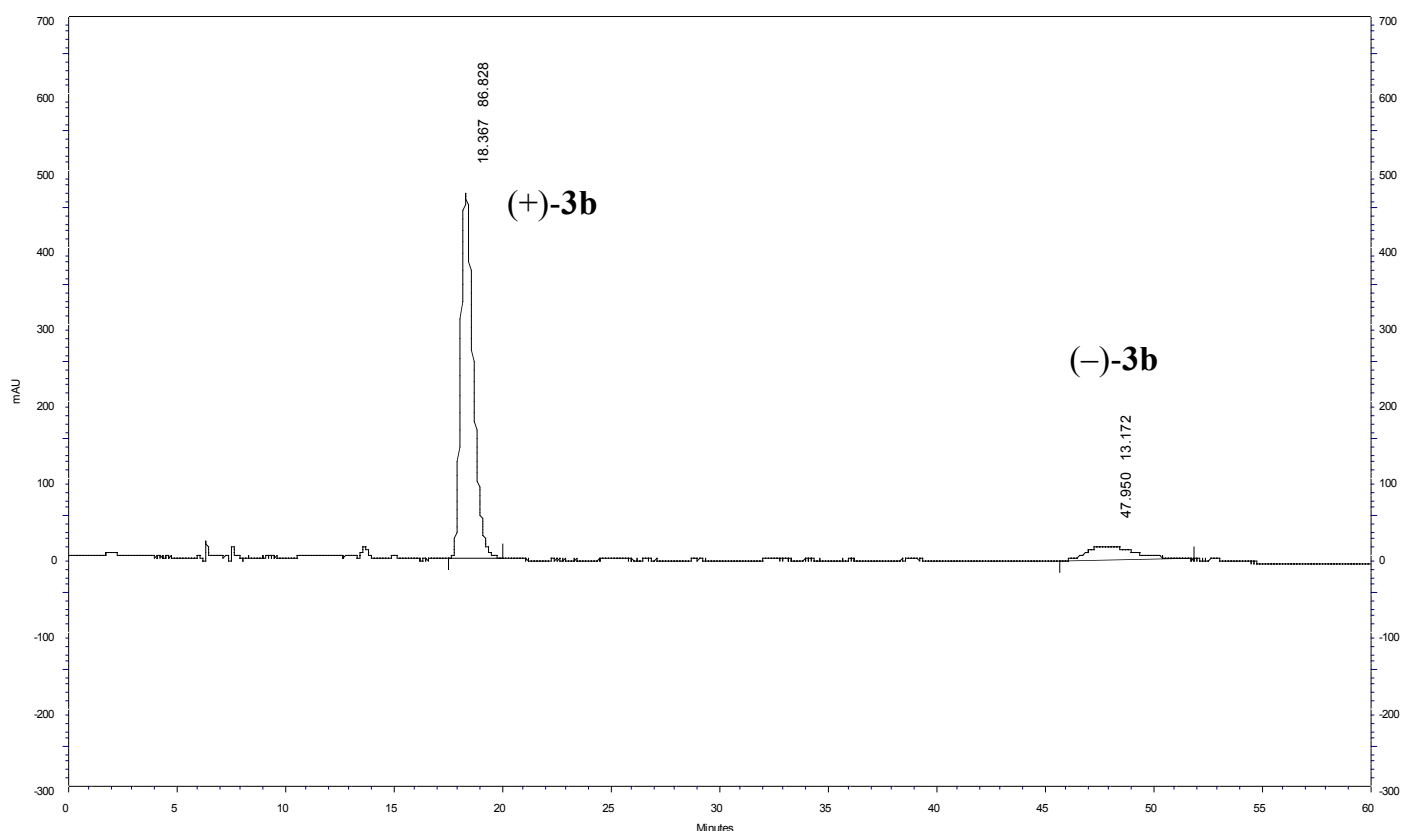

Figure S40. Chiral HPLC traces of $\mathbf{3 b}$ synthesized using $(R, R)-\mathbf{9 a}$.

Chiralpak ${ }^{\circledR}$ AS-H column $(250 \times 4.6 \mathrm{~mm}$ I.D. $), n$-hexane $/ i$-PrOH $(90: 10), 0.5 \mathrm{~mL} / \mathrm{min}$, $\mathrm{UV}$ detection at $254 \mathrm{~nm}$ [retention time $=18.4 \mathrm{~min}$ for $(+)-\mathbf{3 b}$, and $47.9 \mathrm{~min}$ for $(-)-3 \mathbf{b}$ ].

Experiment \#8. Thymol 1b $(25 \mathrm{mg}, 0.167 \mathrm{mmol})$ was subjected to conditions A, in the presence of TFA (13 $\mu \mathrm{L}, 1.0$ equiv), using $(R, R)-9 \mathbf{a}(83 \mathrm{mg}, 0.109 \mathrm{mmol}, 0.65$ equiv) and gave bis(thymol) (3b, $18 \mathrm{mg}, 65 \%$ ) in $\mathbf{4 6 \%} \boldsymbol{e} e$ in favour of (+)-3b (Figure S41). N.B.: incompatibility of TFA and TFE.

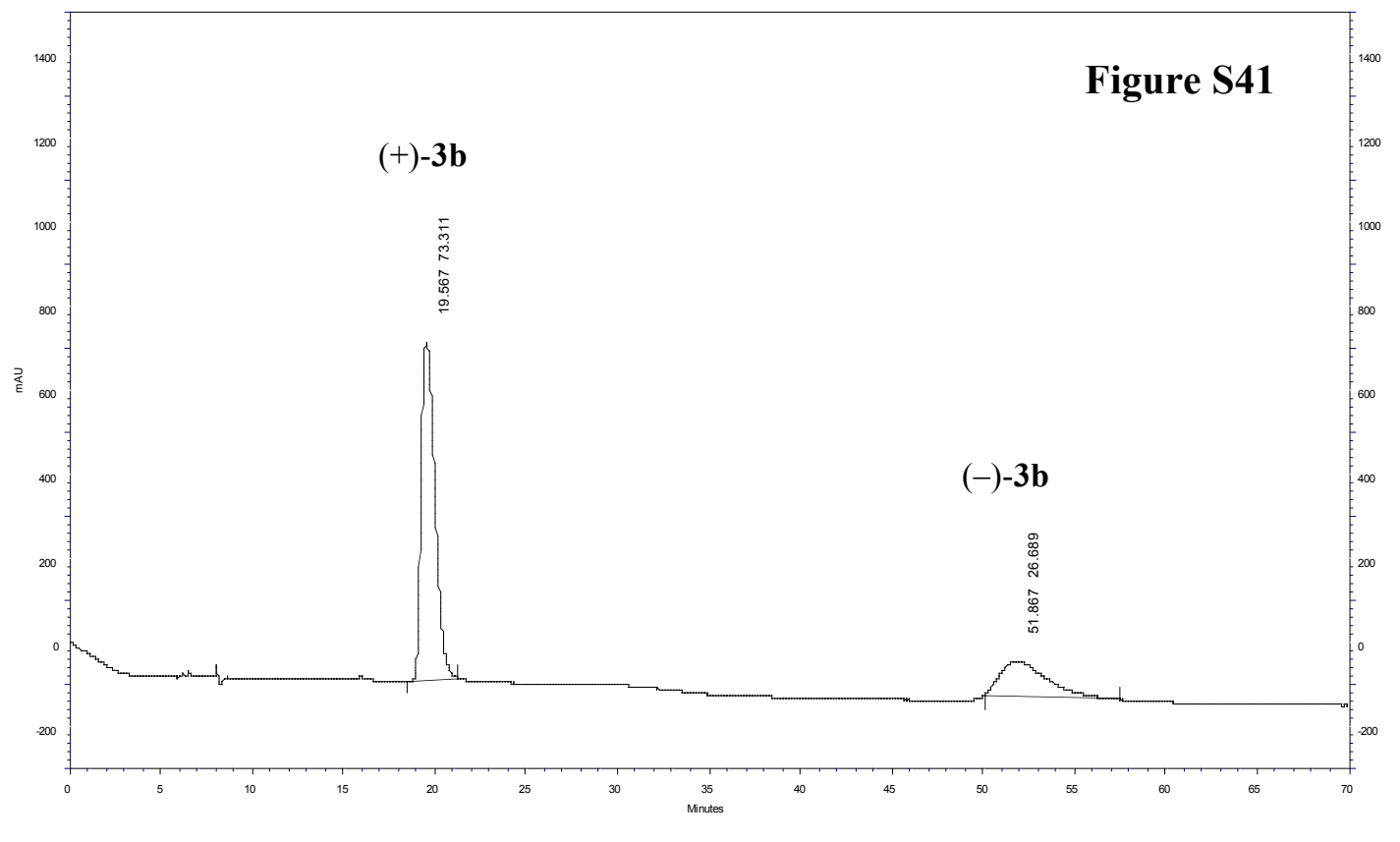


Asymmetric HPD/[4+2]-dimerization cascade conversion of $(R)$ - and $(S)$-curcuphenols for the diastereoselective synthesis of ent-bacchopetiolone and bacchopetiolone, respectively

Unsucessful HPD-induced conversion of curcuphenol (1e) using chiral iodanes A, B1, B2 and $(\boldsymbol{R}, \boldsymbol{R})$-9a (Scheme S10). The first attempts of asymmetric HPD reaction/[4+2] dimerization cascade of curcuphenol (1e) were performed on the $R$-enantiomer using chiral biarylic iodanes and related experimental conditions previously developed by our team. ${ }^{[17]}$ When $(R)$-1e was treated with the $R$-atropoisomer of the $C_{2}$-symmetrical biphenylic bis $\left(\lambda^{5}\right.$-iodane) $\mathbf{A}$ (1.5 equiv) at room temperature for 2 days, TLC monitoring of the reaction did not indicate any formation of the expected ortho-quinol-based [4+2] cyclodimer(s), but a dark yellow spot that quickly evolved to degradation on silica (Scheme S10, and see Scheme 4 in the main text). Under the same conditions, the use of the $S$-atropoisomer of the alcoxylated binaphthylic $\lambda^{3}$-iodanes B1 (1.5 equiv, and even up to 4.0 equiv) and B2 (1.5 equiv) led to similar observations, i.e., no cyclodimer but only traces of an unstable dark yellow compound (see Scheme 4 in the main text). The latter was probably the ortho-quinone derivative 5 resulting from the oxygenation at the unsubstituted ortho position of phenol 1e. These results were confirmed when $(S)-1$ e was treated for 2 days with the Salen-type chiral chiral $(R, R)-9 \mathbf{a}$ in our conditions (vide supra). Indeed, the corresponding unstable ortho-quinone 5 was isolated in $48 \%$ yield (Scheme S10), thus indicating that these four bulky chiral iodanes (i.e., A, B1, B2 and 9a) were not suitable for the HPD-induced conversion of the sterically demanding (6-methylhept-5-en-2-yl)-ortho-bearing curcuphenol (1e).

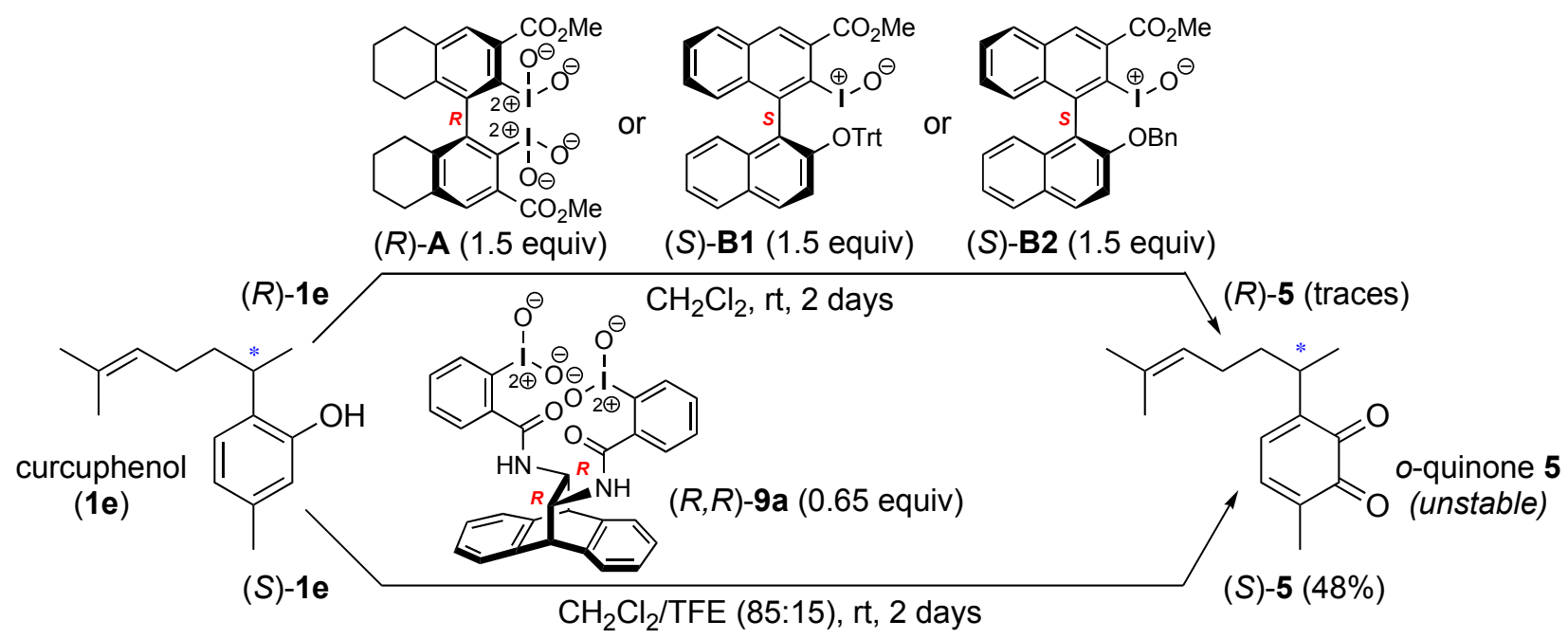

Scheme S10.

3-Methyl-6-[(S)-6-methylhept-5-en-2-yl]cyclohexa-3,5-diene-1,2-dione $[(\boldsymbol{S})$-5]. To a stirred

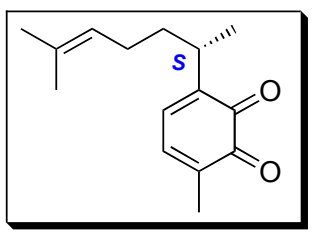
solution of $(S)$-curcuphenol $[(S)-1 \mathbf{e}, 29 \mathrm{mg}, 0.133 \mathrm{mmol})$ in $10 \mathrm{~mL}$ of dry $\mathrm{CH}_{2} \mathrm{Cl}_{2} /$ TFE $(85: 15)$ was added the chiral bis $\left(\lambda^{5}\right.$-iodane) $(R, R)-9 \mathrm{a}(66 \mathrm{mg}$, $0.086 \mathrm{mmol}, 0.65$ equiv). The resulting suspension was stirred at room temperature for 48 hours, after which time it was concentrated under vacuum. The residue was dissolved with the minimum of EtOAc (typically $1 \mathrm{~mL}$ ), and PET (typically $5 \mathrm{~mL}$ ) was added to to precipitate the Salen-type diiodoarene (i.e., 7a). Filtration, and subsequent evaporation to dryness, furnished a brown oil, which was purified by column chromatography, eluting with cyclohexane/EtOAc (3:2), to give the ortho-quinone $(S)$-5 as a yellow oil (15 mg, 48\%): ${ }^{1} \mathbf{H}$ NMR $\left(\mathrm{CDCl}_{3}, 300 \mathrm{MHz}\right) \delta=0.79(\mathrm{~s}, 3 \mathrm{H}), 1.34-1.40(\mathrm{~m}, 2 \mathrm{H}), 1.40(\mathrm{~s}, 3 \mathrm{H})$, 1.59 (s, 3H), 2.75-2.98 (m, 6H), $5.94(\mathrm{~d}, J=8.4 \mathrm{~Hz}, 1 \mathrm{H}), 6.00-6.05(\mathrm{~m}, 1 \mathrm{H}), 6.48(\mathrm{~d}, J=8.4 \mathrm{~Hz}$, $1 \mathrm{H})$.

N.B.: quick degradation of the curcuphenol-derived ortho-quinone $\mathbf{5}$ was observed both on TLC and during ${ }^{1} \mathrm{H}$ NMR spectrum acquisition. 
Asymmetric HPD/[4+2]-dimerization cascade conversion of curcuphenol (1e) promoted by Salen-type chiral iodanes 8 (see Table 1 in the main text). The two enantiomers of curcuphenol (1e) were individually treated with our Salen-type chiral iodanes 8 featuring a transdiaminocyclohexane core, with the aim of promoting the asymmetric HPD-induced conversion of 1e into its corresponding ortho-quinol-based [4+2] cyclodimers 3e. The experimental conditions tested (i.e., concentration of $\mathbf{1 e}$, nature of the solvent, temperature...) were taken from our previous study that was carried out on carvacrol (vide supra).

Diastereomeric ratios $(d r)$ of the cyclodimers 3e produced from each enantiomer of curcuphenol (1e) were determined by HPLC analysis on a chiral stationary phase [Daicel Chiralpak ${ }^{\circledR}$ AS-H column, $250 \times 4.6 \mathrm{~mm}$ I.D.] and by comparison with the HPLC trace obtained for the racemic HPD-induced conversion of curcuphenol (1e) (see Figures S2 and S3).

General procedure. To a stirred solution ( $c a .14 \mathrm{mM}$ ) of curcuphenol (1e, $c a .30 \mathrm{mg}, 1.0$ equiv) in the indicated solvent ( $c a .10 \mathrm{~mL})$ was added the Salen-type bis $\left(\lambda^{5}\right.$-iodane) 8 (0.65 or 1.10 equiv), and the resulting redish mixture was stirred at the indicated temperature until TLC monitoring indicated complete disappearance of the starting material. The reaction mixture was then submitted to either a sequential precipitation-based protocol (see experiments \#1 to \#6) or a cleaner $\mathrm{Na}_{2} \mathrm{~S}_{2} \mathrm{O}_{4}$ mediated reductive workup (see experiments \#7 to \#16) to discard any contamination due to bis(iodoarene) 6 resulting from the reduction of bis(iodane) 8.

- For experiments \#1 to \#6: the reaction mixture was evaporated, and the resulting oily residue was dissolved with the minimum of EtOAc (typically $1 \mathrm{~mL}$ ). Addition of PET $(5 \mathrm{~mL})$ allowed the precipitation of a first crop of the Salen-type diiodoarene 6 by-product, which was thus discarded by filtration. The filtrate was evaporated, and the oily residue was dissolved with $\mathrm{Et}_{2} \mathrm{O}(5 \mathrm{~mL})$, in which a second crop of diiodoarene 6 precipitated. After filtration and evaporation under reduced pressure, the yellow residue was purified by column chromatography, eluting with cyclohexane/EtOAc (90:10) to give the corresponding cyclodimers $\mathbf{3 e}$ as a diastereomeric mixture, whose ratio was determined by chiral HPLC analysis.

- For experiments \#7 to \#16: the reaction mixture was diluted with $\mathrm{CH}_{2} \mathrm{Cl}_{2}(10 \mathrm{~mL})$ and $\mathrm{H}_{2} \mathrm{O}(10$ $\mathrm{mL})$, and treated with $20 \mathrm{~mL}$ of a $1: 1(\mathrm{v} / \mathrm{v})$ solution of saturated aqueous $\mathrm{Na}_{2} \mathrm{~S}_{2} \mathrm{O}_{4}$ and saturated aqueous $\mathrm{NaHCO}_{3}$. The aqueous phase was then extracted with $\mathrm{CH}_{2} \mathrm{Cl}_{2}(3 \times 20 \mathrm{~mL})$, and the combined organic layers were washed with brine $(15 \mathrm{~mL})$, dried over $\mathrm{Na}_{2} \mathrm{SO}_{4}$, filtered and evaporated to dryness. The yellow residue was purified by column chromatography, eluting with cyclohexane/EtOAc (90:10) to give the corresponding cyclodimers $\mathbf{3 e}$ as a diastereomeric mixture, whose ratio was determined by chiral HPLC analysis.

Each experiment and its corresponding HPLC trace are given hereafter. 
Experiment \#1 (see the main text: Table 1, entry 1). The $(R)$-curcuphenol $[(R)-1 \mathbf{e}, 25 \mathrm{mg}, 0.115$ mmol) was dearomatized in $\mathrm{CH}_{2} \mathrm{Cl}_{2} / \mathrm{TFE}(85: 15)$ at room temperature for 16 hours using the Salentype bis $\left(\lambda^{5}\right.$-iodane) $(R, R)-8 \mathbf{a}(47 \mathrm{mg}, 0.074 \mathrm{mmol}, 0.65$ equiv) to afford the cyclodimers (all $R)$-3e / 3e' $(12 \mathrm{mg}, 45 \%)$ in 72:28 $\boldsymbol{d r}$ (Figure $\mathrm{S} 42$ ).

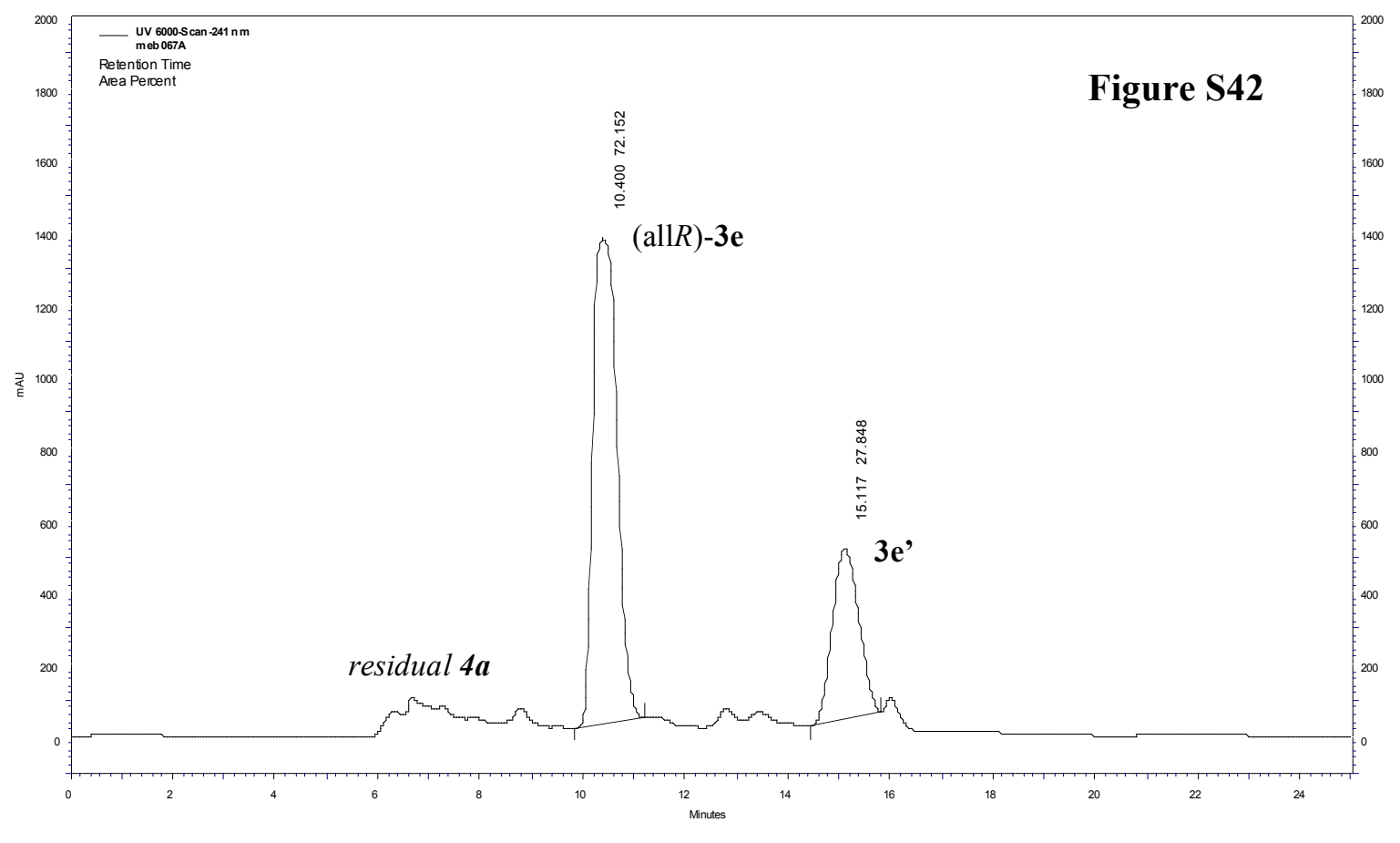

Experiment \#2 (see the main text: Table 1, entry 2). The $(S)$-curcuphenol $[(S)-1 \mathbf{e}, 30 \mathrm{mg}, 0.137$ mmol) was dearomatized in $\mathrm{CH}_{2} \mathrm{Cl}_{2} / \mathrm{TFE}(85: 15)$ at room temperature for 16 hours using the Salentype bis $\left(\lambda^{5}\right.$-iodane) $(R, R)-8 \mathbf{a}(57 \mathrm{mg}, 0.089 \mathrm{mmol}, 0.65$ equiv) to afford the cyclodimers (all $S)$-3e / 3e"' (14 mg, 44\%) in 50:50 dr (Figure S43).

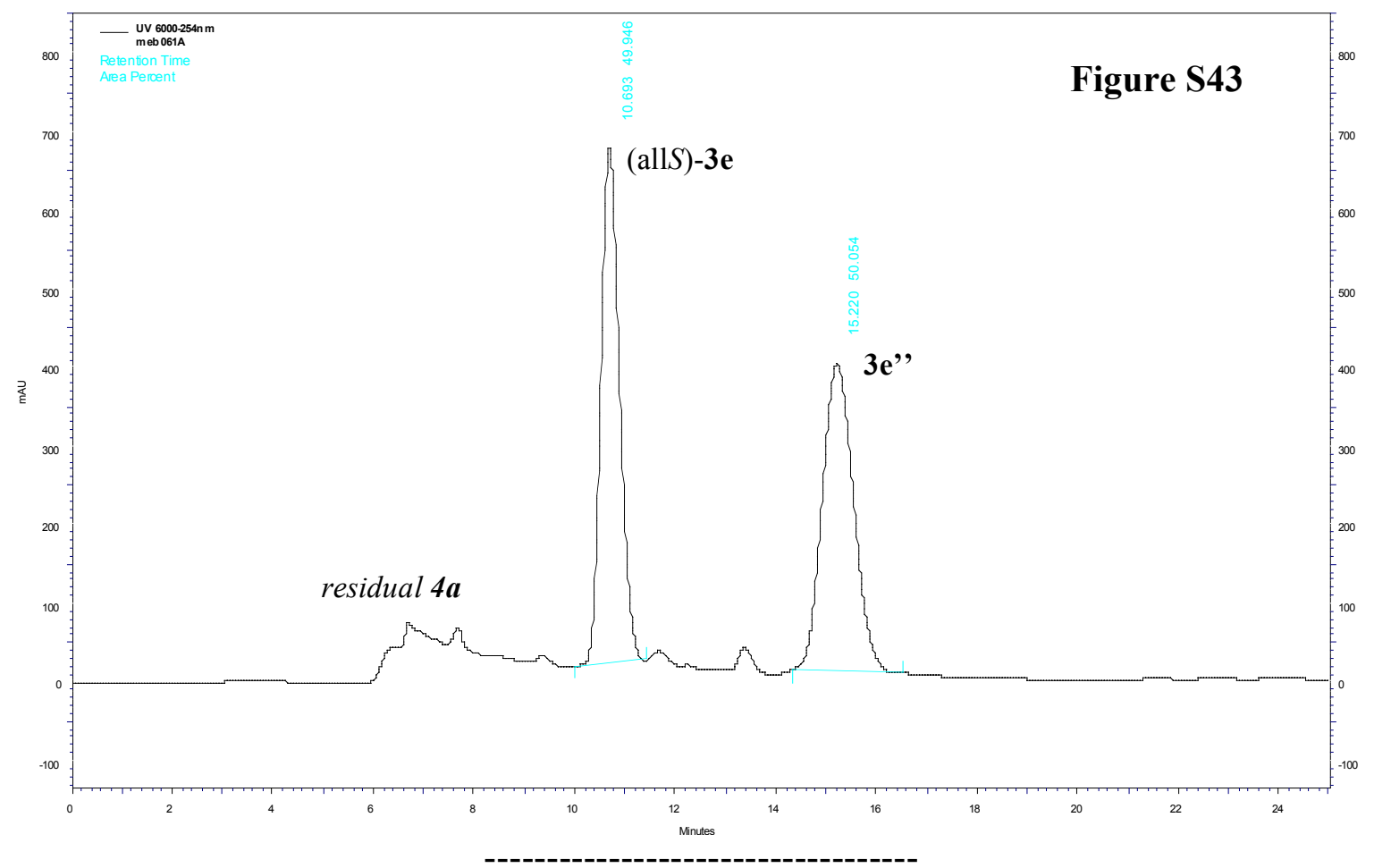


Experiment \#3. The $(R)$-curcuphenol $[(R)-1 \mathrm{e}, 26 \mathrm{mg}, 0.119 \mathrm{mmol})$ was dearomatized in $\mathrm{CH}_{2} \mathrm{Cl}_{2} / \mathrm{TFE}(85: 15)$ at room temperature for 16 hours using the Salen-type bis $\left(\lambda^{5}\right.$-iodane) $(R, R)-8 \mathrm{c}$ (54 mg, $0.077 \mathrm{mmol}, 0.65$ equiv) to afford the cyclodimers (all $R)-3 \mathbf{e} / \mathbf{3 e}$ ' $(10 \mathrm{mg}, 35 \%)$ in $\mathbf{6 5 : 3 5} \mathbf{d r}$ (Figure S44). N.B.: iodane 8c unstable in solution (vide supra).

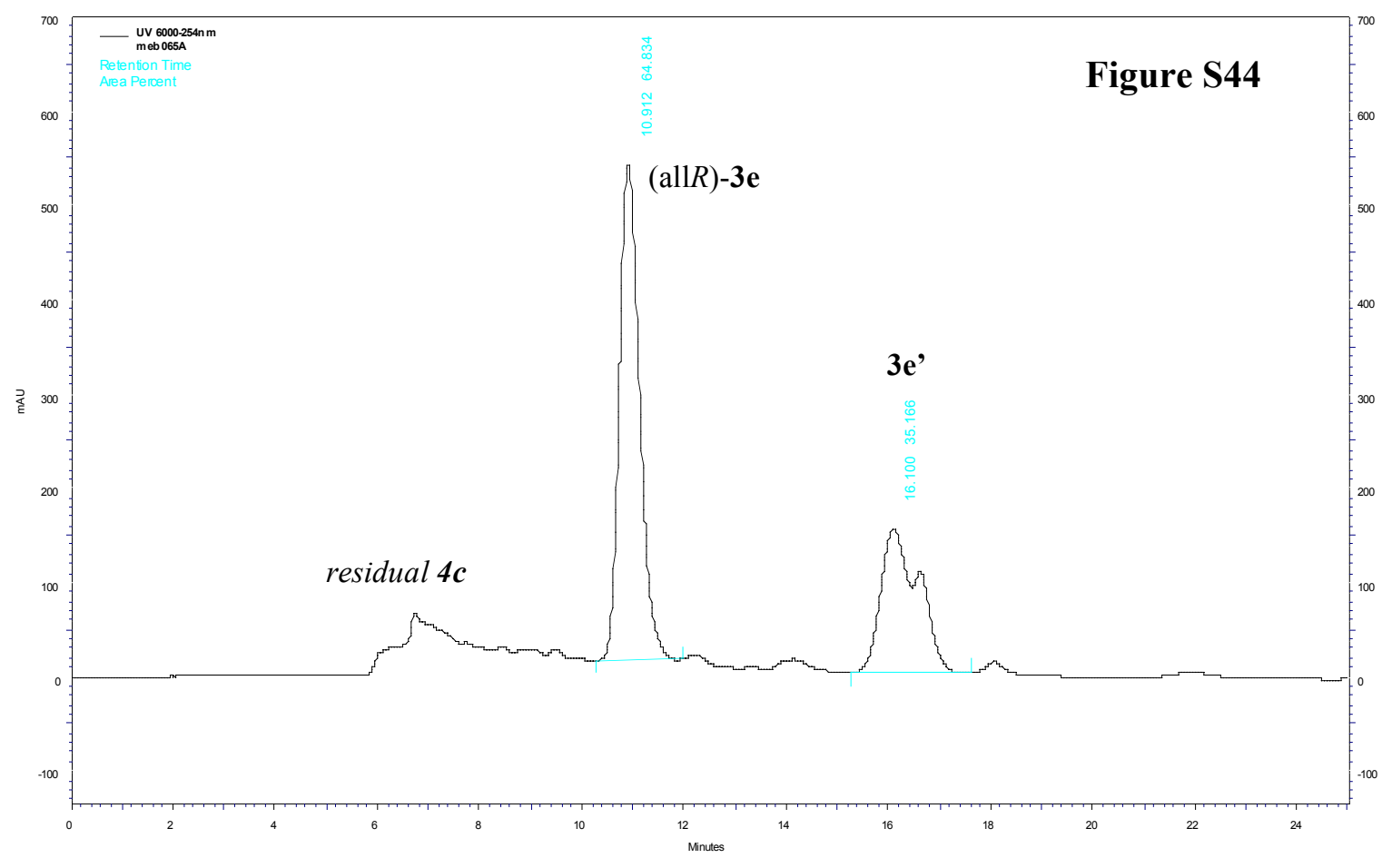

Experiment \#4. The $(S)$-curcuphenol [(S)-1e, $30 \mathrm{mg}, 0.137 \mathrm{mmol})$ was dearomatized in $\mathrm{CH}_{2} \mathrm{Cl}_{2} /$ TFE (85:15) at room temperature for 16 hours using the Salen-type bis $\left(\lambda^{5}\right.$-iodane) $(R, R)-8 \mathrm{c}$ (62 mg, 0.089 mmol, 0.65 equiv) to afford the cyclodimers (all $S)-3 e / 3 e^{\prime \prime}(7 \mathrm{mg}, 22 \%$ ) in $\mathbf{5 4 : 4 6 ~ d r}$ (Figure S45). N.B.: iodane 8c unstable in solution (vide supra).

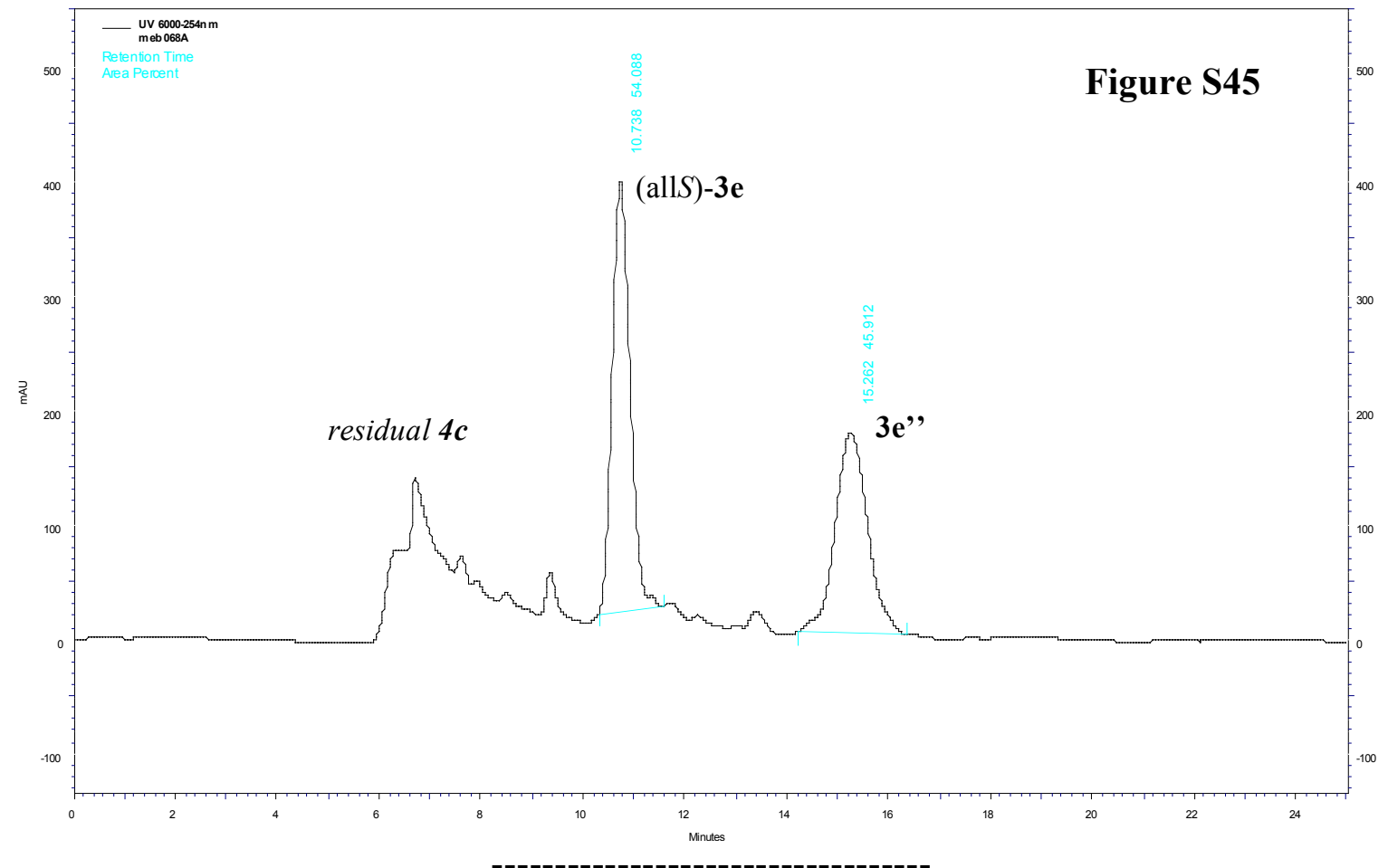


Experiment \#5. The $(R)$-curcuphenol $[(R)$-1e, $24 \mathrm{mg}, 0.110 \mathrm{mmol})$ was dearomatized in $\mathrm{CH}_{2} \mathrm{Cl}_{2} / \mathrm{TFE}$ (85:15) at room temperature for 16 hours using the Salen-type bis $\left(\lambda^{5}\right.$-iodane) $(R, R)-8 \mathbf{d}$ (53 mg, $0.071 \mathrm{mmol}, 0.65$ equiv) to afford the cyclodimers (all $R$ )-3e / 3e' $(9 \mathrm{mg}, 36 \%$ ) in 84:16 $d r$ (Figure S46). N.B.: iodane 8d unstable in solution (vide supra).

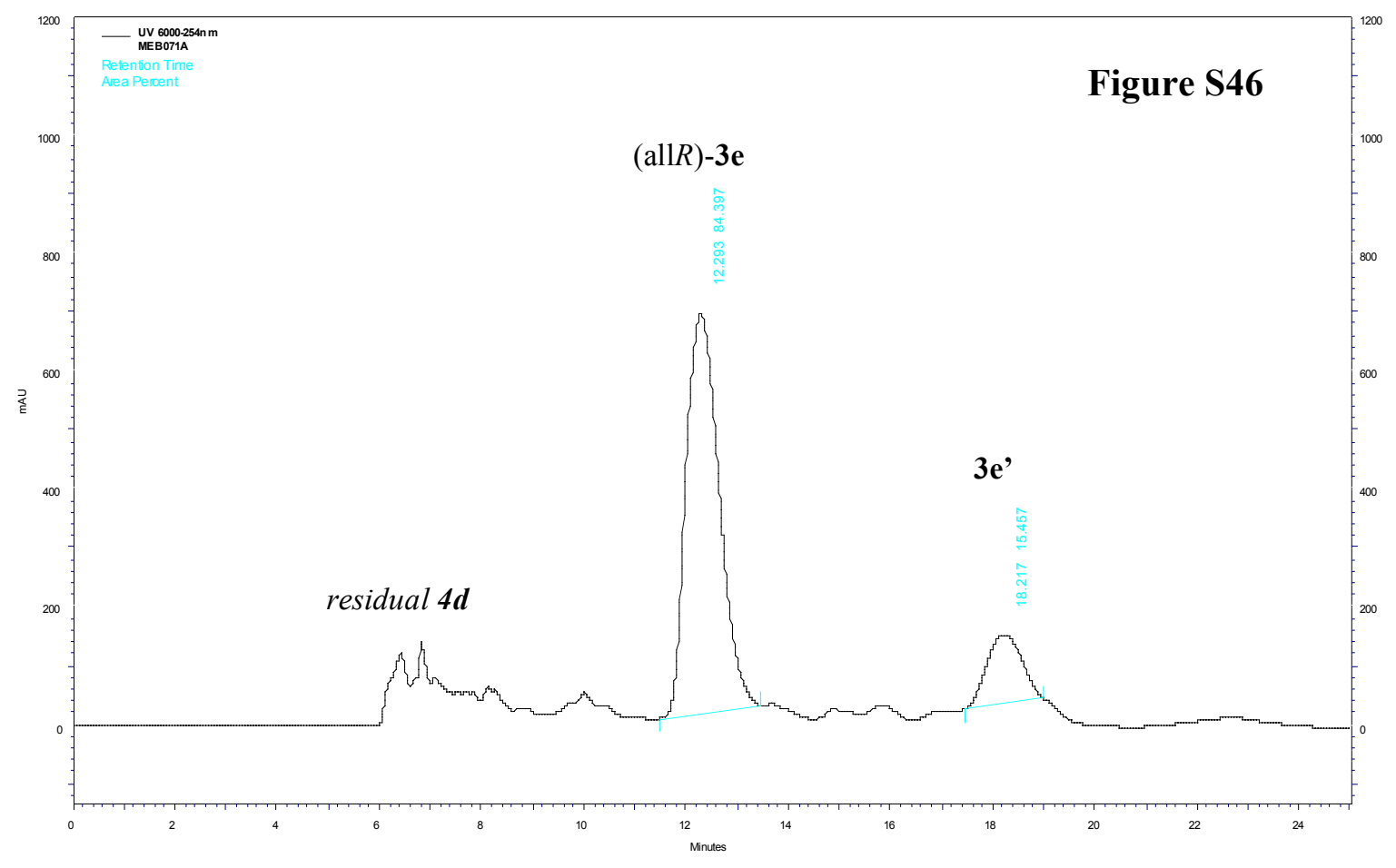

Experiment \#6. The $(S)$-curcuphenol [(S)-1e, $28 \mathrm{mg}, 0.128 \mathrm{mmol})$ was dearomatized in $\mathrm{CH}_{2} \mathrm{Cl}_{2} / \mathrm{TFE}(85: 15)$ at room temperature for 16 hours using the Salen-type bis $\left(\lambda^{5}\right.$-iodane) $(R, R)-8 \mathrm{~d}$ (62 mg, 0.083 mmol, 0.65 equiv) to afford the cyclodimers (all $S)-3 e / 3 e^{\prime \prime}(8 \mathrm{mg}, 28 \%$ ) in $\mathbf{4 1 : 5 9} \mathbf{d r}$ (Figure S47). N.B.: iodane 8d unstable in solution (vide supra).

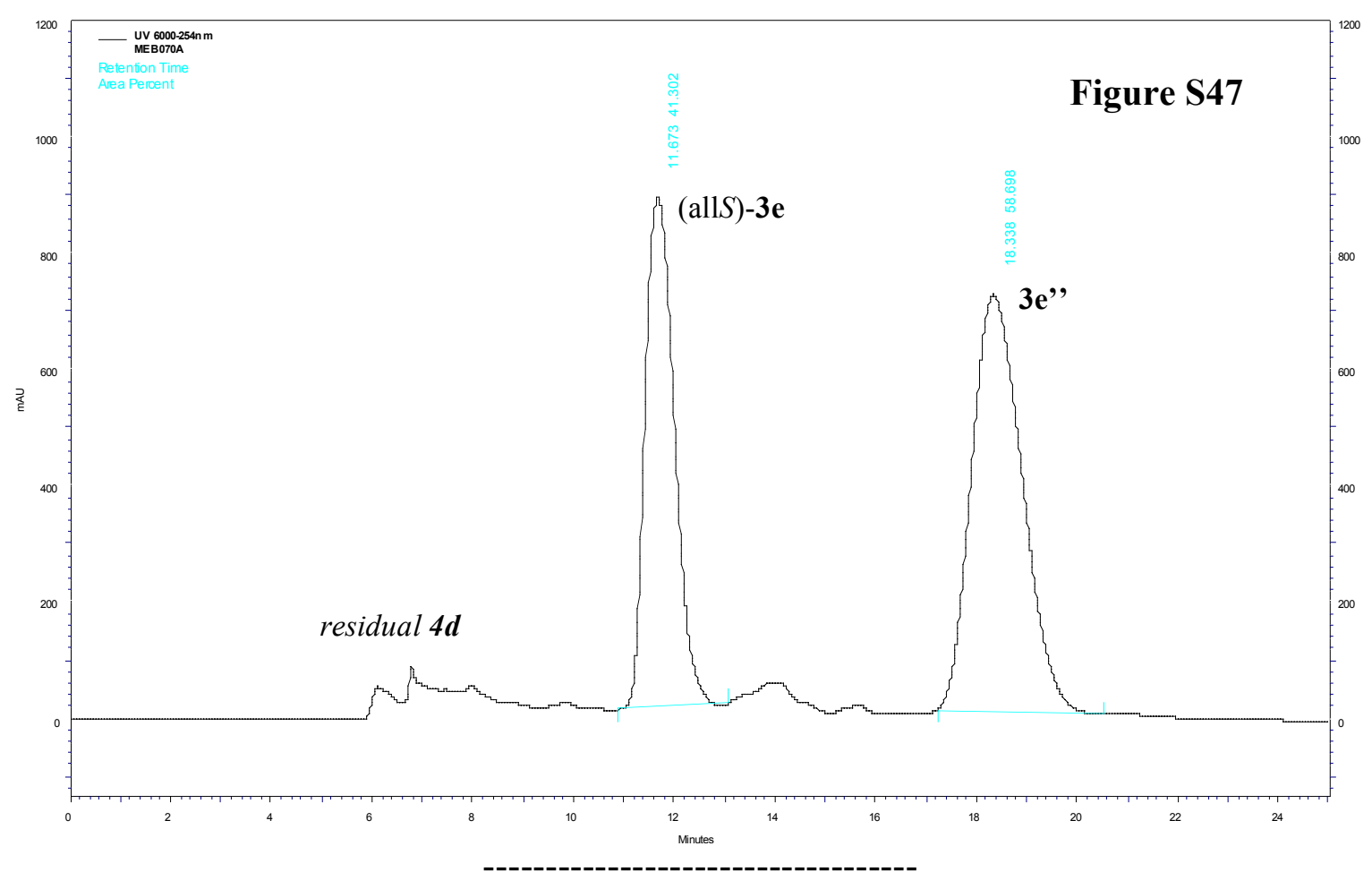


Experiment \#7. The $(R)$-curcuphenol $[(R)-1 \mathrm{e}, 27 \mathrm{mg}, 0.124 \mathrm{mmol})$ was dearomatized in $\mathrm{CH}_{2} \mathrm{Cl}_{2} / \mathrm{TFE}(85: 15)$ at room temperature for 24 hours using the Salen-type bis $\left(\lambda^{5}\right.$-iodane) $(R, R)$-8d (59 mg, $0.080 \mathrm{mmol}, 0.65$ equiv) to afford the cyclodimers (all $R)-\mathbf{3 e} / \mathbf{3 e}$ ' $(11.9 \mathrm{mg}, 41 \%)$ in $\mathbf{6 5 : 3 5}$ $\boldsymbol{d r}$ (Figure S48). N.B.: iodane 8d unstable in solution (vide supra).

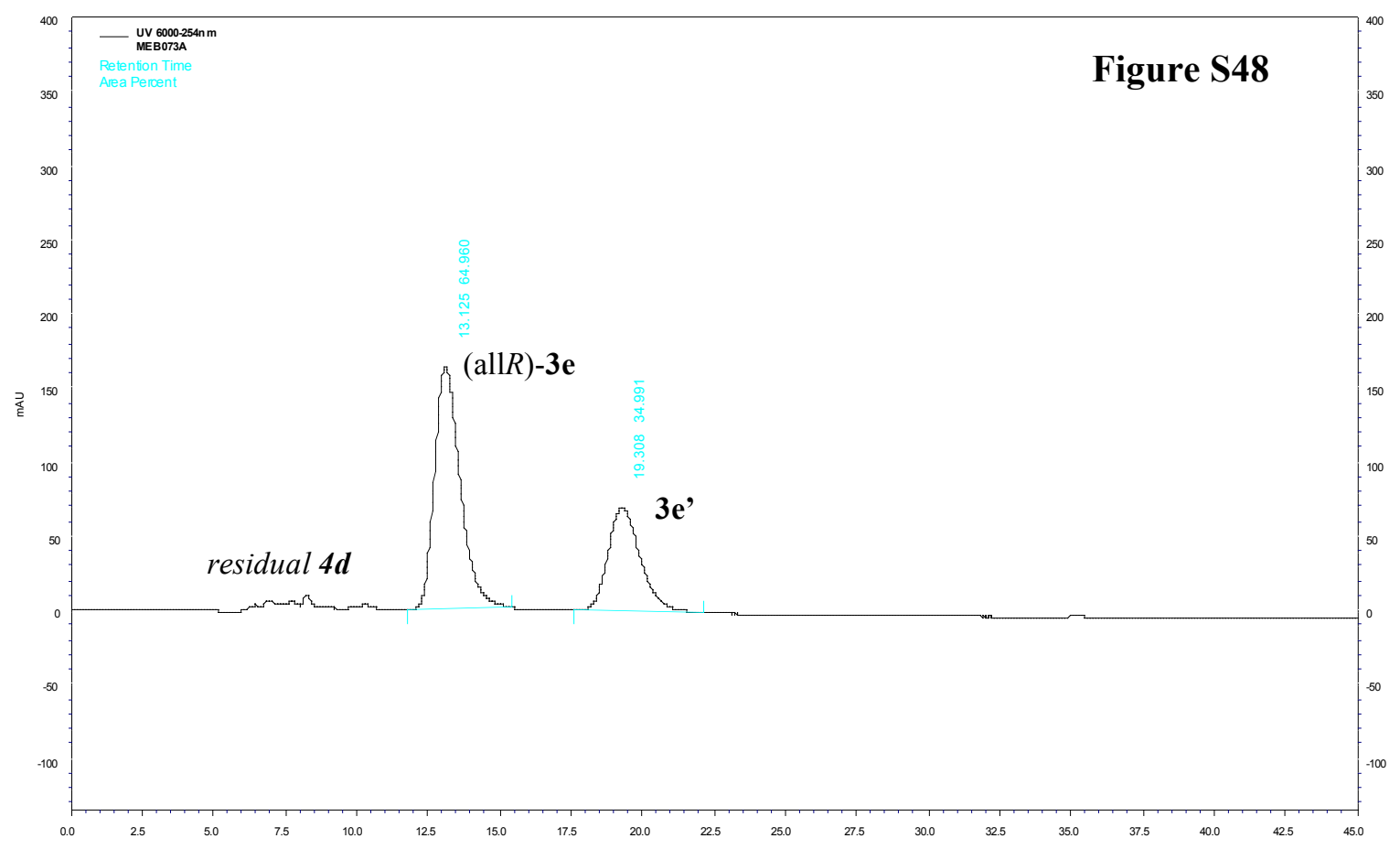

Experiment \#8. The $(R)$-curcuphenol $[(R)-1 \mathrm{e}, 23 \mathrm{mg}, 0.105 \mathrm{mmol})$ was dearomatized in $\mathrm{CH}_{2} \mathrm{Cl}_{2} / \mathrm{TFE}(85: 15)$ at room temperature for 72 hours using the Salen-type bis $\left(\lambda^{5}\right.$-iodane) $(R, R)-8 \mathrm{~d}$ (50 mg, $0.068 \mathrm{mmol}, 0.65$ equiv) to afford the cyclodimers (all $R)-3 \mathbf{e} / \mathbf{3 e}$ ' $(12 \mathrm{mg}, 50 \%)$ in $\mathbf{6 3 : 3 7} \mathbf{d r}$ (Figure S49). N.B.: iodane 8d unstable in solution (vide supra).

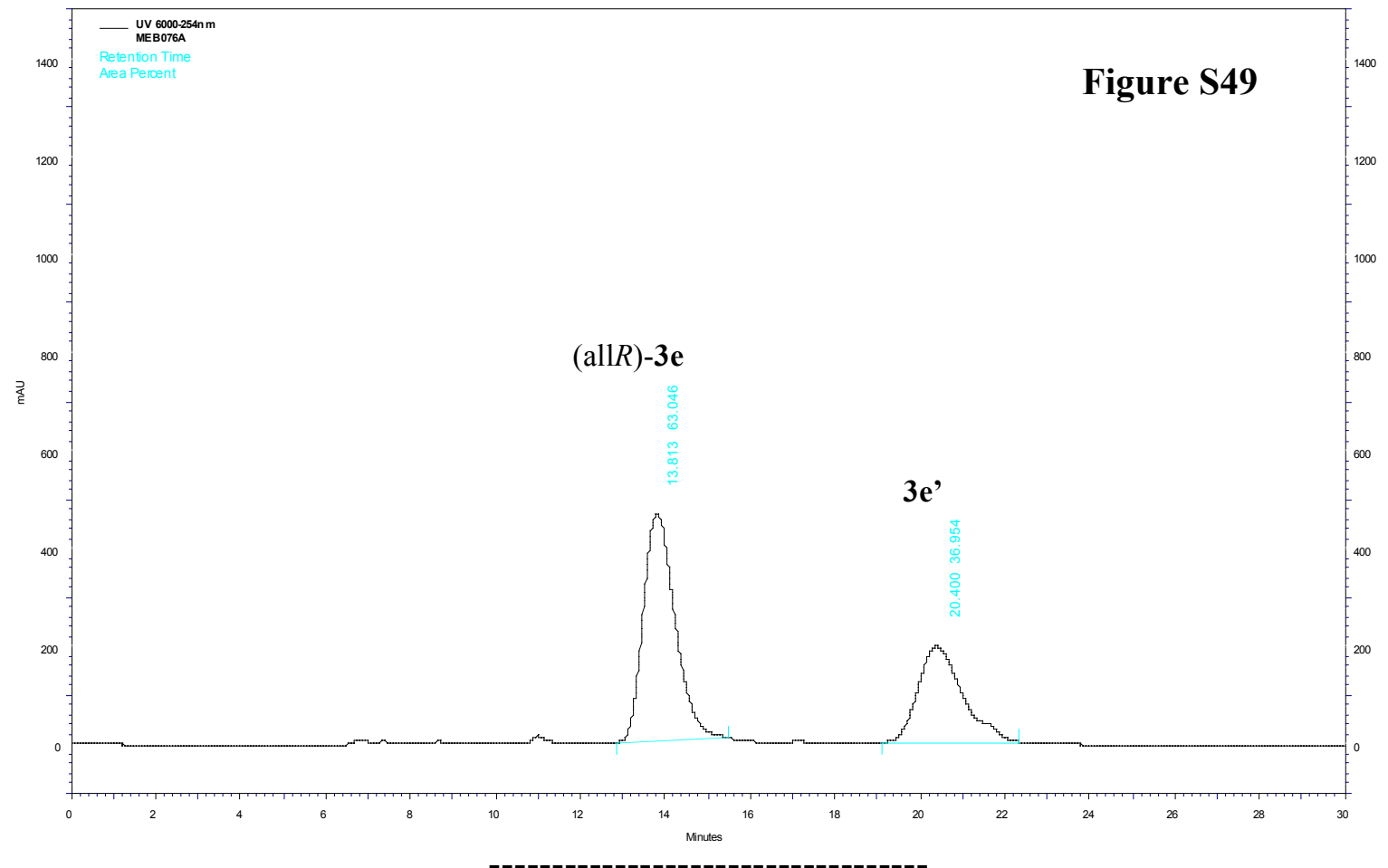


Experiment \#9. The $(R)$-curcuphenol $[(R)-1 \mathrm{e}, 24 \mathrm{mg}, 0.110 \mathrm{mmol})$ was dearomatized in $\mathrm{CH}_{2} \mathrm{Cl}_{2} / \mathrm{TFE}(85: 15)$ at $-35{ }^{\circ} \mathrm{C}$ for 72 hours using the Salen-type bis $\left(\lambda^{5}\right.$-iodane) $(R, R)-8 \mathbf{d}(53 \mathrm{mg}$, $0.072 \mathrm{mmol}, 0.65$ equiv) to afford the cyclodimers (allR)-3e / 3e' $(10 \mathrm{mg}, 40 \%)$ in $\mathbf{6 7 : 3 3} \boldsymbol{d r}$ (Figure S50). N.B.: iodane 8d unstable in solution (vide supra).

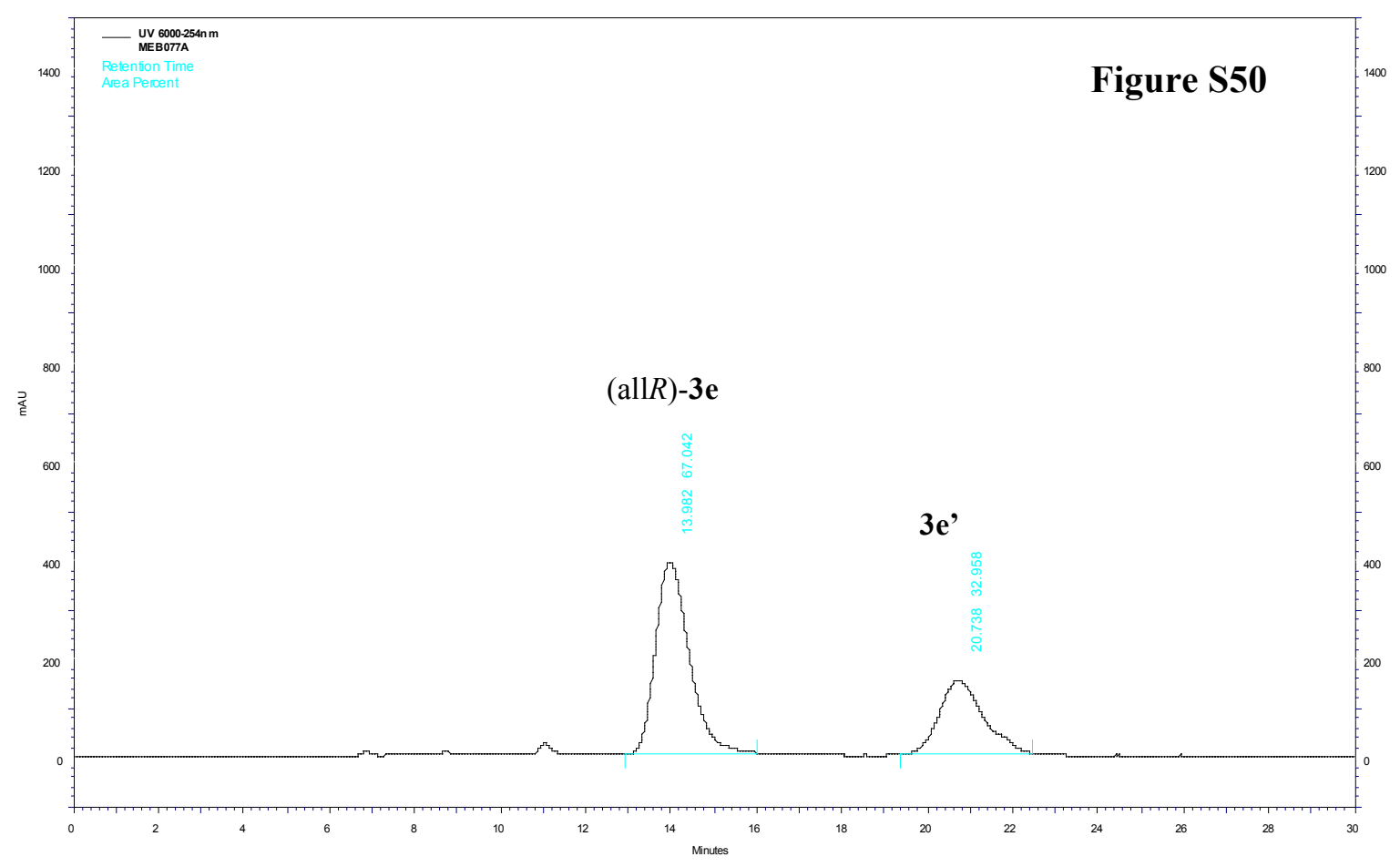

Experiment \#10 (see the main text: Table 1, entry 3). The $(R)$-curcuphenol $[(R)-1 \mathrm{e}, 27 \mathrm{mg}, 0.124$ mmol) was dearomatized in $\mathrm{CH}_{2} \mathrm{Cl}_{2} / \mathrm{TFE}(85: 15)$ at $-35^{\circ} \mathrm{C}$ for 72 hours using the Salen-type $\operatorname{bis}\left(\lambda^{5}\right.$-iodane) $(R, R)-\mathbf{8 a}(51 \mathrm{mg}, 0.080 \mathrm{mmol}, 0.65$ equiv) to afford the cyclodimers (all $R)-\mathbf{3 e} / \mathbf{3 e}$ ' (12.5 mg, 43\%) in 78:22 $\boldsymbol{d r}$ (Figure S51).

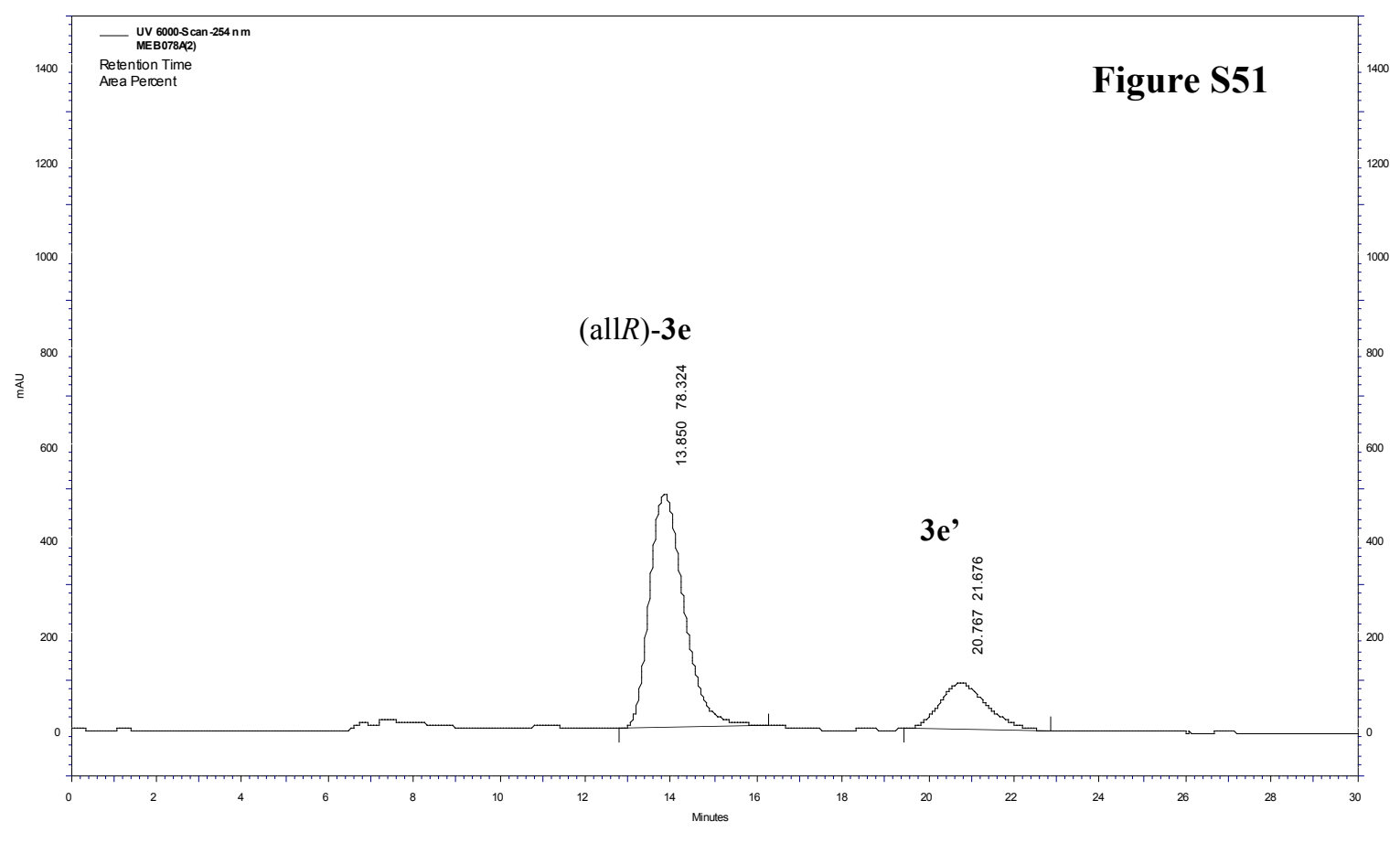


Experiment \#11 (see the main text: Table 1, entry 4). The $(R)$-curcuphenol $[(R)-1 e, 22 \mathrm{mg}, 0.101$ mmol) was dearomatized in $\mathrm{CH}_{2} \mathrm{Cl}_{2} / \mathrm{TFE}(85: 15)$ at $-35^{\circ} \mathrm{C}$ for 72 hours using the Salen-type $\operatorname{bis}\left(\lambda^{5}\right.$-iodane) $(R, R)-\mathbf{8 a}(71 \mathrm{mg}, 0.111 \mathrm{mmol}, 1.10$ equiv) to afford the cyclodimers (all $R)-\mathbf{3 e} / \mathbf{3 e}$ ' (11.8 mg, 50\%) in 79:21 $\boldsymbol{d r}$ (Figure S52).

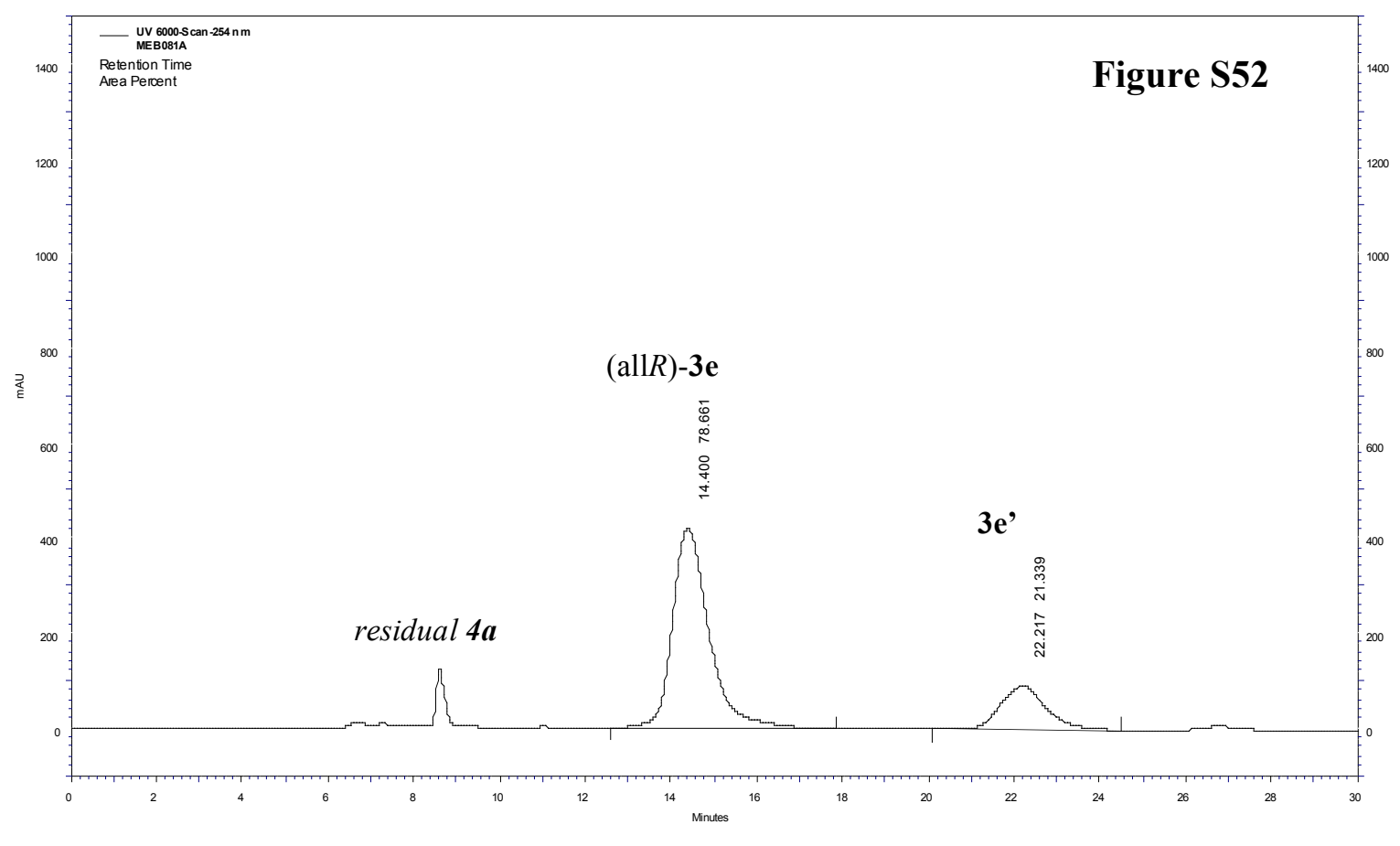

Experiment \#12. The $(R)$-curcuphenol [(R)-1e, $20 \mathrm{mg}, 0.092 \mathrm{mmol})$ was dearomatized in $\mathrm{CH}_{2} \mathrm{Cl}_{2} / \mathrm{TFE}(85: 15)$ at $0{ }^{\circ} \mathrm{C}$ for 48 hours using the Salen-type bis $\left(\lambda^{5}\right.$-iodane) $(R, R)-8 \mathrm{a}(64 \mathrm{mg}$, $0.101 \mathrm{mmol}, 1.10$ equiv) to afford the cyclodimers (all $R)-3 \mathbf{e} / \mathbf{3 e}$ ' $(13.3 \mathrm{mg}, 62 \%)$ in $\mathbf{7 6 : 2 4} \mathbf{d r}$ (Figure S53).

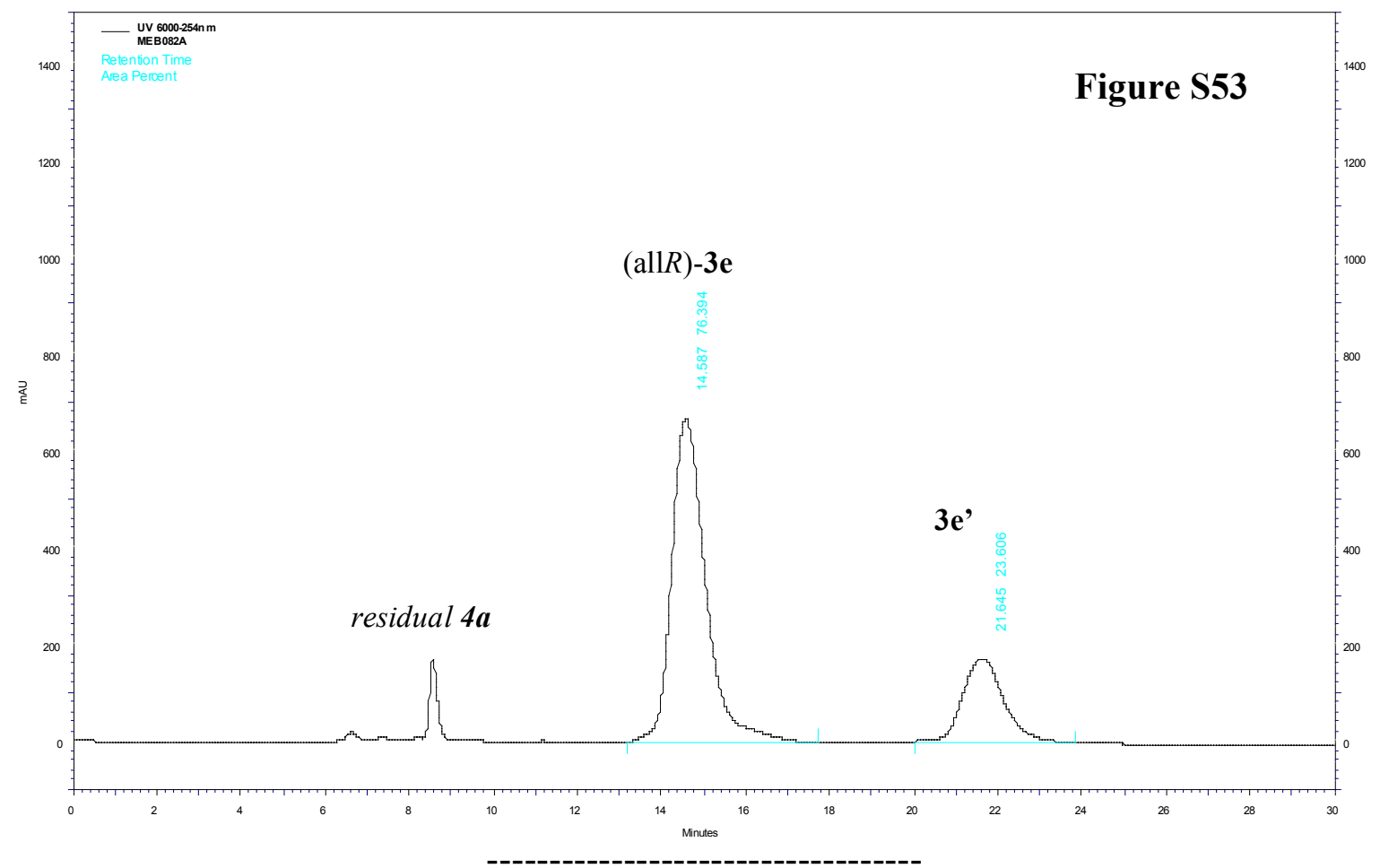


Experiment \#13 (see the main text: Table 1, entry 5). The $(S)$-curcuphenol $[(S)-1 \mathrm{e}, 22 \mathrm{mg}, 0.101$ mmol) was dearomatized in $\mathrm{CH}_{2} \mathrm{Cl}_{2} / \mathrm{TFE}(85: 15)$ at $-35^{\circ} \mathrm{C}$ for 72 hours using the Salen-type bis( $\lambda^{5}$-iodane) $(S, S)-8 \mathbf{a}(71 \mathrm{mg}, 0.111 \mathrm{mmol}, 1.10$ equiv) to afford the cyclodimers (all $S)-\mathbf{3 e} / \mathbf{3 e}$ ", (10 mg, 42\%) in 80:20 $\boldsymbol{d r}$ (Figure S54).

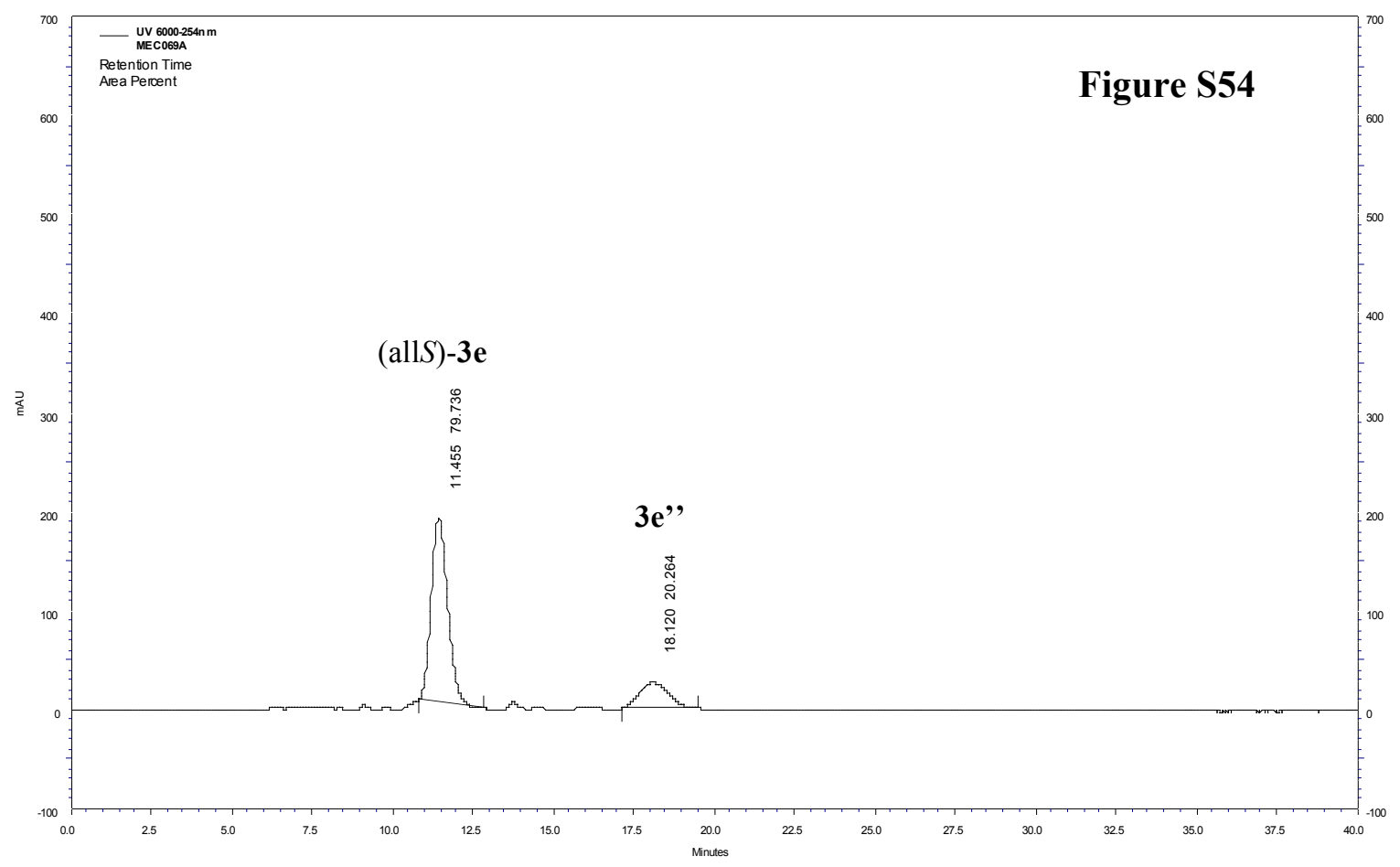

Experiment \#14 (see the main text: Table 1, entry 6). The $(R)$-curcuphenol $[(R)-1 \mathbf{e}, 22 \mathrm{mg}, 0.101$ mmol) was dearomatized in $\mathrm{CH}_{2} \mathrm{Cl}_{2}$ at $-45{ }^{\circ} \mathrm{C}$ for 2 hours, in the presence of TFA $(7.7 \mu \mathrm{L}, 1.0$ equiv), using the Salen-type bis $\left(\lambda^{5}\right.$-iodane) $(R, R)$-8a $(71 \mathrm{mg}, 0.111 \mathrm{mmol}, 1.10$ equiv) to afford the cyclodimers (all $R$ )-3e / 3e' (14 mg, 58\%) in 88:12 $d r$ (Figure S55).

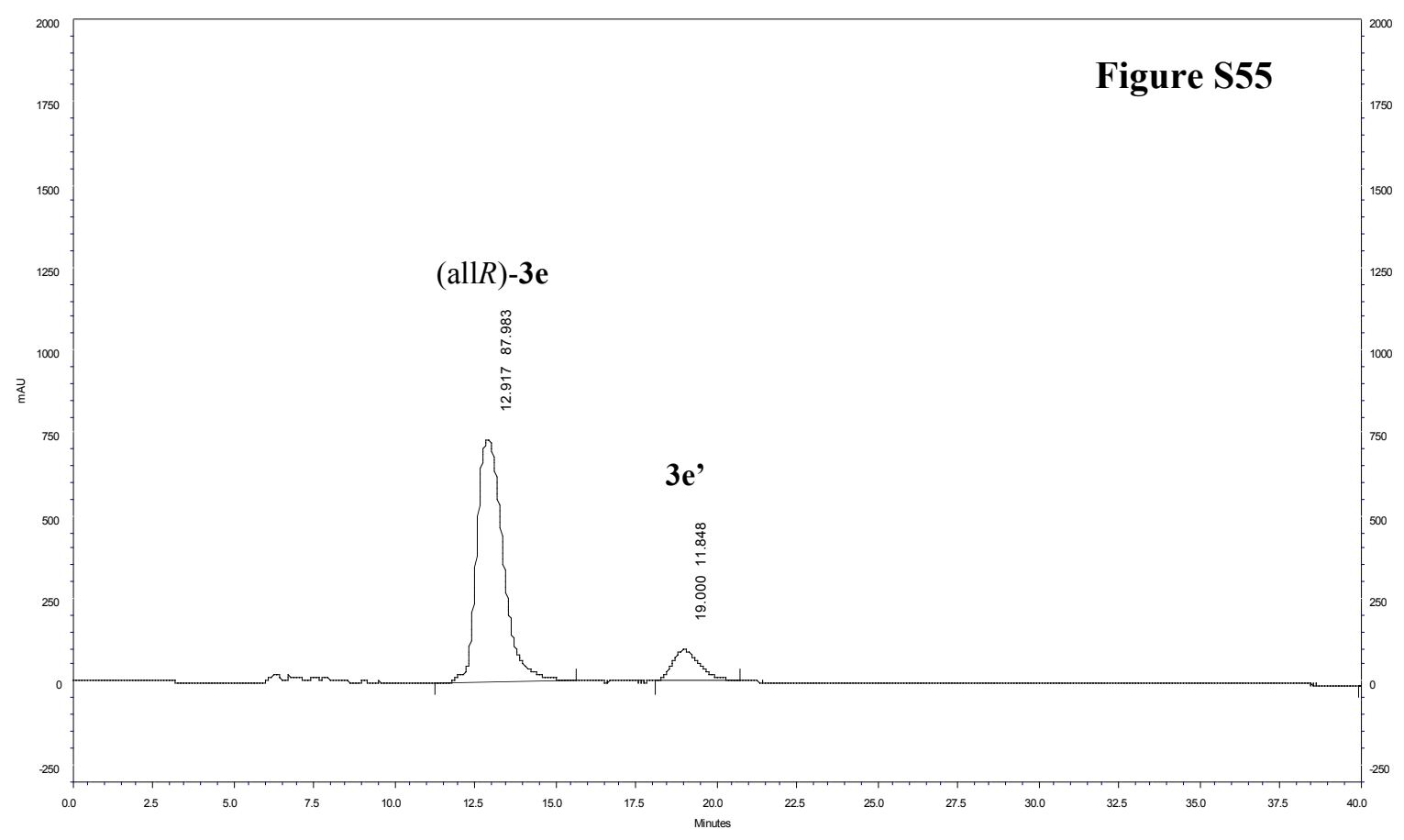


Experiment \#15 (see the main text: Table 1, entry 7). The $(S)$-curcuphenol $[(S)$-1e, $26 \mathrm{mg}, 0.119$ mmol) was dearomatized in $\mathrm{CH}_{2} \mathrm{Cl}_{2}$ at $-45{ }^{\circ} \mathrm{C}$ for 2 hours, in the presence of TFA (9.1 $\mu \mathrm{L}, 1.0$ equiv), using the Salen-type bis $\left(\lambda^{5}\right.$-iodane) $(S, S)-8 \mathbf{a}(84 \mathrm{mg}, 0.131 \mathrm{mmol}, 1.10$ equiv) to afford the cyclodimers (allS)-3e / 3e"' (19 mg, 68\%) in 91:9 dr (Figure S56).

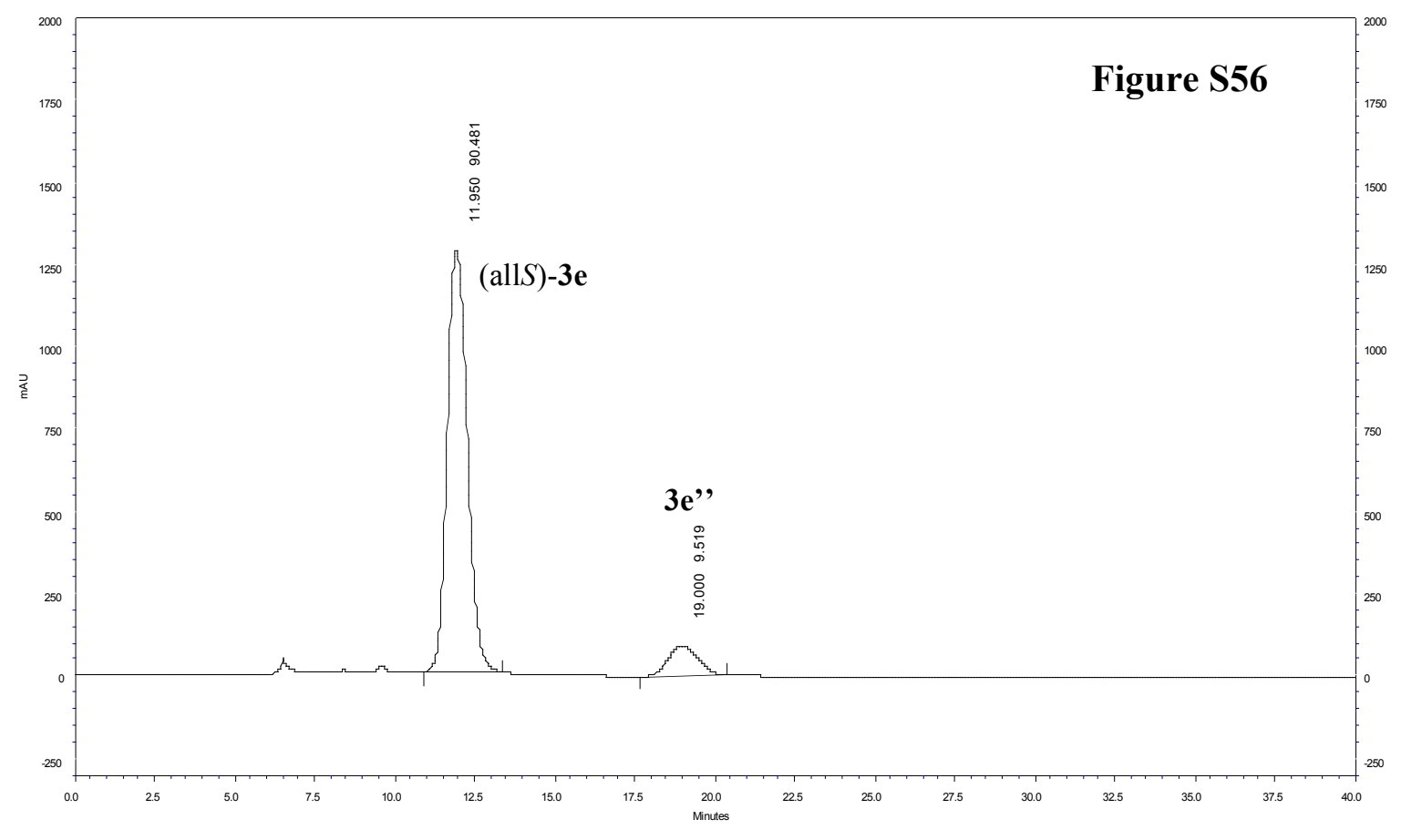

Experiment \#16 (see the main text: Table 1, entry 8). The $(S)$-curcuphenol $[(S)-1 \mathrm{e}, 19 \mathrm{mg}, 0.087$ mmol) was dearomatized in $\mathrm{CH}_{2} \mathrm{Cl}_{2}$ at $-50{ }^{\circ} \mathrm{C}$ for 1.5 hour, in the presence of TFA (6.7 $\mu \mathrm{L}, 1.0$ equiv), using the Salen-type bis $\left(\lambda^{5}\right.$-iodane) $(S, S)$-8a (61 mg, $0.096 \mathrm{mmol}, 1.10$ equiv) to afford the cyclodimers (allS)-3e / 3e', (6.3 mg, 31\%) in 86:14 $\boldsymbol{d r}$ (Figure S57).

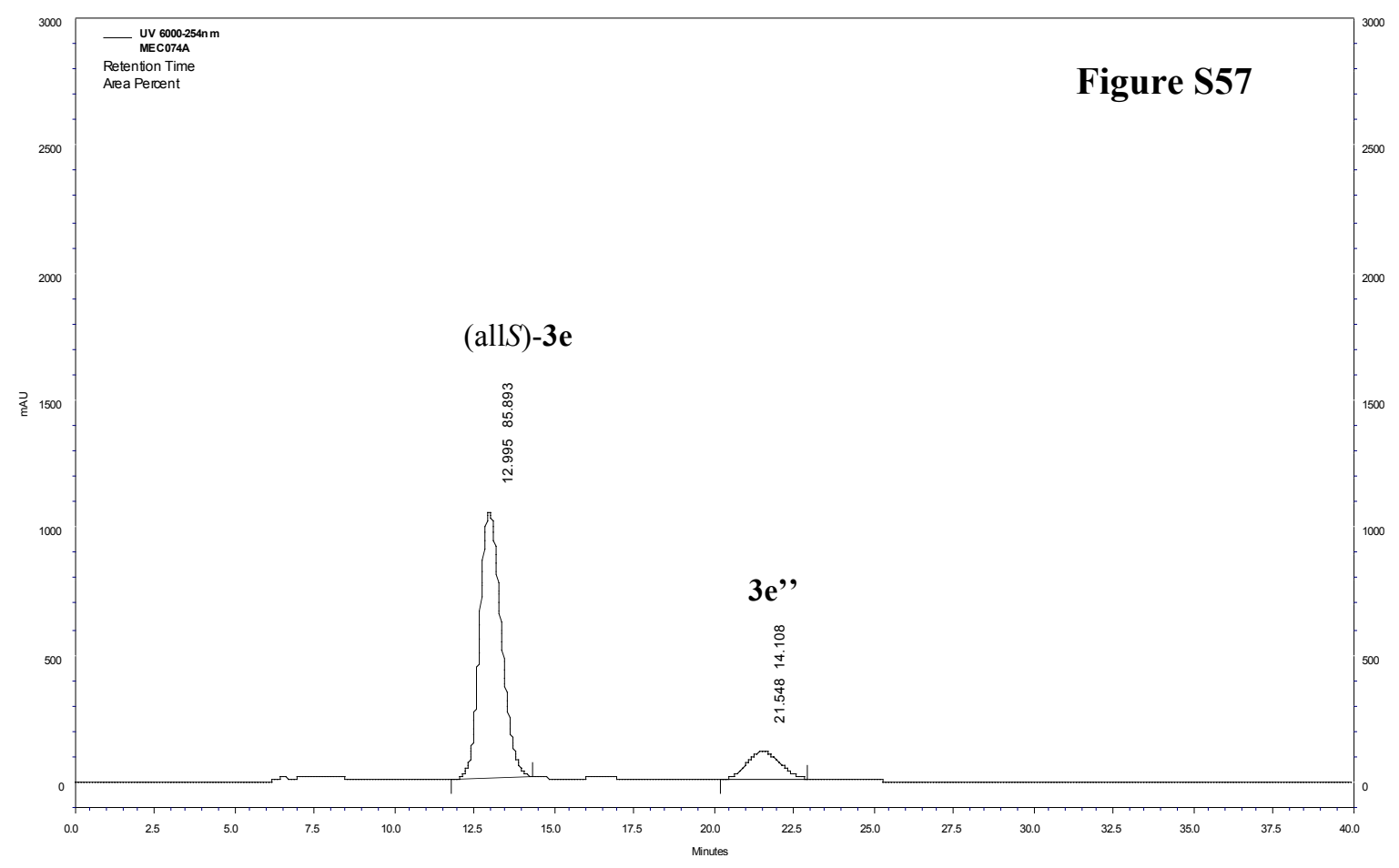


NMR Spectra

$\mathrm{CDCl}_{3}, 300 \mathrm{MHz}$

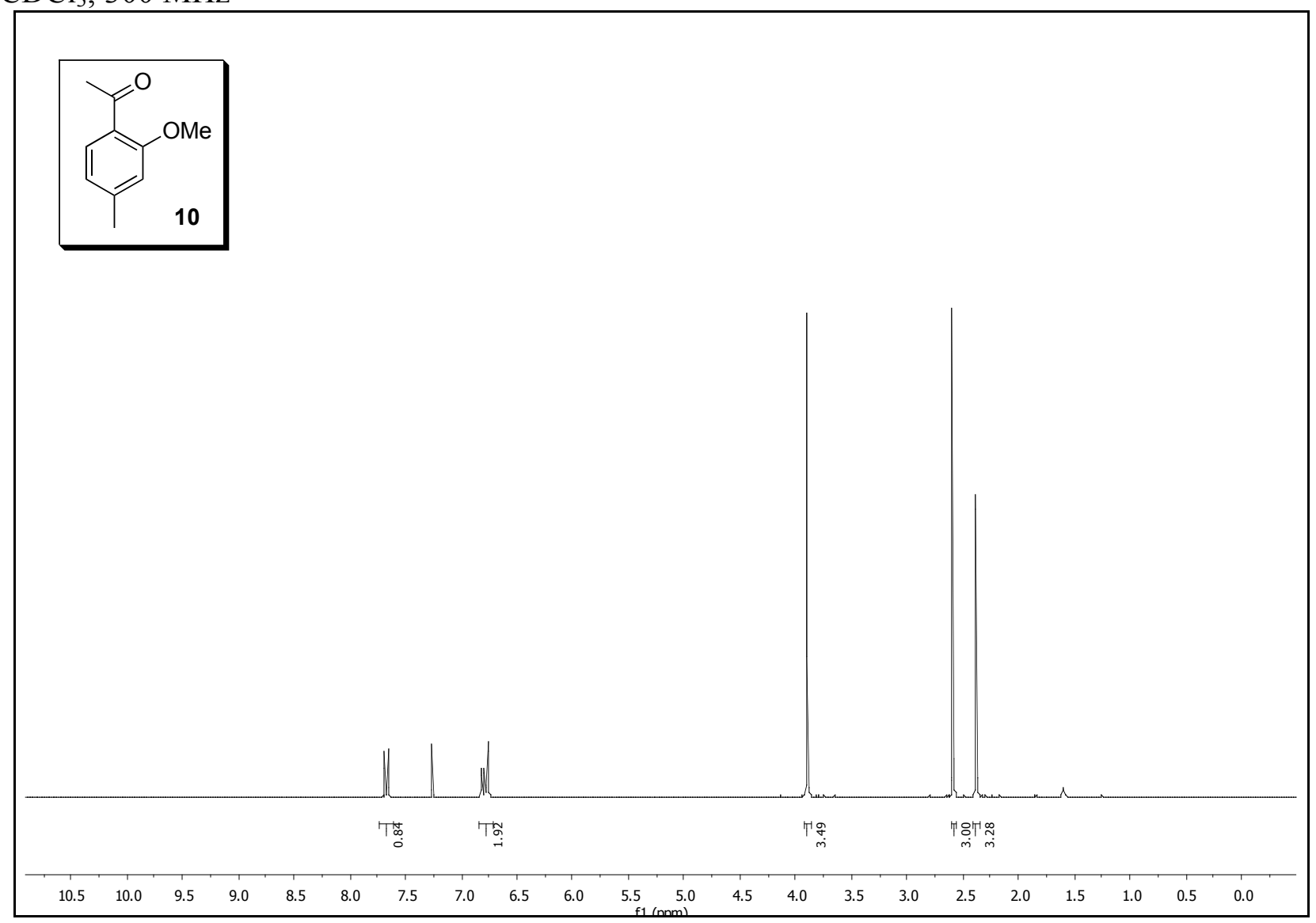

\begin{tabular}{|c|c|c|c|}
\hline Peak & ppm & $\mathrm{Hz}$ & Intensity \\
\hline 1 & 6.77 & 54393553.7 & 3.22 \\
\hline 2 & 7.69 & 45219258.9 & 1.35 \\
\hline 3 & 7.66 & 48468495.2 & 1.35 \\
\hline 4 & 6.82 & 28472349.5 & 0.90 \\
\hline 5 & 7.26 & 51768213.3 & 0.89 \\
\hline 6 & 6.79 & 28012185.0 & 0.94 \\
\hline 7 & 3.90 & 476785584.5 & 1.08 \\
\hline 8 & 2.59 & 479665396.1 & 0.91 \\
\hline 9 & 2.38 & 296781697.7 & 1.78 \\
\hline
\end{tabular}


$\mathrm{CDCl}_{3}, 75 \mathrm{MHz}$
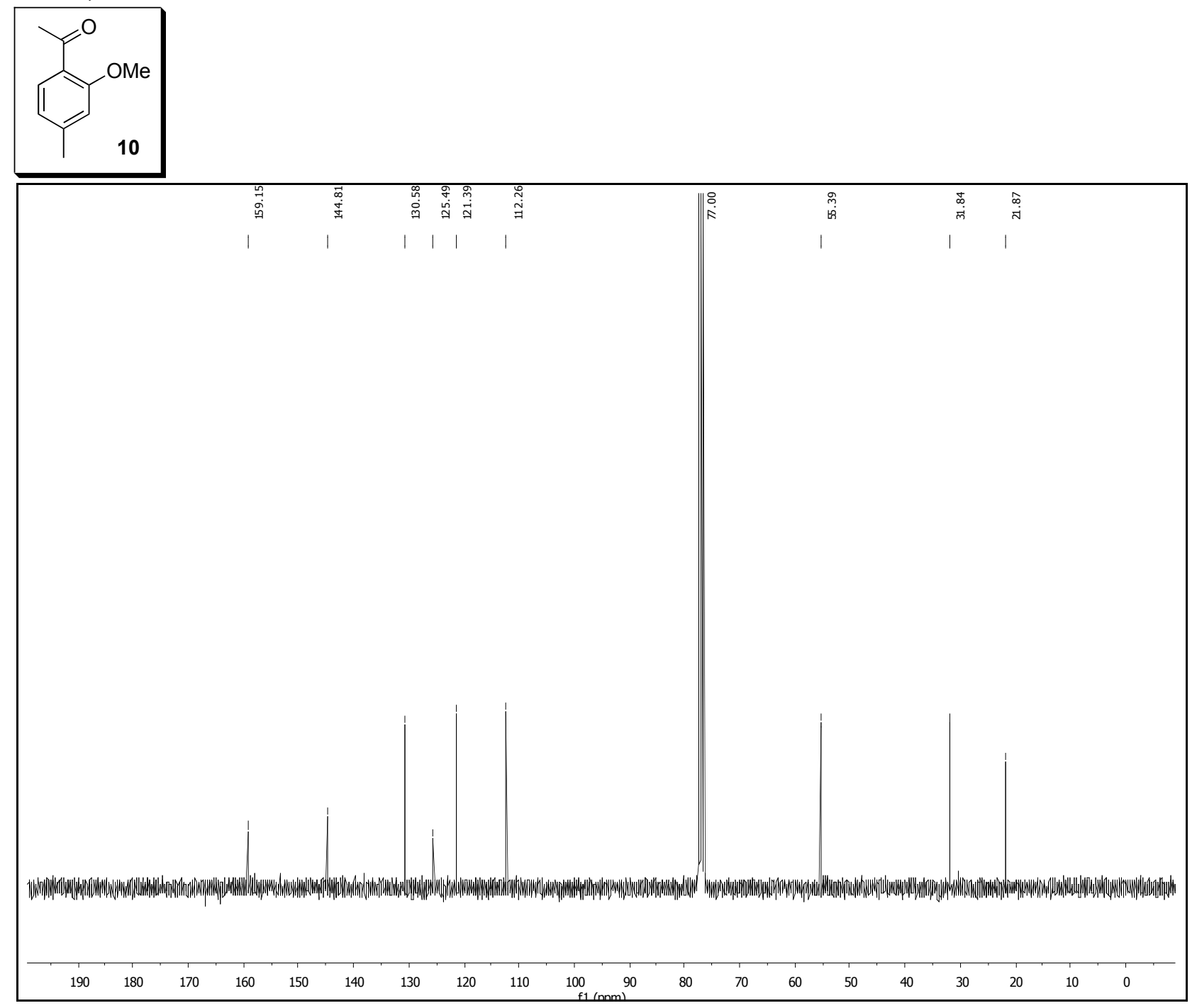
$\mathrm{CDCl}_{3}, 300 \mathrm{MHz}$

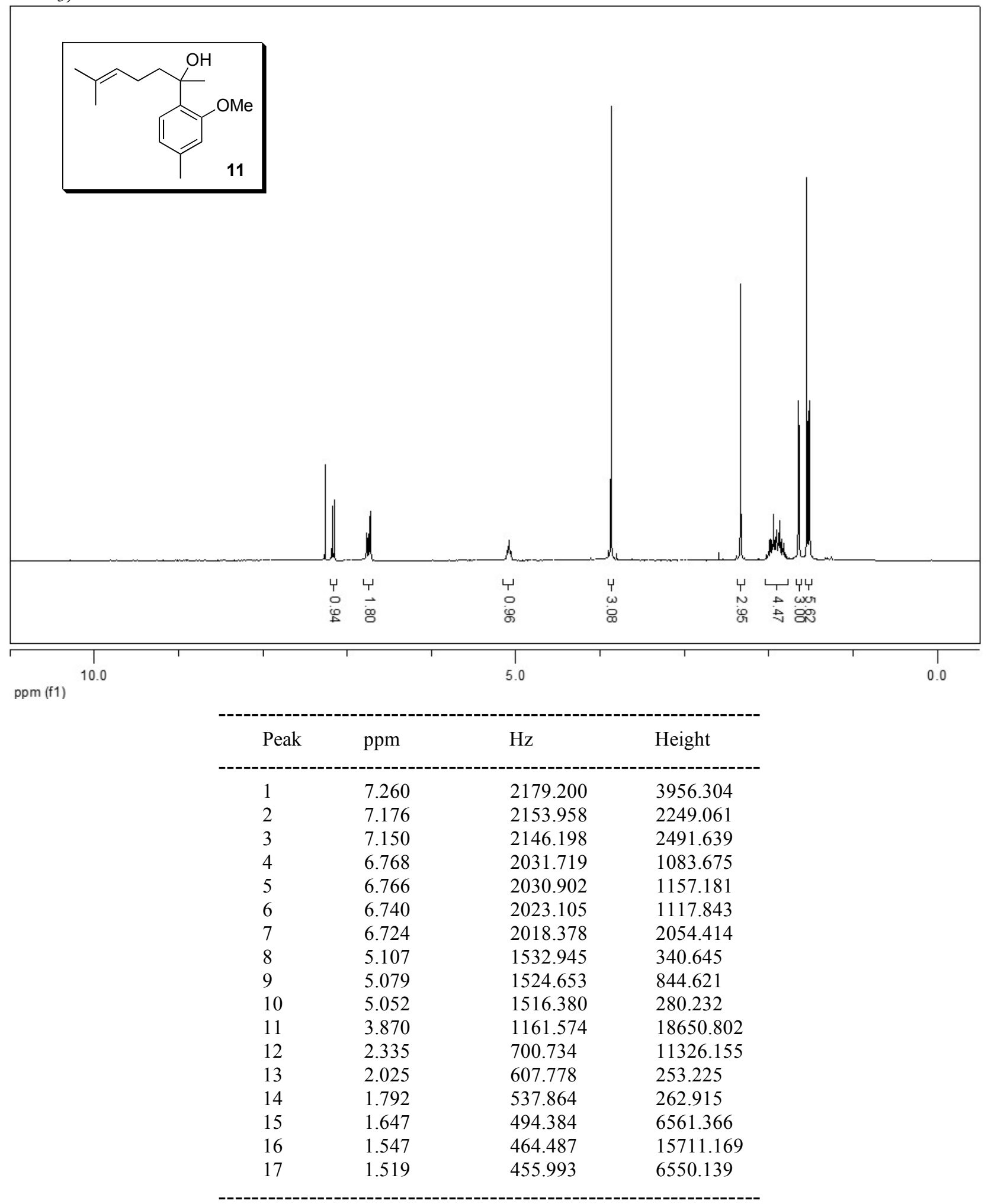


$\mathrm{CDCl}_{3}, 75 \mathrm{MHz}$
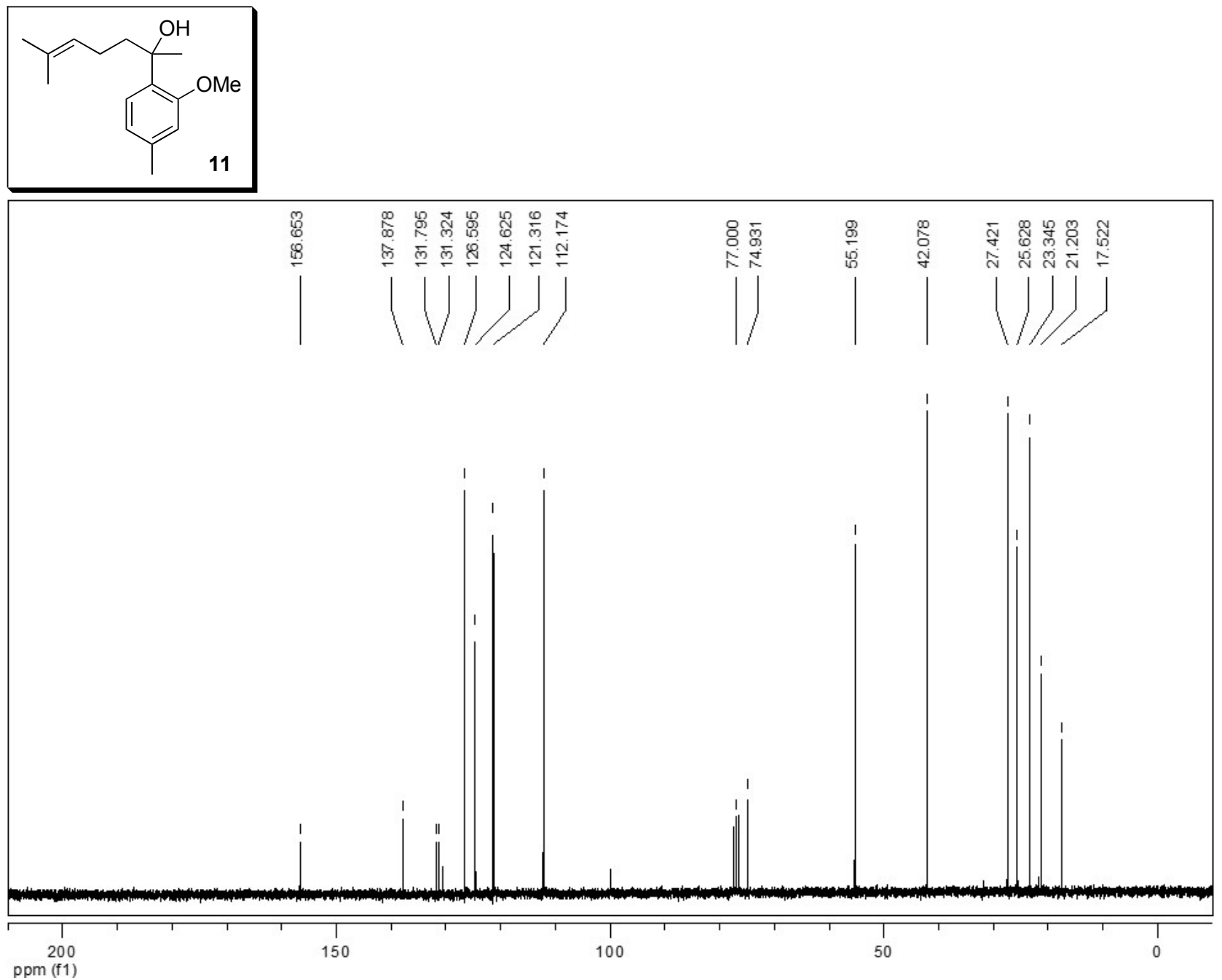


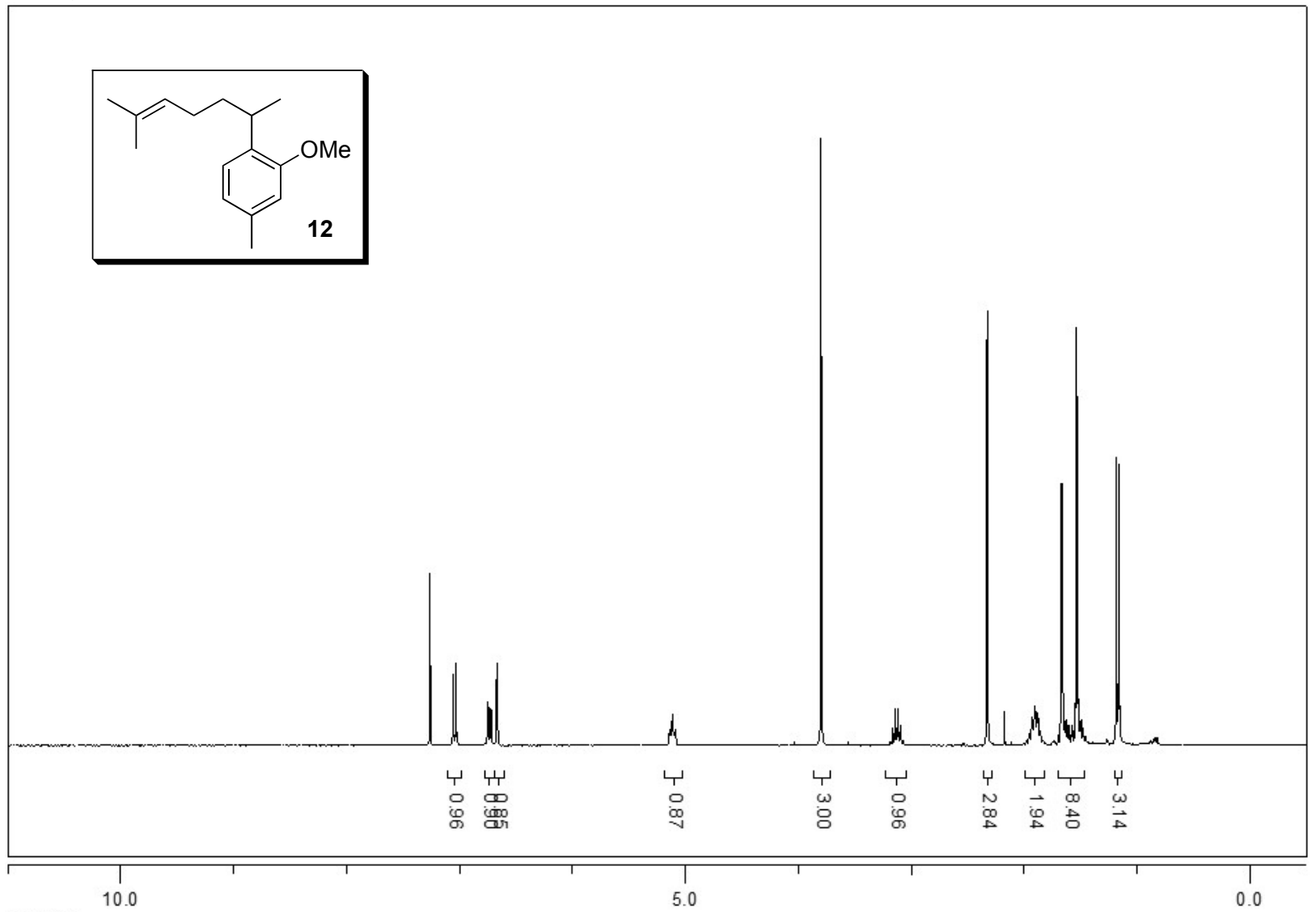

ppm (f1)

\begin{tabular}{llll} 
Peak & ppm & Hz & Height \\
\hline 1 & 7.260 & 2179.196 & 2081.285 \\
2 & 7.059 & 2118.846 & 1566.744 \\
3 & 7.033 & 2111.186 & 1787.810 \\
4 & 6.749 & 2025.914 & 906.494 \\
5 & 6.723 & 2018.220 & 755.727 \\
6 & 6.670 & 2002.216 & 1674.020 \\
7 & 5.145 & 1544.330 & 291.952 \\
8 & 5.140 & 1543.040 & 361.233 \\
9 & 5.136 & 1541.705 & 306.982 \\
10 & 5.131 & 1540.162 & 237.331 \\
11 & 5.121 & 1537.283 & 564.136 \\
12 & 5.117 & 1535.955 & 686.821 \\
13 & 5.112 & 1534.617 & 546.303 \\
14 & 5.103 & 1531.664 & 225.811 \\
15 & 5.098 & 1530.179 & 303.045 \\
16 & 5.093 & 1528.856 & 349.764 \\
17 & 5.089 & 1527.550 & 268.250 \\
18 & 3.800 & 1140.604 & 14739.696 \\
19 & 3.189 & 957.230 & 89.734 \\
20 & 3.166 & 950.214 & 397.314 \\
21 & 3.142 & 943.151 & 780.825 \\
22 & 3.119 & 936.076 & 799.757 \\
23 & 3.095 & 929.031 & 421.040 \\
24 & 3.072 & 921.996 & 95.006 \\
25 & 2.329 & 699.116 & 9325.384 \\
26 & 1.981 & 594.498 & 118.714 \\
27 & 1.957 & 587.484 & 276.255 \\
28 & 1.933 & 580.160 & 644.715 \\
29 & 1.907 & 572.360 & 873.012 \\
& & &
\end{tabular}




\begin{tabular}{rrrl}
30 & 1.883 & 565.125 & 717.963 \\
31 & 1.860 & 558.418 & 332.798 \\
32 & 1.835 & 550.923 & 124.934 \\
33 & 1.702 & 510.924 & 318.031 \\
34 & 1.670 & 501.330 & 5658.997 \\
35 & 1.646 & 494.115 & 355.434 \\
36 & 1.638 & 491.668 & 555.523 \\
37 & 1.633 & 490.299 & 591.018 \\
38 & 1.627 & 488.444 & 579.601 \\
39 & 1.613 & 484.154 & 490.448 \\
40 & 1.607 & 482.329 & 476.232 \\
41 & 1.603 & 481.090 & 504.073 \\
42 & 1.582 & 474.876 & 427.510 \\
43 & 1.574 & 472.444 & 526.175 \\
44 & 1.536 & 461.003 & 5735.631 \\
45 & 1.521 & 456.563 & 955.094 \\
46 & 1.507 & 452.446 & 488.376 \\
47 & 1.498 & 449.759 & 540.457 \\
48 & 1.485 & 445.607 & 256.995 \\
49 & 1.477 & 443.207 & 367.484 \\
50 & 1.454 & 436.415 & 194.818 \\
51 & 1.185 & 355.742 & 6577.545 \\
52 & 1.162 & 348.789 & 6447.217 \\
----------------------------------------------------------- \\
\hline
\end{tabular}

$\mathrm{CDCl}_{3}, 75 \mathrm{MHz}$
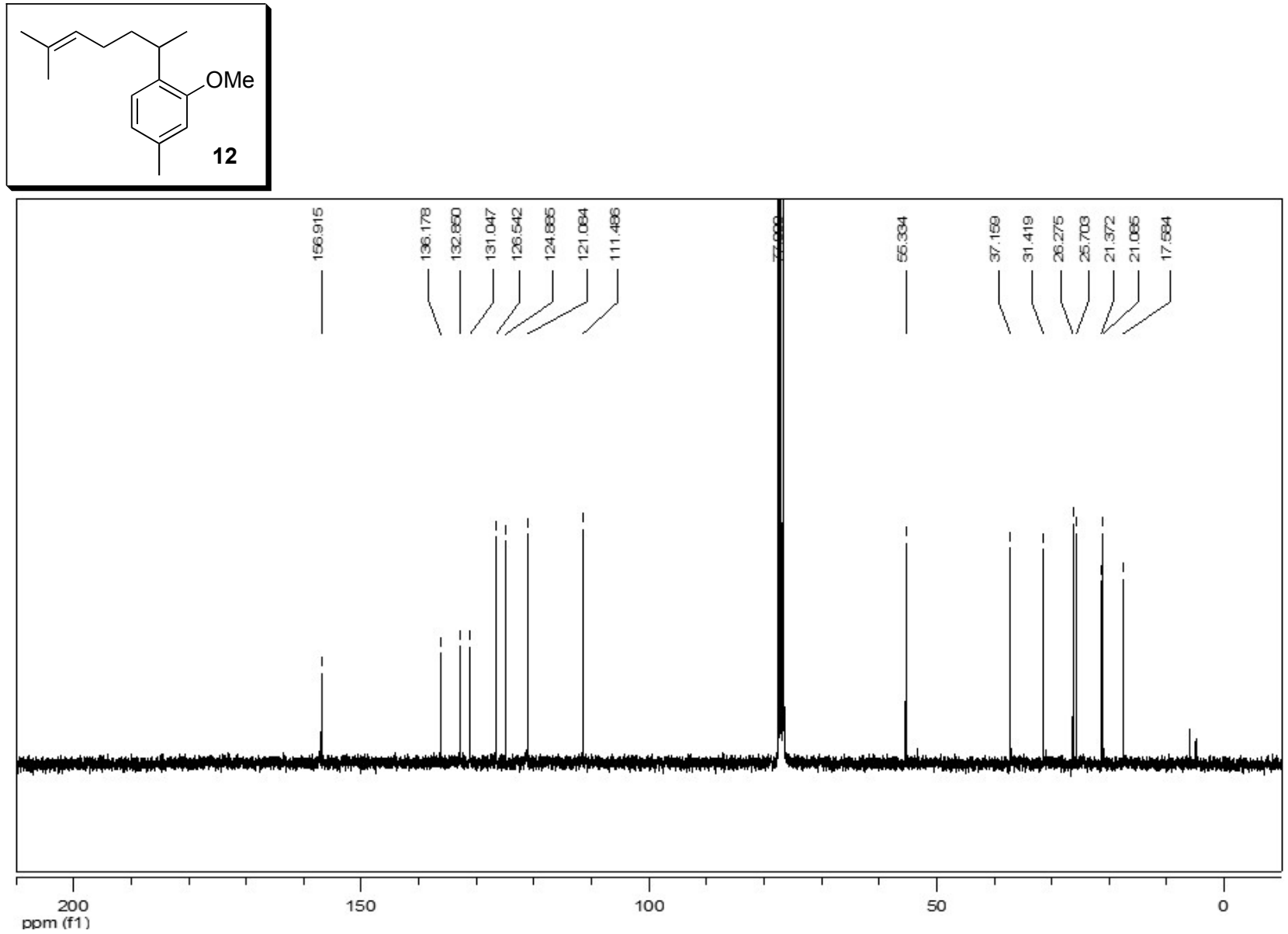


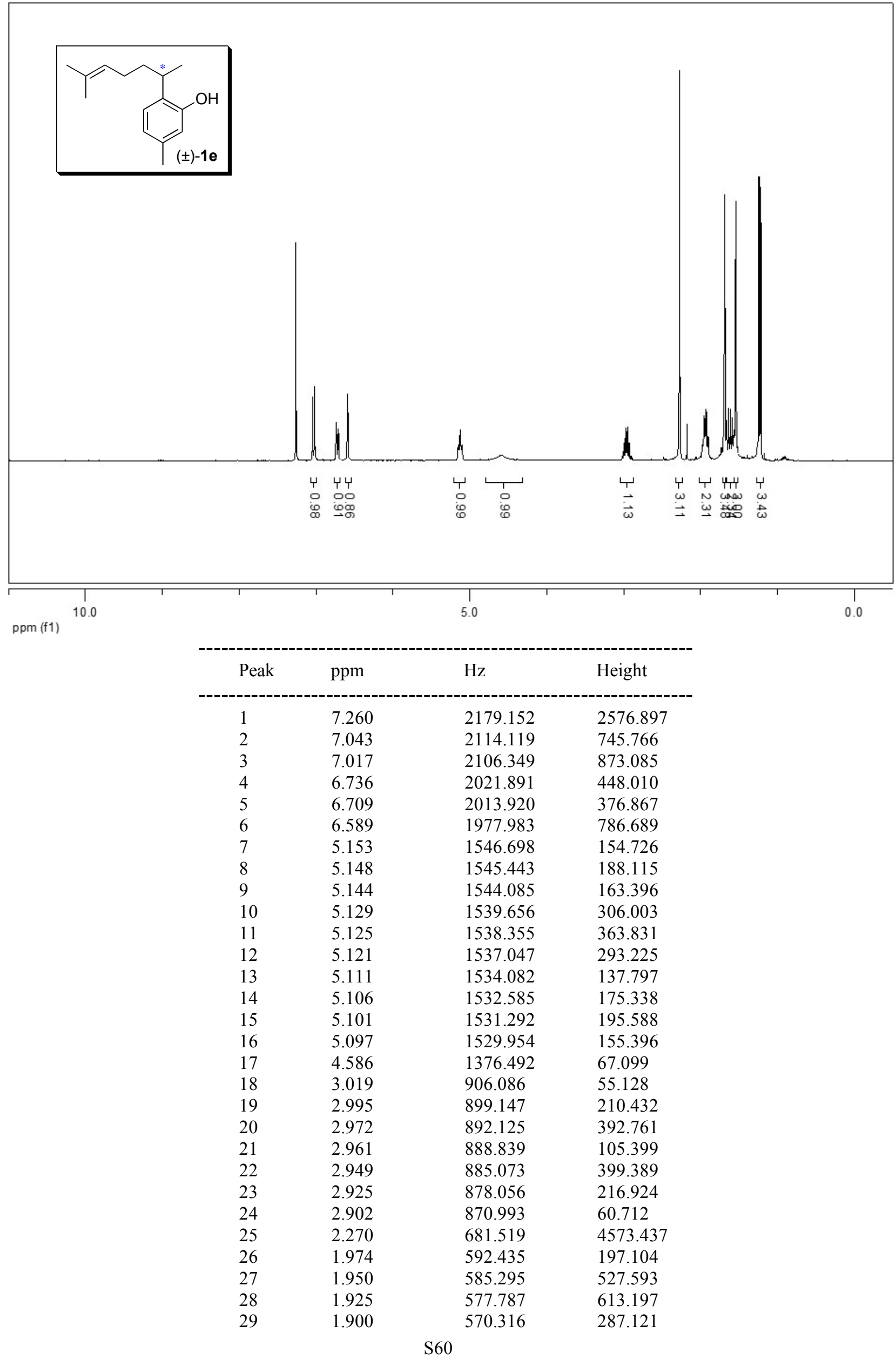




$\begin{array}{llll}30 & 1.684 & 505.437 & 3117.685 \\ 31 & 1.661 & 498.660 & 404.587 \\ 32 & 1.657 & 497.348 & 481.859 \\ 33 & 1.636 & 490.994 & 621.956 \\ 34 & 1.610 & 483.217 & 606.660 \\ 35 & 1.588 & 476.528 & 511.114 \\ 36 & 1.562 & 468.794 & 364.690 \\ 37 & 1.540 & 462.246 & 3041.035 \\ 38 & 1.238 & 371.440 & 3336.658 \\ 39 & 1.214 & 364.529 & 3219.567\end{array}$

\section{$\mathrm{CDCl}_{3}, 75 \mathrm{MHz}$}
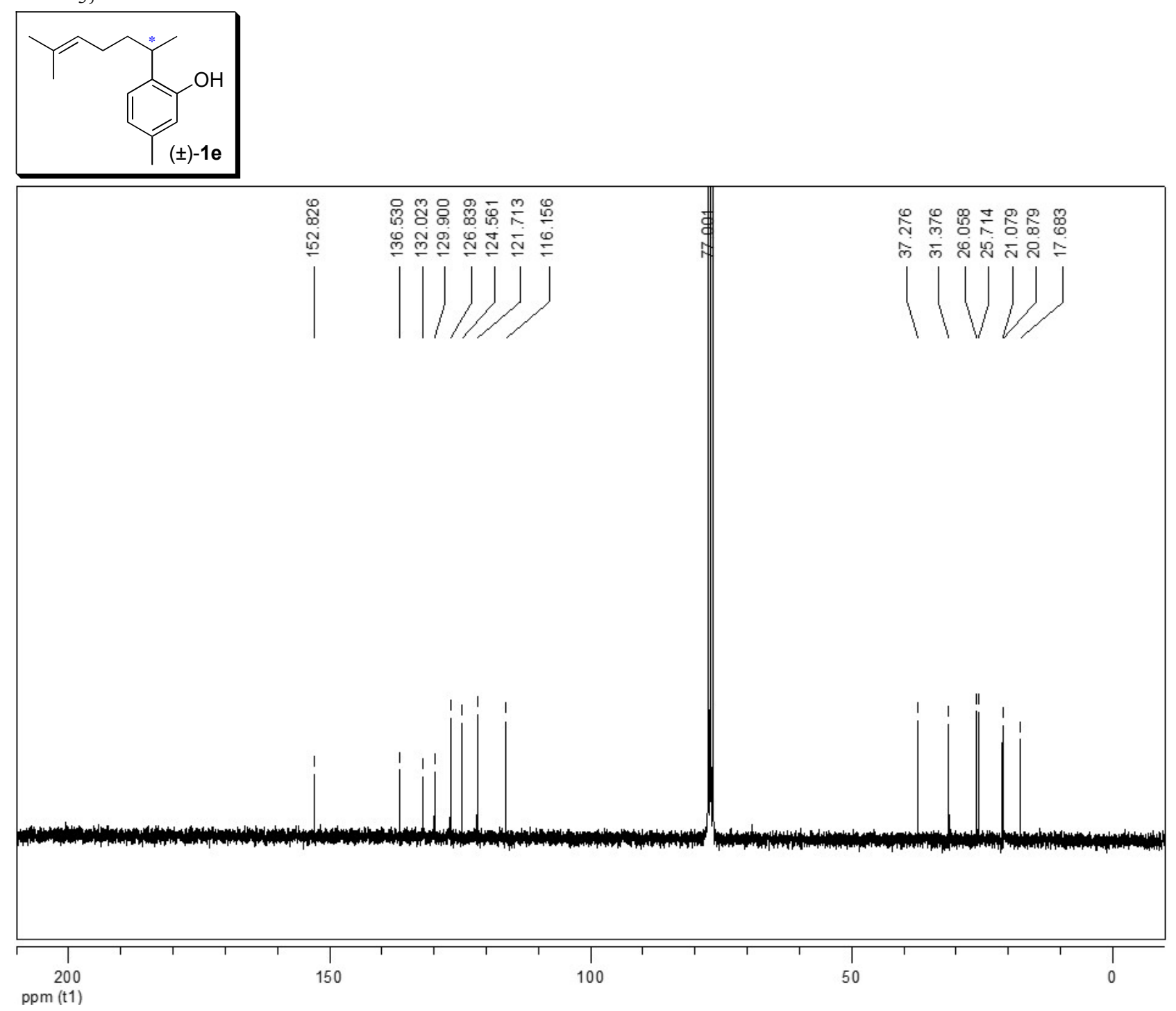


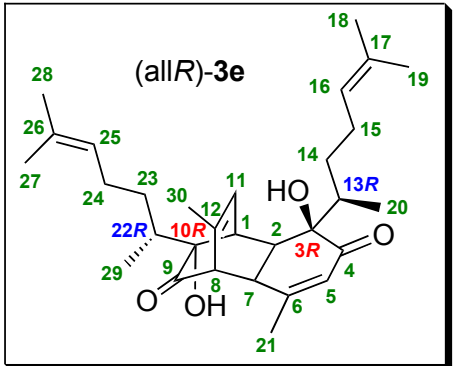

ent-bacchopetiolone

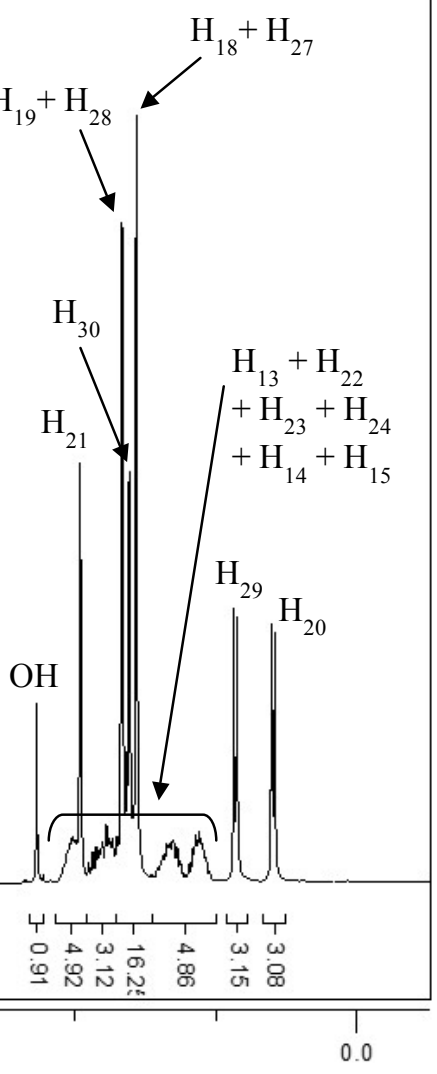

ppm (t1)

10.0

\begin{tabular}{|c|c|c|c|}
\hline Peak & ppm & $\mathrm{Hz}$ & Intensity \\
\hline 1 & 7.259 & 2179.110 & 673.410 \\
\hline 2 & 5.975 & 1793.490 & 1092.458 \\
\hline 3 & 5.808 & 1743.327 & 527.433 \\
\hline 4 & 5.785 & 1736.637 & 513.713 \\
\hline 5 & 5.093 & 1528.794 & 278.981 \\
\hline 6 & 5.089 & 1527.657 & 270.965 \\
\hline 7 & 5.072 & 1522.489 & 482.862 \\
\hline 8 & 5.047 & 1514.853 & 296.295 \\
\hline 9 & 5.027 & 1508.881 & 285.201 \\
\hline 10 & 5.005 & 1502.295 & 462.492 \\
\hline 11 & 5.002 & 1501.419 & 459.417 \\
\hline 12 & 4.980 & 1494.834 & 249.958 \\
\hline 13 & 3.808 & 1143.174 & 2126.760 \\
\hline 14 & 3.359 & 1008.220 & 632.117 \\
\hline 15 & 3.354 & 1006.821 & 678.099 \\
\hline 16 & 3.336 & 1001.457 & 657.387 \\
\hline 17 & 3.332 & 1000.067 & 683.237 \\
\hline 18 & 3.289 & 987.277 & 554.113 \\
\hline 19 & 3.262 & 979.022 & 674.422 \\
\hline 20 & 3.169 & 951.266 & 703.843 \\
\hline 21 & 3.162 & 949.079 & 1016.297 \\
\hline 22 & 3.155 & 947.035 & 755.777 \\
\hline 23 & 3.035 & 911.114 & 532.748 \\
\hline 24 & 3.029 & 909.213 & 508.824 \\
\hline 25 & 3.009 & 903.066 & 446.300 \\
\hline 26 & 3.002 & 901.120 & 410.557 \\
\hline 27 & 2.264 & 679.534 & 1878.606 \\
\hline 28 & 2.050 & 615.196 & 322.951 \\
\hline 29 & 1.957 & 587.542 & 4377.403 \\
\hline
\end{tabular}




\begin{tabular}{cccl}
30 & 1.896 & 569.048 & 209.822 \\
31 & 1.728 & 518.609 & 467.546 \\
32 & 1.698 & 509.711 & 496.578 \\
33 & 1.661 & 498.445 & 6892.423 \\
34 & 1.628 & 488.545 & 1370.604 \\
35 & 1.611 & 483.403 & 4217.420 \\
36 & 1.606 & 482.020 & 4295.262 \\
37 & 1.559 & 467.874 & 8011.323 \\
38 & 1.413 & 424.062 & 154.896 \\
39 & 1.404 & 421.360 & 163.440 \\
40 & 1.067 & 320.376 & 267.097 \\
41 & 1.040 & 312.139 & 133.346 \\
42 & 0.870 & 261.067 & 2861.084 \\
43 & 0.847 & 254.254 & 2767.967 \\
44 & 0.603 & 181.092 & 2704.452 \\
45 & 0.581 & 174.466 & 2612.958 \\
\hline & & &
\end{tabular}

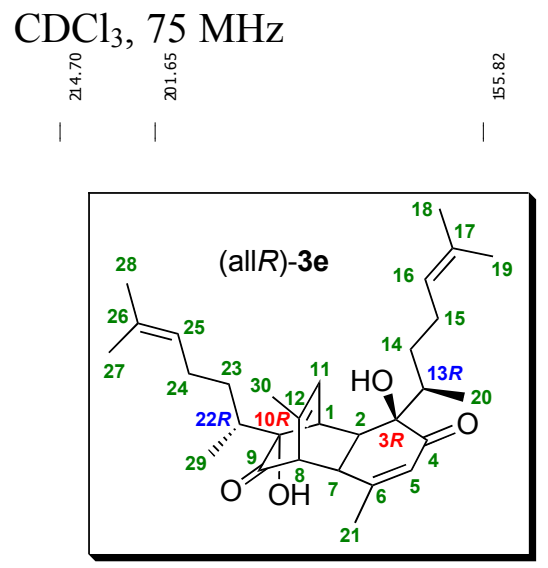

ent-bacchopetiolone

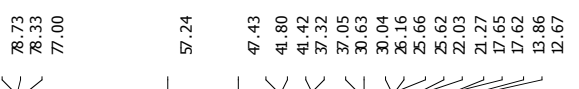

$\checkmark$

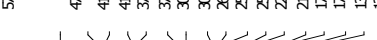

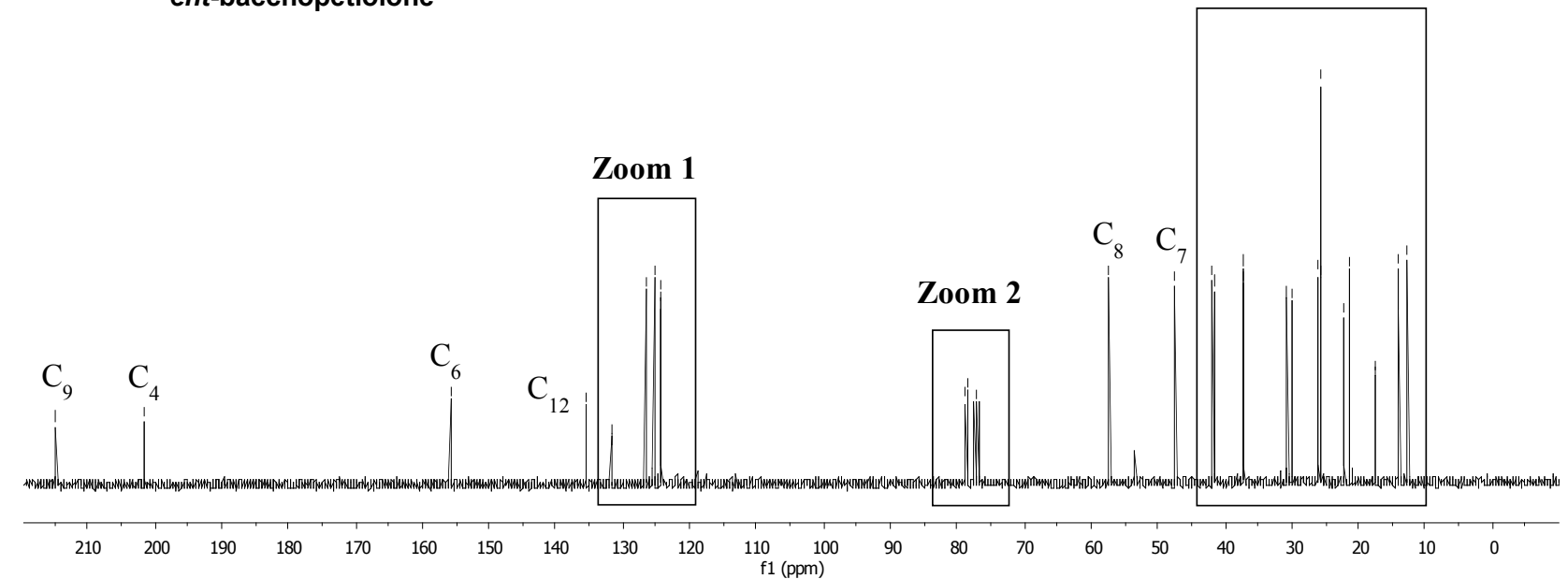


Zoom 1

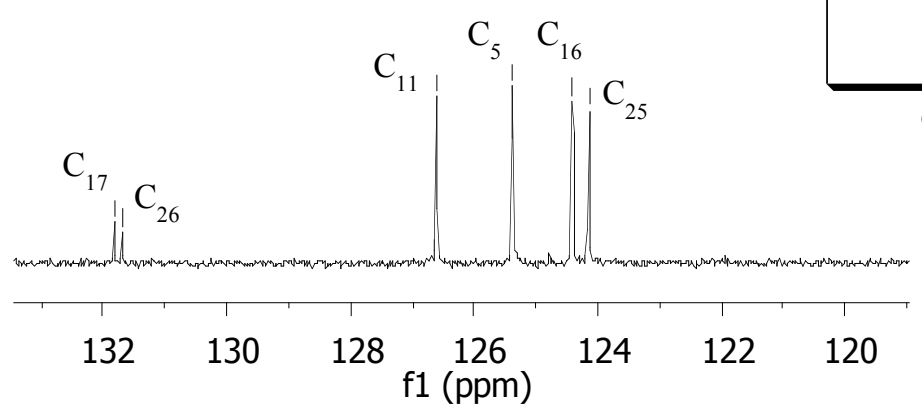

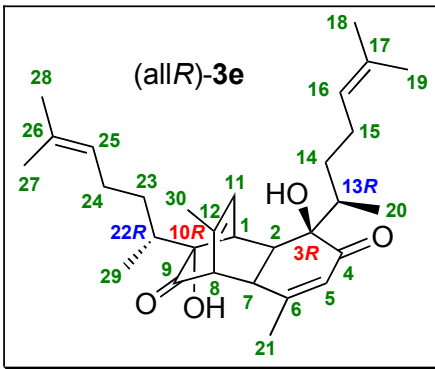

ent-bacchopetiolone

m 8

央只

\!

Zoom 2

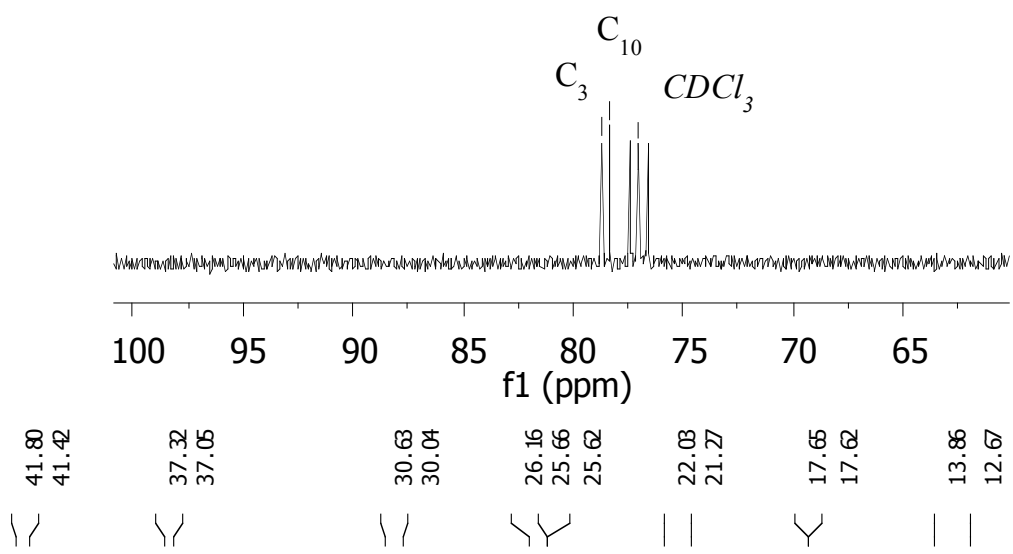

\section{Zoom 3}

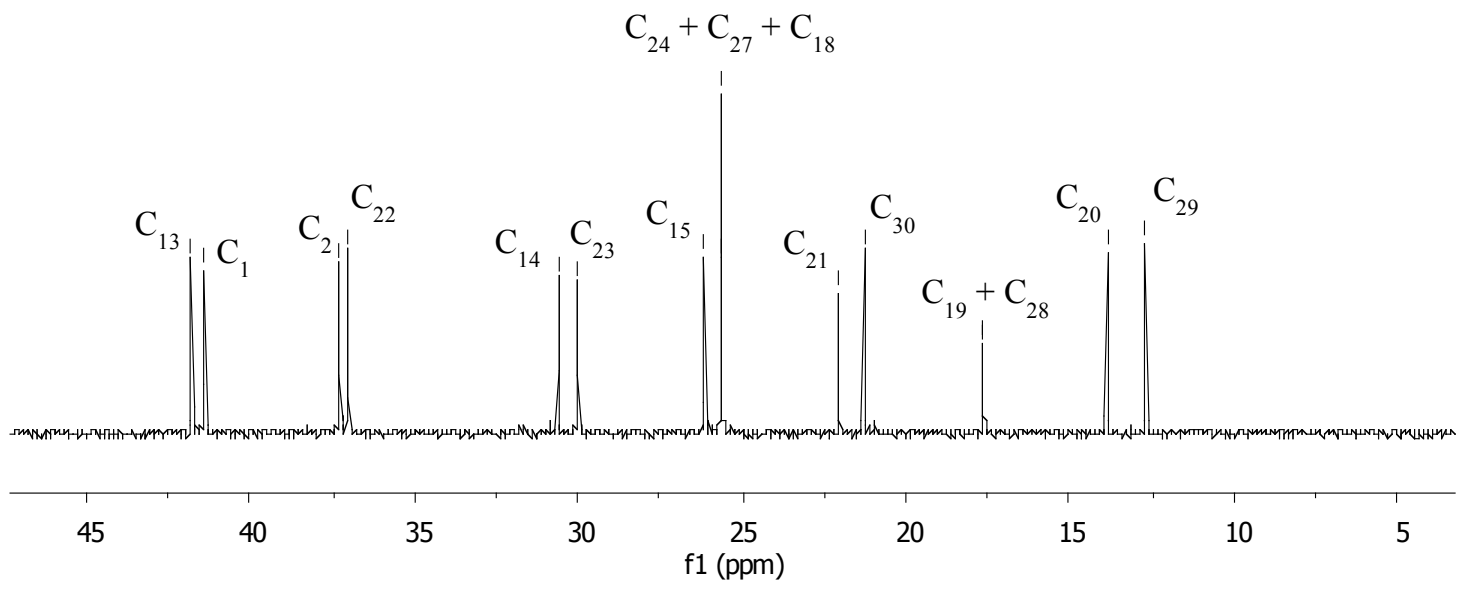




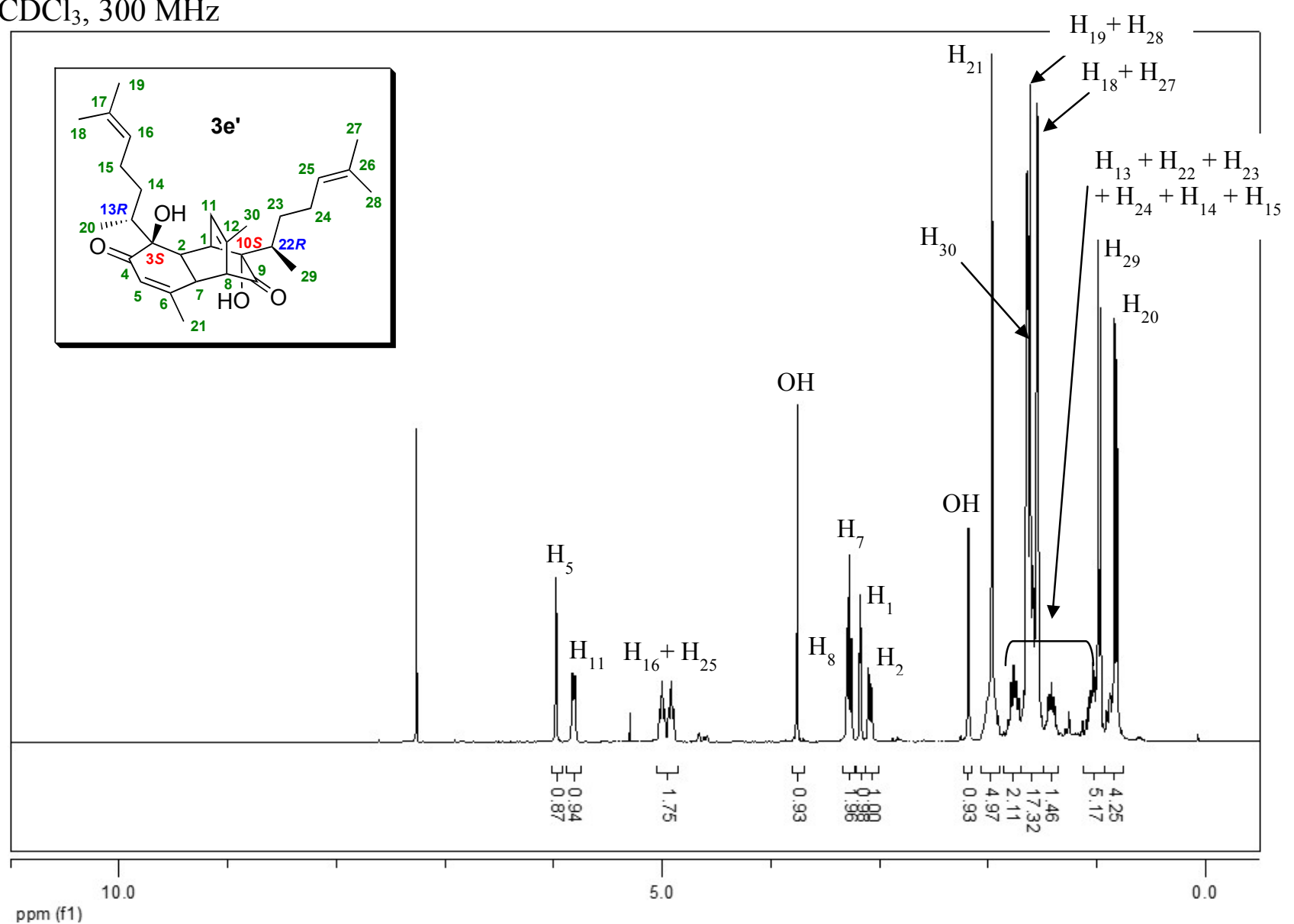

\begin{tabular}{|c|c|c|c|}
\hline Peak & ppm & $\mathrm{Hz}$ & Intensity \\
\hline 1 & 7.259 & 2179.094 & 3773.061 \\
\hline 2 & 5.974 & 1793.132 & 3686.239 \\
\hline 3 & 5.824 & 1748.139 & 1651.909 \\
\hline 4 & 5.801 & 1741.232 & 1609.695 \\
\hline 5 & 5.021 & 1507.244 & 844.480 \\
\hline 6 & 4.998 & 1500.332 & 1566.069 \\
\hline 7 & 4.975 & 1493.365 & 819.742 \\
\hline 8 & 4.938 & 1482.178 & 836.103 \\
\hline 9 & 4.915 & 1475.414 & 1514.144 \\
\hline 10 & 4.892 & 1468.322 & 787.520 \\
\hline 11 & 3.754 & 1126.820 & 7099.096 \\
\hline 12 & 3.296 & 989.298 & 2652.071 \\
\hline 13 & 3.278 & 983.808 & 4356.019 \\
\hline 14 & 3.255 & 977.046 & 2466.447 \\
\hline 15 & 3.180 & 954.537 & 2222.565 \\
\hline 16 & 3.173 & 952.439 & 3464.189 \\
\hline 17 & 3.167 & 950.493 & 2535.820 \\
\hline 18 & 3.101 & 930.689 & 1809.920 \\
\hline 19 & 3.074 & 922.578 & 1400.735 \\
\hline 20 & 2.183 & 655.284 & 5258.404 \\
\hline 21 & 1.961 & 588.757 & 16237.063 \\
\hline 22 & 1.907 & 572.313 & 432.028 \\
\hline 23 & 1.812 & 543.884 & 623.156 \\
\hline 24 & 1.713 & 514.264 & 1173.647 \\
\hline 25 & 1.644 & 493.454 & 14447.024 \\
\hline 26 & 1.631 & 489.676 & 14378.433 \\
\hline 27 & 1.612 & 483.936 & 15335.400 \\
\hline 28 & 1.608 & 482.733 & 15600.699 \\
\hline 29 & 1.548 & 464.708 & 15832.202 \\
\hline
\end{tabular}




$\begin{array}{llll}30 & 1.538 & 461.646 & 15282.465 \\ 31 & 1.450 & 435.084 & 828.809 \\ 32 & 1.362 & 408.822 & 369.062 \\ 33 & 1.098 & 329.511 & 543.539 \\ 34 & 1.007 & 302.133 & 1613.941 \\ 35 & 1.001 & 300.349 & 1657.471 \\ 36 & 0.984 & 295.377 & 10732.233 \\ 37 & 0.962 & 288.757 & 9201.822 \\ 38 & 0.873 & 262.126 & 1241.010 \\ 39 & 0.854 & 256.404 & 1210.603 \\ 40 & 0.833 & 249.923 & 9182.828 \\ 41 & 0.810 & 243.078 & 8323.002\end{array}$

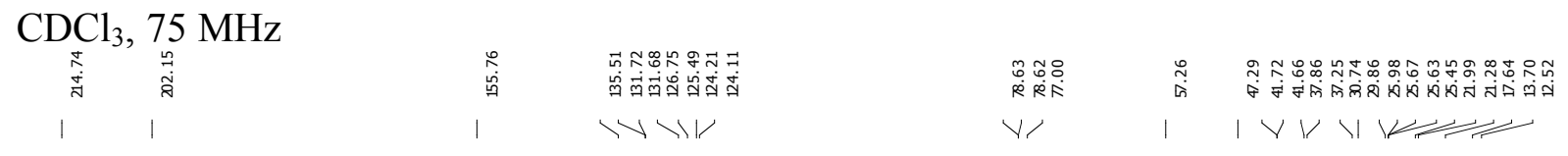

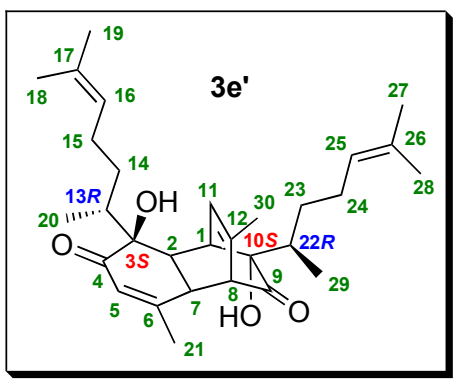

Zoom 2

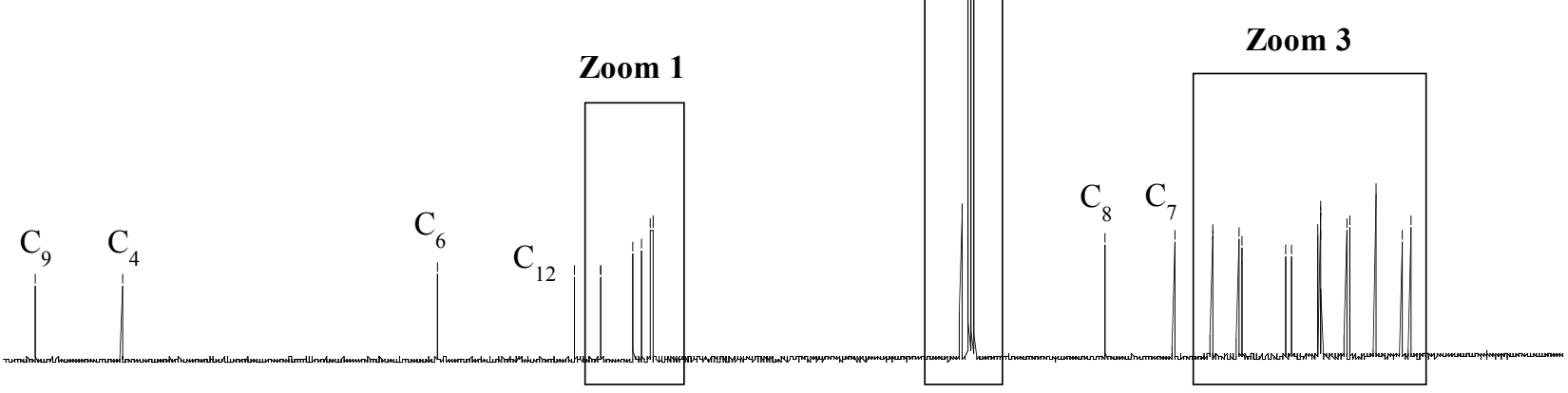

$\begin{array}{lllllllllllllllllllllll}1 & 200 & 190 & 180 & 170 & 160 & 150 & 140 & 130 & 120 & \underset{f 1}{\mathrm{f} 1(\mathrm{ppm})}(100 & 90 & 80 & 70 & 60 & 50 & 40 & 30 & 20 & 10 & 0\end{array}$ 


\section{Zoom 1}
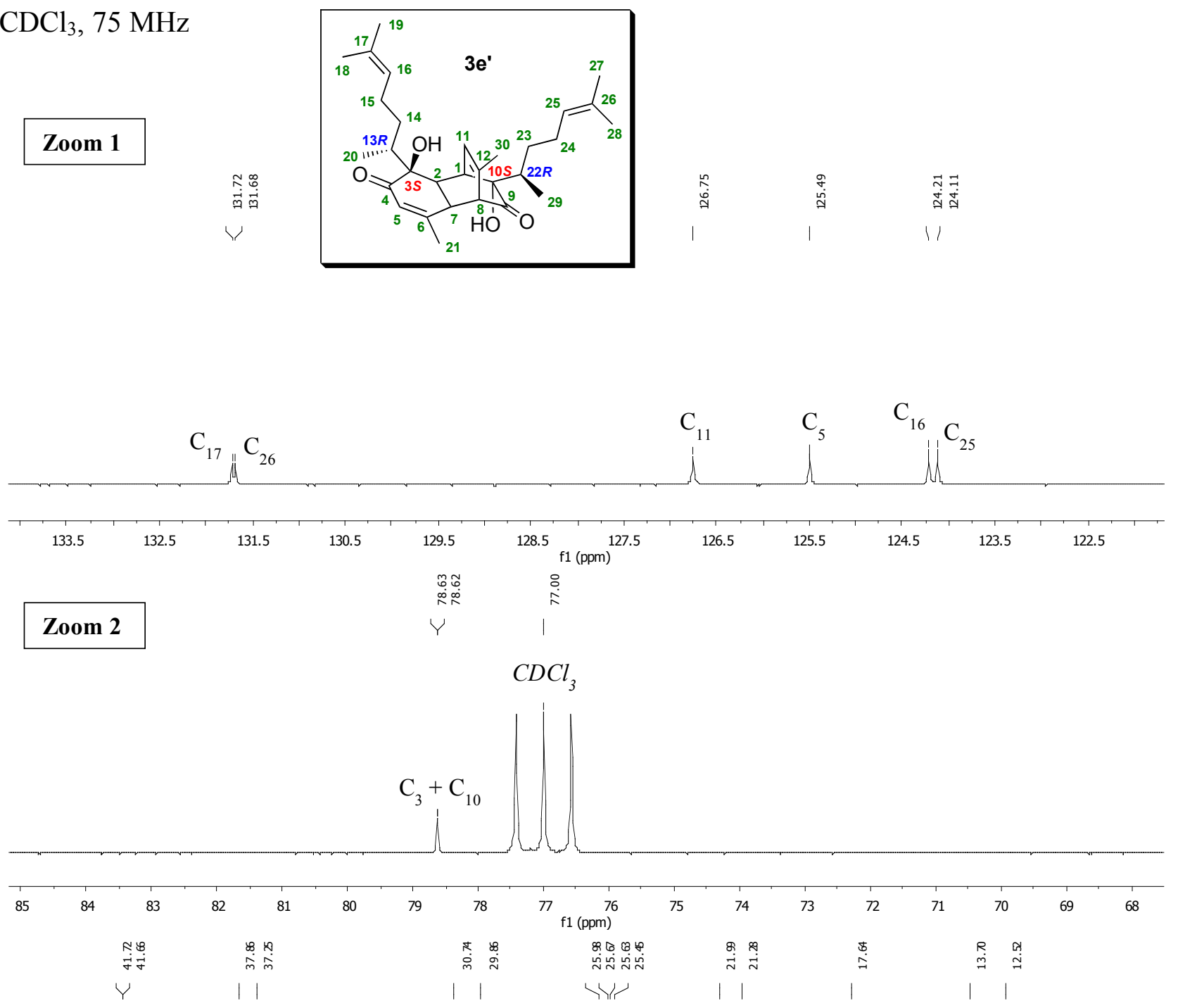

\section{Zoom 3}

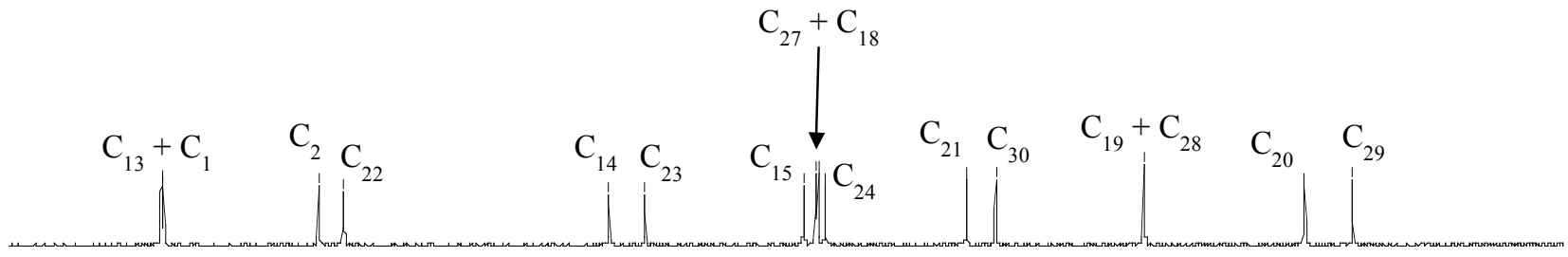

$\begin{array}{lllllllllllllllllllllll}45 & 43 & 41 & 39 & 37 & 35 & 33 & 31 & 29 & 27 & 25 & 23 & 21 & 19 & 17 & 15 & 13 & 11 & 9 & 8\end{array}$ 


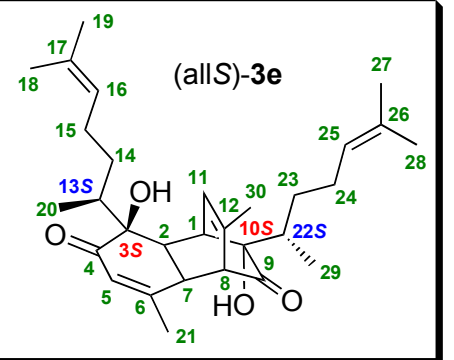

bacchopetiolone

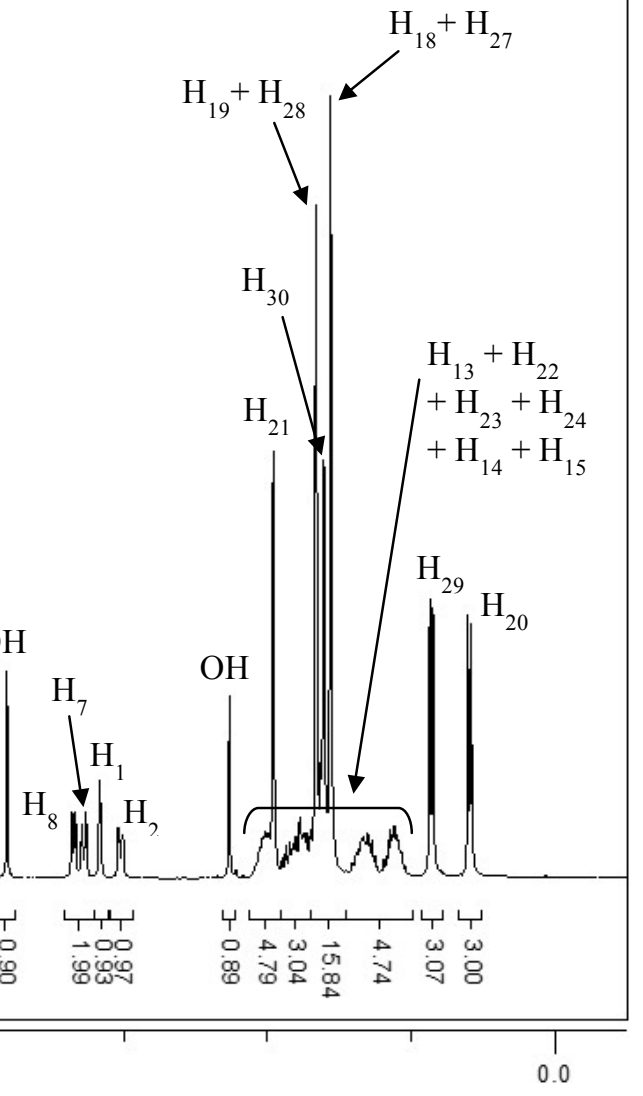

ppm (t1)

\begin{tabular}{llll} 
Peak & ppm & Hz & Intensity \\
\hline 1 & 7.259 & 2179.110 & 673.410 \\
2 & 5.975 & 1793.490 & 1092.458 \\
3 & 5.808 & 1743.327 & 527.433 \\
4 & 5.785 & 1736.637 & 513.713 \\
5 & 5.093 & 1528.794 & 278.981 \\
6 & 5.089 & 1527.657 & 270.965 \\
7 & 5.072 & 1522.489 & 482.862 \\
8 & 5.047 & 1514.853 & 296.295 \\
9 & 5.027 & 1508.881 & 285.201 \\
10 & 5.005 & 1502.295 & 462.492 \\
11 & 5.002 & 1501.419 & 459.417 \\
12 & 4.980 & 1494.834 & 249.958 \\
13 & 3.808 & 1143.174 & 2126.760 \\
14 & 3.359 & 1008.220 & 632.117 \\
15 & 3.354 & 1006.821 & 678.099 \\
16 & 3.336 & 1001.457 & 657.387 \\
17 & 3.332 & 1000.067 & 683.237 \\
18 & 3.289 & 987.277 & 554.113 \\
19 & 3.262 & 979.022 & 674.422 \\
20 & 3.169 & 951.266 & 703.843 \\
21 & 3.162 & 949.079 & 1016.297 \\
22 & 3.155 & 947.035 & 755.777 \\
23 & 3.035 & 911.114 & 532.748 \\
24 & 3.029 & 909.213 & 508.824 \\
25 & 3.009 & 903.066 & 446.300 \\
26 & 3.002 & 901.120 & 410.557 \\
27 & 2.264 & 679.534 & 1878.606 \\
28 & 2.050 & 615.196 & 322.951 \\
& & &
\end{tabular}




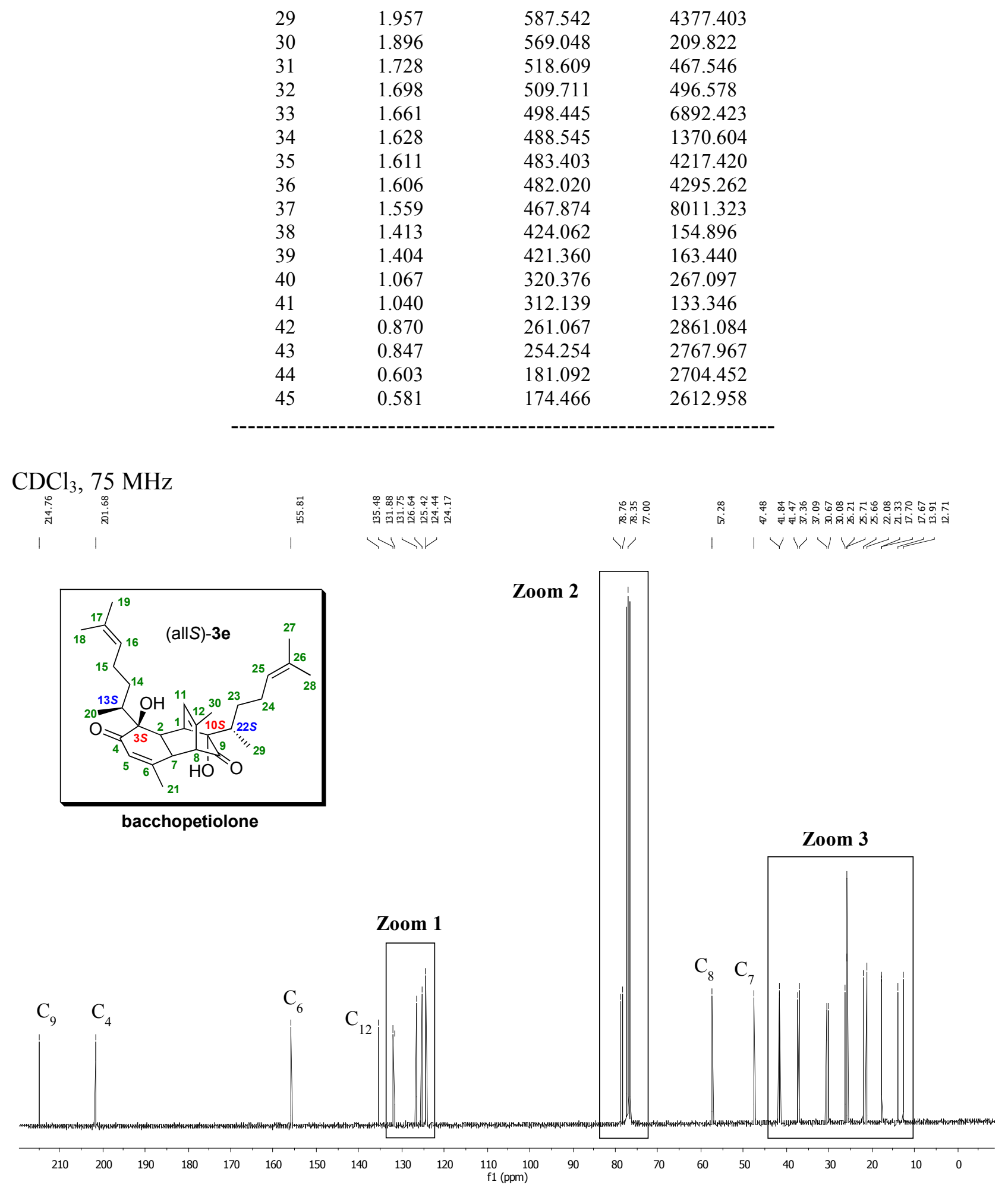


Zoom 1
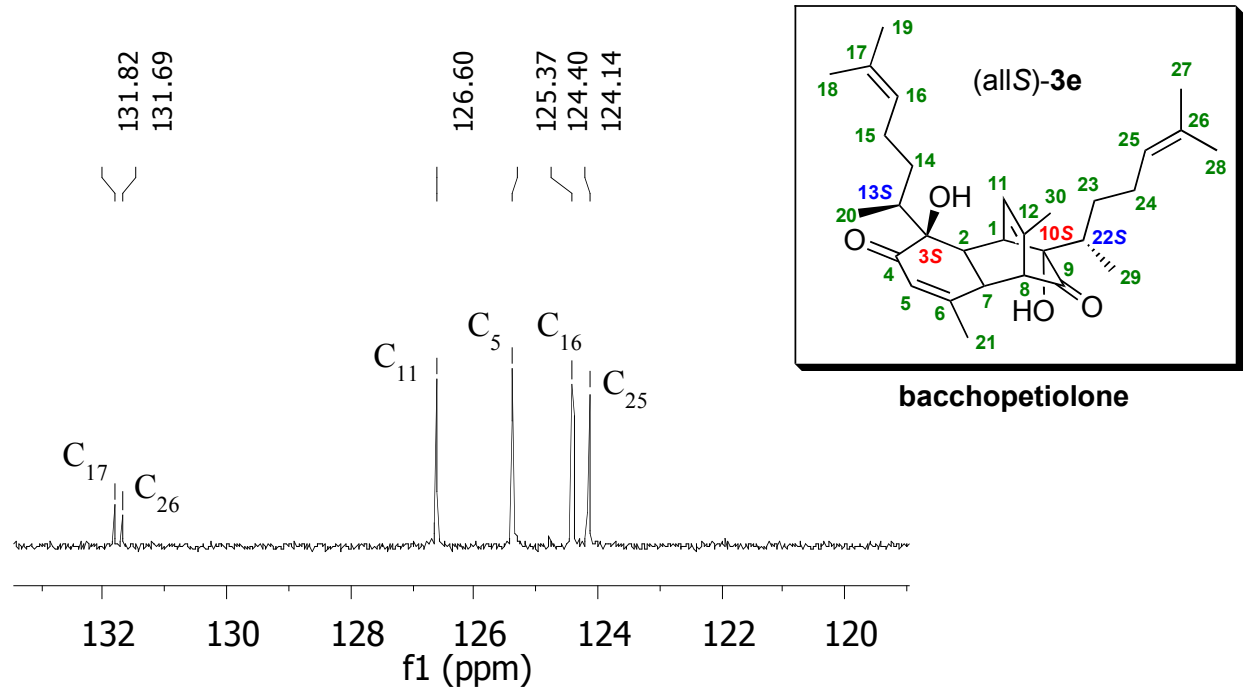

bacchopetiolone

लm 8

央六

) 1

Zoom 2

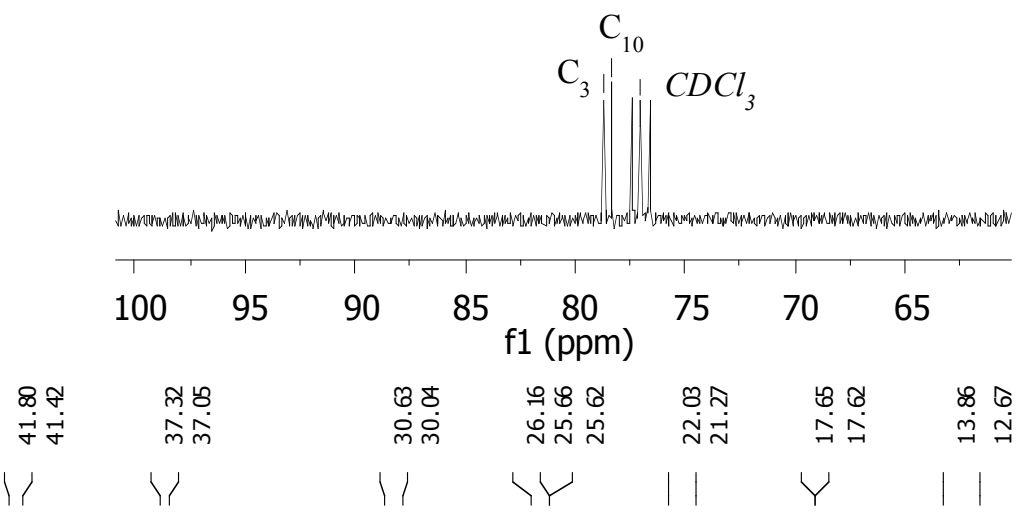

Zoom 3

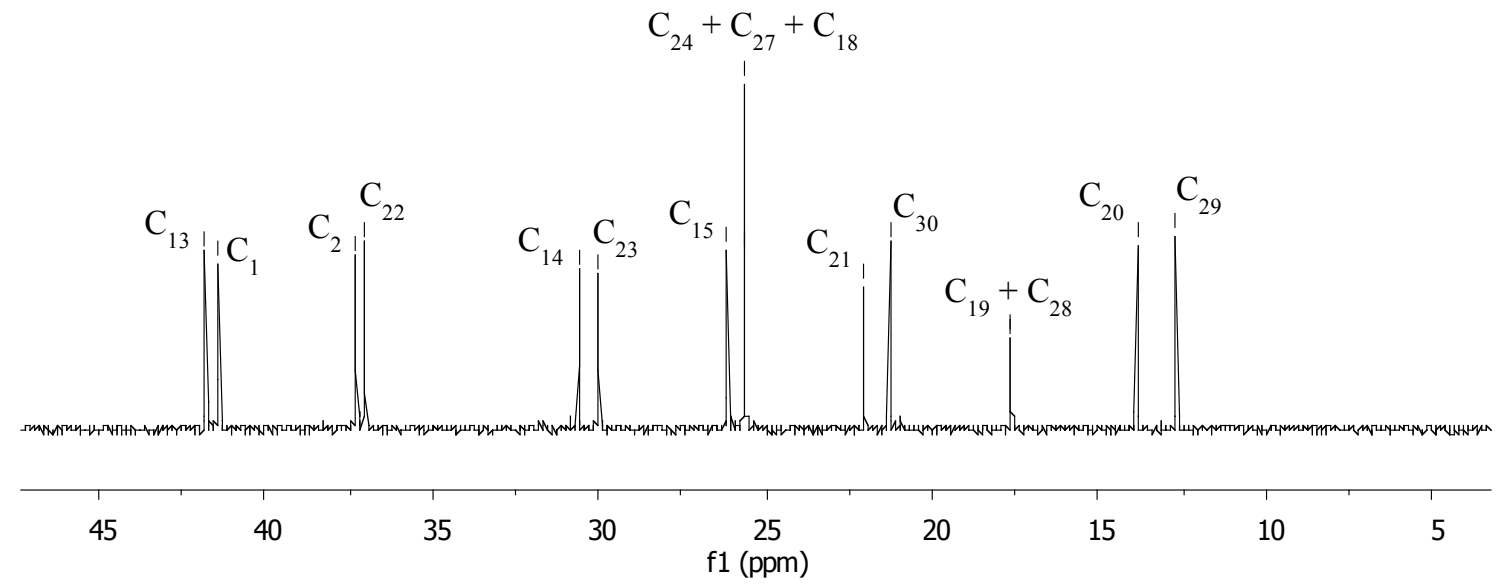




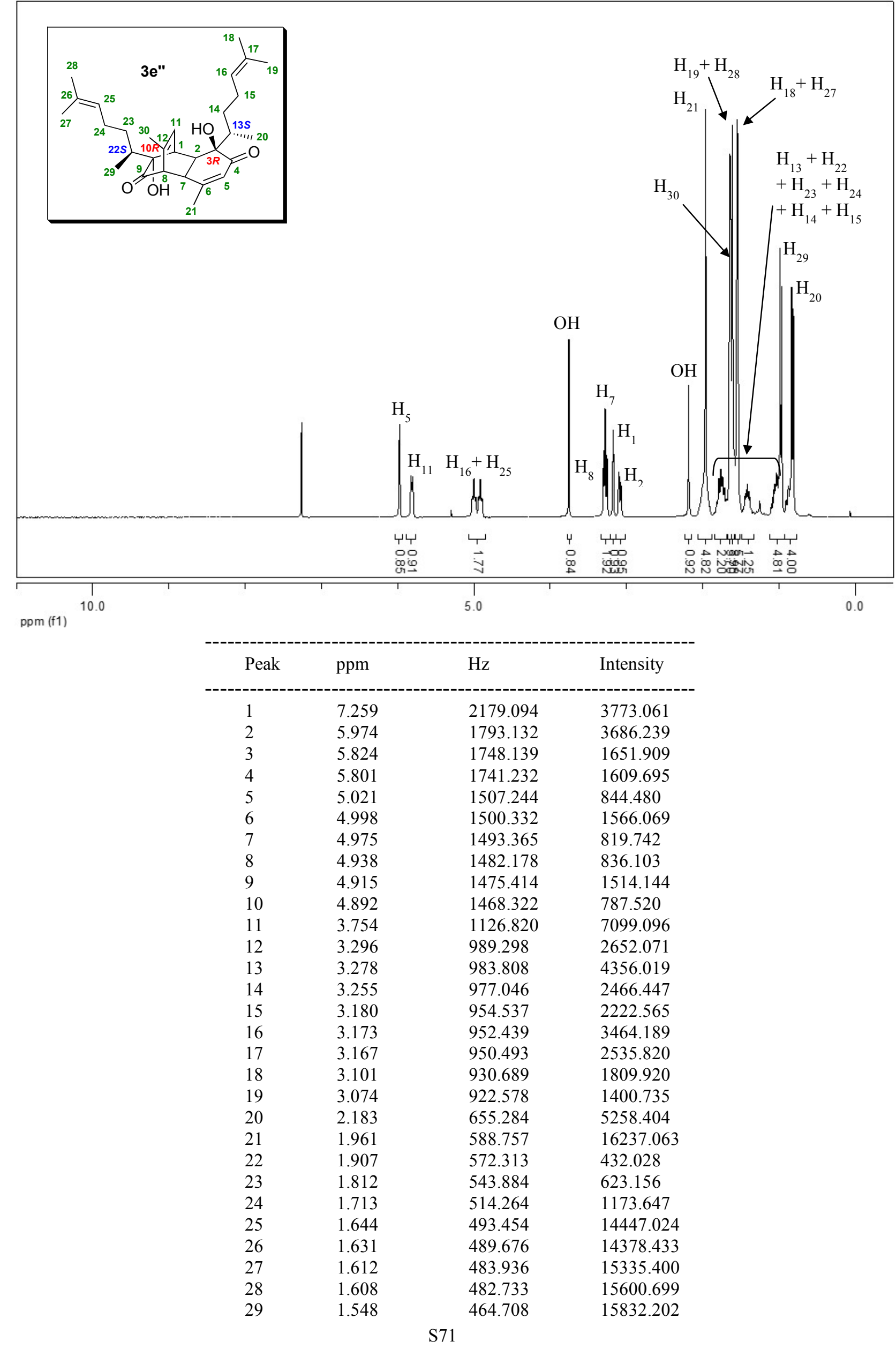




$\begin{array}{llll}30 & 1.538 & 461.646 & 15282.465 \\ 31 & 1.450 & 435.084 & 828.809 \\ 32 & 1.362 & 408.822 & 369.062 \\ 33 & 1.098 & 329.511 & 543.539 \\ 34 & 1.007 & 302.133 & 1613.941 \\ 35 & 1.001 & 300.349 & 1657.471 \\ 36 & 0.984 & 295.377 & 10732.233 \\ 37 & 0.962 & 288.757 & 9201.822 \\ 38 & 0.873 & 262.126 & 1241.010 \\ 39 & 0.854 & 256.404 & 1210.603 \\ 40 & 0.833 & 249.923 & 9182.828 \\ 41 & 0.810 & 243.078 & 8323.002\end{array}$

\begin{tabular}{|c|c|c|c|c|c|c|}
\hline 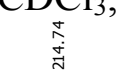 & 年 & 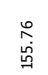 & 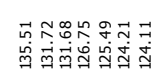 & 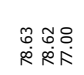 & 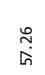 & 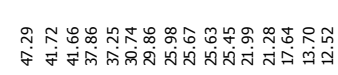 \\
\hline I & 1 & I & $\checkmark v \backslash V$ & V' & I & $1 \times V \backslash$ \\
\hline
\end{tabular}

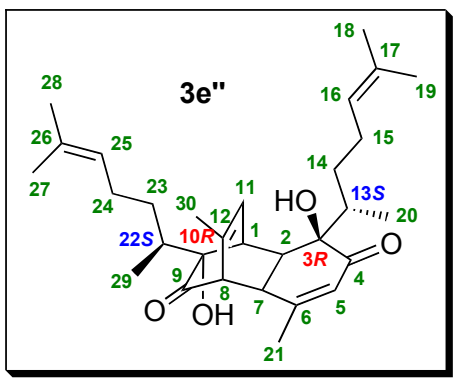

Zoom 2
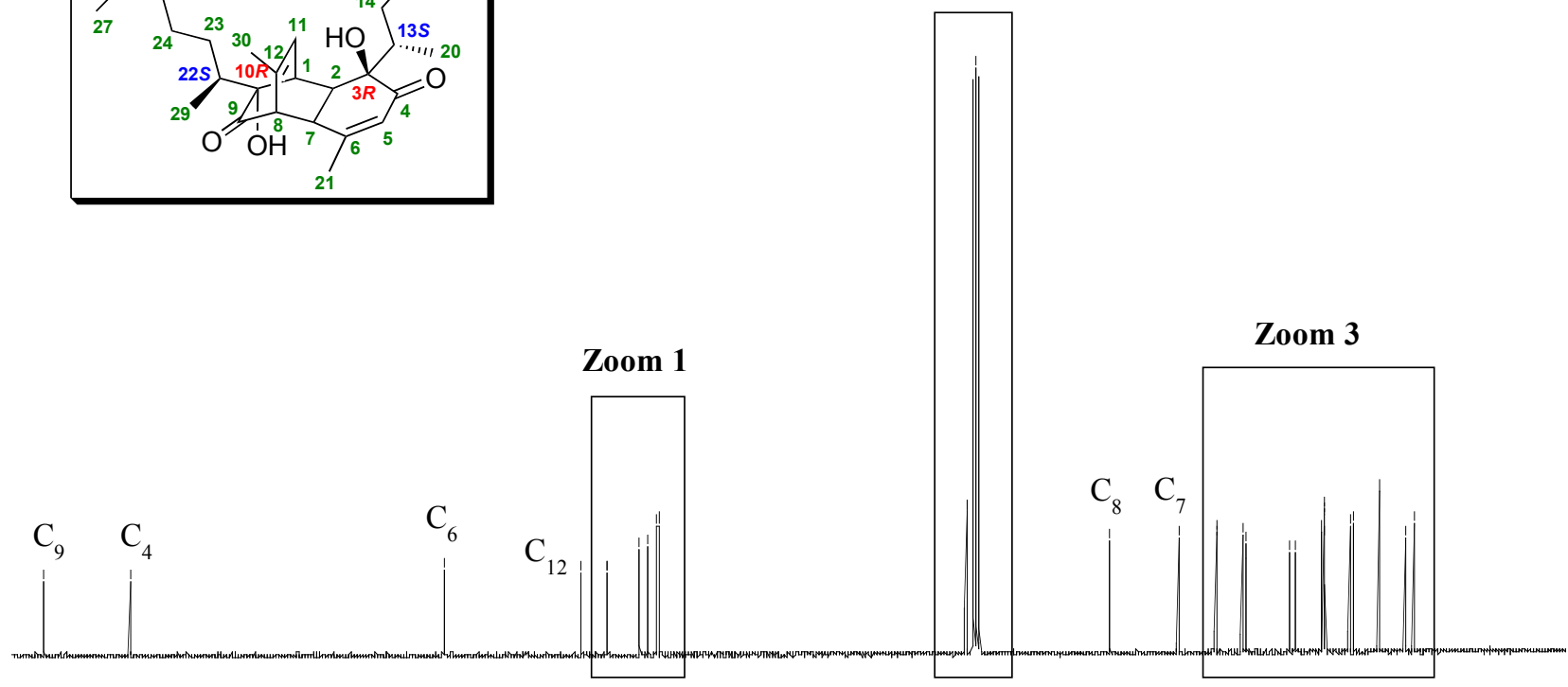

$\begin{array}{lllllllllll}210 & 200 & 190 & 180 & 170 & 160 & 150 & 140 & 130 & 120 & 110 \\ \mathrm{f} 1(\mathrm{ppm}) & 100\end{array}$ 

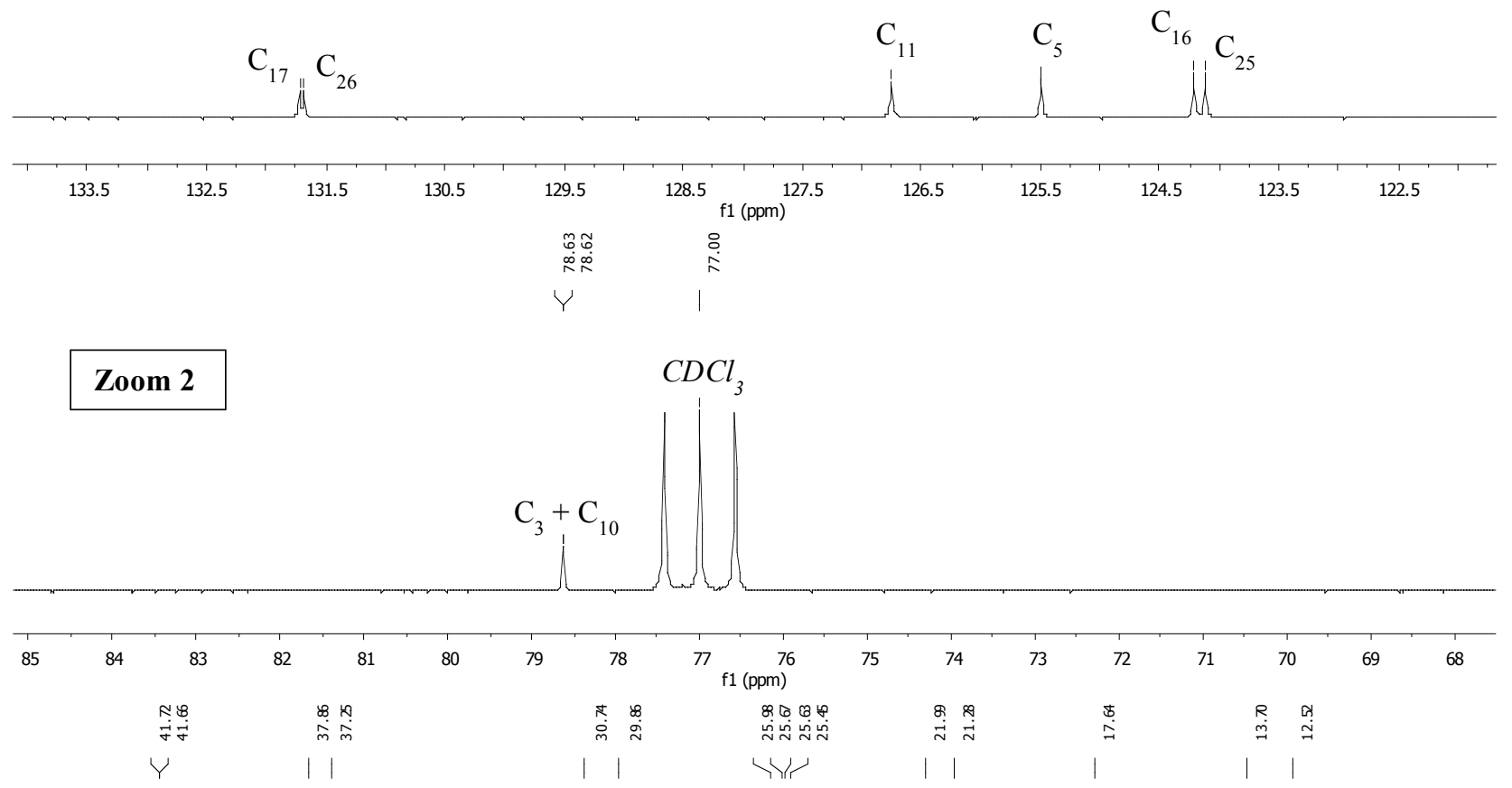

\section{Zoom 3}

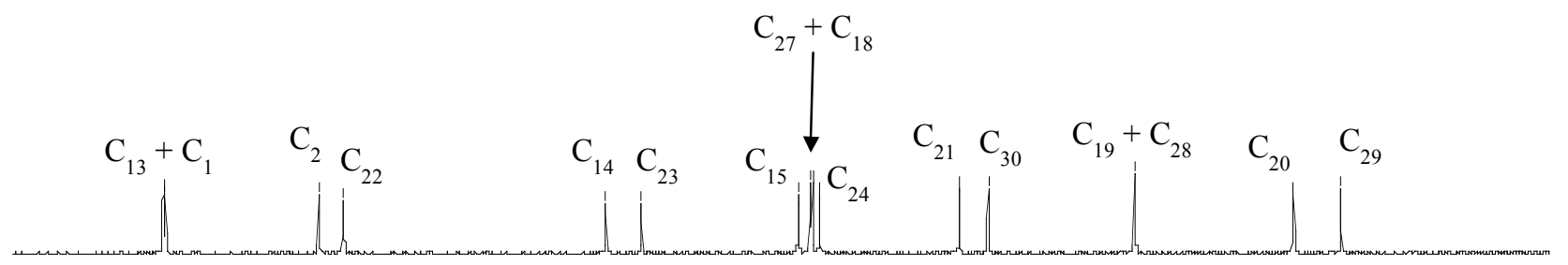

45
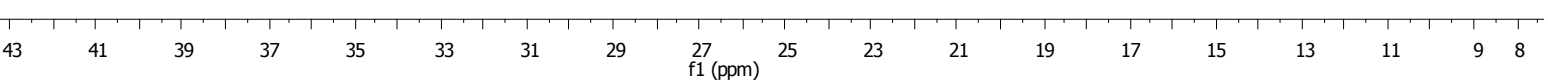
$\mathrm{CDCl}_{3}, 300 \mathrm{MHz}$
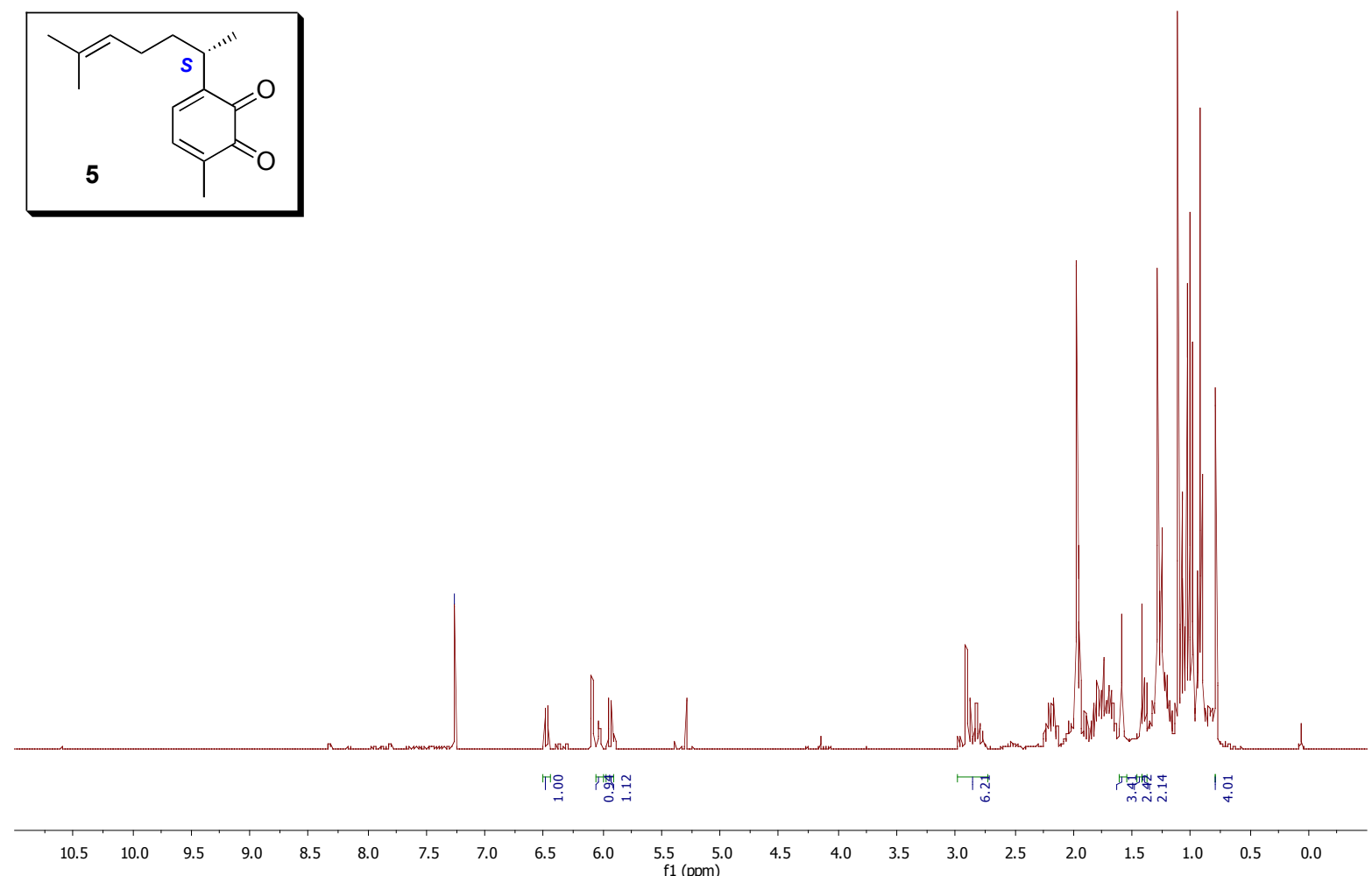

N.B.: quick degradation was observed during ${ }^{1} \mathrm{H}$ NMR spectrum acquisition, thus no ${ }^{13} \mathrm{C}$ NMR was recorded.

\begin{tabular}{llll} 
Peak & ppm & Intensity & Width \\
\hline 1 & 6.50 & 21194742.2 & 1.92 \\
2 & 6.47 & 23302349.0 & 1.91 \\
3 & 6.03 & 15354696.3 & 1.98 \\
4 & 5.95 & 27512042.1 & 1.52 \\
5 & 5.92 & 25096339.9 & 1.51 \\
6 & 2.98 & 7064215.7 & 1.59 \\
7 & 2.95 & 7127433.3 & 1.66 \\
8 & 2.95 & 2055796.7 & 4.06 \\
9 & 2.91 & 55820668.4 & 1.91 \\
10 & 2.90 & 52890645.9 & 1.66 \\
11 & 2.88 & 26929469.8 & 2.11 \\
12 & 2.87 & 26373349.6 & 2.08 \\
13 & 2.85 & 10140470.6 & 3.75 \\
14 & 2.84 & 10726205.5 & 3.69 \\
15 & 2.82 & 24917809.0 & 2.47 \\
16 & 2.82 & 24283992.2 & 2.74 \\
17 & 2.80 & 13216227.8 & 4.90 \\
18 & 2.77 & 9700416.6 & 3.58 \\
19 & 2.75 & 2907029.5 & 2.33 \\
20 & 1.59 & 72715994.4 & 3.14 \\
21 & 1.40 & 38530436.5 & 2.10 \\
22 & 1.38 & 35785117.1 & 2.50 \\
23 & 1.36 & 13683114.7 & 3.73 \\
24 & 1.34 & 14705401.6 & 3.92 \\
25 & 0.79 & 193936762.5 & 1.80 \\
--------------------------------------------------
\end{tabular}


DMSO- $d_{6}, 300 \mathrm{MHz}$<smiles>Cc1cc(C=O)c2c(c1)CCC2</smiles>

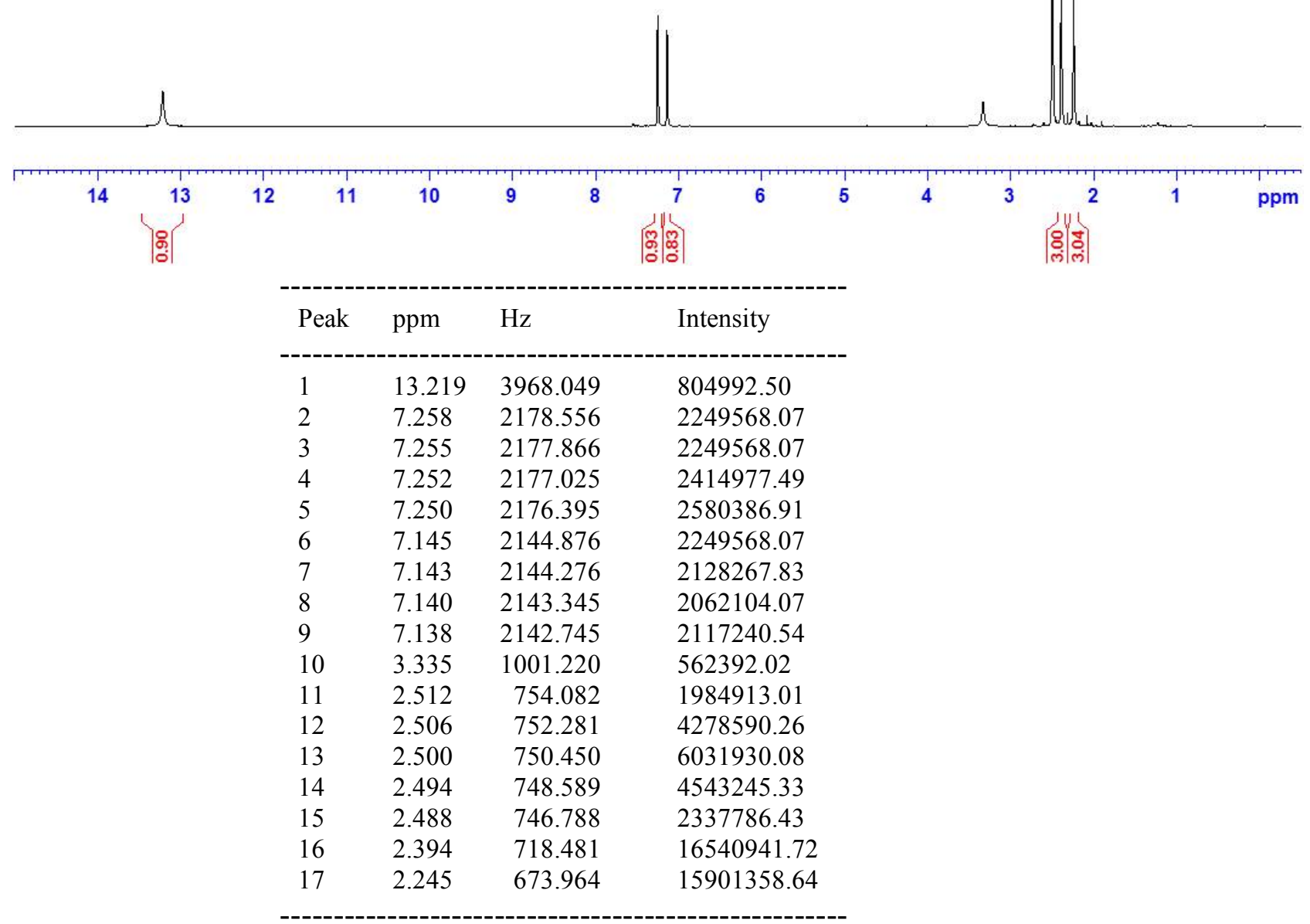


DMSO- $d_{6}, 75 \mathrm{MHz}$

${ }_{16}^{\mathrm{CO}_{2} \mathrm{H}}$

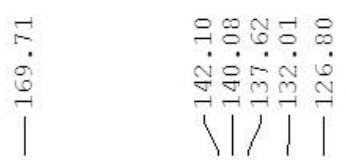

|

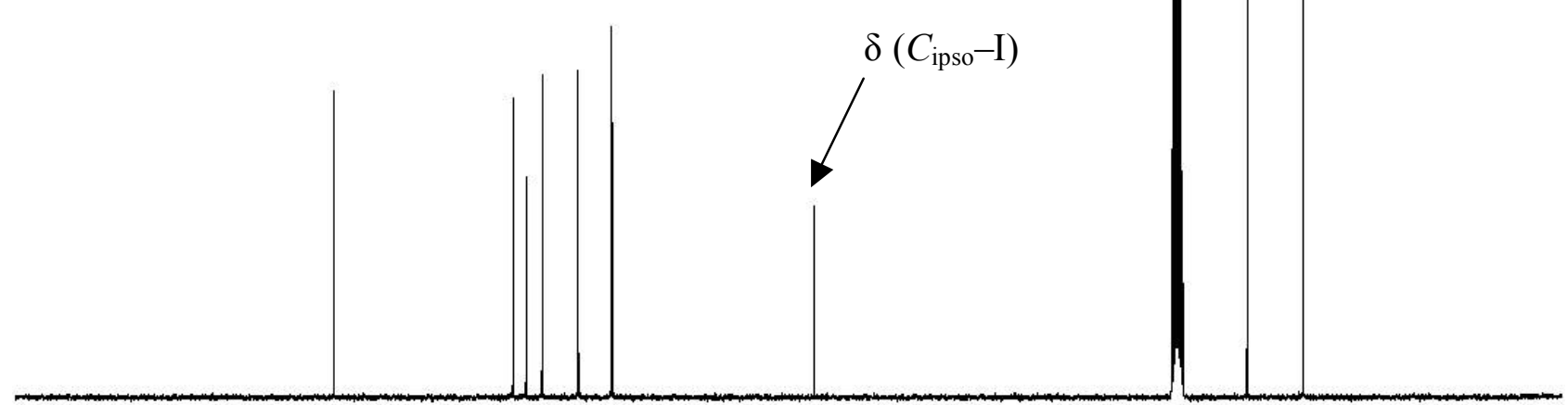

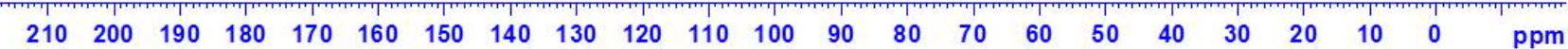


acetone- $d_{6}, 300 \mathrm{MHz}$<smiles>O=C(O)c1cc2ccccc2cc1I</smiles>

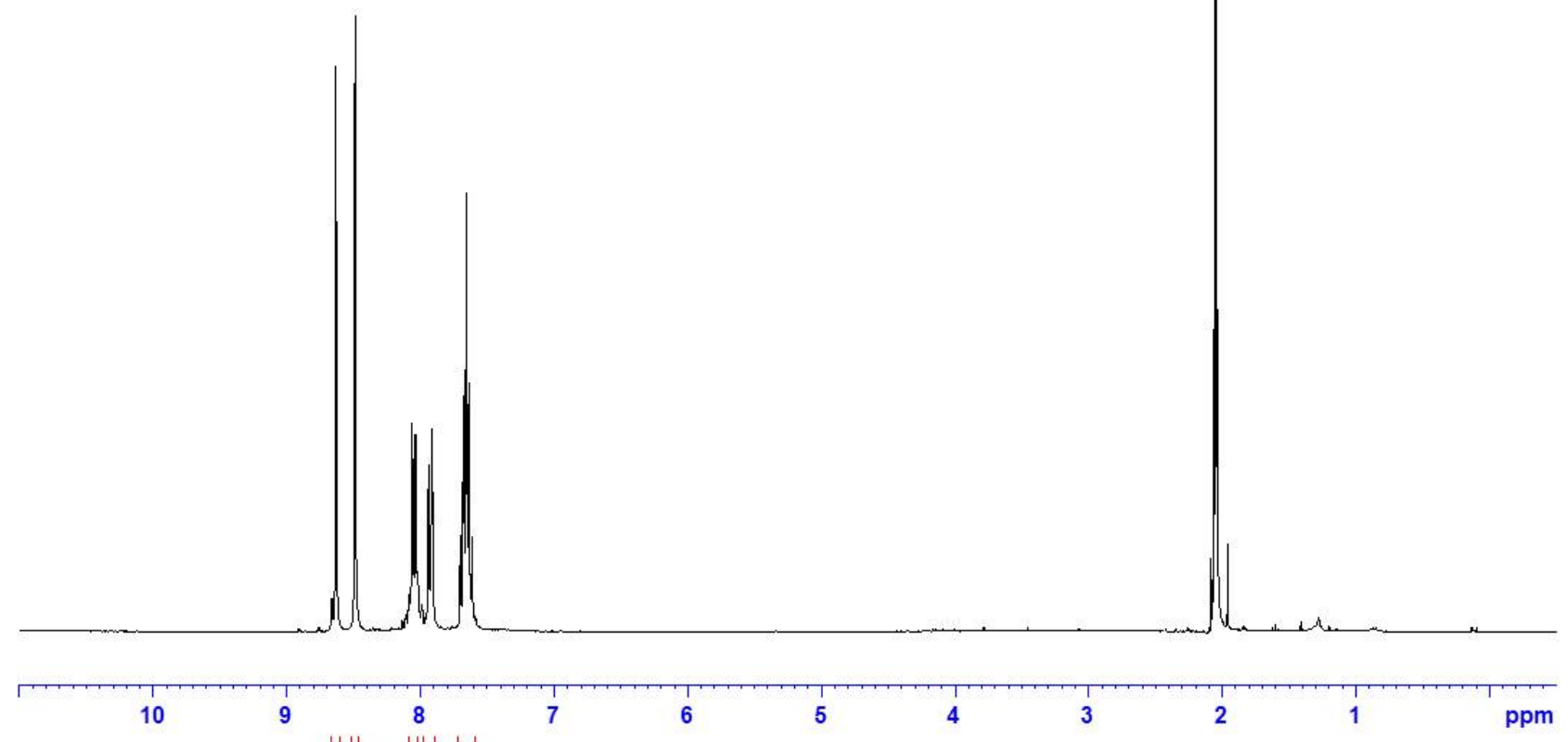

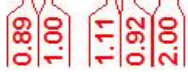

\begin{tabular}{|c|c|c|c|}
\hline Peak & ppm & $\mathrm{Hz}$ & Intensity \\
\hline 1 & 8.633 & 2591.112 & 4791524.57 \\
\hline 2 & 8.490 & 2548.014 & 5227117.71 \\
\hline 3 & 8.064 & 2420.098 & 1761519.52 \\
\hline 4 & 8.040 & 2413.195 & 1675358.24 \\
\hline 5 & 8.035 & 2411.455 & 1665784.77 \\
\hline 6 & 7.944 & 2384.173 & 1201471.20 \\
\hline 7 & 7.938 & 2382.342 & 1416874.40 \\
\hline 8 & 7.914 & 2375.109 & 1718438.88 \\
\hline 9 & 7.705 & 2312.502 & 564835.06 \\
\hline 10 & 7.700 & 2310.881 & 818532.17 \\
\hline 11 & 7.682 & 2305.599 & 2005643.15 \\
\hline 12 & 7.677 & 2303.978 & 1852467.54 \\
\hline 13 & 7.665 & 2300.617 & 2221046.35 \\
\hline 14 & 7.658 & 2298.336 & 3709721.82 \\
\hline 15 & 7.650 & 2296.055 & 1924268.61 \\
\hline 16 & 7.639 & 2292.813 & 1905121.66 \\
\hline 17 & 7.634 & 2291.192 & 2106164.65 \\
\hline 18 & 7.616 & 2285.850 & 804171.96 \\
\hline 19 & 7.611 & 2284.289 & 674930.03 \\
\hline 20 & 2.065 & 619.648 & 2560904.74 \\
\hline 21 & 2.057 & 617.457 & 4978207.35 \\
\hline 22 & 2.050 & 615.267 & 7180106.75 \\
\hline 23 & 2.043 & 613.046 & 5093089.05 \\
\hline 24 & 2.035 & 610.855 & 2738014.04 \\
\hline
\end{tabular}


acetone- $d_{6}, 75 \mathrm{MHz}$
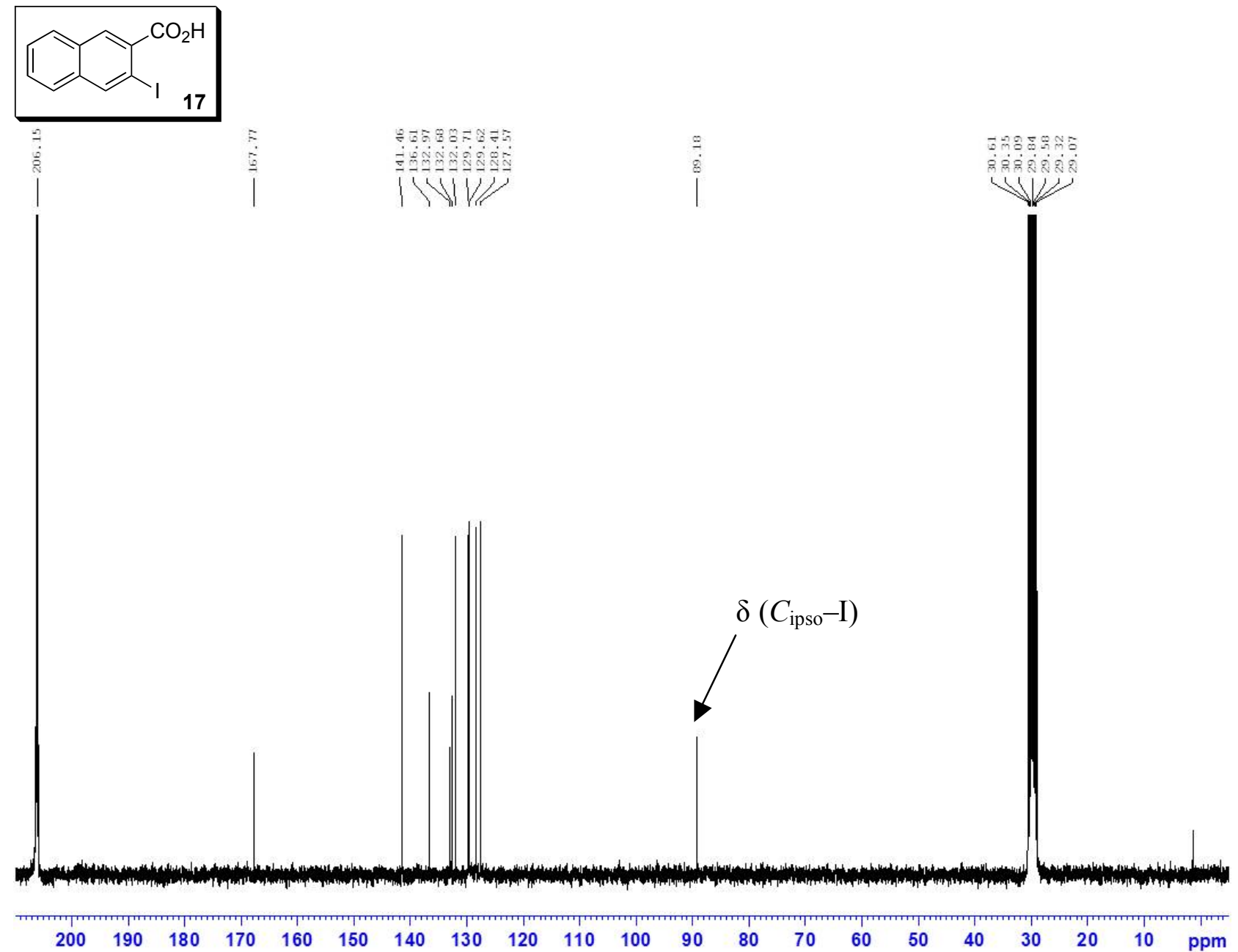
DMSO- $d_{6}, 300 \mathrm{MHz}$
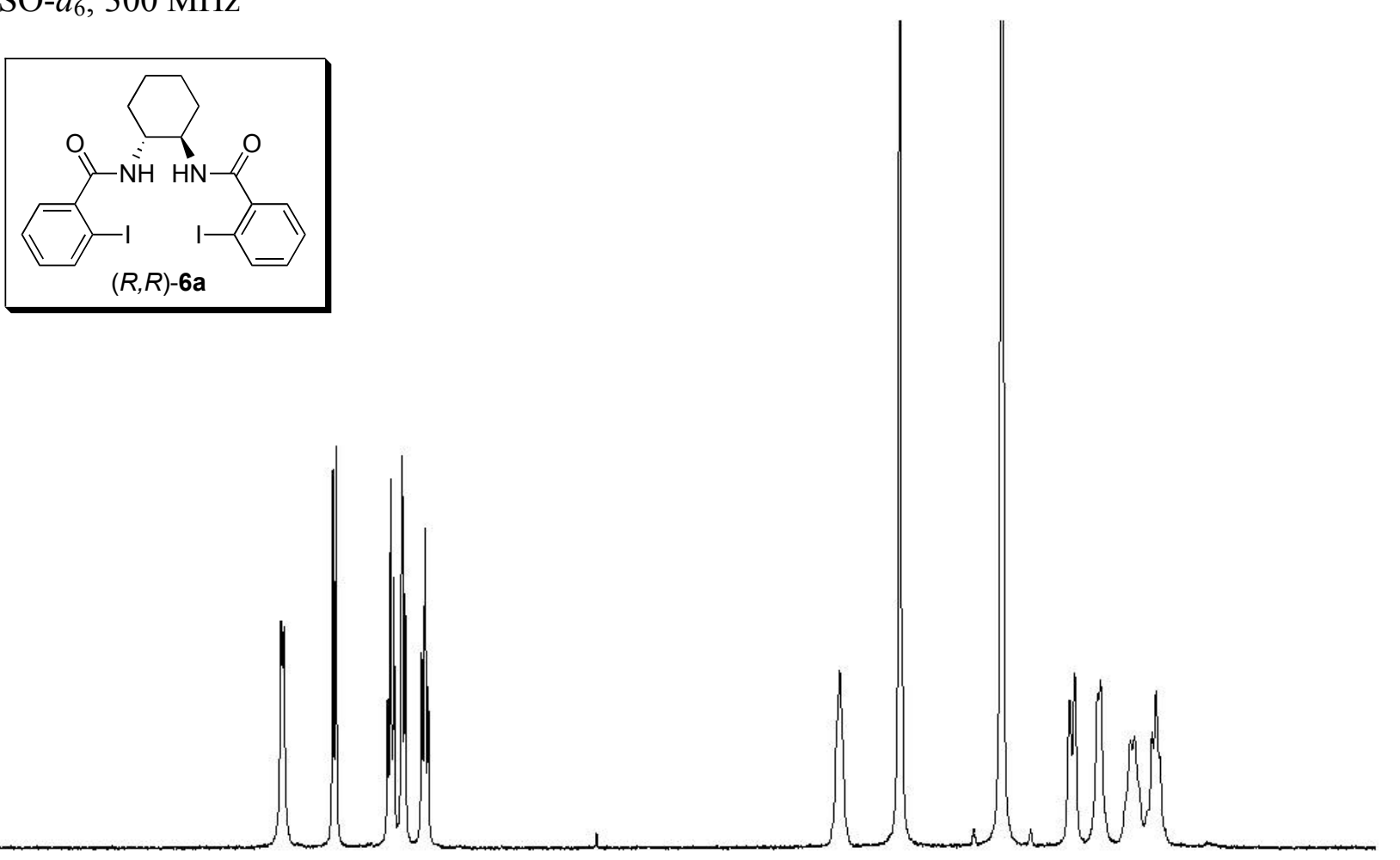

10 9 $\begin{array}{ll}7 & 6\end{array}$ 65 54 |

\begin{tabular}{lrll} 
Peak & ppm & Hz & Intensity \\
\hline 1 & 8.290 & 2488.048 & 285922.93 \\
2 & 8.265 & 2480.604 & 280316.60 \\
3 & 7.872 & 2362.713 & 476538.21 \\
4 & 7.846 & 2354.940 & 507373.04 \\
5 & 7.433 & 2230.836 & 187812.12 \\
6 & 7.408 & 2223.393 & 465325.55 \\
7 & 7.384 & 2216.070 & 341986.25 \\
8 & 7.316 & 2195.721 & 496160.38 \\
9 & 7.295 & 2189.418 & 322364.09 \\
10 & 7.160 & 2148.991 & 246678.61 \\
11 & 7.156 & 2147.670 & 238269.11 \\
12 & 7.135 & 2141.338 & 403655.90 \\
13 & 7.110 & 2133.864 & 201827.95 \\
14 & 3.804 & 1141.785 & 224253.28 \\
15 & 3.320 & 996.492 & 4204748.95 \\
16 & 2.500 & 750.235 & 2918095.77 \\
17 & 1.957 & 587.264 & 187812.12 \\
18 & 1.915 & 574.659 & 221450.11 \\
19 & 1.733 & 520.035 & 193418.45 \\
20 & 1.707 & 512.322 & 213040.61 \\
21 & 1.468 & 440.471 & 134551.97 \\
22 & 1.435 & 430.567 & 140158.30 \\
23 & 1.293 & 388.188 & 145764.63 \\
24 & 1.261 & 378.584 & 199024.78 \\
--------------
\end{tabular}


DMSO- $d_{6}, 75 \mathrm{MHz}$
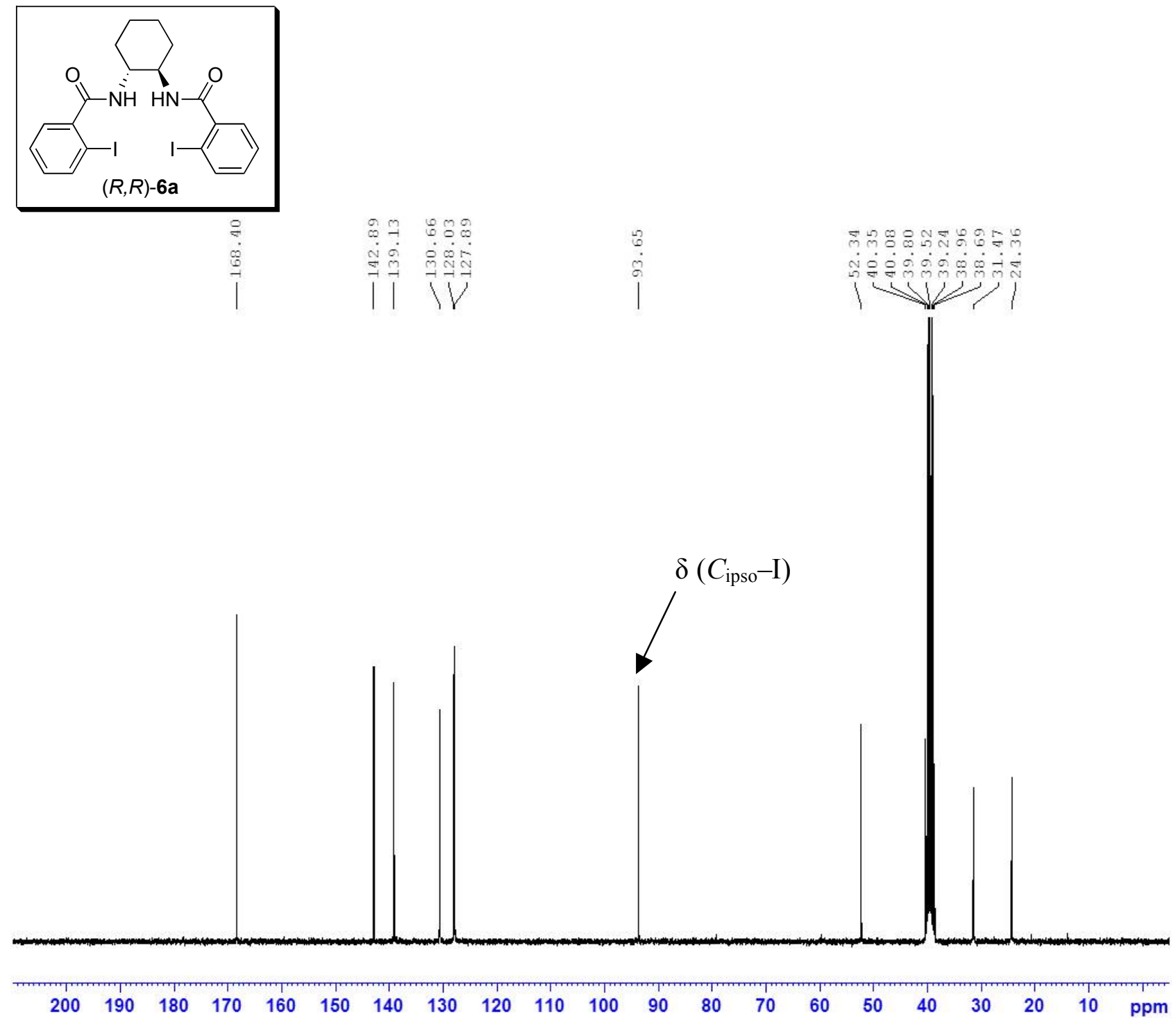
DMSO- $d_{6}, 300 \mathrm{MHz}$

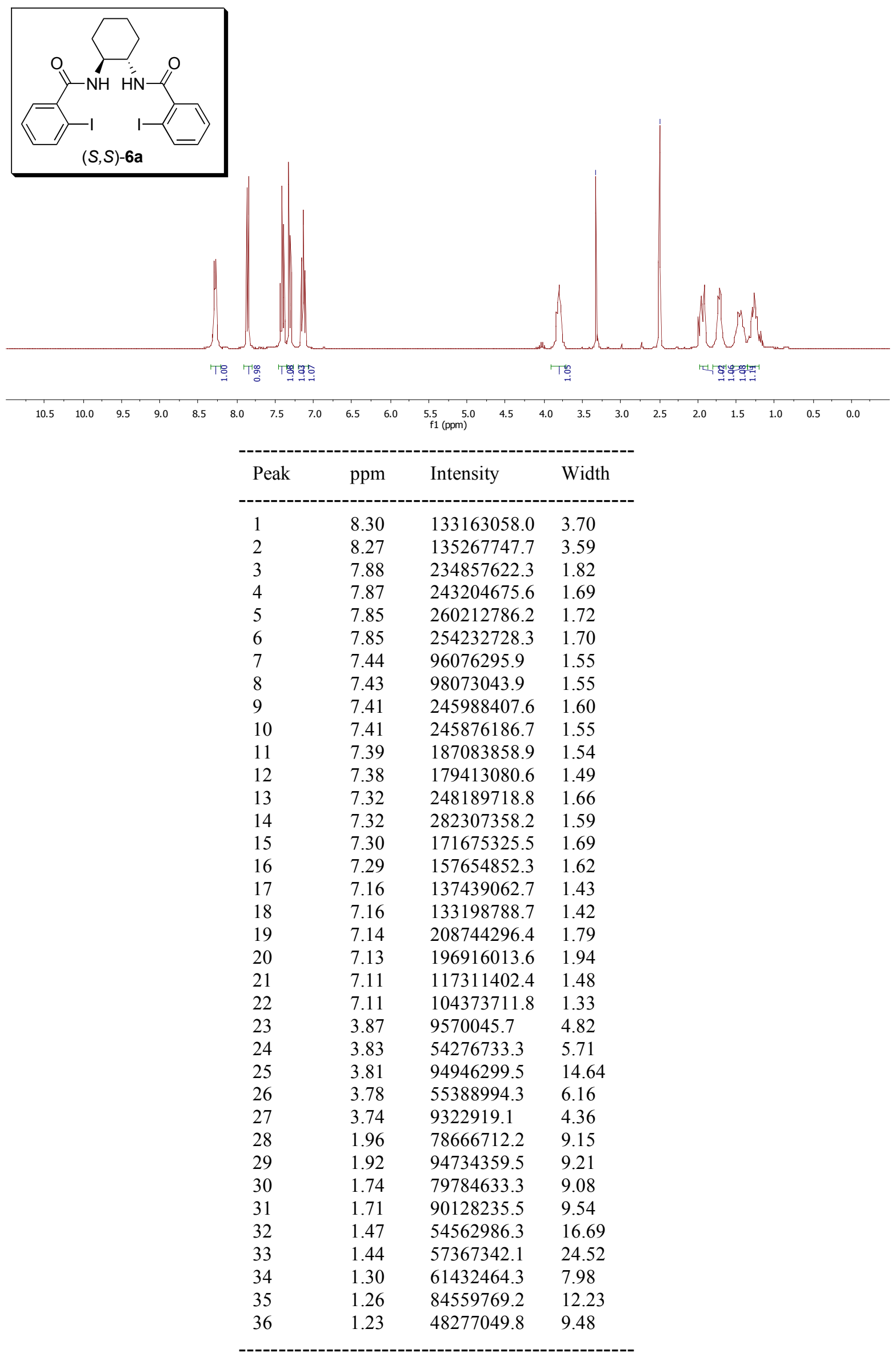


DMSO- $d_{6}, 75 \mathrm{MHz}$

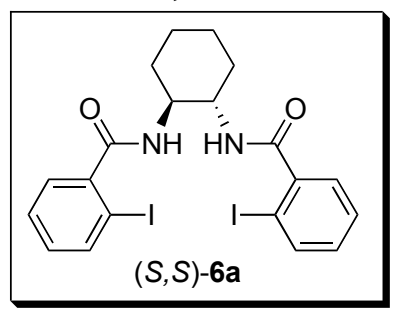

誌

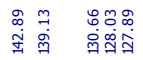

। । IV

$\stackrel{\leftrightarrow}{\circ}$

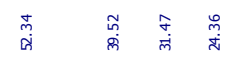

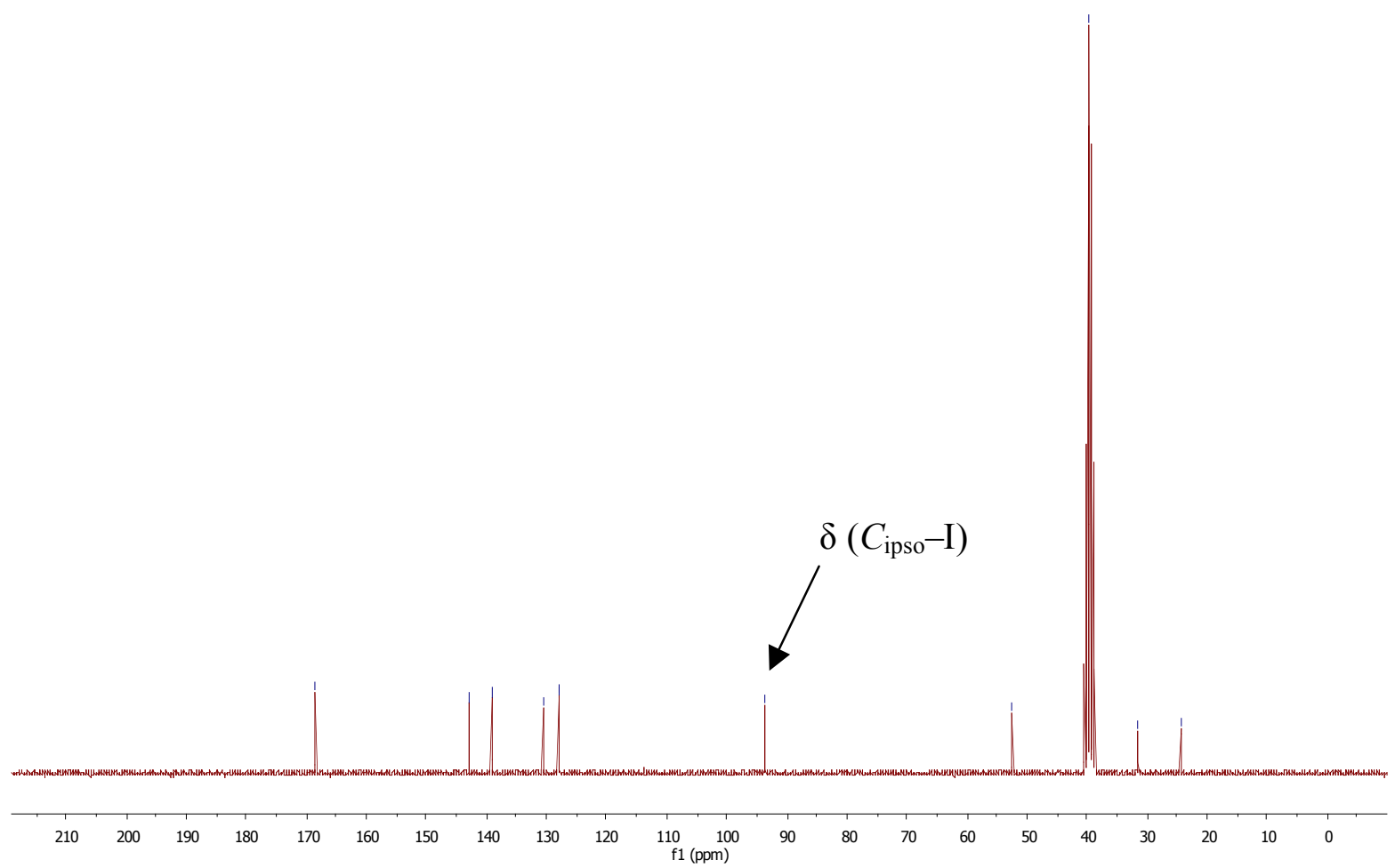


DMSO- $d_{6}, 300 \mathrm{MHz}$
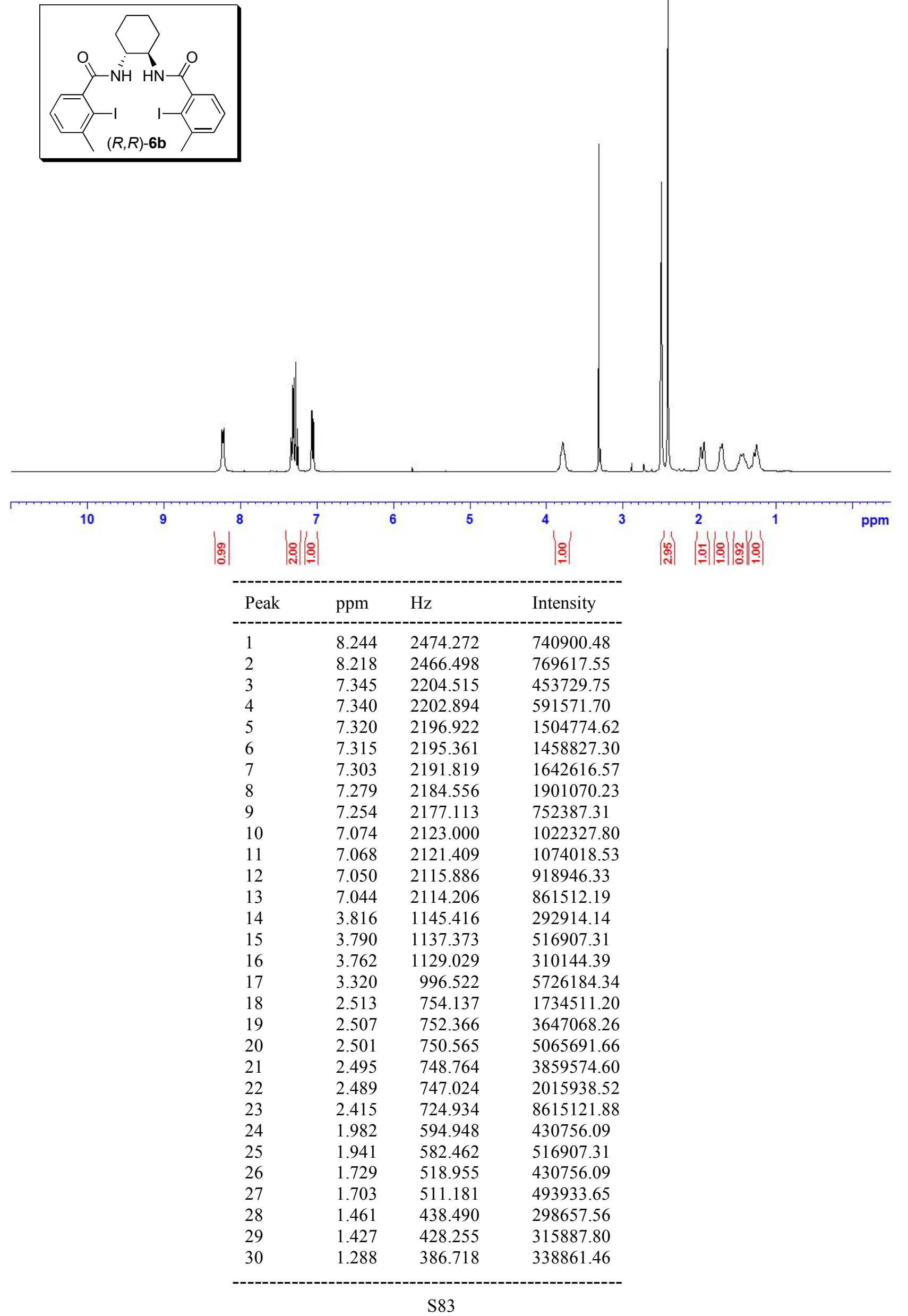
DMSO- $d_{6}, 75 \mathrm{MHz}$

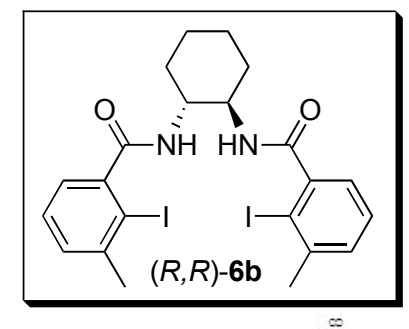

|lll

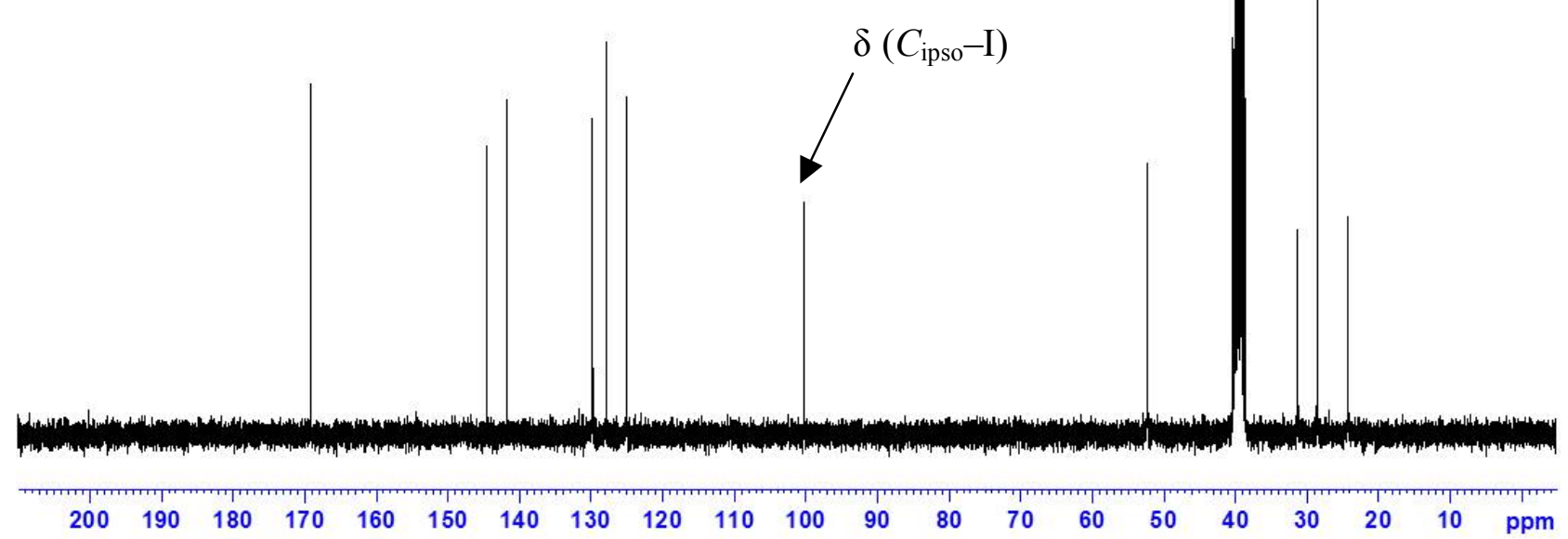


DMSO- $d_{6}, 300 \mathrm{MHz}$
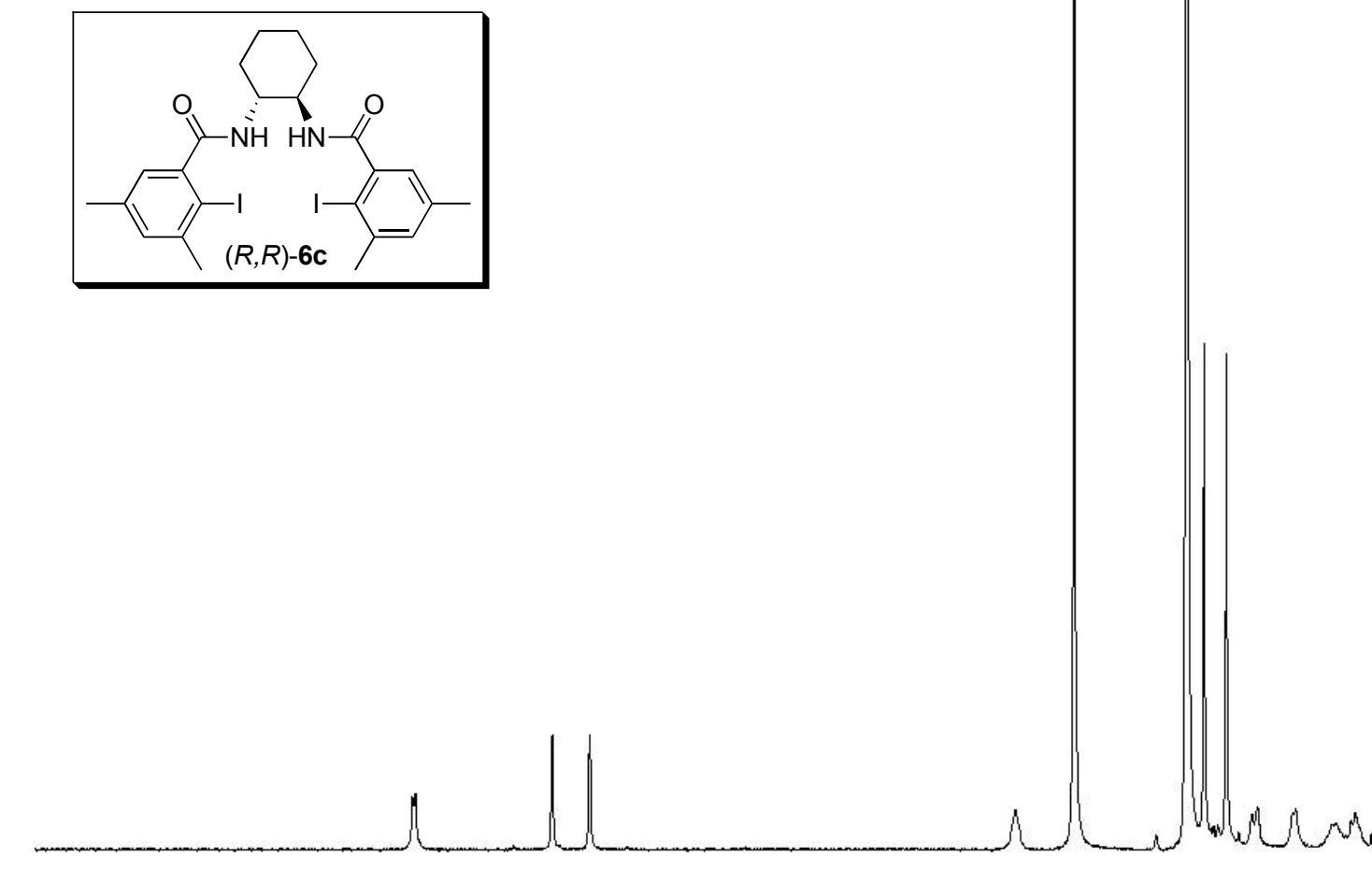

10

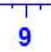

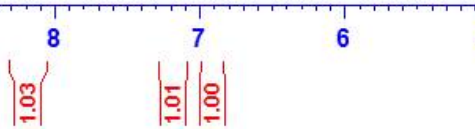

\section{5}

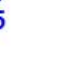

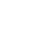

象|

$$
\text { Pea }
$$

------------

1$$
3
$$

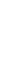$$
5
$$$$
\begin{aligned}
& 5 \\
& 6
\end{aligned}
$$$$
\begin{aligned}
& 6 \\
& 7
\end{aligned}
$$$$
8
$$$$
12
$$$$
1
$$$$
\text { (1) }
$$$$
15
$$$$
15
$$$$
15
$$$$
18
$$

\begin{tabular}{llll}
17 & 1.716 & 515.139 & 89083.23 \\
18 & 1.696 & 508.985 & 101809.41 \\
19 & 1.426 & 427.937 & 60449.34 \\
20 & 1.398 & 419.532 & 66812.42 \\
21 & 1.329 & 398.909 & 34996.98 \\
22 & 1.286 & 385.971 & 69993.97 \\
23 & 1.256 & 377.176 & 92264.78 \\
\hline
\end{tabular}

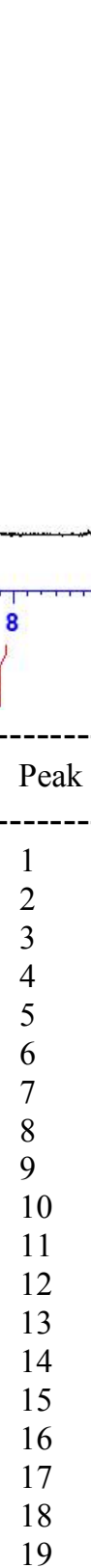


DMSO- $d_{6}, 75 \mathrm{MHz}$

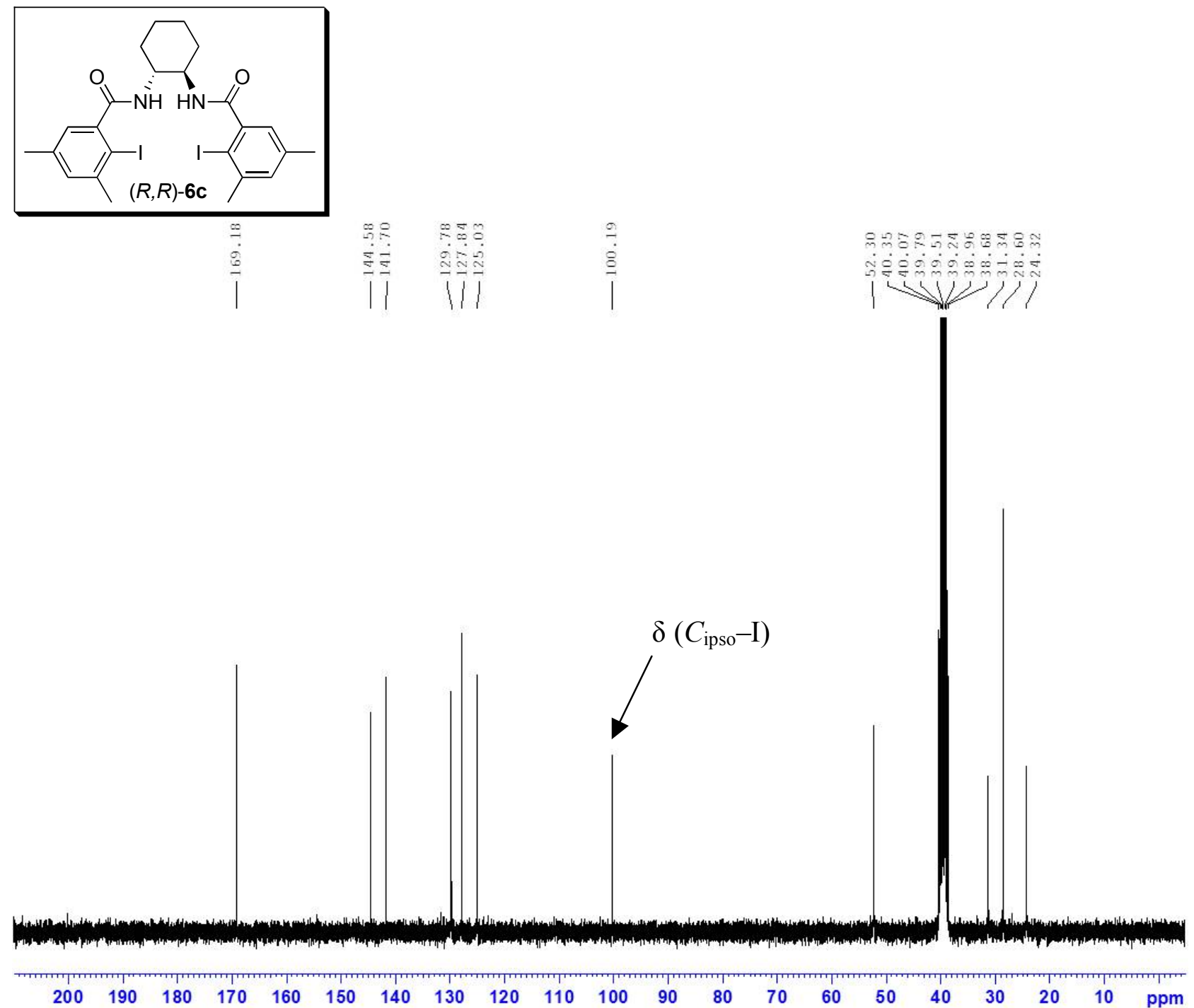


DMSO- $d_{6}, 300 \mathrm{MHz}$

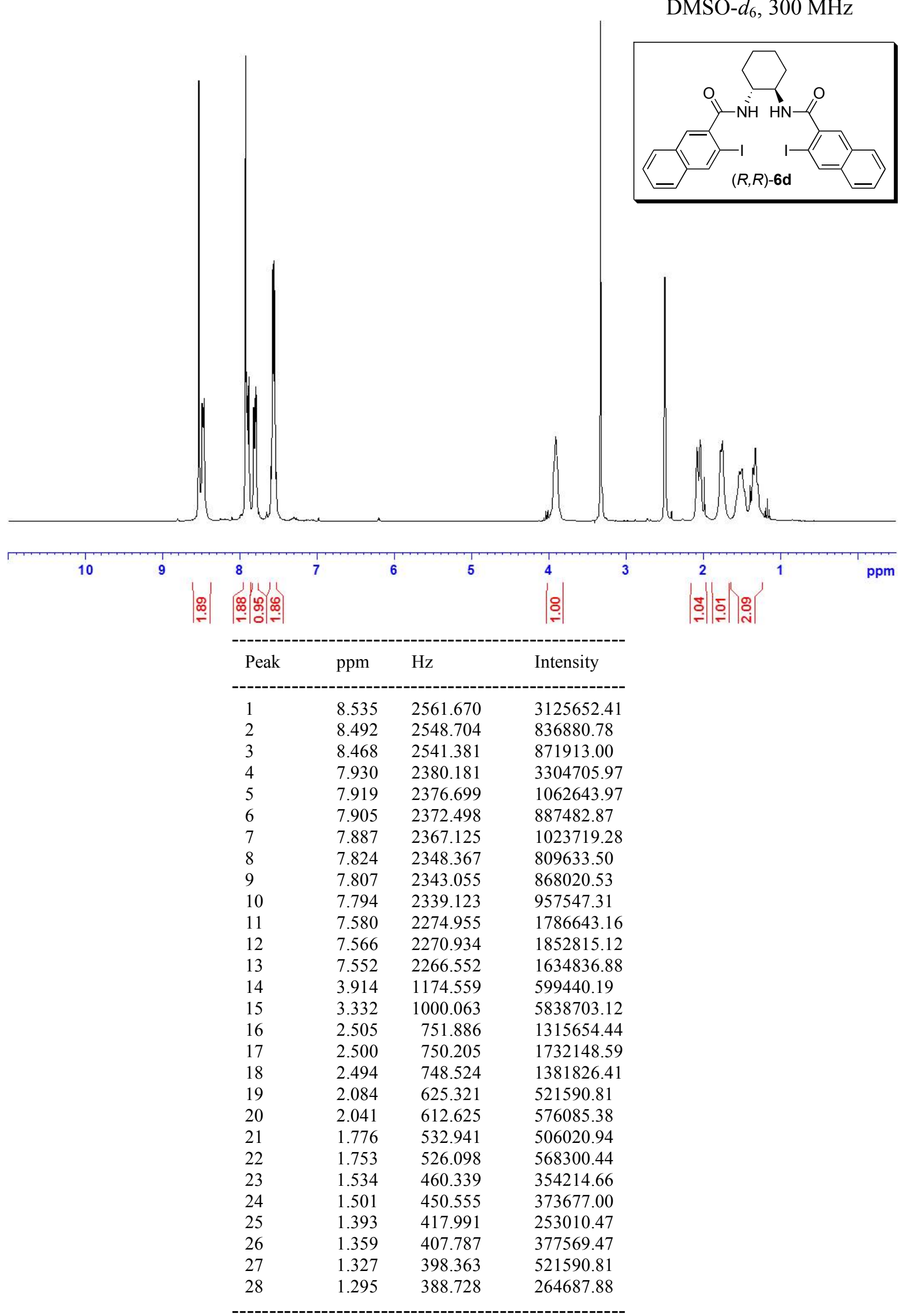


DMSO- $d_{6}, 75 \mathrm{MHz}$
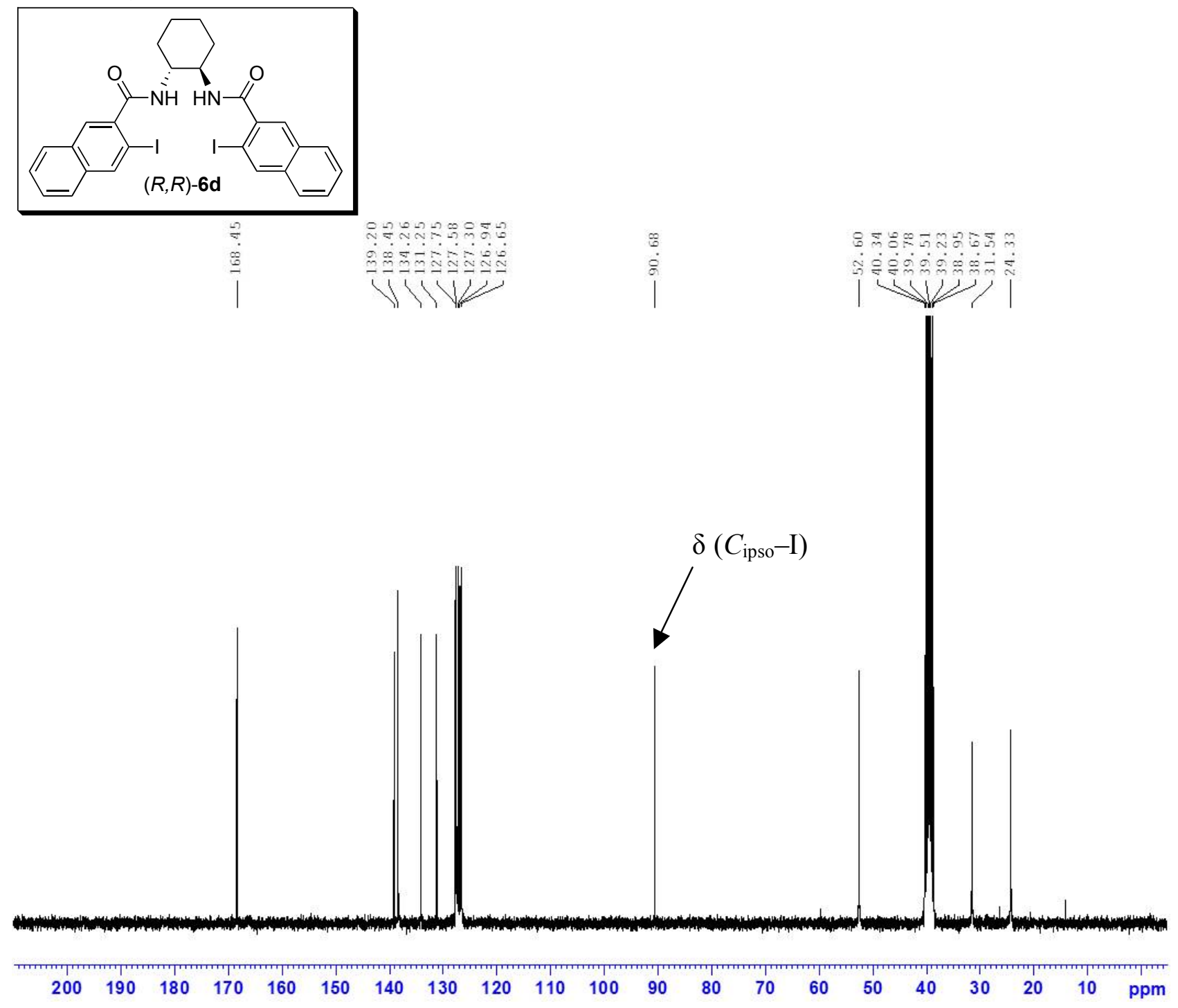
DMSO- $d_{6}, 300 \mathrm{MHz}$
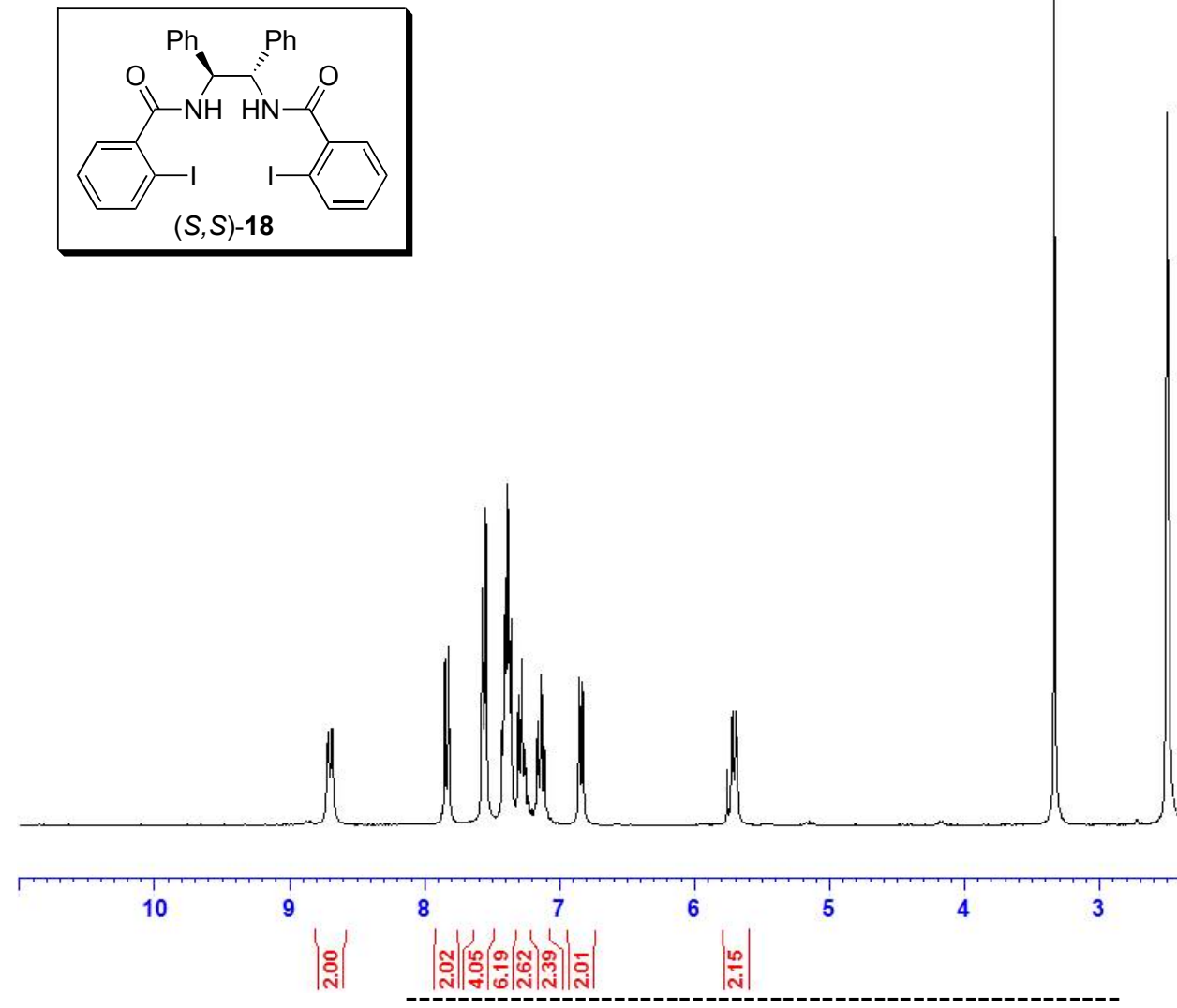

3

는

\begin{tabular}{|c|c|c|c|}
\hline Peak & ppm & $\mathrm{Hz}$ & Intensity \\
\hline 1 & 8.716 & 2616.489 & 961646.29 \\
\hline 2 & 8.688 & 2608.024 & 999806.86 \\
\hline 3 & 7.849 & 2356.113 & 1717225.52 \\
\hline 4 & 7.825 & 2348.818 & 1831707.22 \\
\hline 5 & 7.573 & 2273.293 & 2442276.30 \\
\hline 6 & 7.549 & 2265.969 & 3274176.66 \\
\hline 7 & 7.428 & 2229.707 & 984542.63 \\
\hline 8 & 7.425 & 2228.927 & 1022703.20 \\
\hline 9 & 7.410 & 2224.364 & 1976717.38 \\
\hline 10 & 7.404 & 2222.383 & 2556758.00 \\
\hline 11 & 7.386 & 2217.250 & 3526036.41 \\
\hline 12 & 7.361 & 2209.655 & 2121727.54 \\
\hline 13 & 7.306 & 2193.025 & 1335619.85 \\
\hline 14 & 7.282 & 2185.791 & 1724857.64 \\
\hline 15 & 7.258 & 2178.646 & 778475.57 \\
\hline 16 & 7.235 & 2171.892 & 297652.42 \\
\hline 17 & 7.167 & 2151.360 & 961646.29 \\
\hline 18 & 7.162 & 2149.829 & 1068495.88 \\
\hline 19 & 7.141 & 2143.645 & 1518790.57 \\
\hline 20 & 7.136 & 2142.205 & 1549319.03 \\
\hline 21 & 7.116 & 2136.051 & 816636.14 \\
\hline 22 & 7.111 & 2134.490 & 770843.46 \\
\hline 23 & 6.858 & 2058.634 & 1488262.12 \\
\hline 24 & 6.853 & 2057.254 & 1518790.57 \\
\hline 25 & 6.833 & 2051.100 & 1472997.89 \\
\hline 26 & 6.828 & 2049.719 & 1373780.42 \\
\hline 27 & 5.721 & 1717.450 & 1175345.47 \\
\hline 28 & 5.694 & 1709.165 & 1167713.36 \\
\hline 29 & 3.336 & 1001.521 & 11448170.16 \\
\hline 30 & 2.506 & 752.131 & 5670660.28 \\
\hline 31 & 2.500 & 750.420 & 7357357.35 \\
\hline 32 & 2.494 & 748.709 & 5830934.67 \\
\hline
\end{tabular}


DMSO- $d_{6}, 75 \mathrm{MHz}$
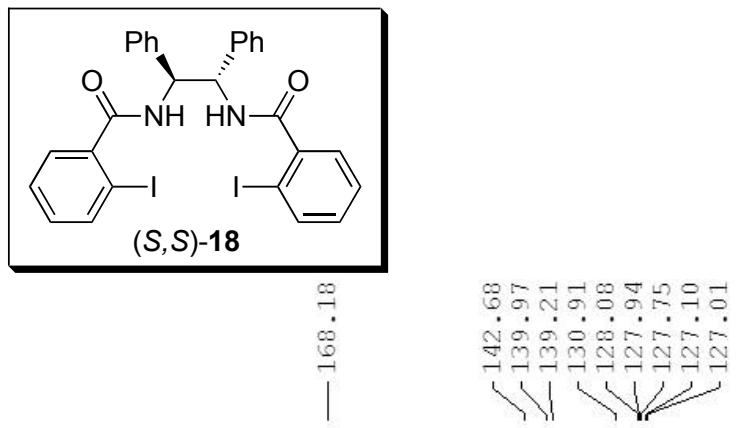

$$
\begin{gathered}
\infty \\
\dot{8} \\
\text { वे }
\end{gathered}
$$
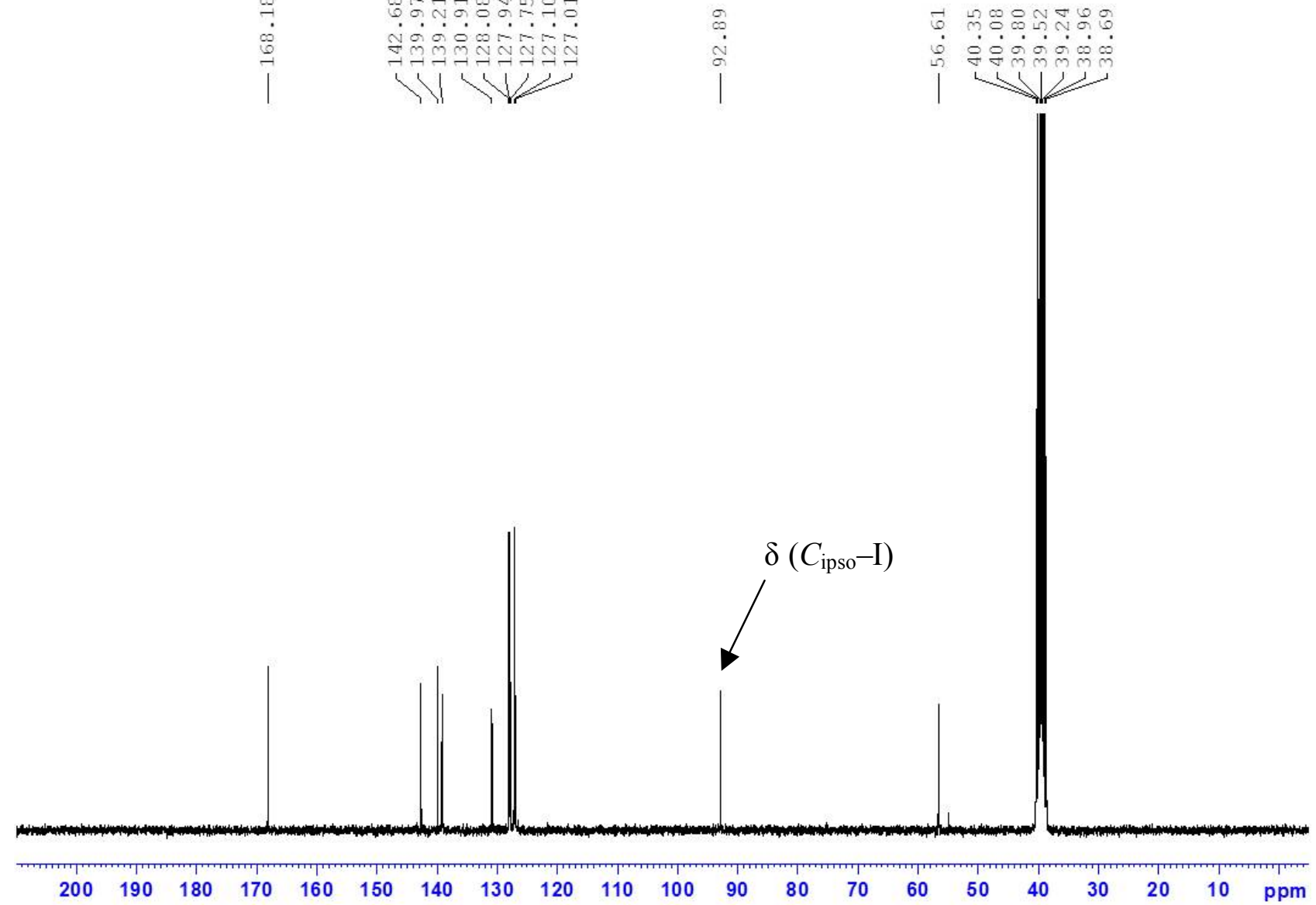
$\mathrm{CDCl}_{3}, 300 \mathrm{MHz}$

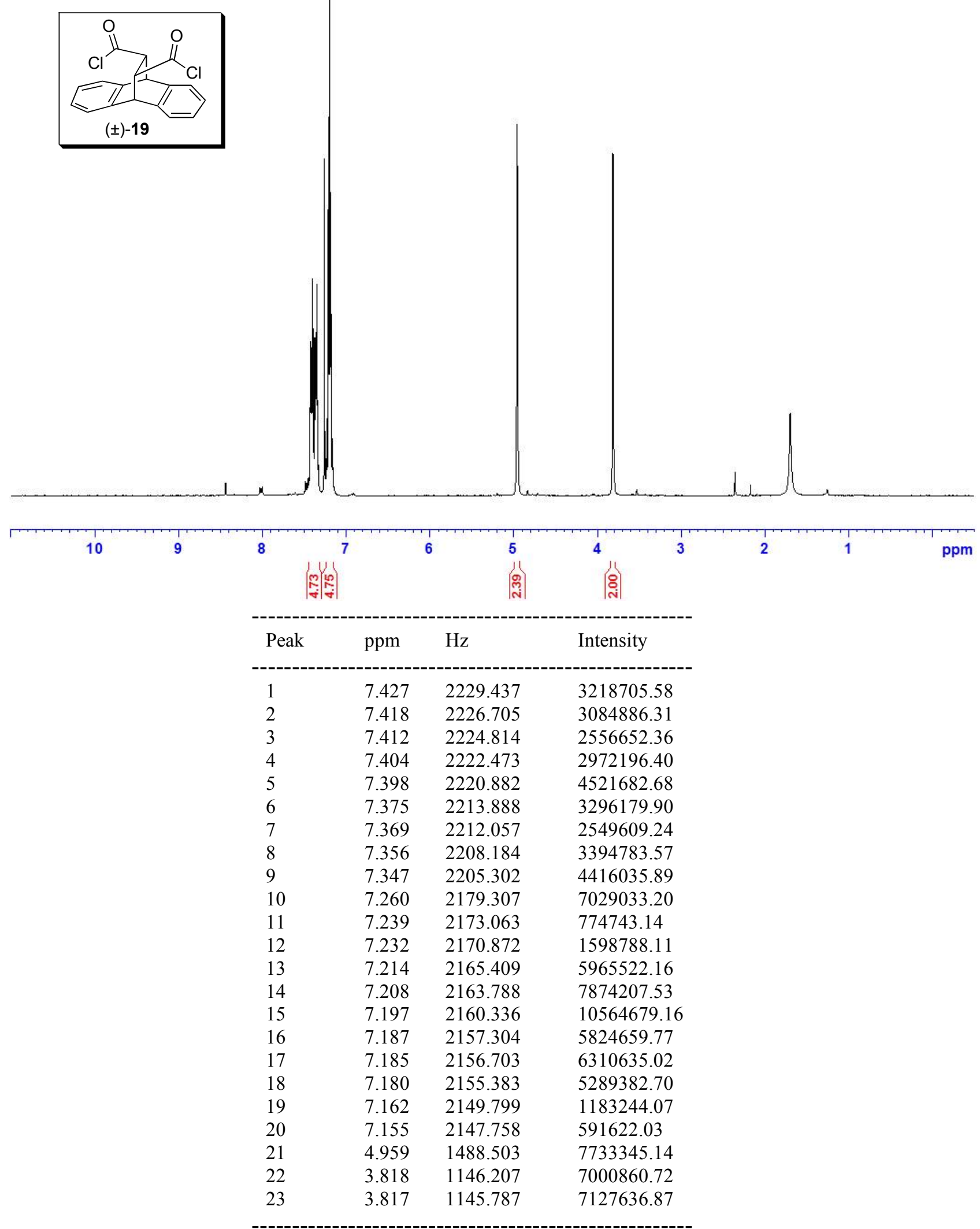


$\mathrm{CDCl}_{3}, 75 \mathrm{MHz}$

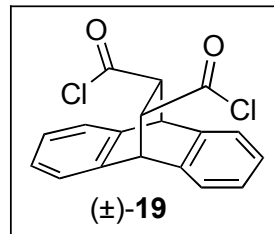

(士)-19

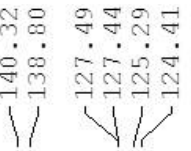

ir

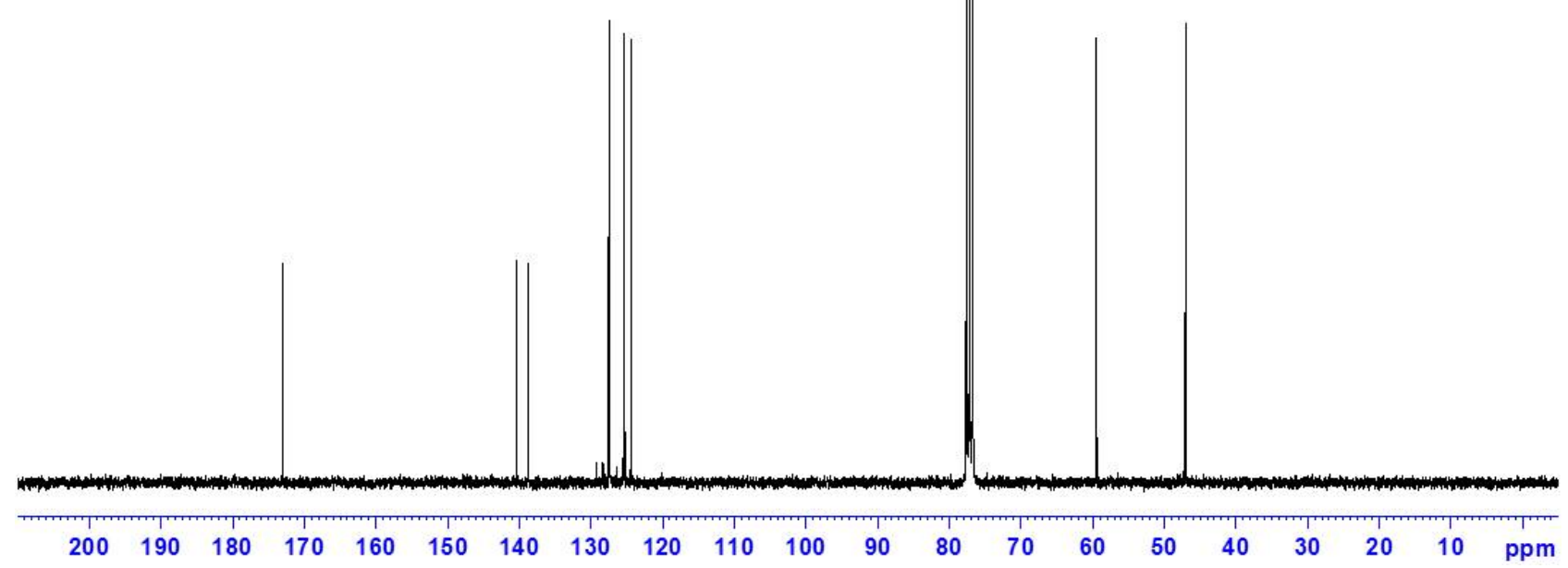


$\mathrm{CDCl}_{3}, 300 \mathrm{MHz}$

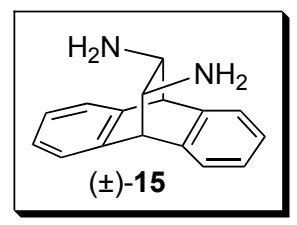

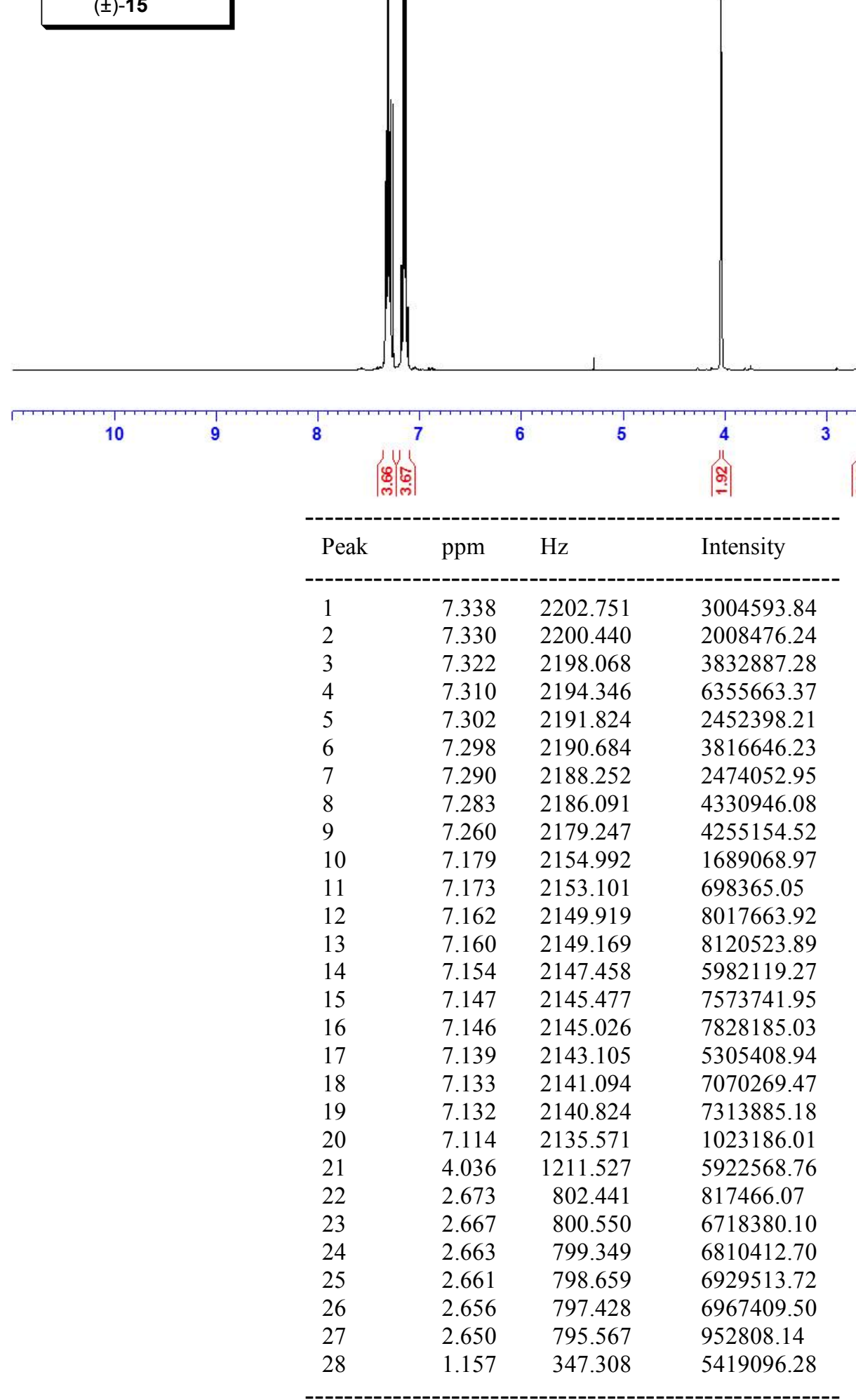


$\mathrm{CDCl}_{3}, 75 \mathrm{MHz}$
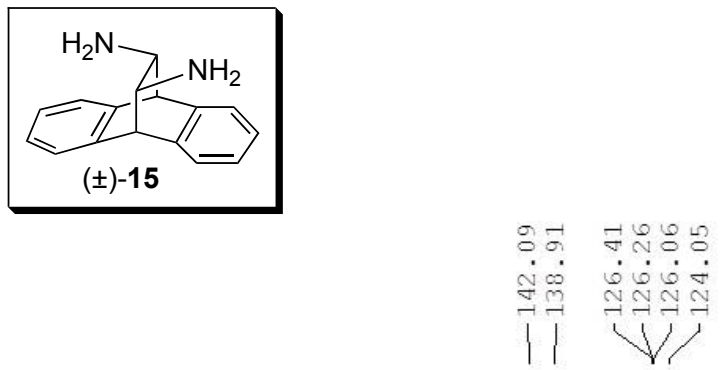

ข้

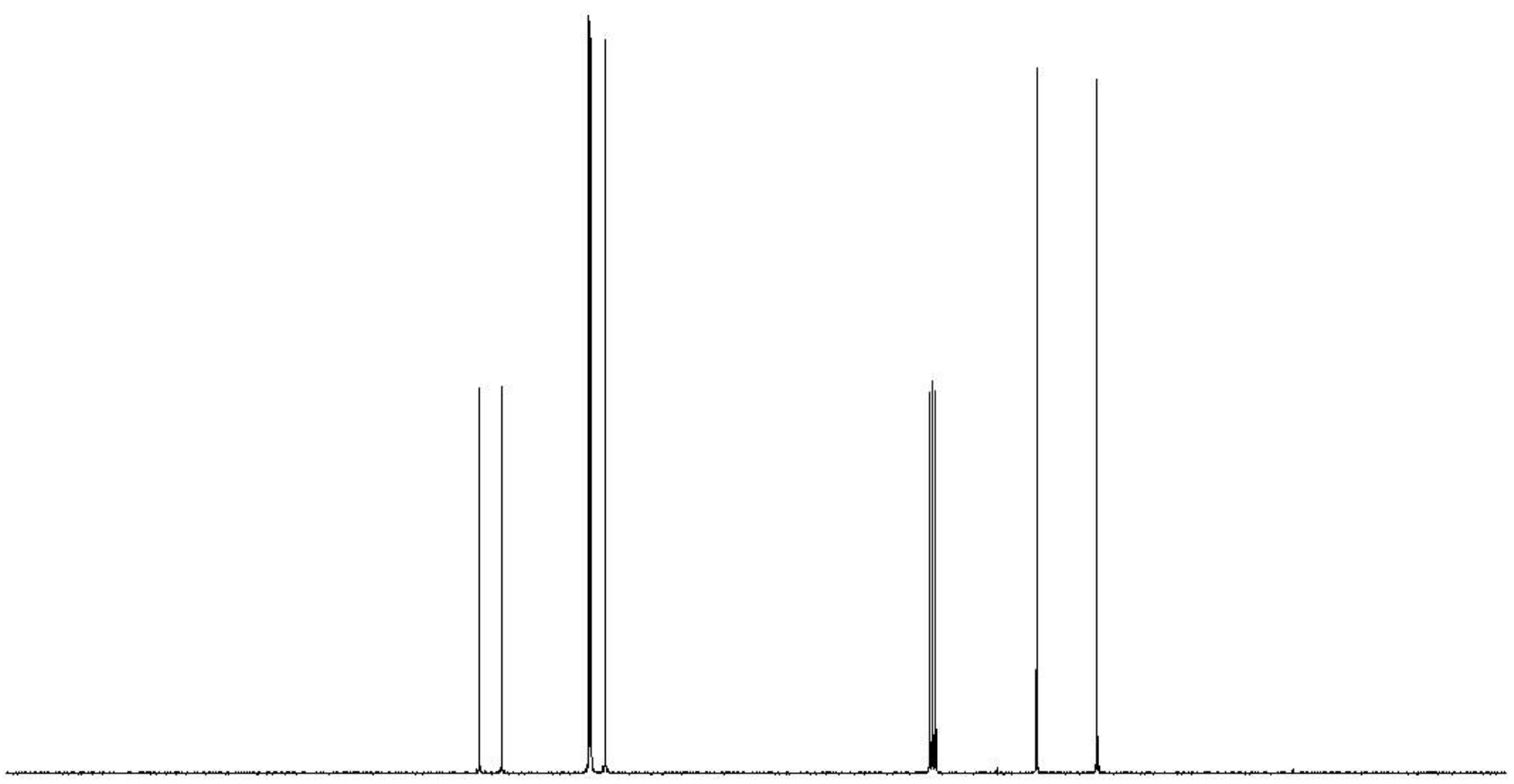

$\begin{array}{lllllllllllllllllllll}200 & 190 & 180 & 170 & 160 & 150 & 140 & 130 & 120 & 110 & 100 & 90 & 80 & 70 & 60 & 50 & 40 & 30 & 20 & 10 & \text { ppm }\end{array}$ 
DMSO- $d_{6}, 300 \mathrm{MHz}$
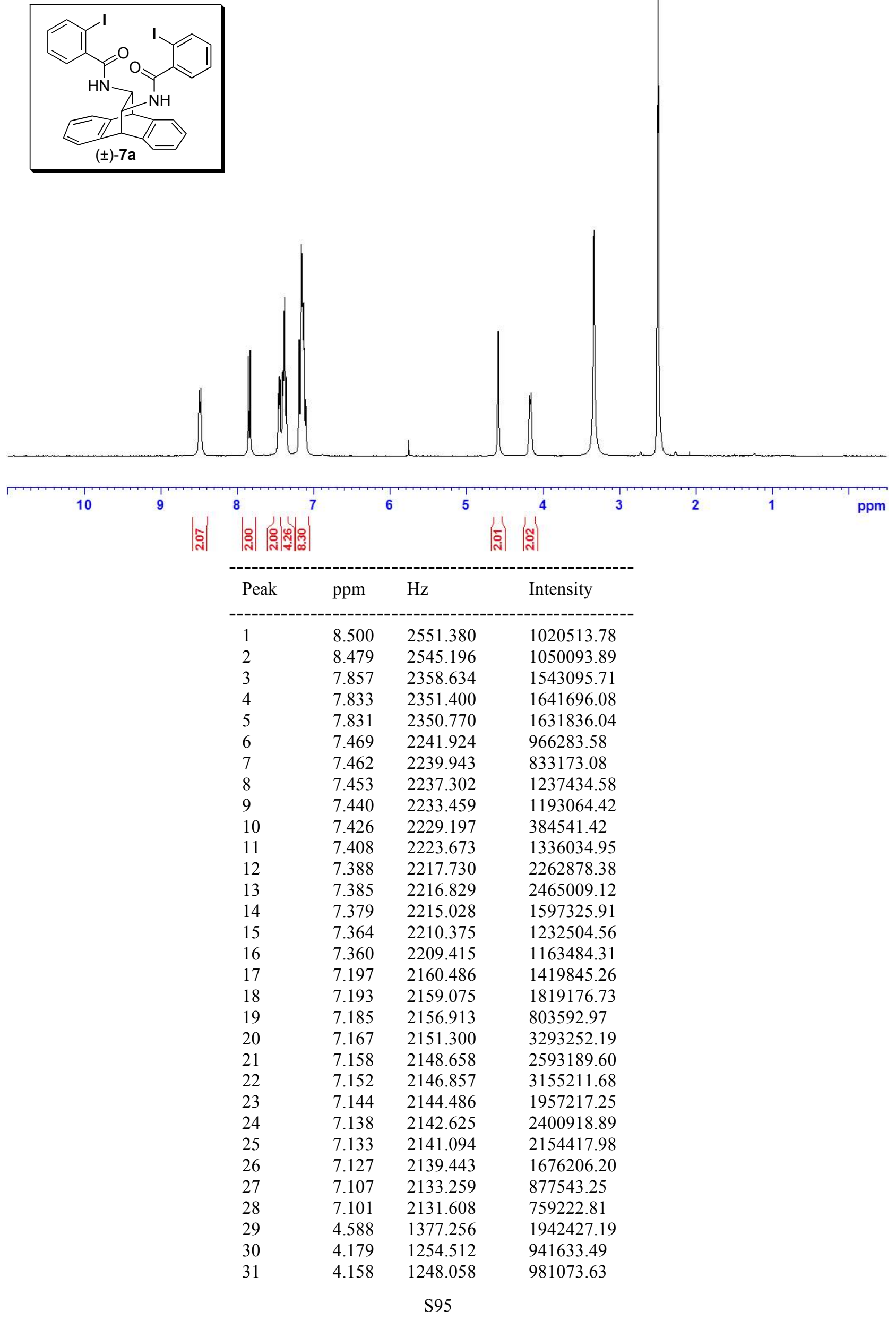


$\begin{array}{rrrr}32 & 3.338 & 1001.941 & 3515103.01 \\ 33 & 2.506 & 752.191 & 5477250.28 \\ 34 & 2.500 & 750.420 & 7395027.37 \\ 35 & 2.494 & 748.649 & 5891371.81\end{array}$

DMSO- $d_{6}, 75 \mathrm{MHz}$

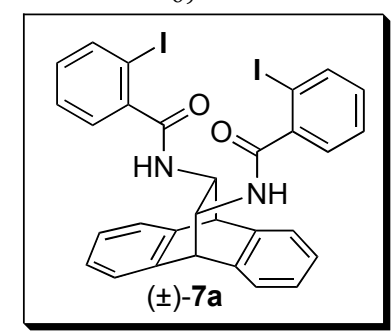

i
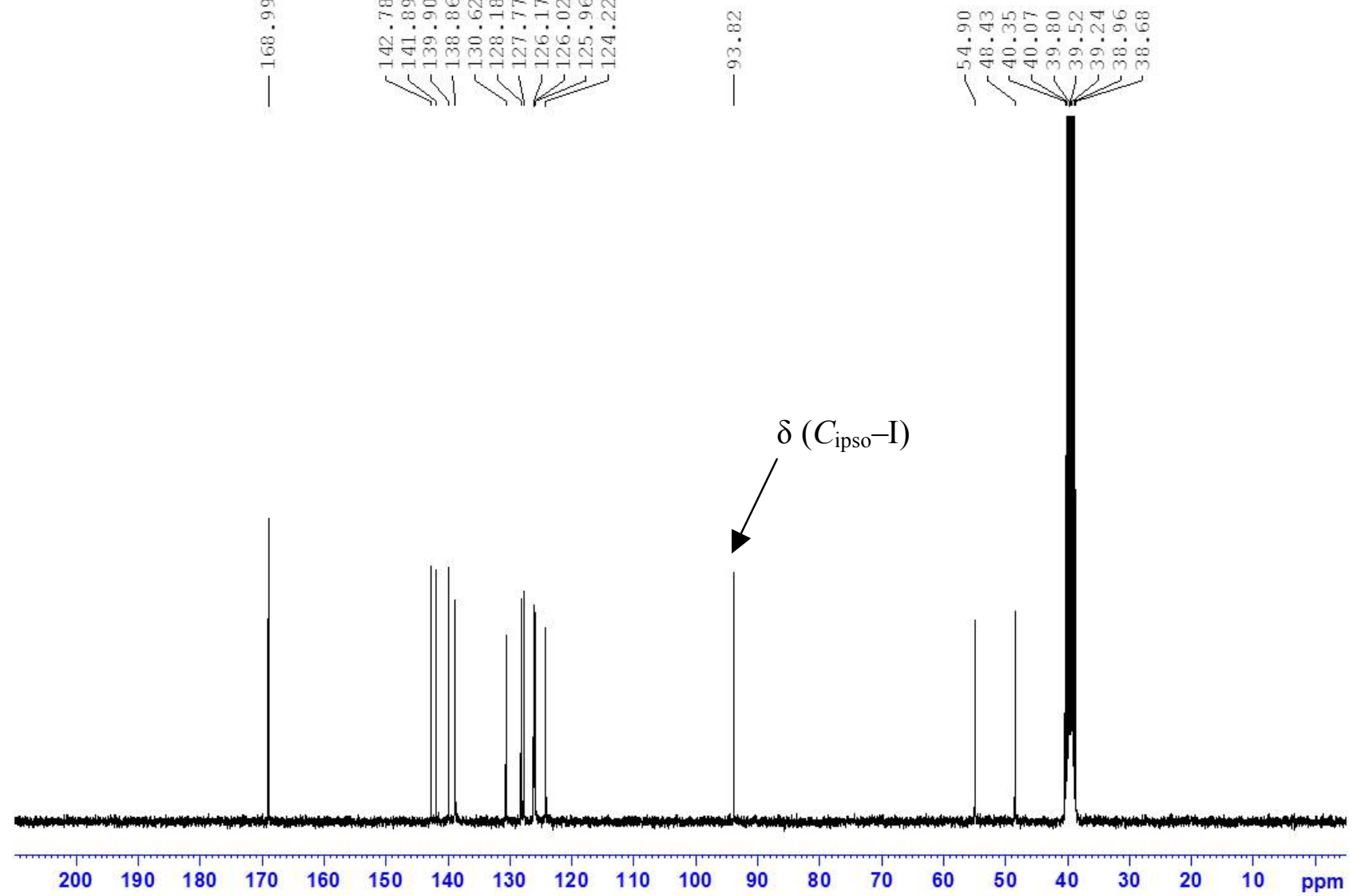
DMSO- $d_{6}, 300 \mathrm{MHz}$
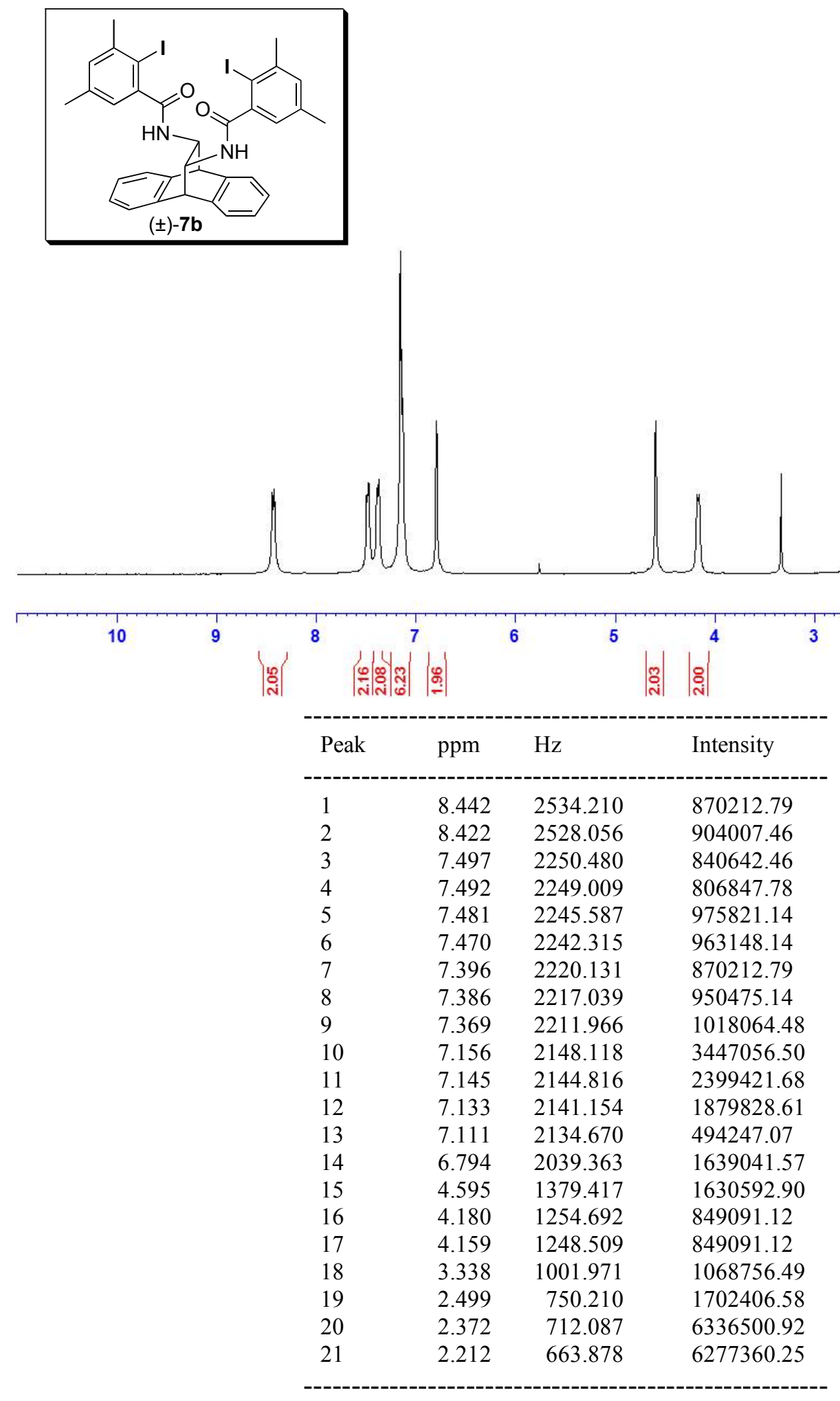
DMSO- $d_{6}, 75 \mathrm{MHz}$

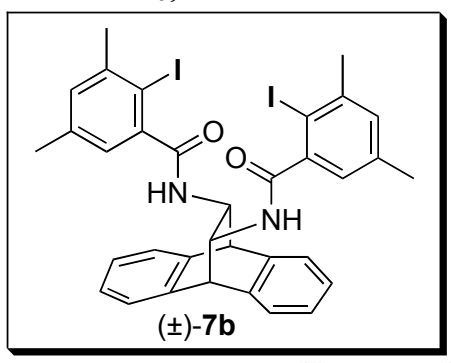

|

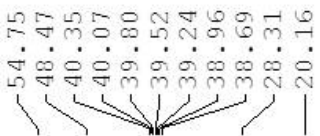

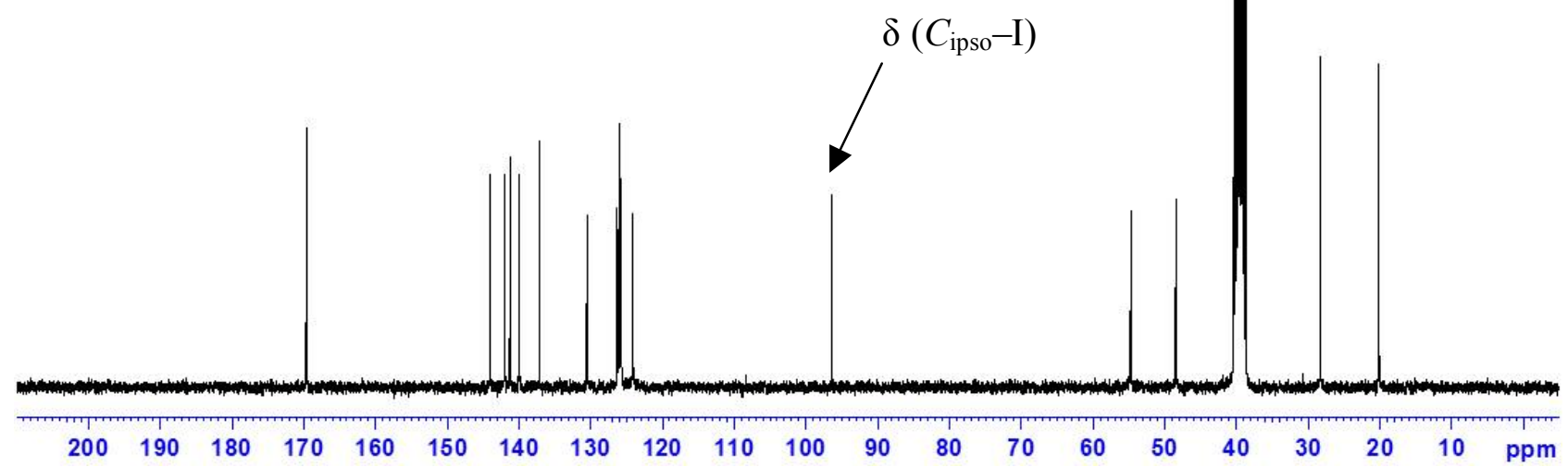


DMSO- $d_{6}, 300 \mathrm{MHz}$

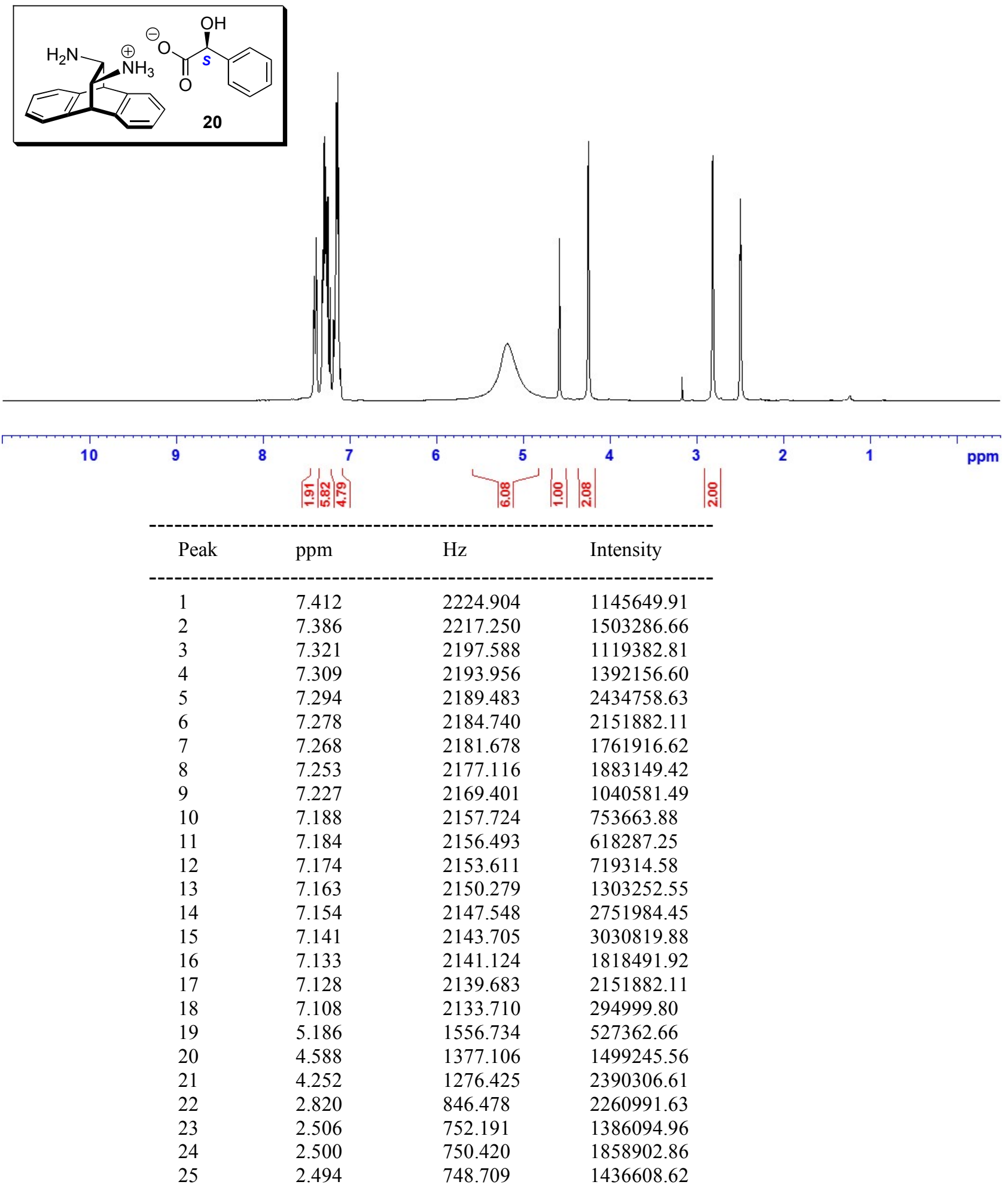


DMSO- $d_{6}, 75 \mathrm{MHz}$

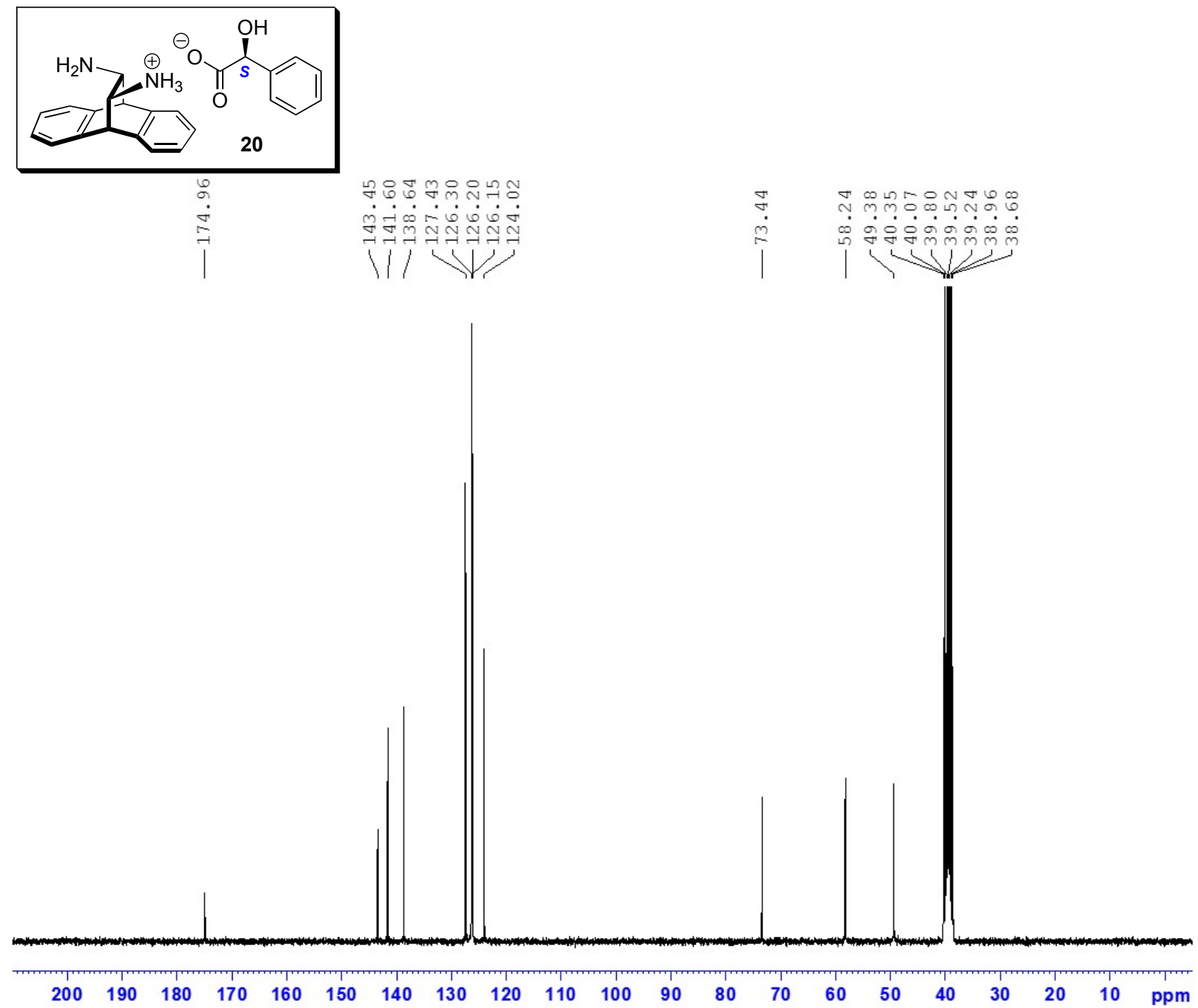


DMSO- $d_{6}, 300 \mathrm{MHz}$

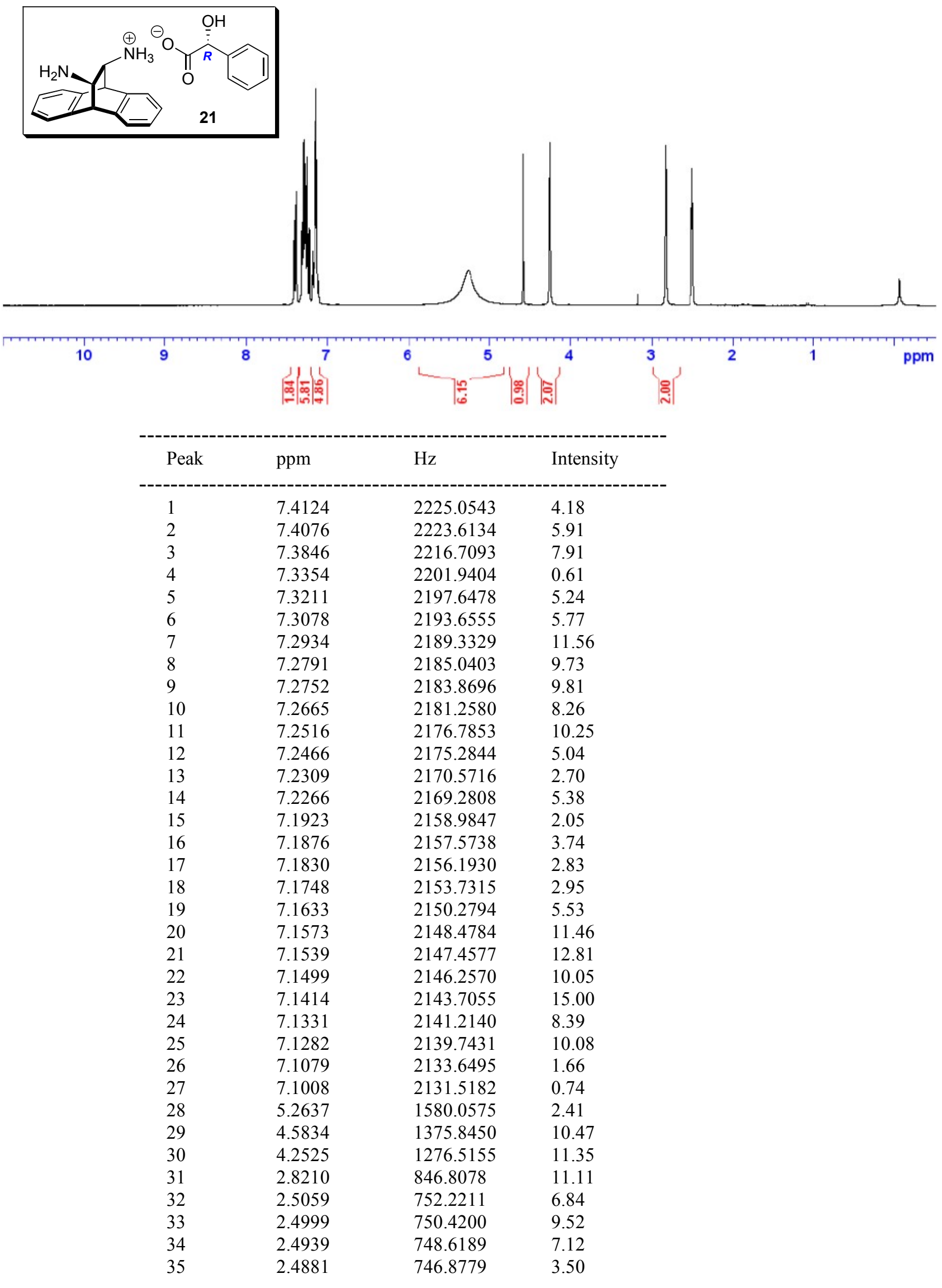


$\mathrm{CDCl}_{3}, 300 \mathrm{MHz}$

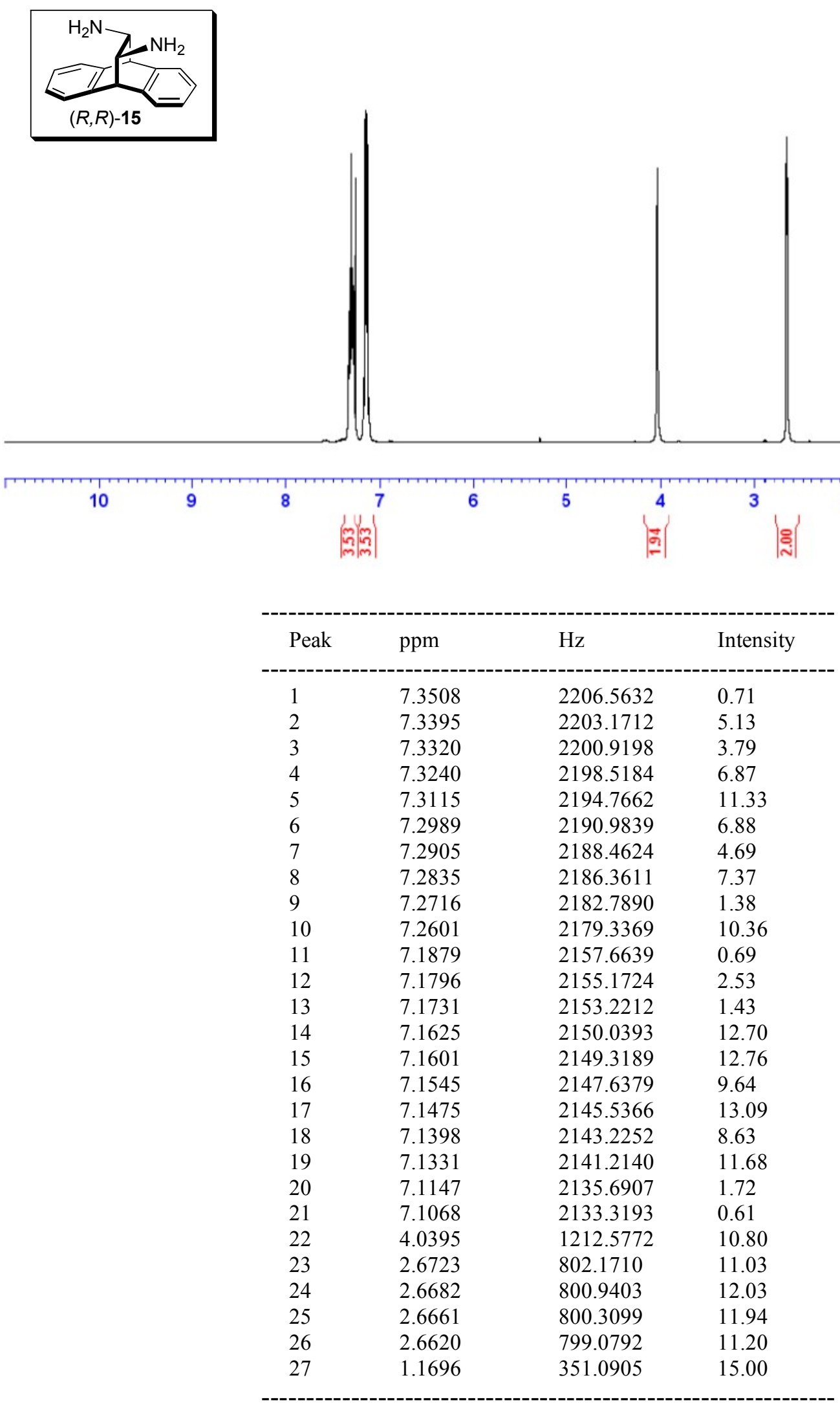


$\mathrm{CDCl}_{3}, 300 \mathrm{MHz}$
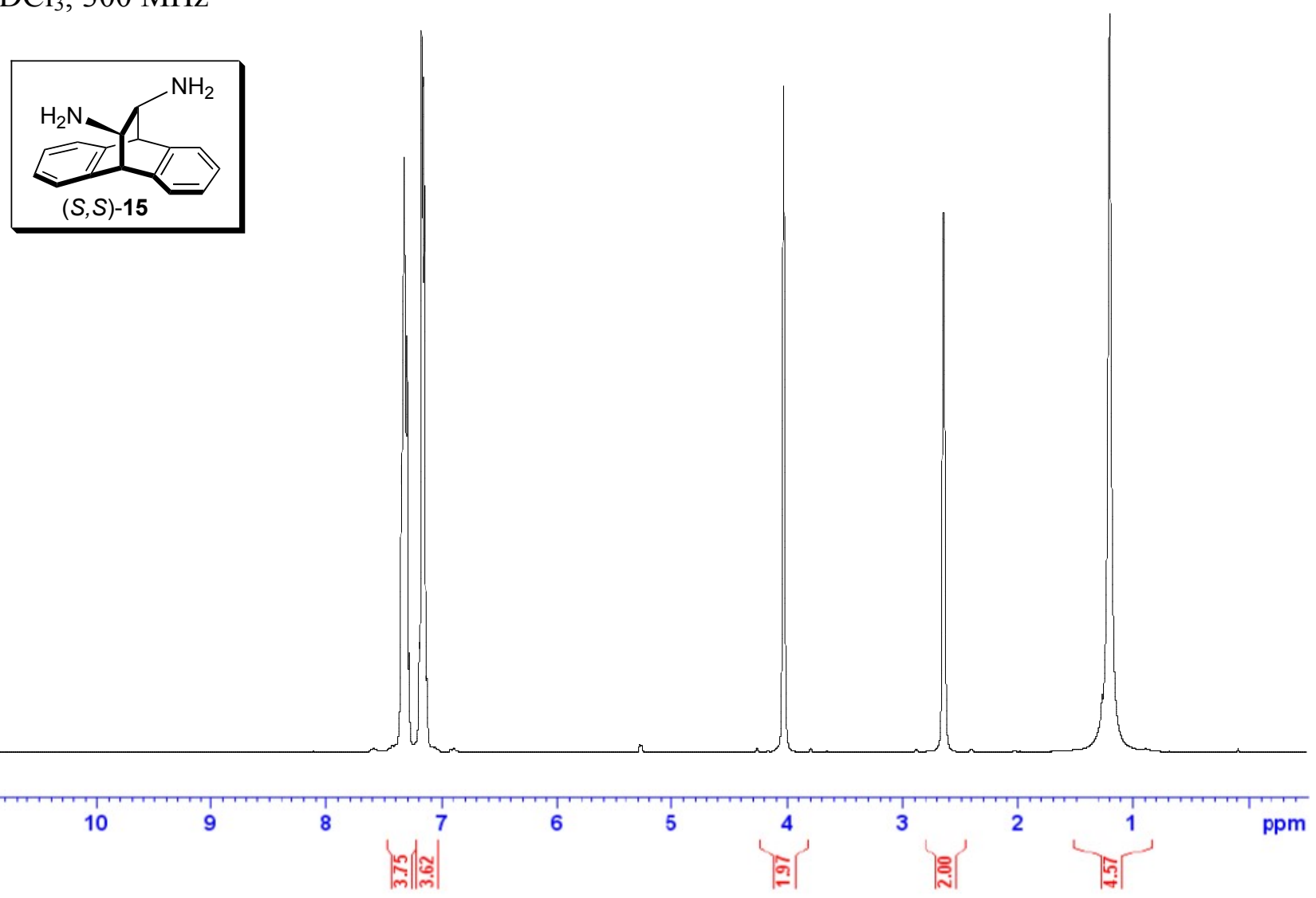

\begin{tabular}{llll} 
Peak & ppm & Hz & \multicolumn{1}{c}{ Intensity } \\
\hline 1 & 7.3267 & 2199.3289 & 5.82 \\
2 & 7.3036 & 2192.3947 & 12.09 \\
3 & 7.2781 & 2184.7401 & 8.46 \\
4 & 7.2596 & 2179.1868 & 2.03 \\
5 & 7.1696 & 2152.1706 & 2.23 \\
6 & 7.1541 & 2147.5178 & 14.66 \\
7 & 7.1407 & 2143.4954 & 13.71 \\
8 & 7.1280 & 2139.6831 & 11.52 \\
9 & 7.1098 & 2134.2198 & 1.55 \\
10 & 4.0213 & 1207.1139 & 13.54 \\
11 & 2.6386 & 792.0550 & 10.95 \\
12 & 1.2009 & 360.4862 & 15.00 \\
-------------------------------------------------------
\end{tabular}


$\mathrm{CDCl}_{3}, 300 \mathrm{MHz}$

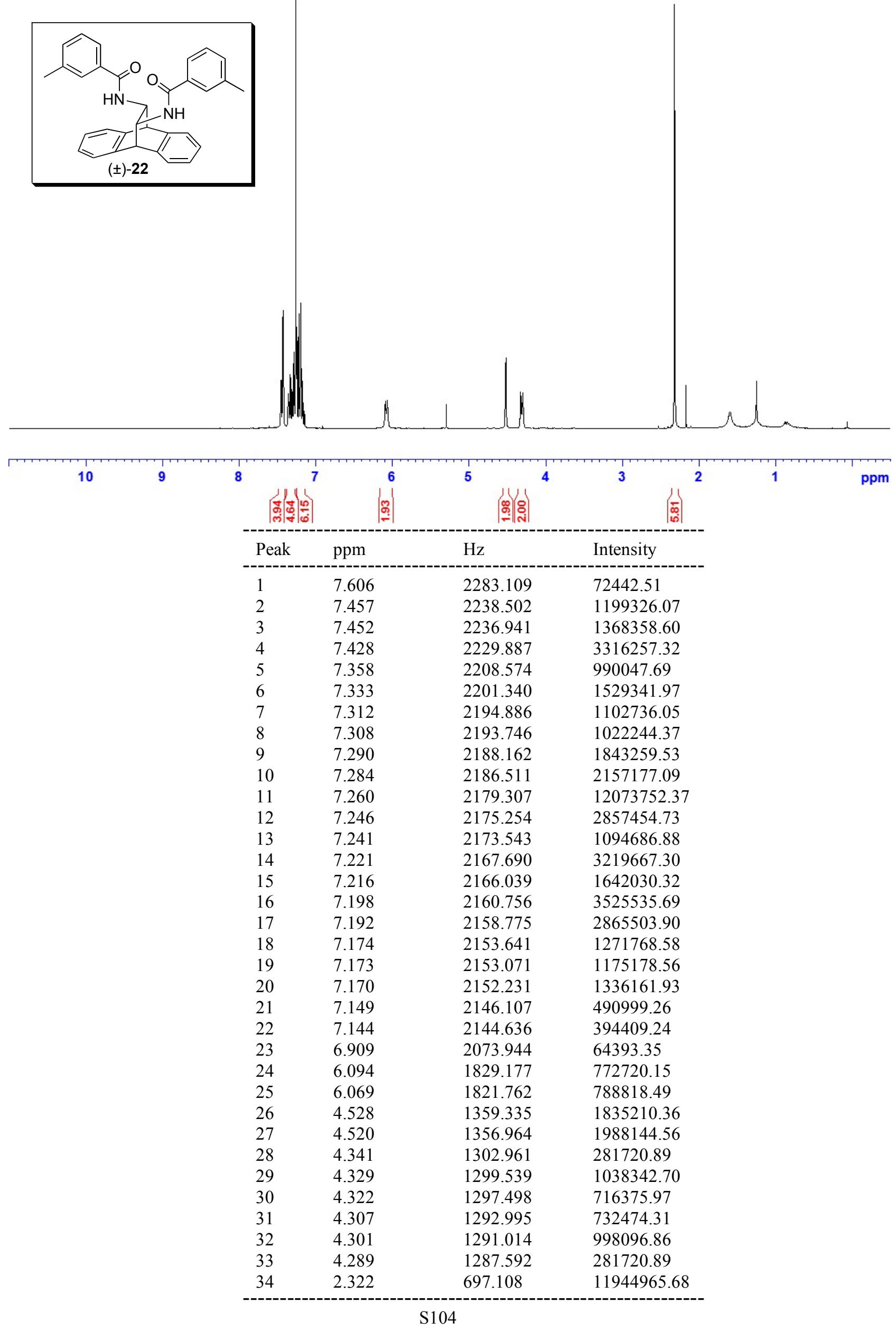


$\mathrm{CDCl}_{3}, 75 \mathrm{MHz}$

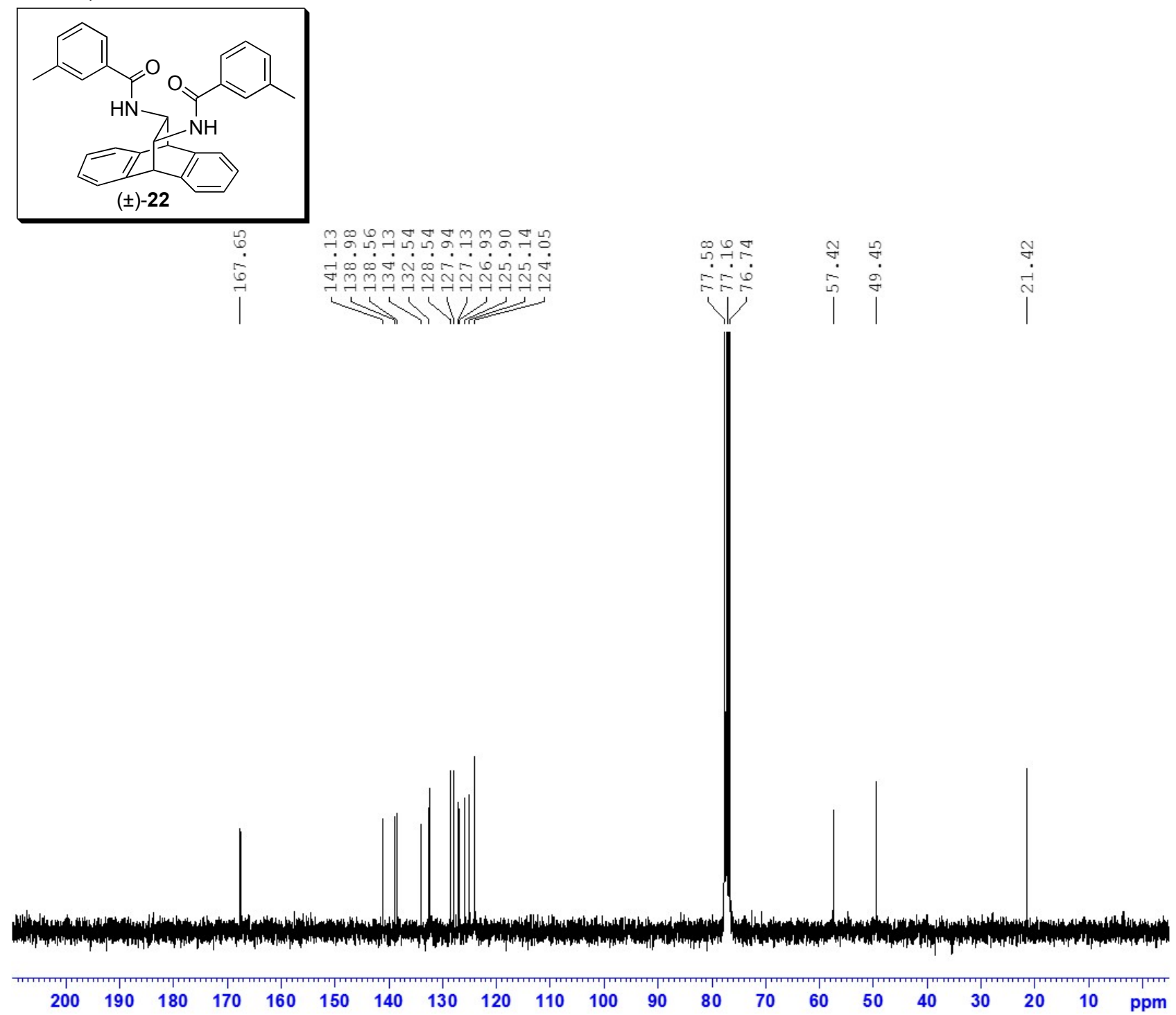


$\mathrm{CDCl}_{3}, 300 \mathrm{MHz}$
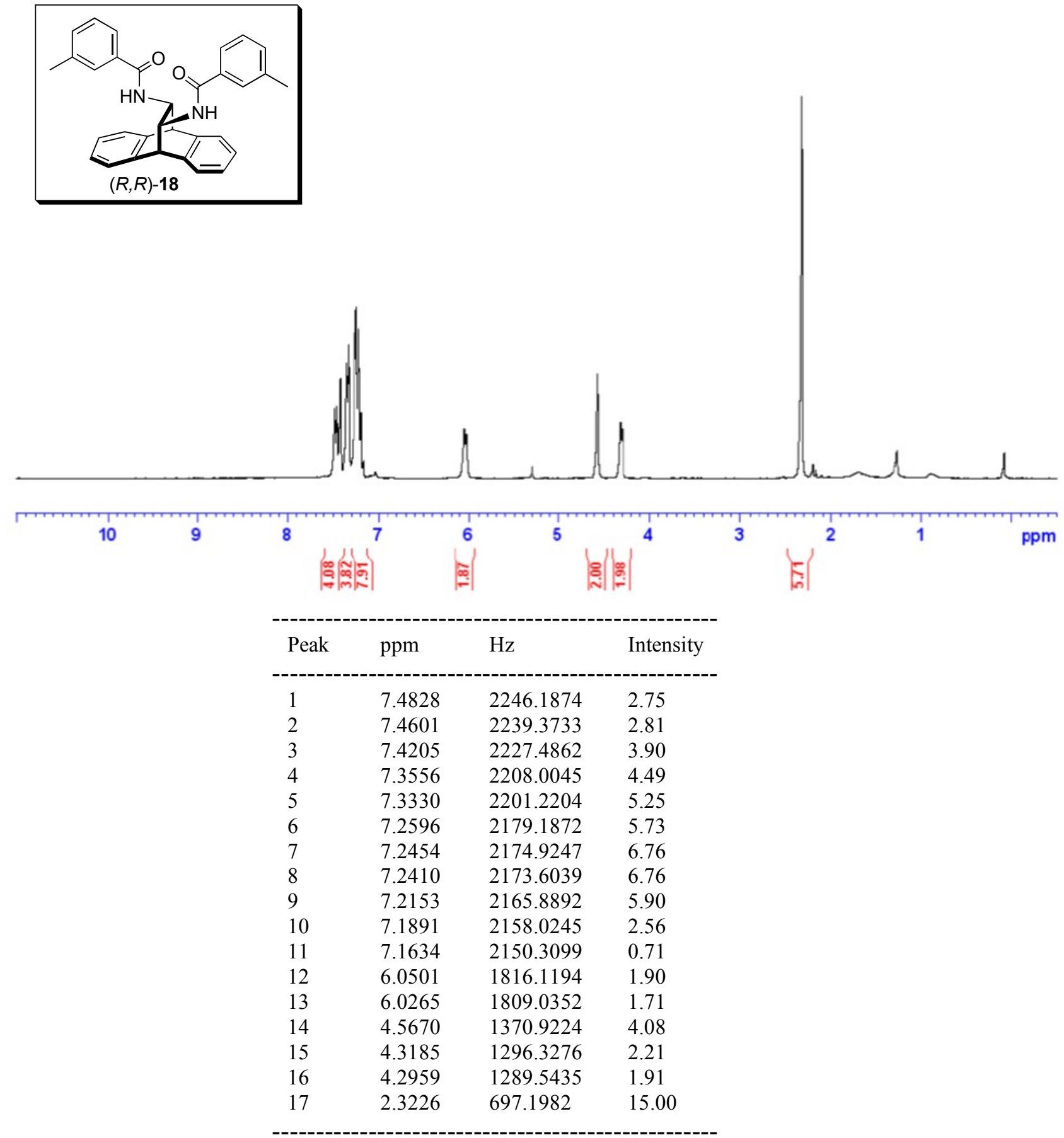

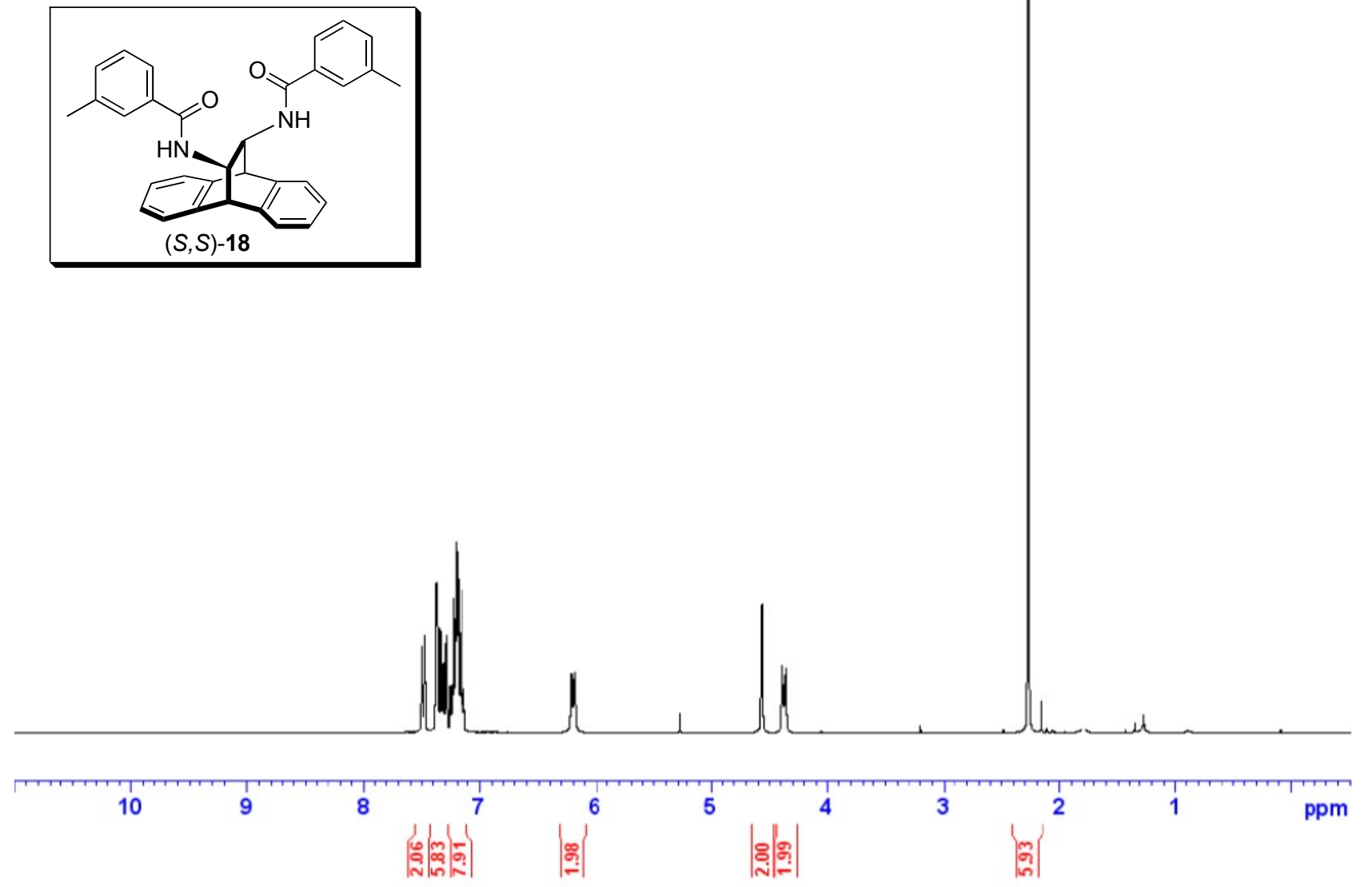

\begin{tabular}{|c|c|c|c|}
\hline Peak & ppm & $\mathrm{Hz}$ & Intensity \\
\hline 1 & 7.4978 & 2250.6897 & 1.62 \\
\hline 2 & 7.4939 & 2249.5190 & 1.76 \\
\hline 3 & 7.4714 & 2242.7649 & 1.97 \\
\hline 4 & 7.3752 & 2213.8876 & 3.02 \\
\hline 5 & 7.3667 & 2211.3361 & 2.36 \\
\hline 6 & 7.3416 & 2203.8016 & 2.10 \\
\hline 7 & 7.3371 & 2202.4508 & 2.05 \\
\hline 8 & 7.3174 & 2196.5372 & 1.42 \\
\hline 9 & 7.2929 & 2189.1828 & 1.97 \\
\hline 10 & 7.2600 & 2179.3069 & 0.95 \\
\hline 11 & 7.2529 & 2177.1756 & 0.80 \\
\hline 12 & 7.2480 & 2175.7047 & 0.97 \\
\hline 13 & 7.2276 & 2169.5810 & 2.70 \\
\hline 14 & 7.2236 & 2168.3803 & 2.27 \\
\hline 15 & 7.2051 & 2162.8270 & 3.83 \\
\hline 16 & 7.1985 & 2160.8458 & 3.63 \\
\hline 17 & 7.1921 & 2158.9247 & 2.59 \\
\hline 18 & 7.1867 & 2157.3037 & 3.11 \\
\hline 19 & 7.1737 & 2153.4013 & 2.02 \\
\hline 20 & 7.1697 & 2152.2006 & 2.03 \\
\hline 21 & 7.1619 & 2149.8592 & 2.88 \\
\hline 22 & 7.1490 & 2145.9869 & 0.84 \\
\hline 23 & 7.1444 & 2144.6061 & 0.69 \\
\hline 24 & 7.1370 & 2142.3847 & 0.91 \\
\hline 25 & 6.2124 & 1864.8383 & 1.20 \\
\hline 26 & 6.1870 & 1857.2137 & 1.22 \\
\hline 27 & 4.5728 & 1372.6632 & 2.48 \\
\hline 28 & 4.5654 & 1370.4418 & 2.61 \\
\hline 29 & 4.3866 & 1316.7696 & 1.37 \\
\hline 30 & 4.3802 & 1314.8485 & 0.97 \\
\hline 31 & 4.3646 & 1310.1657 & 1.00 \\
\hline 32 & 4.3581 & 1308.2145 & 1.30 \\
\hline 33 & 2.2767 & 683.4198 & 15.00 \\
\hline
\end{tabular}


DMSO- $d_{6}, 300 \mathrm{MHz}$
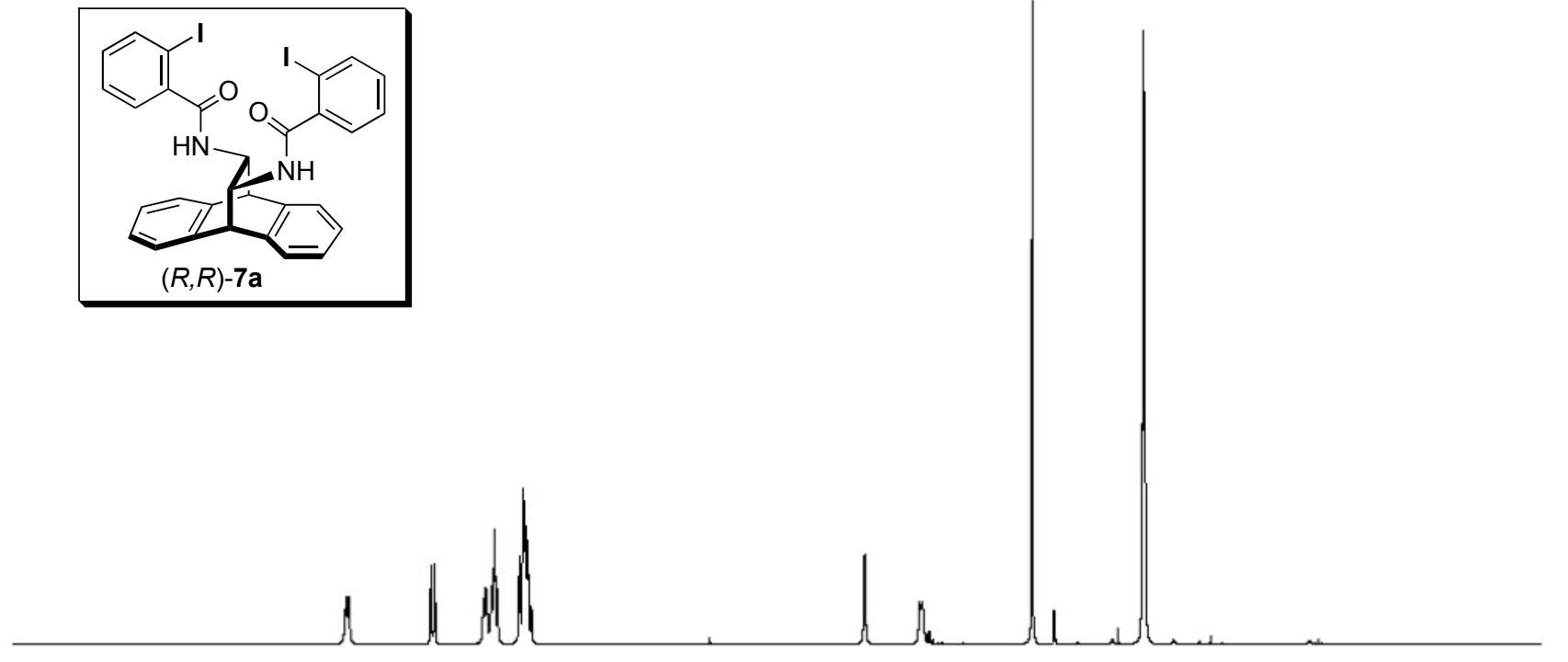

$10 \quad 9$

$\begin{array}{llll}7 & 6 & 5\end{array}$

4

3

ppm

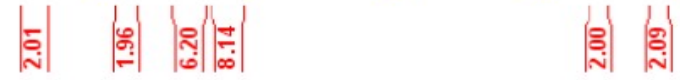

\begin{tabular}{|c|c|c|c|}
\hline Peak & ppm & $\mathrm{Hz}$ & Intensity \\
\hline 1 & 8.5027 & 2552.3405 & 1.11 \\
\hline 2 & 8.4819 & 2546.0968 & 1.12 \\
\hline 3 & 7.8593 & 2359.2047 & 1.69 \\
\hline 4 & 7.8571 & 2358.5443 & 1.80 \\
\hline 5 & 7.8333 & 2351.4000 & 1.87 \\
\hline 6 & 7.8308 & 2350.6496 & 1.86 \\
\hline 7 & 7.4686 & 2241.9244 & 1.07 \\
\hline 8 & 7.4620 & 2239.9432 & 0.84 \\
\hline 9 & 7.4532 & 2237.3016 & 1.33 \\
\hline 10 & 7.4402 & 2233.3993 & 1.28 \\
\hline 11 & 7.4256 & 2229.0167 & 0.30 \\
\hline 12 & 7.4129 & 2225.2044 & 0.98 \\
\hline 13 & 7.4090 & 2224.0337 & 1.35 \\
\hline 14 & 7.4072 & 2223.4933 & 1.35 \\
\hline 15 & 7.3882 & 2217.7899 & 2.38 \\
\hline 16 & 7.3848 & 2216.7693 & 2.67 \\
\hline 17 & 7.3782 & 2214.7881 & 1.57 \\
\hline 18 & 7.3635 & 2210.3755 & 1.30 \\
\hline 19 & 7.3600 & 2209.3248 & 1.24 \\
\hline 20 & 7.1969 & 2160.3655 & 1.56 \\
\hline 21 & 7.1920 & 2158.8946 & 2.07 \\
\hline 22 & 7.1850 & 2156.7933 & 0.72 \\
\hline 23 & 7.1663 & 2151.1800 & 3.65 \\
\hline 24 & 7.1580 & 2148.6885 & 2.63 \\
\hline 25 & 7.1517 & 2146.7974 & 3.38 \\
\hline 26 & 7.1437 & 2144.3959 & 1.81 \\
\hline 27 & 7.1375 & 2142.5348 & 2.42 \\
\hline 28 & 7.1326 & 2141.0639 & 2.18 \\
\hline 29 & 7.1267 & 2139.2929 & 1.62 \\
\hline 30 & 7.1190 & 2136.9815 & 0.54 \\
\hline 31 & 7.1065 & 2133.2292 & 0.91 \\
\hline 32 & 7.1010 & 2131.5782 & 0.77 \\
\hline 33 & 4.5868 & 1376.8657 & 2.08 \\
\hline 34 & 4.1783 & 1254.2421 & 1.01 \\
\hline 35 & 4.1562 & 1247.6081 & 1.01 \\
\hline 36 & 3.3356 & 1001.2804 & 15.00 \\
\hline 37 & 2.5118 & 753.9921 & 5.13 \\
\hline 38 & 2.5060 & 752.2511 & 10.47 \\
\hline 39 & 2.5000 & 750.4500 & 14.33 \\
\hline 40 & 2.4940 & 748.6489 & 10.74 \\
\hline 41 & 2.4884 & 746.9679 & 5.37 \\
\hline
\end{tabular}

S108 
DMSO- $d_{6}, 300 \mathrm{MHz}$
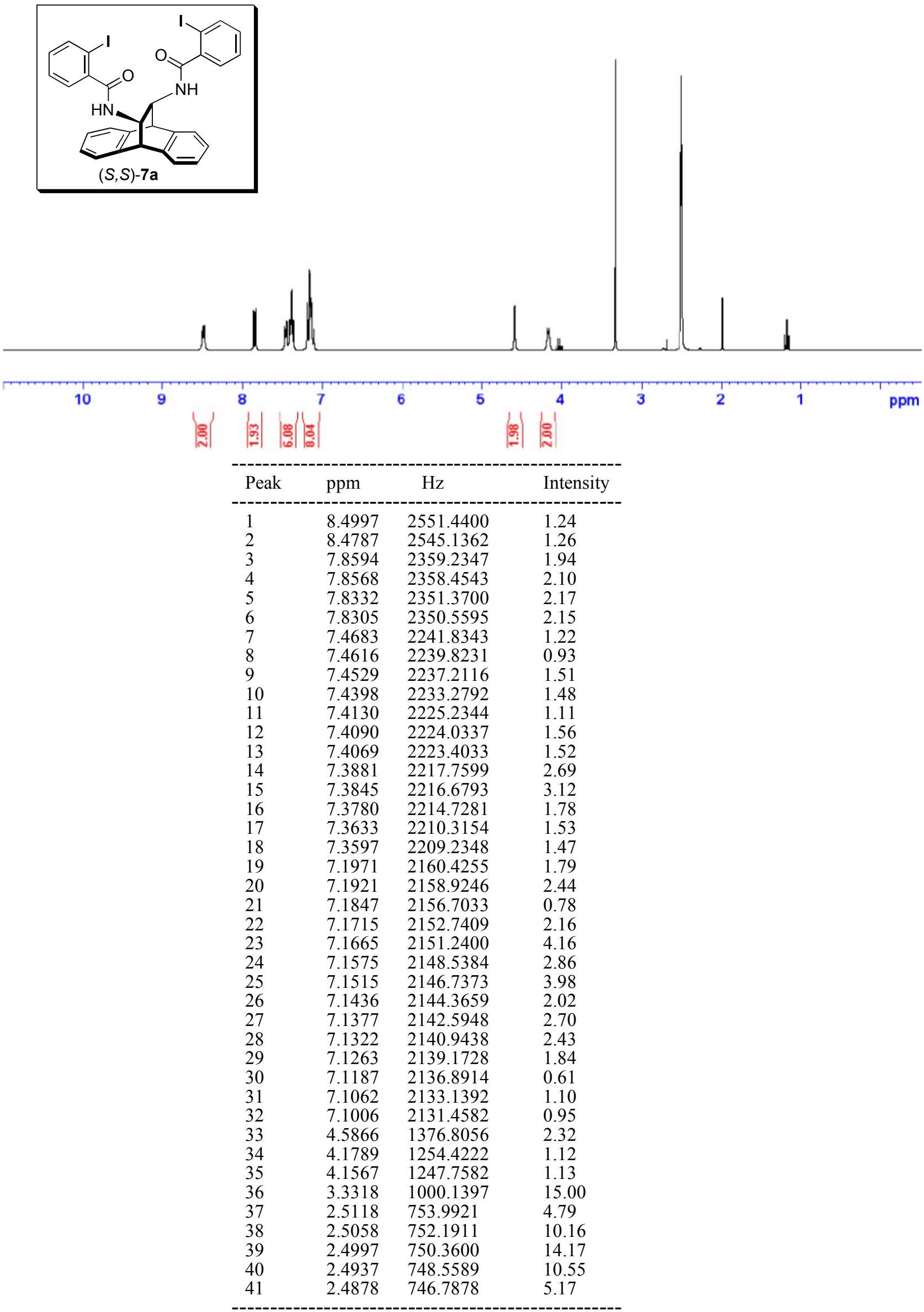
DMSO- $d_{6}, 300 \mathrm{MHz}$
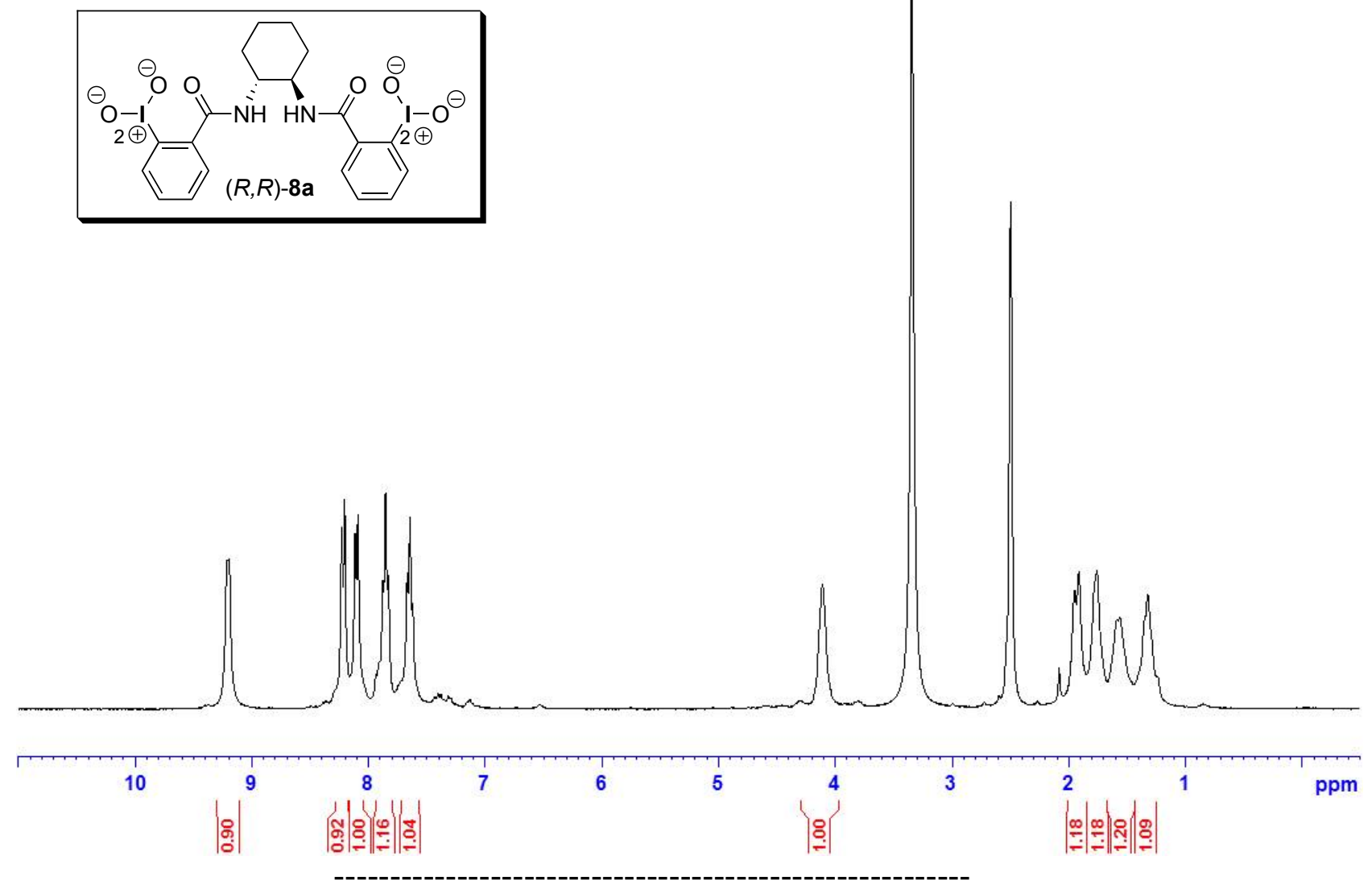

\begin{tabular}{|c|c|c|c|}
\hline Peak & ppm & $\mathrm{Hz}$ & Intensity \\
\hline 1 & 9.210 & 2764.137 & 288623.83 \\
\hline 2 & 9.197 & 2760.386 & 288623.83 \\
\hline 3 & 8.230 & 2470.130 & 350895.41 \\
\hline 4 & 8.205 & 2462.627 & 406247.93 \\
\hline 5 & 8.115 & 2435.585 & 340022.60 \\
\hline 6 & 8.090 & 2428.172 & 375606.36 \\
\hline 7 & 7.907 & 2373.068 & 90936.28 \\
\hline 8 & 7.878 & 2364.574 & 249086.32 \\
\hline 9 & 7.854 & 2357.281 & 418109.18 \\
\hline 10 & 7.831 & 2350.198 & 256993.82 \\
\hline 11 & 7.669 & 2301.577 & 261936.01 \\
\hline 12 & 7.645 & 2294.554 & 370664.17 \\
\hline 13 & 7.621 & 2287.411 & 204606.62 \\
\hline 14 & 4.112 & 1234.285 & 241178.82 \\
\hline 15 & 3.344 & 1003.575 & 1482656.67 \\
\hline 16 & 2.500 & 750.175 & 980530.28 \\
\hline 17 & 1.952 & 585.794 & 228329.13 \\
\hline 18 & 1.914 & 574.419 & 264901.33 \\
\hline 19 & 1.760 & 528.109 & 267866.64 \\
\hline 20 & 1.580 & 474.055 & 172976.61 \\
\hline 21 & 1.561 & 468.593 & 175941.93 \\
\hline 22 & 1.324 & 397.372 & 221410.06 \\
\hline
\end{tabular}


DMSO- $d_{6}, 75 \mathrm{MHz}$

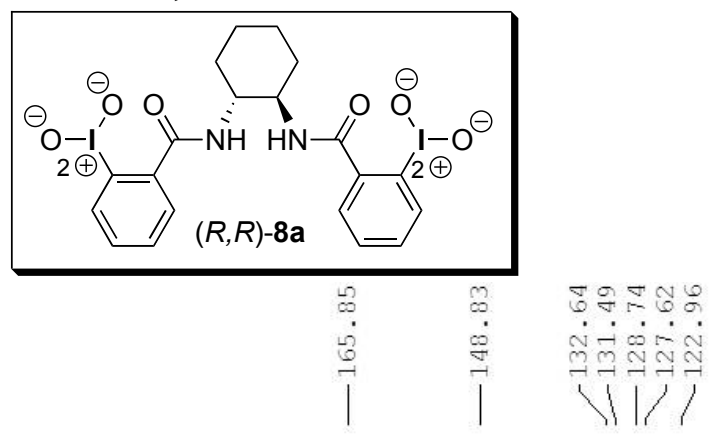

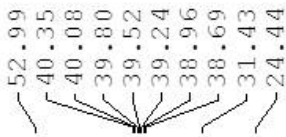

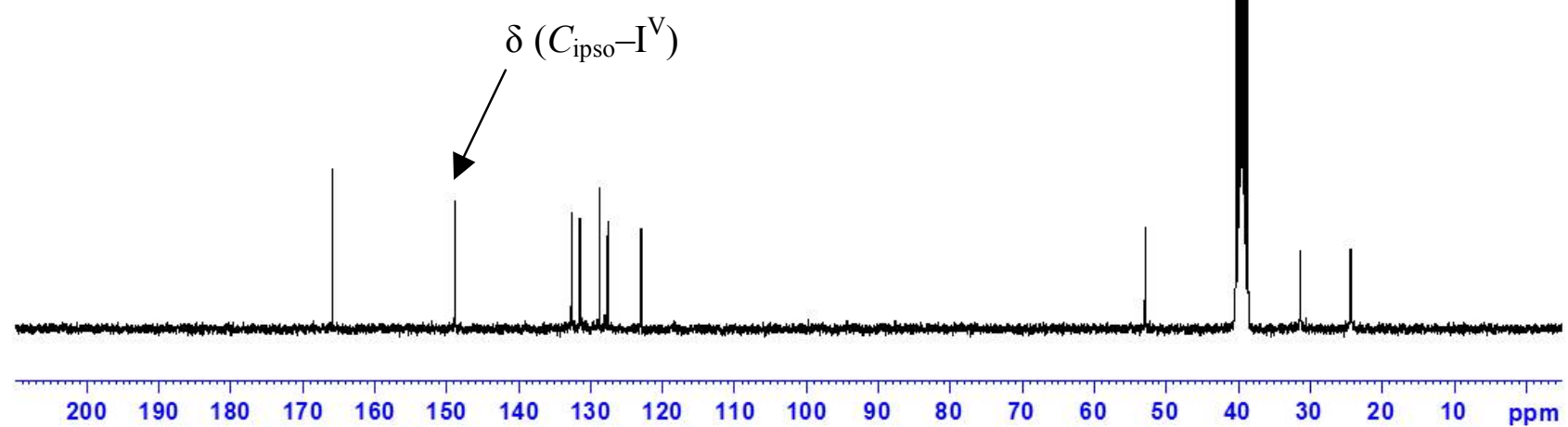


DMSO- $d_{6}, 300 \mathrm{MHz}$
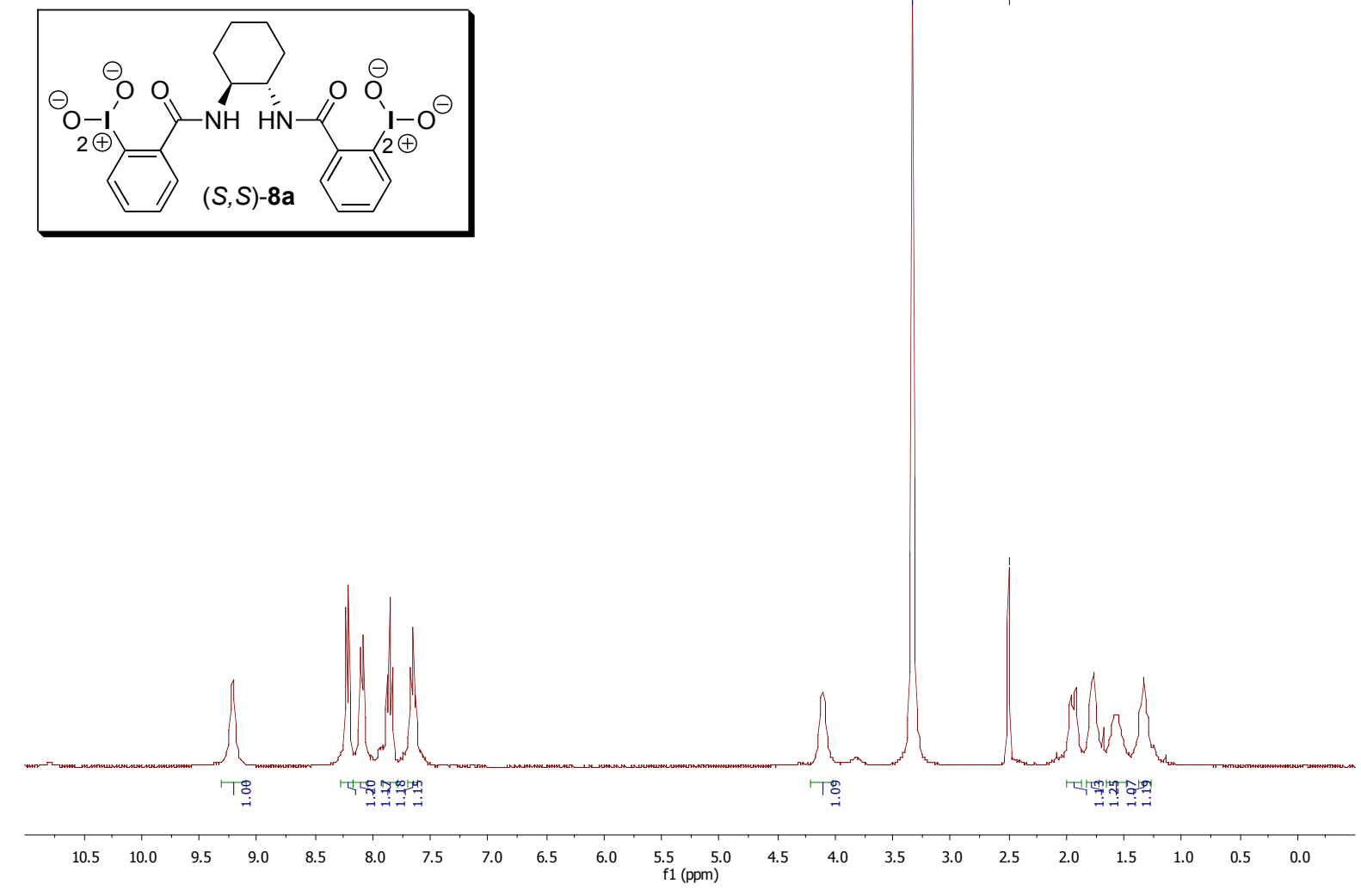

\begin{tabular}{cccl} 
Peak & ppm & Intensity & Width \\
\hline 1 & 9.21 & 18579393.1 & 14.33 \\
2 & 8.23 & 33509544.3 & 4.44 \\
3 & 8.21 & 38290471.9 & 4.32 \\
4 & 8.11 & 25467051.1 & 6.08 \\
5 & 8.08 & 27895422.9 & 5.84 \\
6 & 7.88 & 19639239.9 & 4.58 \\
7 & 7.85 & 35642125.4 & 4.63 \\
8 & 7.83 & 20768090.3 & 4.37 \\
9 & 7.67 & 20750710.1 & 6.27 \\
10 & 7.65 & 29466355.5 & 6.46 \\
11 & 7.62 & 15160062.9 & 6.50 \\
12 & 4.10 & 15869436.9 & 0.76 \\
13 & 1.96 & 15009028.3 & 0.42 \\
14 & 1.92 & 16737795.1 & 12.61 \\
15 & 1.76 & 20161368.9 & 15.21 \\
16 & 1.56 & 11166804.0 & 0.80 \\
17 & 1.36 & 13219065.7 & 11.74 \\
18 & 1.33 & 18973119.4 & 13.79 \\
-----------1 &
\end{tabular}


DMSO- $d_{6}, 75 \mathrm{MHz}$

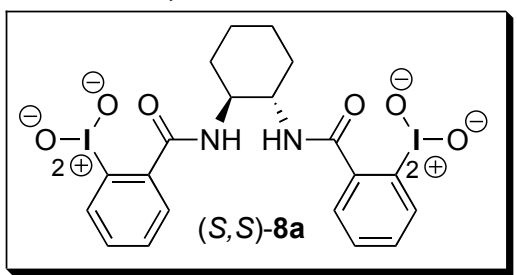

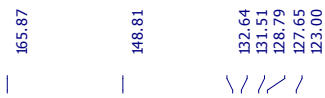

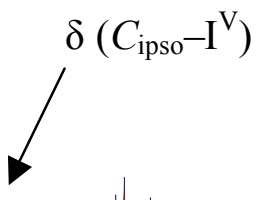

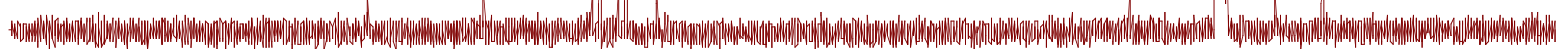

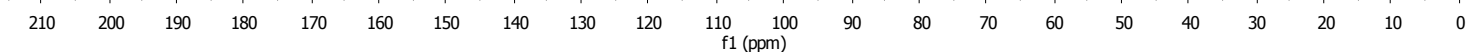


DMSO- $d_{6}, 300 \mathrm{MHz}$
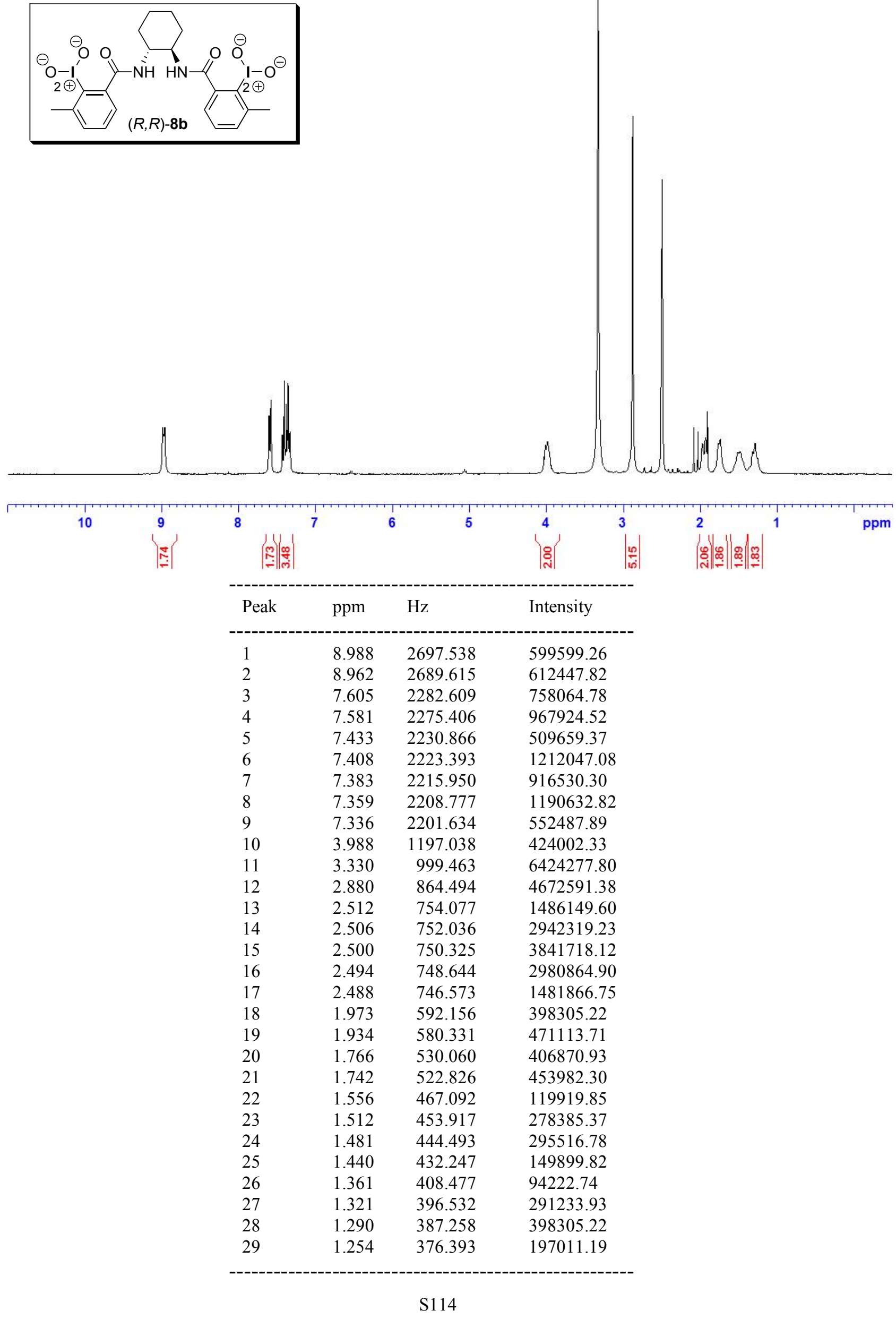
DMSO- $d_{6}, 75 \mathrm{MHz}$
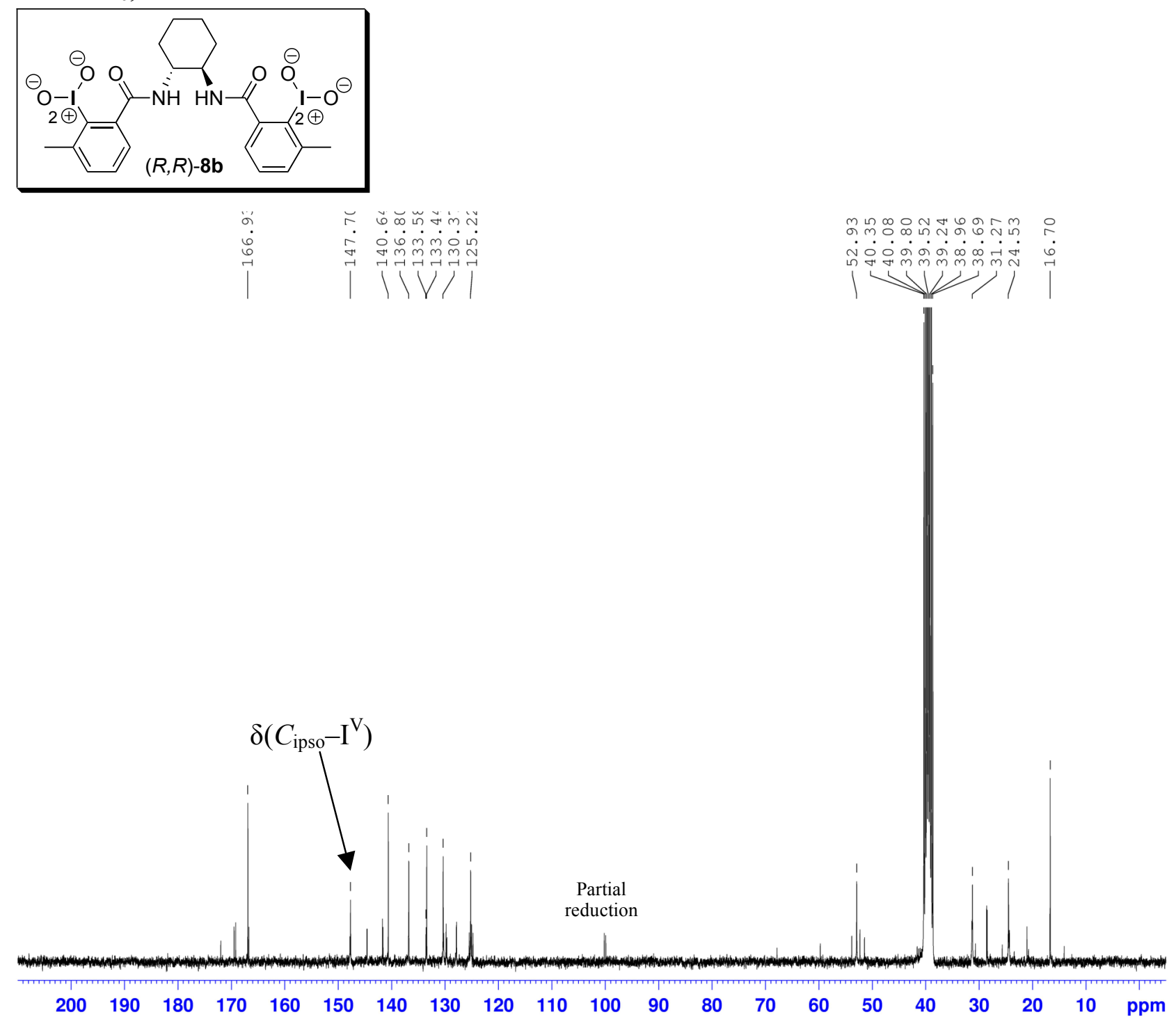
N.B.: partial reduction was observed during ${ }^{13} \mathrm{C}$ NMR spectrum acquisition. 
DMSO- $d_{6}, 300 \mathrm{MHz}$
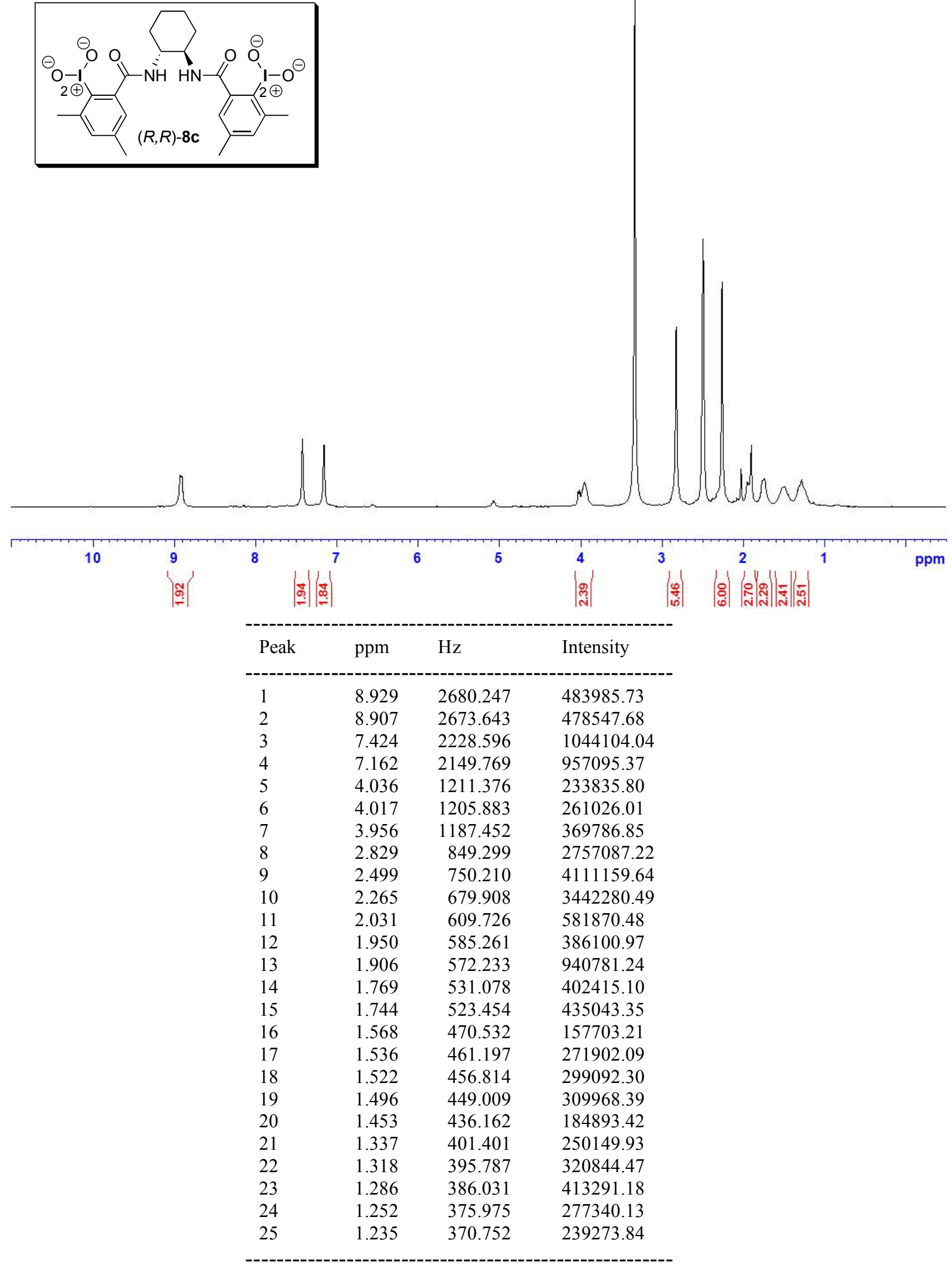
DMSO- $d_{6}, 75 \mathrm{MHz}$
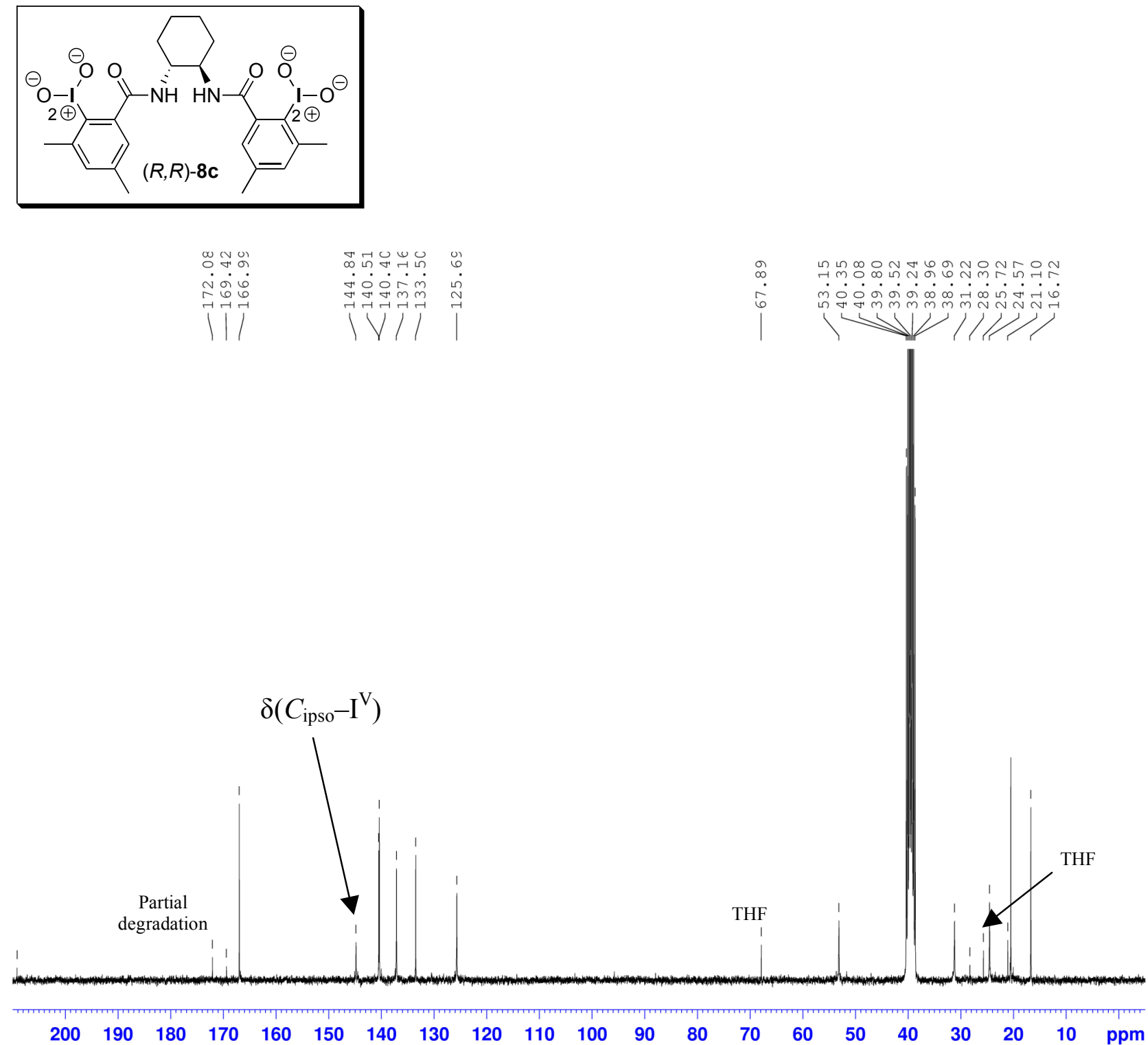
N.B.: partial degradation was observed during ${ }^{13} \mathrm{C}$ NMR spectrum acquisition. 
DMSO- $d_{6}, 300 \mathrm{MHz}$
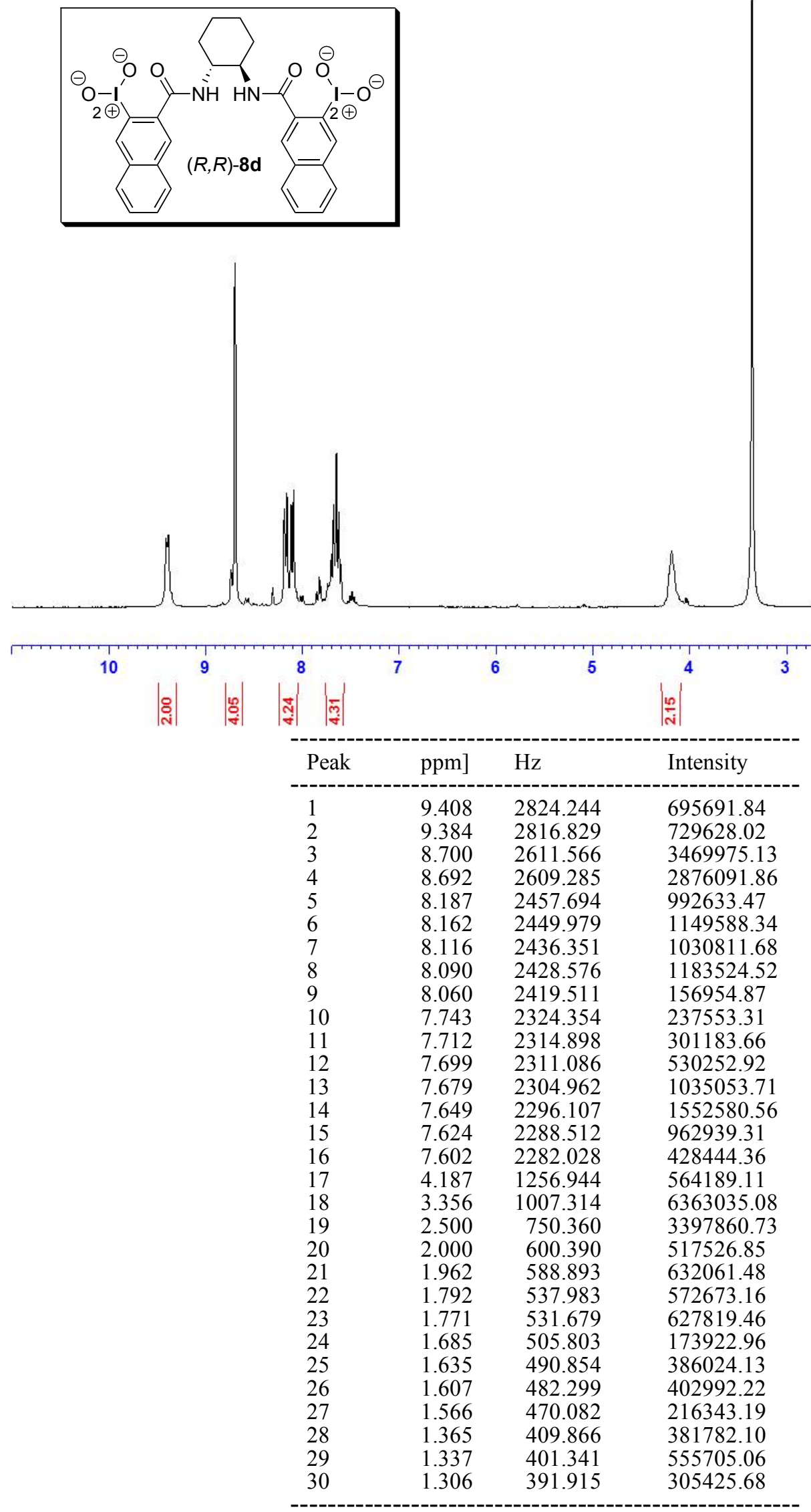
DMSO- $d_{6}, 75 \mathrm{MHz}$
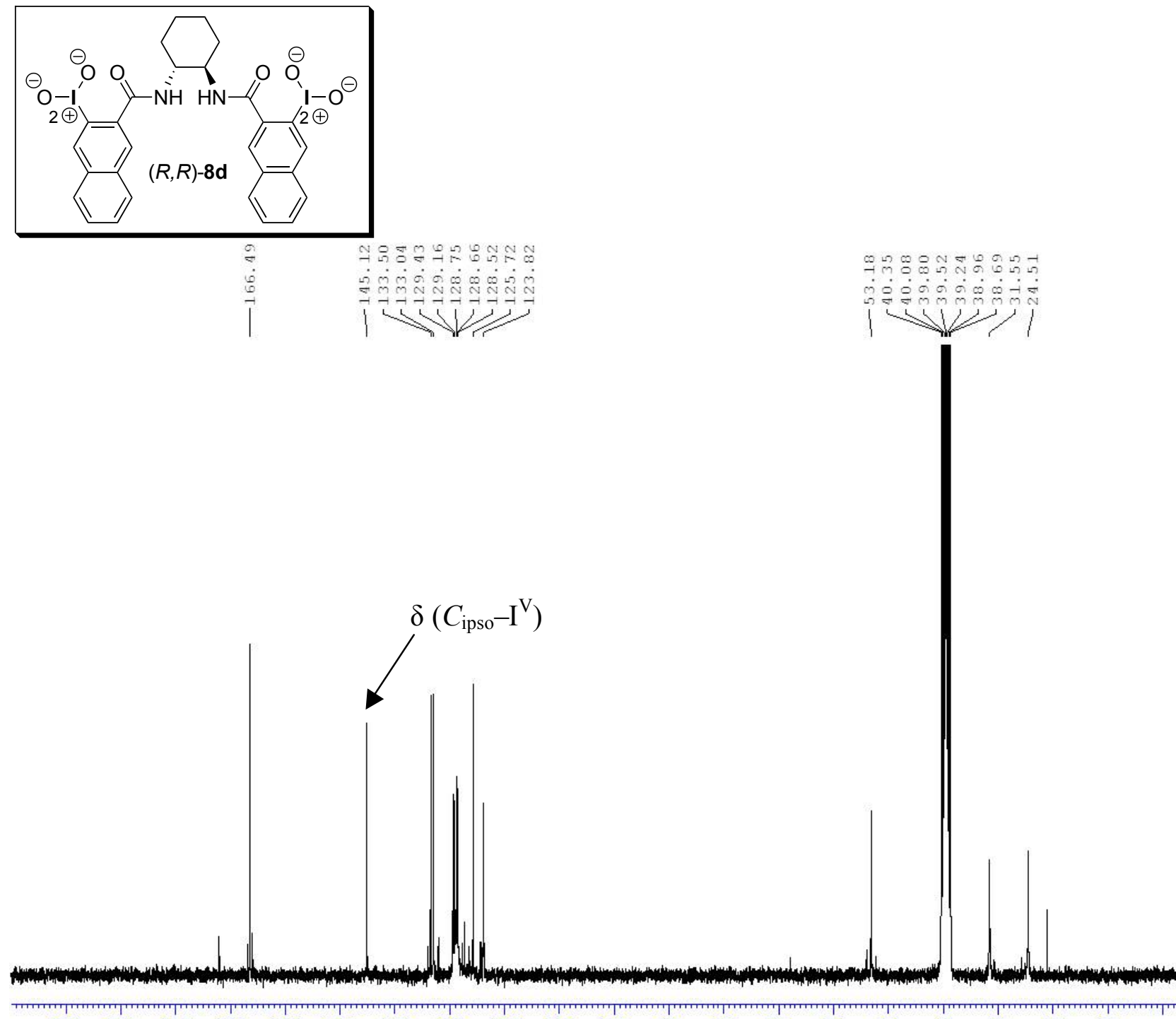

$\begin{array}{lllllllllllllllllllll}200 & 190 & 180 & 170 & 160 & 150 & 140 & 130 & 120 & 110 & 100 & 90 & 80 & 70 & 60 & 50 & 40 & 30 & 20 & 10 & \mathrm{ppm}\end{array}$ N.B.: partial degradation was observed during ${ }^{13} \mathrm{C}$ NMR spectrum acquisition. 
DMSO- $d_{6}, 300 \mathrm{MHz}$
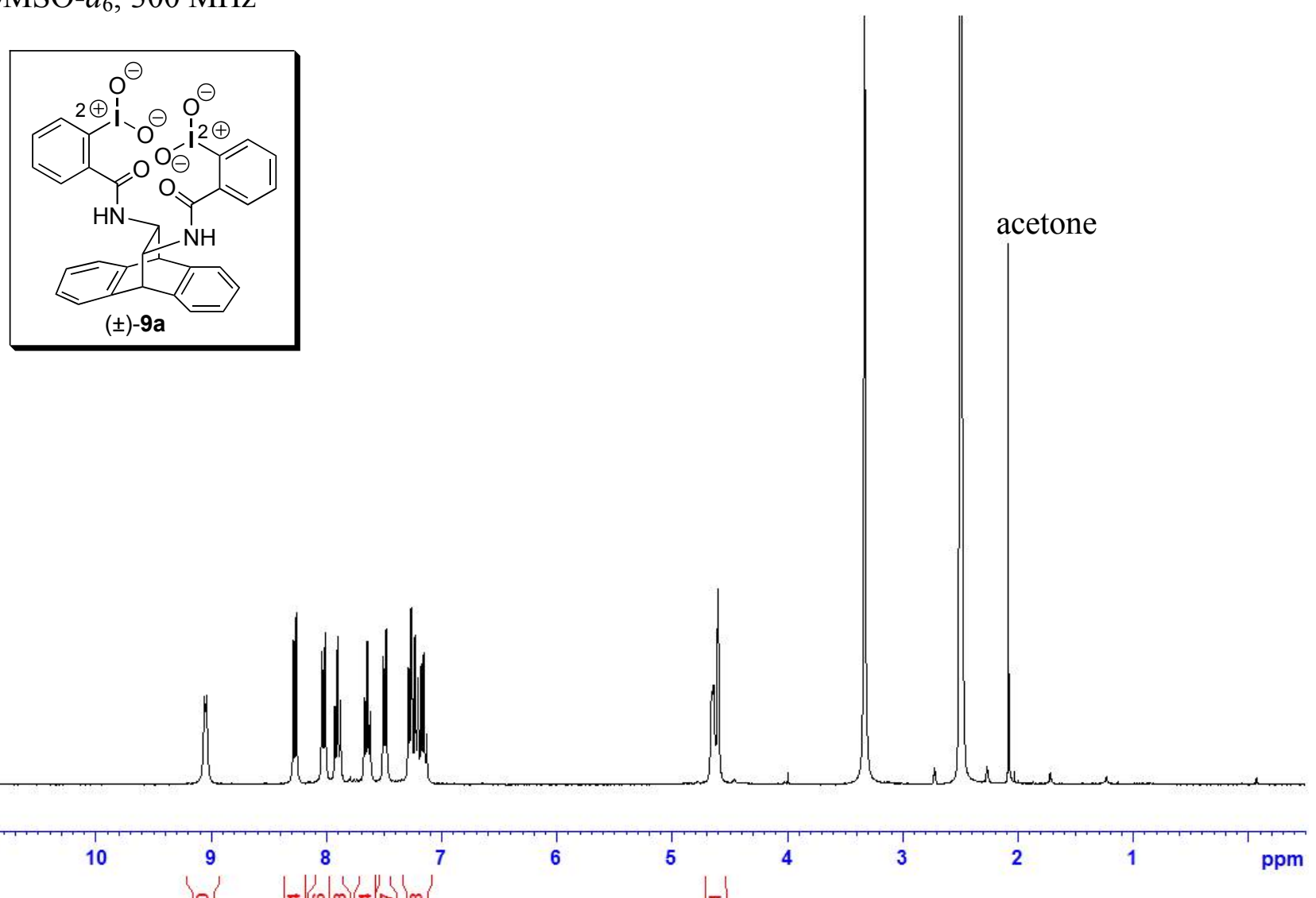

10
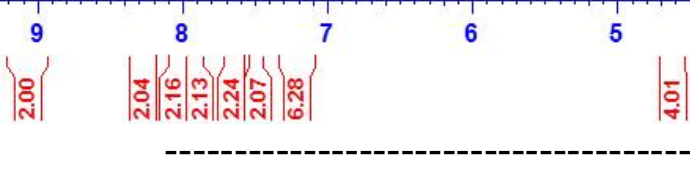

$\left|\begin{array}{l}\delta \\ \dot{q}\end{array}\right|$

\begin{tabular}{llll} 
Peak & ppm & Hz & Intensity \\
\hline 1 & 9.062 & 2720.112 & 529734.08 \\
2 & 9.043 & 2714.588 & 538562.98 \\
3 & 8.290 & 2488.493 & 856403.43 \\
4 & 8.288 & 2487.742 & 865232.33 \\
5 & 8.264 & 2480.748 & 1032981.46 \\
6 & 8.262 & 2479.937 & 997665.86 \\
7 & 8.038 & 2412.907 & 794601.12 \\
8 & 8.014 & 2405.523 & 909376.84 \\
9 & 7.929 & 2380.008 & 476760.67 \\
10 & 7.905 & 2372.833 & 891719.04 \\
11 & 7.880 & 2365.509 & 503247.38 \\
12 & 7.670 & 2302.321 & 520905.18 \\
13 & 7.646 & 2295.297 & 865232.33 \\
14 & 7.623 & 2288.152 & 441445.07 \\
15 & 7.507 & 2253.332 & 768114.42 \\
16 & 7.484 & 2246.397 & 935863.55 \\
17 & 7.289 & 2188.072 & 697483.21 \\
18 & 7.266 & 2180.958 & 1059468.16 \\
19 & 7.254 & 2177.566 & 512076.28 \\
20 & 7.233 & 2171.112 & 891719.04 \\
21 & 7.209 & 2164.058 & 644509.80 \\
22 & 7.205 & 2162.737 & 547391.89 \\
23 & 7.182 & 2155.923 & 706312.11 \\
24 & 7.178 & 2154.842 & 723969.91 \\
25 & 7.156 & 2148.088 & 794601.12 \\
26 & 7.134 & 2141.334 & 309011.55 \\
27 & 7.130 & 2140.284 & 291353.75 \\
28 & 4.658 & 1398.089 & 556220.79 \\
29 & 4.643 & 1393.766 & 600365.29 \\
& & &
\end{tabular}




$\begin{array}{lrrl}30 & 4.607 & 1382.809 & 1174243.88 \\ 31 & 3.334 & 1000.860 & 10356301.31 \\ 32 & 2.512 & 754.052 & 4485081.90 \\ 33 & 2.506 & 752.281 & 9446924.47 \\ 34 & 2.500 & 750.450 & 13243352.06 \\ 35 & 2.494 & 748.649 & 10109092.07 \\ 36 & 2.488 & 746.848 & 5262025.22 \\ 37 & 2.084 & 625.665 & 3249035.71\end{array}$

DMSO- $d_{6}, 75 \mathrm{MHz}$
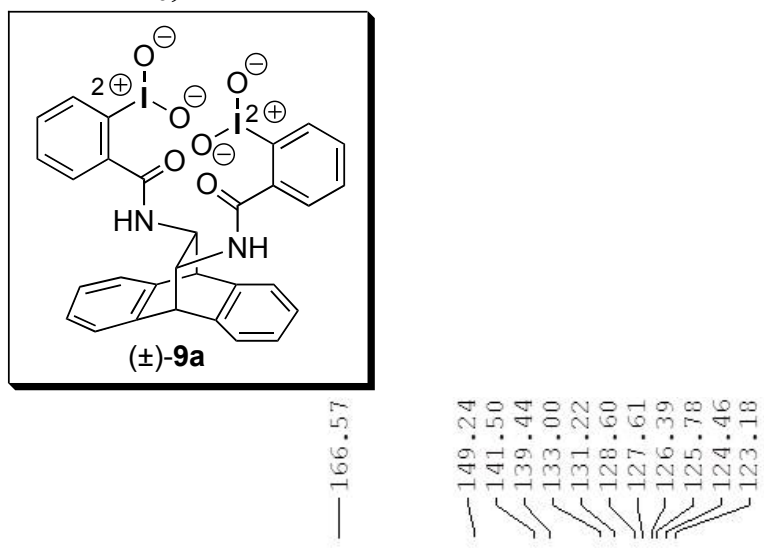

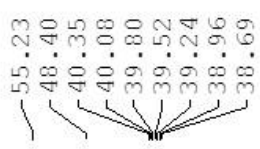

acetone

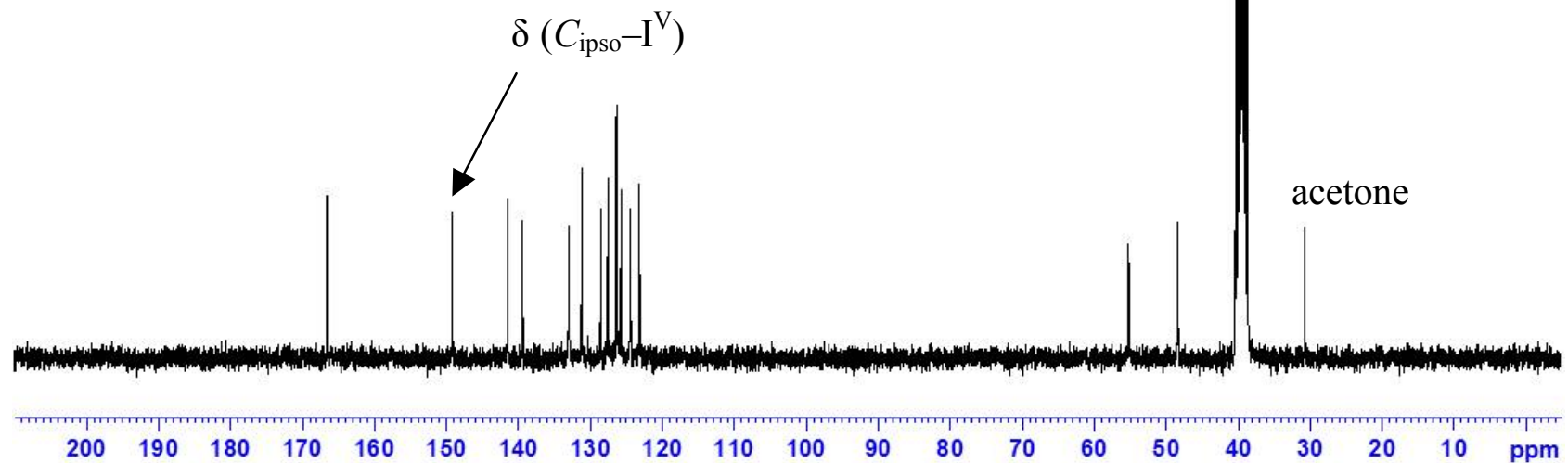


DMSO- $d_{6}, 300 \mathrm{MHz}$
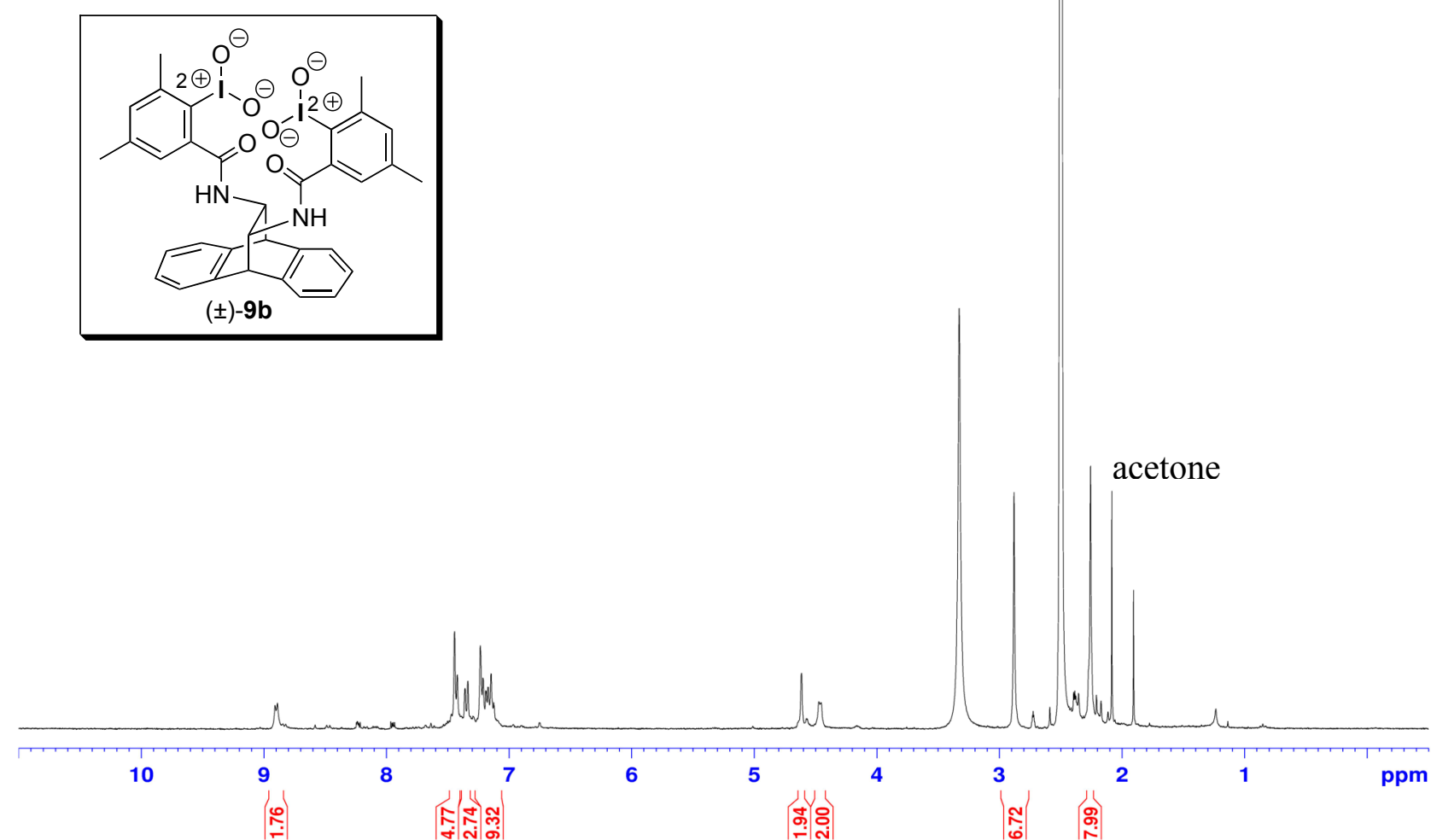

N.B.: partial degradation was observed during ${ }^{1} \mathrm{H}$ NMR spectrum acquisition, and thus no ${ }^{13} \mathrm{C}$ NMR spectrum could be recorded.

\begin{tabular}{|c|c|c|c|}
\hline Peak & ppm & $\mathrm{Hz}$ & Intensity \\
\hline 1 & 8.9107 & 2674.8140 & 120071.52 \\
\hline 2 & 8.8907 & 2668.8104 & 127575.99 \\
\hline 3 & 7.4457 & 2235.0503 & 495295.01 \\
\hline 4 & 7.4231 & 2228.2662 & 277665.38 \\
\hline 5 & 7.3599 & 2209.2948 & 210125.15 \\
\hline 6 & 7.3363 & 2202.2106 & 247647.50 \\
\hline 7 & 7.2356 & 2171.9825 & 427754.78 \\
\hline 8 & 7.2153 & 2165.8888 & 262656.44 \\
\hline 9 & 7.1918 & 2158.8346 & 195116.22 \\
\hline 10 & 7.1869 & 2157.3637 & 195116.22 \\
\hline 11 & 7.1744 & 2153.6114 & 210125.15 \\
\hline 12 & 7.1700 & 2152.2906 & 210125.15 \\
\hline 13 & 7.1489 & 2145.9568 & 285169.85 \\
\hline 14 & 7.1257 & 2138.9927 & 135080.46 \\
\hline 15 & 4.6145 & 1385.1806 & 285169.85 \\
\hline 16 & 4.4734 & 1342.8252 & 135080.46 \\
\hline 17 & 4.4585 & 1338.3526 & 135080.46 \\
\hline 18 & 3.3293 & 999.3893 & 2161287.31 \\
\hline 19 & 2.8820 & 865.1188 & 1215724.11 \\
\hline 20 & 2.5059 & 752.2211 & 8359979.37 \\
\hline 21 & 2.5000 & 750.4500 & 11256704.72 \\
\hline 22 & 2.4941 & 748.6790 & 8525077.71 \\
\hline 23 & 2.2583 & 677.8965 & 1350804.57 \\
\hline
\end{tabular}


DMSO- $d_{6}, 300 \mathrm{MHz}$
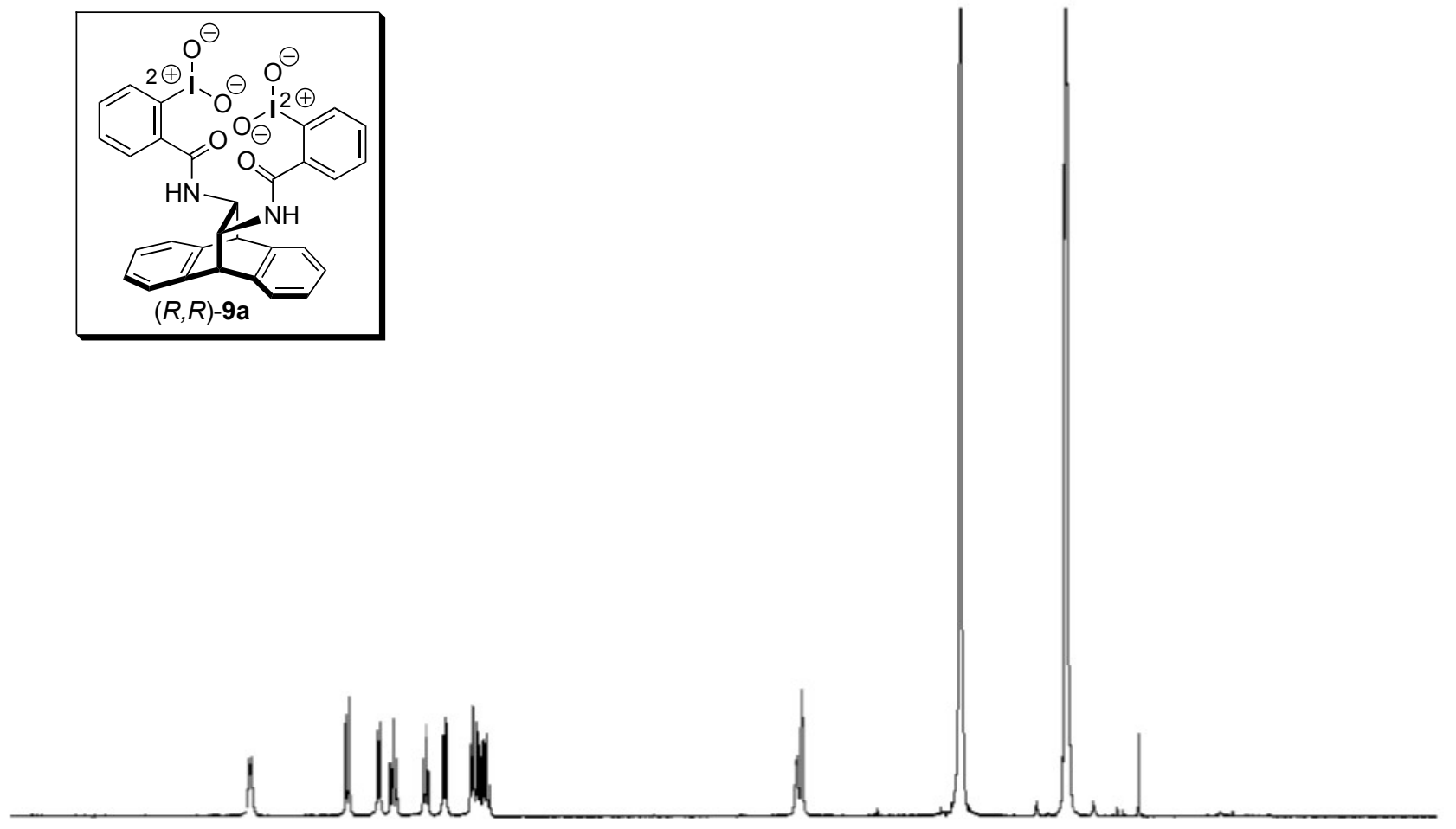

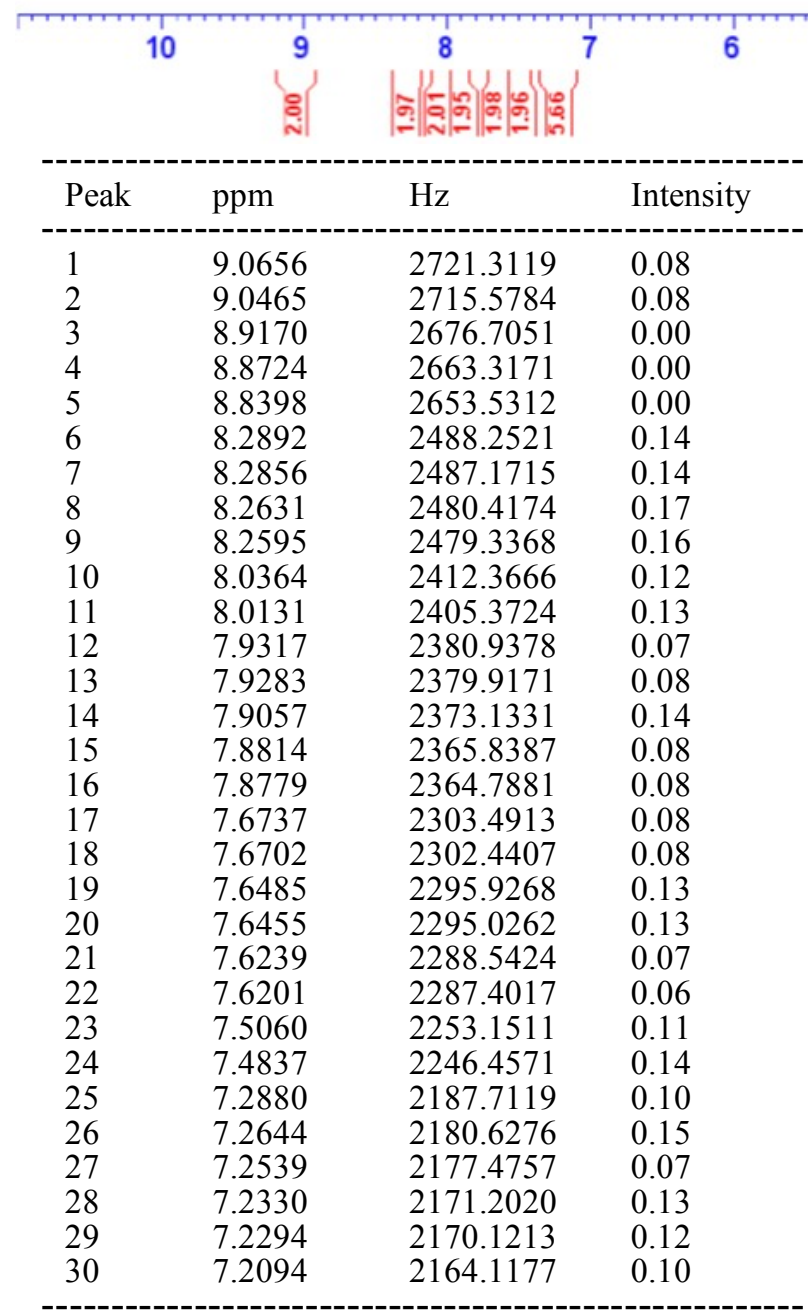

5

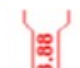

Peak $\quad$ ppm $\mathrm{Hz}$ Intensity

$\begin{array}{llll}31 & 7.2046 & 2162.6769 & 0.08\end{array}$

$\begin{array}{llll}32 & 7.1825 & 2156.0429 & 0.11\end{array}$

$\begin{array}{llll}33 & 7.1783 & 2154.7821 & 0.11\end{array}$

$\begin{array}{llll}34 & 7.1573 & 2148.4784 & 0.11\end{array}$

$\begin{array}{llll}35 & 7.1549 & 2147.7579 & 0.12\end{array}$

$\begin{array}{llll}36 & 7.1337 & 2141.3941 & 0.05\end{array}$

$\begin{array}{llll}37 & 7.1297 & 2140.1934 & 0.04\end{array}$

$\begin{array}{llll}38 & 4.6577 & 1398.1484 & 0.08\end{array}$

$\begin{array}{llll}39 & 4.6412 & 1393.1954 & 0.09\end{array}$

$\begin{array}{llll}40 & 4.6050 & 1382.3289 & 0.18\end{array}$

$\begin{array}{llll}41 & 3.3471 & 1004.7325 & 15.00\end{array}$

$\begin{array}{llll}42 & 2.5121 & 754.0822 & 0.90\end{array}$

$43 \quad 2.5061 \quad 752.2811 \quad 1.91$

$\begin{array}{llll}44 & 2.5000 & 750.4500 & 2.68\end{array}$

$\begin{array}{llll}45 & 2.4939 & 748.6189 & 2.05\end{array}$

$\begin{array}{llll}46 & 2.4880 & 746.8479 & 1.08\end{array}$ 
DMSO- $d_{6}, 300 \mathrm{MHz}$
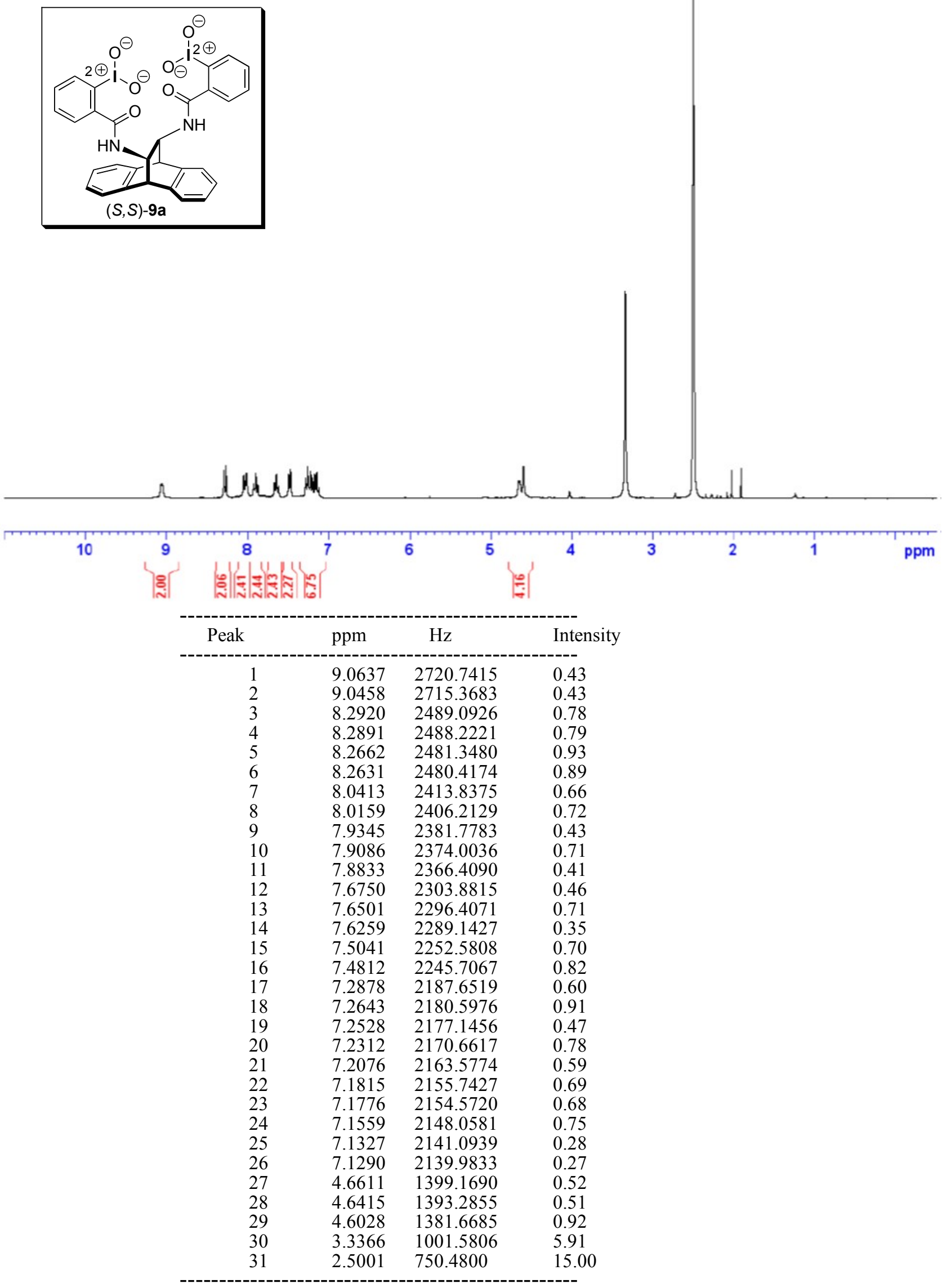


\section{$\mathrm{CDCl}_{3}, 300 \mathrm{MHz}$ bis(carvacrol)}

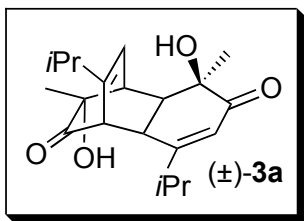

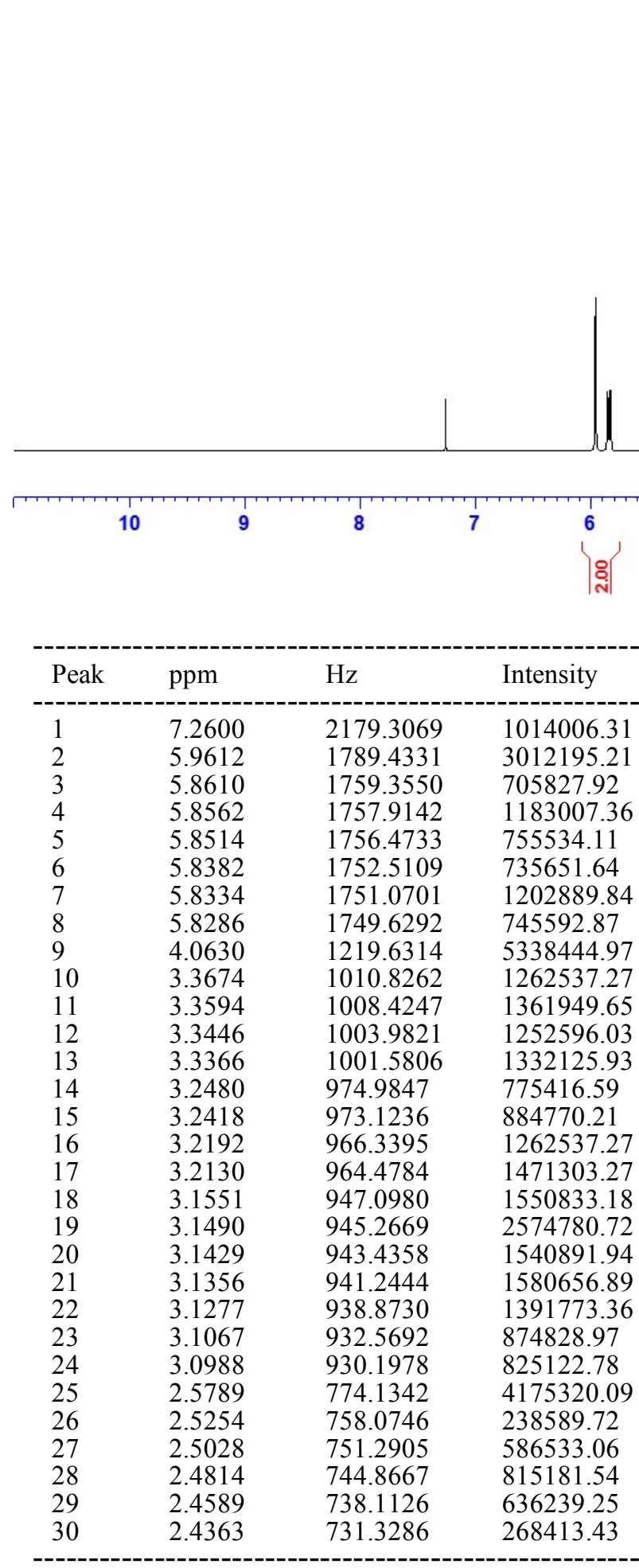


$\mathrm{CDCl}_{3}, 75 \mathrm{MHz}$ bis(carvacrol)

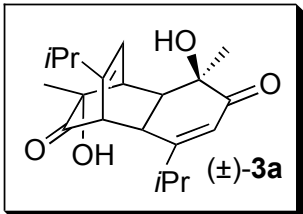

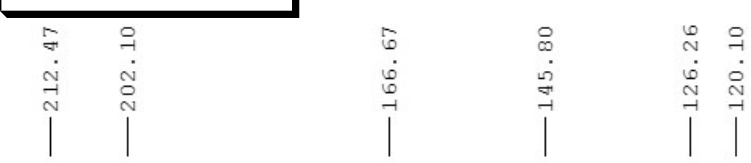

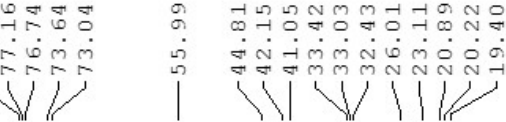

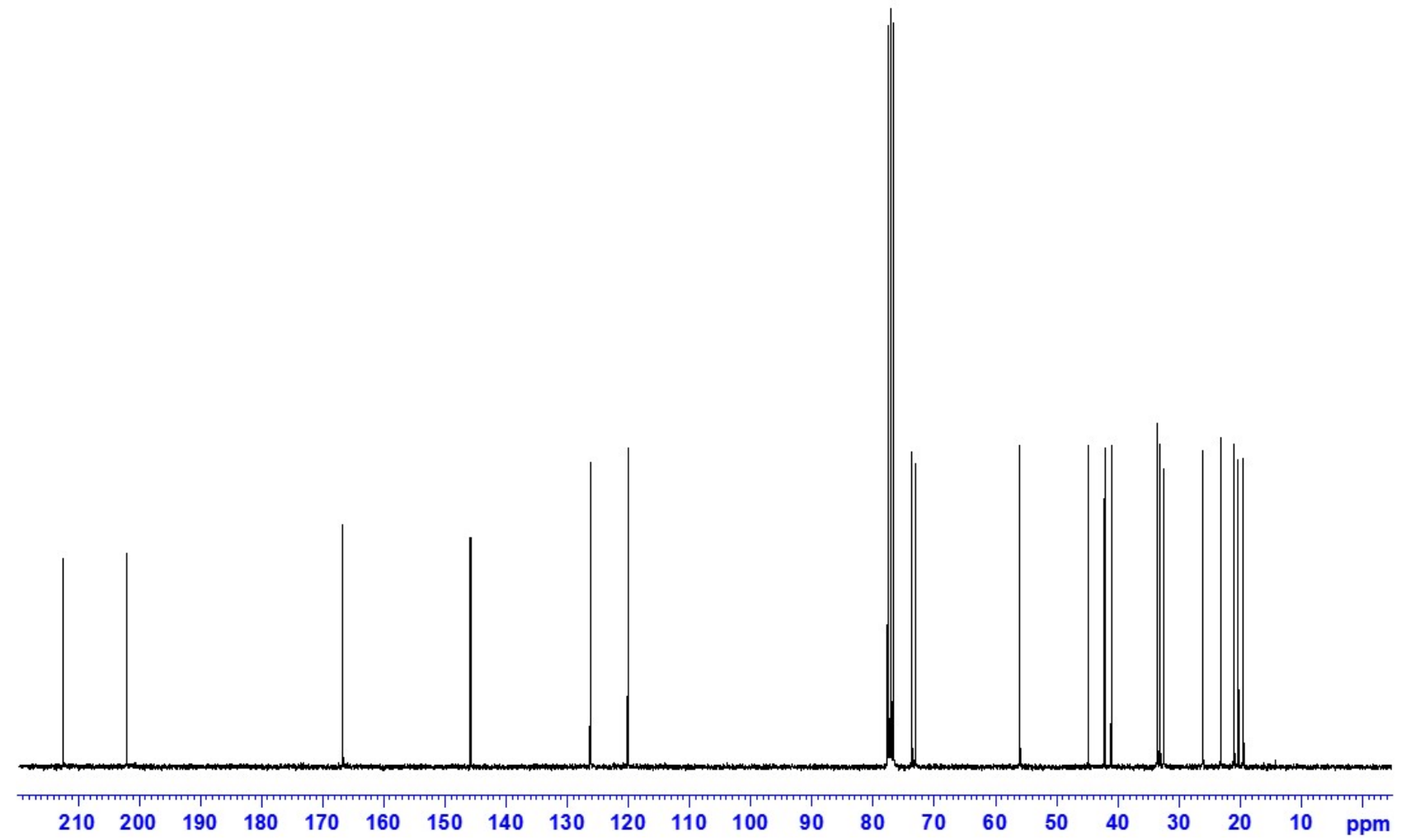


$\mathrm{CDCl}_{3}, 300 \mathrm{MHz}$

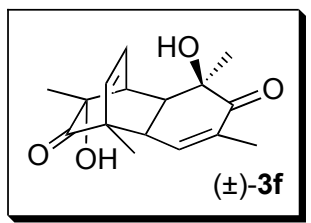

$( \pm)-3 f$

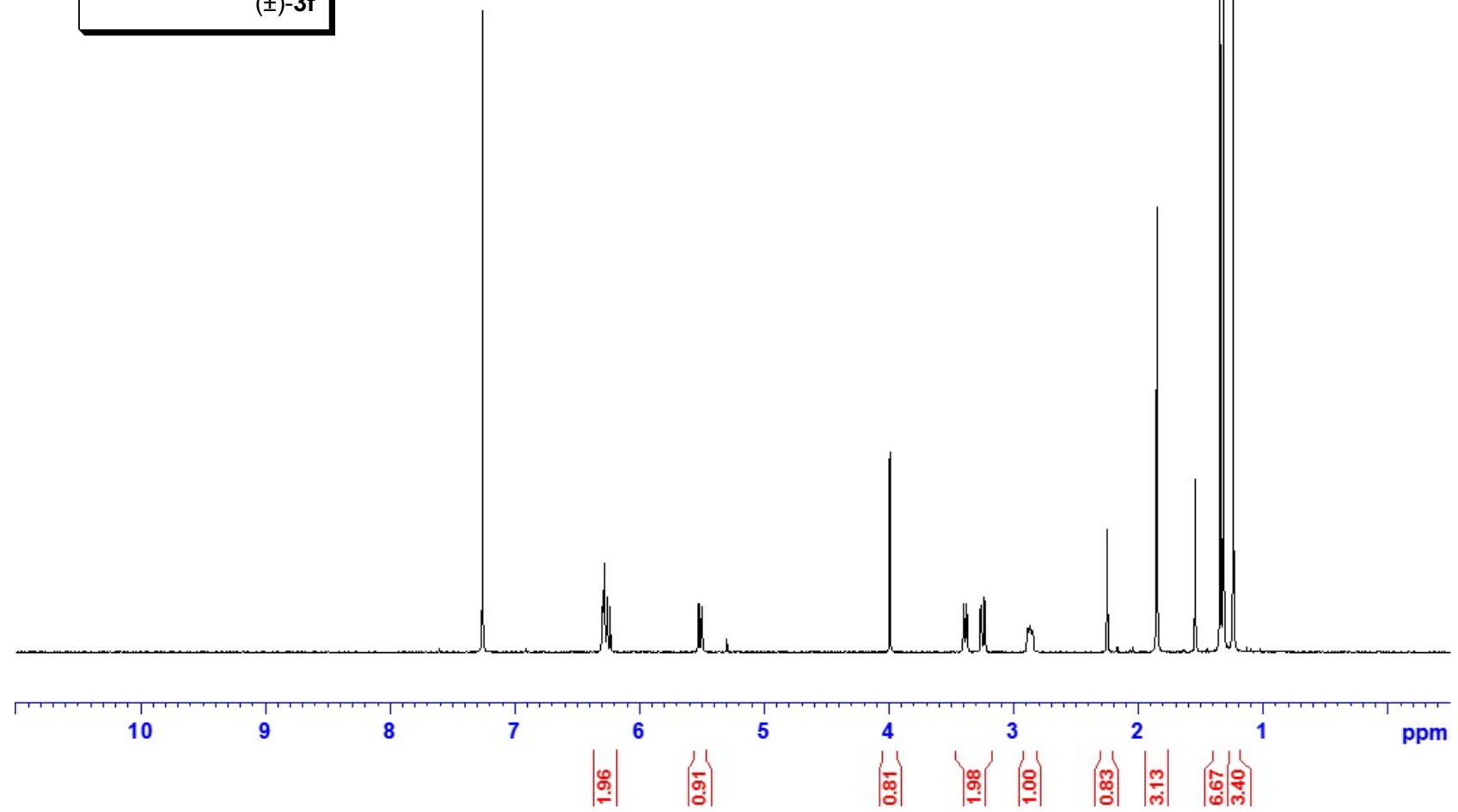

\begin{tabular}{clll}
\hline Peak & ppm & Hz & Intensity \\
\hline 1 & 7.2599 & 2179.2769 & 2156250.32 \\
2 & 6.2999 & 1891.1040 & 152424.59 \\
3 & 6.2951 & 1889.6632 & 165436.45 \\
4 & 6.2851 & 1886.6614 & 301131.51 \\
5 & 6.2619 & 1879.6972 & 180307.14 \\
6 & 6.2587 & 1878.7366 & 185883.65 \\
7 & 6.2355 & 1871.7725 & 156142.26 \\
8 & 5.5287 & 1659.6052 & 161718.77 \\
9 & 5.5255 & 1658.6446 & 165436.45 \\
10 & 5.5016 & 1651.4703 & 152424.59 \\
11 & 5.4983 & 1650.4798 & 152424.59 \\
12 & 3.9945 & 1199.0691 & 672898.81 \\
13 & 3.4058 & 1022.3531 & 92941.82 \\
14 & 3.4001 & 1020.6421 & 165436.45 \\
15 & 3.3944 & 1018.9310 & 105953.68 \\
16 & 3.3833 & 1015.5990 & 98518.33 \\
17 & 3.3775 & 1013.8580 & 163577.61 \\
18 & 3.3718 & 1012.1470 & 100377.17 \\
19 & 3.2658 & 980.3279 & 159859.94 \\
20 & 3.2593 & 978.3767 & 150565.76 \\
-------------------------------------------------
\end{tabular}

\begin{tabular}{|c|c|c|c|}
\hline Peak & ppm & $\mathrm{Hz}$ & Intensity \\
\hline 21 & 3.2378 & 971.9228 & 185883.65 \\
\hline 22 & 3.2313 & 969.9717 & 172871.79 \\
\hline 23 & 2.8883 & 867.0099 & 79929.97 \\
\hline 24 & 2.8720 & 862.1170 & 87365.31 \\
\hline 25 & 2.8659 & 860.2859 & 79929.97 \\
\hline 26 & 2.8506 & 855.6931 & 70635.79 \\
\hline 27 & 2.2527 & 676.2155 & 414520.54 \\
\hline 28 & 1.8587 & 557.9446 & 821605.73 \\
\hline 29 & 1.8538 & 556.4737 & 1498222.21 \\
\hline 30 & 1.8489 & 555.0028 & 845770.60 \\
\hline 31 & 1.5478 & 464.6186 & 581815.82 \\
\hline 32 & 1.3458 & 403.9823 & 2507570.42 \\
\hline 33 & 1.3186 & 395.8174 & 2788254.73 \\
\hline 34 & 1.2408 & 372.4634 & 2407193.25 \\
\hline
\end{tabular}




\section{$\mathrm{CDCl}_{3}, 75 \mathrm{MHz}$}
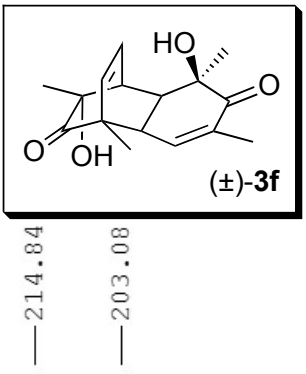

궁. ㅇำ

जin

।

부ㄱㅠㅛ용

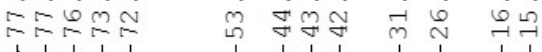

WI I V I I V

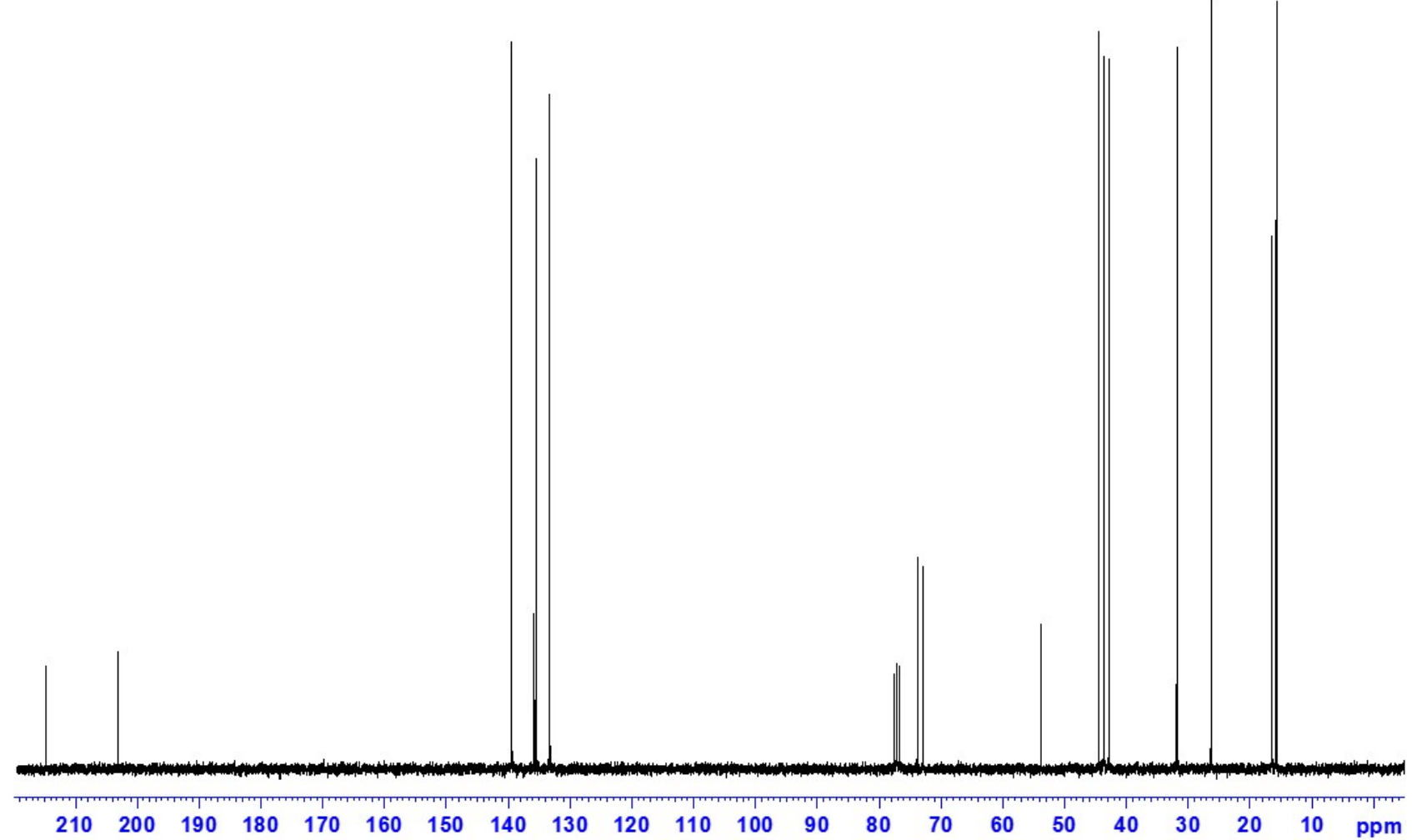


$\mathrm{CDCl}_{3}, 300 \mathrm{MHz}$

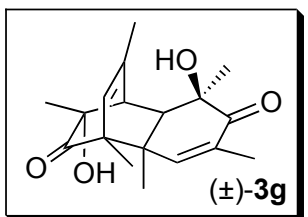

$( \pm)-3 g$

10

9

8

$\begin{array}{cc}6 & 5 \\ \mid \begin{array}{c}8 \\ -1\end{array} & \left|\begin{array}{l}8 \\ 0\end{array}\right|\end{array}$

$5 \quad 4$

4

3

$\left|\begin{array}{l}8 \\ 0 \\ 0\end{array}\right|$

क़े

\begin{tabular}{|c|c|c|c|}
\hline Peak & ppm & $\mathrm{Hz}$ & Intensity \\
\hline \multicolumn{4}{|c|}{ 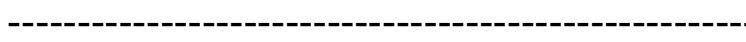 } \\
\hline 1 & 7.2601 & 2179.3369 & 425464.56 \\
\hline 2 & 6.0134 & 1805.1025 & 1049090.70 \\
\hline 3 & 5.0202 & 1506.9637 & 693565.52 \\
\hline 4 & 5.0153 & 1505.4928 & 786818.03 \\
\hline 5 & 3.9291 & 1179.4373 & 472090.82 \\
\hline 6 & 3.1368 & 941.6047 & 635282.70 \\
\hline 7 & 3.1304 & 939.6835 & 1043262.42 \\
\hline 8 & 3.1237 & 937.6723 & 582828.17 \\
\hline 9 & 2.7991 & 840.2339 & 1148171.49 \\
\hline 10 & 2.7922 & 838.1626 & 1119030.08 \\
\hline 11 & 2.5040 & 751.6507 & 110737.35 \\
\hline 12 & 1.8140 & 544.5265 & 4680110.20 \\
\hline 13 & 1.8107 & 543.5359 & 3596049.80 \\
\hline 14 & 1.6852 & 505.8634 & 3625191.21 \\
\hline 15 & 1.3455 & 403.8922 & 6481049.24 \\
\hline 16 & 1.2299 & 369.1914 & 8742422.53 \\
\hline 17 & 1.2243 & 367.5104 & 7372776.33 \\
\hline 18 & 1.1440 & 343.4059 & 6113867.49 \\
\hline
\end{tabular}




\section{$\mathrm{CDCl}_{3}, 75 \mathrm{MHz}$}

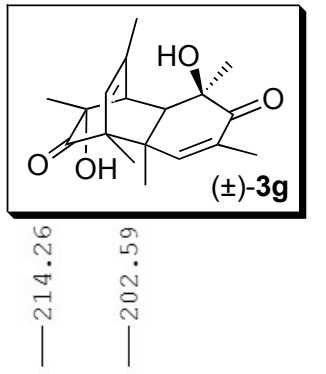

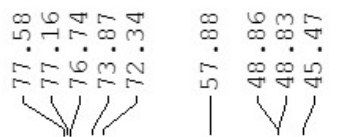

जิ लेलिएक्ष

N $206-1$

1111

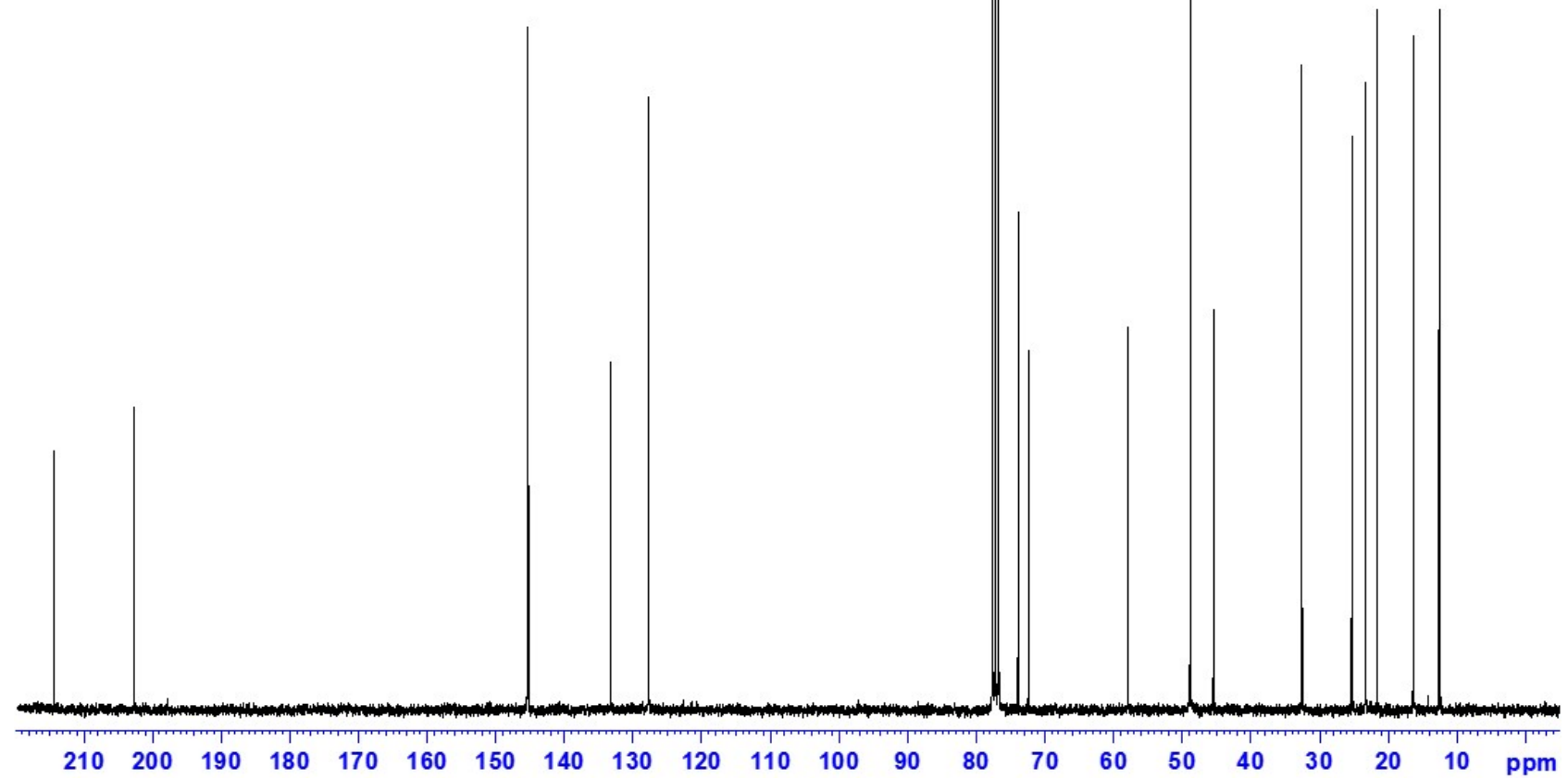


$\mathrm{CDCl}_{3}, 300 \mathrm{MHz}$
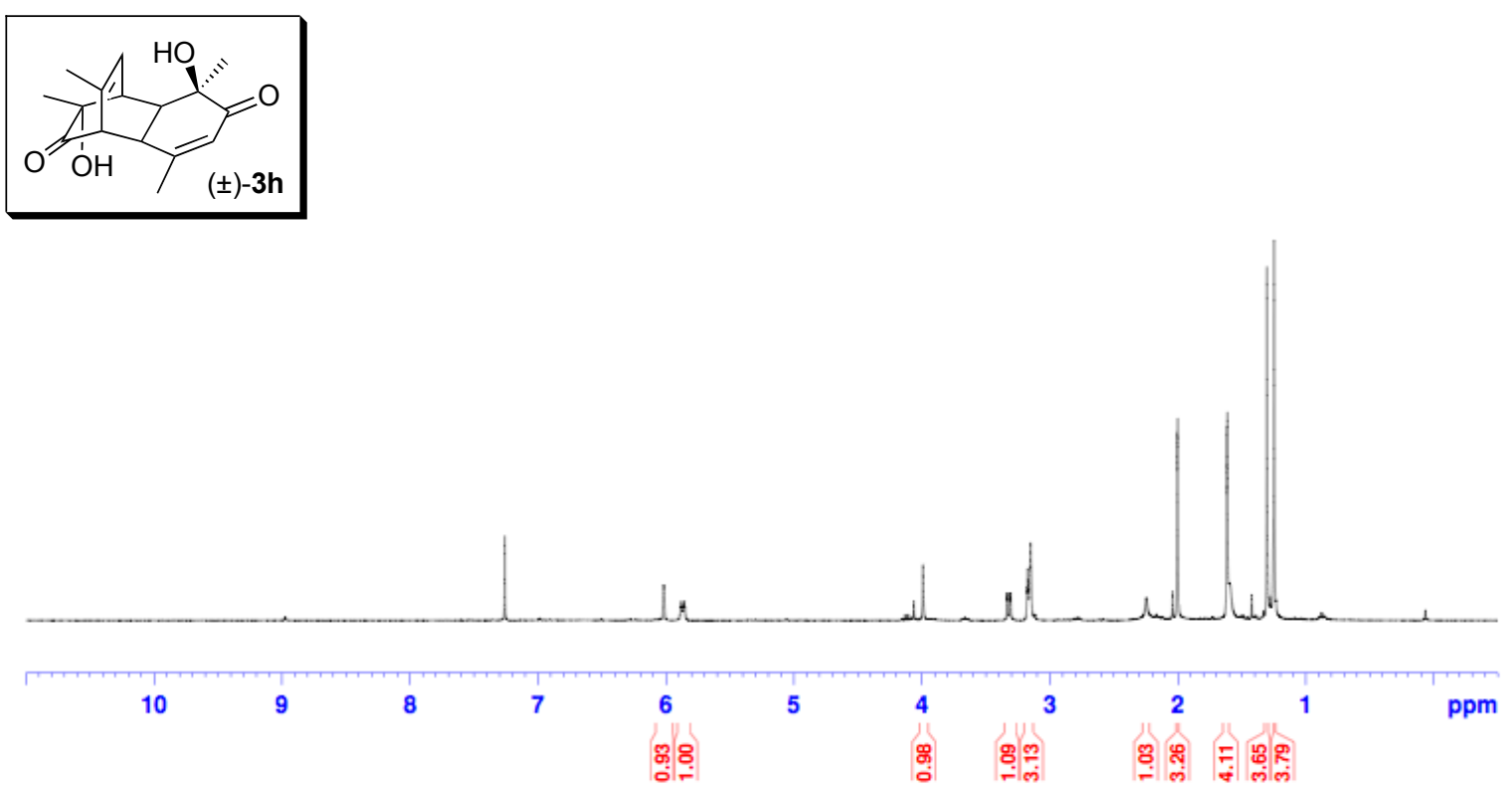

$\begin{array}{cll}\text { Index } & \text { ppm } & \mathrm{Hz} \\ 1 & 7.2599 & 2179.2769 \\ 2 & 6.0178 & 1806.4233 \\ 3 & 5.8855 & 1766.7095 \\ 4 & 5.8803 & 1765.1485 \\ 5 & 5.8750 & 1763.5576 \\ 6 & 5.8690 & 1761.7565 \\ 7 & 5.8629 & 1759.9254 \\ 8 & 5.8576 & 1758.3344 \\ 9 & 5.8526 & 1756.8335 \\ 10 & 3.9919 & 1198.2886 \\ 11 & 3.3355 & 1001.2504 \\ 12 & 3.3302 & 999.6595 \\ 13 & 3.3130 & 994.4964 \\ 14 & 3.3075 & 992.8454 \\ 15 & 3.1789 & 954.2422 \\ 16 & 3.1733 & 952.5612 \\ 17 & 3.1675 & 950.8202 \\ 18 & 3.1515 & 946.0173 \\ 19 & 2.2465 & 674.3544 \\ 20 & 2.0058 & 602.1011 \\ 21 & 2.0017 & 600.8703 \\ 22 & 1.6186 & 485.8714 \\ 23 & 1.6131 & 484.2204 \\ 24 & 1.3045 & 391.5848 \\ 25 & 1.2482 & 374.6847 \\ ------------------\end{array}$




$$
\mathrm{CDCl}_{3}, 75 \mathrm{MHz}
$$

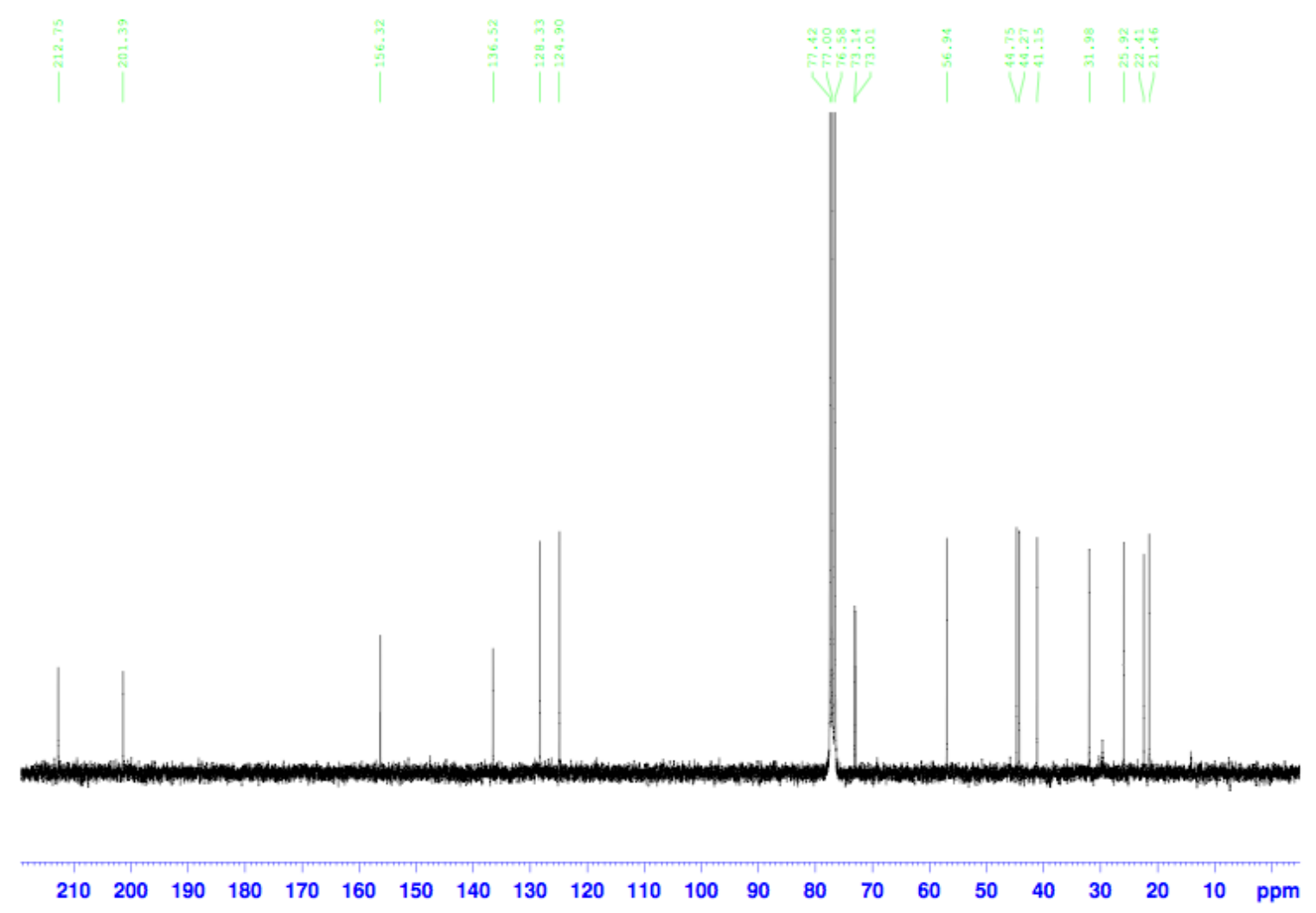




\section{$\mathrm{CDCl}_{3}, 300 \mathrm{MHz}$ bis(thymol)}

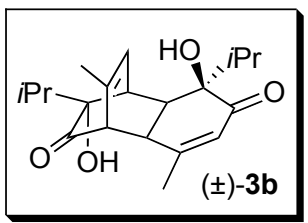

\begin{tabular}{|c|c|c|c|}
\hline Peak & ppm & $\mathrm{Hz}$ & Intensity \\
\hline 1 & 7.2599 & 2179.2769 & 1786141.10 \\
\hline 2 & 5.9937 & 1799.1889 & 1616457.69 \\
\hline 3 & 5.9898 & 1798.0182 & 2170161.43 \\
\hline 4 & 5.9858 & 1796.8175 & 1607526.99 \\
\hline 5 & 5.8526 & 1756.8335 & 643010.79 \\
\hline 6 & 5.8478 & 1755.3927 & 919862.66 \\
\hline 7 & 5.8424 & 1753.7717 & 705525.73 \\
\hline 8 & 5.8364 & 1751.9706 & 473327.39 \\
\hline 9 & 5.8303 & 1750.1395 & 714456.44 \\
\hline 10 & 5.8255 & 1748.6987 & 946654.78 \\
\hline 11 & 5.8201 & 1747.0777 & 687664.32 \\
\hline 12 & 3.7907 & 1137.8924 & 3125746.92 \\
\hline 13 & 3.3209 & 996.8678 & 1366397.94 \\
\hline 14 & 3.3150 & 995.0967 & 1678972.63 \\
\hline 15 & 3.2984 & 990.1137 & 1250298.77 \\
\hline 16 & 3.2925 & 988.3427 & 1848656.03 \\
\hline 17 & 3.2821 & 985.2208 & 1277090.88 \\
\hline 18 & 3.2549 & 977.0559 & 1411051.47 \\
\hline 19 & 3.2500 & 975.5850 & 1241368.06 \\
\hline 20 & 3.1815 & 955.0227 & 1384259.35 \\
\hline 21 & 3.1751 & 953.1016 & 1893309.56 \\
\hline 22 & 3.1726 & 952.3511 & 2009408.73 \\
\hline 23 & 3.1663 & 950.4600 & 1741487.57 \\
\hline 24 & 3.1055 & 932.2090 & 1044892.54 \\
\hline 25 & 3.0978 & 929.8976 & 910931.96 \\
\hline 26 & 3.0785 & 924.1042 & 776971.38 \\
\hline 27 & 3.0707 & 921.7628 & 687664.32 \\
\hline 28 & 2.2600 & 678.4068 & 1277090.88 \\
\hline 29 & 1.9690 & 591.0544 & 8787814.19 \\
\hline 30 & 1.9660 & 590.1539 & 8689576.43 \\
\hline
\end{tabular}

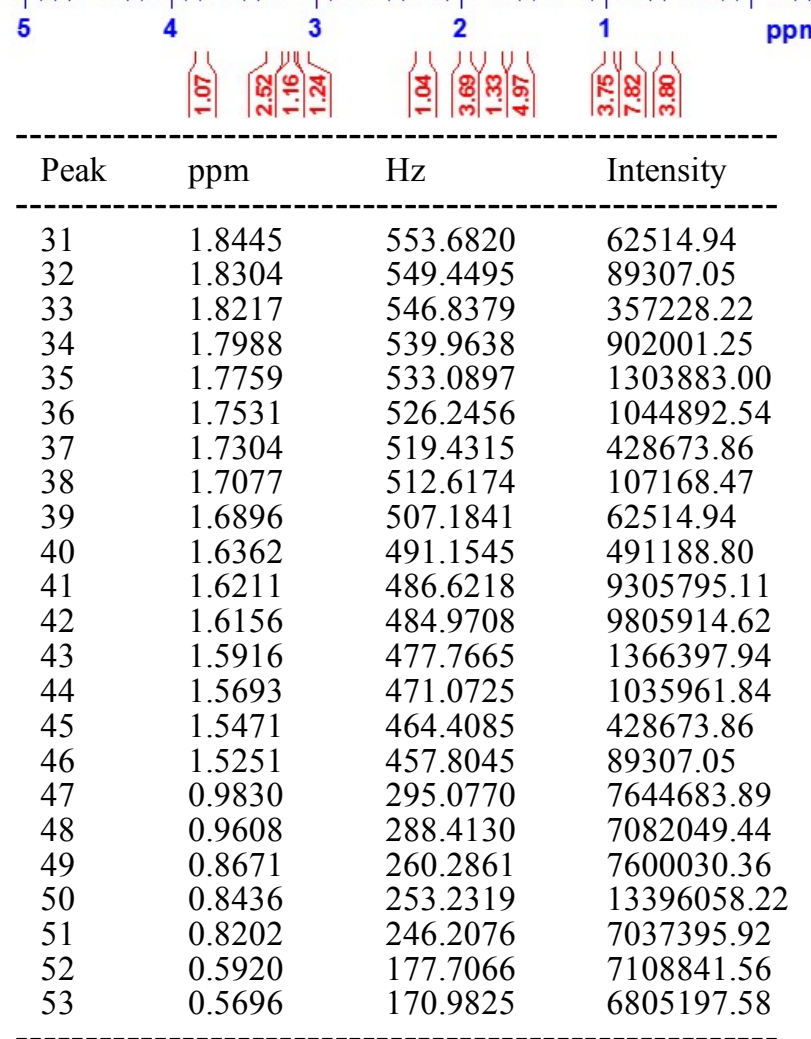


$\mathrm{CDCl}_{3}, 75 \mathrm{MHz} \quad$ bis(thymol)
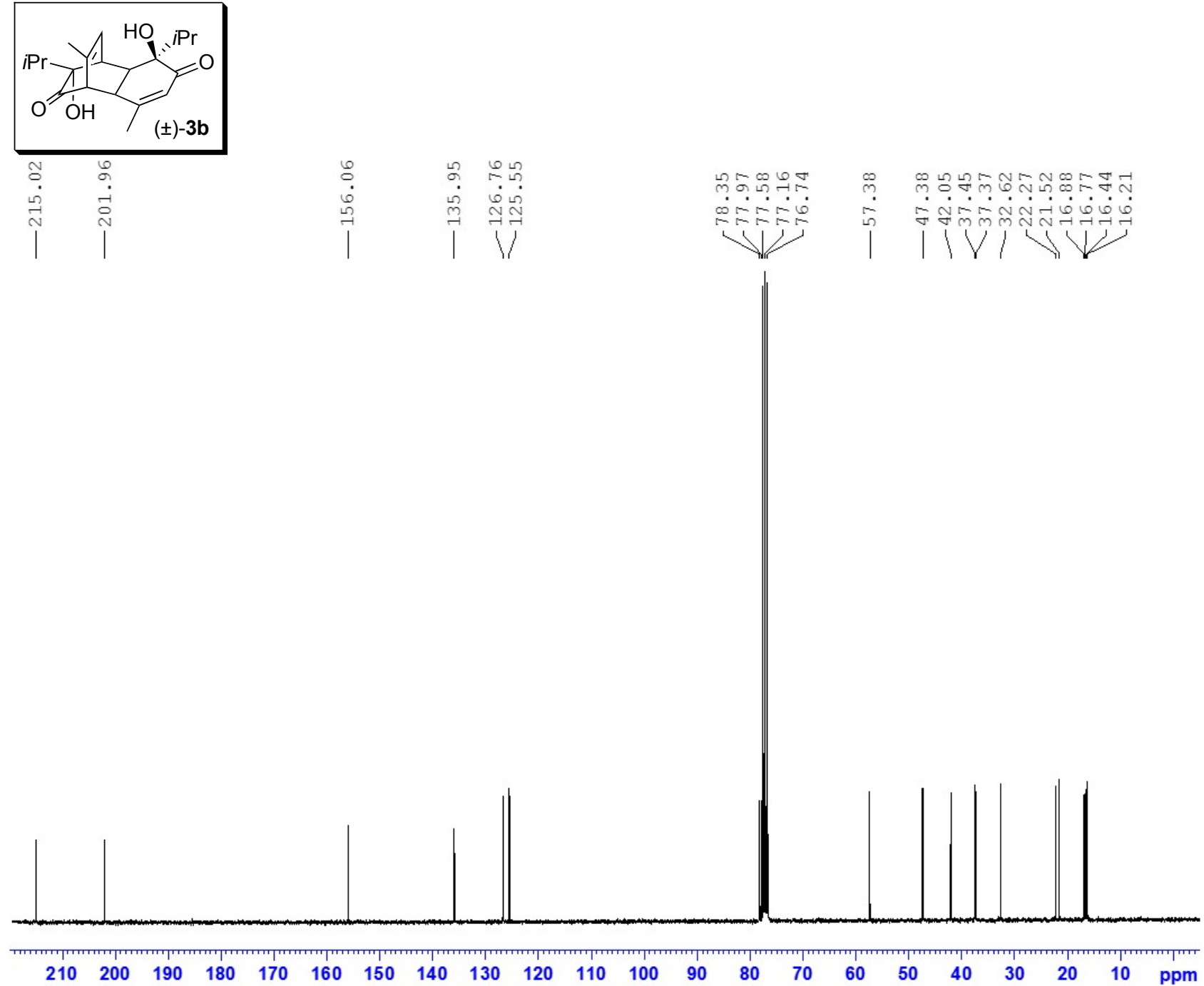


\section{Theoretical Calculations}

General. Calculations were carried out with the Gaussian 09 suite of programs ${ }^{[20]}$ at the Density Functional Theory (DFT) level. The hybrid exchange functional B3LYP was used. B3LYP is a three parameter functional developed by Becke, which combines the Becke gradient-corrected exchange functional and the Lee-Yang-Parr functionals with part of exact HF exchange energy. ${ }^{\text {[21,22] }}$ Iodine atom was treated with a Stuttgart-Dresden pseudopotential in combination with its adapted basis set. ${ }^{[23]}$ Oxygen, Nitrogen, Carbon and Hydrogen atoms have been described with a 6-31G(d,p) double- $\zeta$ basis set. ${ }^{[24]}$ Geometry optimisations were carried out without any symmetry restrictions, the nature of the minimum states was verified with analytical frequency calculations. All total energies and Gibbs free energies have been zero-point energy (ZPE) and temperature corrected using unscaled density functional frequencies. Electronic structure of the different complexes and more particularly Natural Population Analysis was studied using Natural Bond Orbital analysis (NBO-5 program). ${ }^{[25]}$ The electron density of the optimized structures was subjected to an Atom-in Molecules analysis (QTAIM analysis) ${ }^{[26]}$ using AIMA11 software. ${ }^{[27]}$

Several isomers were analyzed and correspond to the position of the two branches (PhI-CO-NH-) relative to each other. The most stable isomer on the potential energy surface corresponds to that shown below. The origin of this stabilization is mainly electronic. For example, we can observe stabilizing interactions thanks to a NBO calculations with cross-interactions between the oxygen lone pair (I-O) with the opposite $\sigma^{*}{ }_{\mathrm{NH}}$ find ( $\sim 9$ and $\sim 13 \mathrm{kcal} / \mathrm{mol}$ with a total of $\sim 44 \mathrm{kcal} / \mathrm{mol}$ ). AIM calculations are consistent and show critical bond critical points (BCP) that match with hydrogen bond. They promote the formation of a kind of "cage".

\section{$(R, R)-8 \mathbf{a}$ (“monomer")}

SCF Done: E(RB3LYP) $=-1357.48950873$ Hartrees

Nuclear repulsion energy $=3024.8090972971$ Hartrees.

$\mathrm{E}(\mathrm{elec})=-4382.29860603$ Hartrees

Sum of electronic and zero-point Energies $=\quad-1357.110449$

Sum of electronic and thermal Energies $=\quad-1357.082479$

Sum of electronic and thermal Enthalpies $=\quad-1357.081535$

Sum of electronic and thermal Free Energies $=-1357.169770$

$\begin{array}{lrrr}\mathrm{C} & -0.25464 & 2.73811 & -0.73801 \\ \mathrm{C} & 0.29522 & 3.97609 & -1.46310 \\ \mathrm{C} & -0.18305 & 5.25169 & -0.74697 \\ \mathrm{C} & 0.18428 & 5.25164 & 0.74684 \\ \mathrm{C} & -0.29431 & 3.97615 & 1.46295 \\ \mathrm{C} & 0.25522 & 2.73804 & 0.73785 \\ \mathrm{H} & 0.23936 & 6.13552 & -1.23840 \\ \mathrm{H} & 1.38991 & 3.93084 & -1.48356 \\ \mathrm{H} & -0.04955 & 3.96886 & -2.50294 \\ \mathrm{H} & -1.34365 & 2.81395 & -0.70927 \\ \mathrm{H} & 1.27560 & 5.32972 & 0.84943 \\ \mathrm{H} & -0.23791 & 6.13557 & 1.23827 \\ \mathrm{H} & 0.05046 & 3.96882 & 2.50279\end{array}$




$\begin{array}{lccc}\mathrm{H} & -1.38902 & 3.93118 & 1.48342 \\ \mathrm{H} & 1.34425 & 2.81360 & 0.70909 \\ \mathrm{H} & -1.27434 & 5.33005 & -0.84957 \\ \mathrm{~N} & 0.00464 & 1.45967 & 1.41772 \\ \mathrm{H} & 0.84438 & 0.88023 & 1.56583 \\ \mathrm{~N} & -0.00434 & 1.45968 & -1.41787 \\ \mathrm{H} & -0.84424 & 0.88048 & -1.56608 \\ \mathrm{C} & -1.19041 & 0.85516 & 1.39810 \\ \mathrm{C} & -1.25679 & -0.60306 & 1.74293 \\ \mathrm{C} & -2.27063 & -1.35030 & 1.14065 \\ \mathrm{C} & -0.37145 & -1.27074 & 2.59827 \\ \mathrm{C} & -2.43231 & -2.71009 & 1.33480 \\ \mathrm{C} & -0.53192 & -2.63889 & 2.83333 \\ \mathrm{H} & 0.44545 & -0.73409 & 3.06748 \\ \mathrm{C} & -1.55264 & -3.35837 & 2.20933 \\ \mathrm{H} & -3.22177 & -3.23340 & 0.79994 \\ \mathrm{H} & 0.15553 & -3.14486 & 3.50401 \\ \mathrm{H} & -1.65954 & -4.42353 & 2.39184 \\ \mathrm{O} & -2.24276 & 1.42272 & 1.02669 \\ \mathrm{C} & 1.19055 & 0.85488 & -1.39817 \\ \mathrm{C} & 1.25660 & -0.60338 & -1.74288 \\ \mathrm{C} & 2.27031 & -1.35075 & -1.14054 \\ \mathrm{C} & 0.37111 & -1.27098 & -2.59812 \\ \mathrm{C} & 2.43171 & -2.71060 & -1.33453 \\ \mathrm{C} & 0.53130 & -2.63918 & -2.83303 \\ \mathrm{H} & -0.44570 & -0.73422 & -3.06737 \\ \mathrm{C} & 1.55188 & -3.35880 & -2.20897 \\ \mathrm{H} & 3.22108 & -3.23400 & -0.79963 \\ \mathrm{H} & -0.15626 & -3.14510 & -3.50363 \\ \mathrm{H} & 1.65857 & -4.42400 & -2.39136 \\ \mathrm{O} & 2.24299 & 1.42215 & -1.02657 \\ \mathrm{I} & 3.59051 & -0.42431 & 0.29945 \\ \mathrm{I} & -3.59062 & -0.42382 & -0.29953 \\ \mathrm{O} & -4.42418 & -1.96267 & -0.77241 \\ \mathrm{O} & 4.42404 & -1.96318 & 0.77233 \\ \mathrm{O} & -2.40838 & -0.03375 & -1.64744 \\ \mathrm{O} & 2.40841 & -0.03408 & 1.64743 \\ & & & \end{array}$

Main interatomic distances $(\AA)$. ("monomer") 
AIM Rho (e.bohr $\left.{ }^{-3}\right)$. ("monomer")

Considering the symmetry and for clarity, only densities for the half part of the molecule are represented. Bond critical points (BCP) are shown in green.

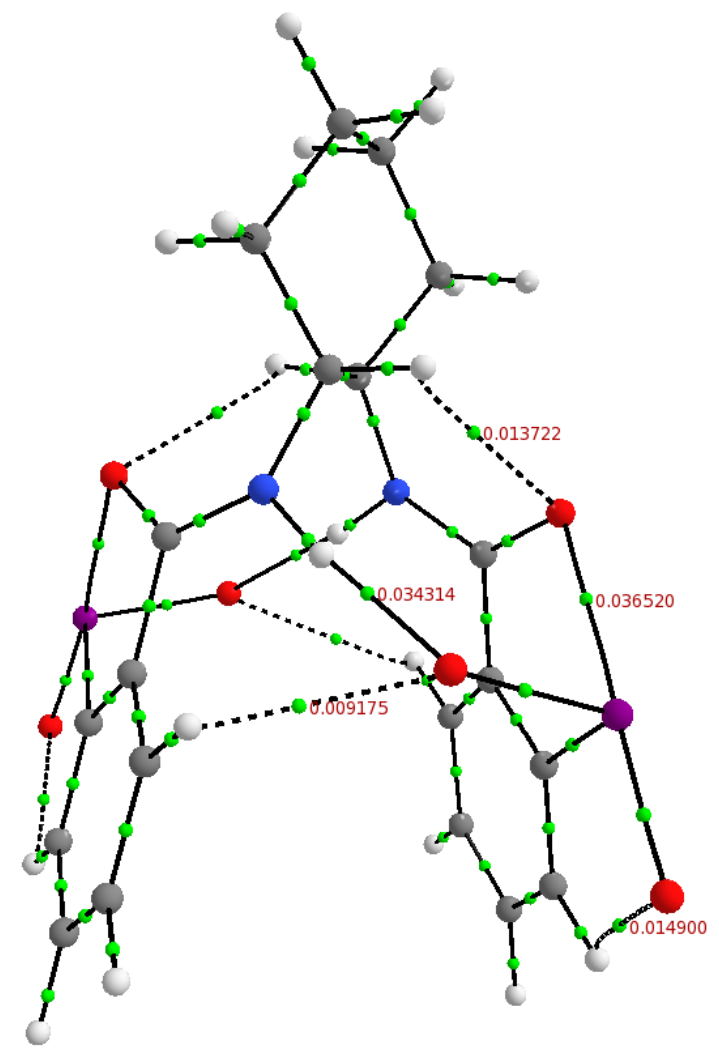

$(R, R)-8 \mathbf{a}$ ("dimer")

SCF Done: E(RB3LYP) $=-2675.6343189$ Hartrees

Nuclear repulsion energy $=8542.9439441670$ Hartrees.

$\mathrm{E}(\mathrm{elec})=-11218.5782631$ Hartrees

Sum of electronic and zero-point Energies $=\quad-2674.905926$

Sum of electronic and thermal Energies $=\quad-2674.847658$

Sum of electronic and thermal Enthalpies $=\quad-2674.846714$

Sum of electronic and thermal Free Energies $=-2675.008548$

$\begin{array}{llll}\mathrm{C} & -5.30229 & -1.48701 & 1.29015 \\ \mathrm{C} & -6.59075 & -1.92738 & 2.00248 \\ \mathrm{C} & -6.24467 & -2.74874 & 3.25642 \\ \mathrm{C} & -5.30164 & -1.98838 & 4.20391 \\ \mathrm{C} & -4.03895 & -1.48726 & 3.48026 \\ \mathrm{C} & -4.43698 & -0.63175 & 2.26765 \\ \mathrm{H} & -7.16331 & -3.02836 & 3.78455 \\ \mathrm{H} & -7.17562 & -1.04049 & 2.27069 \\ \mathrm{H} & -7.19967 & -2.52102 & 1.31198 \\ \mathrm{H} & -4.72636 & -2.38028 & 1.03535 \\ \mathrm{H} & -5.83446 & -1.12643 & 4.62887 \\ \mathrm{H} & -5.01897 & -2.62698 & 5.04869 \\ \mathrm{H} & -3.42200 & -0.88697 & 4.15908\end{array}$

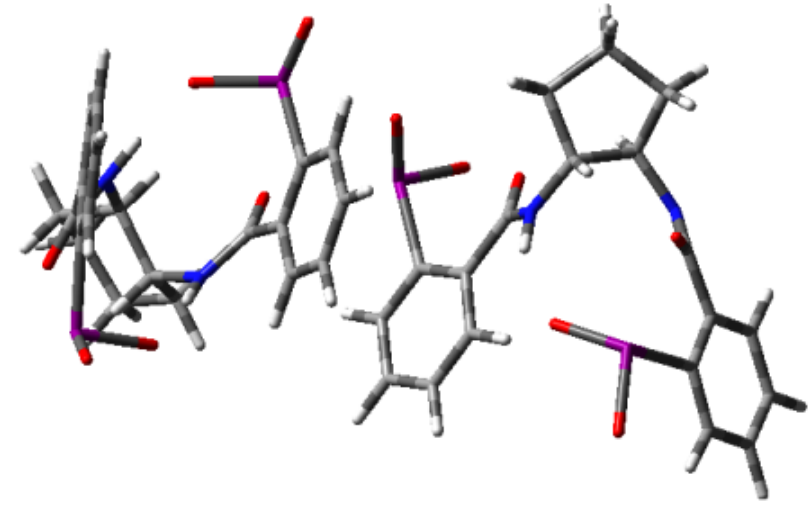

S137 


\begin{tabular}{|c|c|c|c|}
\hline $\mathrm{H}$ & -3.42996 & -2.33388 & 3.14394 \\
\hline $\mathrm{H}$ & -5.05997 & 0.19205 & 2.62181 \\
\hline $\mathrm{H}$ & -5.76498 & -3.68824 & 2.94798 \\
\hline $\mathrm{N}$ & -3.32431 & 0.03498 & 1.57710 \\
\hline $\mathrm{H}$ & -3.46921 & 1.04346 & 1.41335 \\
\hline $\mathrm{N}$ & -5.51106 & -0.81808 & -0.00025 \\
\hline $\mathrm{H}$ & -4.96357 & -1.21778 & -0.78338 \\
\hline $\mathrm{C}$ & -2.45460 & -0.61966 & 0.79544 \\
\hline $\mathrm{C}$ & -1.65926 & 0.17441 & -0.19343 \\
\hline $\mathrm{C}$ & -1.34076 & -0.43435 & -1.41000 \\
\hline $\mathrm{C}$ & -1.23259 & 1.49287 & 0.01577 \\
\hline $\mathrm{C}$ & -0.63569 & 0.20979 & -2.41029 \\
\hline $\mathrm{C}$ & -0.49194 & 2.15001 & -0.96884 \\
\hline $\mathrm{H}$ & -1.48051 & 2.00564 & 0.93830 \\
\hline $\mathrm{C}$ & -0.19184 & 1.51572 & -2.17562 \\
\hline $\mathrm{H}$ & -0.45981 & -0.30949 & -3.34975 \\
\hline $\mathrm{H}$ & -0.15621 & 3.16684 & -0.79119 \\
\hline $\mathrm{H}$ & 0.37490 & 2.03941 & -2.93992 \\
\hline $\mathrm{O}$ & -2.32609 & -1.86832 & 0.80817 \\
\hline $\mathrm{C}$ & -5.92787 & 0.45012 & -0.09476 \\
\hline $\mathrm{C}$ & -5.71832 & 1.17053 & -1.39350 \\
\hline $\mathrm{C}$ & -5.53103 & 2.55230 & -1.32857 \\
\hline $\mathrm{C}$ & -5.67044 & 0.56257 & -2.65412 \\
\hline $\mathrm{C}$ & -5.28752 & 3.34184 & -2.43760 \\
\hline $\mathrm{C}$ & -5.45528 & 1.34293 & -3.79327 \\
\hline $\mathrm{H}$ & -5.77989 & -0.51187 & -2.74766 \\
\hline $\mathrm{C}$ & -5.26517 & 2.72226 & -3.69238 \\
\hline $\mathrm{H}$ & -5.10901 & 4.40636 & -2.30352 \\
\hline $\mathrm{H}$ & -5.42521 & 0.86151 & -4.76575 \\
\hline $\mathrm{H}$ & -5.08638 & 3.31513 & -4.58448 \\
\hline $\mathrm{O}$ & -6.40483 & 1.09477 & 0.86820 \\
\hline I & -5.43781 & 3.53873 & 0.59020 \\
\hline I & -2.11895 & -2.38815 & -1.93068 \\
\hline $\mathrm{O}$ & -1.59769 & -2.30922 & -3.66218 \\
\hline $\mathrm{O}$ & -4.96942 & 5.15901 & -0.07567 \\
\hline $\mathrm{O}$ & -3.90865 & -1.97379 & -1.94895 \\
\hline $\mathrm{O}$ & -3.91035 & 2.79033 & 1.28023 \\
\hline $\mathrm{C}$ & 1.74668 & 1.03199 & 2.89047 \\
\hline $\mathrm{C}$ & 0.70878 & 0.30359 & 3.46858 \\
\hline $\mathrm{C}$ & 0.36118 & -0.94164 & 2.93516 \\
\hline $\mathrm{C}$ & 1.06960 & -1.43774 & 1.84659 \\
\hline $\mathrm{C}$ & 2.11414 & -0.72338 & 1.25063 \\
\hline $\mathrm{C}$ & 2.44245 & 0.52981 & 1.78718 \\
\hline $\mathrm{H}$ & 2.02157 & 2.00133 & 3.29519 \\
\hline $\mathrm{H}$ & 0.16537 & 0.69815 & 4.32180 \\
\hline $\mathrm{H}$ & -0.46688 & -1.50277 & 3.36178 \\
\hline $\mathrm{H}$ & 3.25046 & 1.11789 & 1.35656 \\
\hline I & 0.29049 & -3.36430 & 1.16676 \\
\hline $\mathrm{O}$ & 0.21553 & -3.17285 & -0.64989 \\
\hline $\mathrm{O}$ & 1.48757 & -4.63501 & 1.63564 \\
\hline $\mathrm{C}$ & 2.86961 & -1.36368 & 0.11475 \\
\hline $\mathrm{N}$ & 3.45885 & -0.54187 & -0.78631 \\
\hline $\mathrm{H}$ & 3.49308 & 0.46041 & -0.61992 \\
\hline $\mathrm{O}$ & 2.91864 & -2.59373 & 0.04899 \\
\hline $\mathrm{C}$ & 4.24624 & -1.02687 & -1.91065 \\
\hline $\mathrm{H}$ & 4.67358 & -0.13382 & -2.36837 \\
\hline $\mathrm{C}$ & 3.51703 & -1.84951 & -2.99116 \\
\hline
\end{tabular}




$\begin{array}{lrrr}\mathrm{H} & 2.86043 & -2.57796 & -2.51033 \\ \mathrm{H} & 2.89985 & -1.21393 & -3.63139 \\ \mathrm{C} & 4.66828 & -2.55492 & -3.77131 \\ \mathrm{H} & 4.44016 & -3.61498 & -3.91063 \\ \mathrm{H} & 4.80163 & -2.12654 & -4.76855 \\ \mathrm{C} & 5.41871 & -1.97038 & -1.54169 \\ \mathrm{H} & 4.98775 & -2.84323 & -1.04711 \\ \mathrm{C} & 5.96073 & -2.37094 & -2.92039 \\ \mathrm{H} & 6.57814 & -3.27251 & -2.87936 \\ \mathrm{H} & 6.57949 & -1.55884 & -3.31493 \\ \mathrm{~N} & 6.37049 & -1.41108 & -0.57199 \\ \mathrm{H} & 6.41913 & -1.89154 & 0.31515 \\ \mathrm{C} & 6.82218 & -0.14362 & -0.58539 \\ \mathrm{O} & 6.69061 & 0.62964 & -1.55164 \\ \mathrm{C} & 7.44534 & 0.38110 & 0.67523 \\ \mathrm{C} & 7.26415 & 1.73498 & 0.95768 \\ \mathrm{C} & 8.18663 & -0.38439 & 1.58329 \\ \mathrm{C} & 7.74935 & 2.34090 & 2.10277 \\ \mathrm{C} & 8.71054 & 0.21009 & 2.73435 \\ \mathrm{H} & 8.38045 & -1.43438 & 1.38149 \\ \mathrm{C} & 8.49024 & 1.56297 & 3.00000 \\ \mathrm{H} & 7.53718 & 3.39401 & 2.27530 \\ \mathrm{H} & 9.29530 & -0.38906 & 3.42544 \\ \mathrm{H} & 8.89192 & 2.01349 & 3.90248 \\ \mathrm{I} & 6.06710 & 2.97554 & -0.35693 \\ \mathrm{O} & 4.42213 & 2.20965 & -0.13016 \\ \mathrm{O} & 6.13933 & 4.43909 & 0.70926\end{array}$

Main interatomic distances $(\AA)$.

("dimer")

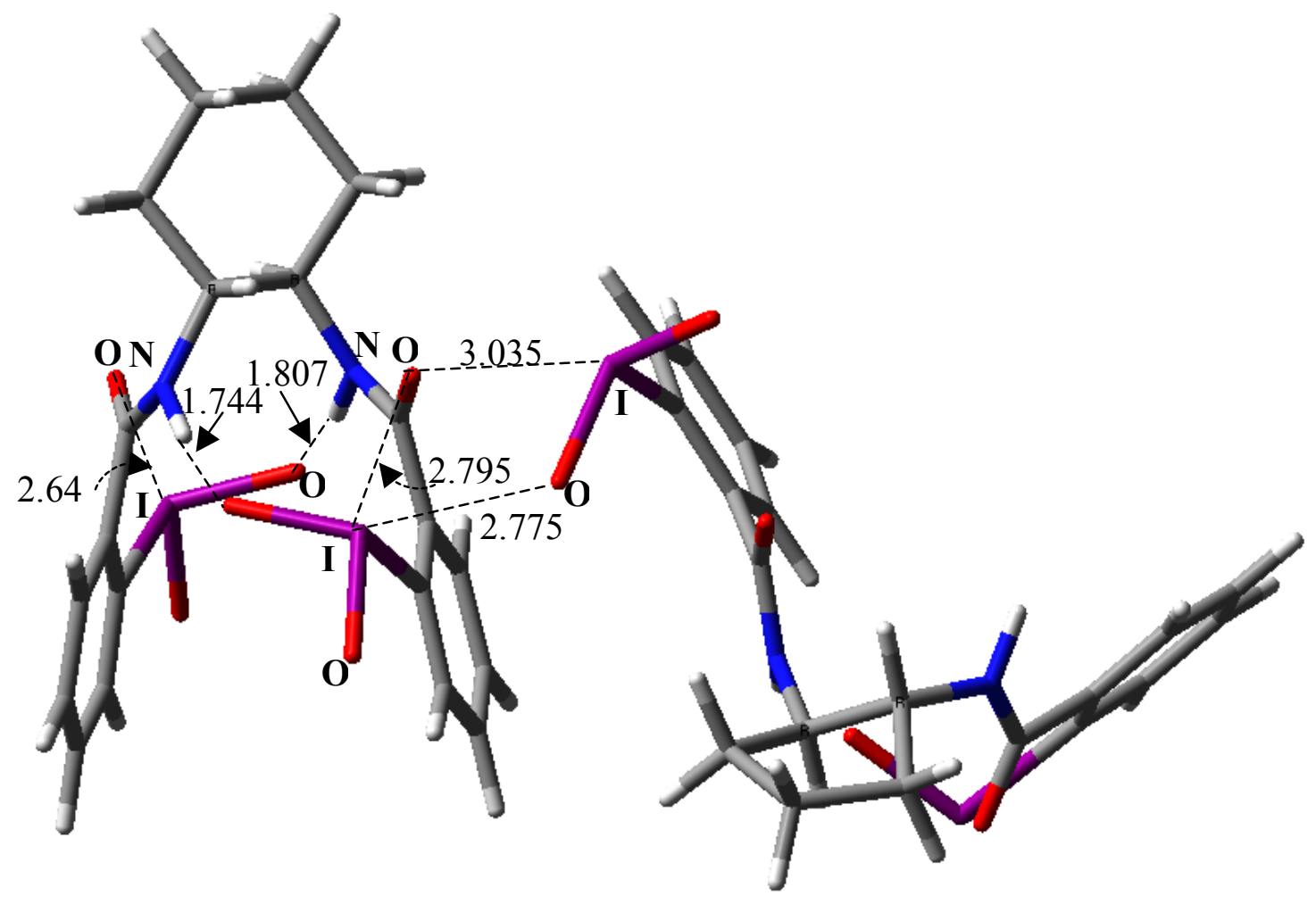


AIM Rho (e.bohr $\left.{ }^{-3}\right)$. (“dimer")

For clarity, only densities values between the two molecules are represented.

All calculated bond critical points (BCP) are shown in green.

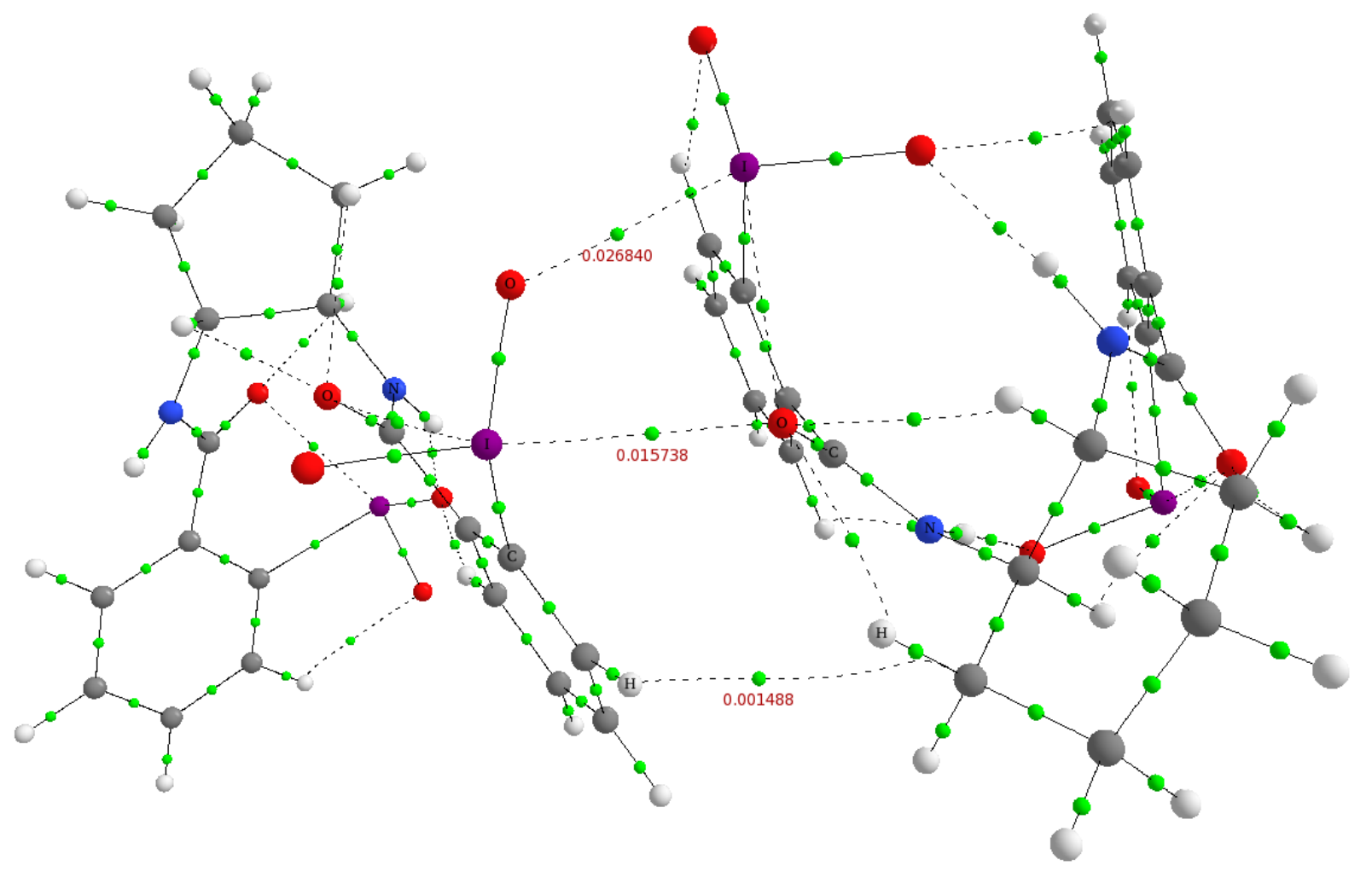

$(R, R)-8 \mathbf{a}$ ("trimer")

SCF Done: $E($ RB3LYP $)=-4033.15234539$ Hartrees

nuclear repulsion energy $=15948.8626840432$ Hartrees.

$\mathrm{E}(\mathrm{elec})=-19982.0150294$ Hartrees

Sum of electronic and zero-point Energies $=\quad-4032.043225$

Sum of electronic and thermal Energies $=\quad-4031.955069$

Sum of electronic and thermal Enthalpies $=\quad-4031.954125$

Sum of electronic and thermal Free Energies $=-4032.185518$

$\begin{array}{llll}\mathrm{C} & 2.22562 & -5.63942 & 1.58608 \\ \mathrm{C} & 1.83112 & -6.91374 & 2.34927 \\ \mathrm{C} & 2.18523 & -6.76627 & 3.83947 \\ \mathrm{C} & 1.55311 & -5.51060 & 4.46313 \\ \mathrm{C} & 1.89294 & -4.23882 & 3.66582 \\ \mathrm{C} & 1.47478 & -4.41630 & 2.19859 \\ \mathrm{H} & 1.86679 & -7.65981 & 4.38834 \\ \mathrm{H} & 0.75729 & -7.09181 & 2.22421 \\ \mathrm{H} & 2.35540 & -7.77147 & 1.91403 \\ \mathrm{H} & 3.29678 & -5.47195 & 1.72506 \\ \mathrm{H} & 0.46147 & -5.63195 & 4.49224 \\ \mathrm{H} & 1.88205 & -5.39875 & 5.50273 \\ \mathrm{H} & 1.37096 & -3.37206 & 4.08780 \\ \mathrm{H} & 2.96806 & -4.03232 & 3.71622 \\ \mathrm{H} & 0.40634 & -4.64031 & 2.17311\end{array}$




\begin{tabular}{|c|c|c|c|}
\hline $\mathrm{H}$ & 3.27787 & -6.70987 & 3.94443 \\
\hline $\mathrm{N}$ & 1.60598 & -3.21642 & 1.36077 \\
\hline $\mathrm{H}$ & 0.76409 & -2.99477 & 0.80789 \\
\hline $\mathbf{N}$ & 2.06414 & -5.71926 & 0.12877 \\
\hline $\mathrm{H}$ & 2.90576 & -5.44939 & -0.4095 \\
\hline $\mathrm{C}$ & 2.78661 & -2.74357 & 0.94057 \\
\hline $\mathrm{C}$ & 2.79513 & -1.82300 & -0.23998 \\
\hline $\mathrm{C}$ & 3.88461 & -1.89337 & -1.1115 \\
\hline $\mathrm{C}$ & 1.77056 & -0.91435 & -0.5377 \\
\hline $\mathrm{C}$ & 3.98515 & -1.11853 & -2.2525 \\
\hline $\mathrm{C}$ & 1.86825 & -0.09885 & $-1.6671 \mathrm{C}$ \\
\hline $\mathrm{H}$ & 0.89985 & -0.84439 & 0.1044 \\
\hline $\mathrm{C}$ & 2.96735 & -0.19709 & -2.5223 \\
\hline $\mathrm{H}$ & 4.84146 & -1.25790 & -2.9087 \\
\hline $\mathrm{H}$ & 1.07456 & 0.61001 & -1.8807 \\
\hline $\mathrm{H}$ & 3.02771 & 0.43168 & -3.40586 \\
\hline $\mathrm{O}$ & 3.88388 & -3.08953 & 1.44342 \\
\hline $\mathrm{C}$ & 0.87028 & -5.64105 & $-0.4722 \varepsilon$ \\
\hline $\mathrm{C}$ & 0.83072 & -5.32687 & $-1.9371^{\circ}$ \\
\hline $\mathrm{C}$ & -0.28384 & -4.62420 & -2.4085 \\
\hline $\mathrm{C}$ & 1.83831 & -5.66847 & -2.8471 \\
\hline $\mathrm{C}$ & -0.41743 & -4.25069 & -3.7367 \\
\hline $\mathrm{C}$ & 1.70570 & -5.32191 & -4.1934 \\
\hline $\mathrm{H}$ & 2.72822 & -6.18605 & -2.5077 \\
\hline $\mathrm{C}$ & 0.58639 & -4.61842 & -4.6394 \\
\hline $\mathrm{H}$ & -1.28354 & -3.67181 & -4.0420 \\
\hline $\mathrm{H}$ & 2.49005 & -5.59611 & -4.8920 \\
\hline $\mathrm{H}$ & 0.49660 & -4.34273 & -5.6861 \\
\hline $\mathrm{O}$ & -0.21802 & -5.73762 & 0.1420 \\
\hline I & -1.79898 & -3.98000 & $-1.010\}$ \\
\hline I & 5.42945 & -3.39193 & -0.8666 \\
\hline $\mathrm{O}$ & 6.21842 & -3.06662 & -2.4635 \\
\hline $\mathrm{O}$ & -2.62871 & -2.93732 & -2.2741 \\
\hline $\mathrm{O}$ & 4.40331 & -4.89196 & -1.1298 \\
\hline $\mathrm{O}$ & -0.81494 & -2.79703 & -0.0297 \\
\hline $\mathrm{C}$ & 2.14984 & 1.89278 & 2.40223 \\
\hline $\mathrm{C}$ & 2.18391 & 0.76072 & 3.2141 \\
\hline $\mathrm{C}$ & 3.31558 & -0.06070 & 3.2032 \\
\hline $\mathrm{C}$ & 4.39660 & 0.27924 & 2.39741 \\
\hline $\mathrm{C}$ & 4.38516 & 1.41266 & $1.5783^{7}$ \\
\hline $\mathrm{C}$ & 3.23600 & 2.21587 & 1.58422 \\
\hline $\mathrm{H}$ & 1.27268 & 2.53277 & 2.3977 \\
\hline $\mathrm{H}$ & 1.33746 & 0.50737 & 3.8452 \\
\hline $\mathrm{H}$ & 3.33478 & -0.96348 & 3.8092 \\
\hline $\mathrm{H}$ & 3.18332 & 3.10160 & 0.9546 \\
\hline I & 5.99996 & -1.20127 & 2.49433 \\
\hline $\mathrm{O}$ & 6.49775 & -1.38534 & 0.7451 \\
\hline $\mathrm{O}$ & 7.34170 & -0.47859 & 3.4663 \\
\hline $\mathrm{C}$ & 5.62267 & 1.75209 & 0.78787 \\
\hline $\mathrm{N}$ & 5.44554 & 2.38902 & -0.3945 \\
\hline $\mathrm{H}$ & 4.52346 & 2.72267 & -0.6614 \\
\hline $\mathrm{O}$ & 6.72636 & 1.44047 & 1.2384 \\
\hline $\mathrm{C}$ & 6.54675 & 2.78603 & -1.2591 \\
\hline $\mathrm{H}$ & 6.08712 & 3.35660 & -2.0670 \\
\hline $\mathrm{C}$ & 7.41690 & 1.66520 & -1.8627 \\
\hline $\mathrm{H}$ & 7.63747 & 0.92199 & -1.0933 \\
\hline . & 6.90130 & 1.15508 & -2.680 \\
\hline
\end{tabular}

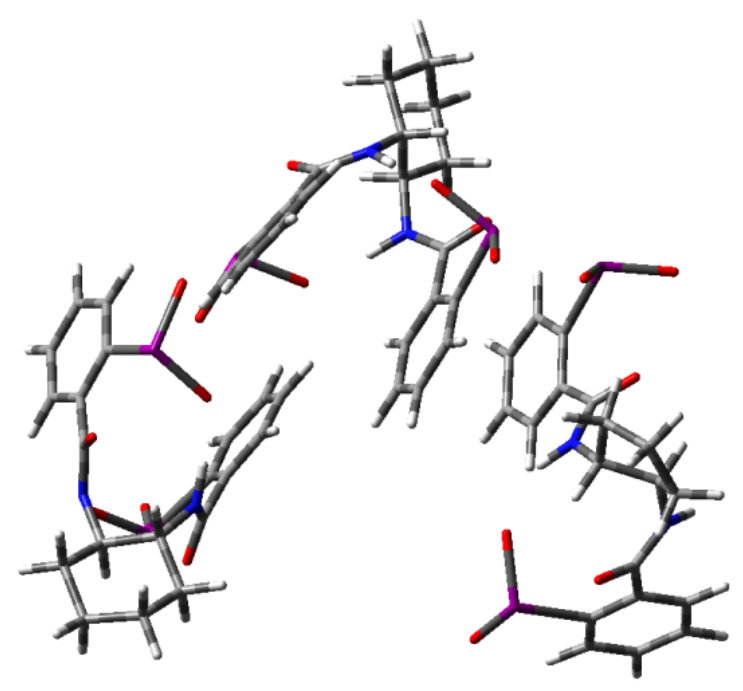




\begin{tabular}{|c|c|c|c|}
\hline $\mathrm{C}$ & 8.71145 & 2.39788 & -2.33019 \\
\hline $\mathrm{H}$ & 9.59856 & 1.85823 & -1.98805 \\
\hline $\mathrm{H}$ & 8.77494 & 2.45124 & -3.42051 \\
\hline $\mathrm{C}$ & 7.61667 & 3.69116 & -0.59817 \\
\hline $\mathrm{H}$ & 8.04200 & 3.13143 & 0.23743 \\
\hline $\mathrm{C}$ & 8.66091 & 3.82798 & -1.71448 \\
\hline $\mathrm{H}$ & 9.63082 & 4.16671 & -1.33986 \\
\hline $\mathrm{H}$ & 8.31071 & 4.56084 & -2.44834 \\
\hline $\mathrm{N}$ & 7.08978 & 4.92747 & -0.00383 \\
\hline $\mathrm{H}$ & 7.20403 & 5.01226 & 0.99612 \\
\hline $\mathrm{C}$ & 6.14394 & 5.70542 & -0.56065 \\
\hline $\mathrm{O}$ & 5.77946 & 5.61349 & -1.74714 \\
\hline $\mathrm{C}$ & 5.43818 & 6.68331 & 0.33301 \\
\hline $\mathrm{C}$ & 4.09978 & 6.95389 & 0.04774 \\
\hline $\mathrm{C}$ & 6.02123 & 7.33971 & 1.42358 \\
\hline $\mathrm{C}$ & 3.32047 & 7.80573 & 0.80964 \\
\hline $\mathrm{C}$ & 5.26280 & 8.22608 & 2.19298 \\
\hline $\mathrm{H}$ & 7.07116 & 7.18433 & 1.65669 \\
\hline $\mathrm{C}$ & 3.91806 & 8.45571 & 1.89578 \\
\hline $\mathrm{H}$ & 2.27276 & 7.94027 & 0.54877 \\
\hline $\mathrm{H}$ & 5.72808 & 8.74052 & 3.02810 \\
\hline $\mathrm{H}$ & 3.33396 & 9.13771 & 2.50611 \\
\hline I & 3.10159 & 5.92754 & -1.57946 \\
\hline $\mathrm{O}$ & 3.12334 & 4.21236 & -0.94631 \\
\hline $\mathrm{O}$ & 1.46688 & 6.62362 & -1.22045 \\
\hline $\mathrm{C}$ & -5.78333 & 2.33316 & -2.11069 \\
\hline $\mathrm{C}$ & -5.30459 & 3.67261 & -2.69067 \\
\hline $\mathrm{C}$ & -5.65305 & 3.74325 & -4.18759 \\
\hline $\mathrm{C}$ & -7.15132 & 3.50856 & -4.44659 \\
\hline $\mathrm{C}$ & -7.65586 & 2.20671 & -3.79837 \\
\hline $\mathrm{C}$ & -7.32885 & 2.21305 & -2.29708 \\
\hline $\mathrm{H}$ & -5.34772 & 4.71341 & -4.59595 \\
\hline $\mathrm{H}$ & -5.77630 & 4.49656 & -2.14357 \\
\hline $\mathrm{H}$ & -4.22270 & 3.76384 & -2.54503 \\
\hline $\mathrm{H}$ & -5.32018 & 1.52597 & -2.68220 \\
\hline $\mathrm{H}$ & -7.72398 & 4.35428 & -4.04086 \\
\hline $\mathrm{H}$ & -7.34865 & 3.48843 & -5.52451 \\
\hline $\mathrm{H}$ & -8.73866 & 2.10707 & -3.93209 \\
\hline $\mathrm{H}$ & -7.18850 & 1.33448 & -4.26873 \\
\hline $\mathrm{H}$ & -7.78466 & 3.09941 & -1.85058 \\
\hline $\mathrm{H}$ & -5.07111 & 2.98174 & -4.72516 \\
\hline $\mathrm{N}$ & -7.90064 & 1.09552 & -1.53250 \\
\hline $\mathrm{H}$ & -8.43571 & 1.37570 & -0.69811 \\
\hline $\mathrm{N}$ & -5.36432 & 2.07333 & -0.72688 \\
\hline $\mathrm{H}$ & -4.89871 & 1.16495 & -0.58692 \\
\hline $\mathrm{C}$ & -7.39199 & -0.14396 & -1.57596 \\
\hline $\mathrm{C}$ & -7.76030 & -1.10588 & -0.48703 \\
\hline $\mathrm{C}$ & -6.81392 & -2.08018 & -0.14918 \\
\hline $\mathrm{C}$ & -8.97064 & -1.07696 & 0.21632 \\
\hline $\mathrm{C}$ & -7.03313 & -3.00391 & 0.86124 \\
\hline $\mathrm{C}$ & -9.21549 & -2.01803 & 1.21859 \\
\hline $\mathrm{H}$ & -9.71440 & -0.32022 & -0.00654 \\
\hline $\mathrm{C}$ & -8.25535 & -2.97737 & 1.54185 \\
\hline $\mathrm{H}$ & -6.25054 & -3.71456 & 1.10900 \\
\hline $\mathrm{H}$ & -10.16006 & -1.99193 & 1.75306 \\
\hline $\mathrm{H}$ & -8.44934 & -3.69928 & 2.32980 \\
\hline $\mathrm{O}$ & -6.56435 & -0.51442 & -2.4390 \\
\hline
\end{tabular}




$\begin{array}{lrrr}\text { C } & -5.94543 & 2.66071 & 0.32603 \\ \text { C } & -5.75954 & 2.04177 & 1.68009 \\ \text { C } & -6.79087 & 2.22118 & 2.60356 \\ \text { C } & -4.65220 & 1.28133 & 2.07581 \\ \text { C } & -6.77924 & 1.67578 & 3.87443 \\ \text { C } & -4.60493 & 0.74215 & 3.36415 \\ \text { H } & -3.83945 & 1.09459 & 1.38293 \\ \text { C } & -5.65683 & 0.93499 & 4.26153 \\ \text { H } & -7.63934 & 1.82522 & 4.52342 \\ \text { H } & -3.74035 & 0.15624 & 3.66033 \\ \text { H } & -5.61282 & 0.50040 & 5.25584 \\ \text { O } & -6.70592 & 3.65109 & 0.22963 \\ \text { I } & -8.60107 & 3.24738 & 2.01887 \\ \text { I } & -4.89236 & -2.09248 & -1.14160 \\ \text { O } & -4.22059 & -3.35573 & 0.00675 \\ \text { O } & -9.48501 & 2.91412 & 3.56700 \\ \text { O } & -4.23277 & -0.51485 & -0.50457 \\ \text { O } & -9.26345 & 2.07694 & 0.77153\end{array}$

Main interatomic distances $(\AA)$.

("trimer")

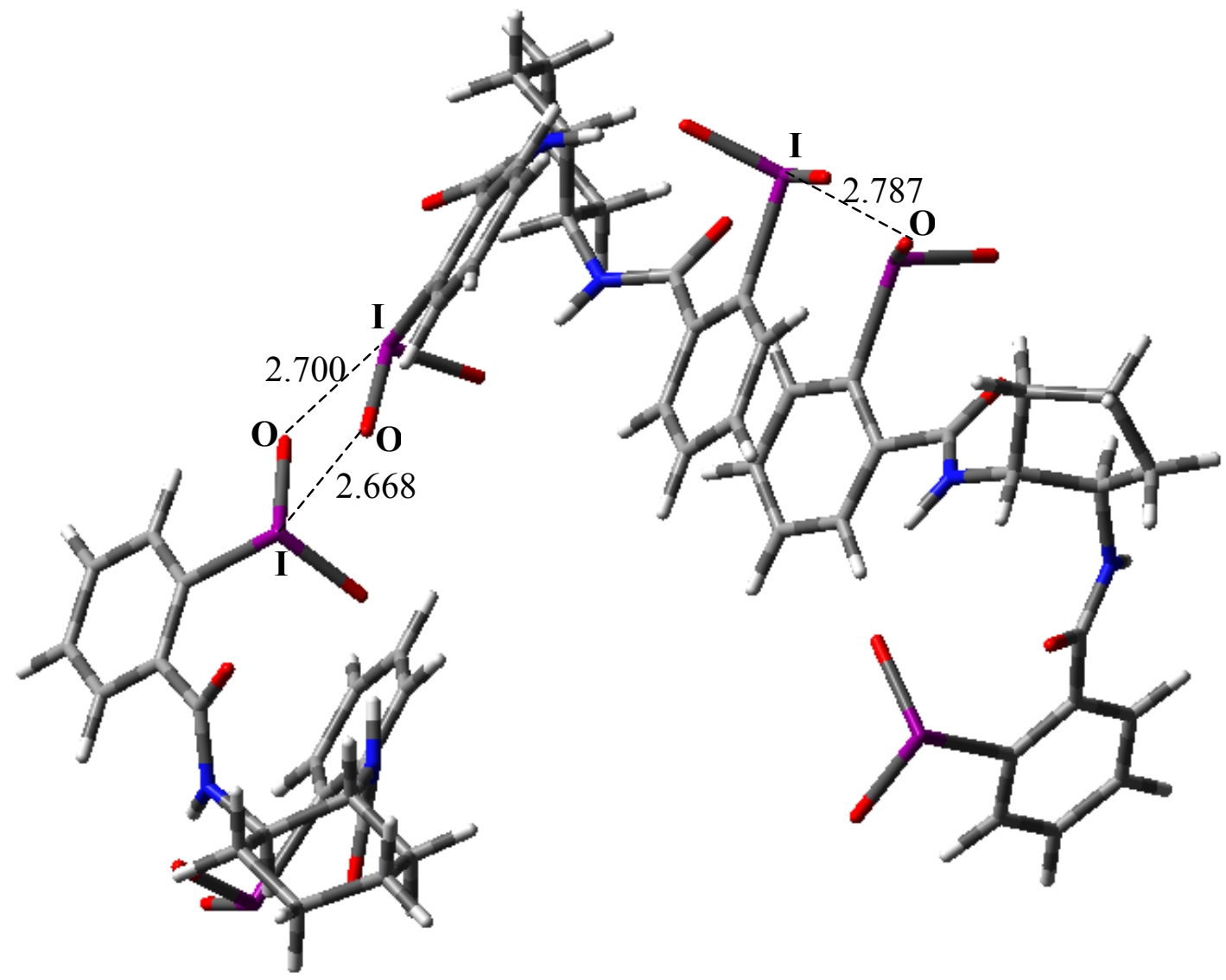


AIM Rho (e.bohr-3). ("trimer")

Only the calculated main densities between molecules are represented.

All calculated bond critical points (BCP) are shown in green.

$\mathrm{O} 32$ - I61 0.016030

I46 - O62 0.026283

$\mathrm{O} 48$ - I143 0.034577

I45 - O144 0.032571

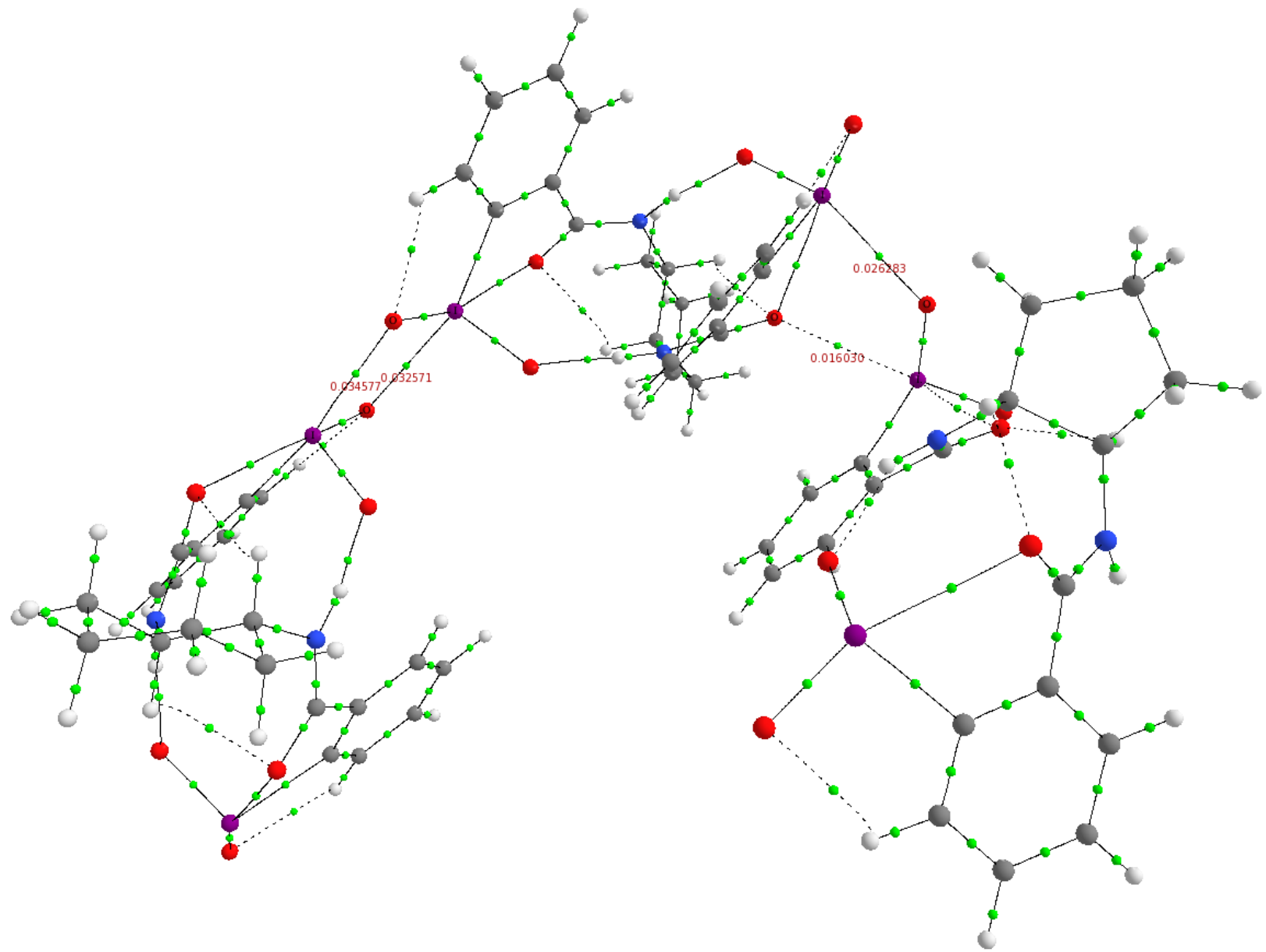




\section{Additional References}

[1] Fulmer, G. R.; Miller, A. J. M.; Sherden, N. H.; Gottlieb, H. E.; A. Nudelman, A.; Stoltz, B. M.; Bercaw, J. E.; Goldberg, K. I. Organometallics 2010, 29, 2176.

[2] Du, Z.; Li, Y.; Wang, Y.; Ding L.; Gao, J. Synth. Commun. 2010, 1920.

[3] Montiel, L. E.; Zepeda, L. G.; Tamariz, J. Helv. Chim. Acta 2010, 93, 1261.

[4] Palais, L.; Alexakis, A. Chem. Eur. J. 2009, 15, 10473.

[5] Ghisalberti, E. L.; Jefferies, P. R.; Stuart, A. D. Aust. J. Chem. 1979, 32, 1627.

[6] Wright, A. E.; Pomponi, S. A.; McConnell, O. J.; Kohmoto, S.; McCarthy, P. J. J. Nat. Prod. 1987, 50, 976.

[7] Lebrasseur, N.; Gagnepain, J.; Ozanne-Beaudenon, A.; Léger, J.-M.; Quideau, S. J. Org. Chem. 2007, 72, 6280.

[8] Gagnepain, J.; Castet, F.; Quideau, S. Angew. Chem. Int. Ed. 2007, 46, 1533, and 2008, 47, 628.

[9] Zdero, C.; Bohlmann, F.; Niemeyer, H. M. Phytochemistry 1991, 30, 1597.

[10] Moorthy, J. N.; Senapati, K.; Parida, K. N.; Jhulki, S.; Sooraj, K.; Nair, N. N. J. Org. Chem. 2011, 76, 9593.

[11] Goldstein, H.; Cornamusaz, E. Helv. Chim. Acta 1931, 14, 200.

[12] Fox, M. E.; Gerlach, A.; Lennon, I. C.; Meek, G.; Praquin, C. Synthesis 2005, 3196.

[13] Trost, B. M.; Van Vranken, D. L.; Bingel, C. J. Am. Chem. Soc. 1992, 114, 9327.

[14] Moteki, S. A.; Xu, S.; Arimitsu, S.; Maruoka, K. J. Am. Chem. Soc. 2010, 132, 17074.

[15] (a) Adam, W.; Bialas, J.; Hadjiarapoglou, L. Chem. Ber. 1991, 124, 2377; (b) Mikula, H.; Svatunek, D.; Lumpi, D.; Glöcklhofer, F.; Hametner, C.; Fröhlich, J. Org. Process Res. Dev. 2013, 17, 313 .

[16] Pouységu, L.; Chassaing, S.; Dejugnac, D.; Lamidey, A.-M.; Miqueu, K.; Sotiropoulos, J.-M.; Quideau, S. Angew. Chem. Int. Ed. 2008, 47, 3552.

[17] Bosset, C.; Coffinier, R.; Peixoto, P. A.; El Assal, M.; Miqueu, K.; Sotiropoulos, J.-M.; Pouységu, L.; Quideau, S. Angew. Chem. Int. Ed. 2014, 53, 9860.

[18] (a) Shuklov, I. A.; Dubrovina, N. V.; Börner, A. Synthesis 2007, 2925; (b) Bégué, J.-P.; Bonnet-Delpon, D.; Crousse, B. Synlett 2004, 18; (c) Ito, M.; Ogawa, C.; Yamaoka, N.; Fujioka, H.; Dohi, T.; Kita, Y. Molecules 2010, 15, 1918.

[19] Uyanik, M.; Yasui, T.; Ishihara, K. Angew. Chem. Int. Ed. 2013, 52, 9215.

[20] Gaussian 09, Revision D.01, Frisch, M. J.; Trucks, G. W.; Schlegel, H. B.; Scuseria, G. E.; Robb, M. A.; Cheeseman, J. R.; Scalmani, G.; Barone, V.; Mennucci, B.; Petersson, G. A.; Nakatsuji, H.; Caricato, M.; Li, X.; Hratchian, H. P.; Izmaylov, A. F.; Bloino, J.; Zheng, G.; Sonnenberg, J. L.; Hada, M.; Ehara, M.; Toyota, K.; Fukuda, R.; Hasegawa, J.; Ishida, M.; Nakajima, T.; Honda, Y.; Kitao, O.; Nakai, H.; Vreven, T.; Montgomery, Jr., J. A.; Peralta, J. E.; Ogliaro, F.; Bearpark, M.; Heyd, J. J.; Brothers, E.; Kudin, K. N.; Staroverov, V. N.; Kobayashi, R.; Normand, J.; Raghavachari, K.; Rendell, A.; Burant, J. C.; Iyengar, S. S.; Tomasi, J.; Cossi, M.; Rega, N.; Millam, J. M.; Klene, M.; Knox, J. E.; Cross, J. B.; Bakken, V.; Adamo, C.; Jaramillo, J.; Gomperts, R.; Stratmann, R. E.; Yazyev, O.; Austin, A. J.; Cammi, R.; Pomelli, C.; Ochterski, J. W.; Martin, R. L.; Morokuma, K.; Zakrzewski, V. G.; Voth, G. A.; Salvador, P.; Dannenberg, J. J.; Dapprich, S.; Daniels, A. D.; Farkas, Ö.; Foresman, J. B.; Ortiz, J. V.; Cioslowski, J.; Fox, D. J. Gaussian, Inc., Wallingford CT, 2009.

[21] Parr, R. G.; Yang, W. Functional Theory of Atoms and Molecules (Eds.: Breslow, R.; Goodenough, J. B.), Oxford University Press, New York, 1989.

[22] (a) Becke, A. D. Phys. Rev. A 1988, 38, 3098; (b) Becke, A. D. J. Chem. Phys. 1993, 98, 5648; (c) Lee, C.; Yang, W.; Parr, R. G. Phys. Rev. B 1988, 37, 785.

[23] Hariharan, P. C.; Pople, J. A. Theor. Chim. Acta 1973, 28, 213.

[24] (a) Dolg, M. in Modern Methods and Algorithm of Quantum Chemistry (Ed.: Grotendorst, J.), John von Neuman Institute for Computing, Jülich, 2000, Vol. 1, pp. 479-508; (b) Dolg, M.; 
Wedig, U.; Stoll, H.; Preuss, H. J. Chem. Phys. 1987, 86, 866; (c) Andrae, D.; Häussermann, U.; Dolg, M.; Stoll, H.; Preuss, H. Theor. Chim. Acta. 1990, 77, 123.

[25] (a) Reed, A. E.; Curtiss, L. A.; Weinhold, F. Chem. Rev. 1988, 88, 899; (b) Foster, J. P.; Weinhold, F. J. Am. Chem. Soc. 1980, 102, 7211.

[26] (a) Bader, R. F. W. Atoms in Molecules: A Quantum Theory, Oxford University Press, NewYork, 1990; (b) Bader, R. F. W. Chem. Rev. 1991, 91, 893.

[27] Keith, T. A. AIMAll (Version 10.10.11), 2010. 